\title{
PERFORMANCE OF A RESIDENTIAL HEAT PUMP OPERATING IN THE COOLING MODE WITH SINGLE FAULTS IMPOSED
}

\author{
Minsung Kim \\ W. Vance Payne \\ Piotr A. Domanski
}

U.S. DEPARTMENT OF COMMERCE National Institute of Standards and Technology Building Environment Division Building and Fire Research Laboratory Gaithersburg, Maryland 20899-8631

Christian J. L. Hermes

HVAC\&R Research Centre Federal University of Santa Catarina 88040-900, Florianopolis-SC, BRAZIL

National Institute of Standards and Technology Technology Administration, U.S. Department of Commerce 

Minsung Kim W. Vance Payne Piotr A. Domanski

U.S. DEPARTMENT OF COMMERCE National Institute of Standards and Technology Building Environment Division Building and Fire Research Laboratory Gaithersburg, Maryland 20899-8631

Christian J. L. Hermes

HVAC\&R Research Centre Federal University of Santa Catarina 88040-900, Florianopolis-SC, BRAZIL

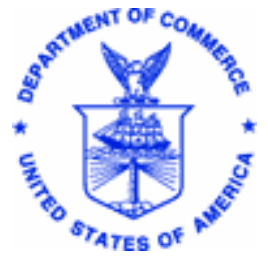

U.S. DEPARTMENT OF COMMERCE Carlos M. Gutierrez, Secretary TECHNOLOGY ADMINISTRATION Robert Cresanti, Under Secretary of Commerce for Technology NATIONAL INSTITUTE OF STANDARDS AND TECHNOLOGY William Jeffrey, Director 



\section{Use of Non-SI Units in a NIST Publication}

It is the policy of the National Institute of Standards and Technology to use the International System of Units (metric units) in all of its publications. However, in North America in the HVAC\&R industry, nonSI units are so widely used instead of SI units that it is more practical and less confusing to include measurement values in customary units within some figures and tables. 


\section{BRIEF SUMMARY OF THE RESEARCH}

System behavior of a R410A residential unitary split heat pump system was investigated. The system was operated in cooling mode and used a thermostatic expansion valve (TXV) as the refrigerant expansion device. Seven artificial faults were tested: compressor/reversing valve leakage, improper outdoor air flow, improper indoor air flow, liquid line restriction, refrigerant undercharge, refrigerant overcharge, and presence of non-condensable gas in the refrigerant.

The no-fault test results were correlated to produce a reference model of $2^{\text {nd }}$ order multivariate regressive polynomials. The reference model used three independent variables, outdoor air temperature, indoor air temperature, and indoor dew point temperature, to correlate all other heat pump features. Standard deviations of liquid line refrigerant subcooling and evaporator exit refrigerant superheat were used as the main indicators for a steady-state detector algorithm. From the no-fault reference model, heat pump feature residuals were derived. Since the system was controlled by a TXV, the system could adapt itself to considerable external variation. Thus faulty behavior was not as detectable as it would have been with an orifice expansion device equipped system. The distinctiveness of a fault depended on the TXV status. Heat exchanger faults' effects upon performance depend on the sizing of the heat exchanger. From the dynamic tests, the system showed that the most influential factor for dynamic behavior was the change of the evaporator refrigerant exit temperature.

\section{ACKNOWLEDGMENTS}

The authors thank Mr. Robert "Dutch" Uselton of Lennox Industries in Carrollton, Texas for donating the heat pump system used in this study. We also thank Dutch and all of his co-workers at Lennox for giving us their time and advice during several meetings at NIST and in Texas. 


\section{TABLE OF CONTENTS}

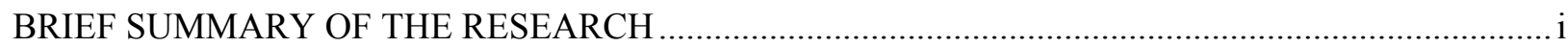

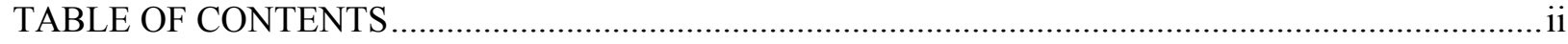

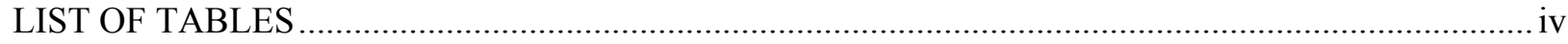

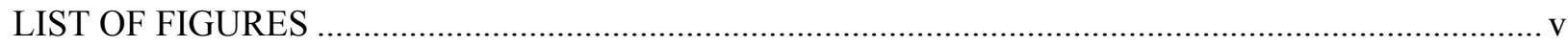

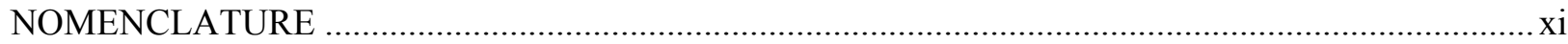

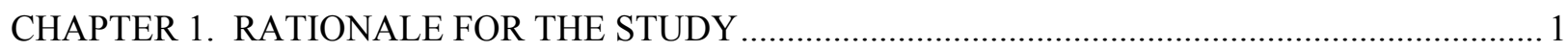

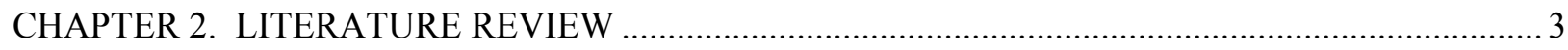

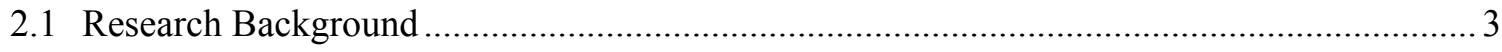

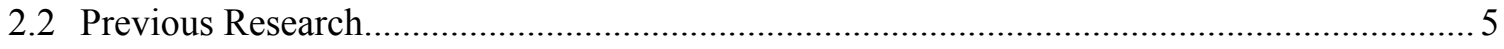

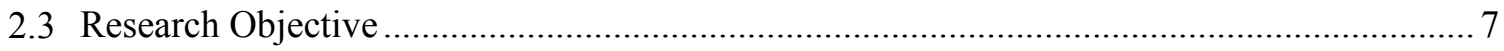

CHAPTER 3. EXPERIMENTAL SETUP AND TEST PROCEDURE ........................................... 8

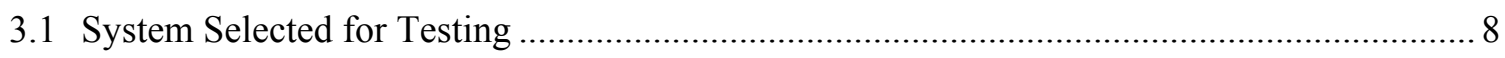

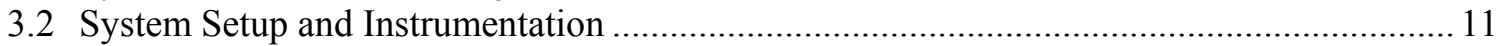

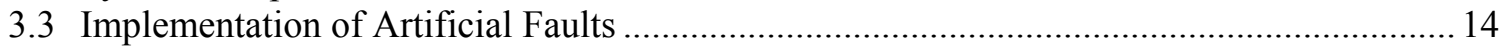

3.3.1 Compressor/reversing valve leakage ........................................................... 14

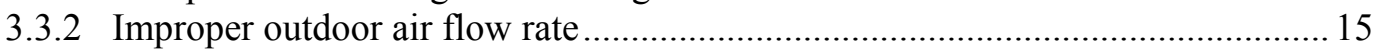

3.3.3 Improper indoor air flow rate ..................................................................... 16

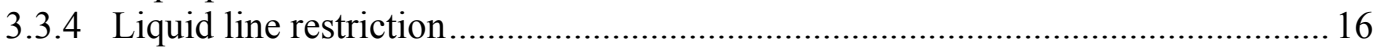

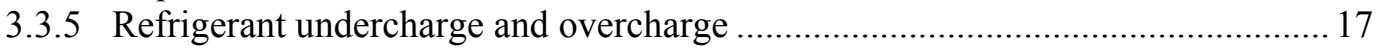

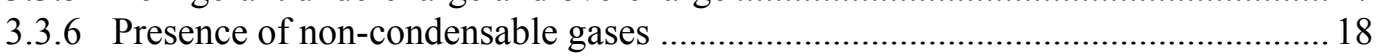

3.4 Experimental Procedure and Test Conditions ................................................................ 18

CHAPTER 4. NO-FAULT TESTS AND SYSTEM CHARACTERISTICS …......................................220

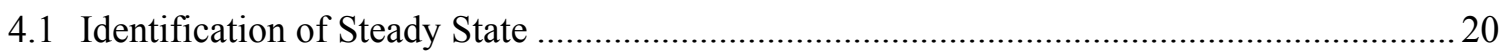

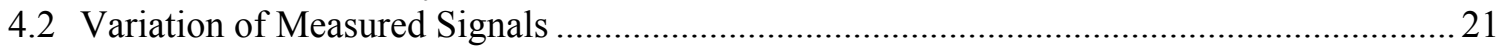

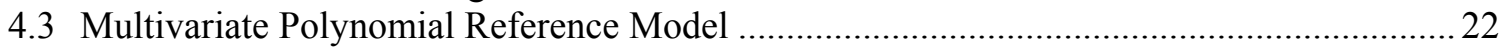

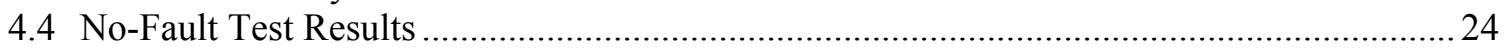

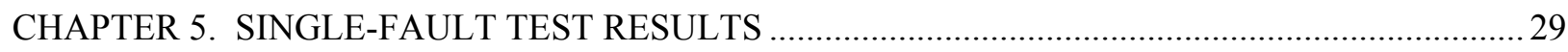

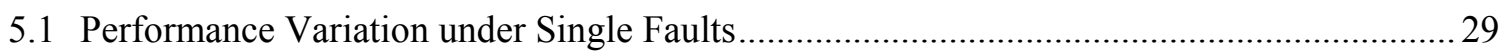

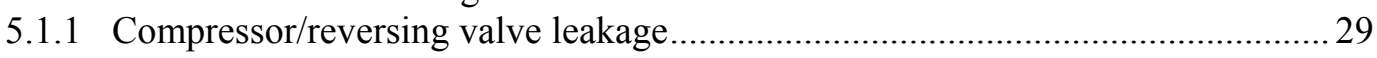

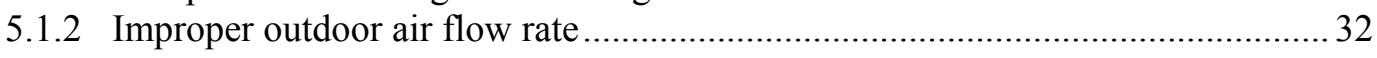

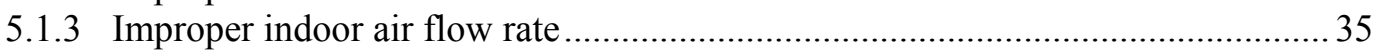

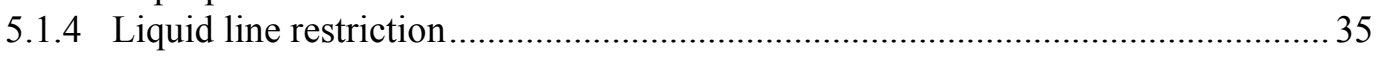

5.1.5 Refrigerant undercharge and overcharge ..................................................... 40

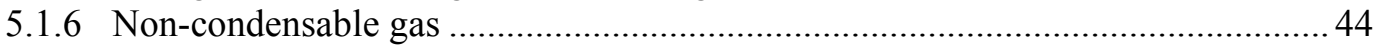

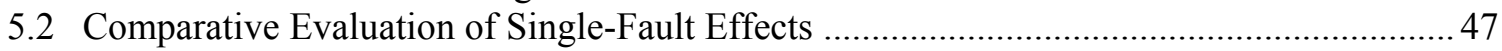

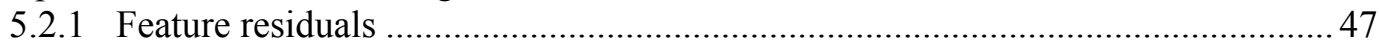

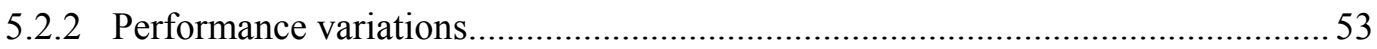

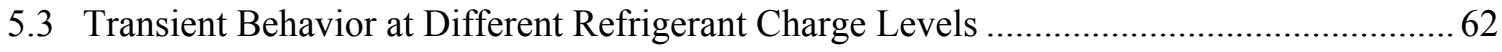

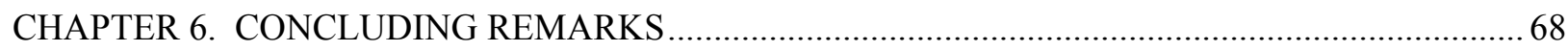

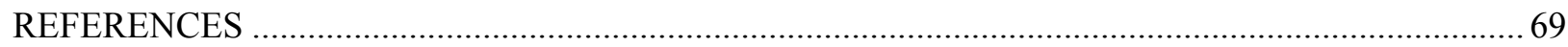


APPENDIX A. LIST OF LABORATORY INSTRUMENTATION …................................................ 72

APPENDIX B. COEFFICIENTS OF MULTIVARIATE REFERENCE MODEL .............................. 76

APPENDIX C. EXTENDED PERFORMANCE CHARTS …........................................................... 77

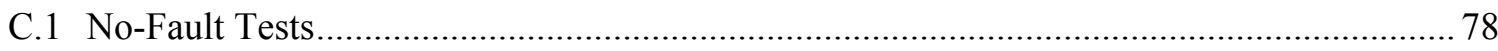

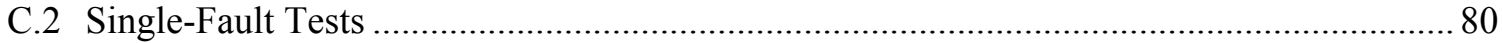

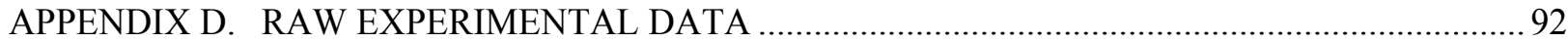

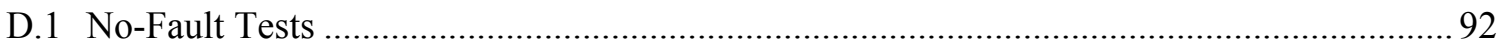

D.2 Compressor/Reversing Valve Leakage Fault Tests ........................................................ 101

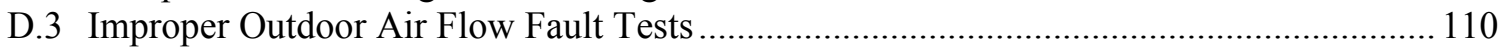

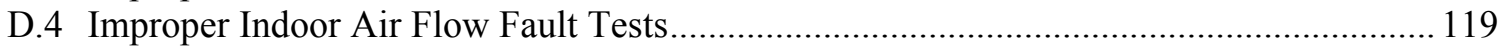

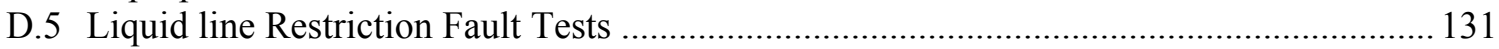

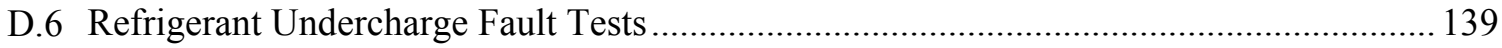

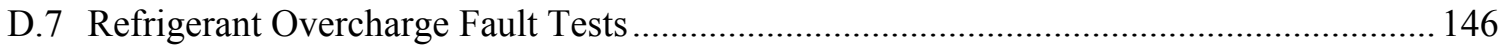

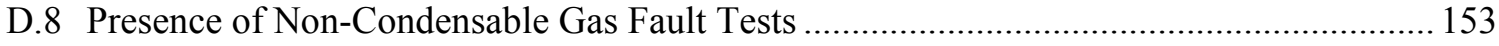




\section{LIST OF TABLES}

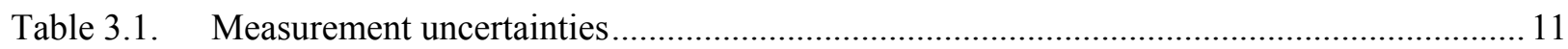

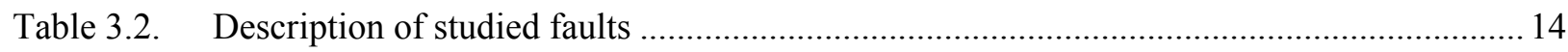

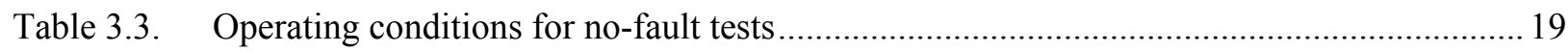

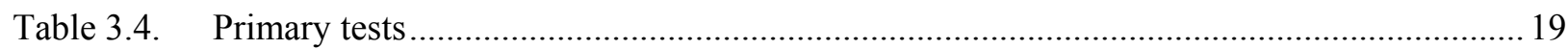

Table A.1. Data acquisition channel assignment for FDD split-system testing ................................. 72

Table A.2. $\quad$ Post-processed data list for FDD analysis .................................................................... 75

Table B.1. Coefficients of second order multivariate polynomial reference model in Equation (4.7b) for selected features and parameters for no-fault estimation ................................... 76

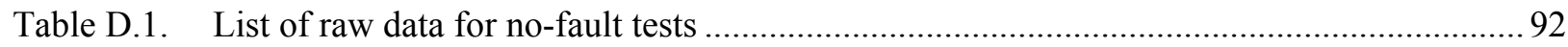

Table D.2. List of raw data for compressor/reversing valve leakage fault tests................................ 101

Table D.3. List of raw data for improper outdoor air flow fault tests .............................................. 110

Table D.4. List of raw data for improper indoor air flow fault tests .................................................. 119

Table D.5. List of raw data for liquid line restriction fault tests ..................................................... 131

Table D.6. List of raw data for refrigerant undercharge fault tests ................................................... 139

Table D.7. List of raw data for refrigerant overcharge fault tests ................................................ 146

Table D.8. List of raw data for presence of non-condensable gas fault tests ................................... 153 


\section{LIST OF FIGURES}

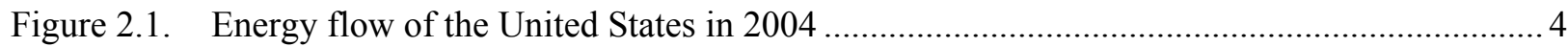

Figure 3.1. Side view of the outdoor section with the flow guide .................................................... 8

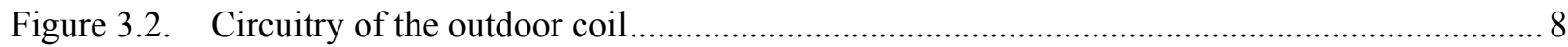

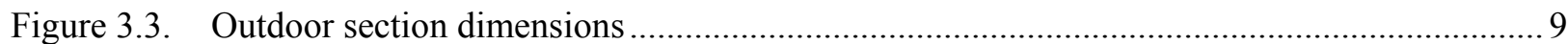

Figure 3.4. Side view of the indoor coil and upflow duct ............................................................ 10

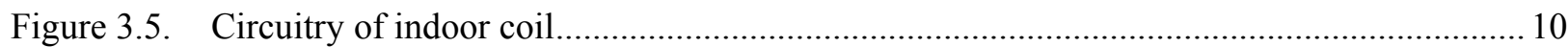

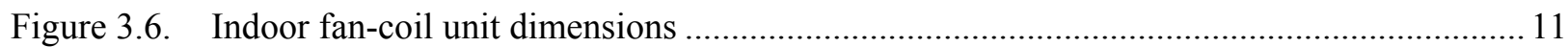

Figure 3.7. Air duct arrangement in the indoor environmental chamber.......................................... 12

Figure 3.8. Experimental setup with the heat pump in the cooling mode .......................................... 13

Figure 3.9. Hot gas bypass used for compressor/reversing valve leakage fault .................................. 15

Figure 3.10. Condenser with lower finned area blocked .................................................................. 16

Figure 3.11. Artificial setup to implement a liquid line restriction fault using a shut-off valve and

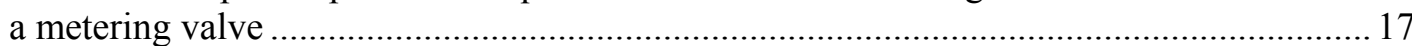

Figure 4.1 Moving windows of $n$ data points at near $k^{\text {th }}$ time ...................................................20

Figure 4.2. Random error of indoor temperature measurement.......................................................23

Figure 4.3. Pressure-enthalpy diagrams for tests at $37.8^{\circ} \mathrm{C}\left(100.0^{\circ} \mathrm{F}\right), 32.2^{\circ} \mathrm{C}\left(90.0^{\circ} \mathrm{F}\right)$, $27.8^{\circ} \mathrm{C}\left(82.0^{\circ} \mathrm{F}\right)$, and $21.1^{\circ} \mathrm{C}\left(70.0^{\circ} \mathrm{F}\right)$ outdoor temperatures with $21.1^{\circ} \mathrm{C}$ $\left(70.0^{\circ} \mathrm{F}\right)$ indoor temperature and $50 \%$ relative humidity

Figure 4.4. Pressure-enthalpy diagrams for tests at $27.8^{\circ} \mathrm{C}\left(82.0^{\circ} \mathrm{F}\right)$ outdoor temperature and four indoor temperature/relative humidity combinations: $26.7^{\circ} \mathrm{C}\left(80.0^{\circ} \mathrm{F}\right) \mathrm{DB} / 50 \%$ $\mathrm{RH}, 26.7^{\circ} \mathrm{C}\left(80.0^{\circ} \mathrm{F}\right) \mathrm{DB} /$ Dry-coil, $21.1^{\circ} \mathrm{C}\left(70.0^{\circ} \mathrm{F}\right) \mathrm{DB} / 50 \% \mathrm{RH}, 21.1^{\circ} \mathrm{C}$ $\left(70.0^{\circ} \mathrm{F}\right) \mathrm{DB} /$ Dry-coil

Figure 4.5. Variation of temperature measurements with regard to outdoor chamber temperature under no-fault condition: From the top left to right: $T_{\mathrm{ER}}-$ evaporator exit saturation temperature; $\Delta T_{\mathrm{sh}}$ - evaporator exit superheat, $T_{\mathrm{DW}}$ - compressor discharge wall temperature, $T_{\mathrm{CR}}$ - condenser inlet saturation temperature, $\Delta T_{\mathrm{sc}}$ - liquid line subcooling, $\Delta T_{\mathrm{CA}}-$ condenser air temperature rise, $\Delta T_{\mathrm{EA}}-$ evaporator air temperature drop, $\Delta T_{\mathrm{LL}}$ - liquid line temperature drop

Figure 4.6. Variation of system performance with regard to outdoor air temperature under nofault conditions: From the top left to right: $Q_{\mathrm{EA}, \text { sens }}$ - indoor air sensible capacity, $Q_{\text {EA,lat }}$ - indoor air latent capacity, $\mathrm{SHR}_{\mathrm{EA}}$ - indoor air sensible heat ratio, $m_{\mathrm{R}}-$ refrigerant mass flow rate, $Q_{\mathrm{CR}}$ - condenser refrigerant-side capacity, $Q_{\mathrm{ER}}-$ evaporator refrigerant-side capacity, $W_{\mathrm{cmp}}$ - compressor work, EER - energy efficiency ratio

Figure 5.1. Residuals for selected feature with compressor fault. From the top left to right: $T_{\mathrm{ER}}$

- evaporator exit saturation temperature; $\Delta T_{\mathrm{sh}}$ - evaporator exit superheat, $T_{\mathrm{DW}}-$ compressor discharge wall temperature, $T_{\mathrm{CR}}-$ condenser inlet saturation 
temperature, $\Delta T_{\mathrm{sc}}$ - liquid line subcooling, $T_{\mathrm{CA}}$ - condenser air temperature rise, $\Delta T_{\mathrm{EA}}$ - evaporator air temperature drop, $\Delta T_{\mathrm{LL}}$ - liquid line temperature drop

Figure 5.2. Variation of selected performance parameters with a compressor fault. From the top left to right: $Q_{\mathrm{EA}, \text { sens }}-$ indoor air sensible capacity, $Q_{\mathrm{AE}, \text { lat }}-$ indoor air latent capacity, SHR - indoor air sensible heat ratio, $m_{\mathrm{R}}$ - refrigerant mass flow rate, $Q_{\mathrm{CR}}-$ condenser refrigerant-side capacity; $Q_{\mathrm{ER}}$ - evaporator refrigerant-side capacity; $W_{\text {comp }}$ - compressor work; EER - energy efficiency ratio.

Figure 5.3. Residuals for selected features with the improper indoor air flow rate fault. From the top left to right: $T_{\mathrm{ER}}$ - evaporator exit saturation temperature, $\Delta T_{\mathrm{sh}}-$ evaporator exit superheat, $T_{\mathrm{DW}}$ - compressor discharge wall temperature, $T_{\mathrm{CR}}-$ condenser inlet saturation temperature, $\Delta T_{\mathrm{sc}}-$ liquid line subcooling, $T_{\mathrm{CA}}-$ condenser air temperature rise, $\Delta T_{\mathrm{EA}}-$ evaporator air temperature drop, $\Delta T_{\mathrm{LL}}$ - liquid line temperature drop

Figure 5.4. Variation of selected performance parameters with the improper indoor air flow rate fault. From the top left to right: $Q_{\mathrm{EA} \text {,sens }}$ - indoor air sensible capacity, $Q_{\mathrm{AE}, \text { lat }}-$ indoor air latent capacity, SHR - indoor air sensible heat ratio, $m_{\mathrm{R}}-$ refrigerant mass flow rate, $Q_{\mathrm{CR}}-$ condenser refrigerant-side capacity, $Q_{\mathrm{ER}}-$ evaporator refrigerant-side capacity, $W_{\text {comp }}$ - compressor work, EER - energy efficiency ratio

Figure 5.5. Residuals for selected features with the improper indoor air flow rate fault. From the top left to right: $T_{\mathrm{ER}}$ - evaporator exit saturation temperature, $\Delta T_{\mathrm{sh}}-$ evaporator exit superheat, $T_{\mathrm{DW}}$ - compressor discharge wall temperature, $T_{\mathrm{CR}}-$ condenser inlet saturation temperature, $\Delta T_{\mathrm{sc}}-$ liquid line subcooling, $T_{\mathrm{CA}}-$ condenser air temperature rise, $\Delta T_{\mathrm{EA}}$ - evaporator air temperature drop, $\Delta T_{\mathrm{LL}}$ - liquid line temperature drop

Figure 5.6. Selected performance parameters with the improper indoor air flow rate fault. From the top left to right: $Q_{\mathrm{EA}, \mathrm{sens}}$ - indoor air sensible capacity, $Q_{\mathrm{AE}, \text { lat }}-$ indoor air latent capacity, SHR - indoor air sensible heat ratio, $m_{\mathrm{R}}$ - refrigerant mass flow rate, $Q_{\mathrm{CR}}$ - condenser refrigerant-side capacity, $Q_{\mathrm{ER}}$ - evaporator refrigerant-side capacity, $W_{\text {comp }}$ - compressor work, EER - energy efficiency ratio

Figure 5.7. Residuals of selected features with the liquid line restriction fault. From the top left to right: $T_{\mathrm{ER}}$ - evaporator exit saturation temperature, $\Delta T_{\mathrm{sh}}$ - evaporator exit superheat, $T_{\mathrm{DW}}$ - compressor discharge wall temperature, $T_{\mathrm{CR}}$ - condenser inlet saturation temperature, $\Delta T_{\mathrm{sc}}-$ liquid line subcooling, $T_{\mathrm{CA}}-$ condenser air temperature rise, $\Delta T_{\mathrm{EA}}$ - evaporator air temperature drop, $\Delta T_{\mathrm{LL}}$ - liquid line temperature drop

Figure 5.8. Selected performance parameters with the liquid line restriction fault. From the top left to right: $Q_{\mathrm{EA}, \text { sens }}-$ indoor air sensible capacity, $Q_{\mathrm{AE}, \mathrm{lat}}-$ indoor air latent capacity, SHR - indoor air sensible heat ratio, $m_{\mathrm{R}}$ - refrigerant mass flow rate, $Q_{\mathrm{CR}}-$ condenser refrigerant-side capacity, $Q_{\mathrm{ER}}$ - evaporator refrigerant-side capacity, $W_{\text {comp }}$ - compressor work, EER - energy efficiency ratio.

Figure 5.9. Residuals for selected features with refrigerant undercharge fault. From the top left to right: $T_{\mathrm{ER}}$ - evaporator exit saturation temperature, $\Delta T_{\mathrm{sh}}-$ evaporator exit superheat, $T_{\mathrm{DW}}$ - compressor discharge wall temperature, $T_{\mathrm{CR}}$ - condenser inlet saturation temperature, $\Delta T_{\mathrm{sc}}-$ liquid line subcooling, $T_{\mathrm{CA}}-$ condenser air temperature rise, $\Delta T_{\mathrm{EA}}$ - evaporator air temperature drop, $\Delta T_{\mathrm{LL}}-$ liquid line temperature drop 
Figure 5.10. Residuals for selected features with refrigerant overcharge fault. From the top left to right: $T_{\mathrm{ER}}$ - evaporator exit saturation temperature, $\Delta T_{\mathrm{sh}}-$ evaporator exit superheat, $T_{\mathrm{DW}}$ - compressor discharge wall temperature, $T_{\mathrm{CR}}$ - condenser inlet saturation temperature, $\Delta T_{\mathrm{sc}}-$ liquid line subcooling, $T_{\mathrm{CA}}-$ condenser air temperature rise, $\Delta T_{\mathrm{EA}}$ - evaporator air temperature drop, $\Delta T_{\mathrm{LL}}$ - liquid line temperature drop .

Figure 5.11. Selected performance parameters with respect to the refrigerant charge level. From the top left to right: $Q_{\mathrm{EA}, \text { sens }}-$ indoor air sensible capacity, $Q_{\mathrm{AE}, \text { lat }}-$ indoor air latent capacity, $\mathrm{SHR}$ - indoor air sensible heat ratio, $m_{\mathrm{R}}$ - refrigerant mass flow rate, $Q_{\mathrm{CR}}$ - condenser refrigerant-side capacity, $Q_{\mathrm{ER}}$ - evaporator refrigerant-side capacity, $W_{\text {comp }}$ - compressor work, EER - energy efficiency ratio

Figure 5.12. Residuals for selected features with non-condensable gas fault. From the top left to right: $T_{\mathrm{ER}}$ - evaporator exit saturation temperature, $\Delta T_{\mathrm{sh}}$ - evaporator exit superheat, $T_{\mathrm{DW}}$ - compressor discharge wall temperature, $T_{\mathrm{CR}}-$ condenser inlet saturation temperature, $\Delta T_{\mathrm{sc}}-$ liquid line subcooling, $T_{\mathrm{CA}}-$ condenser air temperature rise, $\Delta T_{\mathrm{EA}}-$ evaporator air temperature drop, $\Delta T_{\mathrm{LL}}$ - liquid line temperature drop.

Figure 5.13. Selected performance parameters with non-condensable gas fault. From the top left to right: $Q_{\mathrm{EA}, \text { sens }}$ - indoor air sensible capacity, $Q_{\mathrm{AE} \text {,lat }}$ - indoor air latent capacity, SHR - indoor air sensible heat ratio, $m_{\mathrm{R}}$ - refrigerant mass flow rate, $Q_{\mathrm{CR}}-$ condenser refrigerant-side capacity, $Q_{\mathrm{ER}}$ - evaporator refrigerant-side capacity, $W_{\text {comp }}$ - compressor work, EER - energy efficiency ratio

Figure 5.14. Residuals for selected features for different faults. From the top left to right: $T_{\mathrm{ER}}-$ evaporator exit saturation temperature, $\Delta T_{\mathrm{sh}}$ - evaporator exit superheat, $T_{\mathrm{DW}}-$ compressor discharge wall temperature, $T_{\mathrm{CR}}-$ condenser inlet saturation temperature (Test $\# 5$ : $27.8^{\circ} \mathrm{C}\left(82.0^{\circ} \mathrm{F}\right)$ outdoor dry bulb temperature, $26.7^{\circ} \mathrm{C}$ $\left(80.0^{\circ} \mathrm{F}\right)$ indoor dry bulb temperature and $50 \%$ indoor relative humidity.

Figure 5.15. Residuals for selected features for different faults. From the top left to right: $\Delta T_{\mathrm{sc}}-$ liquid line subcooling, $\Delta T_{\mathrm{CA}}$ - condenser air temperature rise, $\Delta T_{\mathrm{EA}}-$ evaporator air temperature drop, $\Delta T_{\mathrm{LL}}$ - liquid line temperature drop (Test $\# 5: 27.8^{\circ} \mathrm{C}\left(82.0^{\circ} \mathrm{F}\right)$ outdoor dry bulb temperature, $26.7^{\circ} \mathrm{C}\left(80.0^{\circ} \mathrm{F}\right)$ indoor dry bulb temperature and $50 \%$ indoor relative humidity)

Figure 5.16. Residuals for selected performance parameters for different faults. From the top left to right: $Q_{\mathrm{EA}, \text { sens }}$ - indoor air sensible capacity, $Q_{\mathrm{AE} \text {,lat }}$ - indoor air latent capacity; SHR - indoor air sensible heat ratio, $m_{\mathrm{R}}$ - refrigerant mass flow rate (Test \#5: $27.8^{\circ} \mathrm{C}\left(82.0^{\circ} \mathrm{F}\right)$ outdoor dry bulb temperature, $26.7^{\circ} \mathrm{C}\left(80.0^{\circ} \mathrm{F}\right)$ indoor dry bulb temperature and $50 \%$ indoor relative humidity)

Figure 5.17. Residuals for selected performance parameters for different faults. From the top left to right: $Q_{\mathrm{CR}}-$ condenser refrigerant-side capacity, $Q_{\mathrm{ER}}-$ evaporator refrigerant-side capacity, $W_{\text {comp }}$ - compressor work, EER - energy efficiency ratio (Test $\# 5: 27.8^{\circ} \mathrm{C}$ $\left(82.0^{\circ} \mathrm{F}\right)$ outdoor dry bulb temperature, $26.7^{\circ} \mathrm{C}\left(80.0^{\circ} \mathrm{F}\right)$ indoor dry bulb temperature and $50 \%$ indoor relative humidity)

Figure 5.18. Variation of evaporator sensible capacity $\left(Q_{\mathrm{EA}, \mathrm{sens}}\right)$ at different faults. From the top left to right: compressor fault (CMF), improper outdoor air flow rate $(\mathrm{CF})$, improper indoor air flow rate (EF), liquid line restriction (LL), refrigerant overcharge (OC), refrigerant undercharge (UC), and presence of non-condensable gases (NON) 
Figure 5.19. Variation of evaporator latent capacity $\left(Q_{\mathrm{EA}, \text { lat }}\right)$ at different faults. From the top left to right: compressor fault (CMF), improper outdoor air flow rate $(\mathrm{CF})$, improper indoor air flow rate (EF), liquid line restriction (LL), refrigerant overcharge (OC), refrigerant undercharge (UC), and presence of non-condensable gases (NON)

Figure 5.20. Variation of indoor air sensible heat ratio (SHR) at different faults. From the top left to right: compressor fault (CMF), improper outdoor air flow rate $(\mathrm{CF})$, improper indoor air flow rate (EF), liquid line restriction (LL), refrigerant overcharge (OC), refrigerant undercharge (UC), and presence of non-condensable gases (NON)

Figure 5.21. Variation of refrigerant mass flow rate $\left(m_{\mathrm{R}}\right)$ at different faults. From the top left to right: compressor fault $(\mathrm{CMF})$, improper outdoor air flow rate $(\mathrm{CF})$, improper indoor air flow rate $(\mathrm{EF})$, liquid line restriction (LL), refrigerant overcharge (OC), refrigerant undercharge (UC), and presence of non-condensable gases (NON)

Figure 5.22. Variation of condenser refrigerant-side capacity $\left(Q_{\mathrm{CR}}\right)$ at different faults. From the top left to right: compressor fault (CMF), improper outdoor air flow rate $(\mathrm{CF})$, improper indoor air flow rate (EF), liquid line restriction (LL), refrigerant overcharge (OC), refrigerant undercharge (UC), and presence of non-condensable gases $(\mathrm{NON})$

Figure 5.23. Variation of evaporator refrigerant-side capacity $\left(Q_{\mathrm{ER}}\right)$ at different faults. From the top left to right: compressor fault (CMF), improper outdoor air flow rate (CF), improper indoor air flow rate (EF), liquid line restriction (LL), refrigerant overcharge (OC), refrigerant undercharge (UC), and presence of non-condensable gases $(\mathrm{NON})$

Figure 5.24. Variation of compressor work $\left(W_{\mathrm{cmp}}\right)$ at different faults. From the top left to right: compressor fault (CMF), improper outdoor air flow rate (CF), improper indoor air flow rate $(\mathrm{EF})$, liquid line restriction (LL), refrigerant overcharge (OC), refrigerant undercharge (UC), and presence of non-condensable gases (NON)

Figure 5.25. Variation of energy efficiency ratio (EER) at different faults. From the top left to right: compressor fault $(\mathrm{CMF})$, improper outdoor air flow rate $(\mathrm{CF})$, improper indoor air flow rate (EF), liquid line restriction (LL), refrigerant overcharge (OC), refrigerant undercharge (UC), and presence of non-condensable gases (NON)

Figure 5.26. Real-time transient test of on-off cyclic operation with different turn-off intervals at the $20 \%$ fault of refrigerant undercharge fault (Test $\# 8: 37.8^{\circ} \mathrm{C}\left(100.0^{\circ} \mathrm{F}\right)$ outdoor dry bulb temperature, $21.1^{\circ} \mathrm{C}\left(70.0^{\circ} \mathrm{F}\right)$ indoor dry bulb temperature and $50 \%$ indoor relative humidity)

Figure 5.27. Time variation of measurements during on-off cyclic operation with different turnoff intervals at the normal refrigerant charge (Test \#8: $37.8^{\circ} \mathrm{C}\left(100.0^{\circ} \mathrm{F}\right)$ outdoor dry bulb temperature, $21.1^{\circ} \mathrm{C}\left(70.0^{\circ} \mathrm{F}\right)$ indoor dry bulb temperature and $50 \%$ indoor relative humidity)

Figure 5.28. Time variation of measurements during on-off cyclic operation with different refrigerant charge levels (Turn-off period: 24 minutes, Test $\# 8: 37.8^{\circ} \mathrm{C}\left(100.0^{\circ} \mathrm{F}\right)$ outdoor dry bulb temperature, $21.1^{\circ} \mathrm{C}\left(70.0^{\circ} \mathrm{F}\right)$ indoor dry bulb temperature and $50 \%$ indoor relative humidity)

Figure C.1. Selected parameters from the no-fault tests. From the top left to right: $\mathrm{SCFM}_{\mathrm{CA}}-$ outdoor air flow rate, $\phi_{\mathrm{EAI}}-$ indoor air inlet relative humidity, $T_{\mathrm{EAOD}}-$ indoor air exit dew point temperature, $\phi_{\mathrm{EAO}}-$ indoor air exit relative humidity, $\mathrm{SCFM}_{\mathrm{EA}}-$ 
indoor air flow rate, $T_{\mathrm{SW}}-$ compressor suction wall temperature, $T_{\mathrm{CRI}}-$ condenser refrigerant inlet temperature, $P_{\mathrm{CRI}}-$ condenser refrigerant inlet pressure

Figure C.2. Selected parameters from the no-fault tests. From the top left to right: $T_{\mathrm{CRO} \text {,sat }}-$ condenser refrigerant exit saturation temperature, $\Delta P_{\mathrm{CR}}-$ condenser refrigerant pressure drop, $P_{\mathrm{TXV} \text {,up }}-\mathrm{TXV}$ upstream pressure, $\Delta P_{\mathrm{LL}}$ - liquid line pressure drop; $T_{\mathrm{ERI}}-$ evaporator refrigerant inlet temperature, $P_{\mathrm{ERO}}-$ evaporator refrigerant exit pressure, $\Delta P_{\mathrm{ER}}$ - evaporator refrigerant pressure drop, $\Delta T_{\mathrm{sh}}-\Delta T_{\mathrm{sc}}$

Figure C.3. Selected parameters with the compressor/reversing valve leakage fault. From the top left to right: $\mathrm{SCFM}_{\mathrm{CA}}-$ outdoor air flow rate, $\phi_{\mathrm{EAI}}-$ indoor air inlet relative humidity, $T_{\mathrm{EAOD}}-$ indoor air exit dew point temperature, $\phi_{\mathrm{EAO}}-$ indoor air exit relative humidity, $\mathrm{SCFM}_{\mathrm{EA}}$ - indoor air flow rate, $T_{\mathrm{SW}}$ - compressor suction wall temperature, $T_{\mathrm{CRI}}-$ condenser refrigerant inlet temperature, $P_{\mathrm{CRI}}-$ condenser refrigerant inlet pressure.

Figure C.4. Selected parameters with the compressor/reversing valve leakage fault. From the top left to right: $T_{\mathrm{CRO} \text {,sat }}-$ condenser refrigerant exit saturation temperature, $\Delta P_{\mathrm{CR}}-$ condenser refrigerant pressure drop, $P_{\mathrm{TXV} \text {,up }}-\mathrm{TXV}$ upstream pressure, $\Delta P_{\mathrm{LL}}-$ liquid line pressure drop; $T_{\mathrm{ERI}}-$ evaporator refrigerant inlet temperature, $P_{\mathrm{ERO}}-$ evaporator refrigerant exit pressure, $\Delta P_{\mathrm{ER}}$ - evaporator refrigerant pressure drop, $\Delta T_{\mathrm{sh}}-\Delta T_{\mathrm{sc}}$

Figure C.5. Selected parameters with the improper outdoor flow rate fault. From the top left to right: $\mathrm{SCFM}_{\mathrm{CA}}-$ outdoor air flow rate, $\phi_{\mathrm{EAI}}-$ indoor air inlet relative humidity, $T_{\text {EAOD }}$ - indoor air exit dew point temperature, $\phi_{\text {EAO }}$ - indoor air exit relative humidity, $\mathrm{SCFM}_{\mathrm{EA}}$ - indoor air flow rate, $T_{\mathrm{SW}}$ - compressor suction wall temperature, $T_{\mathrm{CRI}}-$ condenser refrigerant inlet temperature, $P_{\mathrm{CRI}}-$ condenser refrigerant inlet pressure

Figure C.6. Selected parameters with the improper outdoor flow rate fault. From the top left to right: $T_{\mathrm{CRO} \text {,sat }}-$ condenser refrigerant exit saturation temperature, $\Delta P_{\mathrm{CR}}-$ condenser refrigerant pressure drop, $P_{\mathrm{TXV} \text {,up }}-\mathrm{TXV}$ upstream pressure, $\Delta P_{\mathrm{LL}}-$ liquid line pressure drop; $T_{\text {ERI }}-$ evaporator refrigerant inlet temperature, $P_{\text {ERO }}-$ evaporator refrigerant exit pressure, $\Delta P_{\mathrm{ER}}$ - evaporator refrigerant pressure drop, $\Delta T_{\mathrm{sh}}-\Delta T_{\mathrm{sc}}$

Figure C.7. Selected parameters with the improper indoor flow rate fault. From the top left to right: $\mathrm{SCFM}_{\mathrm{CA}}-$ outdoor air flow rate, $\phi_{\mathrm{EAI}}-$ indoor air inlet relative humidity, $T_{\text {EAOD }}$ - indoor air exit dew point temperature, $\phi_{\text {EAO }}$ - indoor air exit relative humidity, $\mathrm{SCFM}_{\mathrm{EA}}$ - indoor air flow rate, $T_{\mathrm{SW}}$ - compressor suction wall temperature, $T_{\mathrm{CRI}}-$ condenser refrigerant inlet temperature, $P_{\mathrm{CRI}}-$ condenser refrigerant inlet pressure

Figure C.8. Selected parameters with the improper indoor flow rate fault. From the top left to right: $T_{\mathrm{CRO} \text {,sat }}-$ condenser refrigerant exit saturation temperature, $\Delta P_{\mathrm{CR}}-$ condenser refrigerant pressure drop, $P_{\mathrm{TXV} \text {,up }}-\mathrm{TXV}$ upstream pressure, $\Delta P_{\mathrm{LL}}-$ liquid line pressure drop; $T_{\mathrm{ERI}}-$ evaporator refrigerant inlet temperature, $P_{\mathrm{ERO}}-$ evaporator refrigerant exit pressure, $\Delta P_{\mathrm{ER}}$ - evaporator refrigerant pressure drop, $\Delta T_{\mathrm{sh}}-\Delta T_{\mathrm{sc}}$

Figure C.9. Selected parameters with the liquid line restriction fault. From the top left to right: $\mathrm{SCFM}_{\mathrm{CA}}-$ outdoor air flow rate, $\phi_{\mathrm{EAI}}-$ indoor air inlet relative humidity, $T_{\mathrm{EAOD}}-$ indoor air exit dew point temperature, $\phi_{\mathrm{EAO}}$ - indoor air exit relative humidity, 
$\mathrm{SCFM}_{\mathrm{EA}}$ - indoor air flow rate, $T_{\mathrm{SW}}$ - compressor suction wall temperature, $T_{\mathrm{CRI}}-$ condenser refrigerant inlet temperature, $P_{\mathrm{CRI}}-$ condenser refrigerant inlet pressure

Figure C.10. Selected parameters with the liquid line restriction fault. From the top left to right: $T_{\mathrm{CRO} \text {,sat }}-$ condenser refrigerant exit saturation temperature, $\Delta P_{\mathrm{CR}}-$ condenser refrigerant pressure drop, $P_{\mathrm{TXV} \text {,up }}-\mathrm{TXV}$ upstream pressure, $\Delta P_{\mathrm{LL}}-$ liquid line pressure drop; $T_{\mathrm{ERI}}-$ evaporator refrigerant inlet temperature, $P_{\mathrm{ERO}}-$ evaporator refrigerant exit pressure, $\Delta P_{\mathrm{ER}}$ - evaporator refrigerant pressure drop, $\Delta T_{\mathrm{sh}}-\Delta T_{\mathrm{sc}}$

Figure C.11. Selected parameters with the refrigerant undercharge/overcharge fault. From the top left to right: $\mathrm{SCFM}_{\mathrm{CA}}-$ outdoor air flow rate, $\phi_{\mathrm{EAI}}-$ indoor air inlet relative humidity, $T_{\mathrm{EAOD}}-$ indoor air exit dew point temperature, $\phi_{\mathrm{EAO}}-$ indoor air exit relative humidity, $\mathrm{SCFM}_{\mathrm{EA}}$ - indoor air flow rate, $T_{\mathrm{SW}}$ - compressor suction wall temperature, $T_{\mathrm{CRI}}-$ condenser refrigerant inlet temperature, $P_{\mathrm{CRI}}-$ condenser refrigerant inlet pressure

Figure C.12. Selected parameters with the refrigerant undercharge/overcharge fault. From the top left to right: $T_{\mathrm{CRO} \text {,sat }}-$ condenser refrigerant exit saturation temperature, $\Delta P_{\mathrm{CR}}-$ condenser refrigerant pressure drop, $P_{\mathrm{TXV} \text {,up }}-\mathrm{TXV}$ upstream pressure, $\Delta P_{\mathrm{LL}}-$ liquid line pressure drop; $T_{\mathrm{ERI}}-$ evaporator refrigerant inlet temperature, $P_{\mathrm{ERO}}-$ evaporator refrigerant exit pressure, $\Delta P_{\mathrm{ER}}$ - evaporator refrigerant pressure drop, $\Delta T_{\mathrm{sh}}-\Delta T_{\mathrm{sc}}$

Figure C.13. Selected parameters with the non-condensable gas fault. From the top left to right: $\mathrm{SCFM}_{\mathrm{CA}}-$ outdoor air flow rate, $\phi_{\mathrm{EAI}}-$ indoor air inlet relative humidity, $T_{\mathrm{EAOD}}-$ indoor air exit dew point temperature, $\phi_{\mathrm{EAO}}$ - indoor air exit relative humidity, $\mathrm{SCFM}_{\mathrm{EA}}$ - indoor air flow rate, $T_{\mathrm{SW}}$ - compressor suction wall temperature, $T_{\mathrm{CRI}}-$ condenser refrigerant inlet temperature, $P_{\mathrm{CRI}}-$ condenser refrigerant inlet pressure

Figure C.14. Selected parameters with the non-condensable gas fault. From the top left to right: $T_{\mathrm{CRO}, \text { sat }}-$ condenser refrigerant exit saturation temperature, $\Delta P_{\mathrm{CR}}-$ condenser refrigerant pressure drop, $P_{\mathrm{TXV} \text {,up }}-\mathrm{TXV}$ upstream pressure, $\Delta P_{\mathrm{LL}}-$ liquid line pressure drop; $T_{\mathrm{ERI}}-$ evaporator refrigerant inlet temperature, $P_{\mathrm{ERO}}-$ evaporator refrigerant exit pressure, $\Delta P_{\mathrm{ER}}$ - evaporator refrigerant pressure drop, $\Delta T_{\mathrm{sh}}-\Delta T_{\mathrm{sc}}$ 


\section{NOMENCLATURE}

\begin{tabular}{|c|c|}
\hline Symbols & \\
\hline$a$ & coefficient of multivariate polynomial \\
\hline COP & Coefficient of Performance $(-)$ \\
\hline EER & Energy Efficiency Ratio (Btu/ (W h)) \\
\hline$h$ & specific enthalpy, $\mathrm{kJ} / \mathrm{kg}(\mathrm{Btu} / \mathrm{lbm})$ \\
\hline$k$ & specific instant of $k$ th time interval \\
\hline$m_{\mathrm{R}}$ & refrigerant mass flow rate, $\mathrm{kg} / \mathrm{h}(\mathrm{lbm} / \mathrm{h})$ \\
\hline $\mathrm{m}$ & average \\
\hline$n$ & number of data samples in a moving window \\
\hline$P$ & pressure, $\mathrm{kPa}(\mathrm{psia})$ \\
\hline$P_{\mathrm{TXV} \text {,up }}$ & upstream pressure of $\mathrm{TXV}, \mathrm{kPa}$ (psia) \\
\hline$\Delta P_{\mathrm{CR}}$ & condenser refrigerant side pressure drop, $\mathrm{Pa}$ (psid) \\
\hline$\Delta P_{\mathrm{ER}}$ & evaporator refrigerant side pressure drop, $\mathrm{Pa}$ (psid) \\
\hline$\Delta P_{\mathrm{LL}}$ & liquid line pressure drop, $\mathrm{Pa}(\mathrm{psid})$ \\
\hline$Q$ & capacity, W (Btu/h) \\
\hline$Q_{\mathrm{CA}}$ & condenser air-side capacity, W (Btu/h) \\
\hline$Q_{\mathrm{CR}}$ & condenser refrigerant-side capacity, W (Btu/h) \\
\hline$Q_{\mathrm{EA}}$ & evaporator air-side capacity, W $(\mathrm{Btu} / \mathrm{h})$ \\
\hline$Q_{\mathrm{ER}}$ & evaporator refrigerant-side capacity, W (Btu/h) \\
\hline$Q_{\text {EA,lat }}$ & indoor air latent capacity, W (Btu/h) \\
\hline$Q_{\mathrm{EA}, \text { sens }}$ & indoor air sensible capacity, W (Btu/h) \\
\hline $\mathrm{R}$ & residual of features \\
\hline $\mathrm{R}^{*}$ & normalized residual \\
\hline SCFM & air side flow rate $\left(\mathrm{ft}^{3} / \mathrm{min}, \mathrm{scfm}\right)$ \\
\hline SEER & Seasonal Energy Efficiency Ratio (Btu/(W h)) \\
\hline SHR & Sensible Heat Ratio (-) \\
\hline$T$ & temperature, ${ }^{\circ} \mathrm{C}\left({ }^{\circ} \mathrm{F}\right)$ \\
\hline$T_{\mathrm{CR}}$ & condenser inlet saturation temperature, ${ }^{\circ} \mathrm{C}\left({ }^{\circ} \mathrm{F}\right)$ \\
\hline$T_{\mathrm{DW}}$ & compressor discharge-line wall temperature, ${ }^{\circ} \mathrm{C}\left({ }^{\circ} \mathrm{F}\right)$ \\
\hline$T_{\text {EAID }}$ & evaporator air inlet dewpoint temperature, ${ }^{\circ} \mathrm{C}\left({ }^{\circ} \mathrm{F}\right)$ \\
\hline$T_{\text {EAOD }}$ & evaporator air exit dewpoint temperature, ${ }^{\circ} \mathrm{C}\left({ }^{\circ} \mathrm{F}\right)$ \\
\hline$T_{\mathrm{ER}}$ & evaporator exit saturation temperature, ${ }^{\circ} \mathrm{C}\left({ }^{\circ} \mathrm{F}\right)$ \\
\hline$T_{\mathrm{ID}}$ & indoor dry-bulb temperature, ${ }^{\circ} \mathrm{C}\left({ }^{\circ} \mathrm{F}\right)$ \\
\hline$T_{\mathrm{IDP}}$ & indoor dew-point temperature, ${ }^{\circ} \mathrm{C}\left({ }^{\circ} \mathrm{F}\right)$ \\
\hline$T_{\mathrm{OD}}$ & outdoor dry-bulb temperature, ${ }^{\circ} \mathrm{C}\left({ }^{\circ} \mathrm{F}\right)$ \\
\hline$T_{\mathrm{SW}}$ & compressor suction-line wall temperature, ${ }^{\circ} \mathrm{C}\left({ }^{\circ} \mathrm{F}\right)$ \\
\hline$\Delta T_{\mathrm{CA}}$ & condenser air temperature rise, ${ }^{\circ} \mathrm{C}\left({ }^{\circ} \mathrm{F}\right)$ \\
\hline$\Delta T_{\mathrm{EA}}$ & evaporator air temperature drop, ${ }^{\circ} \mathrm{C}\left({ }^{\circ} \mathrm{F}\right)$ \\
\hline$\Delta T_{\mathrm{LL}}$ & liquid line temperature drop, ${ }^{\circ} \mathrm{C}\left({ }^{\circ} \mathrm{F}\right)$ \\
\hline$\Delta T_{\mathrm{sc}}$ & liquid line subcooling, ${ }^{\circ} \mathrm{C}\left({ }^{\circ} \mathrm{F}\right)$ \\
\hline$\Delta T_{\mathrm{sh}}$ & evaporator exit superheat, ${ }^{\circ} \mathrm{C}\left({ }^{\circ} \mathrm{F}\right)$ \\
\hline$v$ & variance \\
\hline$W_{\text {cmp }}$ & compressor work (W) \\
\hline$x$ & measured data \\
\hline $\bar{x}$ & moving window average of measured data \\
\hline
\end{tabular}

\section{Greek symbols}




$\begin{array}{ll}\phi & \text { feature or performance parameter } \\ \phi_{\text {EAI }} & \text { evaporator air inlet relative humidity (-) } \\ \phi_{\text {EAO }} & \text { evaporator air exit relative humidity }(-) \\ \sigma & \text { standard deviation }\end{array}$

\section{Subscripts}

$\begin{array}{ll}\text { avg } & \text { average } \\ \text { cmp } & \text { compressor } \\ \text { CA } & \text { outdoor air } \\ \text { CAI } & \text { outdoor air condenser inlet } \\ \text { CAO } & \text { outdoor air condenser exit } \\ \text { CR } & \text { condenser refrigerant } \\ \text { CRI } & \text { condenser refrigerant inlet } \\ \text { CRO } & \text { condenser refrigerant exit } \\ \text { EA } & \text { indoor air } \\ \text { EAI } & \text { indoor air evaporator inlet } \\ \text { EAO } & \text { indoor air evaporator exit } \\ \text { ER } & \text { evaporator refrigerant } \\ \text { ERI } & \text { evaporator refrigerant inlet } \\ \text { ERO } & \text { evaporator refrigerant exit } \\ \text { DB } & \text { dry bulb } \\ \text { DP } & \text { dew point } \\ \text { ID } & \text { indoor chamber } \\ \text { OD } & \text { outdoor chamber } \\ \text { RH } & \text { relative humidity } \\ \text { sat } & \text { saturation }\end{array}$

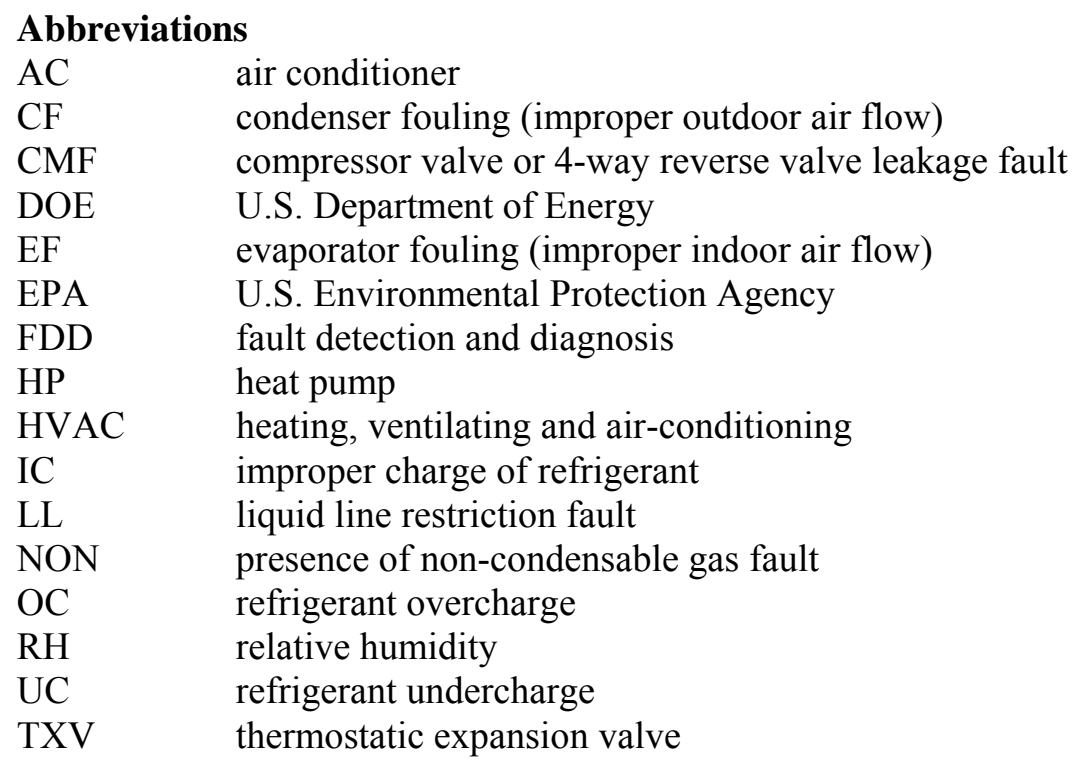




\section{CHAPTER 1. RATIONALE FOR THE STUDY}

An increasing emphasis on energy saving and environmental conservation requires that air conditioners and heat pumps be highly efficient. To this end, several government initiatives have been undertaken. For example, the U.S. Environmental Protection Agency (EPA)'s Global Programs Division is responsible for the assessment of alternative refrigerant performance and enforcement of the Clean Air Act. Another prime example is the ENERGY STAR initiative, a program formulated by the EPA/Climate Protection Partnerships Division and the Department of Energy (DOE), which promotes products that offer energy efficiency gains and pollution reduction. Directly affecting residential equipment, a recent DOE regulation imposes a $30 \%$ increase in the minimum seasonal energy efficiency ratio (SEER) for central air conditioners, from 10.0 to 13.0, beginning January 23, 2006 (Federal Register, 2001).

To assure that heating, ventilating, air-conditioning (HVAC) equipment operates in the field at its design efficiency, the efforts exerted by equipment manufacturers to improve equipment SEER must be paralleled in the field by good equipment installation and maintenance practices. However, a survey of over 55000 residential and commercial units found the refrigerant charge to be incorrect in more than $60 \%$ of the systems (Proctor, 2004). Another independent survey of 1500 rooftop units showed that the average efficiency was only $80 \%$ of the expected value, primarily due to improper refrigerant charge (Rossi, 2004). A low refrigerant charge in the system may be due to a refrigerant leak or improper charging during system installation. While the most common concern about a refrigerant leak is that a greenhouse gas has been released to the atmosphere, a greater impact is caused by the additional $\mathrm{CO}_{2}$ emissions from fossil fuel power plants due to the lowered efficiency of the air-conditioning (AC) unit.

Proctor's survey shows a correlation between the quality of installation and technician training and supervision. Proper training of the technician is a necessary requirement for proper installation. But the survey also showed clearly that the number of return calls to correct improper installation was lowest when routine oversight of the installation work was provided, and that the number of faulty installations markedly increased when post-installation inspection visits were eliminated. At present, the homeowner has no quality assurance method for equipment installation as long as his/her comfort is not compromised.

The goal of this project is to study and develop fault detection and diagnostic (FDD) methods which would provide a technician with a fault diagnosis and could alert a homeowner when performance of their $\mathrm{AC}$ unit falls below the expected range, either during commissioning or post-commissioning operation. For the homeowner, this FDD capability could be incorporated into a future smart thermostat where a readout on performance would allow basic oversight of the service done on the unit and register the effects of that service upon performance.

The benefits of FDD methods for ACs and HPs are numerous and they include;

- reduction of energy use

- reduction in peak demand of electricity

- reduction in $\mathrm{CO}_{2}$ emissions from fossil fuel power plants

- reduction in refrigerant emissions from AC and HP systems

- reduction in down time and maintenance cost

- improvement of thermal comfort

Arguably, development of FDD methods for split equipment presents unique challenges because these systems are assembled on site. Varied assembly skill levels and lack of attention to manufacturer recommendations is the prime reason that automated FDD methods be developed. FDD will provide "Automated Oversight" of servicing and warning of refrigerant charge loss, which is the most frequent 
problem in field assembled systems. It should be noted that the refrigerant leak problem may become even more frequent with the industry transition from medium pressure R22 to higher pressure R410A.

Fault detection and diagnosis is accomplished by comparing a system's current performance or parameters with those expected based on the measurements taken from the system when it was known to operate fault-free. Consequently, FDD method development includes a laboratory phase during which fault-free and faulty operations are mapped. The faults are artificially imposed to learn about the system's response to them. The analytical phase, which follows, is concerned with using the obtained database to develop methods for fault detection and diagnosis. This report documents the laboratory phase of the FDD study carried out on a residential heat pump operating in the cooling mode.

Fault detection and diagnosis has been effectively applied for some time in critical systems and processes, e.g., aerospace and nuclear industry applications, and in chemical processes. FDD methods for HVAC\&R systems have been under development since the late 1980's (McKellar, 1987; Pape et al., 1991; Grimmelius et al., 1995; Stylianou and Nikanpour, 1996). The majority of the early research was devoted to variable air volume air-handling units. On the vapor-compression side, most work was devoted to large systems, particularly to water chillers and single-package air conditioners (Rossi and Braun, 1997; Castro, 2002; Li and Braun, 2003), while split air-conditioning and commercial refrigeration systems received little attention. 


\section{CHAPTER 2. LITERATURE REVIEW}

\subsection{Research Background}

Due to explosively growing energy needs and the global warming problem, energy conservation has become a top priority. For the heating, ventilating, air-conditioning, and refrigerating (HVAC\&R) industry, research has been concentrating on the development of new air-conditioning technologies and improving the energy efficiency of existing vapor compression system designs.

FDD systems were originally developed for the purpose of safety for nuclear power plants or aircraft (Braun, 1999). In such applications, FDD systems are equipped for fail-safe operation disregarding cost. On the other hand, a number of recent industrial applications pursue the reduction of total costs related to equipment downtime, service costs, and utility costs. FDD systems may be applied to reduce costs associated with all of these concerns.

As a result of the decreasing price of sensors and microprocessors, developers can affordably apply FDD systems to automatic management of even non-critical HVAC\&R systems. In addition, remote management systems are being developed using information-based network approaches to increase energy efficiency (Snoonian, 2003). A number of recent research efforts for optimized management systems are being carried out in order to reduce energy consumption (Brownell et al., 1999; Seem et al., 1999; Hayter et al., 1999; Breuker et al., 2000; Roth et al., 2005)

Generally, optimized management systems require the monitored equipment to perform their regular operation without any failure or fault. It is quite possible that the management system may not perform as desired due to internal faults. For difficult cases, some faults that have been neglected or considered as negligible may reveal a fatal problem that requires a costly repair. Therefore, to protect the system from catastrophic failure or performance degradation caused by various faults, it is desirable to introduce the concept of fault detection and diagnostic (FDD) systems to this equipment. To do this, the real time behaviors of residential air-conditioning units should be continuously monitored. Recently, research interests have focused on environmentally-benign household configurations, which encompass the FDD system as an active part of an automated building management system $\equiv$ ang et al., 2000; Wu and Wang, 2002).

The energy savings attributable to FDD depends on the frequency and severity of faults. A brief note based on interviews with practicing engineers and contractors reported that inefficient operation wastes at least $20 \%$ to $30 \%$ of the entire HVAC energy consumption (Westphalen et al., 2003). For rooftop airconditioning units, the average efficiency was estimated at $80 \%$ of the expected value. Approximately $50 \%$ of installations were reported to have efficiency of $80 \%$ or less and $20 \%$ of installations had efficiency of $70 \%$ or less (Rossi, 2004).

Proctor (2004) surveyed over 55,000 commercial and residential air-conditioning units in California. Proctor reported that residential systems are better managed than commercial systems; however, their overall quality control was poor. From the report, $95 \%$ of residential units failed the diagnostic test. The main reasons causing the failures are listed as duct leakage, poor insulation, resistance to air flow, improper refrigerant charge, low evaporator air flow, over-sized units, or non-condensables in the refrigerant. Furthermore, the refrigerant charge in residential air-conditioning units was incorrect $62 \%$ of the time, and charge in commercial units was incorrect $60 \%$ of the time. Proctor also provided other survey results concerning improper installation and management problems. Proctor's survey shows a correlation between the quality of installation and the technician's training and supervision. 
Figure 2.1 represents national energy flow for the United States in 2004 (DOE/EIA-0384, 2005). Numbers by sectors represent units of energy in quads $\left(1\right.$ quad $=1$ quadrillion $\mathrm{BTU}=1 \times 10^{15} \mathrm{BTU}=$ $\left.1.055 \times 10^{15} \mathrm{~kJ}\right)$. Although residential and commercial energy demand occupies approximately $40 \%$ of national energy demand, it has received less attention than industrial demand. Considering that some small commercial users utilize residential HVAC systems, energy savings efforts should be increased for residential HVAC systems. Proper commissioning of HVAC equipment could typically reduce annual energy consumption by $5 \%$ to $30 \%$ depending on the building type (Roth et al., 2003). It could reduce commercial building HVAC energy consumption by about 0.5 quads. Based upon national energy consumption of approximately 100 quads annually, Figure 2.1, the total savings can be estimated at $1 \%$ to $2 \%$ including residential and commercial demands.

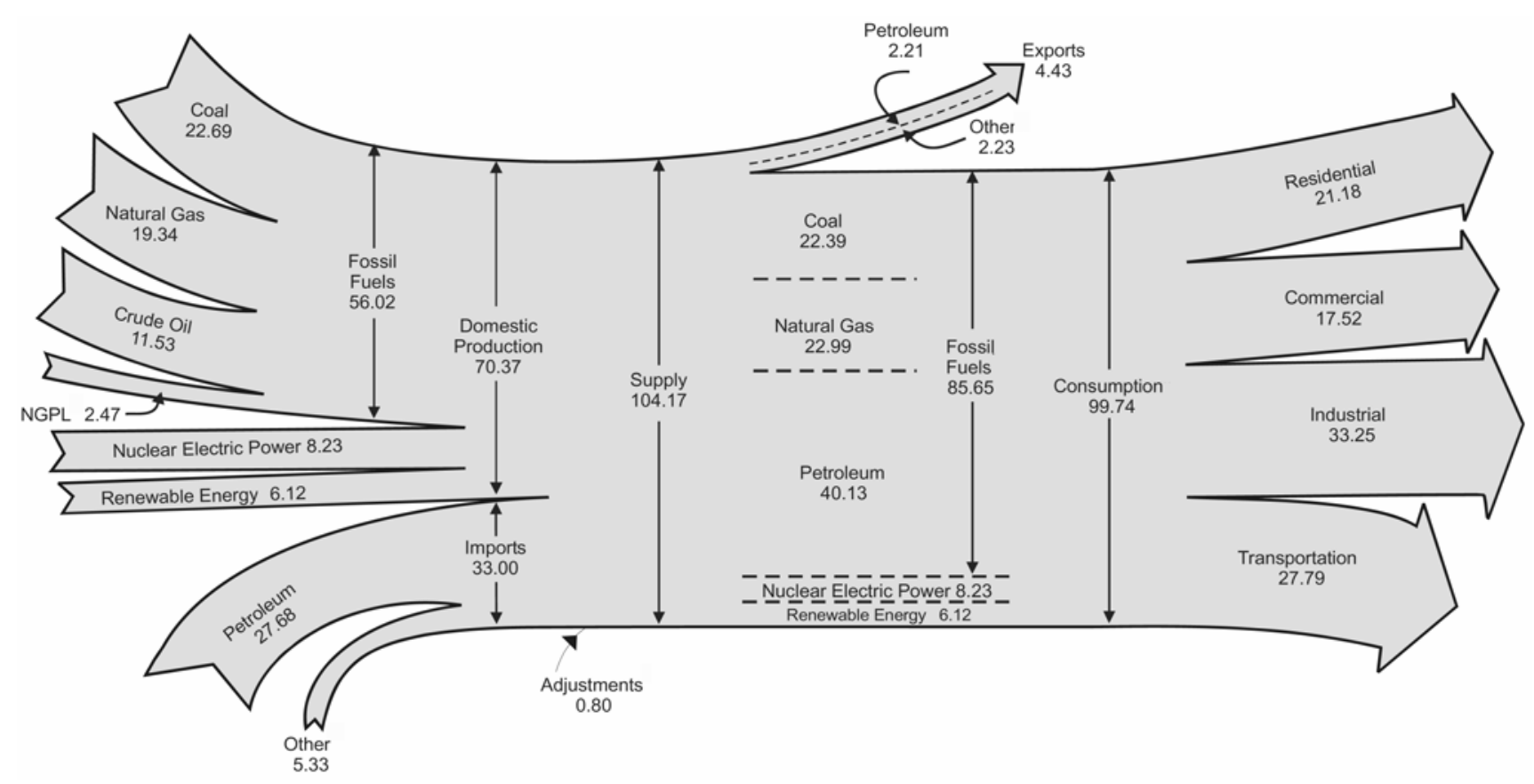

Figure 2.1. Energy flow of the United States in 2004. Units in quadrillion BTU (DOE/EIA-0384, 2005) 


\subsection{Previous Research}

Initial FDD research in the HVAC\&R field was performed for variable air volume air-handling units and chillers. During the development of the first FDD techniques, energy savings was a secondary consideration to preventing equipment malfunction. Anderson et al. (1989) studied statistical analysis preprocessors and rule based expert systems to monitor and diagnose HVAC systems. Pape et al. (1991) developed a methodology for fault detection in HVAC systems based on optimal control. In order to detect faults in system operation, deviation from optimal performance was sensed by comparing the measured system power with the power predicted using the optimal control strategy. Norford and Little (1993) presented a method for diagnosing faults in HVAC systems using parametric models of consumed electric power.

Lee et al. (1996a) represented a scheme for detecting faults in an air-handling unit using recursive parameter identification methods. One approach used in that study was to define residuals that represent the difference between the existing state of the system and the normal state. Residuals that are significantly different from zero represent the occurrence of a fault. In a successive investigation by Lee et al. (1996b), they described the application of an artificial neural network to the problem of fault diagnosis. If the system being monitored is complex, isolating the fault can be challenging, and diagnostic tools should be more adaptable for this purpose. They showed that the artificial neural network method can be a good solution to such problems.

Peitsman and Bakker (1996) applied a black-box model to an HVAC system for fault detection. Multiinput and single-output (MISO) autoregressive with exogenous input models and artificial neural network models are used in the study. The whole HVAC system is regarded as a block box instead of as a collection of component models. With the component model type, the components of the HVAC system are regarded as separate black boxes.

Only recently have investigators begun to examine FDD techniques for vapor compression systems rather than the broader area of the whole HVAC system. FDD for vapor compression systems was initially intended to help technicians servicing individual vapor compression systems. Grimmelius (1995) developed an on-line failure diagnosis system for a vapor compression refrigeration system used in a naval vessel or a refrigerated plant. He established a symptom matrix based on the combination of casual analysis, expert knowledge, and simulated failure modes. Using fuzzy logic, a real-time recognition of the failure model was suggested. The author commented on the need to develop more general skills for reference state estimation, on insensitive pattern recognition routines for failure models, and on transient diagnostic models.

Stylianou and Nikanpour (1996) represented a methodology using thermodynamic modeling, pattern recognition, and expert knowledge to determine the health of a reciprocating chiller and to diagnose selected faults. The authors suggested three fault detection modules for startup, stop, and steady-state operations based on a thermodynamic model and expert knowledge of the chiller. They tried to deal with the sensor drift fault when the chiller was off. In a successive investigation, Stylianou (1997) presented a fault diagnostic methodology using a Bayesian decision rule which assigned different faults, including no-fault, status to single classes.

Rossi and Braun (1997) developed a statistical FDD method for a roof-top air conditioner. The fault diagram was developed with temperature measurements. The residual values are used as performance indices for both fault detection and diagnosis. Statistical properties of the residuals for current and normal operation are used to classify the current operation as faulty or normal. Five kinds of faults can be distinguished from the diagnosis. They suggested a fault detection classifier and a fault diagnostic 
classifier. The fault detection classifier module was based on a Bayesian decision rule, and the fault diagnostic classifier module was developed assuming individual features as a series of independent probabilistic accidents.

Breuker and Braun (1998) surveyed frequently occurring faults for a packaged air conditioner using field data. Based on the field data, Breuker and Braun sorted field faults into three different categories according to the cause of the fault, service frequency, and service cost. With respect to the cause of the fault, system shutdown failures were caused by electrical or control problems approximately $40 \%$ of the time and mechanical problems approximately $60 \%$ of the time. When sorted by service frequency, refrigerant leakage occurs most frequently, followed by condenser, air handling, evaporator, and compressor faults. When sorted by service cost, compressor failure contributes $24 \%$ of total service costs. Control related faults contribute $10 \%$ of total service costs.

Chen and Braun (2001) developed a simplified FDD method for a $17.6 \mathrm{~kW}$ (5 ton) rooftop air conditioner with a TXV. They modified an FDD technique by simplifying Rossi and Braun's method (1997). They used measurements and model predictions of temperatures for normal system operation to compute ratios which were sensitive to individual faults. They also proposed a simple rule-based FDD process of sequential rules developed by comparing the sensitivity of residuals organized within a fault characteristic chart.

Castro (2001) applied a k-nearest neighbor and k-nearest prototype method for fault detection of a chiller. The author calculated Euclidean distances for the current state based on the selected two largest residuals, and estimated the possibility of a fault from the distance information. In this research, the software MATCH was developed as a tool for the controls package to combine monitoring, fault detection, and diagnostic features. After detecting faults, data deemed faulty were input to the rule-based fault diagnosis algorithm. Castro preferred the nearest prototype classifier since the nearest neighbor classifier is more computationally intensive.

Comstock and Braun (2001) tested eight common faults in a $316 \mathrm{~kW}$ (90 ton) centrifugal chiller to identify the sensitivity of different measurements to faults. The identification of common faults was determined through a fault survey among major American chiller manufacturers. The fault testing led to a set of generic rules for the impacts of faults on measurements that could be used for FDD. Impact of faults on cooling capacity and coefficient of performance were also evaluated.

Smith and Braun (2003) performed field-site tests on more than 20 units to identify local installation and operation problems. Using a $10.6 \mathrm{~kW}$ ( 3 ton) rooftop unit with a fixed orifice expansion device and a $17.6 \mathrm{~kW}$ (5 ton) unit with a TXV, the FDD problem was formulated in a mathematical way and a decoupling based unified FDD technique was proposed to handle multiple simultaneous faults. Li (2004) re-examined the statistical rule-based method initially formulated by Rossi and Braun (1997) and presented two additional FDD schemes which improved the sensitivity of the FDD module. He also provided virtual sensors to estimate characteristic parameters from indirect component modeling. For a reference model, Li combined a multivariate polynomial model and a generalized regressive neural network (GRNN).

Kim and Kim (2005) tested a water-to-water heat pump system with a variable speed compressor and an electrical expansion valve (EEV). From the research, the system parameters are found to be less sensitive to faults compared to a constant speed compressor system. They reported that controlling the compressor speed suppressed the changeability of the system. They also provided an FDD algorithm along with two different rule-based charts depending on the compressor status. Kim and Kim suggested that COP 
degradation due to a fault is much more severe with a variable speed compressor than with a constant speed compressor.

\subsection{Research Objective}

The objective of this research was to test a heat pump operating in the cooling mode in order to map system parameters during no-fault and imposed-fault operation. System status was monitored, and performance parameters were recorded. Seven faults were imposed: 1) compressor valve leakage, 2) outdoor improper air flow, 3) indoor improper air flow, 4) liquid line restriction, 5) refrigerant undercharge, 6) refrigerant overcharge, and 7) presence of non-condensable gas. The follow-up study will use the collected results for the development of FDD methods. 


\section{CHAPTER 3. EXPERIMENTAL SETUP AND TEST PROCEDURE}

\subsection{System Selected for Testing}

The studied system was an R410A split residential heat pump of a $8.8 \mathrm{~kW}$ ( 2.5 ton) nominal cooling capacity and Seasonal Energy Efficiency Ratio (SEER) of 13. The unit is comprised of the indoor fancoil section, outdoor section with a compressor, a thermostatic expansion valve (TXV), and connecting tubing. Both the indoor and outdoor air-to-refrigerant heat exchangers were of the finned-tube type. The unit was installed in NIST's environmental chambers and charged with refrigerant according to the manufacturer's specifications.

Figure 3.1 shows the outdoor section. A flow guide was attached to the top of the unit to aid in the traverse of a hot wire anemometer. The coil had $81 \mathrm{~cm} \mathrm{x} 175 \mathrm{~cm}$ (32 in x 69 in) of finned area, with 7 fins/cm (18 fins/in) of a wavy-lanced type fins. Figure 3.2 shows a schematic of the outdoor unit refrigerant circuitry.

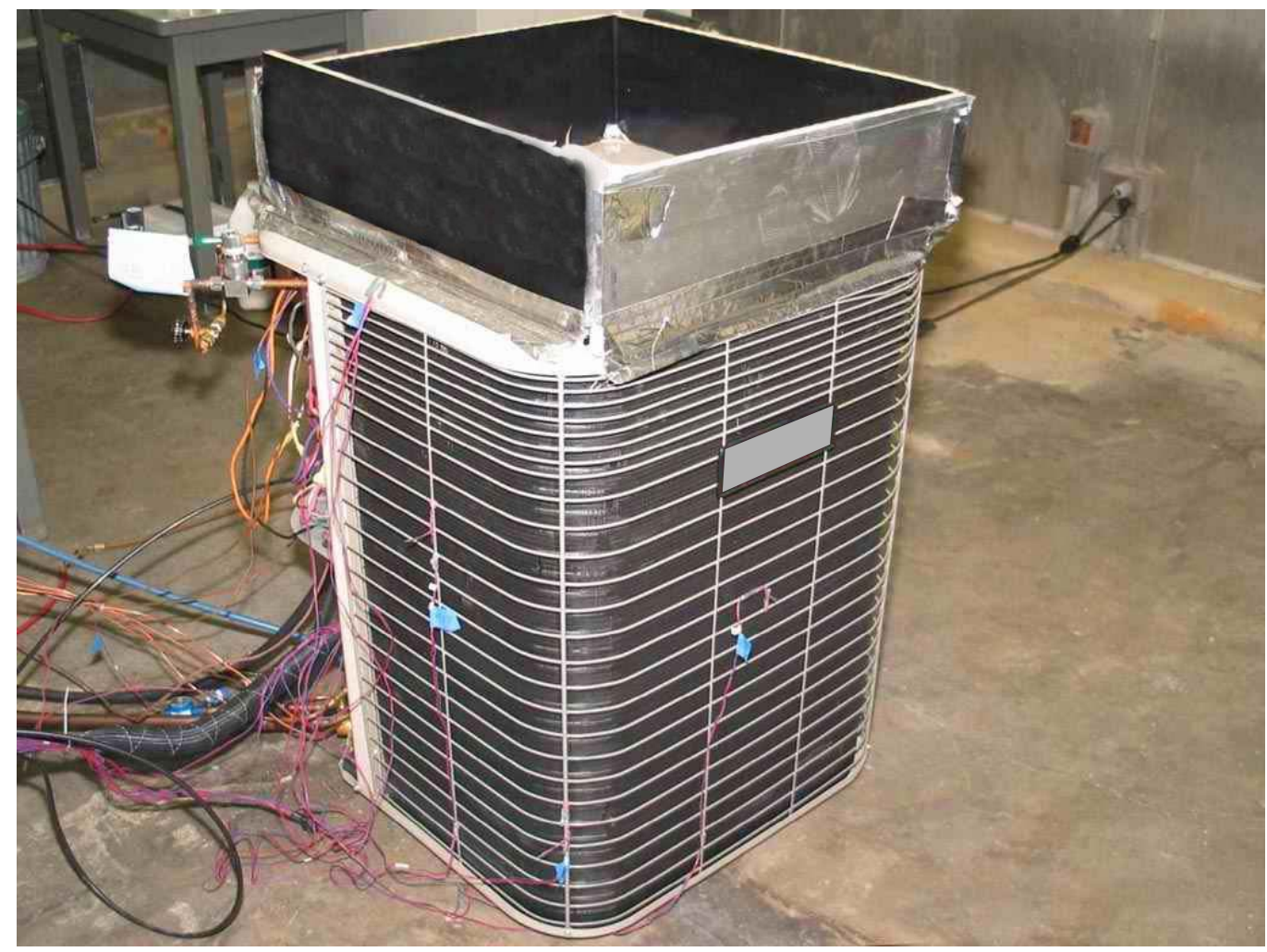

Figure 3.1. Side view of the outdoor section with the flow guide

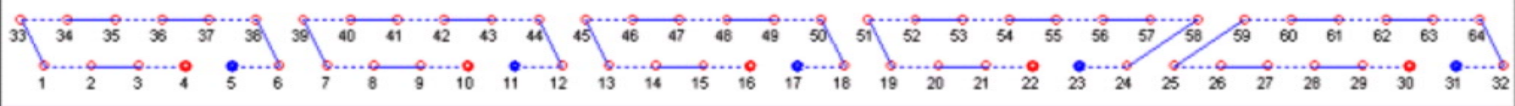

Figure 3.2. Circuitry of the outdoor coil 


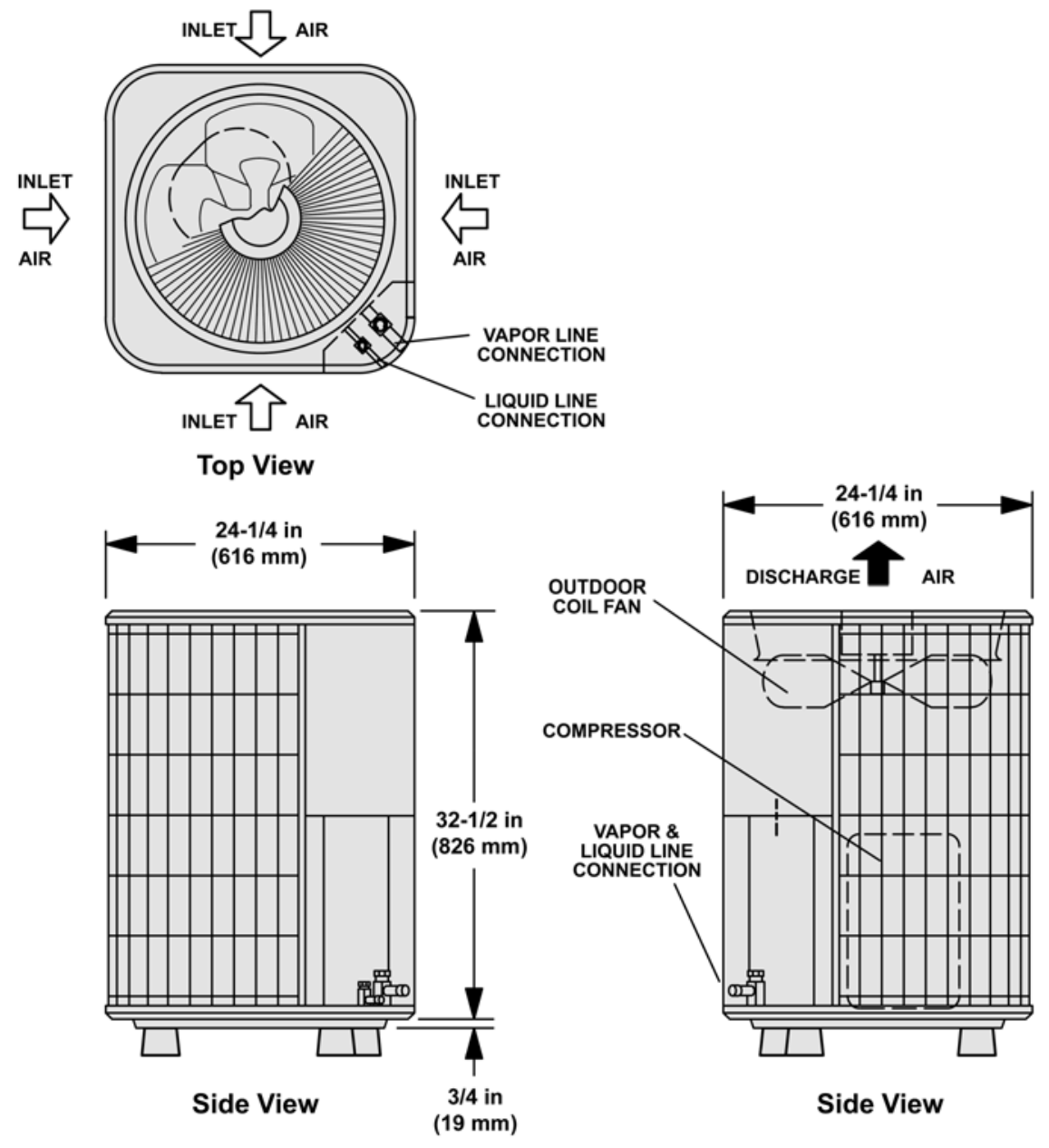

Figure 3.3. Outdoor section dimensions

The circles denote the tubes, the continuous lines indicate the return bends on the near side of the heat exchanger, and the broken lines indicate the return bends on the far side. As Figure 3.2 shows, the outdoor coil had five inlets and five outlets, i.e., it had five independent circuitry branches. Figure 3.3 presents a graphical representation and dimensions of the outdoor unit.

Figure 3.4 shows the side view of the indoor coil assembly. It comprised two identical slabs and was designed for air flow from the bottom to the top. The two slabs had an included angle of $60^{\circ}$ in an Ashape. Each slab of the coil had $48.5 \mathrm{~cm} \mathrm{x} 43 \mathrm{~cm}(19$ in $\times 17$ in) of finned area with 5 fins $/ \mathrm{cm}$ (13 fins/inch) of the wavy-lanced type. Figure 3.5 shows the refrigerant circuitry for both slabs. Each slab had two inlets from the TXV and two outlets connected to the suction manifold. Figure 3.6 shows the configuration and outside dimensions of the indoor fan-coil unit. The air flow rate through the coil was approximately $28.3 \mathrm{~m} / \mathrm{min}(1000.0 \mathrm{scfm})$. Fin thickness for both the indoor and outdoor coils was $0.12 \mathrm{~mm}(0.0047 \mathrm{in})$. 


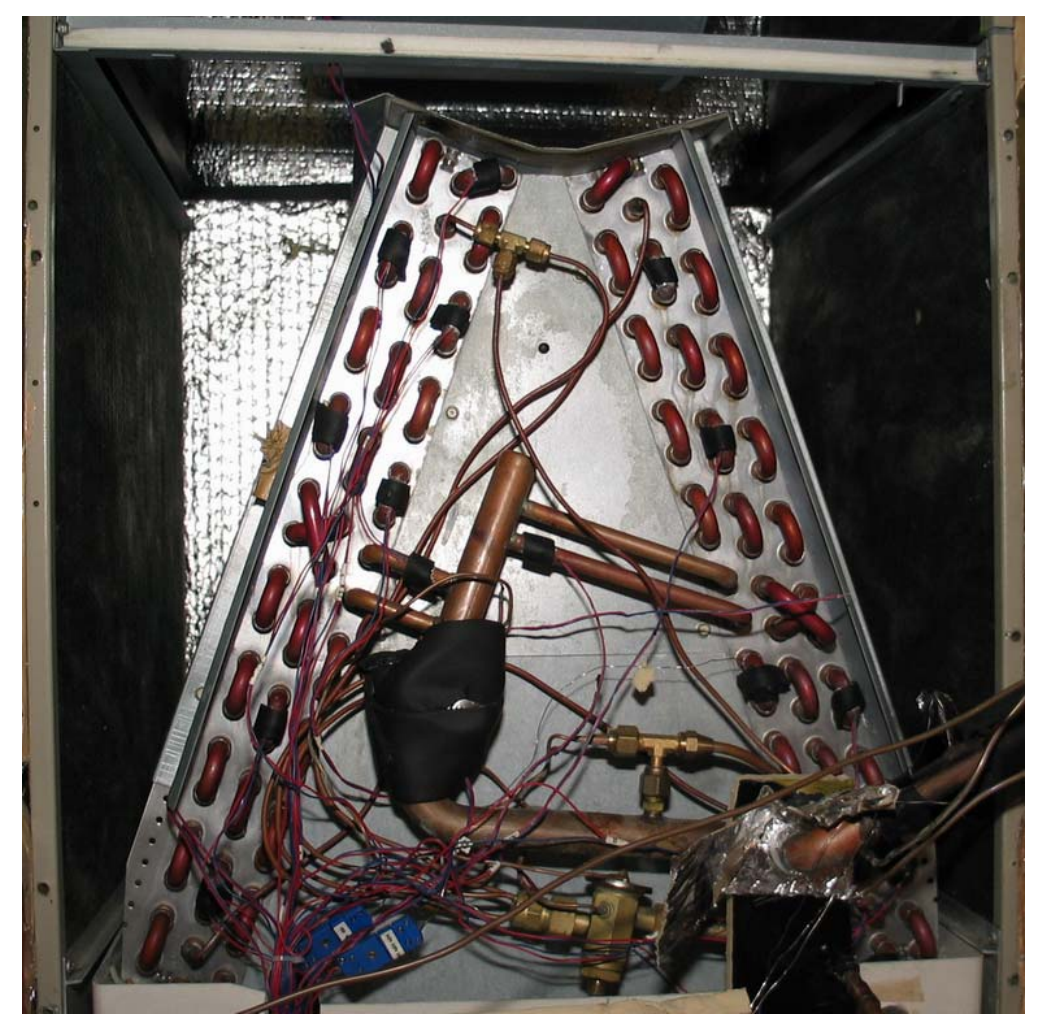

Figure 3.4. Side view of the indoor coil and upflow duct

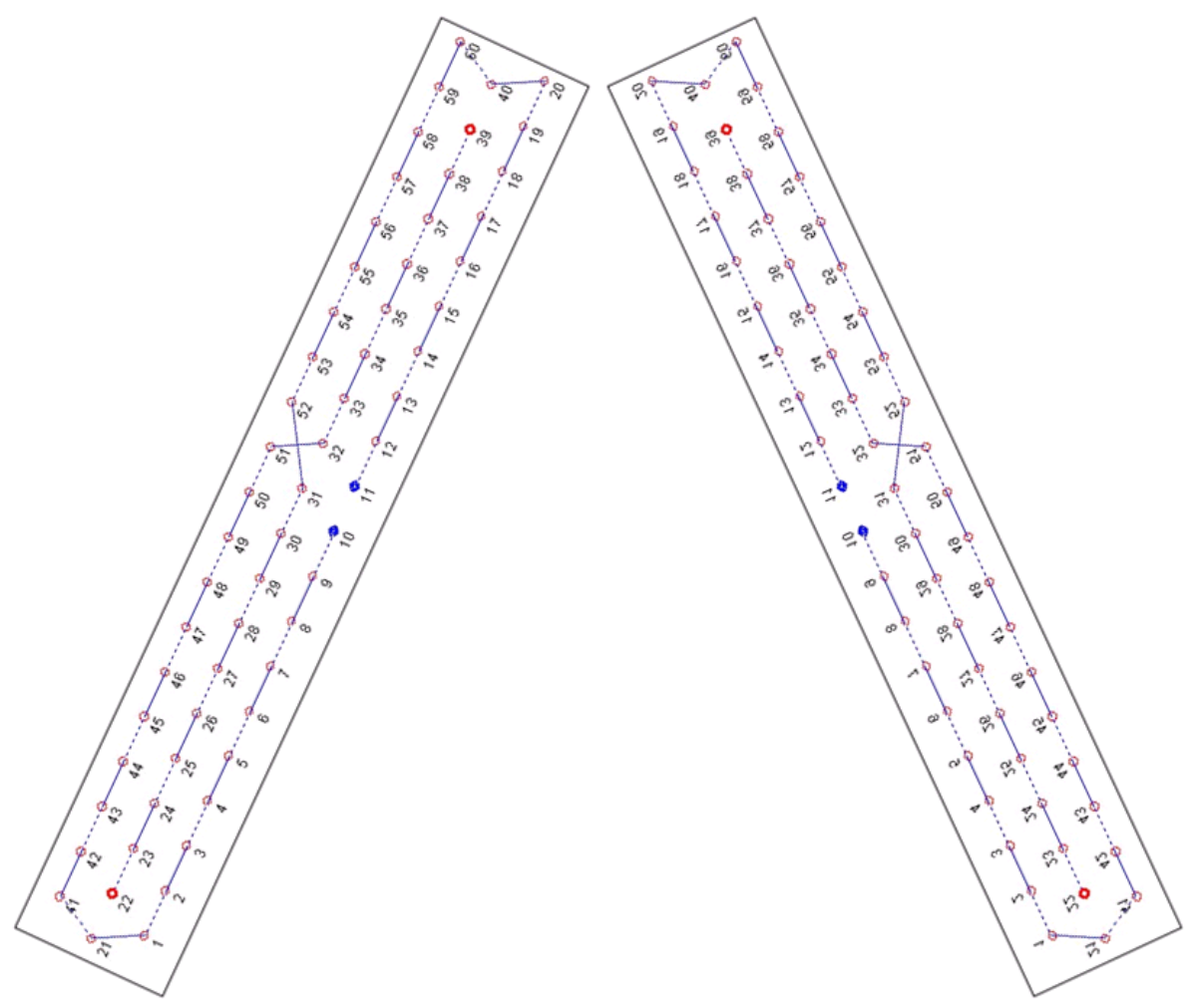

Figure 3.5. Circuitry of indoor coil 


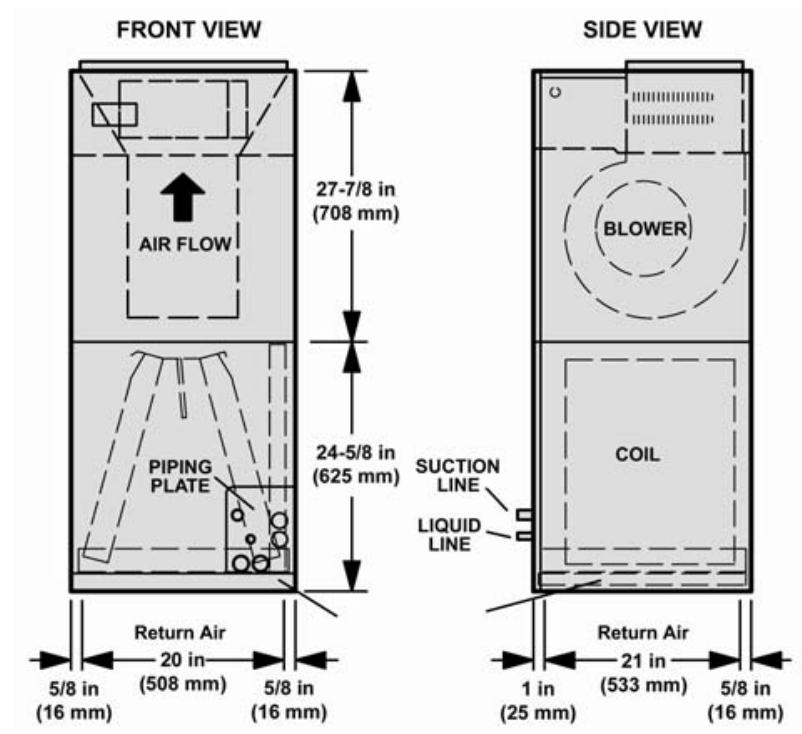

Figure 3.6. Indoor fan-coil unit dimensions

\subsection{System Setup and Instrumentation}

Figure 3.7 shows the air duct arrangement in the indoor environmental chamber. The ductwork was constructed according to the applicable standards (ANSI/ASHRAE Standard 51, ANSI/ASHRAE Standard 37). The air was pulled through the test apparatus by a centrifugal fan located at the outlet of the nozzle chamber ductwork. Figure 3.8 shows the schematic diagram of the heat pump installation. On the air side, the setup involved measurements of dry-bulb and dew-point temperatures, barometric pressure and pressure drop. Dew-point temperature was measured at the inlet of the evaporator ductwork and downstream the evaporator and air mixers. Twenty-five node, T-type thermocouple grids and thermopiles measured air temperatures and temperature change, respectively.

On the refrigerant side, pressure transducers and T-type thermocouple probes were attached at the inlet and exit of every component of the system to take the actual refrigerant pressure and temperature. The refrigerant mass flow rate was also measured using a Coriolis flow meter. The measurements of temperature, pressure, and mass flow rate took place in the locations indicated in Figure 3.8. The air enthalpy method served as the primary measurement of the system capacity, and the refrigerant enthalpy method served as the secondary measurement. These two measurements always agreed within $5 \%$. Additionally, compressor power was measured for calculations of the coefficient of performance (COP). Appendix A lists the measuring devices including the measurements shown in Figure 3.8. Table 3.1 lists characteristic uncertainties of the major quantities measured during this work.

Table 3.1. Measurement uncertainties

\begin{tabular}{|c|c|c|}
\hline Measurement & Range & $\begin{array}{c}\text { Total Uncertainty at the } 95 \% \\
\text { Confidence Level }\end{array}$ \\
\hline \hline Individual Temperature & $-18^{\circ} \mathrm{C}$ to $93^{\circ} \mathrm{C}\left(0{ }^{\circ} \mathrm{F}\right.$ to $\left.200^{\circ} \mathrm{F}\right)$ & $\pm 0.3^{\circ} \mathrm{C}\left( \pm 0.5^{\circ} \mathrm{F}\right)$ \\
\hline Temperature Difference & $0{ }^{\circ} \mathrm{C}$ to $28^{\circ} \mathrm{C}\left(0^{\circ} \mathrm{F}\right.$ to $\left.50^{\circ} \mathrm{F}\right)$ & $\pm 0.3^{\circ} \mathrm{C}\left( \pm 0.5^{\circ} \mathrm{F}\right)$ \\
\hline Air Nozzle Pressure & $0 \mathrm{~Pa}$ to $1245 \mathrm{~Pa}\left(0 \mathrm{in} \mathrm{H}_{2} \mathrm{O}\right.$ to 5.0 in $\left.\mathrm{H}_{2} \mathrm{O}\right)$ & $\pm 1.0 \mathrm{~Pa}\left( \pm 0.004\right.$ in $\left.\mathrm{H}_{2} \mathrm{O}\right)$ \\
\hline Refrigerant Mass Flow Rate & $0 \mathrm{~kg} / \mathrm{h}$ to $544 \mathrm{~kg} / \mathrm{h}(0 \mathrm{lbm} / \mathrm{min}$ to $20 \mathrm{lbm} / \mathrm{min})$ & $\pm 1.0 \%$ \\
\hline Dewpoint Temperature & $\left(32^{\circ} \mathrm{F}\right.$ to $\left.100{ }^{\circ} \mathrm{F}\right)$ & $\pm 0.4^{\circ} \mathrm{C}\left(0.8^{\circ} \mathrm{F}\right)$ \\
\hline Dry-Bulb Temperature & $\left(35^{\circ} \mathrm{F}\right.$ to $\left.100{ }^{\circ} \mathrm{F}\right)$ & $\pm 0.4{ }^{\circ} \mathrm{C}\left(0.8^{\circ} \mathrm{F}\right)$ \\
\hline Total Cooling Capacity & $(15000 \mathrm{Btu} / \mathrm{h}$ to $36000 \mathrm{Btu} / \mathrm{h})$ & $4.0 \%$ \\
\hline COP & 2.5 to 6.0 & $5.5 \%$ \\
\hline
\end{tabular}




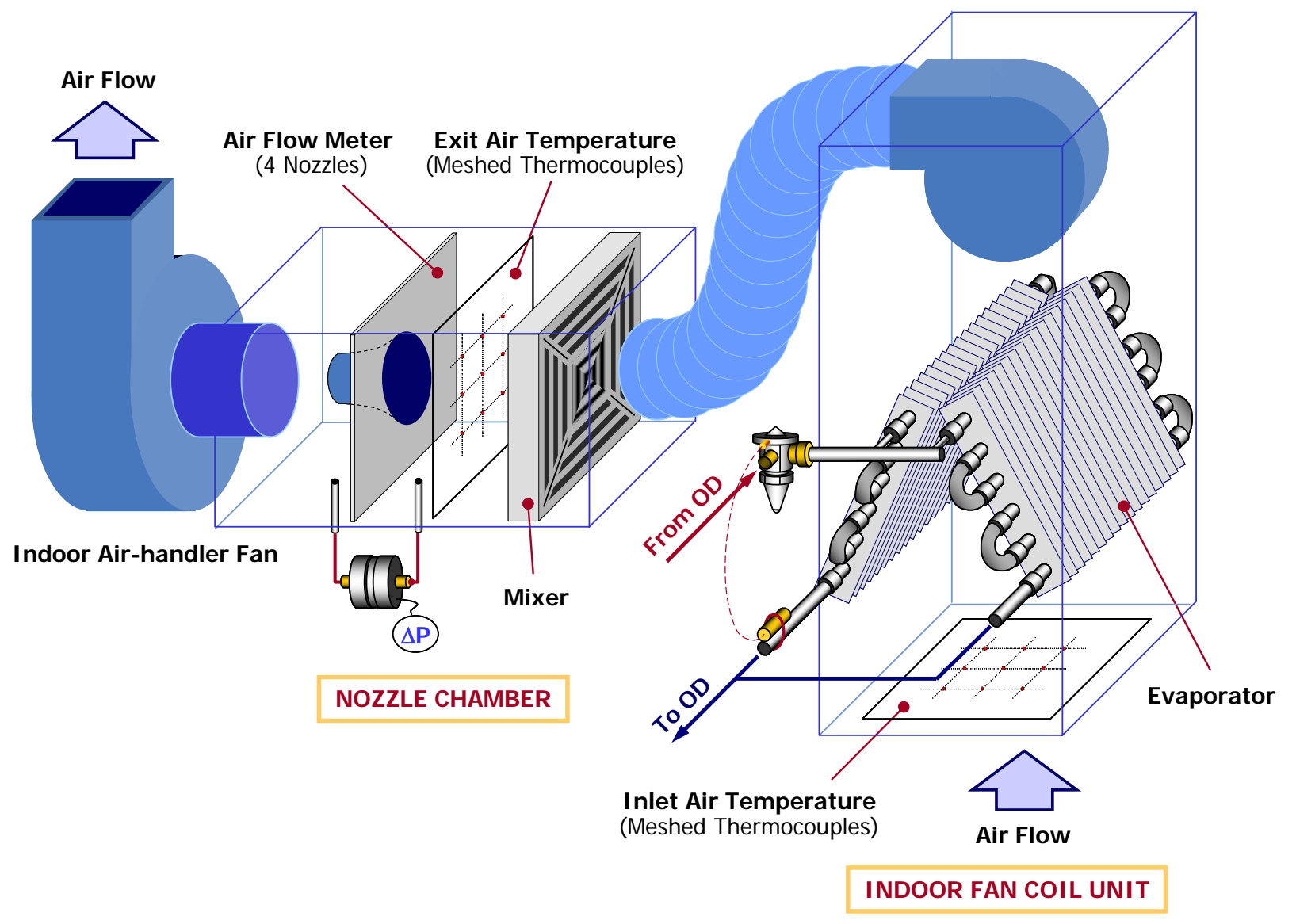

Figure 3.7. Air duct arrangement in the indoor environmental chamber 


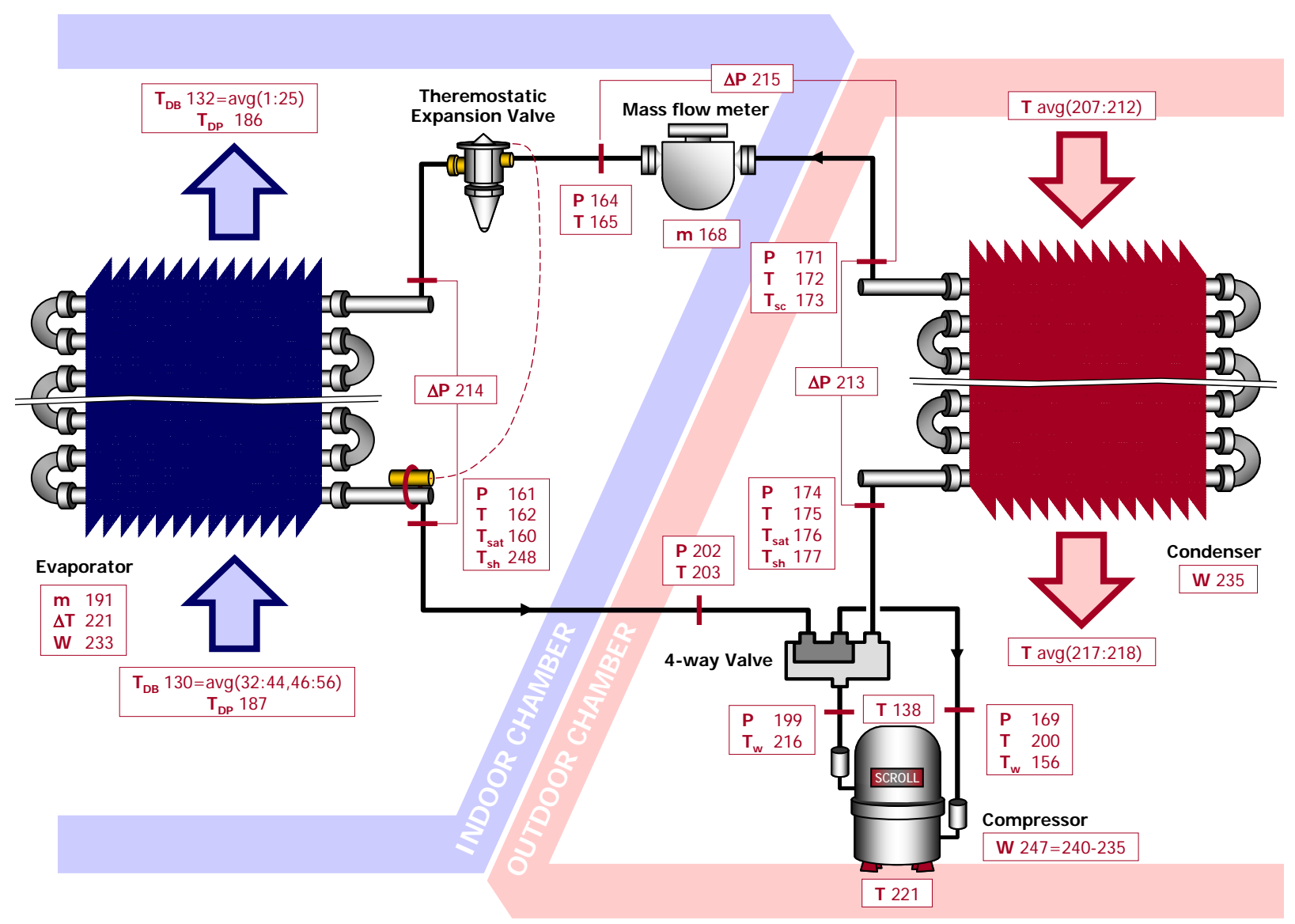

Figure 3.8. Experimental setup with the heat pump in the cooling mode 


\subsection{Implementation of Artificial Faults}

Table 3.1 lists the seven types of common faults which were investigated in this study. The improper indoor air flow, liquid line restriction, refrigerant overcharge, refrigerant undercharge, and presence of a non-condensable gas (air) may result from improper installation. All faults in Table 3.1, except the presence of non-condensables, may also appear in the system after installation over the life of the heat pump. The respective causes may be compressor valve wear, outdoor coil fouling, a dirty air filter or coil fouling, dirty filter/dryer, improper recharge service, and a refrigerant leak. These seven faults and their implementation during tests are discussed in more detail in the sections below.

Table 3.2. Description of studied faults

\begin{tabular}{l|l|l}
\hline Fault & Abbr. & Determination of level of fault during tests \\
\hline Compressor leakage (4-way valve leakage) & CMF & \% of refrigerant flow rate \\
\hline Improper outdoor air flow rate & CF & $\%$ of coil area blocked \\
\hline Improper indoor air flow rate & EF & $\%$ of correct air flow rate \\
\hline Liquid line restriction & LL & $\%$ of normal pressure drop through TXV \\
\hline Refrigerant overcharge & OC & $\%$ overcharge from the correct charge \\
\hline Refrigerant undercharge & UC & $\%$ undercharge from the correct charge \\
\hline Presence of non-condensable gases & NON & $\%$ of non-condensable gas \\
\hline
\end{tabular}

\subsubsection{Compressor/reversing valve leakage}

Compressor faults can arise from various reasons: gas leakage, improper lubrication, motor failure, etc. Brueker and Braun (1998) indicated that approximately $70 \%$ of the classified faults are associated with a motor problem; motor performance degradation may be a result of overloading due to condenser fouling or a high outdoor temperature. Unstable electrical power - such as high/low voltage and voltage spike can also cause motor problems.

The second major compressor fault is due to compressor valve leakage or other leakage which decreases the refrigerant mass flow rate. Wear and tear related to long-time operation of a reciprocating compressor may cause the refrigerant to leak through the suction or discharge valve. For scroll compressors, the refrigerant may leak in tangential directions through radial clearances between the neighboring pockets (flank leakage or tangential leakage) or in the radial direction through axial clearances between the rotating scroll and the body (tip leakage or radial leakage). Improper lubrication can degrade compressibility due to abrasion of contact surfaces like piston rings or cylinder walls. The internal bypasses can arise from the intrusion of liquid refrigerant into the compressor. When the system starts up at low ambient temperatures or has the following faults: evaporator/condenser fouling, refrigerant overcharge, or excessively opened TXV, the compressor suction chamber may be flooded by liquid refrigerant. When the liquid refrigerant intrudes repeatedly into the compressor cylinder, mechanical parts like valves, rods, and piston will be damaged. Each of these faults degrades compression efficiency, whereas fatal compressor breakdown may halt the entire system.

In this research we simulated an internal leak in the compressor by implementing a hot gas bypass shown in Figure 3.9. For no-fault tests, the shut-off valve ensured no refrigerant flow through the bypass. During tests simulating a faulty compressor, fine tuning of the metering valve and a larger crude valve allowed establishment of a desired refrigerant flow rate through the bypass from the compressor discharge line to the suction line. 
We expressed the severity of the artificial compressor leak as the reduction of refrigerant mass flow rate as compared to a no-fault condition. For each operating condition we performed a no-fault test first (with the shut-off valve closed) to obtain the reference mass flow rate. Then, we activated the bypass, and measured the new refrigerant mass flow rate, which was used for calculating the fault level. Refrigerant leakage through a 4-way valve would affect the system performance similarly to the compressor leakage.

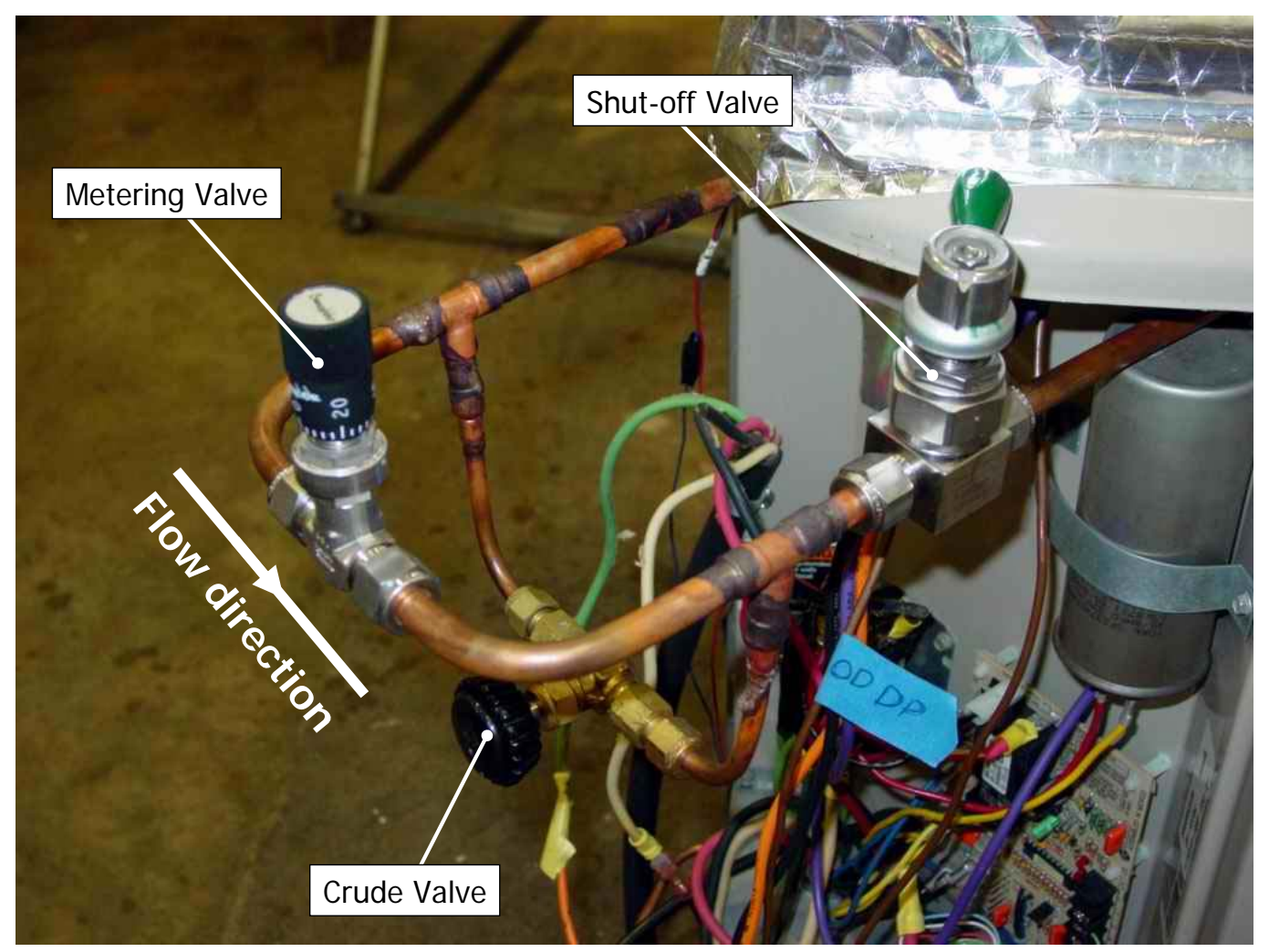

Figure 3.9. Hot gas bypass used for compressor/reversing valve leakage fault

\subsubsection{Improper outdoor air flow rate}

Outdoor sections are exposed to the outdoor environment and are easily contaminated by dirt or debris. Sometimes outdoor sections are surrounded by overgrown weeds or fallen leaves which restrict the air flow to the outdoor heat exchanger. The outdoor air flow may also decrease because of a defective fan motor, loose fan belt, or a poorly installed controller.

We simulated fouling of the outdoor heat exchanger by blocking the bottom part of its finned area with paper strips. The fault level was the percentage of the outdoor coil face area blocked by paper. Figure 3.10 shows the outdoor coil with a blockage or fault level of $35 \%$. 


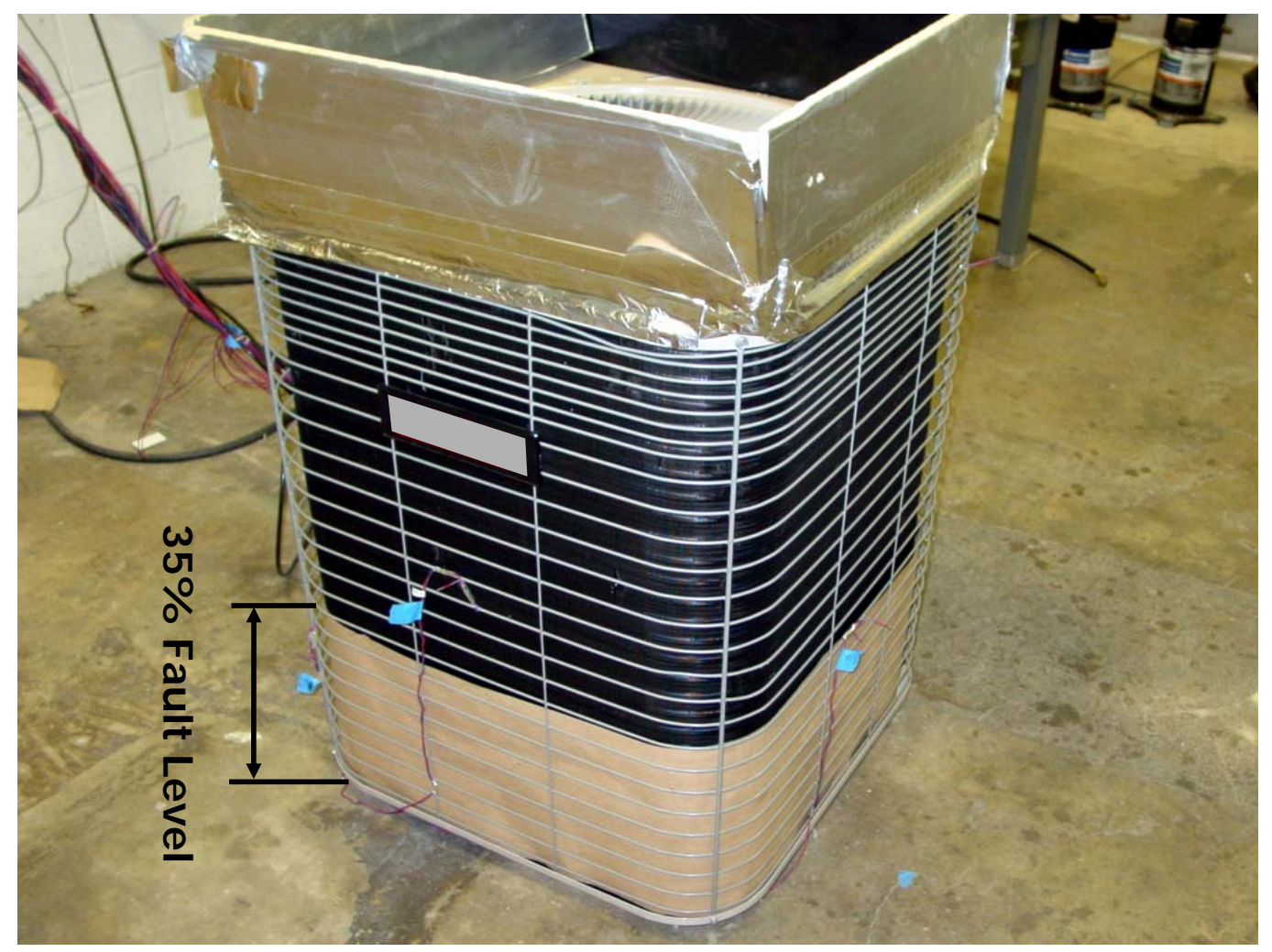

Figure 3.10. Condenser with lower finned area blocked (35\% of the entire finned area blocked)

\subsubsection{Improper indoor air flow rate}

The air flow rate through the indoor section is affected by the size of ductwork, indoor fan sizing, and duct contamination. An improper duct design may burden the fan with an excessive load causing the fan to work below the nominal speed. Dust and debris collected on the heat exchanger may also result in a reduction in the air flow rate. Household articles like textile goods and carpets produce chemically reactive dust, and kitchens and baths also generate chemical vapor. If air filters are not maintained in good condition, these particles can flow into the ductwork and stick on the fan coil unit and duct walls reducing the air flow rate.

For this study the no-fault, reference air mass flow rate was set to $28.3 \mathrm{~m}^{3} / \mathrm{min}(1000 \mathrm{scfm})$. For faulty tests, we reduced the speed of the nozzle chamber fan at the end of ductwork (see Figure 3.7). The fault level was the percent change in air mass flow rate with respect to the reference mass flow rate measured at no-fault conditions.

\subsubsection{Liquid line restriction}

Typically, a filter/dryer is installed in the liquid line to remove moisture and any solid particles from the circulating refrigerant. Moisture may enter the system if a service technician does not follow good refrigerant charging practices during servicing, while some rust may exist in the system because of improper tube joinery technique. Accumulation of these substances will block the filter/dryer and unduly increase the refrigerant flow restriction. 
To simulate an increased liquid line flow restriction, we installed a shut-off valve and metering valve in the liquid refrigerant line in a parallel configuration displayed as shown in Figure 3.10. By modulating the two valves, we controlled the liquid line restriction. The level of the liquid line restriction fault was the percent change in the liquid line pressure drop with respect to the pressure differential between the condenser exit and the evaporator inlet at the no-fault condition.

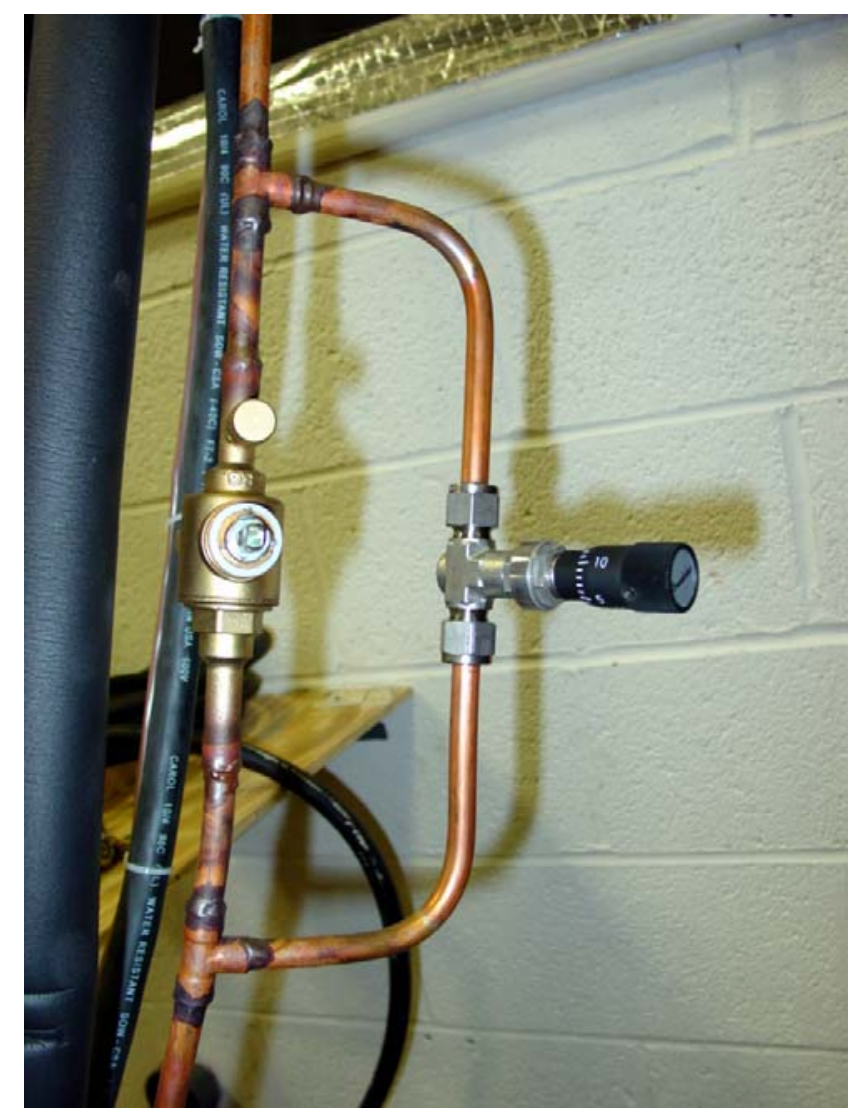

Figure 3.11. Artificial setup to implement a liquid line restriction fault using a shut-off valve and a metering valve

\subsubsection{Refrigerant undercharge and overcharge}

Residential systems are charge sensitive, i.e., their performance is influenced by the amount of refrigerant in the system. Refrigerant overcharge is a result of improper charging by a service technician. Refrigerant undercharge may result from improper charging or from a refrigerant leak. A rapid leak, caused by a component failure such as a fractured heat exchanger wall, is easy to detect because it degrades the system performance abruptly (a so called "hard fault"). A slow leak - e.g., due to a bad fitting in the refrigerant line where a small portion of refrigerant leaks for a long time - is typically difficult to detect, because the change in performance is slow and gradual (a so called "soft fault"). We simulated the overcharge and undercharge faults by adding or reducing the amount of refrigerant in the system. We determined the level of fault as the mass percentage of overcharged or undercharged refrigerant with respect to the optimized no-fault total refrigerant charge.

The improper charge was set by adding more or less refrigerant to the system, but keeping the same amount of POE (polyester) oil. The charge level was established in reference to nominal charge, assumed 
as $100 \%$. A charge of $4.65 \mathrm{~kg}$ of R410A was taken as reference following the manufacturer's optimum charging criteria.

\subsubsection{Presence of non-condensable gases}

Before charging a system with a refrigerant, the system should be evacuated below $500 \mathrm{mTorr}(0.02 \mathrm{inHg}$ absolute) to remove the air and moisture. When a service technician uses a defective vacuum pump or does not operate it correctly, some air and moisture will remain in the system. This air may be particularly detrimental to systems using polyol ester lubricants, which absorb about 10 times more moisture from air than mineral oils and alkyl benzene. (For this reason polyol ester lubricants are packaged with a nitrogen blanket as a moisture barrier and are stored in metal containers rather than plastic since moisture migrates over time through plastic.)

Non-condensable gases raise condensing pressure, which degrades the compressor efficiency and increases energy consumption. A TXV can malfunction at unduly elevated system pressures. The compressor can be damaged in an extreme case.

In this research we injected dry nitrogen gas to simulate non-condensable gas intrusion into the system. Atmospheric pressure nitrogen was set as a $100 \%$ fault level. Fault level was determined as the proportion of injected mass of nitrogen to the nitrogen mass constituting a $100 \%$ fault (completely filling up the internal volume of the system at atmospheric pressure).

\subsection{Experimental Procedure and Test Conditions}

We executed a comprehensive test series to map the performance of the system at normal (no-fault) operation and with imposed faults. Table 3.2 presents operating conditions for the test program at nofault conditions. For indoor conditions, the test program included two temperatures, $21.1^{\circ} \mathrm{C}\left(70.0^{\circ} \mathrm{F}\right)$ and $26.7{ }^{\circ} \mathrm{C}\left(80.0^{\circ} \mathrm{F}\right)$, and two levels of relative humidity, $50 \%$ and dry coil. For outdoor conditions, we selected four temperatures: $21.1^{\circ} \mathrm{C}\left(70.0^{\circ} \mathrm{F}\right), 27.8^{\circ} \mathrm{C}\left(82.0^{\circ} \mathrm{F}\right), 32.2^{\circ} \mathrm{C}\left(90.0^{\circ} \mathrm{F}\right)$, and $37.8^{\circ} \mathrm{C}$ $\left(100.0^{\circ} \mathrm{F}\right)$. Outdoor relative humidity is not an influential parameter for performance of the condenser, and it was controlled roughly around $50 \%$ within the range of $40 \%$ to $60 \%$.

The test schedule for no-fault steady-state involved 17 indexed cases; one ARI 210/240 Standard rating test and 16 full factorial combinations of chamber conditions; 2 indoor temperatures $\times 2$ indoor humidities $\times 4$ outdoor temperatures $=16$ tests. The fault tests were carried out for four operating conditions indicated in Table 3.2 by two asterisks (tests $4,5,8$, and 9). All no-fault tests were performed twice to check experimental repeatability. In addition, a no-fault test preceded a series of tests carried out for a given fault at each of the four operating conditions.

Table 3.3 shows the primary set of tests. The tests listed include the repeatability tests, and transient tests. In total, the table lists 257 tests. The installation of the system, measurements, and data reduction were performed according to the applicable standards (ASHRAE Standard 37, ARI 210/240 Standard). 
Table 3.3. Operating conditions for no-fault tests

\begin{tabular}{|c|c|c|c|c|}
\hline \multirow{2}{*}{$\begin{array}{l}\text { Test } \\
\text { index }\end{array}$} & \multicolumn{2}{|c|}{ Indoor } & \multicolumn{2}{|c|}{ Outdoor } \\
\hline & $\begin{array}{l}\text { Dry-bulb temp. } \\
{ }^{\circ} \mathrm{C}\left({ }^{\circ} \mathrm{F}\right)\end{array}$ & $\begin{array}{c}\text { Relative humidity } \\
\%\end{array}$ & $\begin{array}{l}\text { Dry-bulb temp. } \\
{ }^{\circ} \mathrm{C}\left({ }^{\circ} \mathrm{F}\right)\end{array}$ & $\begin{array}{c}\text { Relative humidity } \\
\%\end{array}$ \\
\hline $1 *$ & $26.7(80.0)$ & 50 & $35.0(95.0)$ & 40 to 60 \\
\hline 2 & $21.1(70.0)$ & 50 & $21.1(70.0)$ & 40 to 60 \\
\hline 3 & $26.7(80.0)$ & 50 & $21.1(70.0)$ & 40 to 60 \\
\hline $4 * *$ & $21.1(70.0)$ & 50 & $27.8(82.0)$ & 40 to 60 \\
\hline $5 * *$ & $26.7(80.0)$ & 50 & $27.8(82.0)$ & 40 to 60 \\
\hline 6 & $21.1(70.0)$ & 50 & $32.2(90.0)$ & 40 to 60 \\
\hline 7 & $26.7(80.0)$ & 50 & $32.2(90.0)$ & 40 to 60 \\
\hline $8 * *$ & $21.1(70.0)$ & 50 & $37.8(100.0)$ & 40 to 60 \\
\hline $9 * *$ & $26.7(80.0)$ & 50 & $37.8(100.0)$ & 40 to 60 \\
\hline 10 & $21.1(70.0)$ & dry coil & $21.1(70.0)$ & 40 to 60 \\
\hline 11 & $26.7(80.0)$ & dry coil & $21.1(70.0)$ & 40 to 60 \\
\hline 12 & $21.1(70.0)$ & dry coil & $27.8(82.0)$ & 40 to 60 \\
\hline 13 & $26.7(80.0)$ & dry coil & $27.8(82.0)$ & 40 to 60 \\
\hline 14 & $21.1(70.0)$ & dry coil & $32.2(90.0)$ & 40 to 60 \\
\hline 15 & $26.7(80.0)$ & dry coil & $32.2(90.0)$ & 40 to 60 \\
\hline 16 & $21.1(70.0)$ & dry coil & $37.8(100.0)$ & 40 to 60 \\
\hline 17 & $26.7(80.0)$ & dry coil & $37.8(100.0)$ & 40 to 60 \\
\hline
\end{tabular}

Table 3.4. Primary tests

\begin{tabular}{c|c|c}
\hline Tests & Types of tests & Number of tests \\
\hline No-fault & 16 & 82 \\
\hline Individual faults & 98 & 118 \\
\hline Dynamic tests & 6 & 12 \\
\hline ARI check & 5 & 5 \\
\hline Total & 177 & 257 \\
\hline
\end{tabular}




\section{CHAPTER 4. NO-FAULT TESTS AND SYSTEM CHARACTERISTICS}

\subsection{Identification of Steady State}

Most FDD schemes applied to various types of equipment detect and diagnose faults during steady-state operation. In this study, we envision the FDD process to be performed every time the system is in steady state, or more precisely, when the system is statistically identified to be nearly in a steady state.

Steady state can be detected by observing the entire system, or - more simply - by monitoring selected system parameters. If the goal was to check the system performance, providing enough time to reach steady-state capacity could be a sufficient approach. However, reaching a steady capacity would not guarantee the actual steady state of all parameters used in a particular FDD scheme. Since steady-state schemes are widely used in fault detection, identification of steady-state operation is an important task for satisfactory FDD analysis.

A steady-state detector makes the determination as to whether the system operates in a steady state. The concept of the steady-state detector originates from a noise filter. When parameter measurements are unstable, they are said to be affected by noise, or the system is regarded as being in a transient state. The standard deviation of these measurements indicates the statistical spread in the data distribution, and it can be used to characterize random variation of the measured signal. The system is far from steady-state operation when the standard deviation is large. There are many different ways to design a steady-state detector, but the most common ones have their roots in simple averaging over a predefined moving time window (see Figure 4.1).

In this research, we selected the evaporator exit refrigerant superheat and liquid line refrigerant subcooling as the parameters used for steady-state detection. We applied a steady-state detector which uses the calculation of the mean and standard deviation of these parameters in a recursive fashion. A recursive solution depends on a previously calculated value. Suppose that at any instant $k$, the average of the latest $n$ samples of a data sequence, $x_{i}$, is given by,

$$
\bar{x}_{k}=\frac{1}{n} \sum_{i=k-n+1}^{k} x_{i}
$$

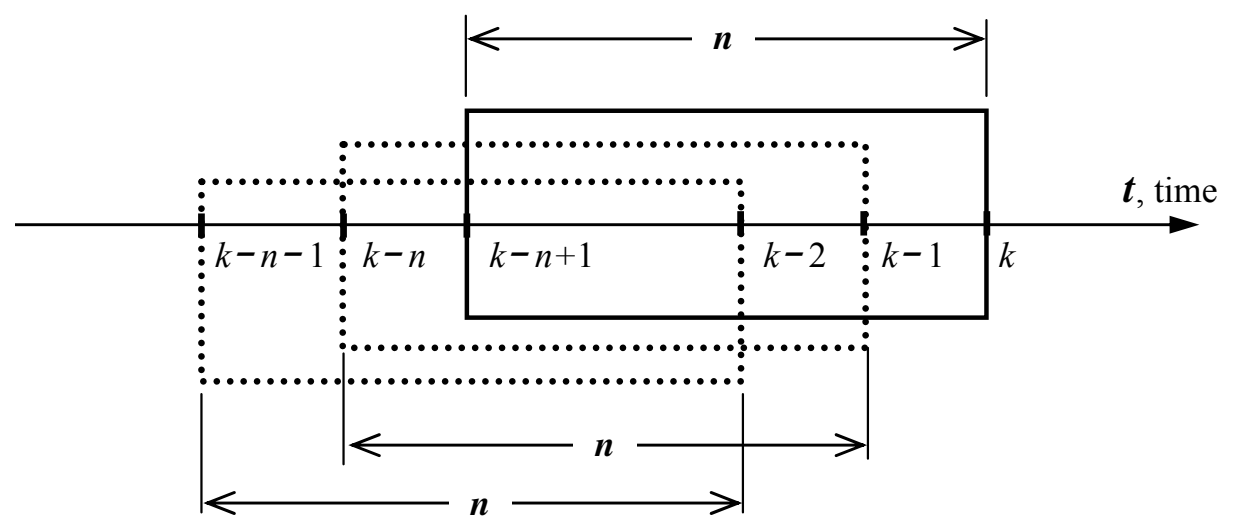

Figure 4.1. Moving windows of $n$ data points at near $k^{\text {th }}$ time 
A difference between two averages of the latest $n$ samples at the current time, $k$, and at the previous time instant, $k-1$, is,

$$
\bar{x}_{k}-\bar{x}_{k-1}=\frac{1}{n}\left[\sum_{i=k-n+1}^{k} x_{i}-\sum_{i=k-n}^{k-1} x_{i}\right]=\frac{1}{n}\left[x_{k}-x_{k-n}\right]
$$

Rearranged, the current average is calculated by,

$$
\bar{x}_{k}=\bar{x}_{k-1}+\frac{1}{n}\left(x_{k}-x_{k-n}\right)
$$

This approach is known as a moving window average because the average at each $k^{\text {th }}$ instant is based on the most recent set of $n$ values. In other words, at any instant, a moving window of $n$ values is used to calculate the average of the next data sequence.

A moving window variance can be defined similarly. Suppose the variance of the latest $n$ samples is

$$
v_{k}=\frac{1}{n} \sum_{i=k-n+1}^{k}\left(x_{i}-\bar{x}_{k}\right)^{2}=\frac{1}{n} \sum_{i=k-n+1}^{k} x_{i}^{2}-\bar{x}_{k}^{2} .
$$

Therefore,

$$
v_{k}=v_{k-1}+\frac{1}{n}\left(x_{k}^{2}-x_{k-n}^{2}\right)-\left(\bar{x}_{k}^{2}-\bar{x}_{k-1}^{2}\right)
$$

Moving window standard deviation is given as

$$
\sigma_{k}=\sqrt{v_{k}}
$$

The steady state detector identified steady-state operation if the standard deviations for the evaporator exit refrigerant superheat and liquid line refrigerant subcooling fell below the pre-specified threshold value of $0.44{ }^{\circ} \mathrm{C}\left(0.8^{\circ} \mathrm{F}\right)$. The size of the moving window was set to 5 samples at 78 second intervals.

\subsection{Variation of Measured Signals}

The performance of an FDD system is closely related to the performance of its sensors. Before developing any FDD system, required sensor accuracy and sensor cost should be evaluated. Cost issues are improving as new sensor technologies are developed; however, there always exist unavoidable uncertainties for measurement systems.

Fundamentally, every sensor has its own uncertainty. When a system is tested with various measurement sensors, uncertainties such as random error (measurement noise, signal noise) and bias error (systematic error) may appear. Uncertainties due to signal noise can be classified as random error which is associated with noise from the instrumentation system and from short-term variations in the process being measured. Measurement noise is similar in shape to sound wave white noise. Normally measurement noise is less than other uncertainties, but in some cases the measurement noise may be severe, e.g., when electrical equipment such as inverters, turbines, and compressors generate strong electromagnetic fields. Some 
sensors are so sensitive to external noise that even slight interference can influence the measurement. In these cases, the sensor should be properly shielded from the noise in order to prevent the measurement from being distorted.

In this research, test conditions are specified by three parameters: outdoor temperature, indoor temperature, and indoor humidity. Figure 4.2 shows the variation of indoor chamber temperature at a setpoint of $21.1^{\circ} \mathrm{C}\left(70.0^{\circ} \mathrm{F}\right)$. The data in the figure were collected after the system was at steady state. Figure 4.2(a) shows a $40 \mathrm{~min}$ variation of one of the temperature sensors at the inlet air duct thermocouple grid with a sampling interval of $78 \mathrm{~s}$. As seen in the plot, indoor temperature is stabile but has fluctuation. In the fluctuation, the effect of random error is dominant compared to the thermocouple measurement total error, i.e., the measurement does not appear to have a bias error. Figure 4.2(b) shows indoor dry bulb temperature for 17 different experiments with a sampling size of 10 measurements. The indoor temperature setpoint was $21.1^{\circ} \mathrm{C}\left(70.0^{\circ} \mathrm{F}\right)$. The stepped horizontal solid lines represent the average of each experiment, and the thick solid line $(\mathrm{m})$ is the overall average of the indoor temperature for all of the 17 experiments.

\subsection{Multivariate Polynomial Reference Model}

The objective of the no-fault tests was to take measurements at different environmental operating conditions at different system locations to formulate key systems parameters - referred to as features and to develop models to correlate these parameters. In this research the outdoor dry-bulb temperature, $T_{O D}$, indoor dry-bulb temperature, $T_{I D}$, and indoor dew-point temperature, $T_{I D P}$, are the independent variables that define operating conditions. All features, $\phi_{i}$, can be explicitly described by multivariate polynomials correlated to the no-fault experimental data. Equations $4.7 \mathrm{a}, 4.7 \mathrm{~b}$, and $4.7 \mathrm{c}$ represent general formulations of $1^{\text {st }}, 2^{\text {nd }}$, and $3^{\text {rd }}$ order multivariate polynomial equations using the independent variables, respectively.

$$
\begin{gathered}
\phi_{i}=a_{0}+a_{1} T_{O D}+a_{2} T_{I D}+a_{3} T_{I D P} \\
\phi_{i}=a_{0}+a_{1} T_{O D}+a_{2} T_{I D}+a_{3} T_{I D P}+a_{4} T_{O D} T_{I D}+a_{5} T_{I D} T_{I D P}+a_{6} T_{I D P} T_{O D}+a_{7} T_{O D}^{2}+a_{8} T_{I D}^{2}+a_{9} T_{I D P}^{2} \\
\phi_{i}=a_{0}+a_{1} T_{O D}+a_{2} T_{I D}+a_{3} T_{I D P}+a_{4} T_{O D} T_{I D}+a_{5} T_{I D} T_{I D P}+a_{6} T_{I D P} T_{O D}+a_{7} T_{O D}^{2}+a_{8} T_{I D}^{2}+a_{9} T_{I D P}^{2} \\
+a_{10} T_{O D}^{2} T_{I D}+a_{11} T_{O D} T_{I D}^{2}+a_{12} T_{I D}^{2} T_{I D P}+a_{13} T_{I D} T_{I D P}^{2}+a_{14} T_{I D P}^{2} T_{O D}+a_{15} T_{I D P} T_{O D}^{2} \\
+a_{16} T_{O D}^{3}+a_{17} T_{I D}^{3}+a_{18} T_{I D P}^{3}
\end{gathered}
$$

The $1^{\text {st }}$ order polynomial equation requires only 4 coefficients which may offer only a rough estimate of the reference. The $3^{\text {rd }}$ order polynomial requires 19 coefficients, which is too many coefficients. In this research, all the features selected are estimated using $2^{\text {nd }}$ order polynomials with 10 coefficients, which estimate the reference with acceptable accuracy. The coefficients of selected features are listed in Appendix C.

In the latter sections of this report, eight features are plotted for graphical presentation: $T_{\mathrm{ER}}$ - evaporator exit refrigerant saturation temperature, $\Delta T_{\mathrm{sh}}$ - evaporator exit refrigerant superheat; $T_{\mathrm{DW}}$ - compressor discharge wall temperature; $T_{\mathrm{CR}}-$ condenser inlet refrigerant saturation temperature; $\Delta T_{\mathrm{sc}}-$ liquid line 


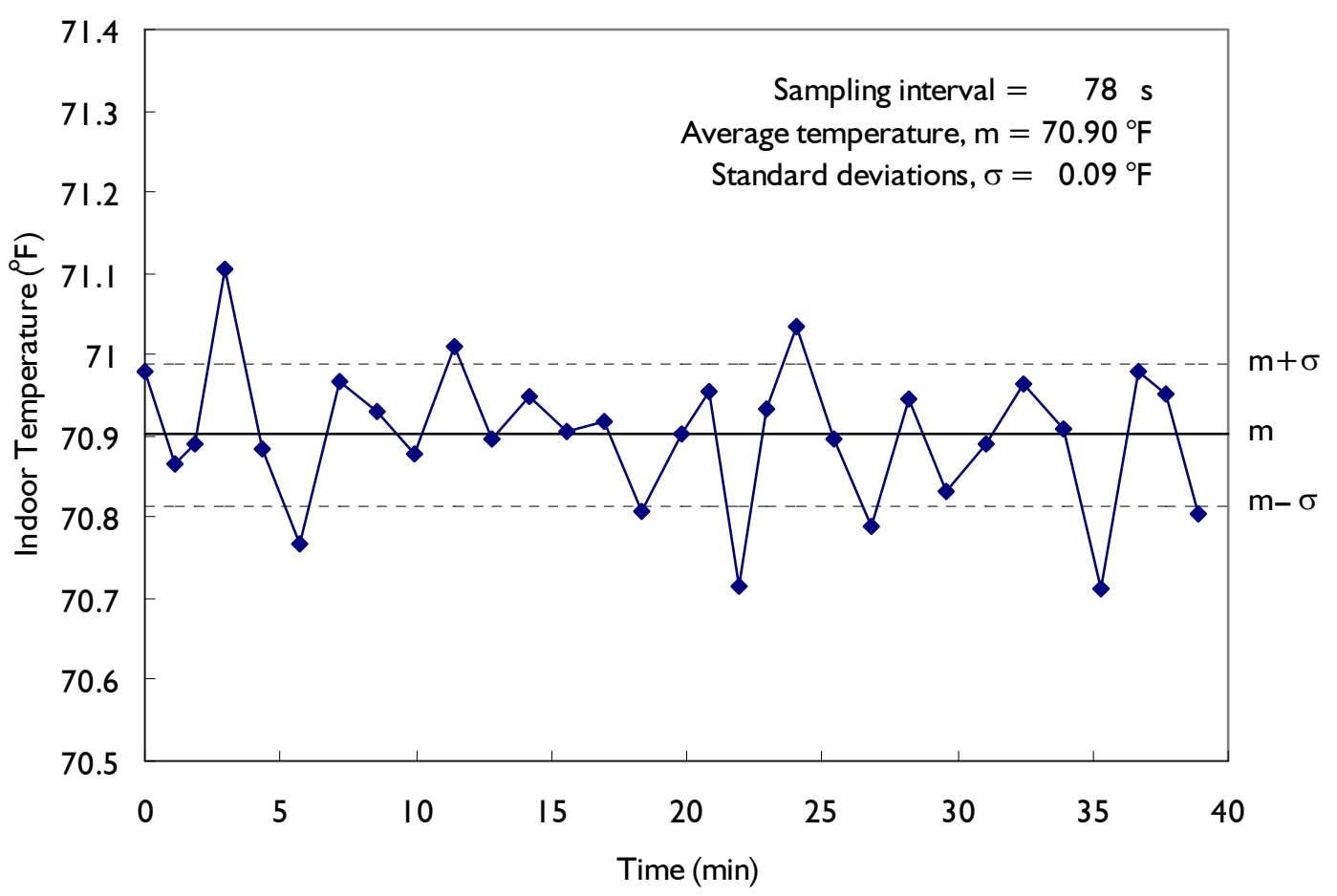

(a) Time change of indoor temperature

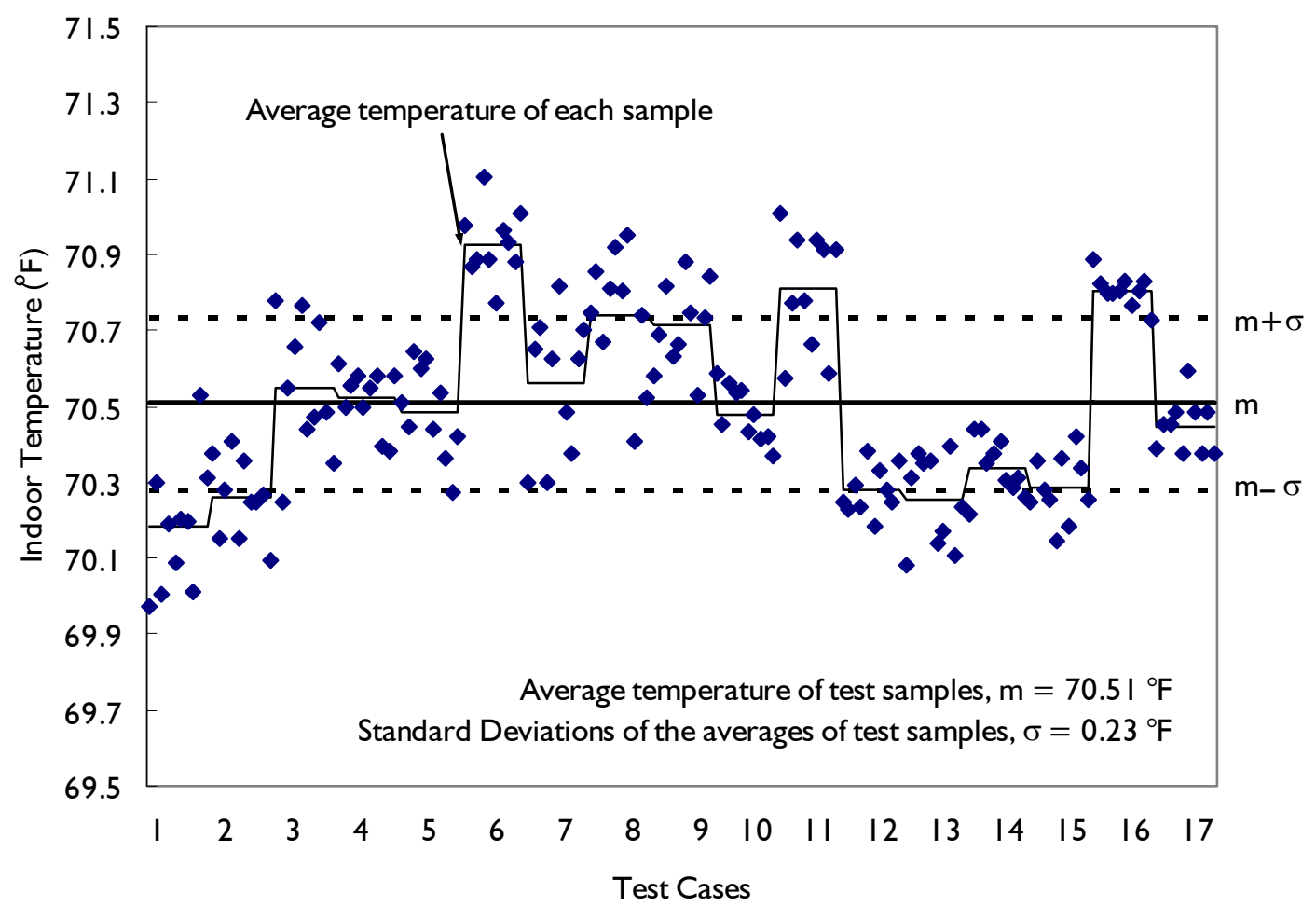

(b) Repeatability of indoor temperature

Figure 4.2. Random error of indoor temperature measurement 
refrigerant subcooling; $T_{\mathrm{CA}}$ - condenser air temperature rise; $\Delta T_{\mathrm{EA}}-$ evaporator air temperature drop; and $\Delta T_{\mathrm{LL}}$ - liquid line refrigerant temperature drop. The features can be expressed by residuals calculated by Equation 4.8. Here residual is defined as the difference between the measured value and the value calculated by the reference model in Equation 4.7.

$$
\mathrm{R}\left(\phi_{i}\right)=\phi_{i, \text { measurements }}-\phi_{i, \text { reference }}
$$

Even though the environmental chamber's control parameters are preset by an operator at a constant value, the temperature will be different and will have some random and systematic errors. In Figure 4.2(b), all the indoor dry-bulb temperatures were controlled to be $21.1^{\circ} \mathrm{C}\left(70.0^{\circ} \mathrm{F}\right)$; however, the obtained temperatures deviated from the target value. As seen in Figure 4.2(b), the 17 cases intended to have $21.1^{\circ} \mathrm{C}\left(70.0^{\circ} \mathrm{F}\right)$ indoor temperature do not represent exactly the same conditions. When we compare the raw measurements, these inevitable deviations function like an external noise and should be considered within the uncertainty analysis. However, when the residuals of the measurements are compared, this deviation can be compensated by mathematical model estimation. When the mathematical model evaluates the current status of the system properly, the trend of the residuals will be much clearer.

In addition to the features, the presented results include the following performance parameters: $Q_{\mathrm{EA}, \text { sens }}-$ indoor air sensible capacity; $Q_{\mathrm{AE}, \text { lat }}$ - indoor air latent capacity; $\mathrm{SHR}_{\mathrm{EA}}$ - indoor air sensible heat ratio; $m_{\mathrm{R}}$ - refrigerant mass flow rate; $Q_{\mathrm{CR}}-$ condenser refrigerant-side capacity; $Q_{\mathrm{ER}}$ - evaporator refrigerantside capacity; $W_{\text {comp }}$ - compressor work; and EER - energy efficiency ratio.

\subsection{No-Fault Test Results}

Figure 4.3 shows the pressure-enthalpy $(P-h)$ diagram for four tests at the same indoor temperature of $21.1^{\circ} \mathrm{C}\left(70.0^{\circ} \mathrm{F}\right)$ and relative humidity of $50 \%$, and four outdoor temperatures of $21.1^{\circ} \mathrm{C}\left(70.0^{\circ} \mathrm{F}\right)$, $27.8^{\circ} \mathrm{C}\left(82.0^{\circ} \mathrm{F}\right), 32.2^{\circ} \mathrm{C}\left(90.0^{\circ} \mathrm{F}\right)$, and $37.8^{\circ} \mathrm{C}\left(100.0^{\circ} \mathrm{F}\right)$ (tests $2,4,6$, and 8 of Table 3.2). The figure shows that the specific enthalpy change in the evaporator $\left(h_{1}-h_{4}\right)$ decreased significantly when outdoor temperature increased, but the specific enthalpy change in the condenser $\left(h_{2}-h_{3}\right)$ changed much less compared to the evaporator.

Figure 4.4 shows the pressure-enthalpy $(P-h)$ diagram for four tests at the same outdoor temperature of $27.8^{\circ} \mathrm{C}\left(82.0^{\circ} \mathrm{F}\right)$ and four different indoor conditions defined by the following set of indoor temperatures and relative humidity: $21.1^{\circ} \mathrm{C}\left(70.0^{\circ} \mathrm{F}\right) / 50 \%, 26.7^{\circ} \mathrm{C}\left(80.0^{\circ} \mathrm{F}\right) / 50 \%, 21.1^{\circ} \mathrm{C}\left(70.0^{\circ} \mathrm{F}\right) /$ dry-coil, and $26.7^{\circ} \mathrm{C}\left(80.0^{\circ} \mathrm{F}\right) /$ dry-coil (tests $4,5,12$, and 13 of Table 3.2). Contrary to Figure 4.2, the specific enthalpy change in both the evaporator and condenser did not vary significantly between the different indoor operating conditions.

Figure 4.5 provides an overview of the variation of eight temperature measurements with regard to the outdoor chamber temperature. 'ID $21.1^{\circ} \mathrm{C}\left(70.0^{\circ} \mathrm{F}\right) \mathrm{DB}$ ', '50\% $\mathrm{RH}$ ', and 'Dry-coil' in the legend represent indoor air dry bulb temperature of $21.1^{\circ} \mathrm{C}\left(70.0^{\circ} \mathrm{F}\right)$, indoor relative humidity of $50 \%$, and an indoor dry-coil test with low relative humidity, respectively. Each line denotes different indoor conditions of dry-bulb temperature and relative humidity.

The first figure in the left-hand column shows that the evaporator saturation temperature for the wet-coil condition $(50 \% \mathrm{RH})$ is higher than that for the dry-coil condition. This is due to the moisture removal enhancing the air-side heat transfer coefficient, resulting in an evaporation temperature closer to the air 


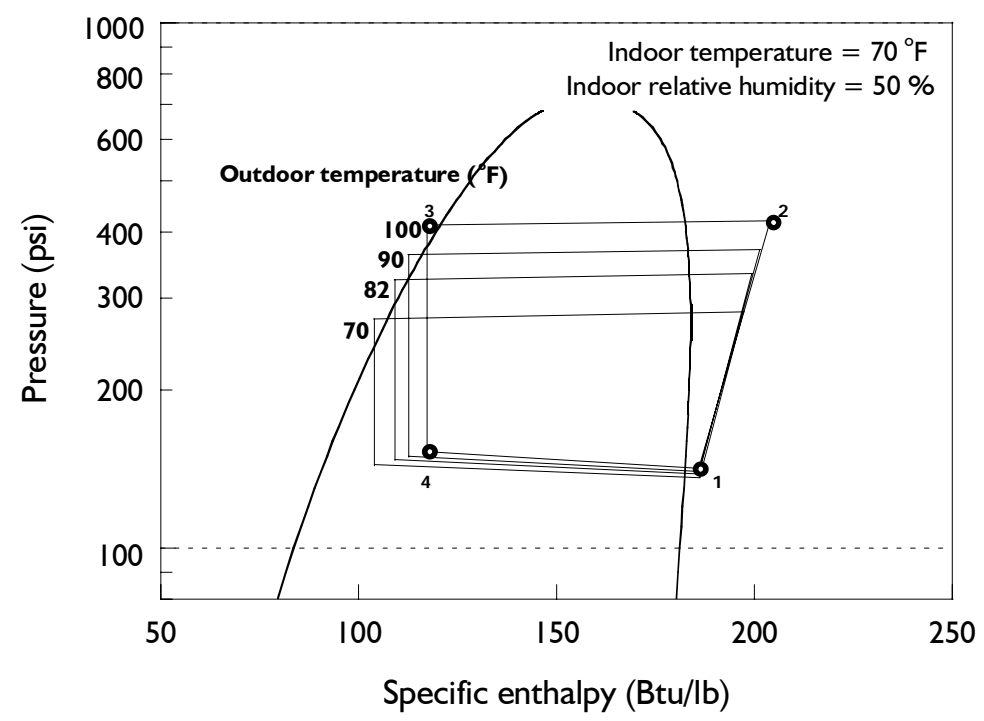

Figure 4.3. Pressure-enthalpy diagrams for tests at $37.8^{\circ} \mathrm{C}\left(100.0^{\circ} \mathrm{F}\right), 32.2^{\circ} \mathrm{C}\left(90.0{ }^{\circ} \mathrm{F}\right), 27.8^{\circ} \mathrm{C}$ $\left(82.0^{\circ} \mathrm{F}\right)$, and $21.1^{\circ} \mathrm{C}\left(70.0^{\circ} \mathrm{F}\right)$ outdoor temperatures with $21.1^{\circ} \mathrm{C}\left(70.0^{\circ} \mathrm{F}\right)$ indoor temperature and $50 \%$ relative humidity

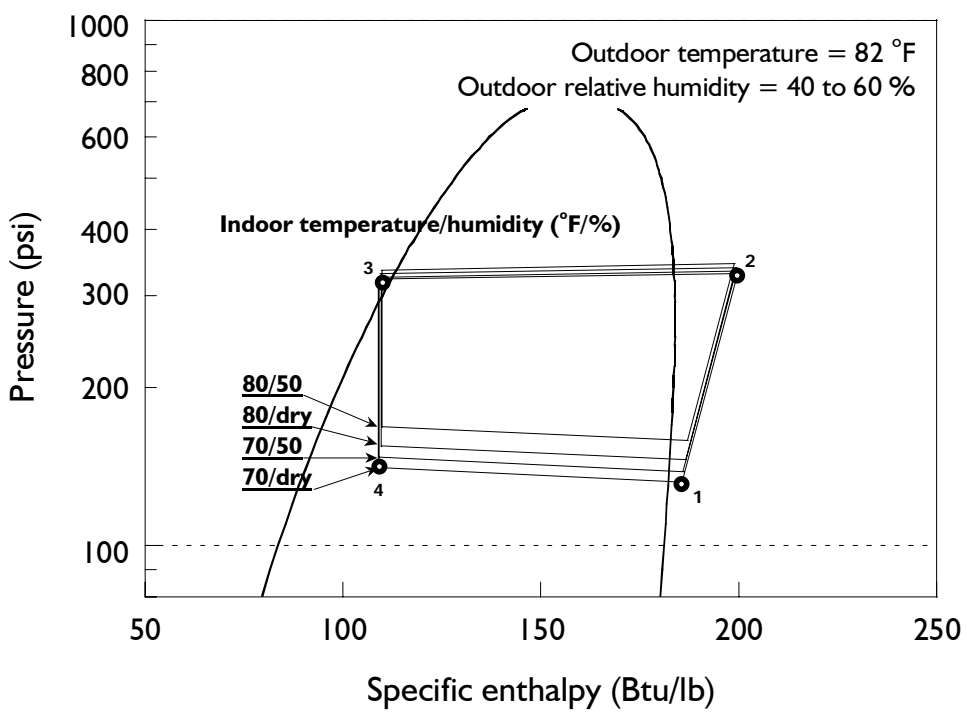

Figure 4.4. Pressure-enthalpy diagrams for tests at $27.8^{\circ} \mathrm{C}\left(82.0^{\circ} \mathrm{F}\right)$ outdoor temperature and four indoor temperature/relative humidity combinations: $26.7^{\circ} \mathrm{C}\left(80.0^{\circ} \mathrm{F}\right) \mathrm{DB} / 50 \% \mathrm{RH}, 26.7^{\circ} \mathrm{C}$ $\left(80.0^{\circ} \mathrm{F}\right) \mathrm{DB} /$ Dry-coil, $21.1^{\circ} \mathrm{C}\left(70.0^{\circ} \mathrm{F}\right) \mathrm{DB} / 50 \% \mathrm{RH}, 21.1^{\circ} \mathrm{C}\left(70.0^{\circ} \mathrm{F}\right) \mathrm{DB} /$ Dry-coil

the second plot in the right-hand column. This figure also shows that the indoor conditions have a small influence on the condenser temperature.

The first figure in the right-hand side column of Figure 4.5 displays the variation of refrigerant superheat at the evaporator exit, $\Delta T_{\mathrm{sh}}$. As the plot shows, the degree of superheat increases at lower outdoor 
temperature. The figure also shows that the evaporator temperature increases as the outdoor temperature increases. This trend is even stronger for the condenser refrigerant saturation temperature, $T_{\mathrm{CR}}$, shown in temperatures. This increase is particularly pronounced for the test with $26.7^{\circ} \mathrm{C}\left(80.0^{\circ} \mathrm{F}\right)$ dry-bulb temperature, where the TXV does not open wide enough to provide enough refrigerant flow at the small pressure differential between the evaporator and condenser. This observation is related to the increased subcooling, $\Delta T_{\mathrm{sc}}$, shown in the third figure of the left-hand column. Since the TXV does not open wide enough, the subcooling increases at low ambient temperatures.

The third figure in the right-hand column and the forth figure in the left-hand column, present the outdoor air temperature gain through the condenser, $\Delta T_{\mathrm{CA}}$, and the indoor air temperature drop through the evaporator, $\Delta T_{\mathrm{EA}}$, respectively. While the indoor air temperature change decreases for higher outdoor temperatures, the outdoor air gain remains at an approximately constant level.

The fourth plot in the right-hand column of Figure 4.5 shows the refrigerant temperature drop through the liquid line. As expected, liquid line temperature drop increases for a higher temperature difference between indoor and outdoor.

Figure 4.6 shows performance charts. All the points in the plots describe averaged measurements or residuals. The first three plots present the trends in the sensible capacity, latent capacity, and sensible heat ratio on the indoor air side. Sensible heat ratio is defined by the following equation:

$$
\mathrm{SHR}_{\mathrm{EA}}=\frac{Q_{\mathrm{EA}, \text { sens }}}{Q_{\mathrm{EA}}}=\frac{Q_{\mathrm{EA}, \text { sens }}}{Q_{\mathrm{EA}, \text { sens }}+Q_{\mathrm{EA}, \text { lat }}}
$$

Since there is no moisture removal during dry-coil tests, lines for 'ID $21.1^{\circ} \mathrm{C}\left(70.0^{\circ} \mathrm{F}\right) \mathrm{DB} / \mathrm{Dry}$-coil' and 'ID $26.7^{\circ} \mathrm{C}\left(80.0^{\circ} \mathrm{F}\right) \mathrm{DB} / \mathrm{Dry}-\mathrm{coil}$ ' overlap on the plots for $Q_{\mathrm{EA}, \text { lat }}$ and sensible heat ratio.

Refrigerant mass flow rate, $m_{\mathrm{R}}$, is little affected by the ambient temperature (second plot in the right-hand column). This is consistent with the results presented in Figure 4.4 showing that refrigerant states at the compressor suction are little changed with a change of the outdoor temperature condition. Although the compressor mass flow rate decreases with an increasing compression ratio (due to a degraded volumetric efficiency), in our case this trend must have been compensated for by a decrease in the suction superheat, which increases refrigerant density and mass flow rate pumped by the compressor.

On the contrary, the refrigerant mass flow rate is significantly influenced by a change of indoor conditions because this significantly affects the refrigerant state at the evaporator exit. When the evaporator temperature is reduced, vapor density at the compressor suction decreases and the mass flow rate also decreases.

The two plots in the third row of Figure 4.6 show the refrigerant-side capacities for the condenser and evaporator, $Q_{\mathrm{CR}}$ and $Q_{\mathrm{ER}}$, respectively. The measurements show similar trends for both heat exchangers.

And finally, the plots in the bottom row show the compressor power and system EER. As the outdoor temperature increases, the compressor requires more power. However, the compressor power is a rather weak function of the indoor operating conditions; the lines representing compressor power for the four indoor conditions considered in this study nearly overlap each other. The EER plot shows some differences due to the differences in evaporator capacities. 

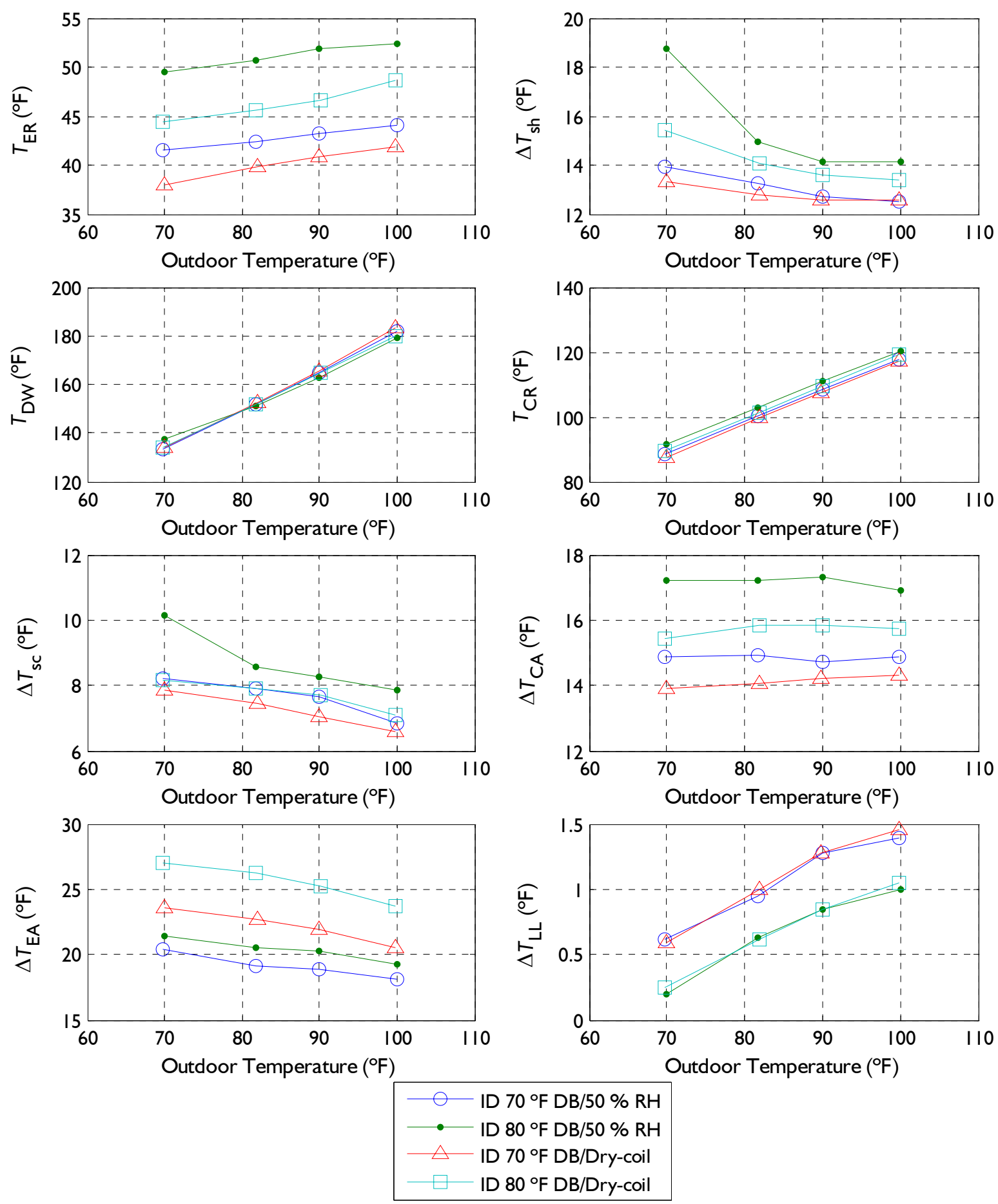

Figure 4.5. Variation of temperature measurements with regard to outdoor chamber temperature under no-fault condition: From the top left to right: $T_{\mathrm{ER}}$ - evaporator exit saturation temperature; $\Delta T_{\mathrm{sh}}-$ evaporator exit superheat, $T_{\mathrm{DW}}$ - compressor discharge wall temperature, $T_{\mathrm{CR}}-$ condenser inlet saturation temperature, $\Delta T_{\mathrm{sc}}$ - liquid line subcooling, $\Delta T_{\mathrm{CA}}$ - condenser air temperature rise, $\Delta T_{\mathrm{EA}}$ - evaporator air temperature drop, $\Delta T_{\mathrm{LL}}$ - liquid line temperature drop 

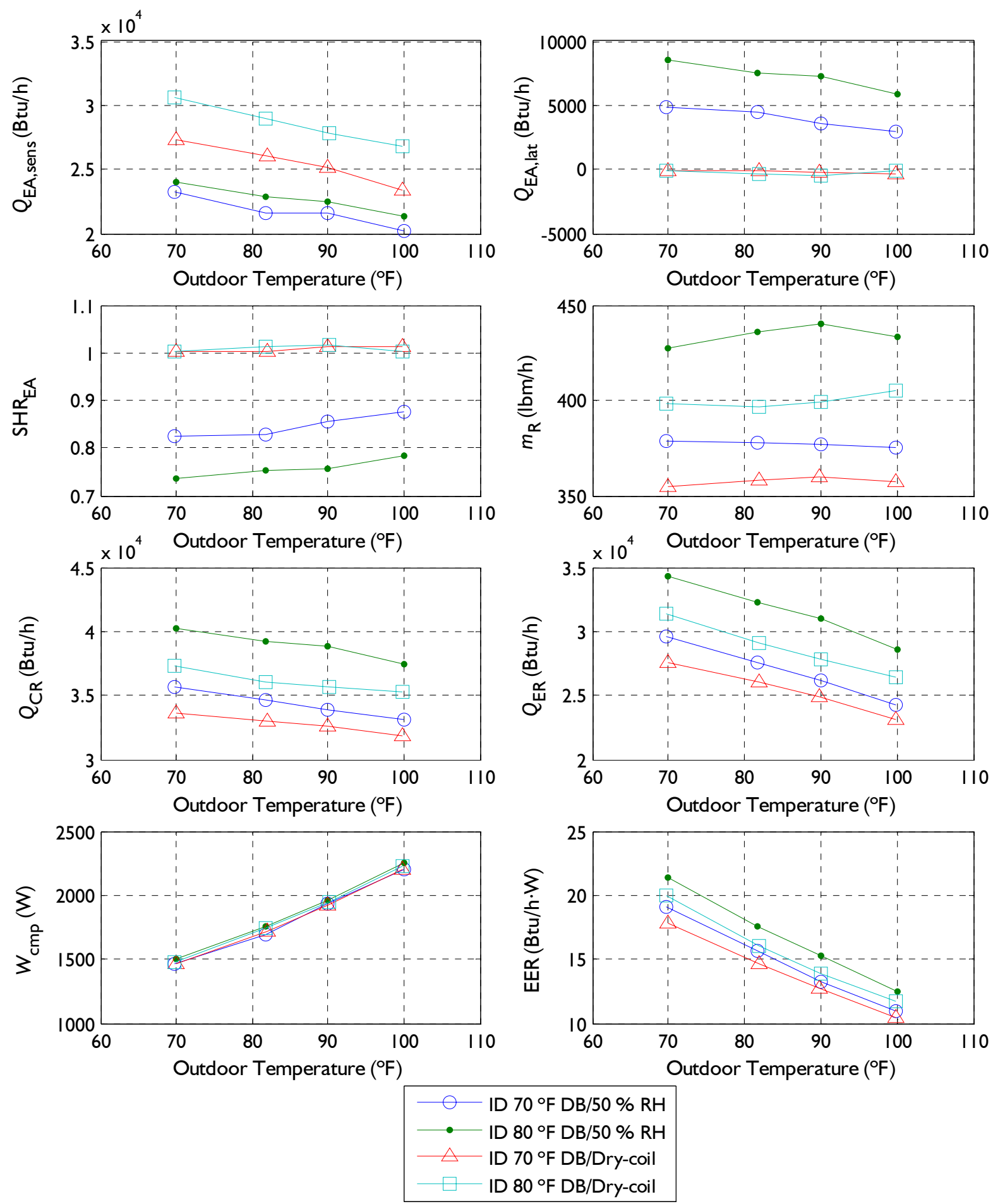

Figure 4.6. Variation of system performance with regard to outdoor air temperature under no-fault conditions: From the top left to right: $Q_{\mathrm{EA}, \text { sens }}$ - indoor air sensible capacity, $Q_{\mathrm{EA}, l a t}-$ indoor air latent capacity, $\mathrm{SHR}_{\mathrm{EA}}$ - indoor air sensible heat ratio, $m_{\mathrm{R}}$ - refrigerant mass flow rate, $Q_{\mathrm{CR}}$ - condenser refrigerant-side capacity, $Q_{\mathrm{ER}}$ - evaporator refrigerant-side capacity, $W_{\mathrm{cmp}}-$ compressor work, EER - energy efficiency ratio 


\section{CHAPTER 5. SINGLE-FAULT TEST RESULTS}

\subsection{Performance Variation under Single Faults}

This section presents the results of single-fault tests. We tested the effect of individual faults at four operating conditions corresponding to the test index of 4, 5, 8, and 9 in Table 3.2. The subsections below present residuals, $R(\ldots)$, for the following eight features:

1. $T_{\mathrm{ER}}-$ evaporator exit saturation temperature

2. $\Delta T_{\mathrm{sh}}$ - evaporator exit superheat

3. $T_{\mathrm{DW}}$ - compressor discharge wall temperature

4. $T_{\mathrm{CR}}-$ condenser inlet saturation temperature

5. $\Delta T_{\mathrm{sc}}$ - liquid line subcooling

6. $T_{\mathrm{CA}}-$ condenser air temperature rise

7. $\Delta T_{\mathrm{EA}}$ - evaporator air temperature drop

8. $\Delta T_{\mathrm{LL}}$ - liquid line temperature drop.

We calculated each residual as a difference between the measured value and the value provided by the reference model for a given feature. In addition to the residuals, the results include the following performance parameters:

1. $Q_{\mathrm{EA}, \text { sens }}-$ indoor air sensible capacity

2. $Q_{\mathrm{EA}, \text { lat }}-$ indoor air latent capacity

3. SHR - indoor air sensible heat ratio

4. $m_{\mathrm{R}}$ - refrigerant mass flow rate

5. $Q_{\mathrm{CR}}-$ condenser refrigerant-side capacity

6. $Q_{\mathrm{ER}}-$ evaporator refrigerant-side capacity

7. $W_{\mathrm{cmp}}$ - compressor work

8. EER - energy efficiency ratio.

\subsubsection{Compressor/reversing valve leakage}

The compressor/reversing valve leakage fault involved at least three fault levels. The fault level was calculated as the ratio of refrigerant mass flow through the system with the fault imposed divided by the refrigerant mass flow rate during no-fault operation. Figure 5.1 shows the residuals described in Equation 4.8 for the eight selected features. The feature residuals in the plots were calculated based on the averaged measurements of fault tests and $2^{\text {nd }}$ order no-fault polynomial model. Figure 5.2 shows the variations in averaged performance parameters.

From Figure 5.1, the refrigerant saturation temperature for the evaporator and condenser $\left(T_{\mathrm{ER}}\right.$ and $T_{\mathrm{CR}}$, respectively) show consistent responses for all four operating conditions. Also, the change in air temperature difference across the evaporator and condenser is similar for the operating conditions studied. This system characteristic corresponds to the similar slopes of the capacity lines for the evaporator and condenser presented in Figure 5.2. From the same figure, it is worth noticing that the refrigerant mass flow rate $\left(m_{\mathrm{R}}\right)$ and compressor power $\left(W_{\mathrm{cmp}}\right)$ are strongly affected by the outdoor temperature, while the indoor condition has a small influence on them. The compressor power slightly decreases with the increasing level of fault because of the corresponding reduction of the temperature (pressure) lift produced by the increased evaporator temperature and decreased condenser temperature. The EER is 

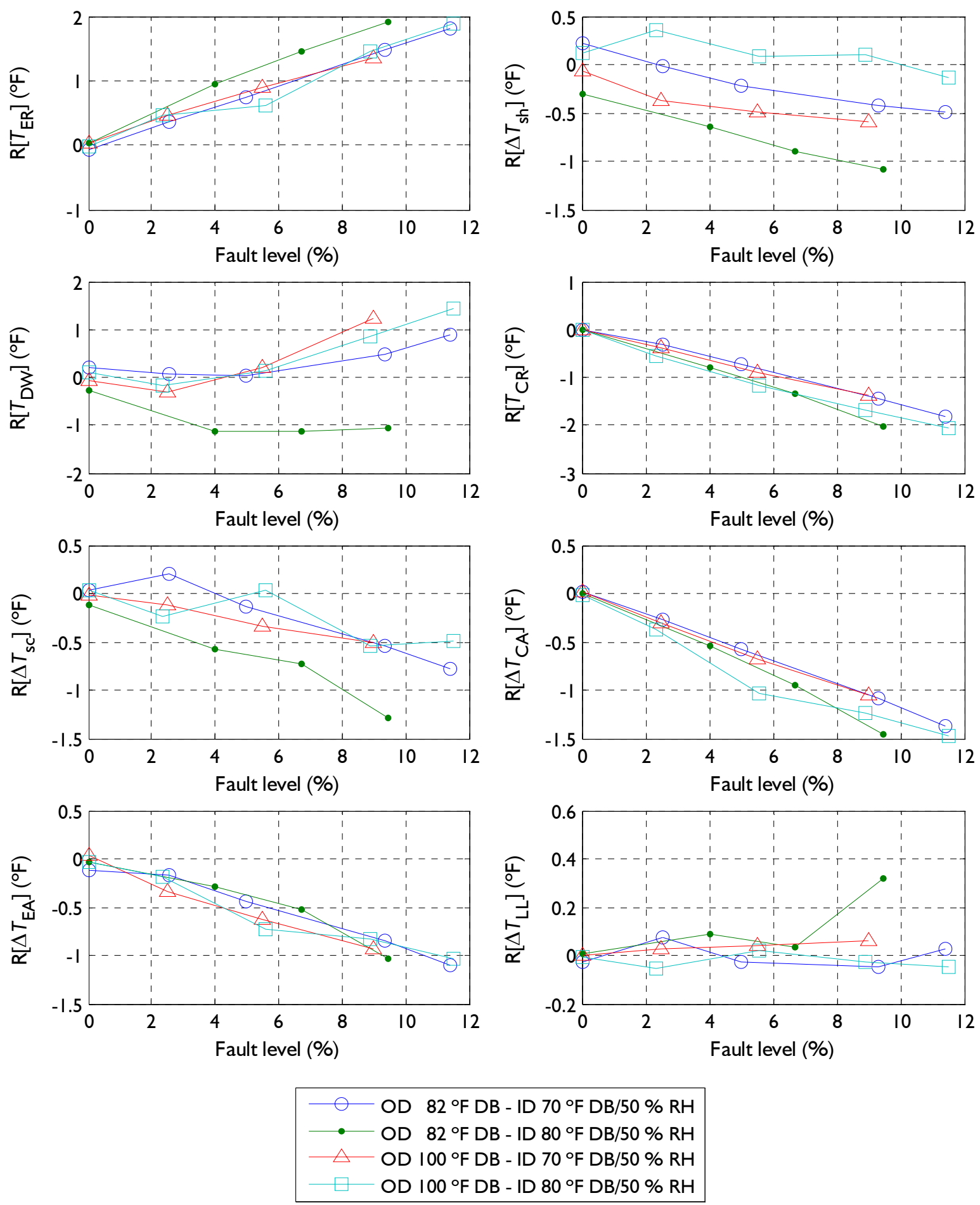

Figure 5.1. Residuals for selected feature with compressor fault. From the top left to right: $T_{\mathrm{ER}}-$ evaporator exit saturation temperature; $\Delta T_{\mathrm{sh}}$ - evaporator exit superheat, $T_{\mathrm{DW}}$ - compressor discharge wall temperature, $T_{\mathrm{CR}}$ - condenser inlet saturation temperature, $\Delta T_{\mathrm{sc}}$ - liquid line subcooling, $T_{\mathrm{CA}}-$ condenser air temperature rise, $\Delta T_{\mathrm{EA}}-$ evaporator air temperature drop, $\Delta T_{\mathrm{LL}}$ - liquid line temperature drop 

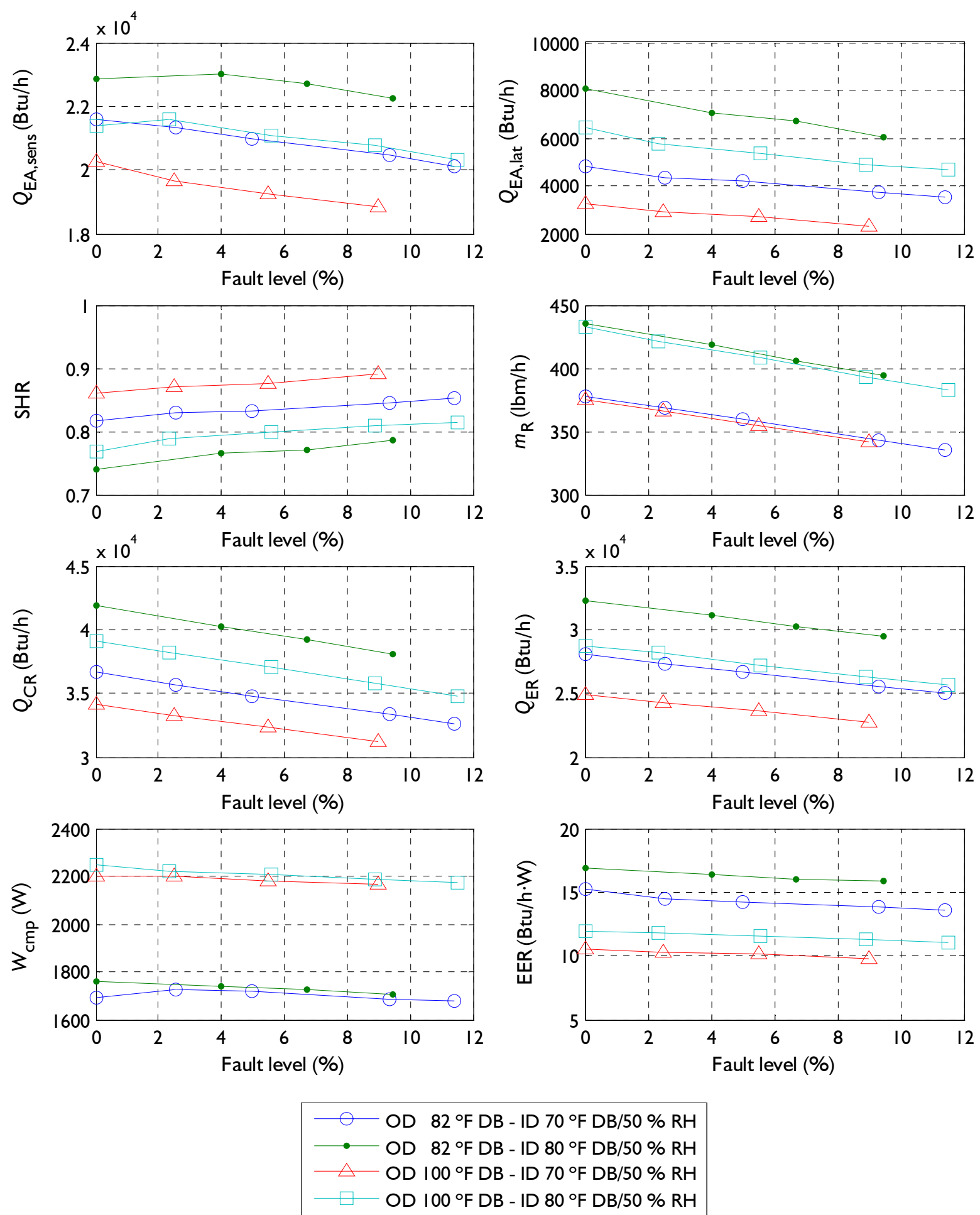

Figure 5.2. Variation of selected performance parameters with a compressor fault. From the top left to right: $Q_{\mathrm{EA}, \text { sens }}$ - indoor air sensible capacity, $Q_{\mathrm{AE}, \text { lat }}$ - indoor air latent capacity, SHR indoor air sensible heat ratio, $m_{\mathrm{R}}$ - refrigerant mass flow rate, $Q_{\mathrm{CR}}-$ condenser refrigerantside capacity; $Q_{\mathrm{ER}}$ - evaporator refrigerant-side capacity; $W_{\text {comp }}-$ compressor work; EER energy efficiency ratio 
degraded, however, because the reduction in the cooling capacity is greater than the reduction in the compressor power.

\subsubsection{Improper outdoor coil air flow rate (condenser fouling)}

We implemented fault levels of $5 \%, 10 \%, 20 \%, 35 \%$ and $50 \%$ by blocking the corresponding percentage of the finned frontal area of the condenser. The fault level of $50 \%$ was tested only for the operating conditions of $26.7^{\circ} \mathrm{C}\left(80.0^{\circ} \mathrm{F}\right)$ and $27.8^{\circ} \mathrm{C}\left(82.0^{\circ} \mathrm{F}\right)$ indoor and outdoor air temperatures, respectively, because of a concern of raising the condensing pressure too high and overloading the compressor.

Figure 5.3 shows residuals for the selected features, and Figure 5.4 shows variations of the performance parameters. Since condenser fouling is a fault occurring at a component level, its effect manifests itself most profoundly in condenser data. The change of evaporator temperature $\left(T_{\mathrm{ER}}\right)$ is minor, but the condenser temperature $\left(T_{\mathrm{CR}}\right)$ increases significantly for a higher condenser fouling level. The lines indicating the residuals overlap tightly showing so sensitivity the indoor and outdoor operating conditions (second plot in the right-hand side column). The compressor discharge temperature $\left(T_{\mathrm{DW}}\right)$ also increases with the increased level of fault.

All residuals "behave" in an expected, systematic fashion except those associated with the test at $26.7^{\circ} \mathrm{C}$ $\left(80.0^{\circ} \mathrm{F}\right) / 27.8^{\circ} \mathrm{C}\left(82.0^{\circ} \mathrm{F}\right)$ indoor/outdoor temperature at $35 \%$ and $50 \%$ fault levels. We speculate that during these two conditions, with greatly reduced condenser air flow, the refrigerant entering the TXV carried a substantial amount of bubbles, reducing the mass flow rate of refrigerant. Because of the amount of bubbles, the TXV could not allow sufficient refrigerant mass flow even if it were fully open. This condition is known as actuator saturation. The resulting reduction in refrigerant mass flow rate is shown in Figure 5.4 (second plot in the right-hand column) and is reflected also in the higher evaporator superheat shown in Figure 5.3.

The plot with the liquid line temperature change $\left(\Delta T_{\mathrm{LL}}\right)$ provides an indication of the lack of refrigerant subcooling, or small subcooling, at the condenser outlet. Since the heat transfer between the liquid line and ambient is typically small, the temperature change in the liquid line is negligible unless two-phase refrigerant is entering the line or refrigerant flashes in the line due to its pressure drop. If the refrigerant is two-phase, the temperature decreases along the liquid line in proportion to the pressure drop. Most of the conditions with a fault level greater than $35 \%$ show distinct temperature change in the liquid line.

Since the mass flow meter in the current investigation underestimates the value when the refrigerant is two-phase, all the performance parameters calculated from the refrigerant mass flow rate, i.e. condenser/evaporator refrigerant capacity, EER based on refrigerant capacity, etc., show excessive degradation at the specified conditions above. Compressor work increases with increasing fault level. In spite of the reduced refrigerant flow rate, increased condensing pressure requires additional compressor work. 

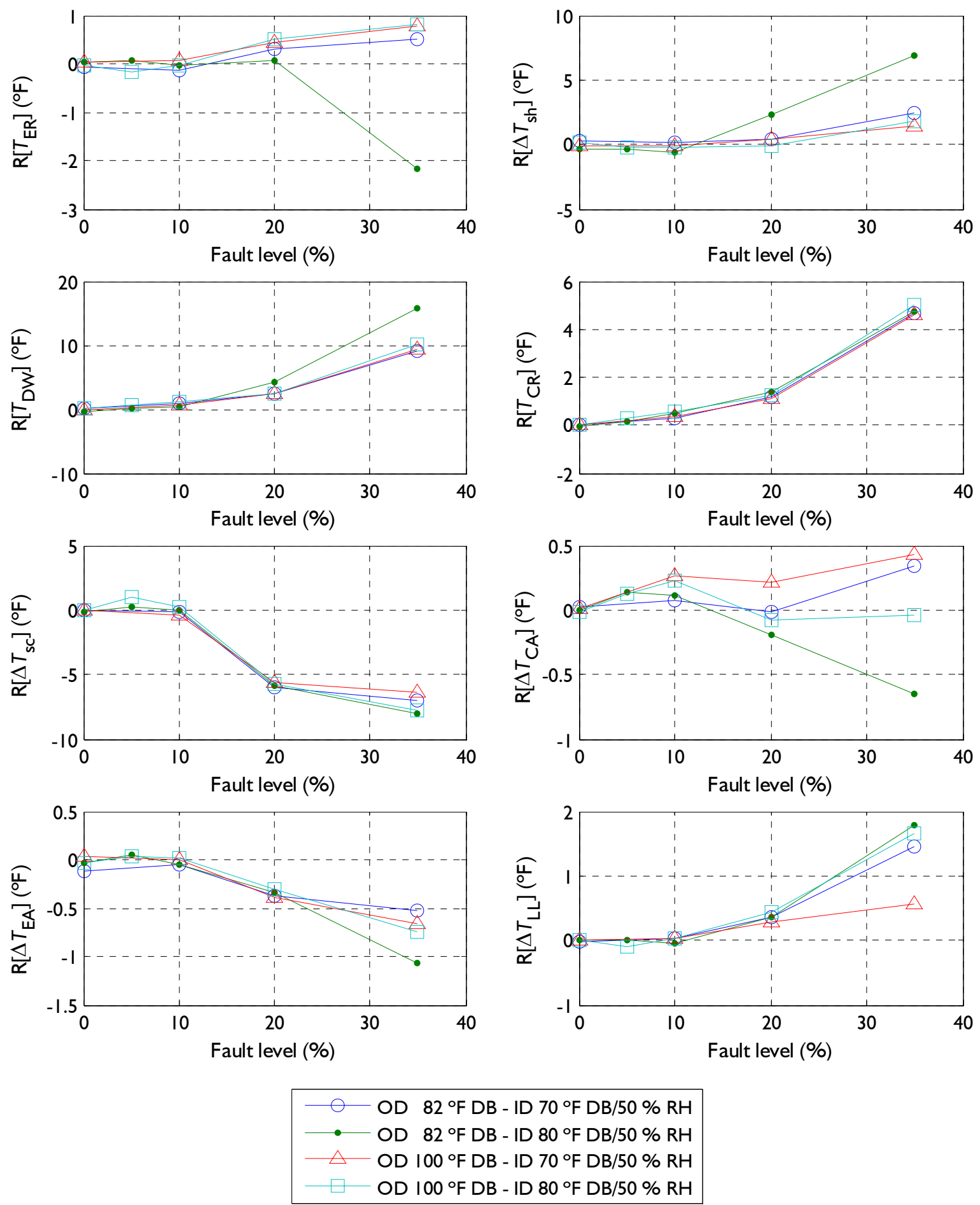

Figure 5.3. Residuals for selected features with the improper indoor air flow rate fault. From the top left to right: $T_{\mathrm{ER}}$ - evaporator exit saturation temperature, $\Delta T_{\mathrm{sh}}$ - evaporator exit superheat, $T_{\mathrm{DW}}$ - compressor discharge wall temperature, $T_{\mathrm{CR}}$ - condenser inlet saturation temperature, $\Delta T_{\mathrm{sc}}-$ liquid line subcooling, $T_{\mathrm{CA}}-$ condenser air temperature rise, $\Delta T_{\mathrm{EA}}-$ evaporator air temperature drop, $\Delta T_{\mathrm{LL}}$ - liquid line temperature drop 

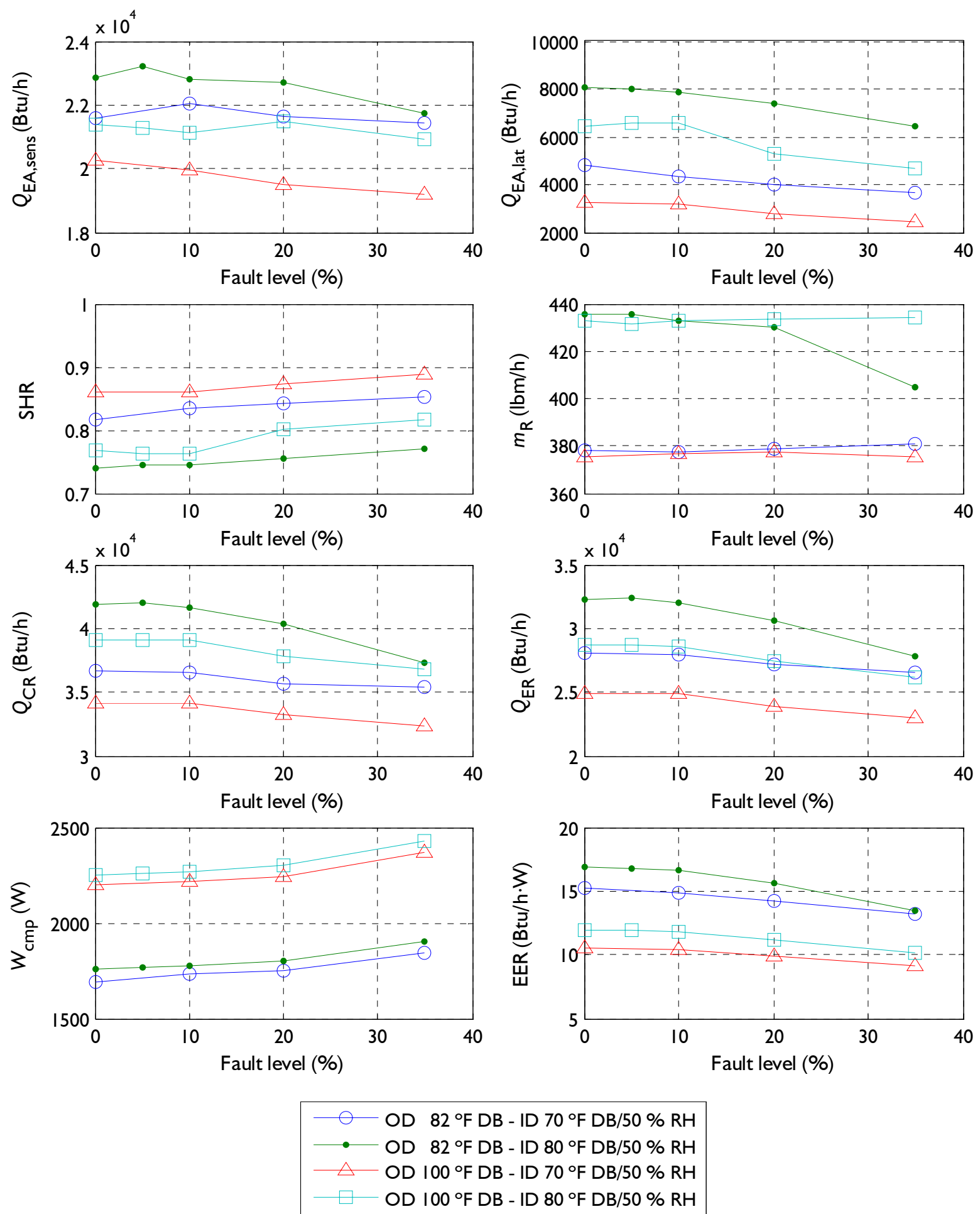

Figure 5.4. Variation of selected performance parameters with the improper indoor air flow rate fault. From the top left to right: $Q_{\mathrm{EA}, \text { sens }}-$ indoor air sensible capacity, $Q_{\mathrm{AE} \text {,lat }}-$ indoor air latent capacity, SHR - indoor air sensible heat ratio, $m_{\mathrm{R}}$ - refrigerant mass flow rate, $Q_{\mathrm{CR}}-$ condenser refrigerant-side capacity, $Q_{\text {ER }}$ - evaporator refrigerant-side capacity, $W_{\text {comp }}-$ compressor work, EER - energy efficiency ratio 


\subsubsection{Improper indoor air flow rate (evaporator fouling)}

We implemented the improper indoor air flow rate fault by controlling the speed of the air fan located at the end of the ductwork. Reducing the indoor air flow approximates evaporator fouling. The tests included three fault levels at approximately $10 \%, 20 \%$, and $30 \%$, which corresponded to the respective reductions of the air flow rate from the no-fault condition. Figure 5.5 shows residuals for the selected features, and Figure 5.6 shows variations of the performance parameters.

A change in the evaporator saturation temperature $\left(T_{\mathrm{ER}}\right)$ is the strongest indication of the reduced air flow. This change is very similar for all four operating conditions used. A change in the air temperature drop across the evaporator $\left(\Delta T_{\mathrm{EA}}\right)$ is the second consistent system response for all operating conditions. The condenser saturation temperature also drops uniformly with the increased fault level; however, the temperature drop is only $0.6^{\circ} \mathrm{C}\left(1.0^{\circ} \mathrm{F}\right)$ for $30 \%$ reduction in the indoor air flow. Also, the compressor discharge temperature $\left(\Delta T_{\mathrm{DW}}\right)$ and liquid line temperature drop $\left(\Delta T_{\mathrm{LL}}\right)$ show small changes in their residuals.

From Figure 5.6, both the sensible and latent capacity change linearly with reduced air flow. This is opposite of SHR trends seen for the compressor fault and condenser fouling fault, where the sensible heat ratio increased. The lowered evaporator temperature decreased the refrigerant density in the suction line causing a decrease in the refrigerant mass flow rate $\left(m_{\mathrm{R}}\right)$. However, the compressor work stays relatively constant throughout the fault tests because of the increased compression ratio. As expected, EER decreases.

\subsubsection{Liquid line restriction}

We implemented the restriction fault by modulating the settings of two valves installed in parallel in the liquid line. The level of the liquid line restriction fault was numerically assigned by the ratio of the increase in the liquid line pressure drop and the pressure differential between the upstream and downstream of the TXV at the no-fault condition. Figure 5.7 shows residuals for the selected features, and Figure 5.8 shows variations of the performance parameters.

In a system equipped with a variable opening expansion device - such as a TXV - the expansion device tends to compensate for over-restriction in the liquid line. Consequently, the over-restriction will not change the system performance as long as the expansion device can open enough to maintain refrigerant mass flow rate at the smaller available pressure differential that exists between the expansion device inlet and the inlet to the evaporator. In our case, the TVX was able to compensate for the restriction fault up to approximately a $10 \%$ increase in liquid line pressure drop. Only after the restriction exceeded the $10 \%$ fault level did the residuals for the selected features start to show a departure from their no-fault values. The fault was most pronounced for the evaporator superheat $\left(\Delta T_{\mathrm{sh}}\right)$, evaporator saturation temperature, $\left(T_{\mathrm{ER}}\right)$, and the compressor discharge temperature $\left(T_{\mathrm{DW}}\right)$. All of the performance parameters plotted in Figure 5.8 were basically unaffected up to the $10 \%$ fault level. Beyond this point, all performance parameters except the compressor work $\left(W_{\mathrm{cmp}}\right)$ and latent capacity $\left(Q_{\mathrm{EA}, \mathrm{lat}}\right)$ deteriorated. 

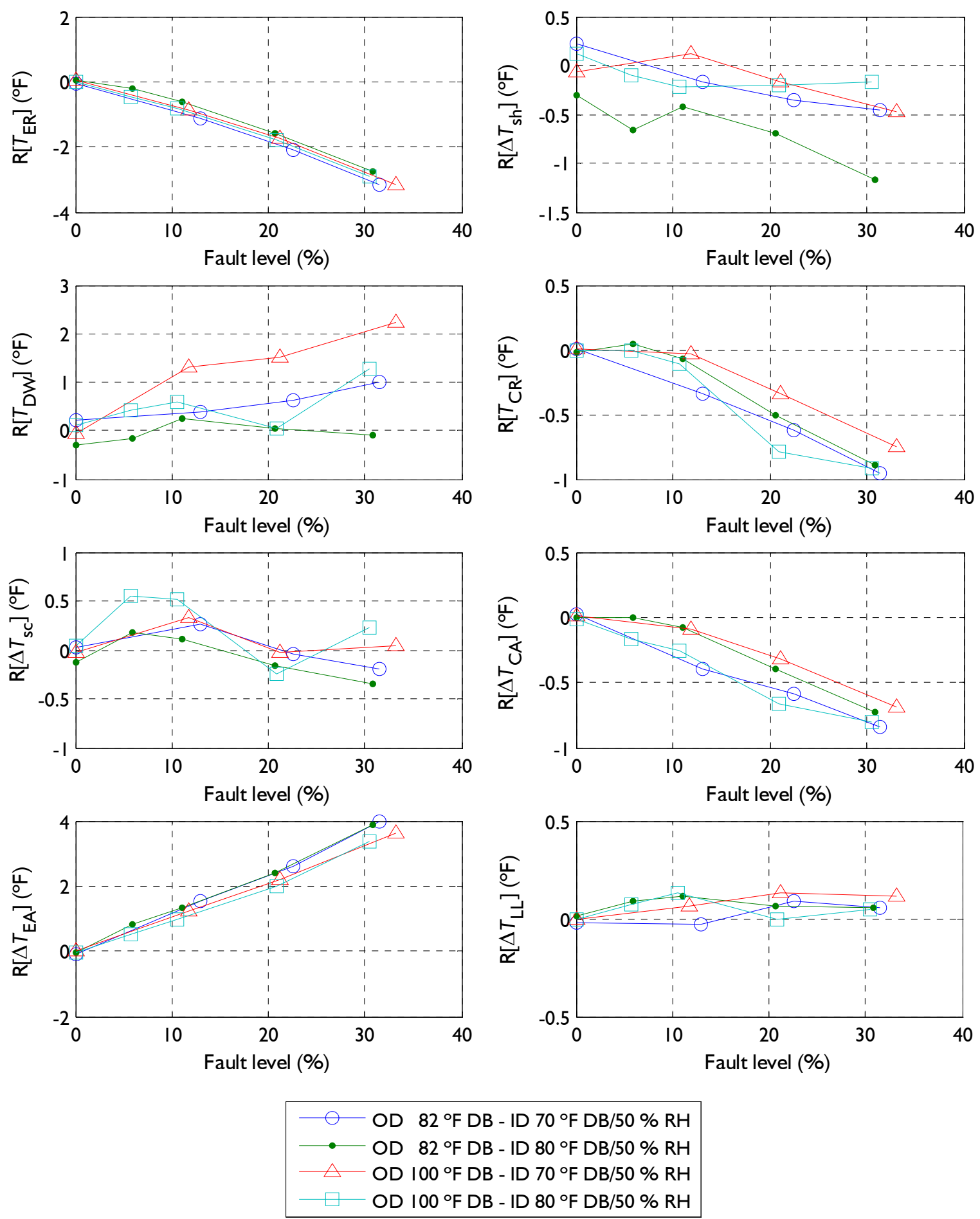

Figure 5.5. Residuals for selected features with the improper indoor air flow rate fault. From the top left to right: $T_{\mathrm{ER}}$ - evaporator exit saturation temperature, $\Delta T_{\mathrm{sh}}$ - evaporator exit superheat, $T_{\mathrm{DW}}$ - compressor discharge wall temperature, $T_{\mathrm{CR}}$ - condenser inlet saturation temperature, $\Delta T_{\mathrm{sc}}-$ liquid line subcooling, $T_{\mathrm{CA}}-$ condenser air temperature rise, $\Delta T_{\mathrm{EA}}-$ evaporator air temperature drop, $\Delta T_{\mathrm{LL}}$ - liquid line temperature drop 

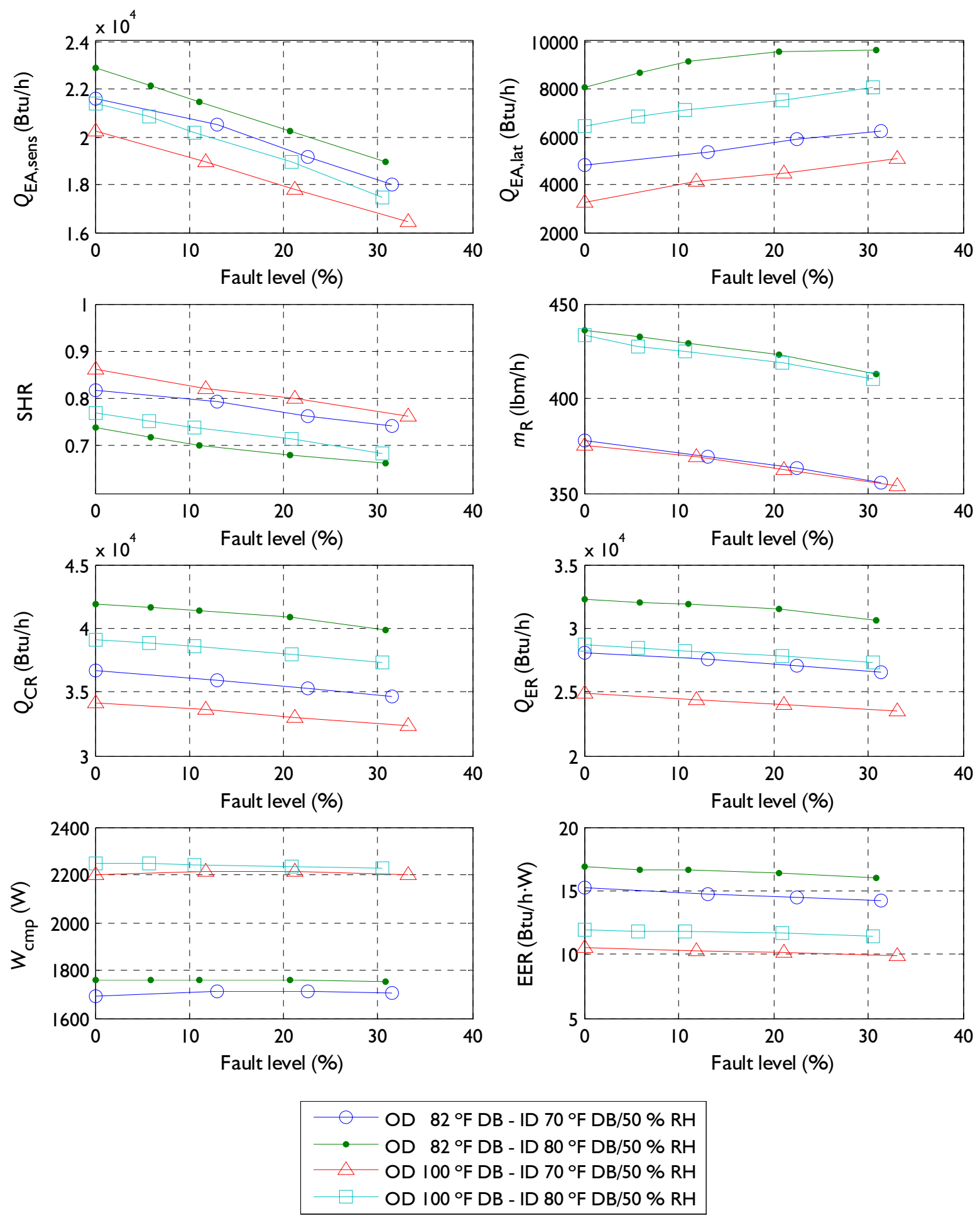

Figure 5.6. Selected performance parameters with the improper indoor air flow rate fault. From the top left to right: $Q_{\mathrm{EA}, \text { sens }}-$ indoor air sensible capacity, $Q_{\mathrm{AE}, \text { lat }}-$ indoor air latent capacity, SHR indoor air sensible heat ratio, $m_{\mathrm{R}}$ - refrigerant mass flow rate, $Q_{\mathrm{CR}}-$ condenser refrigerantside capacity, $Q_{\mathrm{ER}}$ - evaporator refrigerant-side capacity, $W_{\text {comp }}-$ compressor work, EER energy efficiency ratio 

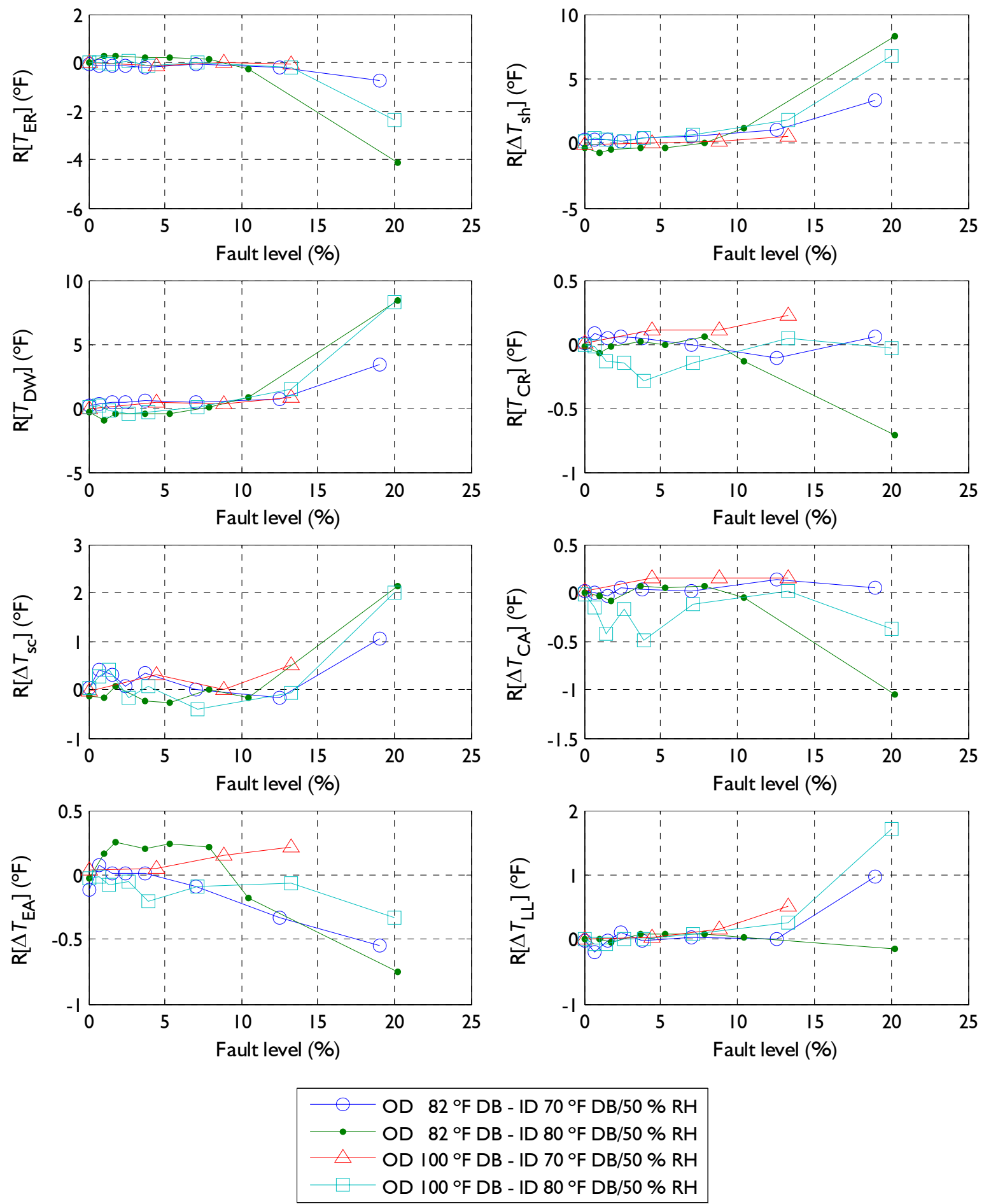

Figure 5.7. Residuals of selected features with the liquid line restriction fault. From the top left to right: $T_{\mathrm{ER}}$ - evaporator exit saturation temperature, $\Delta T_{\mathrm{sh}}$ - evaporator exit superheat, $T_{\mathrm{DW}}-$ compressor discharge wall temperature, $T_{\mathrm{CR}}$ - condenser inlet saturation temperature, $\Delta T_{\mathrm{sc}}-$ liquid line subcooling, $T_{\mathrm{CA}}-$ condenser air temperature rise, $\Delta T_{\mathrm{EA}}-$ evaporator air temperature drop, $\Delta T_{\mathrm{LL}}-$ liquid line temperature drop 

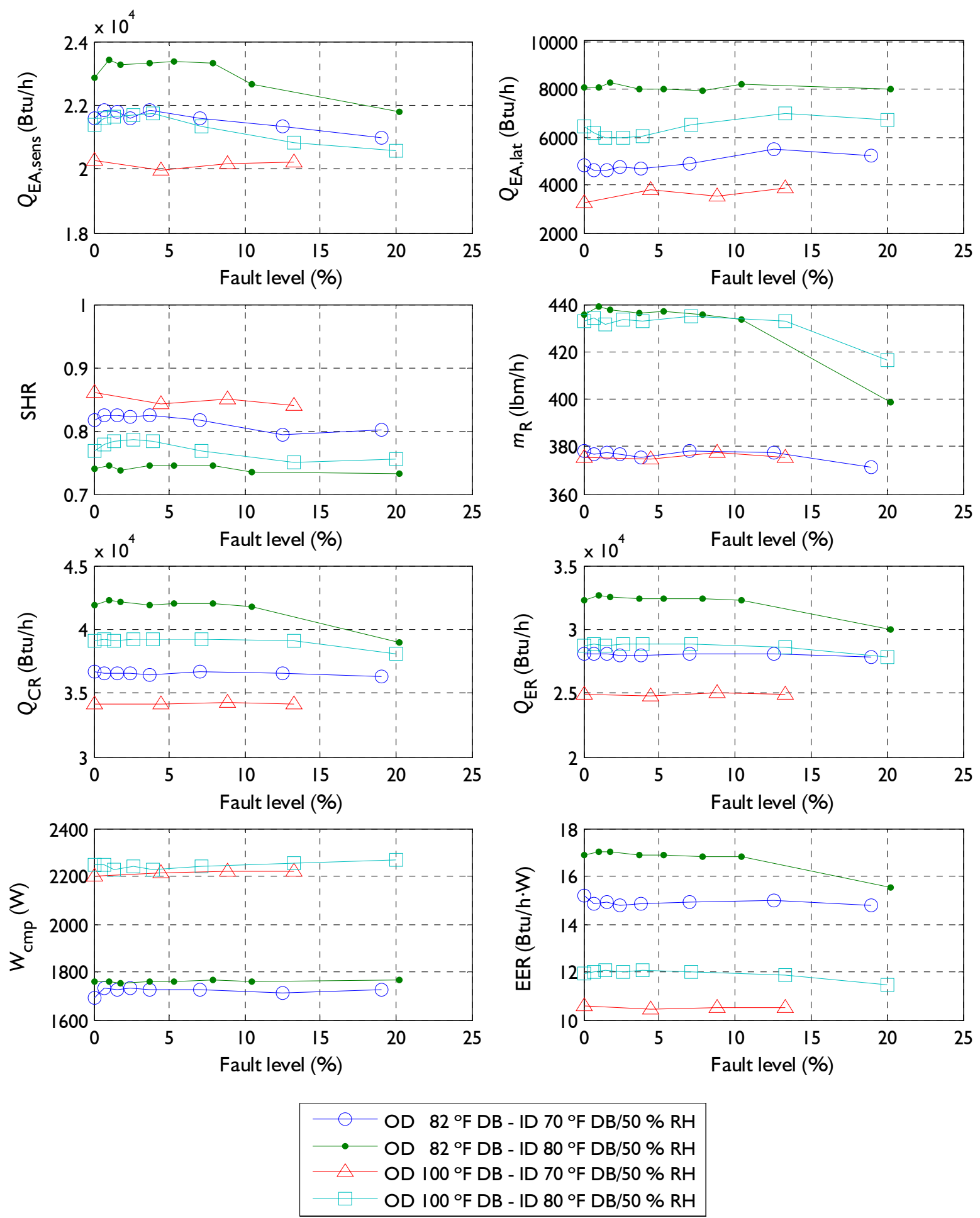

Figure 5.8. Selected performance parameters with the liquid line restriction fault. From the top left to right: $Q_{\mathrm{EA}, \text { sens }}$ - indoor air sensible capacity, $Q_{\mathrm{AE}, \text { lat }}-$ indoor air latent capacity, SHR indoor air sensible heat ratio, $m_{\mathrm{R}}$ - refrigerant mass flow rate, $Q_{\mathrm{CR}}-$ condenser refrigerantside capacity, $Q_{\mathrm{ER}}$ - evaporator refrigerant-side capacity, $W_{\text {comp }}-$ compressor work, EER energy efficiency ratio 


\subsubsection{Refrigerant undercharge and overcharge}

The fault level for refrigerant undercharge (or refrigerant overcharge) was calculated as the ratio of the charge reduction (or charge excess) and the optimal refrigerant charge in the system. The test program included three fault levels: $10 \%, 20 \%$, and $30 \%$. Figures 5.9 and 5.10 show residuals for the selected features for the undercharge and overcharge faults, respectively.

With an undercharge, the liquid line subcooling $\left(\Delta T_{\mathrm{sc}}\right)$ is the most indicative of the fault starting at the $10 \%$ fault level regardless of the operating conditions. The plot for liquid line temperature drop $\left(\Delta T_{\mathrm{LL}}\right)$ provides a complementary indication, although its strength is influenced by the operating regime. As in previous cases, the liquid line temperature drop - if it is significant - is caused by a drop of the saturation temperature of the two-phase refrigerant flowing in the line. A reduced refrigerant charge causes the condenser temperature $\left(T_{\mathrm{CR}}\right)$ to decrease beginning at the $10 \%$ fault; however, the rate of decrease varies somewhat with operating conditions. The compressor wall discharge temperature $\left(T_{\mathrm{DW}}\right)$, evaporator saturation temperature $\left(T_{\mathrm{ER}}\right)$, and evaporator superheat $\left(\Delta T_{\mathrm{sh}}\right)$ provide non-linear signals with a strong dependence on operating conditions.

For the overcharging fault (Figure 5.10), the liquid line subcooling $\left(\Delta T_{\mathrm{sc}}\right)$ and the condenser saturation temperature $\left(\Delta T_{\mathrm{sc}}\right)$ increase steadily with the increasing refrigerant overcharge, and the plot for the four operating conditions almost overlap. The liquid line temperature drop $\left(\Delta T_{\mathrm{LL}}\right)$ data indicate a decrease in the relative temperature drop and may provide a useful signal on the overcharge fault. The compressor wall discharge temperature $\left(T_{\mathrm{DW}}\right)$ decreases, but the strength of this trend varies somewhat between the tested cases. Other features do not provide a strong or consistent indication of refrigerant overcharging.

Figure 5.11 shows the variation of performance parameters for the undercharge and overcharge faults. Among the most important parameters, the evaporator capacity and compressor work increase with refrigerant charge level but at a different rate. Consequently, the EER plot has a maximum, which is reached at the optimal refrigerant charge in the system. 

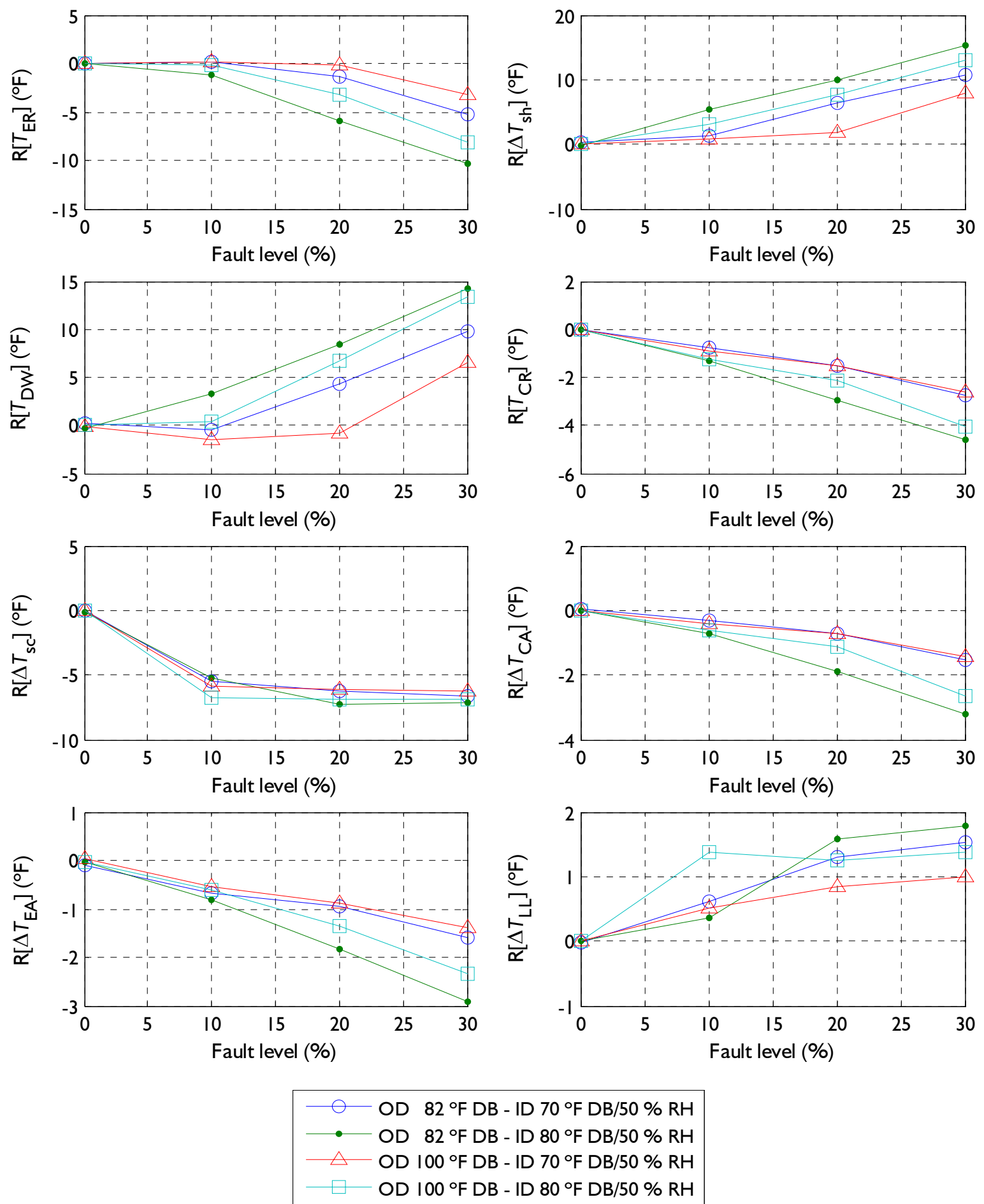

Figure 5.9. Residuals for selected features with refrigerant undercharge fault. From the top left to right: $T_{\mathrm{ER}}$ - evaporator exit saturation temperature, $\Delta T_{\mathrm{sh}}$ - evaporator exit superheat, $T_{\mathrm{DW}}-$ compressor discharge wall temperature, $T_{\mathrm{CR}}$ - condenser inlet saturation temperature, $\Delta T_{\mathrm{sc}}-$ liquid line subcooling, $T_{\mathrm{CA}}$ - condenser air temperature rise, $\Delta T_{\mathrm{EA}}-$ evaporator air temperature drop, $\Delta T_{\mathrm{LL}}$ - liquid line temperature drop 

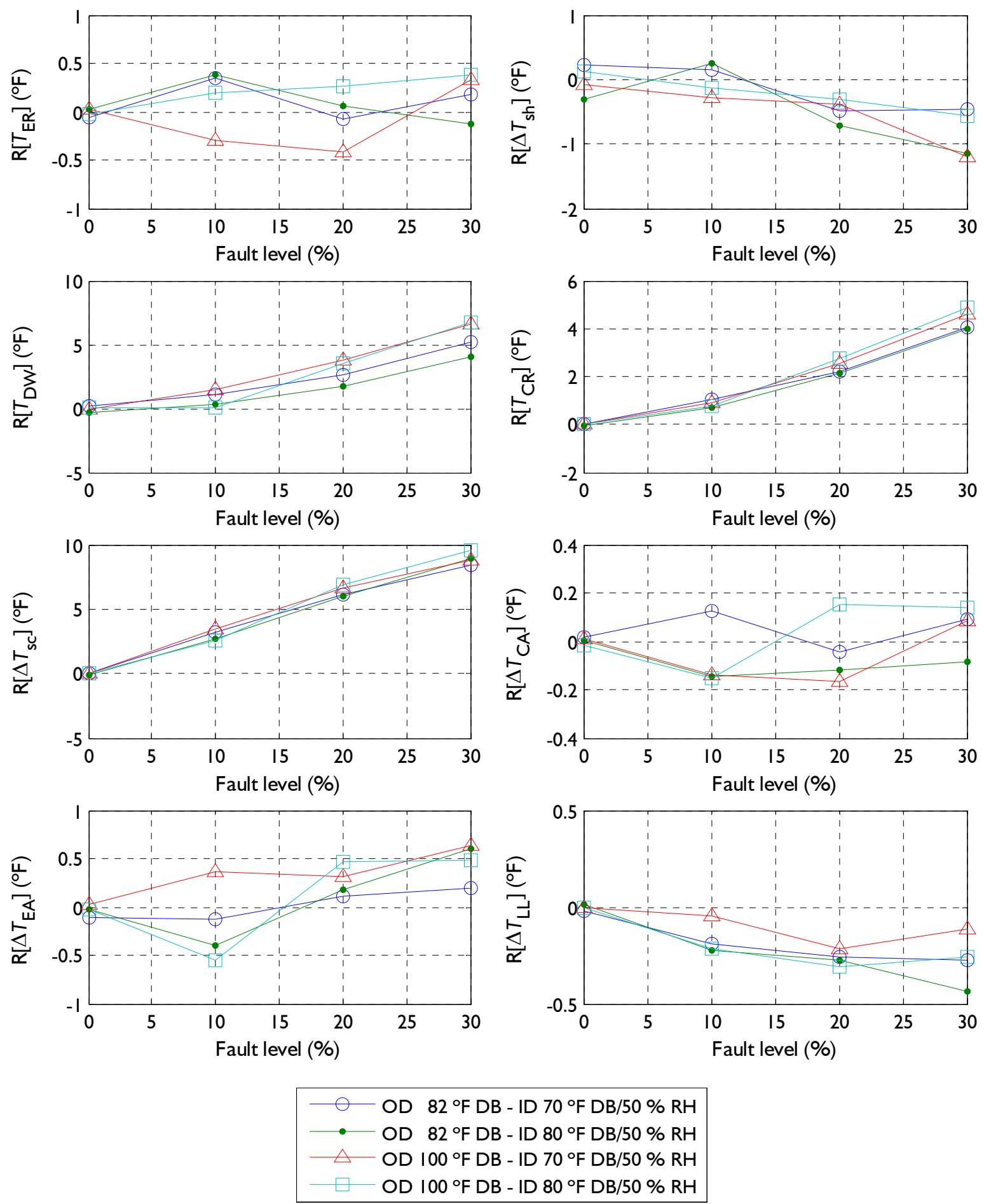

Figure 5.10. Residuals for selected features with refrigerant overcharge fault. From the top left to right: $T_{\mathrm{ER}}$ - evaporator exit saturation temperature, $\Delta T_{\mathrm{sh}}$ - evaporator exit superheat, $T_{\mathrm{DW}}-$ compressor discharge wall temperature, $T_{\mathrm{CR}}$ - condenser inlet saturation temperature, $\Delta T_{\mathrm{sc}}-$ liquid line subcooling, $T_{\mathrm{CA}}$ - condenser air temperature rise, $\Delta T_{\mathrm{EA}}-$ evaporator air temperature drop, $\Delta T_{\mathrm{LL}}$ - liquid line temperature drop 

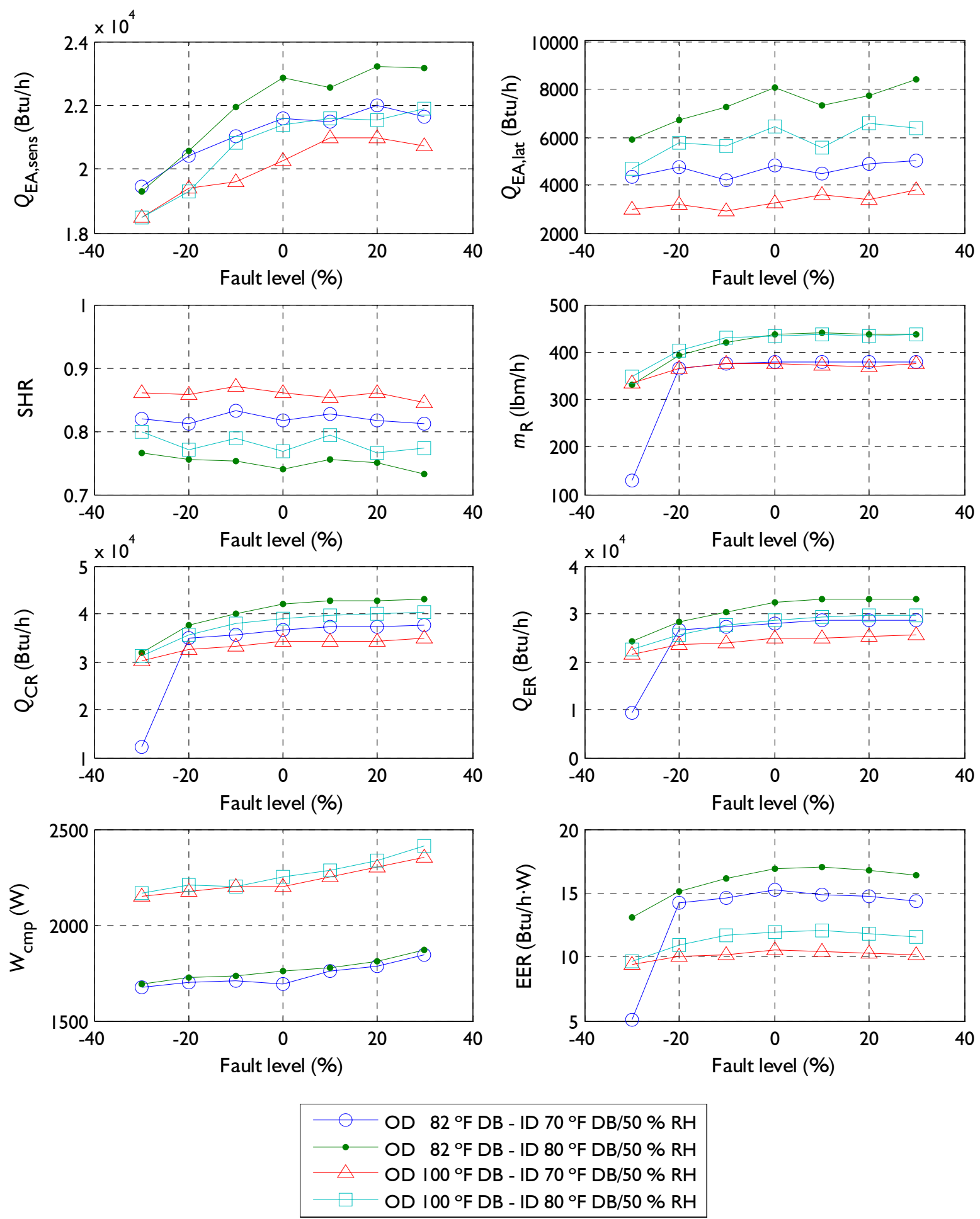

Figure 5.11. Selected performance parameters with respect to the refrigerant charge level. From the top left to right: $Q_{\mathrm{EA}, \text { sens }}-$ indoor air sensible capacity, $Q_{\mathrm{AE}, \text { lat }}-$ indoor air latent capacity, SHR indoor air sensible heat ratio, $m_{\mathrm{R}}$ - refrigerant mass flow rate, $Q_{\mathrm{CR}}-$ condenser refrigerantside capacity, $Q_{\mathrm{ER}}$ - evaporator refrigerant-side capacity, $W_{\text {comp }}-$ compressor work, EER energy efficiency ratio 


\subsubsection{Non-condensable gas}

We implemented this fault by charging a controlled amount of dry nitrogen into the system. The mass of charged nitrogen divided by the mass of nitrogen that could occupy the system at atmospheric pressure indicated the fault level. We estimated that a typical level of this fault found in the field installation should not exceed $5 \%$, and for this level we performed tests for all four operating conditions applied to other faults. To include more severe scenarios, we carried out tests for $10 \%, 15 \%$, and $20 \%$ fault levels at two extreme operating conditions of outdoor $27.8^{\circ} \mathrm{C}\left(82.0^{\circ} \mathrm{F}\right) \mathrm{DB}$ - indoor $26.7^{\circ} \mathrm{C}\left(80.0^{\circ} \mathrm{F}\right) \mathrm{DB} / 50 \%$ $\mathrm{RH}$ and outdoor $37.8^{\circ} \mathrm{C}\left(100.0^{\circ} \mathrm{F}\right) \mathrm{DB}-$ indoor $21.1^{\circ} \mathrm{C}\left(70.0^{\circ} \mathrm{F}\right) \mathrm{DB} / 50 \% \mathrm{RH}$. Figure 5.12 shows residuals for the selected features, and Figure 5.13 shows variations of the performance parameters.

Among the features presented in Figure 5.12, the residuals for the liquid line subcooling $\left(\Delta T_{\mathrm{sc}}\right)$ provide the strongest and most consistent indication of the increasing level of fault. Equally consistent is the plot for the condenser saturation temperature $\left(T_{\mathrm{CR}}\right)$ with a somewhat weaker sensitivity than that of $\Delta T_{\mathrm{sc}}$. The plot with the compressor discharge wall temperature $\left(T_{\mathrm{DW}}\right)$ also has a positive trend with the increasing level of fault; however, the collected data have a scatter that typically burdens compressor discharge temperature readings. All of the above features are related to the condenser, which can be explained by the fact that non-condensable gases are likely to accumulate in the condenser. Non-condensables collect on the high pressure side of the system and raise the condensing pressure above that corresponding to the temperature at which the refrigerant is actually condensing. This increases power consumption and reduces capacity. The excess pressure is caused by the partial pressure of the non-condensables. (ASHRAE Handbook - HVAC Systems and Equipment 35.6)

Performance parameter (Figure 5.13) changes are small. But due to the condenser pressure increase, the compressor work steadily increases and EER decreases with an increasing level of non-condensable. 

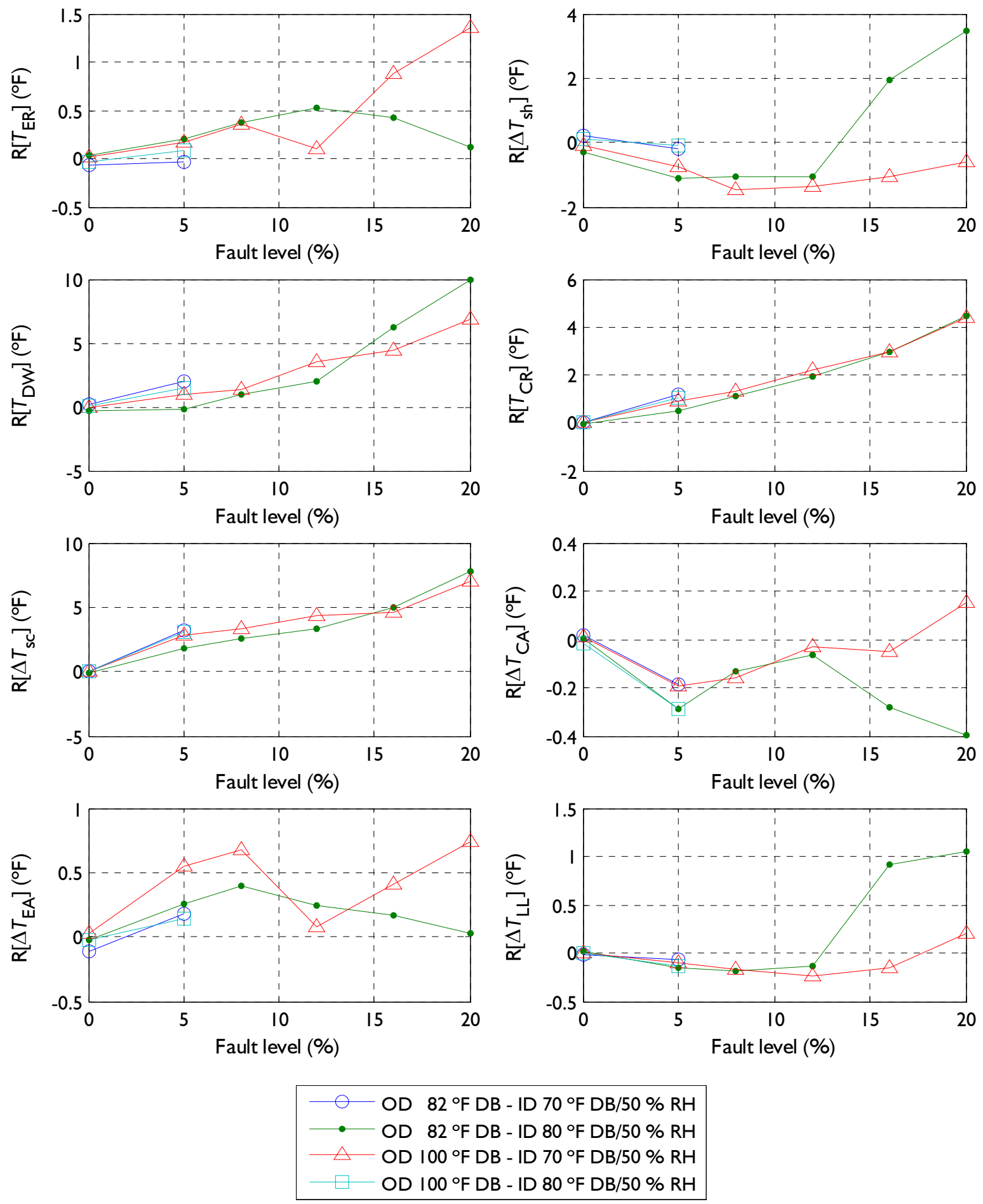

Figure 5.12. Residuals for selected features with non-condensable gas fault. From the top left to right: $T_{\mathrm{ER}}$ - evaporator exit saturation temperature, $\Delta T_{\mathrm{sh}}$ - evaporator exit superheat, $T_{\mathrm{DW}}-$ compressor discharge wall temperature, $T_{\mathrm{CR}}$ - condenser inlet saturation temperature, $\Delta T_{\mathrm{sc}}-$ liquid line subcooling, $T_{\mathrm{CA}}$ - condenser air temperature rise, $\Delta T_{\mathrm{EA}}-$ evaporator air temperature drop, $\Delta T_{\mathrm{LL}}$ - liquid line temperature drop 

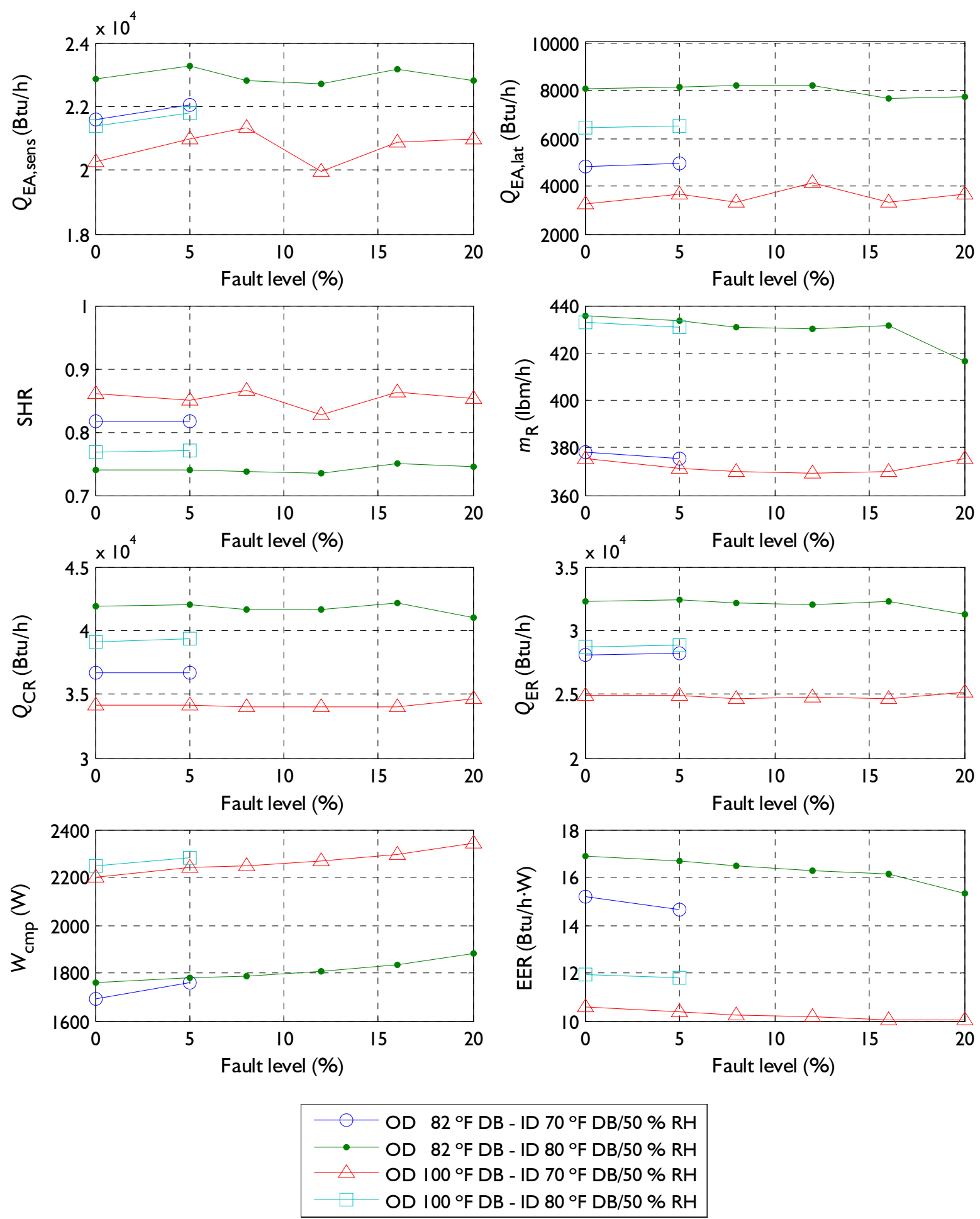

Figure 5.13. Selected performance parameters with non-condensable gas fault. From the top left to right: $Q_{\mathrm{EA}, \text { sens }}$ - indoor air sensible capacity, $Q_{\mathrm{AE} \text {,lat }}$ - indoor air latent capacity, SHR - indoor air sensible heat ratio, $m_{\mathrm{R}}$ - refrigerant mass flow rate, $Q_{\mathrm{CR}}-$ condenser refrigerant-side capacity, $Q_{\mathrm{ER}}-$ evaporator refrigerant-side capacity, $W_{\text {comp }}-$ compressor work, EER energy efficiency ratio 


\subsection{Comparative Evaluation of Single-Fault Effects}

\subsubsection{Feature residuals}

This section contains a comparative presentation of the effects of single faults on the eight selected features at $27.8^{\circ} \mathrm{C}\left(82.0^{\circ} \mathrm{F}\right)$ outdoor dry bulb temperature, $26.7^{\circ} \mathrm{C}\left(80.0^{\circ} \mathrm{F}\right)$ indoor dry bulb temperature, and $50 \%$ indoor relative humidity (Test \#5).

The evaporator saturation temperature ( $T_{\mathrm{ER}}$, Figure 5.14) is affected most by refrigerant undercharge and liquid line restriction yielding a negative residual. Other faults have a small impact except compressor/reversing valve leakage, which results in a $1.1^{\circ} \mathrm{C}\left(2.0^{\circ} \mathrm{F}\right)$ positive $T_{\mathrm{ER}}$ residual for $10 \%$ level fault.

The suction line superheat ( $\Delta T_{\mathrm{sh}}$, Figure 5.14) is affected most by refrigerant undercharge, liquid line restriction, non-condensable gases, and improper outdoor air flow rate. The $\mathrm{R}\left(\Delta T_{\mathrm{sh}}\right)$ chart shows that the TXV was able to properly control refrigerant superheat for when other faults were applied.

The compressor discharge wall temperature $\left(T_{\mathrm{DW}}\right.$, Figure 5.14) feature has significant positive residuals for refrigerant undercharge, non-condensable gases, liquid line restriction, and improper outdoor air flow rate, and it has a moderate positive residual for refrigerant overcharge. Other faults have a minimal effect.

The condenser inlet saturation temperature $\left(T_{\mathrm{CR}}\right.$, Figure 5.14$)$ is minimally affected by refrigerant overcharge, and liquid line restriction. Positive residuals for this residual were obtained for noncondensable gases, refrigerant overcharge, and low outdoor air flow rate; while negative residuals were calculated for compressor/reversing valve leakage and refrigerant undercharge.

The residuals of liquid line subcooling $\left(\Delta T_{\mathrm{sc}}\right.$, Figure 5.15) are large enough for FDD methods for noncondensable gases and refrigerant overcharge (positive), and refrigerant undercharge and low outdoor air flow rate (negative).

The condenser air temperature gain $\left(\Delta T_{\mathrm{CA}}\right.$, Figure 5.15) is negatively affected by each fault; however, the residuals are small in general, and only refrigerant undercharge and possibly compressor/reversing valve leakage could be detected using this feature.

The evaporator air temperature drop $\left(\Delta T_{\mathrm{EA}}\right.$, Figure 5.15) residuals are suitable for FDD methods for low indoor air flow rate (positive) and refrigerant undercharge (negative). Other residuals are within $0.6{ }^{\circ} \mathrm{C}$ $\left(1.0^{\circ} \mathrm{F}\right)$ for the faults studied.

The liquid line temperature drop $\left(\Delta T_{\mathrm{LL}}\right.$, Figure 5.15) has residuals within $1.1^{\circ} \mathrm{C}\left(2.0^{\circ} \mathrm{F}\right)$ for all studied faults offering limited opportunity for fault detection. The most influential faults for this feature are refrigerant undercharge, non-condensable gases, and improper outdoor air flow rate.

Figures 5.16 and 5.17 compare the impact of different single faults on performance parameters shown as residuals. The reference values of performance parameters were calculated by the 2 nd order multivariate polynomial described in section 4.3. The sensible capacity ( $Q_{\text {EA,sens, }}$ Figure 5.16 ) decreased for all faults except refrigerant overcharge for which capacity was rather steady, and the latent capacity $\left(Q_{\mathrm{EA}, \text { lat }}\right.$, Figure 5.16) decreased for all faults except low indoor air flow for which latent capacity increased. 

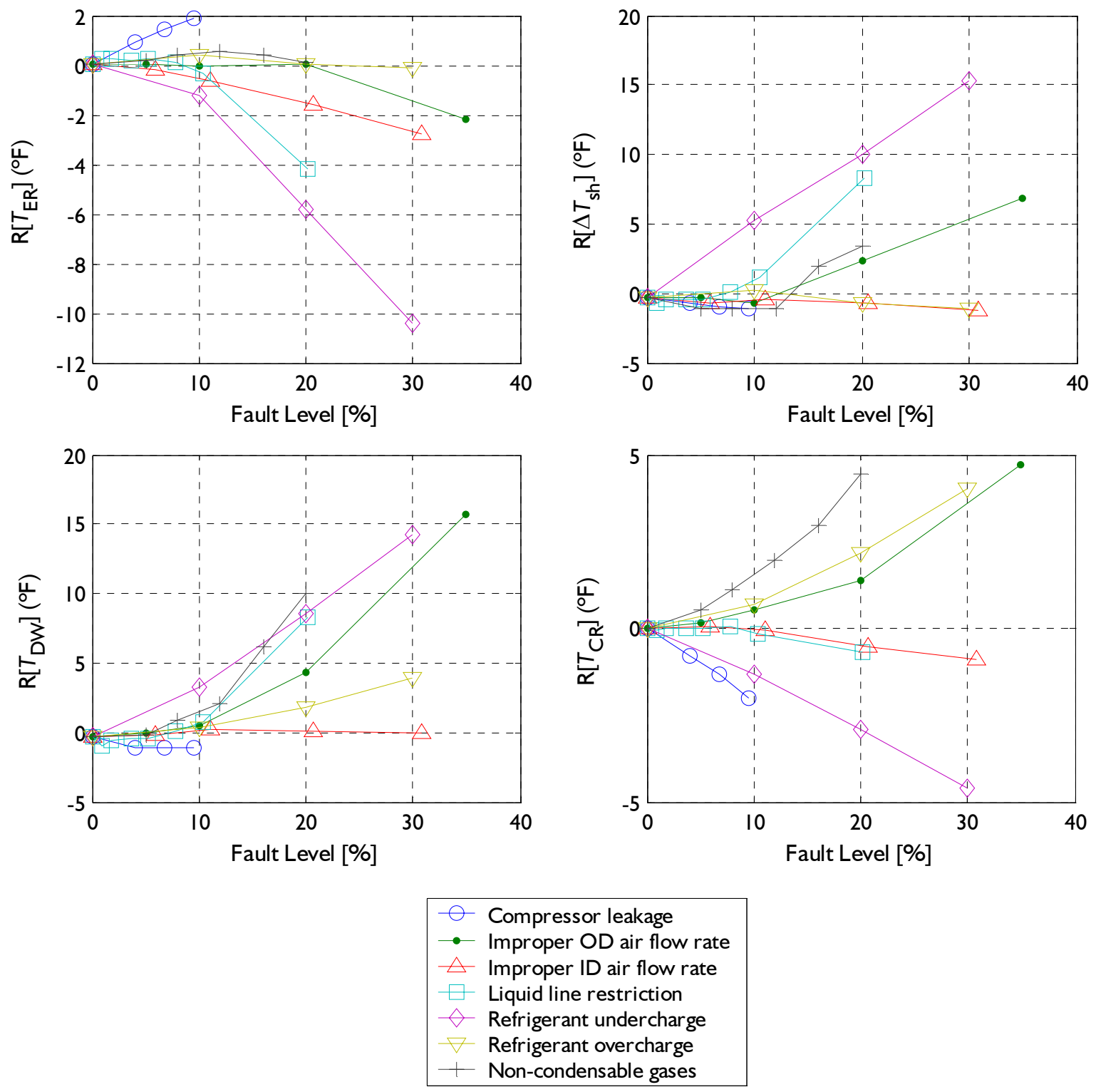

Figure 5.14. Residuals for selected features for different faults. From the top left to right: $T_{\mathrm{ER}}-$ evaporator exit saturation temperature, $\Delta T_{\mathrm{sh}}$ - evaporator exit superheat, $T_{\mathrm{DW}}$ - compressor discharge wall temperature, $T_{\mathrm{CR}}$ - condenser inlet saturation temperature

(Test \#5: $27.8^{\circ} \mathrm{C}\left(82.0^{\circ} \mathrm{F}\right)$ outdoor dry bulb temperature, $26.7^{\circ} \mathrm{C}\left(80.0^{\circ} \mathrm{F}\right)$ indoor dry bulb temperature and $50 \%$ indoor relative humidity) 

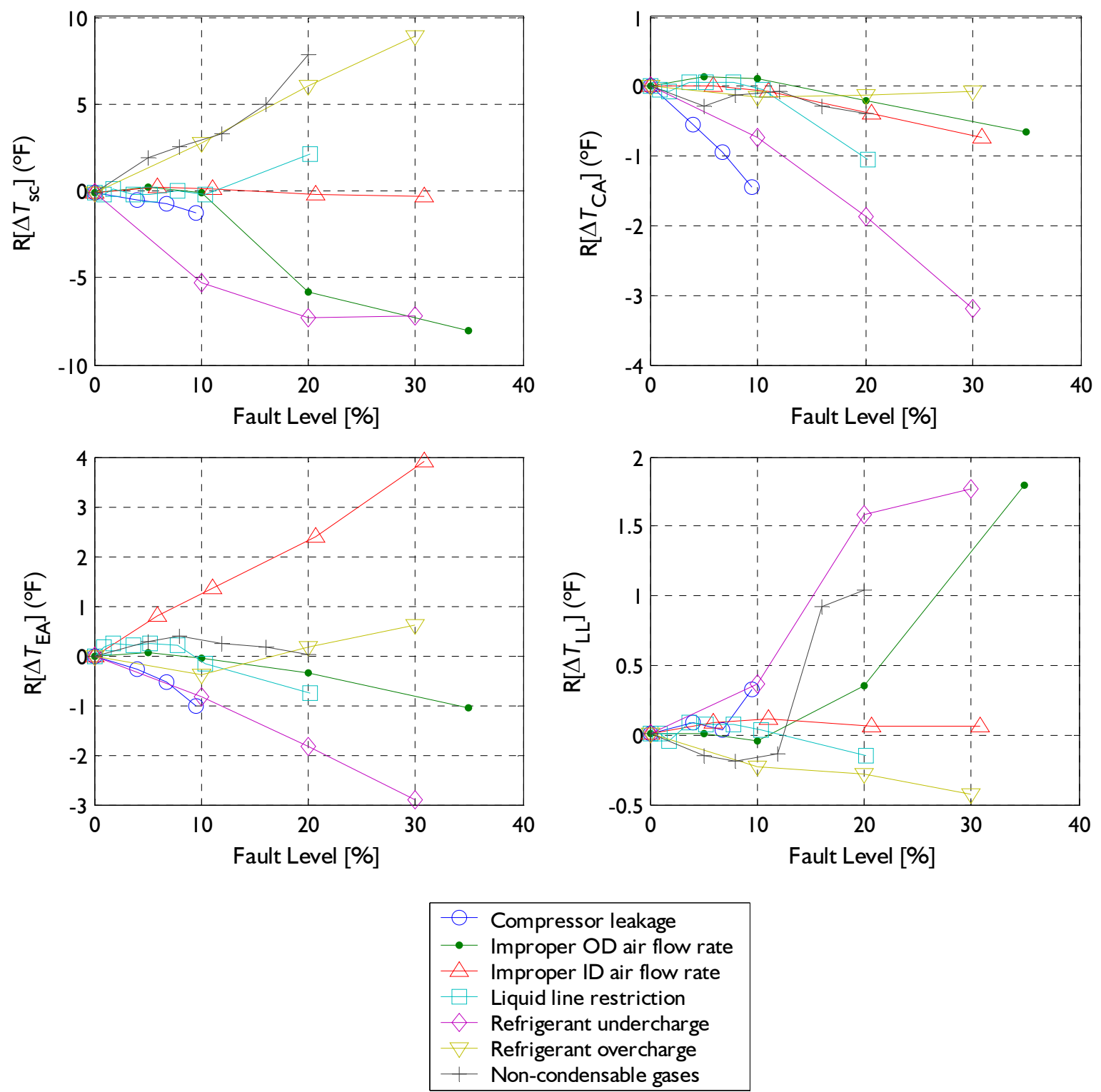

Figure 5.15. Residuals for selected features for different faults. From the top left to right: $\Delta T_{\mathrm{sc}}-$ liquid line subcooling, $\Delta T_{\mathrm{CA}}-$ condenser air temperature rise, $\Delta T_{\mathrm{EA}}$ - evaporator air temperature drop, $\Delta T_{\mathrm{LL}}-$ liquid line temperature drop

(Test \#5: $27.8^{\circ} \mathrm{C}\left(82.0^{\circ} \mathrm{F}\right)$ outdoor dry bulb temperature, $26.7^{\circ} \mathrm{C}\left(80.0^{\circ} \mathrm{F}\right)$ indoor dry bulb temperature and $50 \%$ indoor relative humidity) 

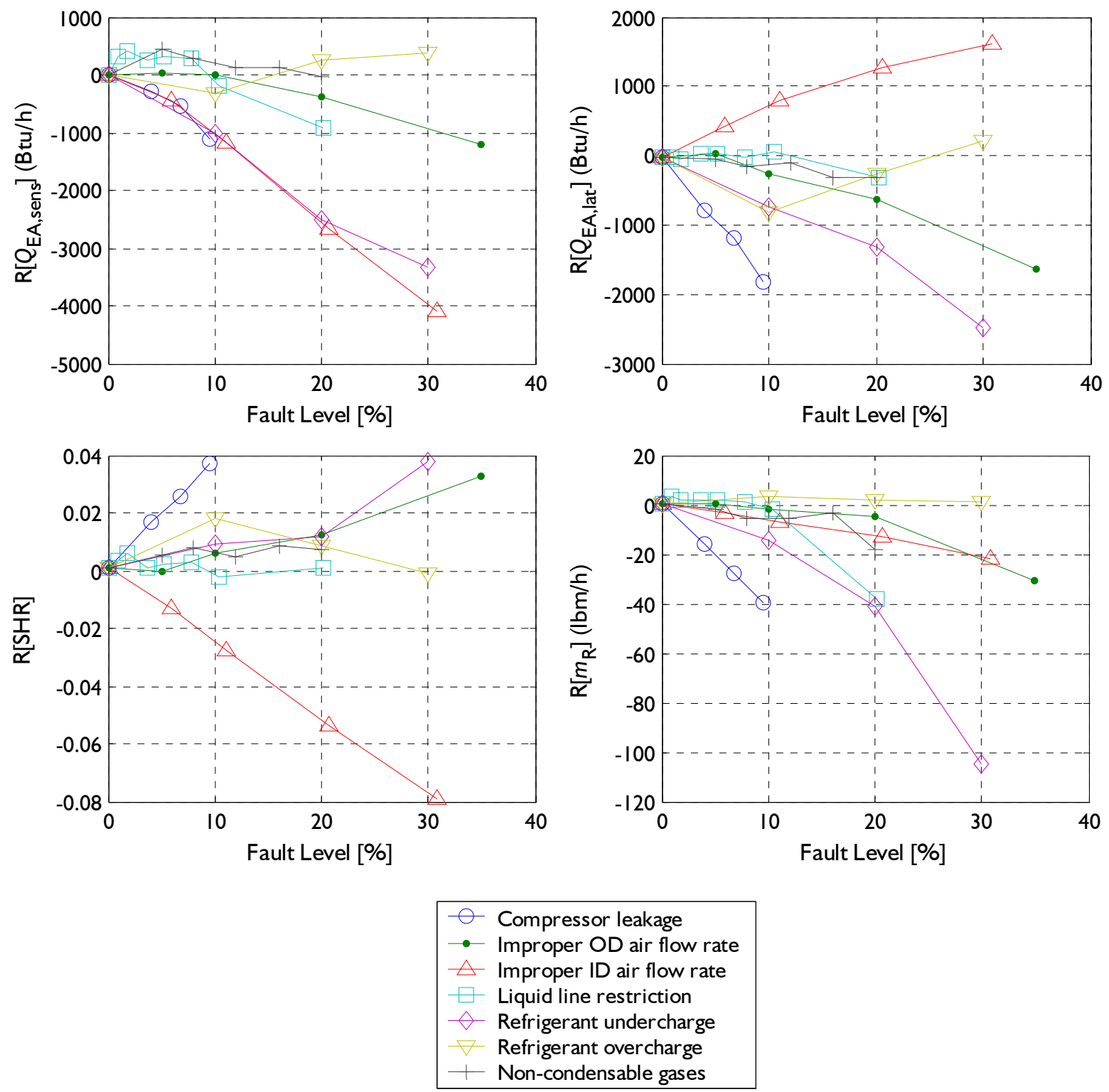

Figure 5.16. Residuals for selected performance parameters for different faults. From the top left to right: $Q_{\mathrm{EA}, \mathrm{sens}}$ - indoor air sensible capacity, $Q_{\mathrm{AE}, \text { lat }}$ - indoor air latent capacity; SHR indoor air sensible heat ratio, $m_{\mathrm{R}}$ - refrigerant mass flow rate

(Test \#5: $27.8^{\circ} \mathrm{C}\left(82.0^{\circ} \mathrm{F}\right)$ outdoor dry bulb temperature, $26.7^{\circ} \mathrm{C}\left(80.0^{\circ} \mathrm{F}\right)$ indoor dry bulb temperature and $50 \%$ indoor relative humidity) 
The refrigerant mass flow rate $\left(m_{\mathrm{R}}\right.$, Figure 5.16) was unchanged for refrigerant overcharge, but decreased markedly for all other faults.

As expected, condenser capacity $\left(Q_{\mathrm{CR}}\right.$, Figure 5.17$)$ and evaporator capacity $\left(Q_{\mathrm{ER}}\right.$, Figure 5.17$)$ decreased for each fault except refrigerant overcharge. The compressor work ( $W_{\text {cmp }}$, Figure 5.17) increased for noncondensable gases, refrigerant overcharge, and low outdoor air flow rate; and it did not change or decreased for the remaining faults. The consequence of these changes in $Q_{\mathrm{ER}}$ and $W_{\mathrm{cmp}}$ is a degraded EER for each fault (Figure 5.17).

Even though the performance degradation due to refrigerant overcharge is not large, refrigerant overcharge may cause a serious problem, especially for a heat pump system. During winter, the refrigerant usually floods the evaporator. In the overcharge system, this flooding will be more severe and may results in liquid refrigerant entering the compressor and damaging it.

We may note that the sensitivity of residuals to a fault level depends on the system design. For example, heat exchanger faults will generally have a smaller effect on different residuals if heat exchangers are oversized. Or, the refrigerant overcharge fault is less apparent in systems equipped with a suitable liquid line receiver. Even the non-condensable gases fault can be mitigated by a large receiver since noncondensables tend to accumulate in it. 

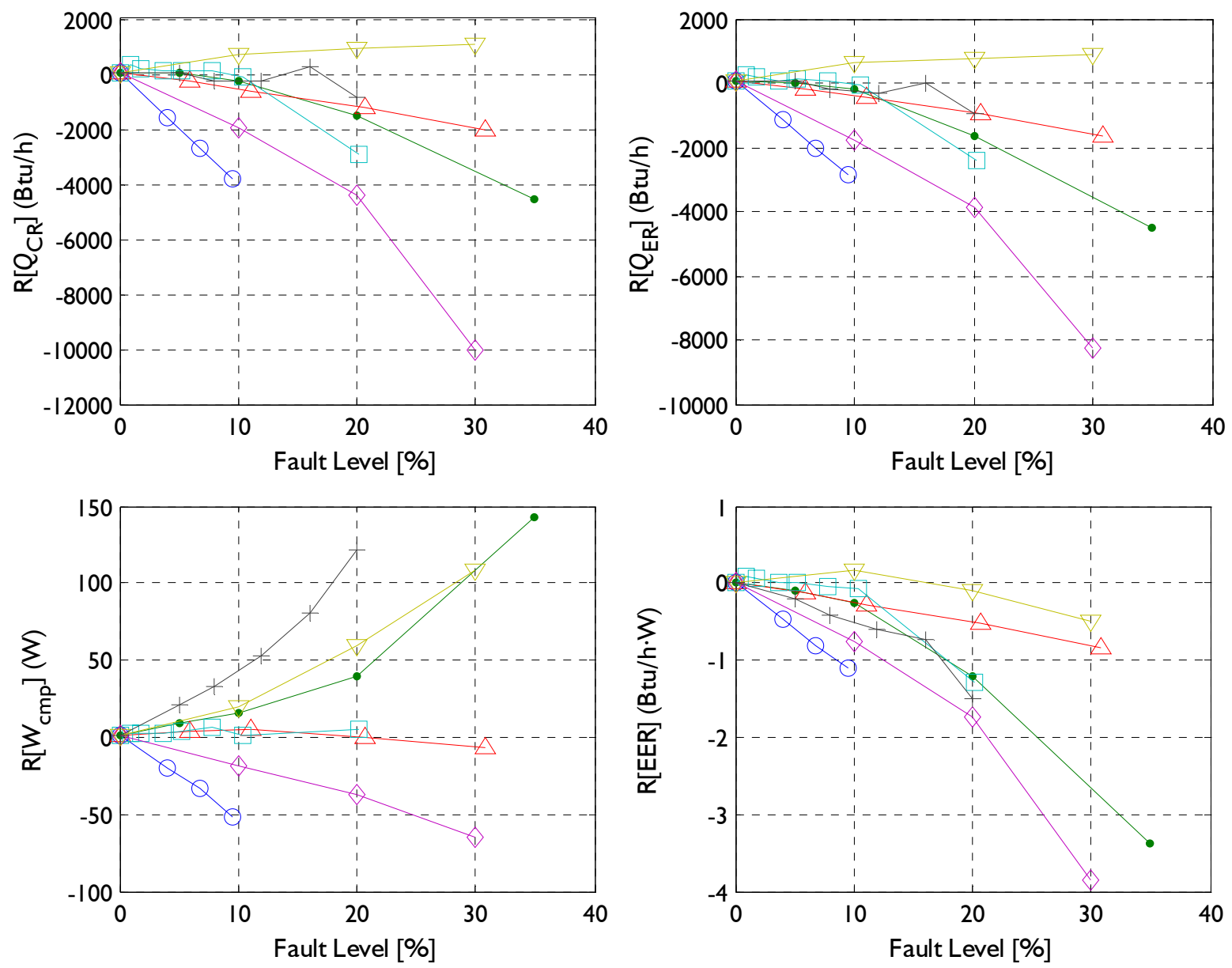

\section{Compressor leakage \\ Improper OD air flow rate Improper ID air flow rate \\ Liquid line restriction \\ Refrigerant undercharge \\ Refrigerant overcharge \\ Non-condensable gases}

Figure 5.17. Residuals for selected performance parameters for different faults. From the top left to right: $Q_{\mathrm{CR}}-$ condenser refrigerant-side capacity, $Q_{\mathrm{ER}}$ - evaporator refrigerant-side capacity, $W_{\text {comp }}$ - compressor work, EER - energy efficiency ratio

(Test $\# 5: 27.8^{\circ} \mathrm{C}\left(82.0^{\circ} \mathrm{F}\right)$ outdoor dry bulb temperature, $26.7^{\circ} \mathrm{C}\left(80.0^{\circ} \mathrm{F}\right)$ indoor dry bulb temperature and $50 \%$ indoor relative humidity) 


\subsubsection{Performance variations}

Figures 5.18 to 5.25 present percent variations of performance parameters $\mathrm{R}^{*}\left(\phi_{i}\right)$ for different single-fault experiments and four operating conditions, where:

$$
\mathrm{R}^{*}\left(\phi_{i}\right)=\frac{\phi_{i, \text { measurements }}-\phi_{i, \text { reference }}}{\phi_{i, \text { reference }}}=\frac{\mathrm{R}\left(\phi_{i}\right)}{\phi_{i, \text { reference }}}
$$

Variation of residuals is denoted by the subscript which abbreviates the corresponding fault in Table 3.1. Reference values were obtained from $2^{\text {nd }}$ order multivariate polynomial models described in Section 4.3.

Figures 5.18 and 5.19 show the variation of evaporator sensible capacity ( $\left.Q_{\mathrm{EA}, \text { sens }}\right)$ and latent capacity $\left(Q_{\text {EA,lat }}\right)$. The sensible capacity is most significantly degraded by low indoor air flow, refrigerant undercharge, and compressor fault. The latent capacity is degraded by the compressor fault, low outdoor air flow rate, but is increased at the low indoor air flow rate. This increase of latent capacity can be explained by a decreased air velocity allowing for longer contact between the air and the evaporator surface. The changes in the sensible and latent capacities are reflected in changes in the indoor air sensible heat ratio (SHR) shown in Figure 5.20. Sensible heat ratio increases as the latent capacity decreases since the faults degrade moisture condensation performance for the evaporator.

Refrigerant mass flow rate $\left(m_{\mathrm{R}}\right)$ is most affected by the compressor fault and low indoor air flow (Figure 5.21). The same two faults affect the condenser capacity $\left(Q_{\mathrm{CR}}\right)$ and evaporator capacity $\left(Q_{\mathrm{ER}}\right)$ which starts its degrading influence at the $10 \%$ fault level of reduced air flow (Figures 5.22 and 5.23, respectively). Compressor work ( $\left.W_{\mathrm{cmp}}\right)$ is increased with increasing fault levels for non-condensable gases, refrigerant overcharge, low outdoor air flow rate, and is decreased somewhat with the compressor fault and refrigerant undercharge (Figure 5.24).

Figures 5.22 and 5.23 show the condenser refrigerant capacity $\left(Q_{\mathrm{CR}}\right)$ and evaporator refrigerant capacity $\left(Q_{\mathrm{ER}}\right)$, respectively. Each capacity is calculated based on the refrigerant flow rate and the local enthalpies at the inlet and exit of the heat exchanger. Condenser exit enthalpy was used as evaporator inlet enthalpy as it was. In case that the refrigerant in condenser exit is in two phase, the local enthalpy was calculated based on the assumption of a saturated liquid. Both of heat capacities were changed similarly with the previous performance parameters, but they increases uniquely for refrigerant overcharge fault. It means refrigerant overcharge fault does give a benefit in capacity. However, EER will be decreased since compressor work is increased more than the capacity benefit.

Figure 5.25 shows the variation of energy efficiency ratio (EER). As expected, EER is decreased in all fault experiments. In cases of refrigerant overcharge and liquid line restriction, EER is relatively robust to fault level. EER shows no change at a low level of liquid line restriction fault. Since the TXV can control the suction line superheat close to its preset value, EER degradation appears only at a high fault level when the subcooled liquid refrigerant is flashed into two phase near the TXV. With the refrigerant overcharge fault, the increase of evaporator capacity can partially compensate compressor work. Thus only slight EER degradation is observed. However, the refrigerant overcharge fault should be monitored carefully since it can lead to compressor damage. 

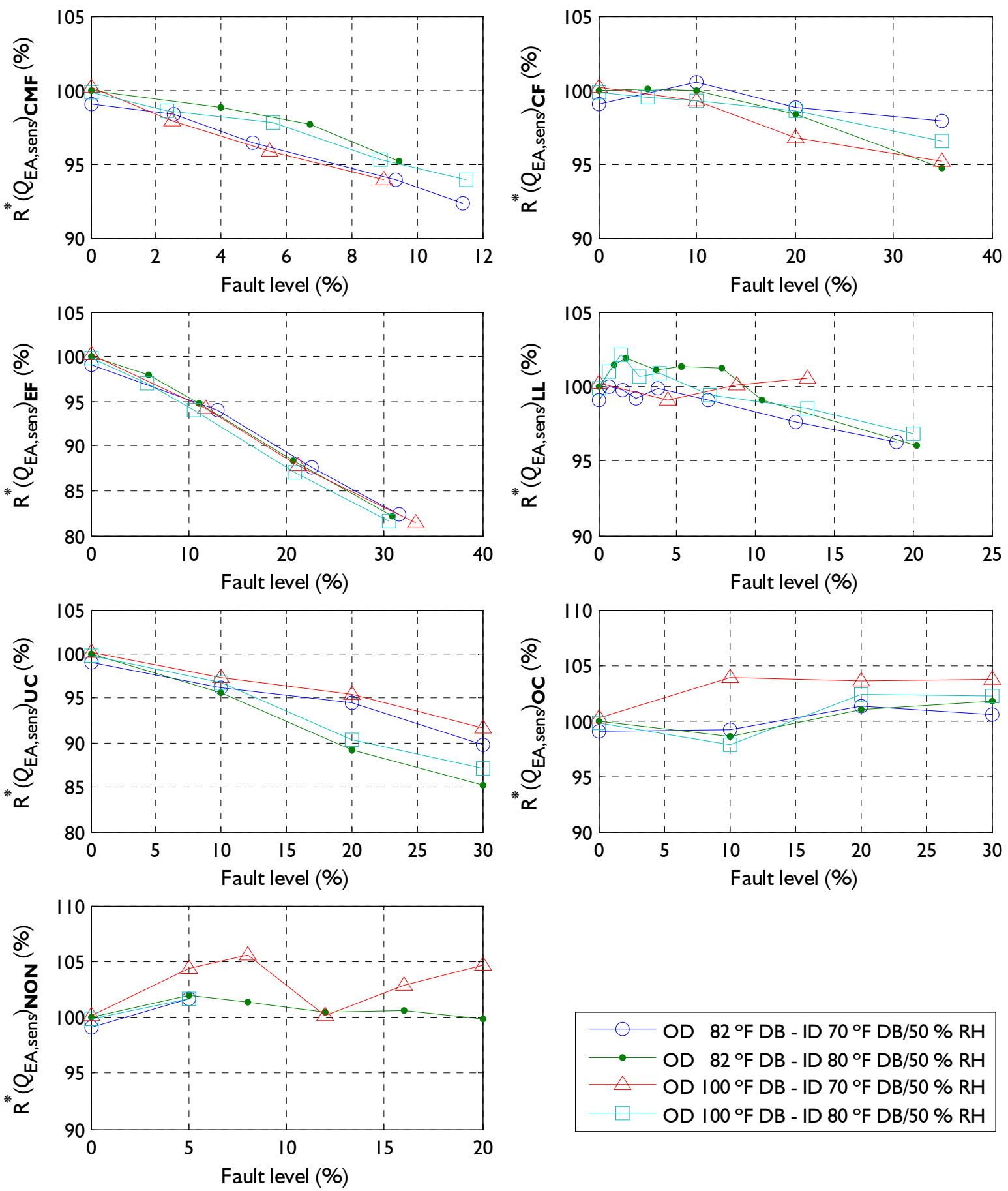

Figure 5.18. Variation of evaporator sensible capacity $\left(Q_{\mathrm{EA}, \mathrm{sens}}\right)$ at different faults. From the top left to right: compressor fault $(\mathrm{CMF})$, improper outdoor air flow rate $(\mathrm{CF})$, improper indoor air flow rate (EF), liquid line restriction (LL), refrigerant overcharge (OC), refrigerant undercharge (UC), and presence of non-condensable gases (NON) 

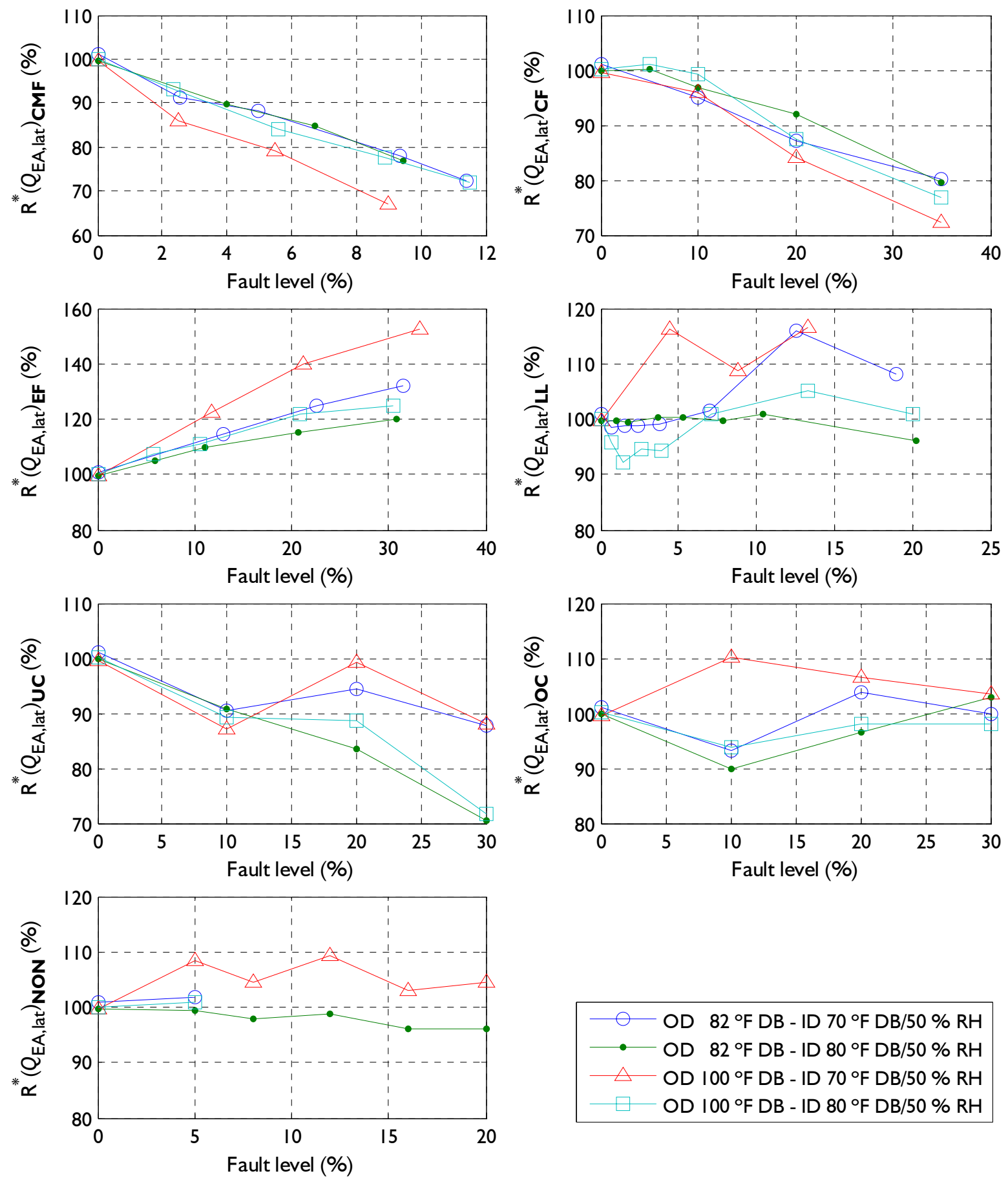

Figure 5.19. Variation of evaporator latent capacity $\left(Q_{\mathrm{EA}, \text { lat }}\right)$ at different faults. From the top left to right: compressor fault (CMF), improper outdoor air flow rate $(\mathrm{CF})$, improper indoor air flow rate (EF), liquid line restriction (LL), refrigerant overcharge (OC), refrigerant undercharge (UC), and presence of non-condensable gases (NON) 

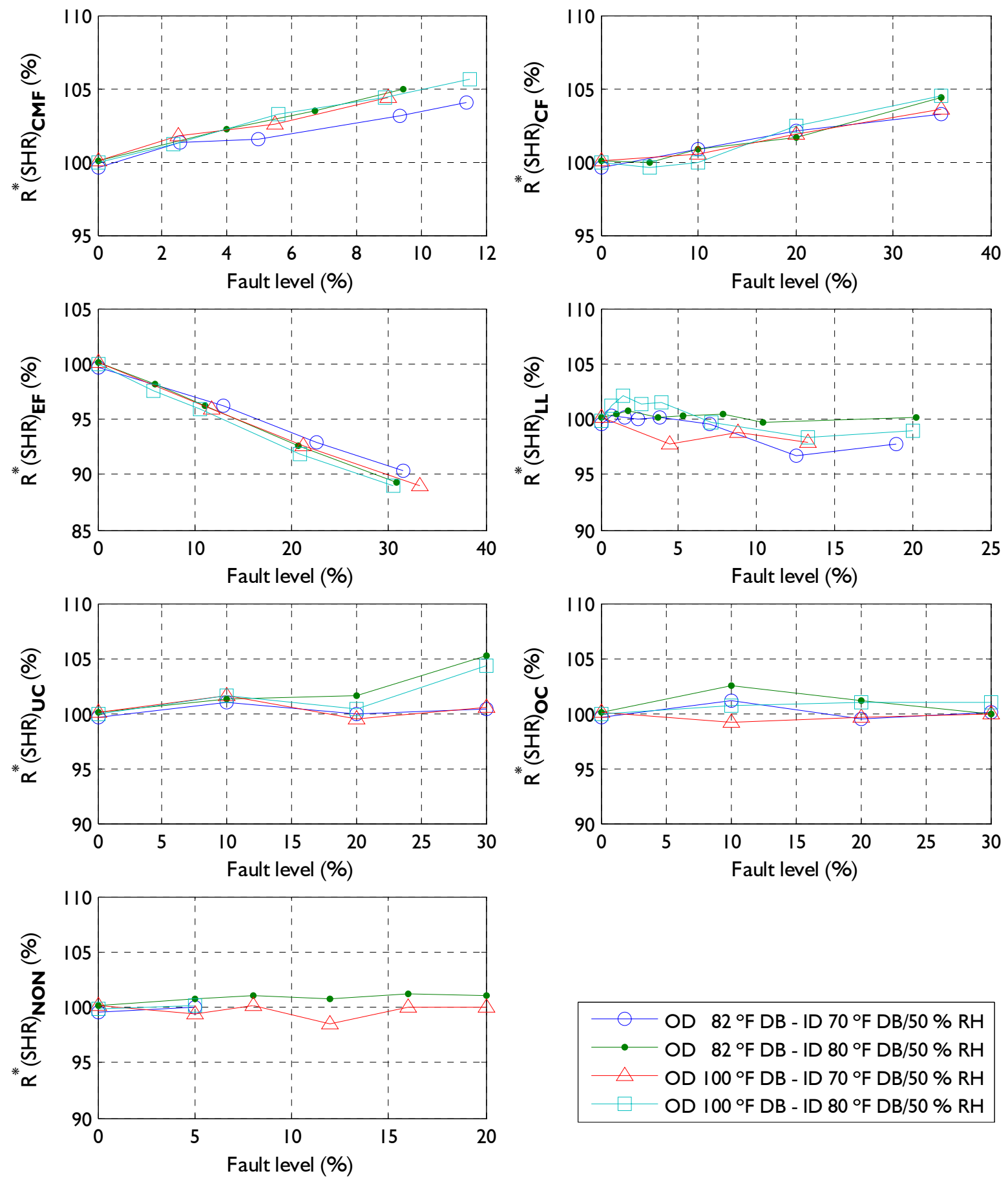

Figure 5.20. Variation of indoor air sensible heat ratio (SHR) at different faults. From the top left to right: compressor fault $(\mathrm{CMF})$, improper outdoor air flow rate $(\mathrm{CF})$, improper indoor air flow rate (EF), liquid line restriction (LL), refrigerant overcharge (OC), refrigerant undercharge (UC), and presence of non-condensable gases (NON) 

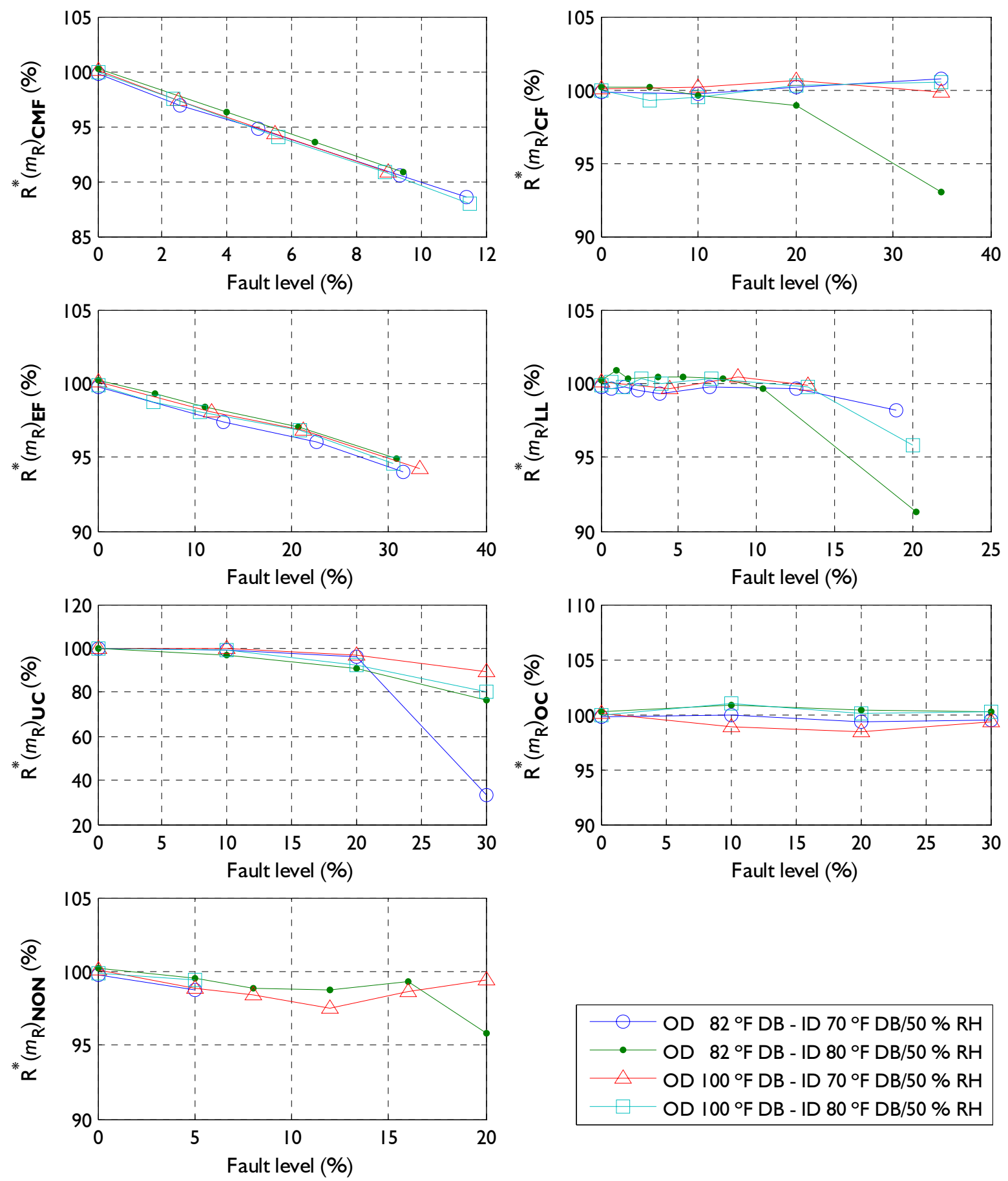

Figure 5.21. Variation of refrigerant mass flow rate $\left(m_{\mathrm{R}}\right)$ at different faults. From the top left to right: compressor fault $(\mathrm{CMF})$, improper outdoor air flow rate $(\mathrm{CF})$, improper indoor air flow rate (EF), liquid line restriction (LL), refrigerant overcharge (OC), refrigerant undercharge (UC), and presence of non-condensable gases (NON) 

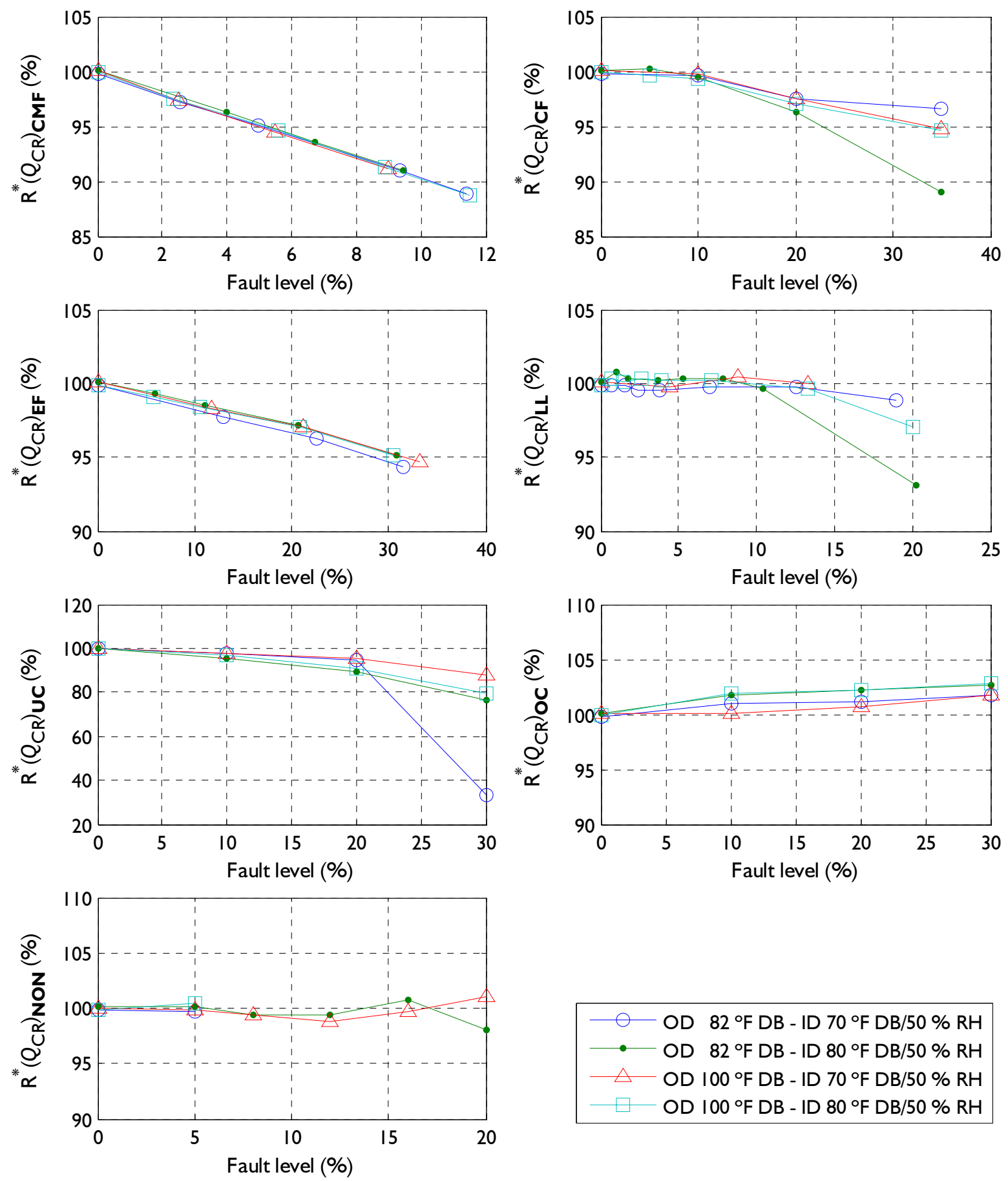

Figure 5.22. Variation of condenser refrigerant-side capacity $\left(Q_{\mathrm{CR}}\right)$ at different faults. From the top left to right: compressor fault (CMF), improper outdoor air flow rate (CF), improper indoor air flow rate $(\mathrm{EF})$, liquid line restriction (LL), refrigerant overcharge (OC), refrigerant undercharge (UC), and presence of non-condensable gases (NON) 

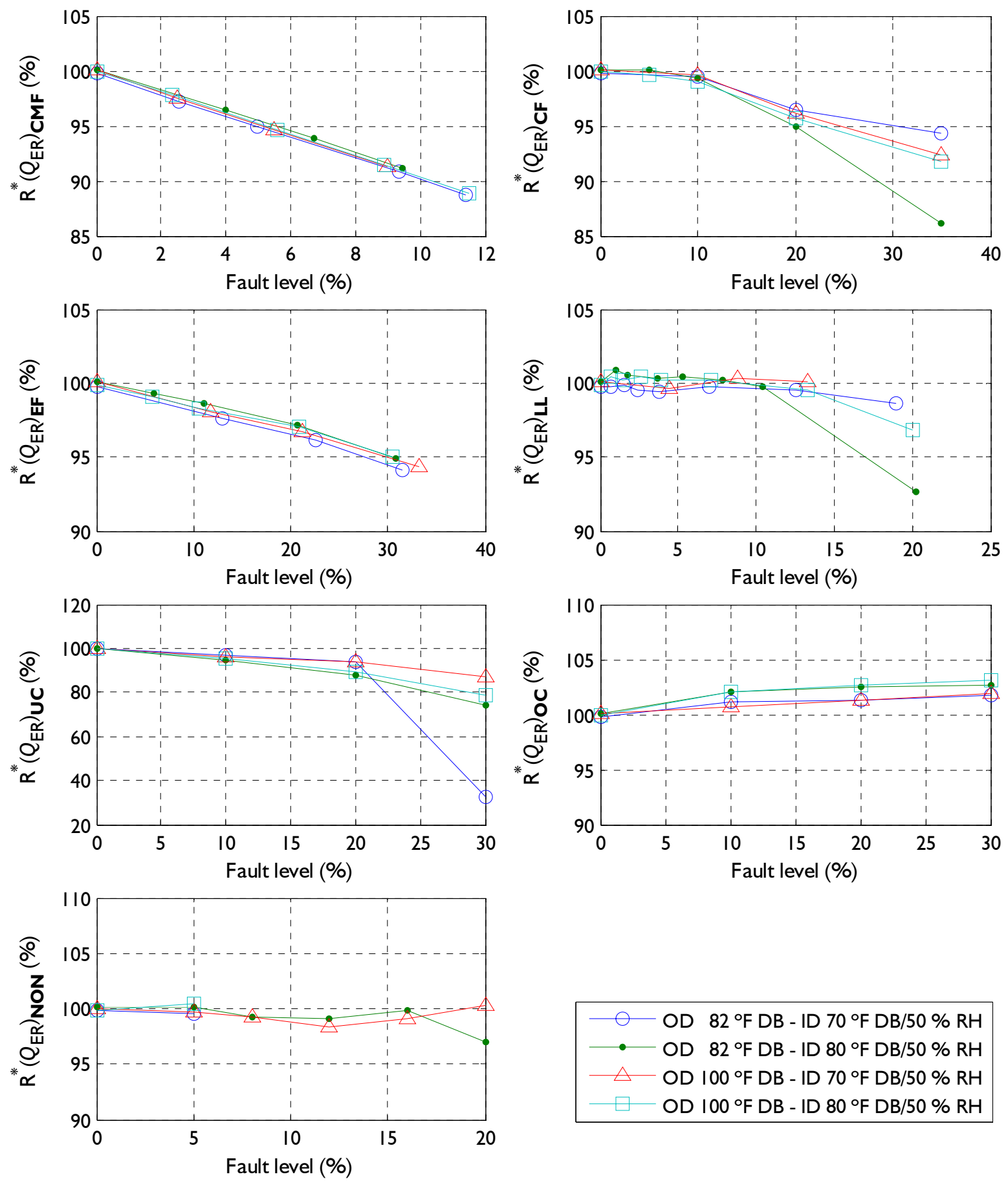

Figure 5.23. Variation of evaporator refrigerant-side capacity $\left(Q_{\mathrm{ER}}\right)$ at different faults. From the top left to right: compressor fault (CMF), improper outdoor air flow rate (CF), improper indoor air flow rate $(\mathrm{EF})$, liquid line restriction (LL), refrigerant overcharge (OC), refrigerant undercharge (UC), and presence of non-condensable gases (NON) 

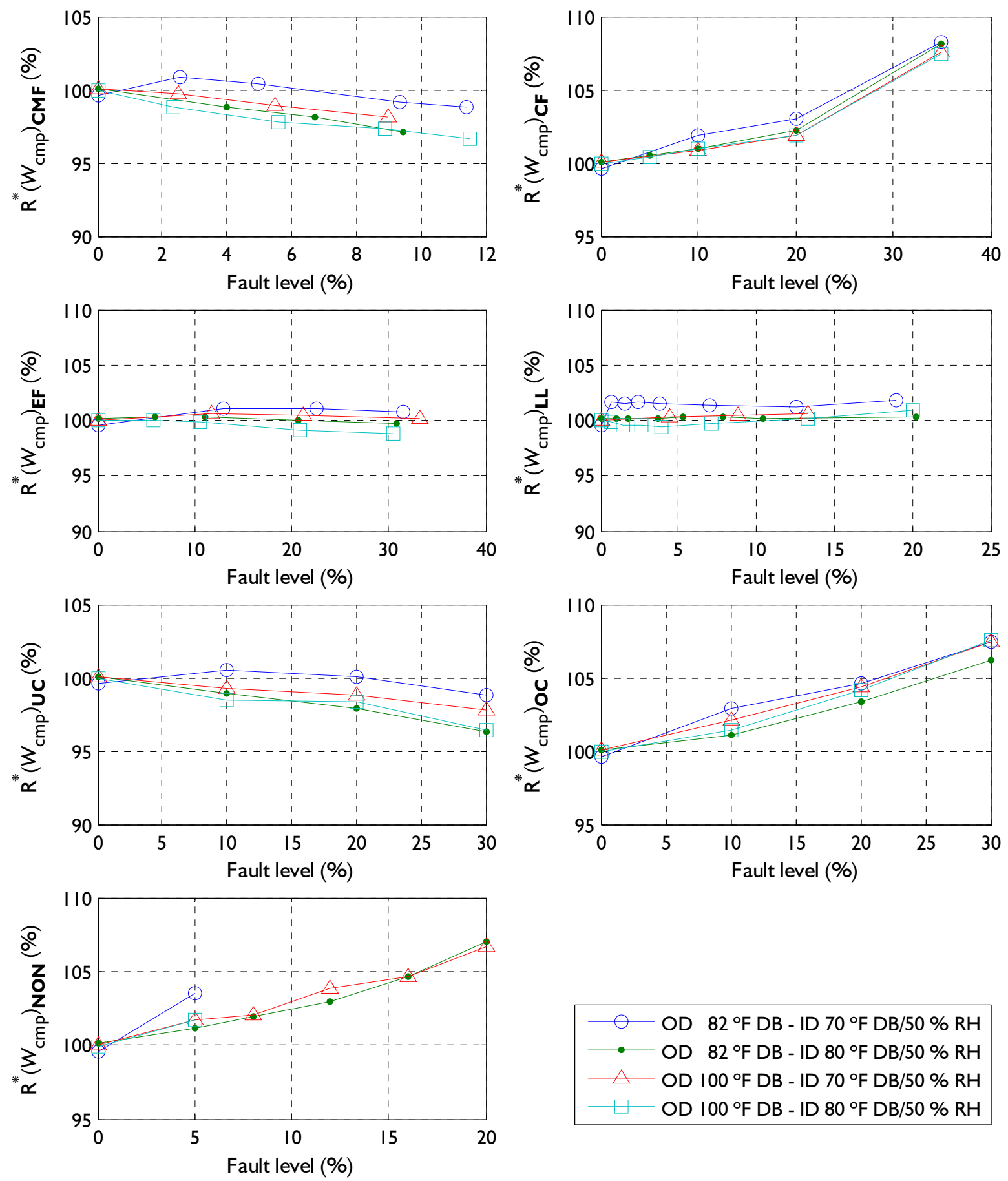

Figure 5.24. Variation of compressor work $\left(W_{\mathrm{cmp}}\right)$ at different faults. From the top left to right: compressor fault $(\mathrm{CMF})$, improper outdoor air flow rate $(\mathrm{CF})$, improper indoor air flow rate (EF), liquid line restriction (LL), refrigerant overcharge (OC), refrigerant undercharge (UC), and presence of non-condensable gases (NON) 

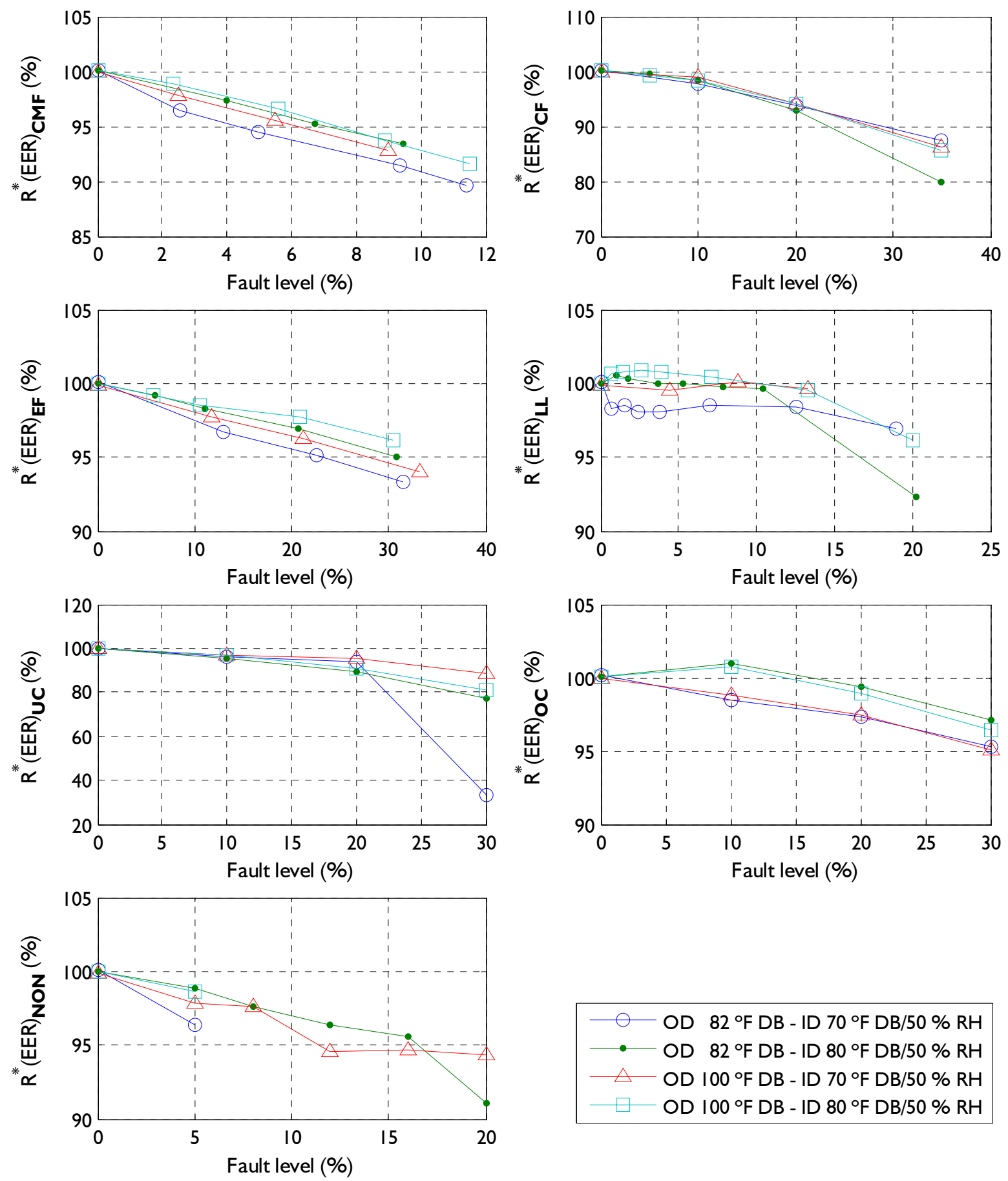

Figure 5.25. Variation of energy efficiency ratio (EER) at different faults. From the top left to right: compressor fault (CMF), improper outdoor air flow rate $(\mathrm{CF})$, improper indoor air flow rate (EF), liquid line restriction (LL), refrigerant overcharge (OC), refrigerant undercharge (UC), and presence of non-condensable gases (NON) 


\subsection{Transient Behavior at Different Refrigerant Charge Levels}

Figure 5.26 represents a sample of a transient test at the condition of $37.8^{\circ} \mathrm{C}\left(100.0{ }^{\circ} \mathrm{F}\right)$ outdoor dry bulb temperature, $21.1^{\circ} \mathrm{C}\left(70.0^{\circ} \mathrm{F}\right)$ indoor dry bulb temperature and $50 \%$ indoor relative humidity (Test \#8). The refrigerant charge level was $20 \%$ undercharged. The test was done with on-off cyclic operation with different turn-off intervals. Five temperature measurements, condenser saturation temperature $\left(T_{\mathrm{CR}}\right)$, evaporator saturation temperature $\left(T_{\mathrm{ER}}\right)$, compressor discharge wall temperature $\left(T_{\mathrm{DW}}\right)$, evaporator exit superheat $\left(\Delta T_{\mathrm{sh}}\right)$, and liquid line subcooling $\left(\Delta T_{\mathrm{sc}}\right)$ were recorded every $5 \mathrm{~s}$. As shown at the top of Figure 5.26 , the turn-off period varied with $(24,24,6$, and 12) min off with a 6 min on-period in between each off period. The first two 24 minute off-periods were intended to verify the repeatability of any startup transients.

Figure 5.27 shows the time variation of measurements during on-off cyclic operation with different turnoff intervals at the normal refrigerant charge. Without regard to the turn-off period, all the measurements show similar transient behavior. Less variation during the turn-on transients is observed when the system is turned off for a shorter period. Based on the superheat change in Figure 5.27(d), the TXV behavior can be indirectly estimated. The TXV is mostly closed during the off period since superheat is less than the normal level which is approximately $8.3^{\circ} \mathrm{C}\left(15.0^{\circ} \mathrm{F}\right)$. Right after the system is turned on, the TXV is still closed and superheat decreases. Shortly thereafter, the TXV is opened due to increased superheat since there is no refrigerant supply through the TXV. After the TXV opens, liquid refrigerant flows out of the evaporator. This drops superheat to nothing, meaning two-phase flow, and the TXV shuts again. After the liquid refrigerant evaporates, the TXV reopens and then starts to control superheat. This trend is also shown in the evaporator saturation temperature in Figure 5.27(b) and refrigerant mass flow rate in Figure 5.27(f). Figure 5.27(e) shows the variation of liquid line subcooling. A little while after startup, subcooling is slowly increased to a desired value as expected. In the current system, the subcooling thermocouple was attached right before the TXV. After the system was turned off, the temperature at the TXV upstream gradually approaches the indoor temperature of $21.1^{\circ} \mathrm{C}\left(70.0^{\circ} \mathrm{F}\right)$. Since the condenser and liquid line pressure stayed at about the same level, corresponding to the saturation temperature of $37.8^{\circ} \mathrm{C}\left(100.0^{\circ} \mathrm{F}\right)$, subcooling increases after the system shutdown.

Figure 5.28 shows time variation of measurements with different refrigerant charge levels. Normal refrigerant charge, $20 \%$ undercharge, and $30 \%$ undercharge were selected. The system was cyclically operated for 24 min off, 6 min on, and 24 min off. Distinct differences during the off period are not observed. During the on period, superheat variation in Figure 5.28(d) shows that transient behaviors vary with charge levels; however, the observed differences are not large enough for use by a FDD scheme for detecting improper refrigerant charge in the system. 


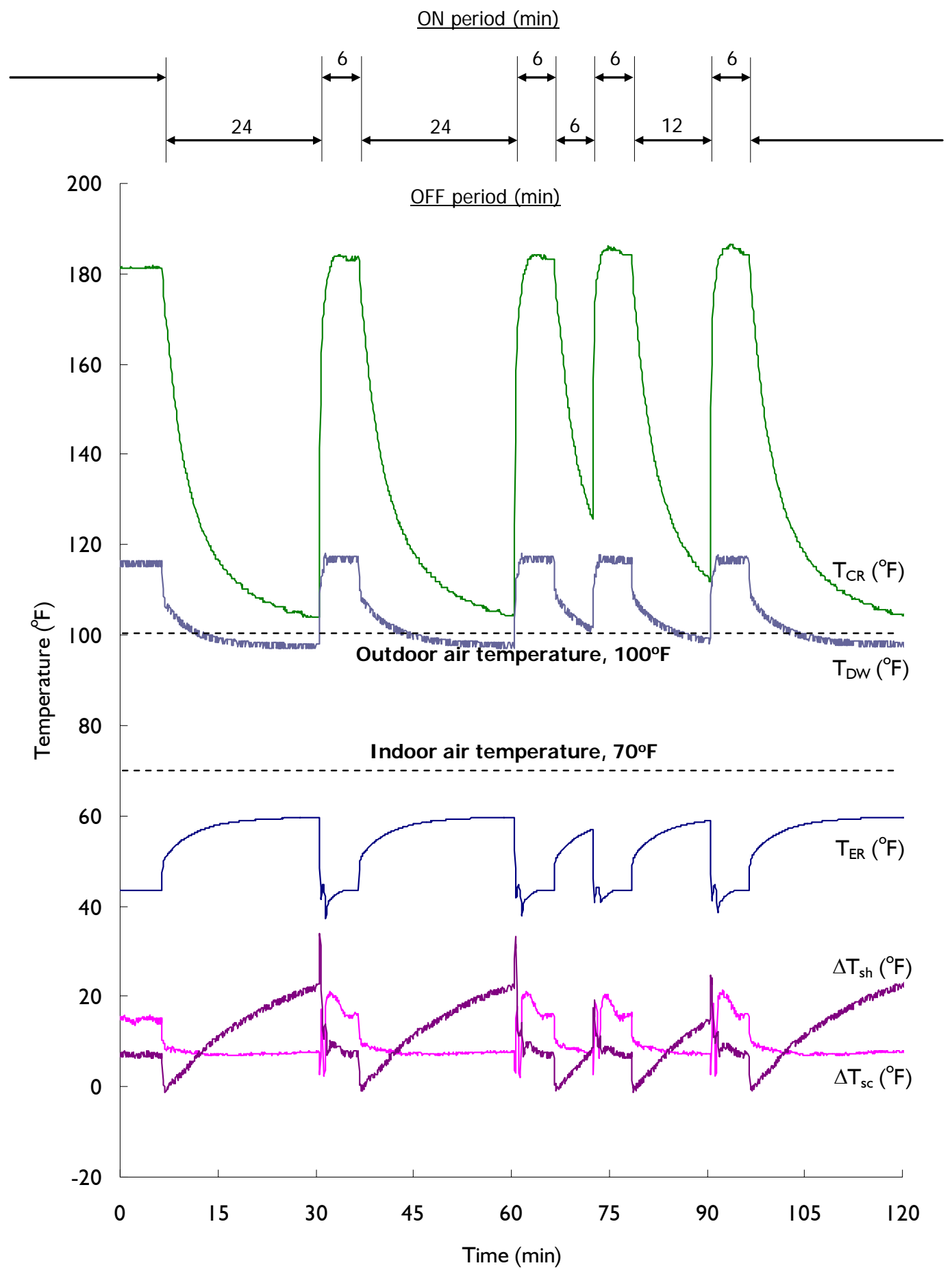

Figure 5.26. Real-time transient test of on-off cyclic operation with different turn-off intervals at the $20 \%$ fault of refrigerant undercharge fault (Test $\# 8: 37.8^{\circ} \mathrm{C}\left(100.0^{\circ} \mathrm{F}\right)$ outdoor dry bulb temperature, $21.1^{\circ} \mathrm{C}\left(70.0^{\circ} \mathrm{F}\right)$ indoor dry bulb temperature and $50 \%$ indoor relative humidity) 


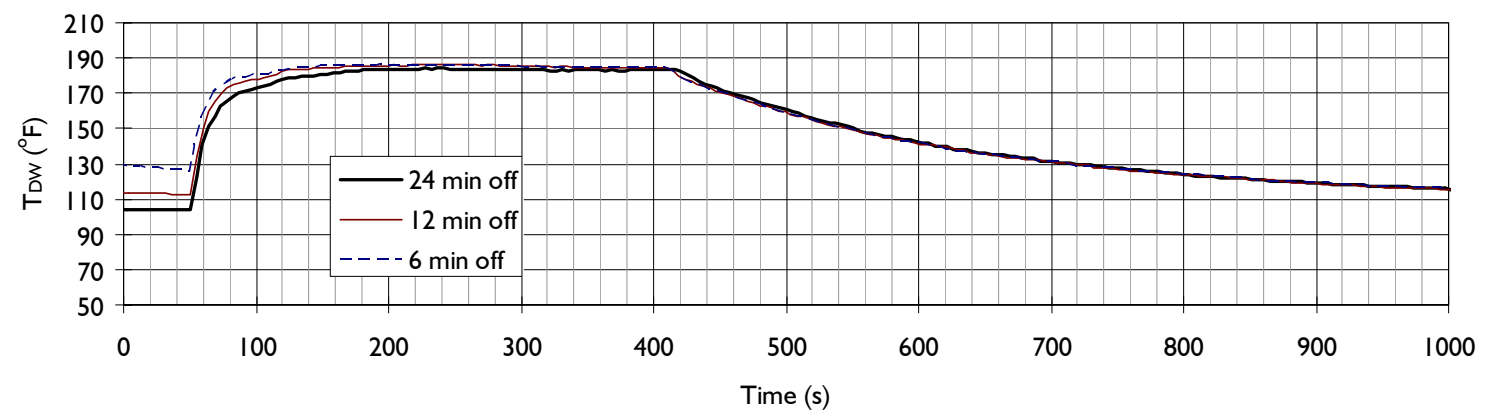

(a) Compressor discharge wall temperature

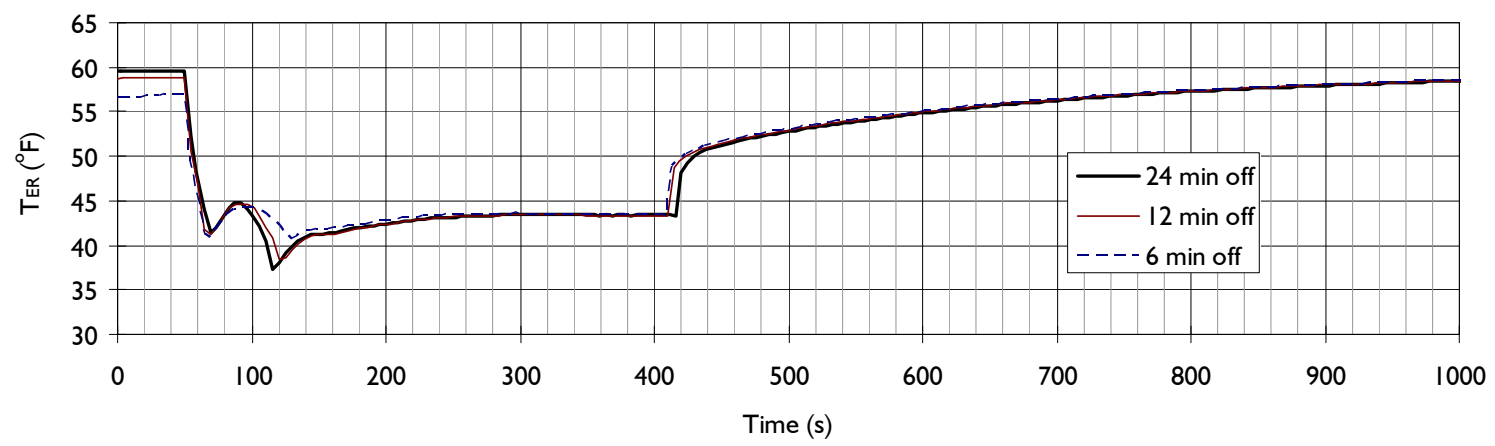

(b) Evaporator exit saturation temperature

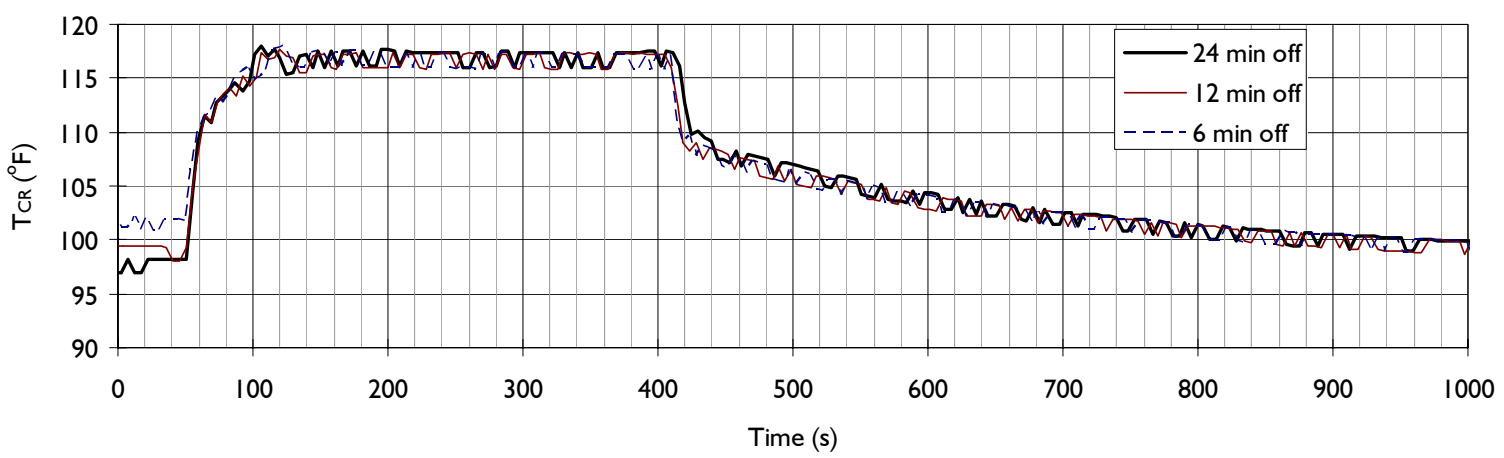

(c) Condenser inlet saturation temperature

Figure 5.27. Time variation of measurements during on-off cyclic operation with different turn-off intervals at the normal refrigerant charge (Test $\# 8: 37.8^{\circ} \mathrm{C}\left(100.0^{\circ} \mathrm{F}\right)$ outdoor dry bulb temperature, $21.1^{\circ} \mathrm{C}\left(70.0^{\circ} \mathrm{F}\right)$ indoor dry bulb temperature and $50 \%$ indoor relative humidity) 


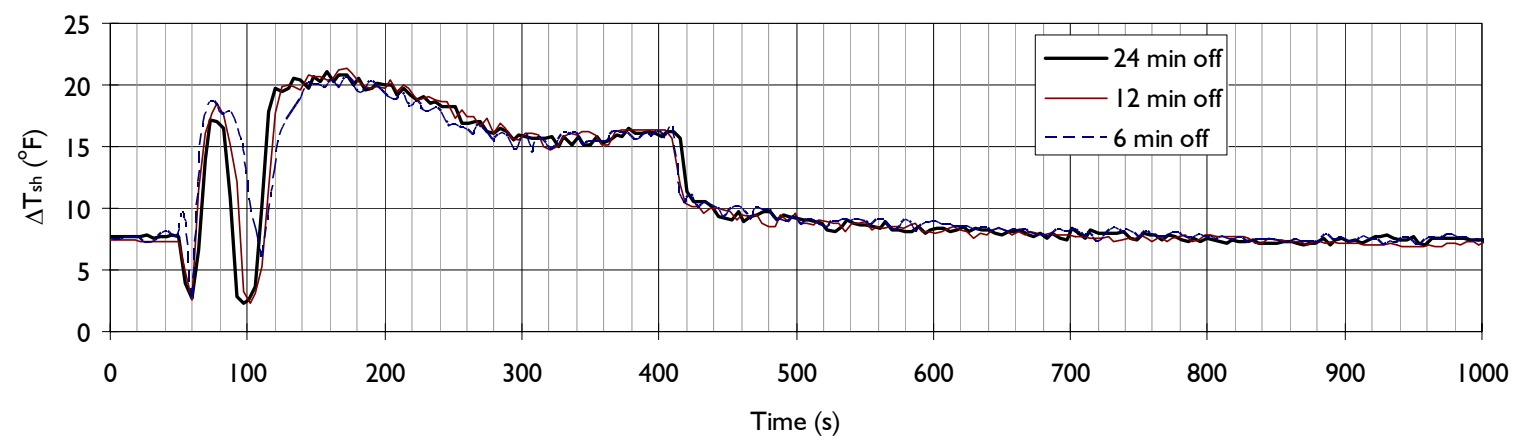

(d) Evaporator exit superheat

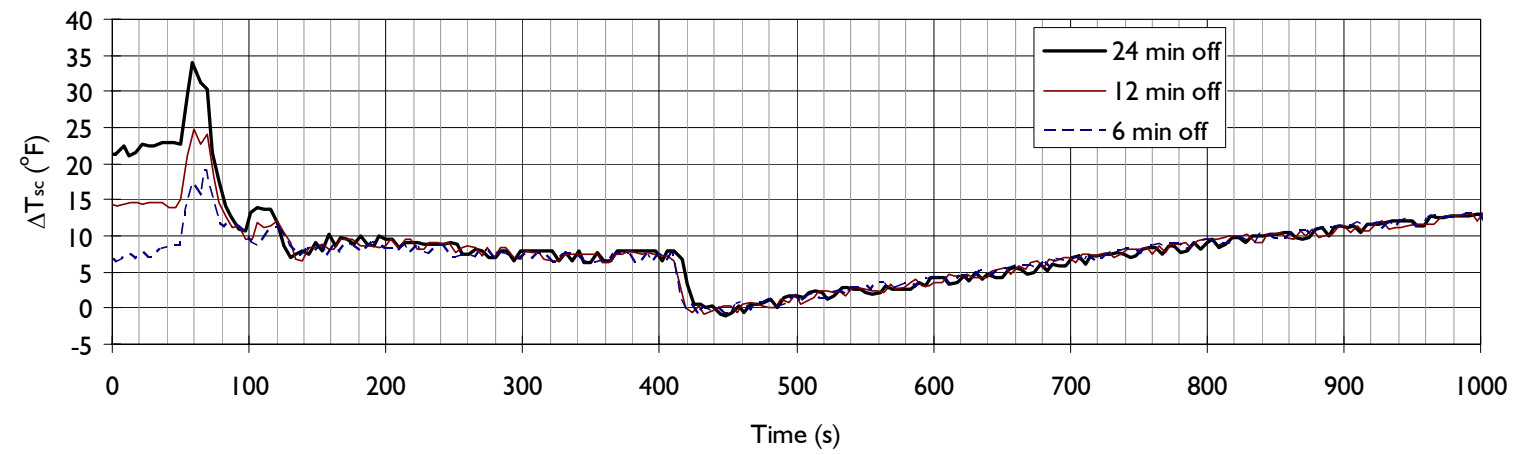

(e) Condenser exit liquid line subcooling

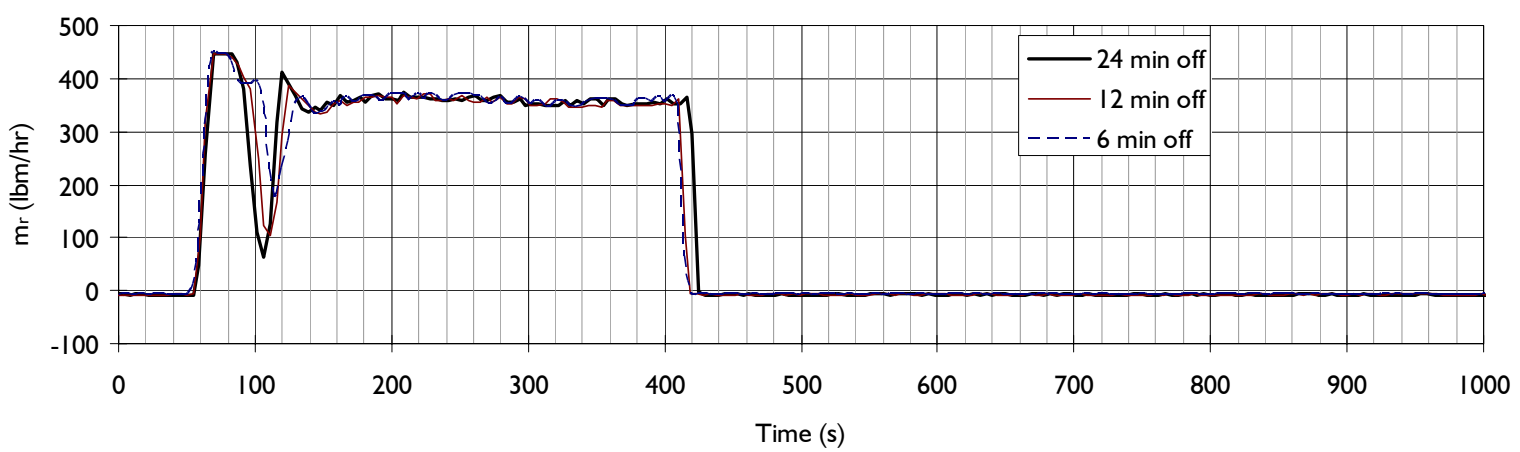

(f) Refrigerant mass flow rate

Figure 5.27. Time variation of measurements during on-off cyclic operation with different turn-off intervals at the normal refrigerant charge (Test $\# 8: 37.8^{\circ} \mathrm{C}\left(100.0^{\circ} \mathrm{F}\right)$ outdoor dry bulb temperature, $21.1^{\circ} \mathrm{C}\left(70.0^{\circ} \mathrm{F}\right)$ indoor dry bulb temperature and $50 \%$ indoor relative humidity) (continued) 


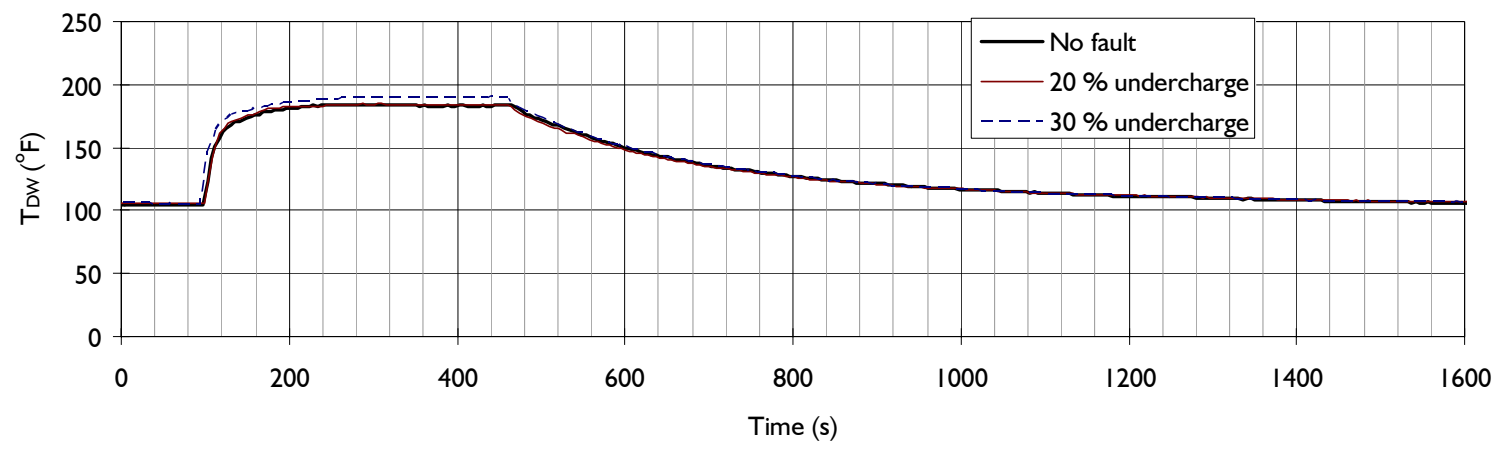

(a) Compressor discharge wall temperature

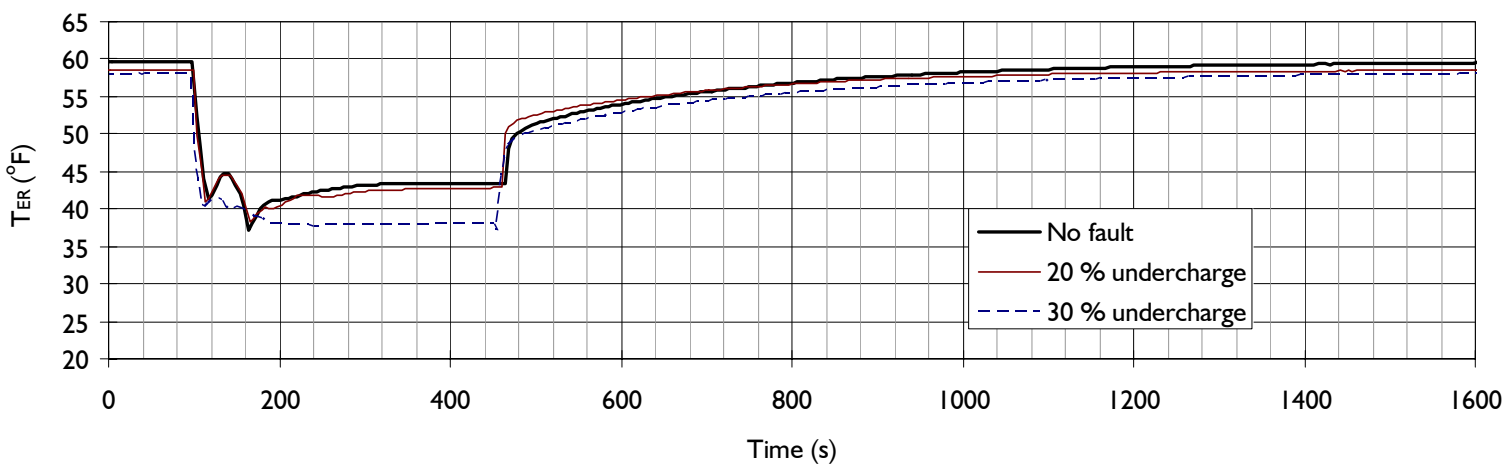

(b) Evaporator exit saturation temperature

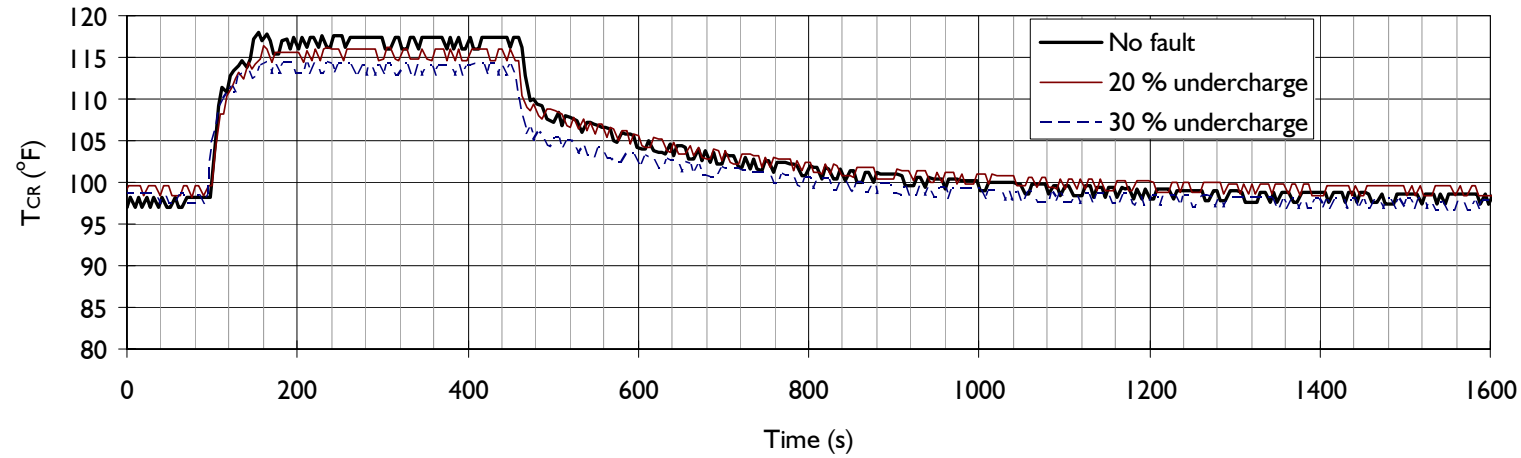

(c) Condenser inlet saturation temperature

Figure 5.28. Time variation of measurements during on-off cyclic operation with different refrigerant charge levels (Turn-off period: $24 \mathrm{~min}$, Test \#8: $37.8^{\circ} \mathrm{C}\left(100.0^{\circ} \mathrm{F}\right)$ outdoor dry bulb temperature, $21.1^{\circ} \mathrm{C}\left(70.0^{\circ} \mathrm{F}\right)$ indoor dry bulb temperature and $50 \%$ indoor relative humidity) 


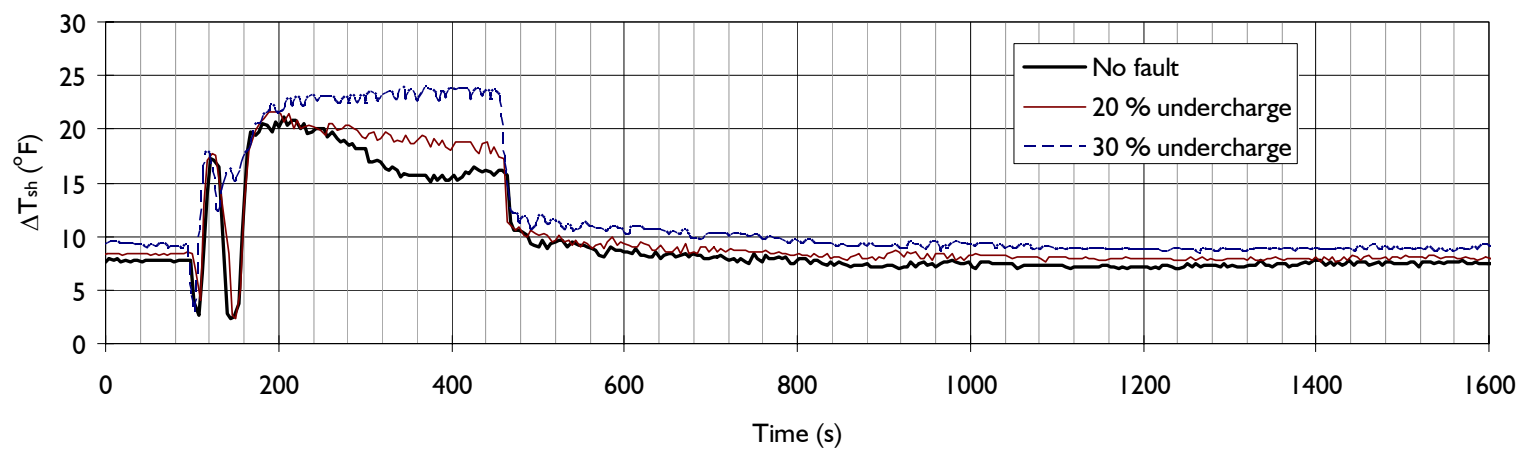

(d) Evaporator exit superheat

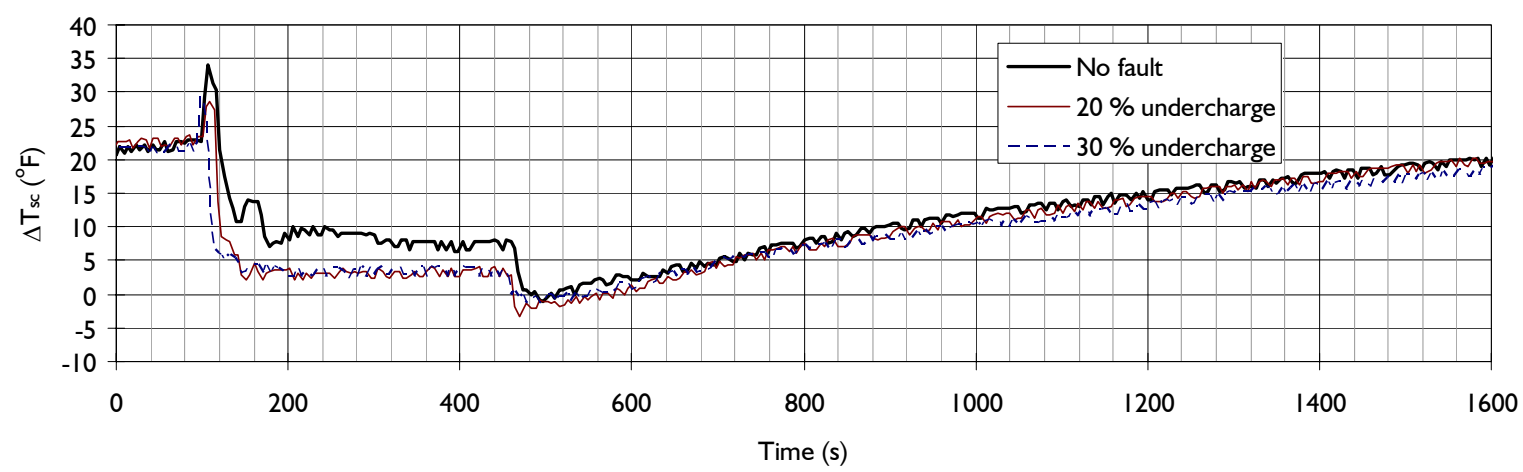

(e) Condenser exit liquid line subcooling

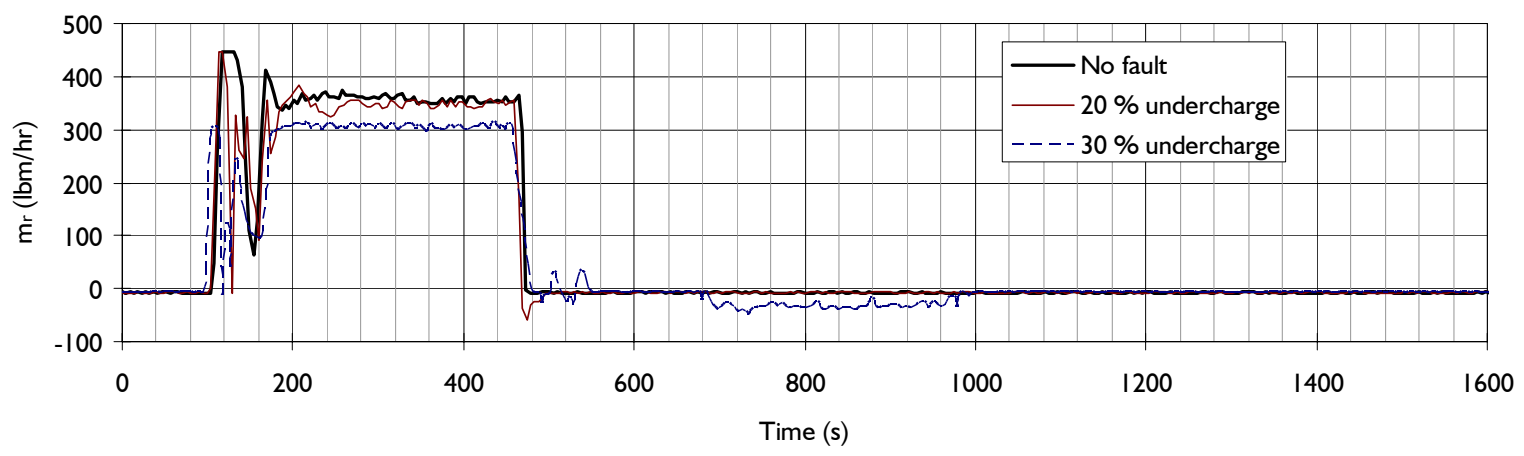

(f) Refrigerant mass flow rate

Figure 5.28. Time variation of measurements during on-off cyclic operation with different refrigerant charge levels (Turn-off period: $24 \mathrm{~min}$, Test \#8: $37.8^{\circ} \mathrm{C}\left(100.0^{\circ} \mathrm{F}\right)$ outdoor dry bulb temperature, $21.1^{\circ} \mathrm{C}\left(70.0^{\circ} \mathrm{F}\right)$ indoor dry bulb temperature and $50 \%$ indoor relative humidity) (continued) 


\section{CHAPTER 6. CONCLUDING REMARKS}

This report provides basic information on the behavior of a R410A residential unitary split heat pump during no-fault and fault operation. The system was installed in two separate environmental chambers and was operated in the cooling mode. Superheat at the evaporator exit was controlled by a TXV. The system was modified to implement seven artificial faults: compressor/reversing valve leakage, improper outdoor air flow, improper indoor air flow, liquid line restriction, refrigerant undercharge, refrigerant overcharge, and presence of non-condensable gas. These faults were imposed at two or more levels.

To estimate the reference values of the system behavior, no-fault tests were performed. The no-fault test results were used in the formulation of the reference model, which consisted of $2^{\text {nd }}$ order multivariate regressive polynomials calculated as a function of three input parameters: outdoor air temperature, indoor air temperature, and indoor dew point temperature. The developed steady-state detector calculated standard deviations of liquid line subcooling and evaporator exit superheat measurements for determining whether the system reached steady state. The steady-state detector filtered measured data based on a moving window and thresholds. In this study, at least 12 min were monitored to minimize false steadystate indications.

Using the no-fault model as a reference, feature residuals were observed for single faults. Since the system was controlled by a TXV, the system could adapt itself to external variation very well. Thus faulty behavior was not as clear as would be the case for a system equipped with an orifice expansion device; however, some measurements showed enough large variations to detect faults.

The distinctiveness of a fault depended on the TXV status. For the tests with liquid line restriction, little variation was observed due to the TXV's control of superheat. But once the liquid line was restricted until the subcooled refrigerant started to flash, even the maximum opening of the TXV could not control the superheat, and the system responded like a fixed orifice system. In this case, a TXV with a larger orifice size would be required, which implies that the fault effect is also influenced by the effective orifice size of the TXV.

For the heat exchanger fault caused by improper air flow, the fault behavior depends on the sizing of the heat exchanger. Oversizing the heat exchanger or fan capacity makes the system more robust in the presence of an improper air flow fault. Installing a liquid line receiver could also mollify the refrigerant undercharge/overcharge fault and non-condensable gas fault.

The dynamic tests at different refrigerant charges showed minor effects on the system behavior for various off-periods between shutoff and startup of the system. The most influenced parameter was the evaporator exit temperature; however, none of the monitored features varied sufficiently to diagnose improper refrigerant charge.

The results reported here will be used in a follow-up study for the development of FDD methods for airconditioners and heat pumps operating in the cooling mode. 


\section{REFERENCES}

Anderson, D., Graves, L., Reinert, W., Kreider, J.F., Dow, J., and Wubbena, H., 1989, "A Quasi-RealTime Expert System for Commercial Building HVAC Diagnostics," ASHRAE Transactions, Vol. 95, Part 2, pp. 25-28.

ANSI/ASHRAE Standard 37-1988. "Methods of Testing for Rating Unitary Air-Conditioning and Heat Pump Equipment", American Society of Heating, Refrigerating, and Air-Conditioning Engineers, Inc., Atlanta, GA.

ANSI/ASHRAE Standard 51-1985. "Laboratory Methods of Testing Fans for Aerodynamic Performance Rating”, American Society of Heating, Refrigerating, and Air-Conditioning Engineers, Inc., Atlanta, GA.

ARI Standard 210/240-2006. "Standard for Unitary Air Conditioning and Air Source Heat Pump Equipment," Air Conditioning and Refrigeration Institute, Fairfax, VA.

ASHRAE, 2004, “ASHRAE Handbook - HVAC Systems and Equipment," American Society of Heating, Refrigerating, and Air-Conditioning Engineers, Inc., Atlanta GA.

Braun, J.E., 1999, "Automated fault detection and diagnostics for the HVAC\&R industry," $H V A C \& R$ Research, Vol. 5, No. 2, pp. 85-86.

Breuker, M., Rossi, T., and Braun J.E., 2000, "Smart Maintenance for Rooftop Units," ASHRAE Journal, Vol. 42, No. 11, pp. 41-47.

Breuker, M.S. and Braun, J.E., 1998, "Common Faults and Their Impacts for Rooftop Air Conditioners," HVAC\&R Research, Vol. 4, No. 3, pp. 303-318.

Brownell, K.A., Klein, S.A., and Reindl, D.T., 1999, "Refrigeration System Malfunctions," ASHRAE Journal, Vol. 41, No. 2, pp. 40-47.

Castro, N.S., 2002, "Performance Evaluation of a Reciprocating Chiller Using Experimental Data and Model Predictions for Fault Detection and Diagnosis," ASHARE Transactions, Vol. 108, Part 1, pp. 889903.

Chen, B. and Braun, J.E., 2001, "Simple Rule-Based Methods for Fault Detection and Diagnostics Applied to Packaged Air Conditioners," ASHRAE Transactions, Vol. 107, Part 1, pp. 847-857.

Comstock, M.C., Braun, J.E., and Groll, E.A., 2001, "The Sensitivity of Chiller Performance to Common Faults," HVAC\&R Research, Vol. 7, No. 3, pp. 263-279.

DOE/EIA-0384, 2005, “Annual Energy Review 2004," Energy Information Administration, U.S. Department of Energy, Washington, DC 20585.

Federal Register, 2001, Vol. 66, No. 14, January 22nd.

Grimmelius, H.T., Woud, J.K., and Been, G., 1995, "On-line Failure Diagnosis for Compression Refrigeration Plants," International Journal of Refrigeration, Vol. 18, No. 1, pp. 31-41. 
Hayter, S.J., Torcelli, P.A., and Judkoff, R., 1999, "Optimizing Building and HVAC Systems," ASHRAE Journal, Vol. 41, No. 12, pp. 46-49.

Kim, M. and Kim, M.S., 2005, "Performance Investigation of a Variable Speed Vapor Compression System for Fault Detection and Diagnosis," International Journal of Refrigeration, Vol. 28, No. 4, pp. 481-488.

Lee, W.Y., House, J.M., Park, C., and Kelly, G.E., 1996b, "Fault Diagnosis of Air-Handling Unit Using Artificial Neural Networks," ASHRAE Transactions, Vol. 102, Part. 1, pp. 540-549.

Lee, W.Y., Park, C., and Kelly, G.E., 1996a, "Fault Detection in an Air-Handling Unit Using Residual and Recursive Parameter Identification Methods," ASHRAE Transactions, Vol. 102, Part 1, pp. 528-539.

Li, H. and Braun, J.E., 2003, "An Improved Method for Fault Detection and Diagnosis Applied to Package Air Conditioners," ASHRAE Transactions, Vol. 109, Part 2, pp. 683-692.

Li, H., 2004, "A Decoupling-Based Unified Fault Detection and Diagnosis Approach for Packaged Air Conditioners," Ph.D. Thesis, Purdue University, West Lafayette, IN.

McKellar, M.G., 1987. "Failure Diagnosis for a Household Refrigerator," M.S. Thesis, Purdue University, West Lafayette, IN.

Moen, R.D., Nolan, T.W., and Provost, L.P., 1998, "Quality Improvement through Planned Experimentation," 2nd Ed., McGraw-Hill, USA

Norford, L.K. and Little, R.D., 1993, "Fault Detection and Load Monitoring in Ventilation System," ASHRAE Transactions, Vol. 99, Part 1, pp. 590-602.

Pape, F.L.F., Mitchell, J.W., and Beckman, W.A., 1991, "Optimal Control and Fault Detection in Heating, Ventilating, and Air-Conditioning System," ASHRAE Transactions, Vol. 97, Part 1, pp. 729745.

Peitsman, H.C. and Bakker, V.E., 1996, "Application of Black-Box Models to HVAC Systems for Fault Detection," ASHRAE Transactions, Vol. 102, Part. 1, pp. 628-640.

Proctor, J., 2004, "Residential and Small Commercial Central Air Conditioning; Rated Efficiency isn't Automatic," Presentation at the Public Session. ASHRAE Winter Meeting, January 26, Anaheim, CA.

Rossi, T.M. and Braun, J.E., 1997, "A Statistical, Rule-based Fault Detection and Diagnostic Method for Vapor Compression Air Conditioners," HVAC\&R Research, Vol. 3, No. 1, pp. 19-37.

Rossi, T.M., 2004, "Unitary Air Conditioner Field Performance," International Refrigeration and Air Conditioning Conference at Purdue, Paper No. R146, July 12-15, West Lafayette, IN.

Roth, K., Llana, P., Westphalen, D., Brodrick, J., 2005, “Automated Whole Building Diagnostics," ASHRAE Journal, Vol. 47, No. 5, pp. 82-84.

Roth, K.W., Westphalten, D., and Brodrick, J., 2003, "Saving Energy with Building Commissioning," ASHRAE Journal, Vol. 45, No. 11, pp. 65-66. 
Seem, J.E., House, J.M., and Monroe, R.H., "On-line Monitoring and Fault Detection," ASHRAE Journal, Vo. 41, No. 7, pp. 21-26.

Smith, V.A. and Braun, J.E., 2003, "Fault Detection and Diagnostics for Rooftop Air Conditioners," Final Report Compilation for Project 2.1, Publication \#P500-03-096, California Energy Commission, http://www.archenergy.com/cec-eeb/reports.htm

Snoonian, D., 2003, “Smart Buildings,” IEEE Spectrum, Vol. 40, No. 8, pp. 18-23.

Stylianou, M. and Nikanpour, D., 1996, "Performance Monitoring, Fault Detection, and Diagnosis of Reciprocating Chillers," ASHRAE Transactions, Vol. 102, Part 1, pp. 615-627.

Stylianou, M.P., 1997, "Application of Classification Functions to Chiller Fault Detection and Diagnosis," ASHRAE Transactions, Vol. 103, Pt. 1, pp. 645-656.

Wang, Y.-M., Russell, W., Arora, A., Xu, J., and Jagannatthan, R.K., 2000, “Towards Dependable Home Networking: An Experience Report," Proceedings of the International Conference on Dependable Systems and Networks, 25-28 June, New York, USA, pp. 43-48.

Westphalen, D., Roth, K.W., and Brodrick, J., 2003, "System and Component Diagnostics," ASHRAE Journal, Vol. 45, No. 4, pp. 58-59.

Wu, Q., Wang, F.-Y., 2002, “The Open Distributed Intelligent Management System Architecture and Prototype for Internet Connected Homes," IEEE International Symposium on Intelligent Control Proceedings, Oct 27-30, Vancouver, Canada, pp. 415-420 


\section{APPENDIX A. LIST OF LABORATORY INSTRUMENTATION}

Table A.1. Data acquisition channel assignment for FDD split-system testing ${ }^{1}$

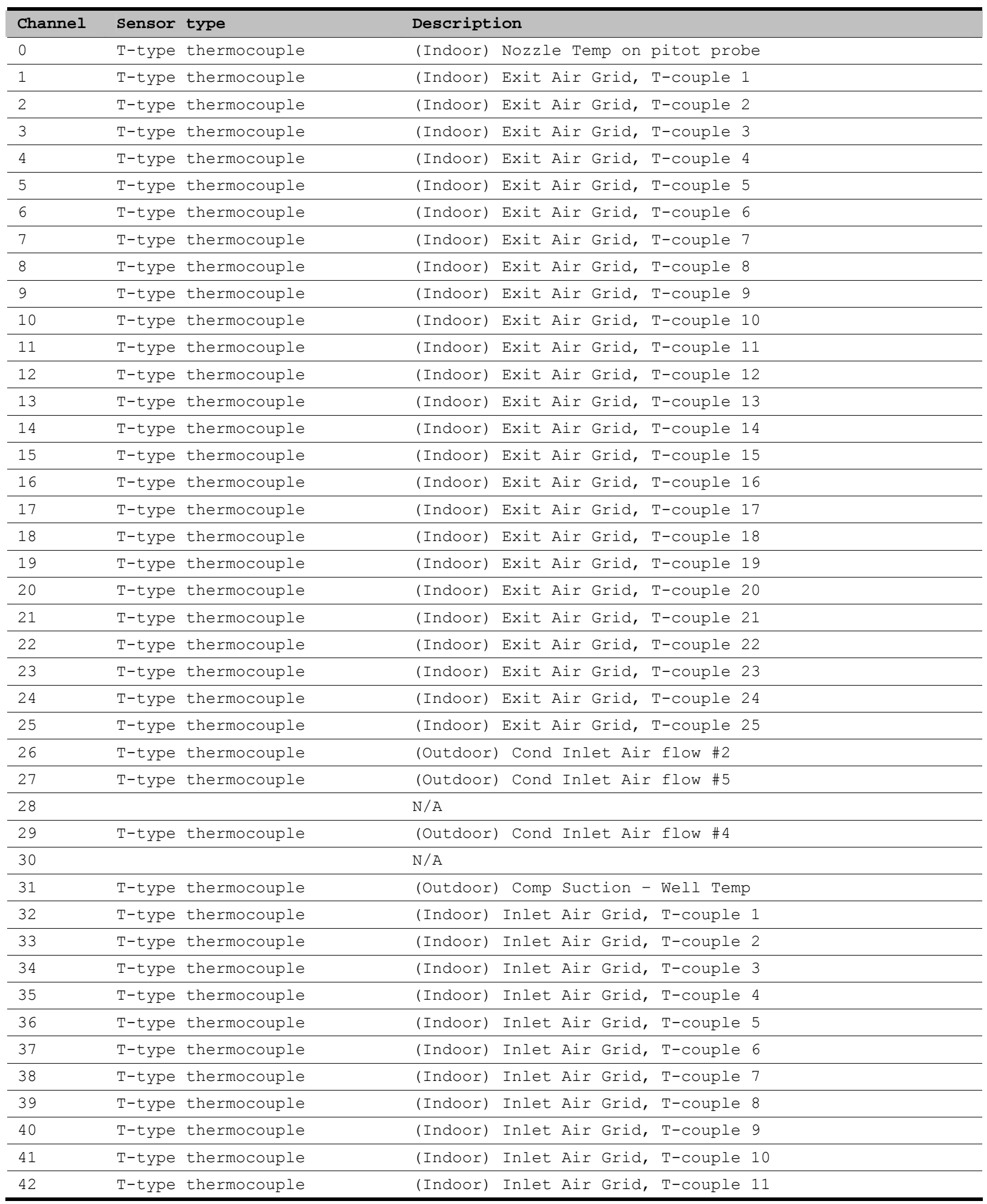




\begin{tabular}{|c|c|c|}
\hline Channel & Sensor type & Description \\
\hline 43 & T-type thermocouple & Inlet Air Grid, T-couple 12 \\
\hline 44 & T-type thermocouple & (Indoor) Inlet Air Grid, T-couple 13 \\
\hline 45 & T-type thermocouple & (Indoor) Inlet Air Grid, T-couple 14 \\
\hline 46 & T-type thermocouple & (Indoor) Inlet Air Grid, T-couple 15 \\
\hline 47 & T-type thermocouple & (Indoor) Inlet Air Grid, T-couple 16 \\
\hline 48 & T-type thermocouple & (Indoor) Inlet Air Grid, T-couple 17 \\
\hline 49 & T-type thermocouple & (Indoor) Inlet Air Grid, T-couple 18 \\
\hline 50 & T-type thermocouple & (Indoor) Inlet Air Grid, T-couple 19 \\
\hline 51 & T-type thermocouple & (Indoor) Inlet Air Grid, T-couple 20 \\
\hline 52 & T-type thermocouple & (Indoor) Inlet Air Grid, T-couple 21 \\
\hline 53 & T-type thermocouple & (Indoor) Inlet Air Grid, T-couple 22 \\
\hline 54 & T-type thermocouple & (Indoor) Inlet Air Grid, T-couple 23 \\
\hline 55 & T-type thermocouple & (Indoor) Inlet Air Grid, T-couple 24 \\
\hline 56 & T-type thermocouple & (Indoor) Inlet Air Grid, T-couple 25 \\
\hline 57 & T-type thermocouple & (Indoor) Evap Bend 23 - $24 \mathrm{R}$ \\
\hline 58 & T-type thermocouple & (Indoor) Evap Outlet (11) R \\
\hline 59 & T-type thermocouple & (Indoor) Evap Bend $27-28 \mathrm{R}$ \\
\hline 60 & & $\mathrm{~N} / \mathrm{A}$ \\
\hline 61 & T-type thermocouple & (Indoor) Cond Inlet 2nd bunch (Large diameter tubing) \\
\hline 62 & T-type thermocouple & (Outdoor) Comp Discharge Line Wall \\
\hline 63 & T-type thermocouple & (Outdoor) Cond Inlet Air flow \#3 \\
\hline 64 & & $\mathrm{~N} / \mathrm{A}$ \\
\hline 65 & & $\mathrm{~N} / \mathrm{A}$ \\
\hline 66 & & $\mathrm{~N} / \mathrm{A}$ \\
\hline 67 & T-type thermocouple & (Indoor) Evap Bend $12-13 \mathrm{R}$ \\
\hline 68 & T-type thermocouple & (Indoor) Vapor Ref Evap exit \#2 Well \\
\hline 69 & T-type thermocouple & (Indoor) Vapor Ref Evap Exit \#1 Well \\
\hline 70 & & $\mathrm{~N} / \mathrm{A}$ \\
\hline 71 & T-type thermocouple & (Indoor) Liq Ref Evap Inlet \#2 \\
\hline 72 & & $\mathrm{~N} / \mathrm{A}$ \\
\hline 73 & T-type thermocouple & (Indoor) Liq Ref Evap Inlet \#1 \\
\hline 74 & T-type thermocouple & (Indoor) Evap Bend 53 - 54 L \\
\hline 75 & T-type thermocouple & (Indoor) Evap Bend $16-17 \mathrm{R}$ \\
\hline 76 & T-type thermocouple & (Indoor) Evap Bend $20-40 \mathrm{R}$ \\
\hline 77 & T-type thermocouple & (Indoor) Evap Outlet, L exit 11 \\
\hline 78 & T-type thermocouple & (Indoor) Evap Bend 53 - $54 \mathrm{R}$ \\
\hline 79 & T-type thermocouple & (Indoor) Evap Bend $27-28 \mathrm{~L}$ \\
\hline 80 & T-type thermocouple & (Indoor) Evap Bend $13-12 \mathrm{~L}$ \\
\hline 81 & T-type thermocouple & (Indoor) Evap Bend $17-16 \mathrm{~L}$ \\
\hline 82 & T-type thermocouple & (Indoor) Evap Bend 57 - $58 \mathrm{R}$ \\
\hline 83 & T-type thermocouple & (Indoor) Evap Bend $40-20 \mathrm{~L}$ \\
\hline 84 & T-type thermocouple & (Indoor) Evap Bend $57-58 \mathrm{~L}$ \\
\hline 85 & T-type thermocouple & (Indoor) Outlet Air Temp\#1 a MEMS RH Sensor \\
\hline 86 & T-type thermocouple & (Indoor) Evap Bend $23-24$ L \\
\hline 87 & T-type thermocouple & (Outdoor) Comp Shell - TOP \\
\hline 88 & T-type thermocouple & (Outdoor) Comp Suction Line - Wall \\
\hline 89 & T-type thermocouple & (Indoor) Outlet Air Temp\#2 @ MEMS RH Sensor \\
\hline 90 & T-type thermocouple & (Outdoor) Cond Exit Air flow Temp \#1 ON TOP OF FAN \\
\hline
\end{tabular}




\begin{tabular}{|c|c|c|}
\hline Channel & Sensor type & Description \\
\hline 91 & T-type thermocouple & (Outdoor) Fan Motor Case Temp (F) \\
\hline 92 & T-type thermocouple & (Outdoor) Cond Exit Air flow Temp \#2 ON TOP OF FAN \\
\hline 93 & T-type thermocouple & (Indoor) Coriollis Flow Meter Inlet Temp - Wall \\
\hline 94 & T-type thermocouple & (Outdoor) Cond Internal Air Right side wrt Comp \\
\hline 95 & T-type thermocouple & (Outdoor) Cond Internal Air Left side wrt Comp \\
\hline 96 & T-type thermocouple & (Outdoor) Cond Inlet Air flow Temp \#1 \\
\hline 97 & T-type thermocouple & (Outdoor) Cond Air flow Inlet Temp \#6 \\
\hline 98 & T-type thermocouple & (Outdoor) Cond Outlet - 2nd Bunch (on small feeder tube) \\
\hline 99 & T-type thermocouple & (Outdoor) Liq Line Temp \& Service Valve \\
\hline 100 & T-type thermocouple & (Outdoor) Comp Shell at Bottom - Oil Level \\
\hline 101 & T-type thermocouple & (Outdoor) Vapor Temp a Service Valve \\
\hline 102 & AP transducer & (Outdoor) P1, Comp Discharge Pressure, VDC \\
\hline 103 & AP transducer & (Outdoor) P2, Vapor Coil Inlet, VDC \\
\hline 104 & AP transducer & (Outdoor) P6, Vapor Service Valve, VDC \\
\hline 105 & AP transducer $(0-500$ psia) & (Outdoor) P5, Comp suction, VDC \\
\hline 106 & & $\mathrm{~N} / \mathrm{A}$ \\
\hline 107 & DP transducer $\left(0-1 " \mathrm{H}_{2} \mathrm{O}\right)$ & (Outdoor) Coil Air DP, 0-5 VDC \\
\hline 108 & DP transducer $\left(0-1 " \mathrm{H}_{2} \mathrm{O}\right)$ & (Indoor) Nozzle AIR DP \#2, 0-5 VDC \\
\hline 109 & DP transducer $(0-10$ psid) & (Indoor) Coil Refrig DP, 0.05-5.05VDC \\
\hline 110 & DP transducer $(0-25$ psid) & (Outdoor) Coil Refrig DP, 0-5 VDC \\
\hline 111 & DP transducer $(0-25$ psid) & (Outdoor) Liquid line Refrig DP, 0.05-5.05 VDC \\
\hline 112 & Coriolis mass flow meter & (Indoor) Refrigerant mass flow meter a Evap Inlet, $1 \mathrm{bm} / \mathrm{h}$ \\
\hline 113 & $\begin{array}{l}\text { Coriolis mass flow meter } \\
(30-1201 \mathrm{bm} / \mathrm{ft} 3)\end{array}$ & (Indoor) Refrigerant density a Evap Inlet \\
\hline 114 & DP transducer & (Indoor) Evap Coil Airside DP (in H2O) \\
\hline 115 & DP transducer & (Indoor) Nozzle DP in Airchamber (in H2O) \\
\hline 116 & Dewpoint sensor & (Indoor) Evap Inlet Dewpoint (F) \\
\hline 117 & Dewpoint sensor & (Indoor) Evap Exit Dewpoint (F) \\
\hline 118 & & $\mathrm{~N} / \mathrm{A}$ \\
\hline 119 & RH sensor & (Indoor) MEMS Sensor, Inlet $\mathrm{RH} \%$ \\
\hline 120 & T-type thermocouple & (Indoor) Airside Evap Tpile voltage, VDC \\
\hline 121 & $\begin{array}{l}\text { Barometric pressure } \\
\text { transducer }\end{array}$ & Barometric Pressure, 0-10 VDC \\
\hline 122 & RH sensor & (Indoor) MEMS Sensor, Exit RH\% \\
\hline 123 & DC Power meter & (Indoor) MEMS Sensor Power Supply Voltage (VDC) \\
\hline 124 & & $\mathrm{~N} / \mathrm{A}$ \\
\hline 125 & AP transducer $(0-500$ psia) & (Indoor) Overall evap exit pres \\
\hline 126 & AP transducer $(0-500$ psia) & (Outdoor) Liquid Line Pres a Service Valve \\
\hline 127 & AP transducer $(0-500$ psia) & (Indoor) Evap Inlet Liquid Pres, VDC \\
\hline
\end{tabular}

${ }^{1}$ In Figure 3.8, numbers less than 128 are identical with channel number in Table A.1. Numbers over 127 can be calculated by the listed measurements in Table A.1. 
Table A.2. Post-processed data list for FDD analysis

\begin{tabular}{|c|c|c|c|}
\hline List \# & Abbreviation & BG unit & SI unit \\
\hline 0 & Barometric Pressure & inHg & $\mathrm{kPa}$ \\
\hline 1 & OD Air Inlet Temp & ${ }^{\circ} \mathrm{F}$ & ${ }^{\circ} \mathrm{C}$ \\
\hline 2 & OD Air Inlet DewPoint Temp & ${ }^{\circ} \mathrm{F}$ & ${ }^{\circ} \mathrm{C}$ \\
\hline 3 & OD Air Inlet Relative Humidity & - & - \\
\hline 4 & OD Air Inlet Density & $1 \mathrm{bm} / \mathrm{ft}^{3}$ & $\mathrm{~kg} / \mathrm{m}^{3}$ \\
\hline 5 & OD Air Temp Increase & ${ }^{\circ} \mathrm{F}$ & ${ }^{\circ} \mathrm{C}$ \\
\hline 6 & OD Air Exit Temp & ${ }^{\circ} \mathrm{F}$ & ${ }^{\circ} \mathrm{C}$ \\
\hline 7 & OD Air Flow Rate & SCFM & $\mathrm{m}^{3} / \mathrm{s}$ \\
\hline 8 & ID Air Inlet Temp & ${ }^{\circ} \mathrm{F}$ & ${ }^{\circ} \mathrm{C}$ \\
\hline 9 & ID Air Inlet DewPoint Temp & ${ }^{\circ} \mathrm{F}$ & ${ }^{\circ} \mathrm{C}$ \\
\hline 10 & ID Air Inlet Rel Humidity & - & - \\
\hline 11 & ID Air Inlet Density & $1 \mathrm{bm} / \mathrm{ft}^{3}$ & $\mathrm{~kg} / \mathrm{m}^{3}$ \\
\hline 12 & ID Air Temp Drop & ${ }^{\circ} \mathrm{F}$ & ${ }^{\circ} \mathrm{C}$ \\
\hline 13 & ID Air Exit Temp & ${ }^{\circ} \mathrm{F}$ & ${ }^{\circ} \mathrm{C}$ \\
\hline 14 & ID Air Exit DewPoint Temp & ${ }^{\circ} \mathrm{F}$ & ${ }^{\circ} \mathrm{C}$ \\
\hline 15 & ID Air Exit Rel Humidity & - & - \\
\hline 16 & ID Air Flow Rate & SCFM & $\mathrm{m}^{3} / \mathrm{s}$ \\
\hline 17 & ID Sensible Capacity & Btu/h & $\mathrm{W}$ \\
\hline 18 & ID Latent Capacity & Btu/h & W \\
\hline 19 & ID Air Total Capacity & Btu/h & W \\
\hline 20 & ID Air Sensible Heat Ratio & - & - \\
\hline 21 & COMP Suction Temp & ${ }^{\circ} \mathrm{F}$ & ${ }^{\circ} \mathrm{C}$ \\
\hline 22 & COMP Discharge Temp & ${ }^{\circ} \mathrm{F}$ & ${ }^{\circ} \mathrm{C}$ \\
\hline 23 & COND Inlet Temp & ${ }^{\circ} \mathrm{F}$ & ${ }^{\circ} \mathrm{C}$ \\
\hline 24 & COND Inlet Pressure & psia & $\mathrm{kPa}$ \\
\hline 25 & COND Inlet Tsat & ${ }^{\circ} \mathrm{F}$ & ${ }^{\circ} \mathrm{C}$ \\
\hline 26 & COND Exit Temp & ${ }^{\circ} \mathrm{F}$ & ${ }^{\circ} \mathrm{C}$ \\
\hline 27 & COND Exit Pressure & psia & $\mathrm{kPa}$ \\
\hline 28 & COND Exit Tsat & ${ }^{\circ} \mathrm{F}$ & ${ }^{\circ} \mathrm{C}$ \\
\hline 29 & COND Exit Subcooling & ${ }^{\circ} \mathrm{F}$ & ${ }^{\circ} \mathrm{C}$ \\
\hline 30 & COND DP & psid & $\mathrm{kPa}$ \\
\hline 31 & TXV Upstream P & psia & $\mathrm{kPa}$ \\
\hline 32 & Liquid Line DP & psia & $\mathrm{kPa}$ \\
\hline 33 & Liquid Line DT & ${ }^{\circ} \mathrm{F}$ & ${ }^{\circ} \mathrm{C}$ \\
\hline 34 & Refrigerant Flow Rate & $1 \mathrm{bm} / \mathrm{h}$ & $\mathrm{kg} / \mathrm{s}$ \\
\hline 35 & TXV DP & psia & $\mathrm{kPa}$ \\
\hline 36 & EVAP Inlet Temp & ${ }^{\circ} \mathrm{F}$ & ${ }^{\circ} \mathrm{C}$ \\
\hline 37 & EVAP Exit Temp & ${ }^{\circ} \mathrm{F}$ & ${ }^{\circ} \mathrm{C}$ \\
\hline 38 & EVAP Exit Pressure & psia & $\mathrm{kPa}$ \\
\hline 39 & EVAP Exit Tsat & ${ }^{\circ} \mathrm{F}$ & ${ }^{\circ} \mathrm{C}$ \\
\hline 40 & EVAP Exit Superheat & ${ }^{\circ} \mathrm{F}$ & ${ }^{\circ} \mathrm{C}$ \\
\hline 41 & EVAP DP & psid & $\mathrm{kPa}$ \\
\hline 42 & COND Capacity & Btu/h & $\mathrm{W}$ \\
\hline 43 & EVAP Capacity & Btu/h & $\mathrm{W}$ \\
\hline 44 & COMP Power & $\mathrm{W}$ & $\mathrm{W}$ \\
\hline 45 & $\operatorname{EER}(\mathrm{BG}) / \mathrm{COP}(\mathrm{SI})$ & $\mathrm{Btu} / \mathrm{h} \cdot \mathrm{W}$ & - \\
\hline
\end{tabular}




\section{APPENDIX B. COEFFICIENTS OF MULTIVARIATE REFERENCE MODEL}

Table B.1. Coefficients of second order multivariate polynomial reference model in Equation (4.7b) for selected features and parameters for nofault estimation

$$
\phi_{i}=a_{0}+a_{1} T_{O D}+a_{2} T_{I D}+a_{3} T_{I D P}+a_{4} T_{O D} T_{I D}+a_{5} T_{I D} T_{I D P}+a_{6} T_{I D P} T_{O D}+a_{7} T_{O D}^{2}+a_{8} T_{I D}^{2}+a_{9} T_{I D P}^{2}
$$

\begin{tabular}{|c|c|c|c|c|c|c|c|c|c|c|c|}
\hline $\begin{array}{l}\text { Feature/ } \\
\text { parameters }\end{array}$ & unit & $\mathbf{a}_{0}$ & $a_{1}$ & $\mathbf{a}_{2}$ & $a_{3}$ & $\mathbf{a}_{4}$ & $a_{5}$ & $a_{6}$ & $a_{7}$ & $a_{8}$ & $a_{9}$ \\
\hline $\mathrm{T}_{\mathrm{ER}}$ & ${ }^{\circ} \mathrm{F}$ & $4.37 E+05$ & $-1.57 \mathrm{E}+02$ & $-1.08 \mathrm{E}+04$ & $-3.69 E+02$ & $-6.76 \mathrm{E}-01$ & $1.04 \mathrm{E}+01$ & $1.87 \mathrm{E}+00$ & $1.25 \mathrm{E}-01$ & $7.20 E+01$ & $-8.90 E+00$ \\
\hline$\Delta \mathrm{T}_{\mathrm{sh}}$ & ${ }^{\circ} \mathrm{F}$ & $-1.16 \mathrm{E}+05$ & $1.23 \mathrm{E}+02$ & $2.93 \mathrm{E}+03$ & $1.51 \mathrm{E}+02$ & $1.35 \mathrm{E}+00$ & $-1.44 \mathrm{E}+01$ & $-3.32 E+00$ & $-7.18 \mathrm{E}-01$ & $-1.71 \mathrm{E}+01$ & $1.66 \mathrm{E}+01$ \\
\hline $\mathrm{T}_{\mathrm{DW}}$ & ${ }^{\circ} \mathrm{F}$ & $6.78 \mathrm{E}+00$ & $-1.52 \mathrm{E}-03$ & $-1.49 \mathrm{E}-01$ & $-1.16 \mathrm{E}-02$ & $-7.82 \mathrm{E}-05$ & $6.46 \mathrm{E}-04$ & $6.69 \mathrm{E}-05$ & $3.22 \mathrm{E}-05$ & $8.94 \mathrm{E}-04$ & $-5.86 \mathrm{E}-04$ \\
\hline $\mathrm{T}_{\mathrm{CR}}$ & ${ }^{\circ} \mathrm{F}$ & $-1.15 \mathrm{E}+03$ & $1.83 \mathrm{E}+00$ & $3.48 \mathrm{E}+01$ & $5.69 \mathrm{E}-02$ & $1.61 \mathrm{E}-02$ & $-1.22 \mathrm{E}-01$ & $-7.23 \mathrm{E}-03$ & $-1.54 \mathrm{E}-02$ & $-1.85 \mathrm{E}-01$ & $1.24 \mathrm{E}-01$ \\
\hline$\Delta \mathrm{T}_{\mathrm{sc}}$ & ${ }^{\circ} \mathrm{F}$ & $1.20 \mathrm{E}+03$ & $7.21 \mathrm{E}+01$ & $5.56 \mathrm{E}+02$ & $3.34 \mathrm{E}+01$ & $-4.84 \mathrm{E}-01$ & $-7.60 \mathrm{E}+00$ & $-1.17 \mathrm{E}+00$ & $-3.46 \mathrm{E}-01$ & $5.10 \mathrm{E}-01$ & $8.32 \mathrm{E}+00$ \\
\hline$\Delta \mathrm{T}_{\mathrm{CA}}$ & ${ }^{\circ} \mathrm{F}$ & $-1.19 E+04$ & $1.11 \mathrm{E}+02$ & $7.71 E+02$ & $4.14 \mathrm{E}+01$ & $-9.11 \mathrm{E}-01$ & $-7.38 \mathrm{E}+00$ & $-1.28 \mathrm{E}+00$ & $-9.15 \mathrm{E}-01$ & $-7.42 \mathrm{E}-01$ & $8.14 \mathrm{E}+00$ \\
\hline$\Delta \mathrm{T}_{\mathrm{EA}}$ & ${ }^{\circ} \mathrm{F}$ & $-1.93 E+03$ & $-1.08 \mathrm{E}+01$ & $8.47 \mathrm{E}+01$ & $-9.05 E+00$ & $-3.15 E-02$ & $3.01 \mathrm{E}-01$ & $5.06 \mathrm{E}-03$ & $2.22 \mathrm{E}-01$ & $-6.01 \mathrm{E}-01$ & $-1.54 \mathrm{E}-01$ \\
\hline$\Delta \mathrm{T}_{\mathrm{IL}}$ & ${ }^{\circ} \mathrm{F}$ & $8.24 E+01$ & $-3.05 E-01$ & $-1.36 \mathrm{E}+00$ & $1.35 \mathrm{E}-01$ & $-1.46 \mathrm{E}-03$ & $-6.21 \mathrm{E}-03$ & $-1.10 \mathrm{E}-03$ & $1.12 \mathrm{E}-03$ & $1.23 E-02$ & $5.35 \mathrm{E}-03$ \\
\hline $\mathrm{Q}_{\mathrm{EA}, \text { sens }}$ & $\mathrm{Btu} / \mathrm{h}$ & $4.26 \mathrm{E}+01$ & $1.36 \mathrm{E}-01$ & $-9.02 \mathrm{E}-01$ & $6.75 \mathrm{E}-02$ & $1.66 \mathrm{E}-03$ & $-1.13 \mathrm{E}-02$ & $-1.88 \mathrm{E}-03$ & $-3.81 \mathrm{E}-04$ & $1.17 \mathrm{E}-02$ & $1.25 \mathrm{E}-02$ \\
\hline$Q_{E A}$, lat & Btu/h & $-1.89 \mathrm{E}+00$ & $-3.68 \mathrm{E}-01$ & $6.74 \mathrm{E}-01$ & $5.77 \mathrm{E}-02$ & $-3.05 E-03$ & $4.74 \mathrm{E}-03$ & $-1.41 \mathrm{E}-03$ & $3.46 \mathrm{E}-03$ & $-2.84 \mathrm{E}-03$ & $-3.03 E-03$ \\
\hline SHR & - & $2.72 E+02$ & $1.02 \mathrm{E}+00$ & $-6.01 E+00$ & $-2.25 E-02$ & $-1.11 \mathrm{E}-02$ & $2.08 \mathrm{E}-02$ & $-2.84 \mathrm{E}-03$ & $8.73 E-03$ & $4.08 \mathrm{E}-02$ & $-1.51 \mathrm{E}-02$ \\
\hline$m_{R}$ & $1 \mathrm{bm} / \mathrm{h}$ & $1.08 \mathrm{E}+02$ & $1.19 \mathrm{E}+00$ & $-2.80 \mathrm{E}+00$ & $3.52 \mathrm{E}-02$ & $-4.19 \mathrm{E}-04$ & $9.65 \mathrm{E}-04$ & $-9.30 \mathrm{E}-04$ & $-8.23 E-04$ & $1.99 \mathrm{E}-02$ & $2.86 \mathrm{E}-04$ \\
\hline$Q_{C R}$ & $\mathrm{Btu} / \mathrm{h}$ & $5.48 \mathrm{E}+02$ & $-2.31 \mathrm{E}-01$ & $-1.42 \mathrm{E}+01$ & $-3.71 \mathrm{E}-02$ & $1.34 \mathrm{E}-03$ & $7.83 E-03$ & $-8.02 \mathrm{E}-04$ & $6.98 \mathrm{E}-04$ & $9.25 \mathrm{E}-02$ & $-5.18 \mathrm{E}-03$ \\
\hline$Q_{E R}$ & $\mathrm{Btu} / \mathrm{h}$ & $-1.96 \mathrm{E}+01$ & $1.47 \mathrm{E}-01$ & $5.62 \mathrm{E}-01$ & $2.96 \mathrm{E}-02$ & $-5.75 \mathrm{E}-04$ & $5.51 \mathrm{E}-04$ & $-7.00 \mathrm{E}-04$ & $-4.11 \mathrm{E}-04$ & $-2.53 E-03$ & $4.27 \mathrm{E}-04$ \\
\hline $\mathrm{W}_{\mathrm{cmp}}$ & W & $2.10 \mathrm{E}+02$ & $1.96 \mathrm{E}-02$ & $-5.16 \mathrm{E}+00$ & $-1.64 \mathrm{E}-01$ & $-1.53 E-03$ & $1.23 \mathrm{E}-02$ & $1.69 \mathrm{E}-03$ & $-3.68 \mathrm{E}-04$ & $3.46 \mathrm{E}-02$ & $-1.23 E-02$ \\
\hline EER & $\mathrm{Btu} / \mathrm{h} \cdot \mathrm{W}$ & $8.69 E+00$ & $1.04 \mathrm{E}-01$ & $-3.14 \mathrm{E}-01$ & $-1.36 \mathrm{E}-02$ & $-2.19 \mathrm{E}-04$ & $4.29 \mathrm{E}-04$ & $-6.21 \mathrm{E}-05$ & $-3.38 \mathrm{E}-04$ & $1.86 \mathrm{E}-03$ & $-1.72 E-04$ \\
\hline
\end{tabular}

${ }^{1}$ Input temperature parameters of $T_{\mathrm{ID}}, T_{\mathrm{OD}}$, and $T_{\mathrm{IDP}}$ have the unit of ${ }^{\circ} \mathrm{F}$. The features and parameters $\phi_{i}$ are interpolated within the range of $21.1^{\circ} \mathrm{C}\left(70.0{ }^{\circ} \mathrm{F}\right) \leq T_{\mathrm{ID}} \leq 26.7^{\circ} \mathrm{C}$ $\left(80.0^{\circ} \mathrm{F}\right)$ and $21.1^{\circ} \mathrm{C}\left(70.0^{\circ} \mathrm{F}\right) \leq T_{\mathrm{OD}} \leq 37.8^{\circ} \mathrm{C}\left(100.0^{\circ} \mathrm{F}\right)$. The interpolation range for $T_{\mathrm{IDP}}$ is associated with the test condition from dry coil evaporator condition to relative humidity of $50 \%$. For example, $-1.1^{\circ} \mathrm{C}\left(30 .{ }^{\circ} \mathrm{F}\right) \leq T_{\mathrm{IDP}} \leq 10.3^{\circ} \mathrm{C}\left(50.5^{\circ} \mathrm{F}\right)$ for $T_{\mathrm{ID}}=21.1{ }^{\circ} \mathrm{C}\left(70.0^{\circ} \mathrm{F}\right)$ and $-1.1^{\circ} \mathrm{C}\left(30.0^{\circ} \mathrm{F}\right) \leq T_{\mathrm{IDP}} \leq 15.8^{\circ} \mathrm{C}\left(60.4^{\circ} \mathrm{F}\right)$ for $T_{\mathrm{ID}}=26.7^{\circ} \mathrm{C}$ $\left(80.0^{\circ} \mathrm{F}\right)$. 


\section{APPENDIX C. EXTENDED PERFORMANCE CHARTS}

Charts of an additional 16 parameters are plotted for no-fault and single-fault tests. These charts are extended plots of single-fault plots in section 5.1. Below is the list of 16 parameters.

$\mathrm{SCFM}_{\mathrm{CA}} \quad$ outdoor air flow rate $\left(\mathrm{ft}^{3} / \mathrm{min}\right)$

$\phi_{\mathrm{EAI}} \quad$ indoor air inlet relative humidity

$T_{\mathrm{EAOD}} \quad$ indoor air exit dew point temperature $\left({ }^{\circ} \mathrm{F}\right)$

$\phi_{\mathrm{EAO}} \quad$ indoor air exit relative humidity

$\mathrm{SCFM}_{\mathrm{EA}}$ indoor air flow rate $\left(\mathrm{ft}^{3} / \mathrm{min}\right)$

$T_{\mathrm{SW}} \quad$ compressor suction wall temperature $\left({ }^{\circ} \mathrm{F}\right)$

$T_{\mathrm{CRI}} \quad$ condenser refrigerant inlet temperature $\left({ }^{\circ} \mathrm{F}\right)$

$P_{\mathrm{CRI}} \quad$ condenser refrigerant inlet pressure (psia)

$T_{\mathrm{CRO} \text {,sat }} \quad$ condenser refrigerant exit saturation temperature $\left({ }^{\circ} \mathrm{F}\right)$

$\Delta P_{\mathrm{CR}} \quad$ condenser refrigerant pressure drop (psid)

$P_{\mathrm{TXV}, \text { up }} \quad$ TXV upstream pressure (psia)

$\Delta P_{\mathrm{LL}} \quad$ liquid line pressure drop (psid)

$T_{\text {ERI }} \quad$ evaporator refrigerant inlet temperature $\left({ }^{\circ} \mathrm{F}\right)$

$P_{\text {ERO }} \quad$ evaporator refrigerant exit pressure (psia)

$\Delta P_{\mathrm{ER}} \quad$ evaporator refrigerant pressure drop (psid)

$\Delta T_{\mathrm{sh}}-\Delta T_{\mathrm{sc}} \quad$ difference between superheat and subcooling $\left({ }^{\circ} \mathrm{F}\right)$ 


\section{C.1 No-Fault Tests}
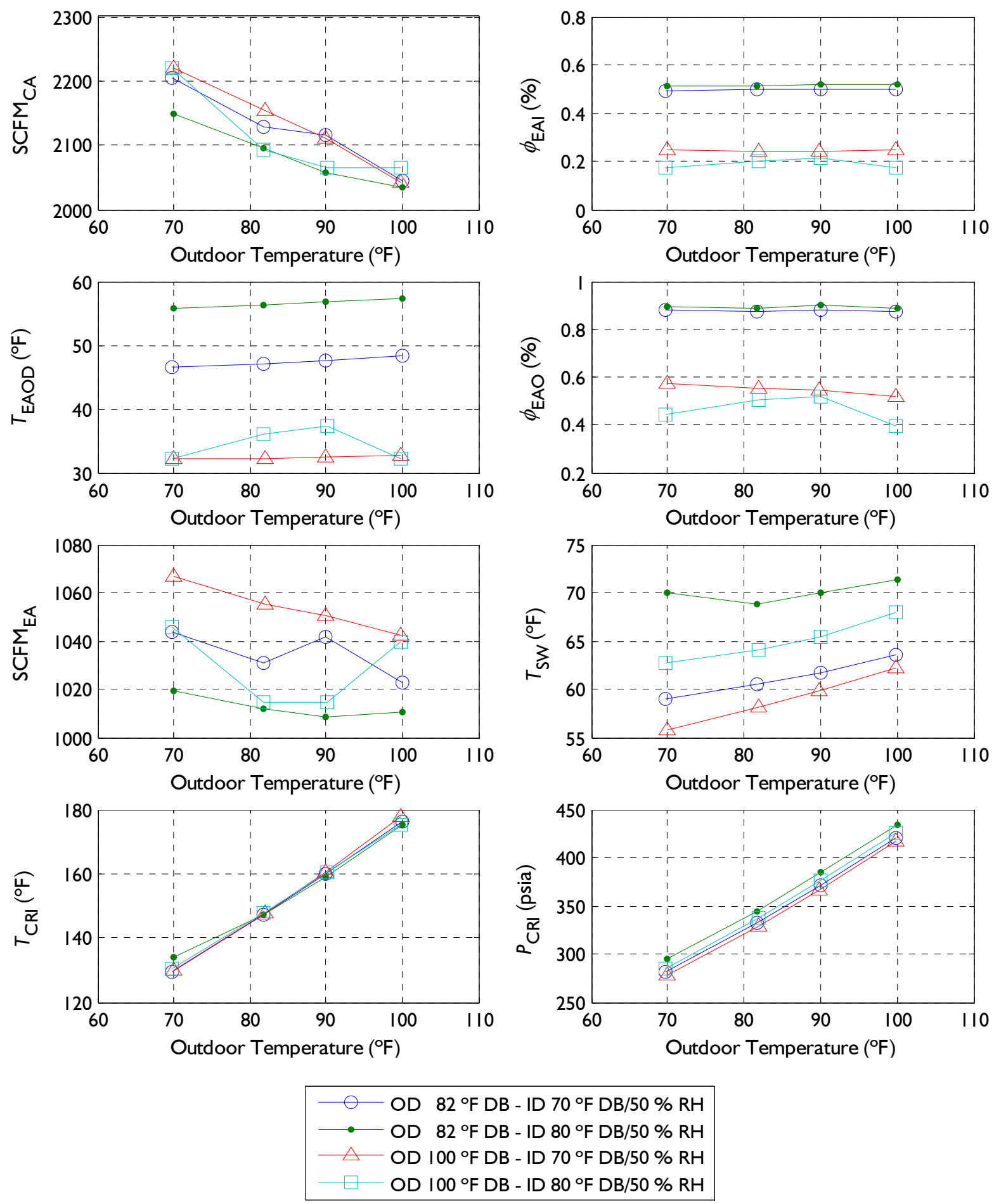

Figure C.1. Selected parameters from the no-fault tests. From the top left to right: $\mathrm{SCFM}_{\mathrm{CA}}-$ outdoor air flow rate, $\phi_{\mathrm{EAI}}$ - indoor air inlet relative humidity, $T_{\mathrm{EAOD}}$ - indoor air exit dew point temperature, $\phi_{\mathrm{EAO}}$ - indoor air exit relative humidity, $\mathrm{SCFM}_{\mathrm{EA}}$ - indoor air flow rate, $T_{\mathrm{SW}}-$ compressor suction wall temperature, $T_{\mathrm{CRI}}-$ condenser refrigerant inlet temperature, $P_{\mathrm{CRI}}-$ condenser refrigerant inlet pressure 

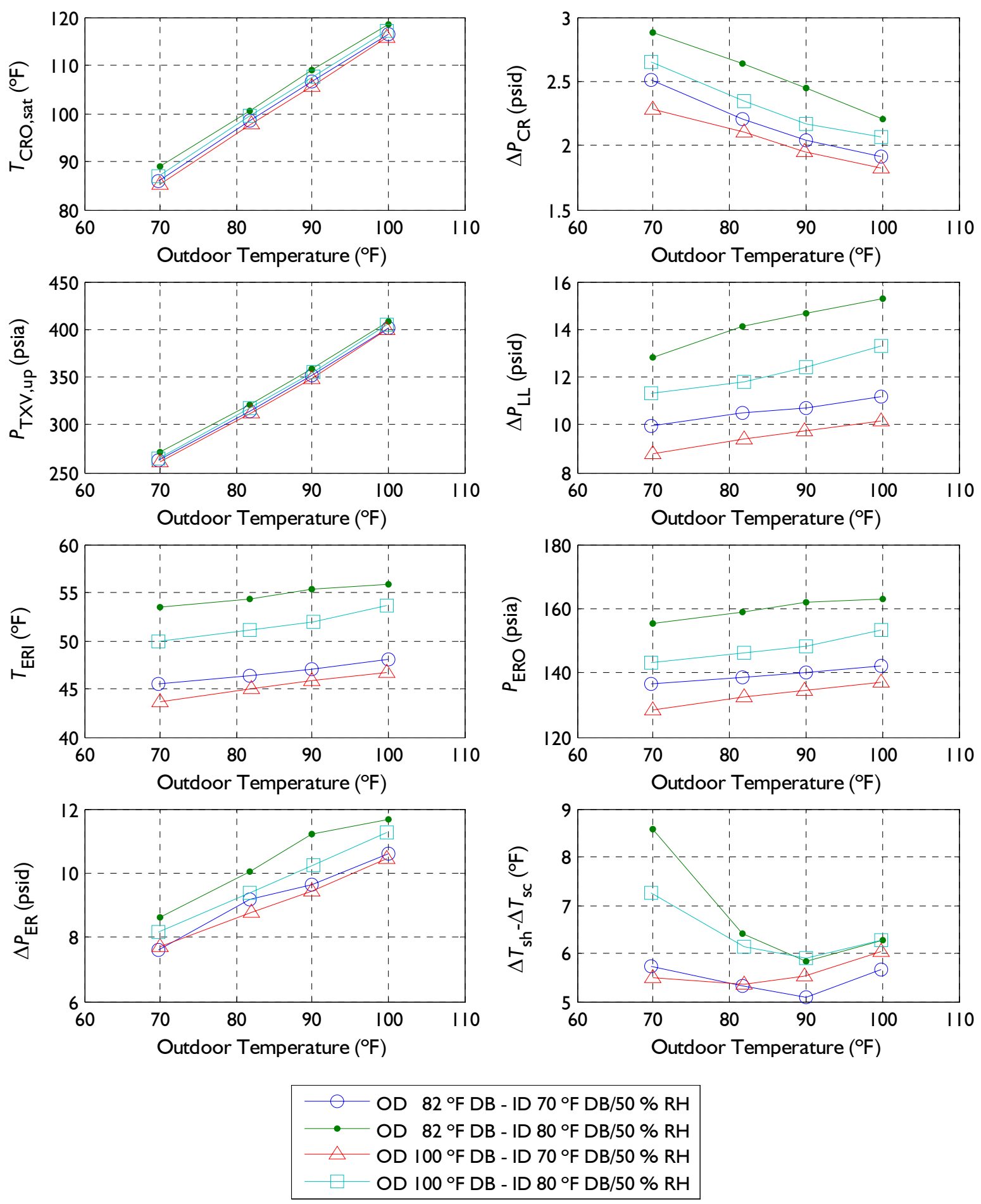

Figure C.2. Selected parameters from the no-fault tests. From the top left to right: $T_{\mathrm{CRO} \text {,sat }}-$ condenser refrigerant exit saturation temperature, $\Delta P_{\mathrm{CR}}-$ condenser refrigerant pressure drop, $P_{\mathrm{TXV} \text {,up }}-$ TXV upstream pressure, $\Delta P_{\mathrm{LL}}$ - liquid line pressure drop; $T_{\mathrm{ERI}}-$ evaporator refrigerant inlet temperature, $P_{\mathrm{ERO}}-$ evaporator refrigerant exit pressure, $\Delta P_{\mathrm{ER}}-$ evaporator refrigerant pressure drop, $\Delta T_{\mathrm{sh}}-\Delta T_{\mathrm{sc}}$ 


\section{C.2 Single-Fault Tests}
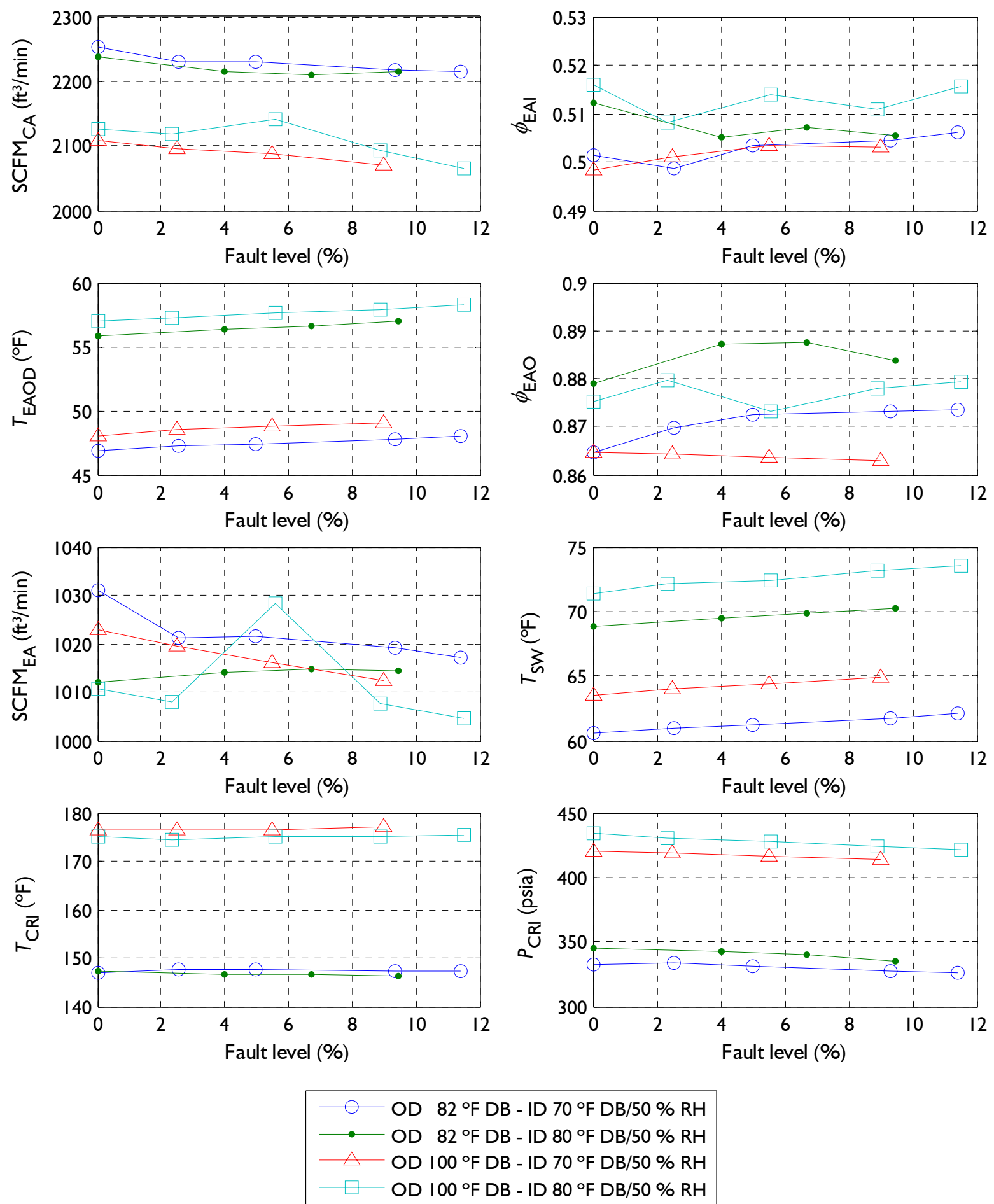

Figure C.3. Selected parameters with the compressor/reversing valve leakage fault. From the top left to right: $\mathrm{SCFM}_{\mathrm{CA}}-$ outdoor air flow rate, $\phi_{\mathrm{EAI}}$ - indoor air inlet relative humidity, $T_{\mathrm{EAOD}}-$ indoor air exit dew point temperature, $\phi_{\mathrm{EAO}}$ - indoor air exit relative humidity, $\mathrm{SCFM}_{\mathrm{EA}}-$ indoor air flow rate, $T_{\mathrm{SW}}-$ compressor suction wall temperature, $T_{\mathrm{CRI}}-$ condenser refrigerant inlet temperature, $P_{\mathrm{CRI}}-$ condenser refrigerant inlet pressure 

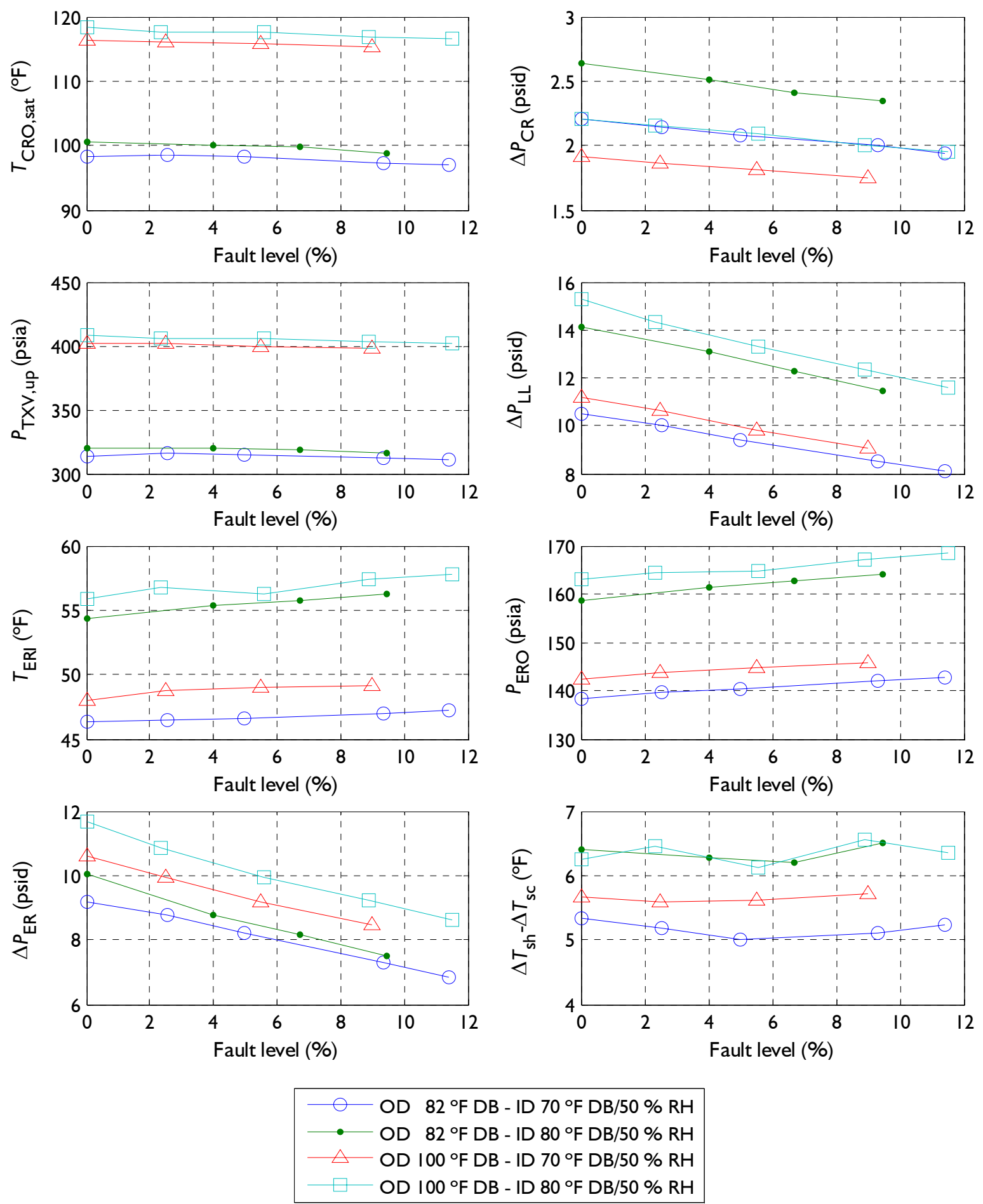

Figure C.4. Selected parameters with the compressor/reversing valve leakage fault. From the top left to right: $T_{\mathrm{CRO} \text {,sat }}-$ condenser refrigerant exit saturation temperature, $\Delta P_{\mathrm{CR}}-$ condenser refrigerant pressure drop, $P_{\mathrm{TXV} \text {,up }}-\mathrm{TXV}$ upstream pressure, $\Delta P_{\mathrm{LL}}$ - liquid line pressure drop; $T_{\mathrm{ERI}}$ - evaporator refrigerant inlet temperature, $P_{\mathrm{ERO}}$ - evaporator refrigerant exit pressure, $\Delta P_{\mathrm{ER}}$ - evaporator refrigerant pressure drop, $\Delta T_{\mathrm{sh}}-\Delta T_{\mathrm{sc}}$ 

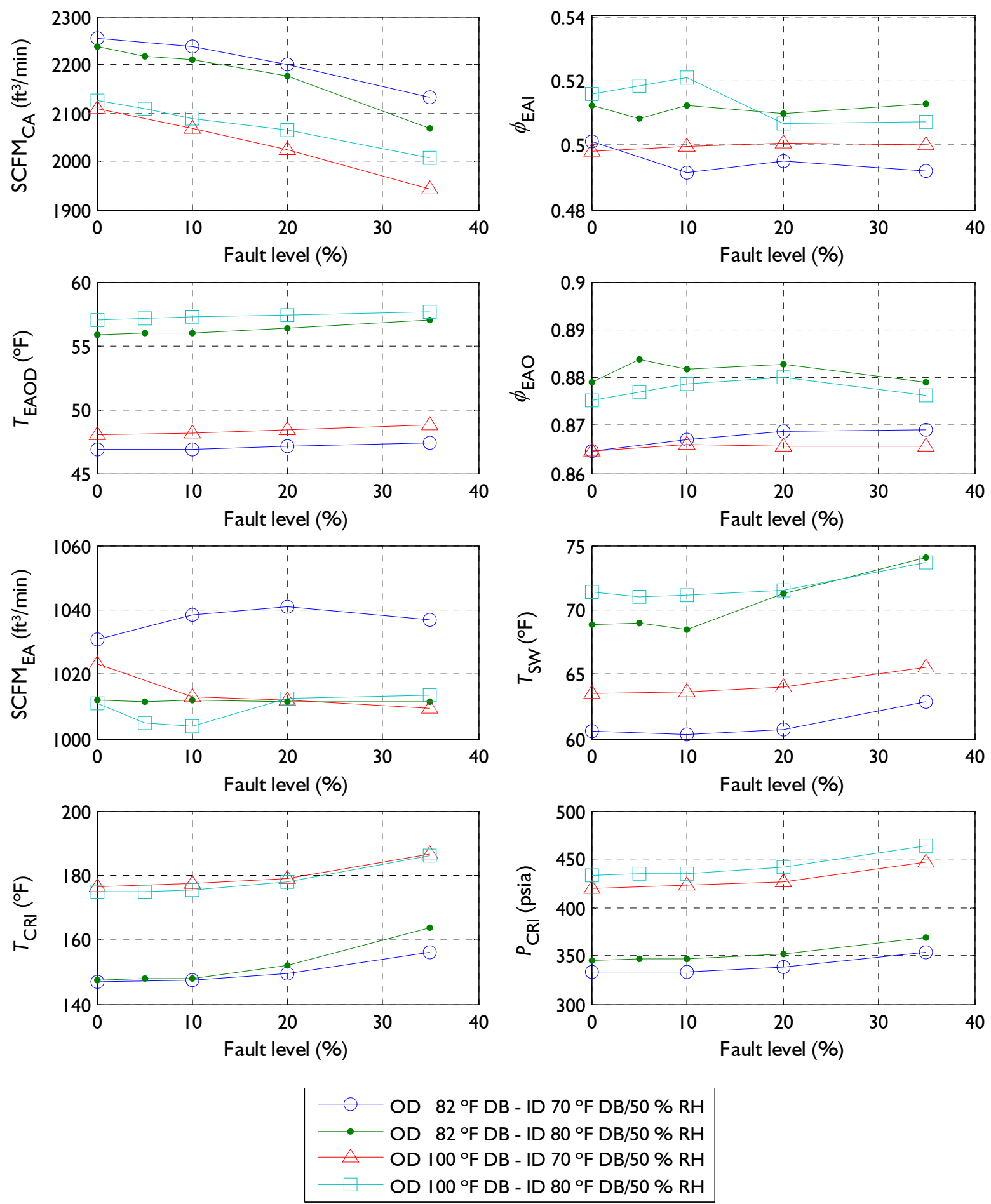

Figure C.5. Selected parameters with the improper outdoor flow rate fault. From the top left to right: $\mathrm{SCFM}_{\mathrm{CA}}$ - outdoor air flow rate, $\phi_{\mathrm{EAI}}$ - indoor air inlet relative humidity, $T_{\mathrm{EAOD}}$ - indoor air exit dew point temperature, $\phi_{\mathrm{EAO}}$ - indoor air exit relative humidity, $\mathrm{SCFM}_{\mathrm{EA}}$ - indoor air flow rate, $T_{\mathrm{SW}}$ - compressor suction wall temperature, $T_{\mathrm{CRI}}$ - condenser refrigerant inlet temperature, $P_{\mathrm{CRI}}-$ condenser refrigerant inlet pressure 

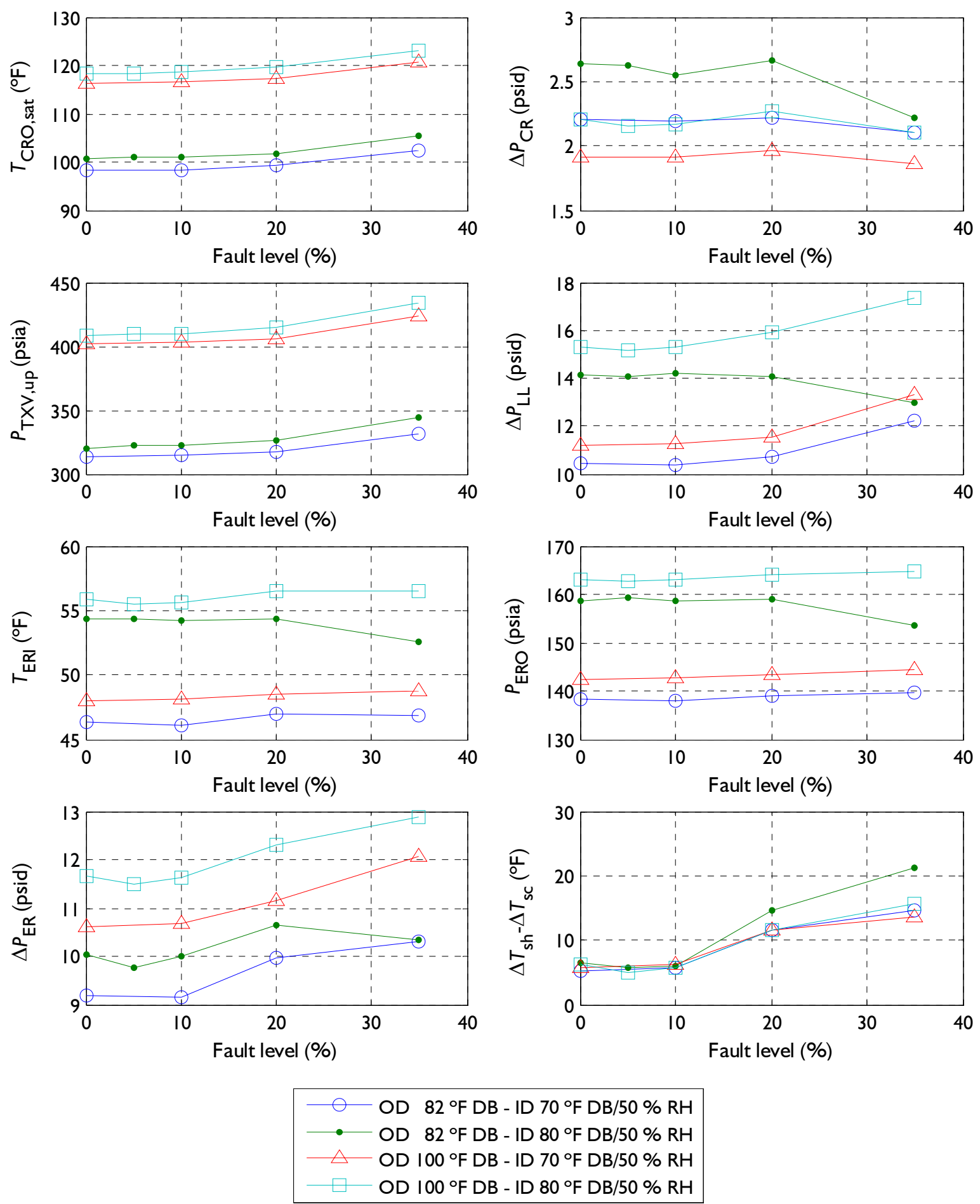

Figure C.6. Selected parameters with the improper outdoor flow rate fault. From the top left to right: $T_{\mathrm{CRO} \text {,sat }}-$ condenser refrigerant exit saturation temperature, $\Delta P_{\mathrm{CR}}-$ condenser refrigerant pressure drop, $P_{\mathrm{TXV} \text {,up }}-\mathrm{TXV}$ upstream pressure, $\Delta P_{\mathrm{LL}}$ - liquid line pressure drop; $T_{\mathrm{ERI}}-$ evaporator refrigerant inlet temperature, $P_{\mathrm{ERO}}$ - evaporator refrigerant exit pressure, $\Delta P_{\mathrm{ER}}-$ evaporator refrigerant pressure drop, $\Delta T_{\mathrm{sh}}-\Delta T_{\mathrm{sc}}$ 

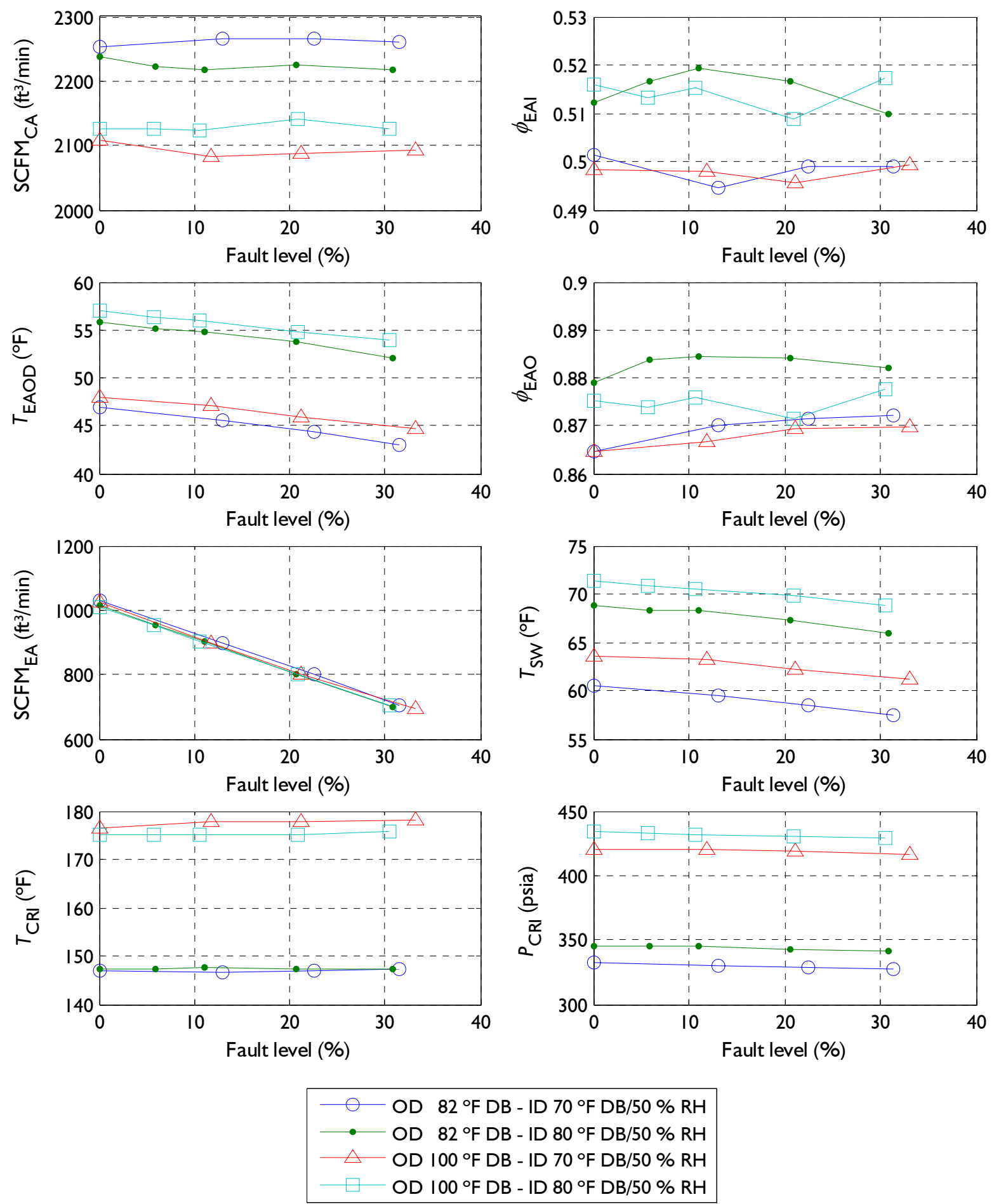

Figure C.7. Selected parameters with the improper indoor flow rate fault. From the top left to right: $\mathrm{SCFM}_{\mathrm{CA}}-$ outdoor air flow rate, $\phi_{\mathrm{EAI}}$ - indoor air inlet relative humidity, $T_{\mathrm{EAOD}}$ - indoor air exit dew point temperature, $\phi_{\mathrm{EAO}}$ - indoor air exit relative humidity, $\mathrm{SCFM}_{\mathrm{EA}}$ - indoor air flow rate, $T_{\mathrm{SW}}$ - compressor suction wall temperature, $T_{\mathrm{CRI}}$ - condenser refrigerant inlet temperature, $P_{\mathrm{CRI}}-$ condenser refrigerant inlet pressure 

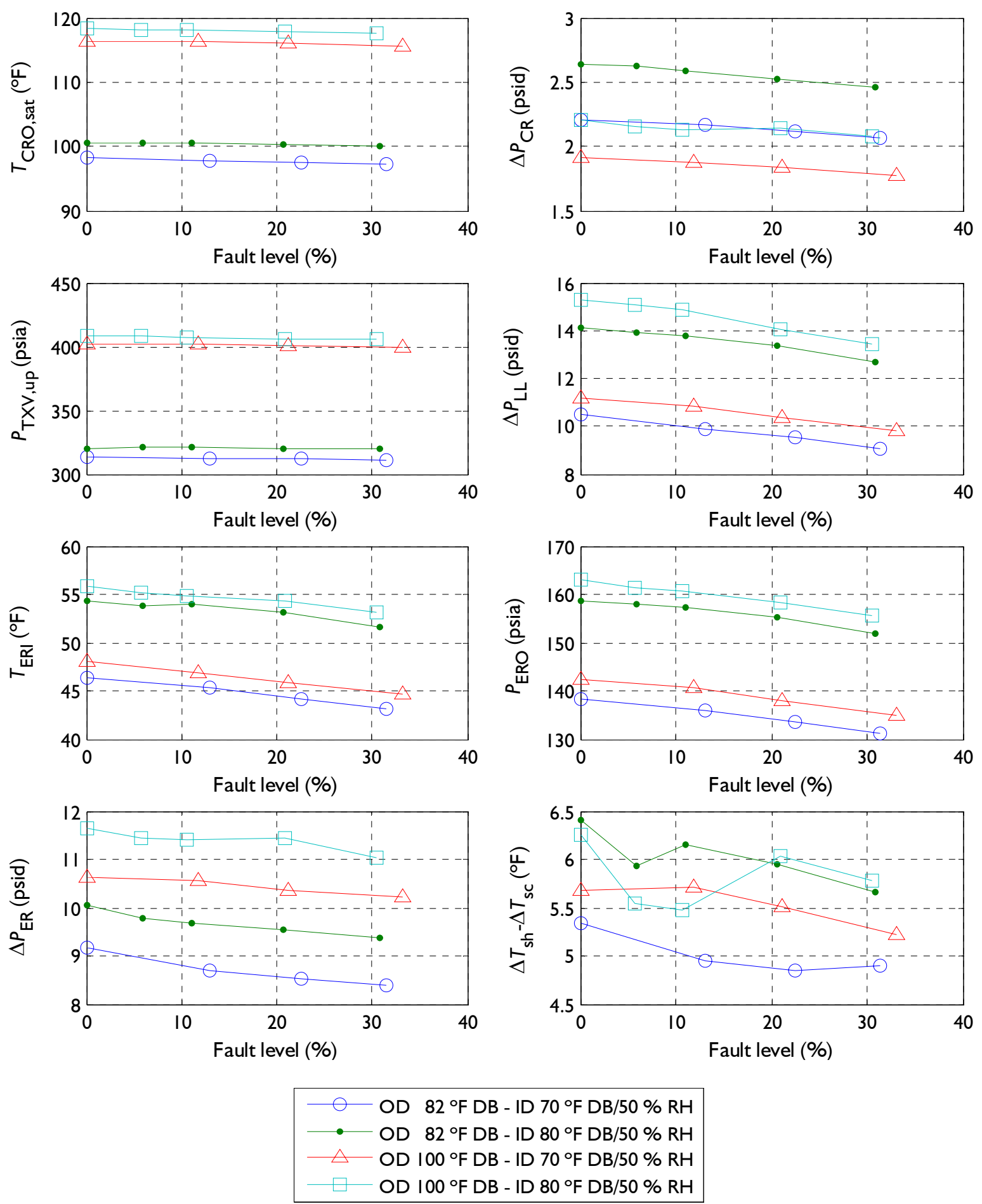

Figure C.8. Selected parameters with the improper indoor flow rate fault. From the top left to right: $T_{\mathrm{CRO} \text {,sat }}-$ condenser refrigerant exit saturation temperature, $\Delta P_{\mathrm{CR}}-$ condenser refrigerant pressure drop, $P_{\mathrm{TXV} \text {,up }}-\mathrm{TXV}$ upstream pressure, $\Delta P_{\mathrm{LL}}$ - liquid line pressure drop; $T_{\mathrm{ERI}}-$ evaporator refrigerant inlet temperature, $P_{\mathrm{ERO}}$ - evaporator refrigerant exit pressure, $\Delta P_{\mathrm{ER}}-$ evaporator refrigerant pressure drop, $\Delta T_{\mathrm{sh}}-\Delta T_{\mathrm{sc}}$ 

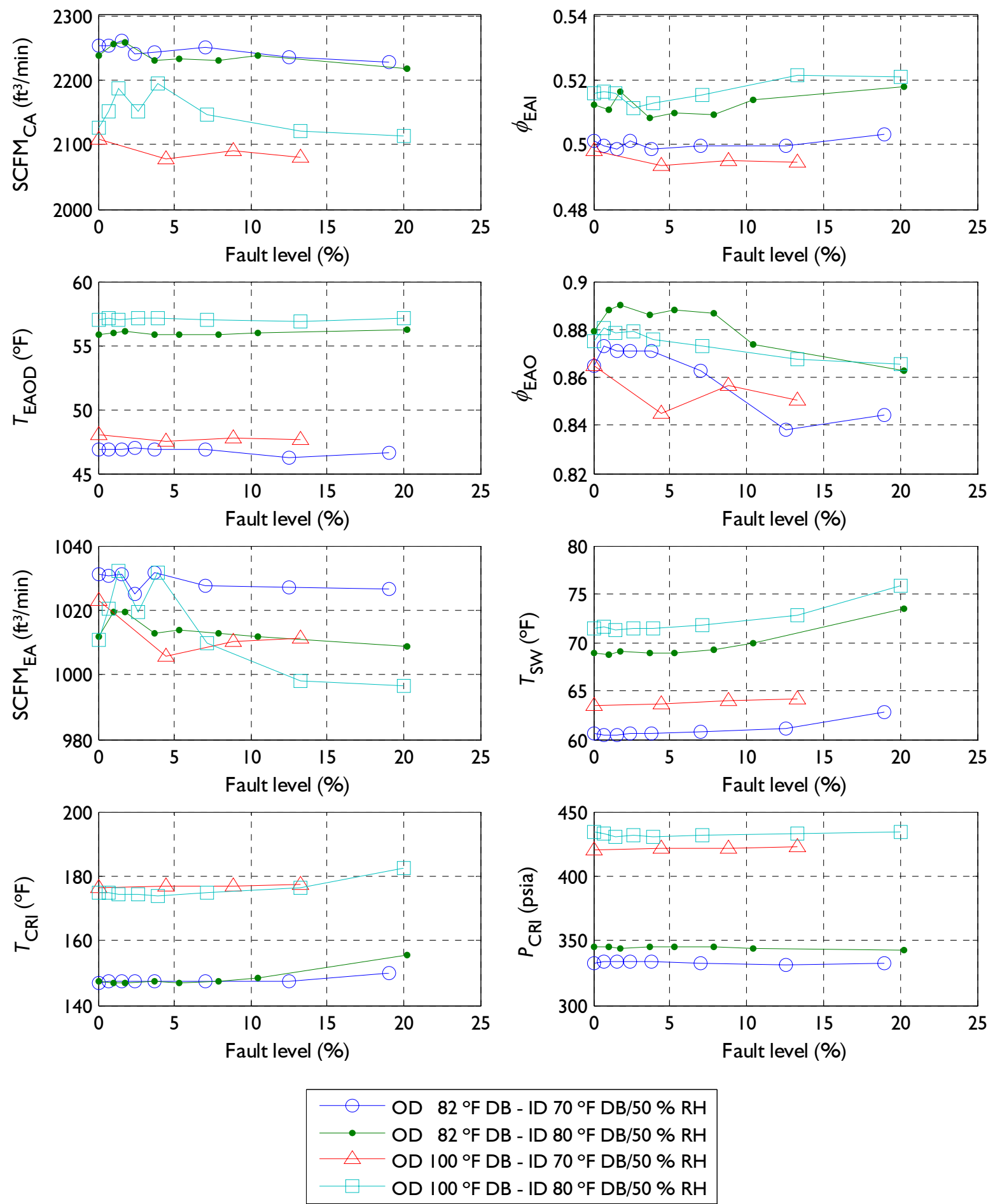

Figure C.9. Selected parameters with the liquid line restriction fault. From the top left to right: $\mathrm{SCFM}_{\mathrm{CA}}$ - outdoor air flow rate, $\phi_{\mathrm{EAI}}-$ indoor air inlet relative humidity, $T_{\mathrm{EAOD}}-$ indoor air exit dew point temperature, $\phi_{\mathrm{EAO}}$ - indoor air exit relative humidity, $\mathrm{SCFM}_{\mathrm{EA}}$ - indoor air flow rate, $T_{\mathrm{SW}}$ - compressor suction wall temperature, $T_{\mathrm{CRI}}-$ condenser refrigerant inlet temperature, $P_{\mathrm{CRI}}-$ condenser refrigerant inlet pressure 

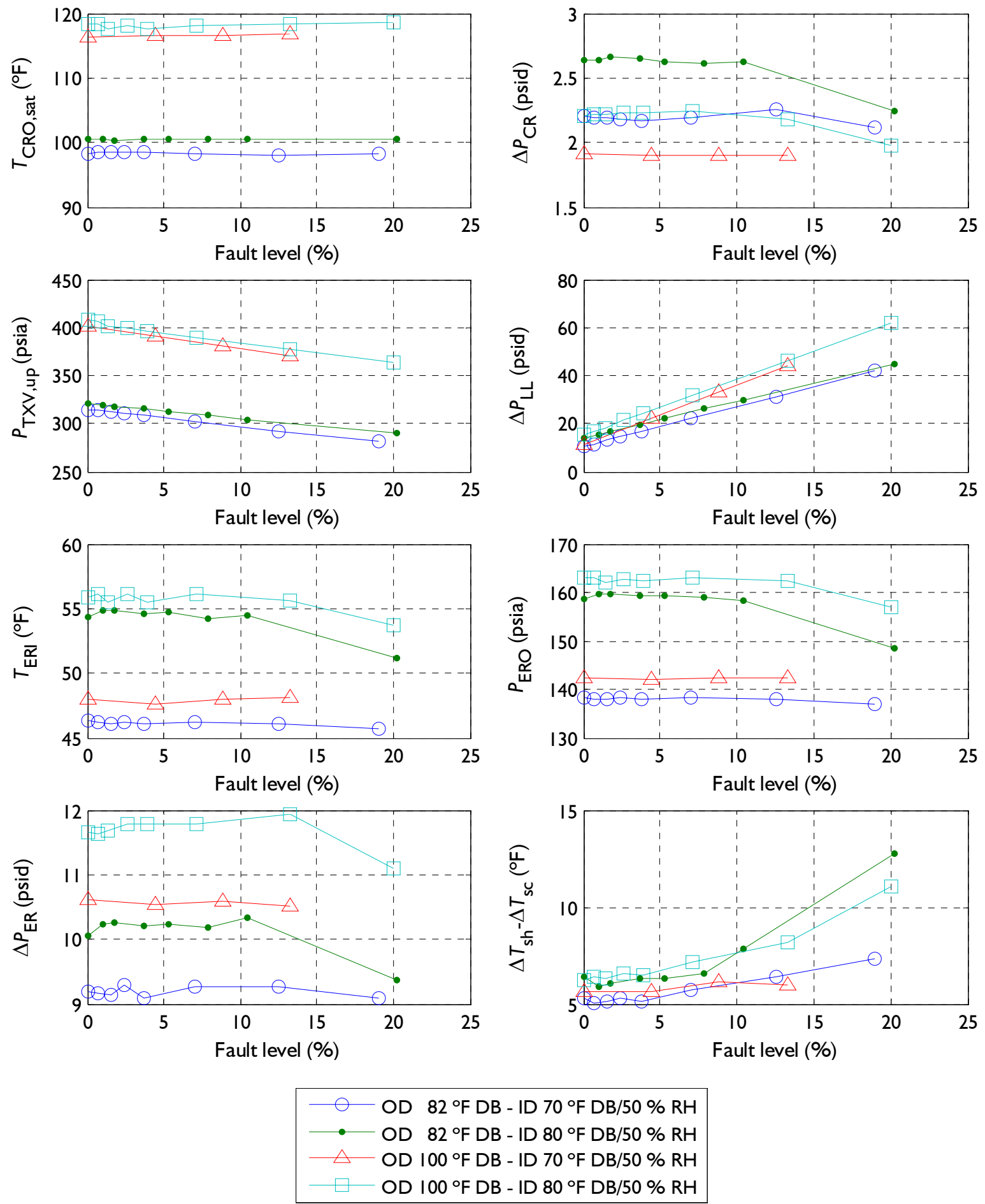

Figure C.10. Selected parameters with the liquid line restriction fault. From the top left to right: $T_{\mathrm{CRO} \text {,sat }}-$ condenser refrigerant exit saturation temperature, $\Delta P_{\mathrm{CR}}$ - condenser refrigerant pressure drop, $P_{\mathrm{TXV} \text {,up }}-\mathrm{TXV}$ upstream pressure, $\Delta P_{\mathrm{LL}}$ - liquid line pressure drop; $T_{\mathrm{ERI}}$ - evaporator refrigerant inlet temperature, $P_{\mathrm{ERO}}$ - evaporator refrigerant exit pressure, $\Delta P_{\mathrm{ER}}$ - evaporator refrigerant pressure drop, $\Delta T_{\mathrm{sh}}-\Delta T_{\mathrm{sc}}$ 

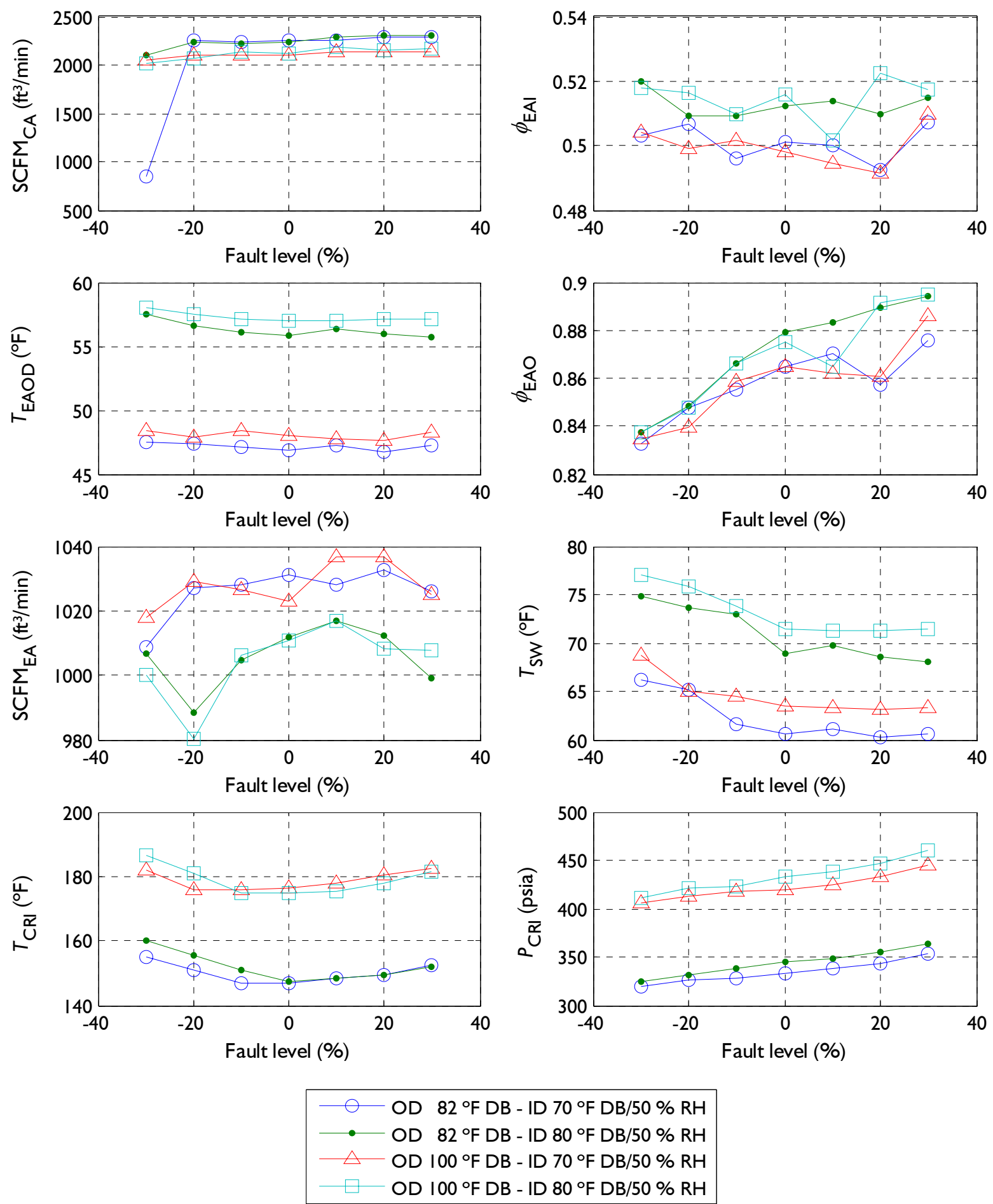

Figure C.11. Selected parameters with the refrigerant undercharge/overcharge fault. From the top left to right: $\mathrm{SCFM}_{\mathrm{CA}}-$ outdoor air flow rate, $\phi_{\mathrm{EAI}}-$ indoor air inlet relative humidity, $T_{\mathrm{EAOD}}-$ indoor air exit dew point temperature, $\phi_{\mathrm{EAO}}$ - indoor air exit relative humidity, $\mathrm{SCFM}_{\mathrm{EA}}-$ indoor air flow rate, $T_{\mathrm{SW}}-$ compressor suction wall temperature, $T_{\mathrm{CRI}}-$ condenser refrigerant inlet temperature, $P_{\mathrm{CRI}}$ - condenser refrigerant inlet pressure 

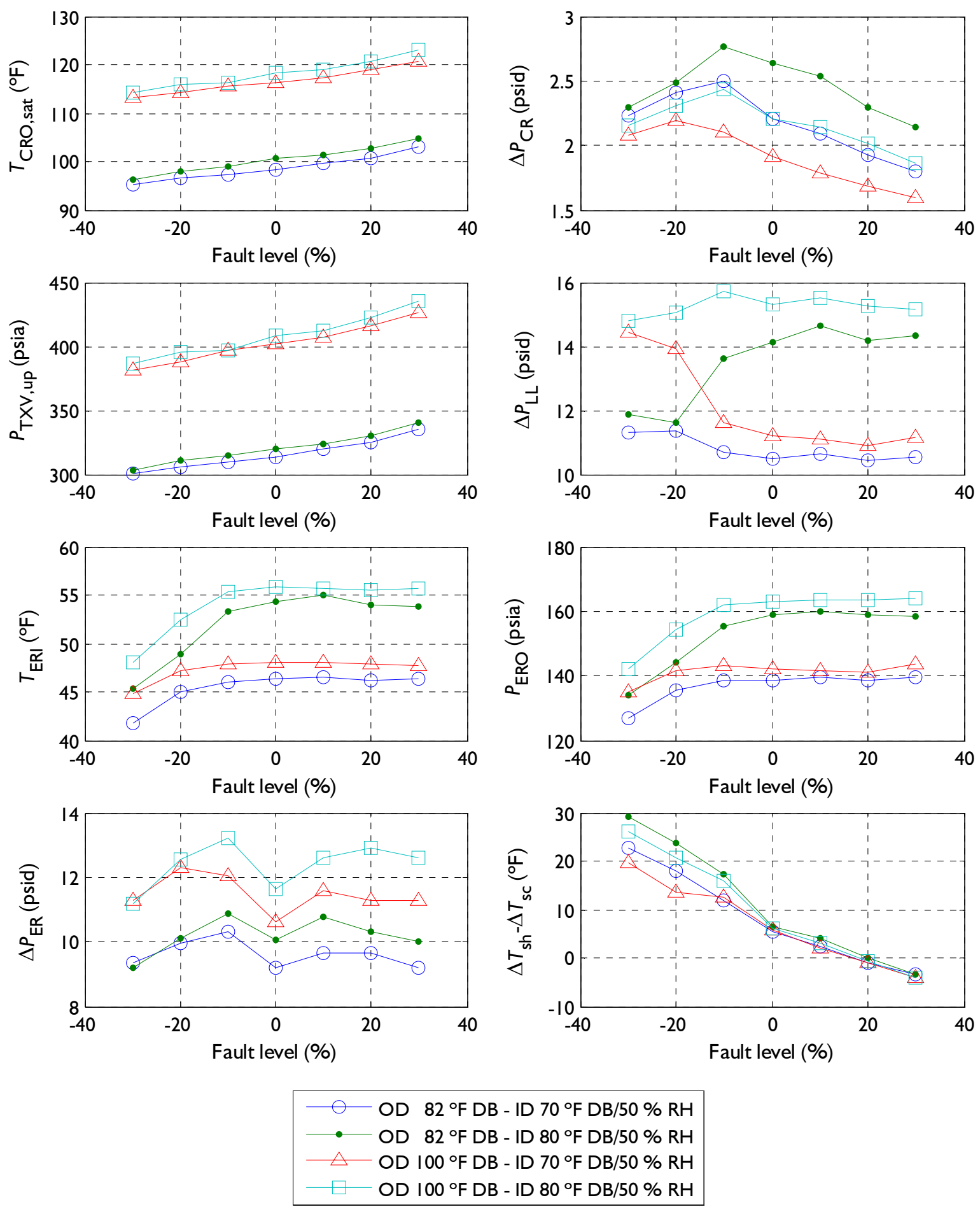

Figure C.12. Selected parameters with the refrigerant undercharge/overcharge fault. From the top left to right: $T_{\mathrm{CRO} \text {,sat }}-$ condenser refrigerant exit saturation temperature, $\Delta P_{\mathrm{CR}}-$ condenser refrigerant pressure drop, $P_{\mathrm{TXV} \text {,up }}-\mathrm{TXV}$ upstream pressure, $\Delta P_{\mathrm{LL}}$ - liquid line pressure drop; $T_{\mathrm{ERI}}$ - evaporator refrigerant inlet temperature, $P_{\mathrm{ERO}}$ - evaporator refrigerant exit pressure, $\Delta P_{\mathrm{ER}}-$ evaporator refrigerant pressure drop, $\Delta T_{\mathrm{sh}}-\Delta T_{\mathrm{sc}}$ 

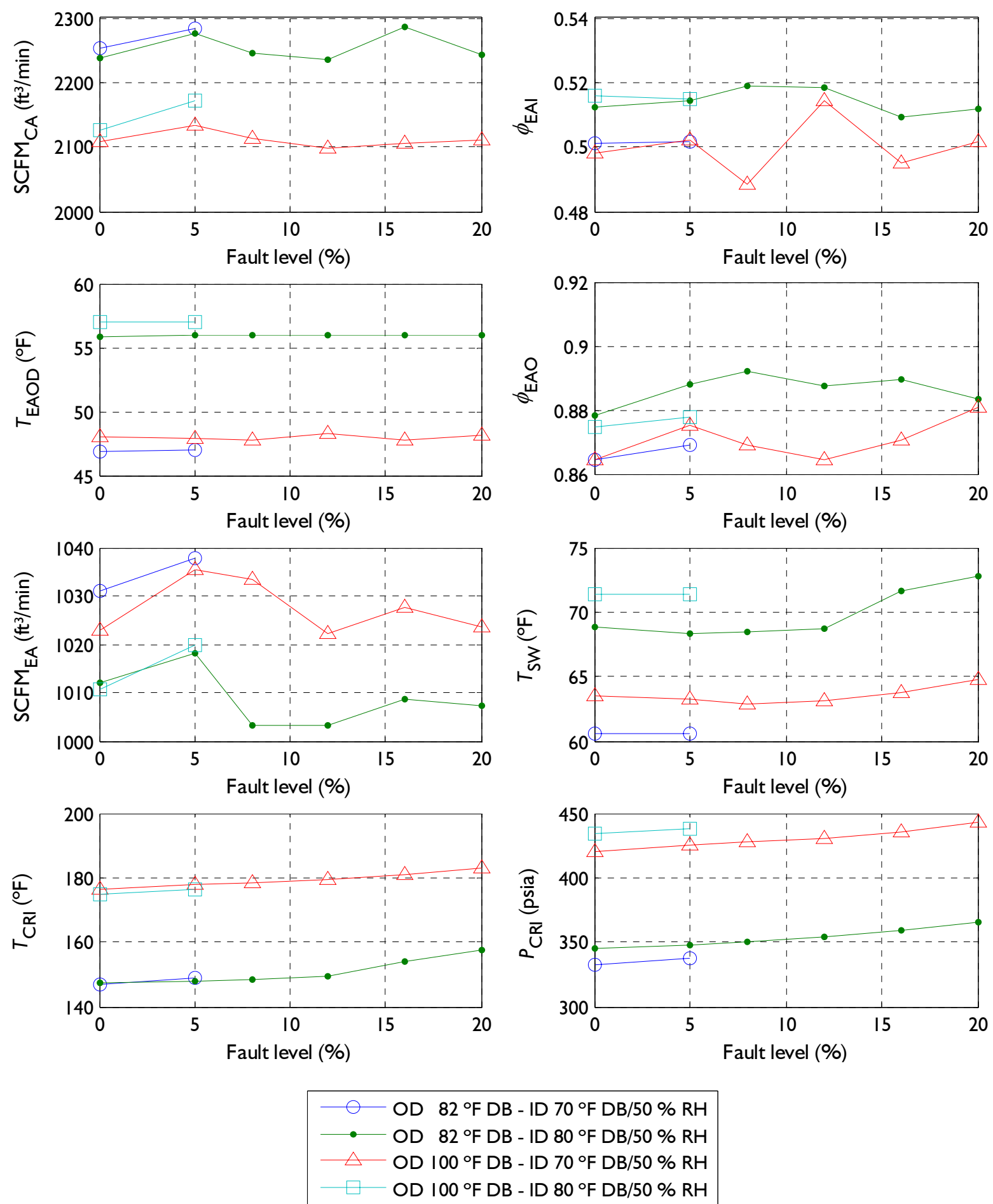

Figure C.13. Selected parameters with the non-condensable gas fault. From the top left to right: $\mathrm{SCFM}_{\mathrm{CA}}$ - outdoor air flow rate, $\phi_{\mathrm{EAI}}-$ indoor air inlet relative humidity, $T_{\mathrm{EAOD}}-$ indoor air exit dew point temperature, $\phi_{\mathrm{EAO}}$ - indoor air exit relative humidity, $\mathrm{SCFM}_{\mathrm{EA}}$ - indoor air flow rate, $T_{\mathrm{SW}}$ - compressor suction wall temperature, $T_{\mathrm{CRI}}-$ condenser refrigerant inlet temperature, $P_{\mathrm{CRI}}-$ condenser refrigerant inlet pressure 

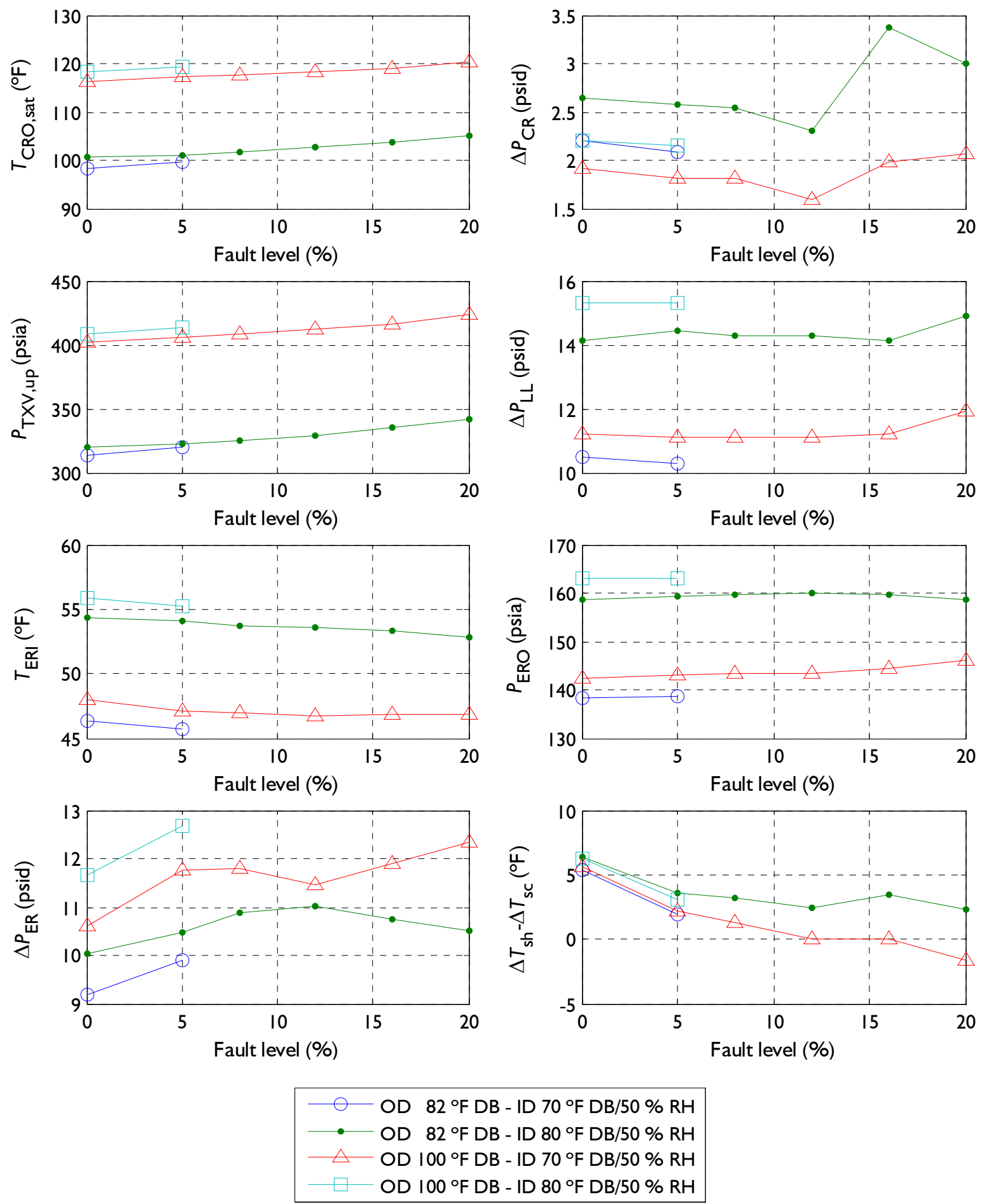

Figure C.14. Selected parameters with the non-condensable gas fault. From the top left to right: $T_{\mathrm{CRO} \text {,sat }}-$ condenser refrigerant exit saturation temperature, $\Delta P_{\mathrm{CR}}$ - condenser refrigerant pressure drop, $P_{\mathrm{TXV} \text {,up }}-\mathrm{TXV}$ upstream pressure, $\Delta P_{\mathrm{LL}}-$ liquid line pressure drop; $T_{\mathrm{ERI}}-$ evaporator refrigerant inlet temperature, $P_{\mathrm{ERO}}$ - evaporator refrigerant exit pressure, $\Delta P_{\mathrm{ER}}$ - evaporator refrigerant pressure drop, $\Delta T_{\mathrm{sh}}-\Delta T_{\mathrm{sc}}$ 
APPENDIX D. RAW EXPERIMENTAL DATA ${ }^{1}$

\section{D.1 No-Fault Tests}

Table D.1. List of raw data for no-fault tests

\begin{tabular}{r|r|r|r|r|r}
\hline \multirow{2}{*}{$\begin{array}{c}\text { Test } \\
\text { condition \# }\end{array}$} & \multicolumn{2}{|c|}{ Nominal chamber condition } & \multirow{2}{*}{ Fault Type } & $\begin{array}{c}\text { Fault level } \\
(\%)\end{array}$ \\
\cline { 2 - 4 }$T_{I D}\left({ }^{\circ} \mathrm{F}\right)$ & \multicolumn{1}{c}{$\phi_{I D}(\%)$} & $T_{O D}\left({ }^{\circ} \mathrm{F}\right)$ & \\
\hline 2 & 70 & 50 & 70 & $\mathrm{NF}$ & 0.0 \\
\hline 3 & 80 & 50 & 70 & $\mathrm{NF}$ & 0.0 \\
\hline 4 & 70 & 50 & 82 & $\mathrm{NF}$ & 0.0 \\
\hline 5 & 80 & 50 & 82 & $\mathrm{NF}$ & 0.0 \\
\hline 6 & 70 & 50 & 90 & $\mathrm{NF}$ & 0.0 \\
\hline 7 & 80 & 50 & 90 & $\mathrm{NF}$ & 0.0 \\
\hline 8 & 70 & 50 & 100 & $\mathrm{NF}$ & 0.0 \\
\hline 9 & 80 & 50 & 100 & $\mathrm{NF}$ & 0.0 \\
\hline 10 & 70 & $\mathrm{dry}$ & 70 & $\mathrm{NF}$ & 0.0 \\
\hline 11 & 80 & $\mathrm{dry}$ & 70 & $\mathrm{NF}$ & 0.0 \\
\hline 12 & 70 & $\mathrm{dry}$ & 82 & $\mathrm{NF}$ & 0.0 \\
\hline 13 & 80 & $\mathrm{dry}$ & 82 & $\mathrm{NF}$ & 0.0 \\
\hline 14 & 70 & $\mathrm{dry}$ & 90 & $\mathrm{NF}$ & 0.0 \\
\hline 15 & 80 & $\mathrm{dry}$ & 90 & $\mathrm{NF}$ & 0.0 \\
\hline 16 & 70 & $\mathrm{dry}$ & 100 & $\mathrm{NF}$ & 0.0 \\
\hline 17 & 80 & $\mathrm{dry}$ & 100 & $\mathrm{NF}$ & 0.0 \\
\hline
\end{tabular}

\footnotetext{
${ }^{1}$ Data listed here was averaged from the repetition tests with the same nominal condition.
} 
HEAT PUMP FAULT TEST SUMMARY

INDOOR/OUTDOOR CONDITION \#: 02

FAULT TYPE: NO-FAULT

FAULT LEVEL [\%]: 0

RUNNING CONDITIONS

Barometric Pressure (inHg): Indoor Dry-Bulb Temperature $\left({ }^{\circ} \mathrm{F}\right)$ : Indoor Dew-Point Temperature $\left({ }^{\circ} \mathrm{F}\right)$ : Outdoor Dry-Bulb Temperature $\left({ }^{\circ} \mathrm{F}\right)$ : AIR SIDE CONDITIONS

(INDOOR UNIT)

Inlet Dry-Bulb Temperature $\left({ }^{\circ} \mathrm{F}\right)$ : Inlet Dew-Point Temperature $\left({ }^{\circ} \mathrm{F}\right)$ : Exit Dry-Bulb Temperature $\left({ }^{\circ} \mathrm{F}\right)$ : Exit Dew-Point Temperature $\left({ }^{\circ} \mathrm{F}\right)$ : Inlet Relative Humidity (-): Exit Relative Humidity (-): Evaporator Coil Temp Drop $\left({ }^{\circ} \mathrm{F}\right)$ : Air Flow Rate (SCFM): Fan Power Consumption (W) : (OUTDOOR UNIT)

Inlet Temperature $\left({ }^{\circ} \mathrm{F}\right)$ : Exit Temperature $\left({ }^{\circ} \mathrm{F}\right)$ : Condensing Unit Temp Gain $\left({ }^{\circ} \mathrm{F}\right)$ : Fan Power Consumption (W): (OVERALL PERFORMANCE)

Latent Capacity (Btu/h): Sensible Capacity (Btu/h): Overall Capacity (Btu/h): Sensible Heat Ratio (-): Overall Power Consumption (W): NET Cooling EER (Btu/h.W): Evaporator Energy Imbalance (\%): REFRIGERANT SIDE CONDITIONS (EVAPORATOR)

Inlet Temperature $\left({ }^{\circ} \mathrm{F}\right)$ : Exit Temperature $\left({ }^{\circ} \mathrm{F}\right)$ : Inlet Pressure (psia): Exit Pressure (psia): Pressure Drop (psid): Exit Superheat $\left({ }^{\circ} \mathrm{F}\right)$ : Exit Sat. Temperature $\left({ }^{\circ} \mathrm{F}\right)$ : Evaporator Capacity (Btu/h): (CONDENSER)

$$
\begin{array}{rr}
\text { Inlet Temperature }\left({ }^{\circ} \mathrm{F}\right): & 129.56 \\
\text { Exit Temperature }\left({ }^{\circ} \mathrm{F}\right): & 76.81 \\
\text { Inlet Pressure }(\mathrm{psia}): & 281.62 \\
\text { Exit Pressure }(\mathrm{psia}): & 279.11 \\
\text { Pressure Drop }(\mathrm{psid}): & 2.51 \\
\text { Exit Subcooling }\left({ }^{\circ} \mathrm{F}\right): & 8.24 \\
\text { Inlet Sat. Temperature }\left({ }^{\circ} \mathrm{F}\right): & 88.41
\end{array}
$$

Condenser Capacity (Btu/h): (LIQUID LINE AND TXV)

Cond Unit Exit Temp $\left({ }^{\circ} \mathrm{F}\right)$ :

Cond Unit Exit Pres (psia): Liq-line Pressure Drop (psid): TXV Upstream Pressure (psia): TXV Pressure Drop (psid): Temperature Drop $\left({ }^{\circ} \mathrm{F}\right)$ : (COMPRESSOR)

Suction Temperature $\left({ }^{\circ} \mathrm{F}\right)$ : Discharge Temperature $\left({ }^{\circ} \mathrm{F}\right)$ : Suction Pressure (psia):

Discharge Pressure (psia): Discharge Superheat $\left({ }^{\circ} \mathrm{F}\right)$ : Comp Bottom Shell Temp $\left({ }^{\circ} \mathrm{F}\right)$ : Mass Flow Rate (l bm/h):

Comp Power Consumption (W) :

Cond Unit Inlet Temp $\left({ }^{\circ} \mathrm{F}\right)$ : Cond Unit Inlet Pres (psia):
30.69

70.29

.27

70.29

40.27

46.57

0.490

0.883

1043.6

431.35

69.69

14.86

164.47

4893.5

23297.5

8191.0

0.826
2063.0

13.67

3. 41

45.44

55.54

136.44

7.62

13.96
41.58

9633.9

35639.9

77.86

273.34

9.93

263.42

119.35

0.62

59.01

133.51

134.17

282.75

45.10

99.75

378.63

1467.1

57.28

135.49
HEAT PUMP FAULT TEST SUMMARY

INDOOR/OUTDOOR CONDITION \#: 03

FAULT TYPE: NO-FAULT

FAULT LEVEL [] : 0

RUNNING CONDITIONS

Barometric Pressure (inHg): Indoor Dry-Bulb Temperature $\left({ }^{\circ} \mathrm{F}\right)$ : Indoor Dew-Point Temperature $\left({ }^{\circ} \mathrm{F}\right)$ : Outdoor Dry-Bulb Temperature $\left({ }^{\circ} \mathrm{F}\right)$ : AIR SIDE CONDITIONS (INDOOR UNIT)

Inlet Dry-Bulb Temperature $\left({ }^{\circ} \mathrm{F}\right)$ : Inlet Dew-Point Temperature $\left({ }^{\circ} \mathrm{F}\right)$ : Exit Dry-Bulb Temperature $\left({ }^{\circ} \mathrm{F}\right)$ : Exit Dew-Point Temperature $\left({ }^{\circ} \mathrm{F}\right)$ : Inlet Relative Humidity (-) : Exit Relative Humidity (-) : Evaporator Coil Temp Drop $\left({ }^{\circ} \mathrm{F}\right)$ : Air Flow Rate (SCFM) : Fan Power Consumption (W): (OUTDOOR UNIT)

Inlet Temperature $\left({ }^{\circ} \mathrm{F}\right)$ : Exit Temperature $\left({ }^{\circ} \mathrm{F}\right)$ :

Condensing Unit Temp Gain $\left({ }^{\circ} \mathrm{F}\right)$ : Fan Power Consumption (W): (OVERALL PERFORMANCE)

Latent Capacity (Btu/h) : Sensible Capacity (Btu/h): Overall Capacity (Btu/h): Sensible Heat Ratio (-) :

Overall Power Consumption (W) : NET Cooling EER (Btu/h.W): Evaporator Energy Imbalance (\%): REFRIGERANT SIDE CONDITIONS

(EVAPORATOR)

Inlet Temperature $\left({ }^{\circ} \mathrm{F}\right)$ : Exit Temperature $\left({ }^{\circ} \mathrm{F}\right)$ : Inlet Pressure (psia): Exit Pressure (psia): Pressure Drop (psid): Exit Superheat $\left({ }^{\circ} \mathrm{F}\right)$ : Exit Sat. Temperature $\left({ }^{\circ} \mathrm{F}\right)$ : Evaporator Capacity (Btu/h): (CONDENSER)

Inlet Temperature $\left({ }^{\circ} \mathrm{F}\right)$ : Exit Temperature $\left({ }^{\circ} \mathrm{F}\right)$ : Inlet Pressure (psia): Exit Pressure (psia): Pressure Drop (psid): Exit Subcooling $\left({ }^{\circ} \mathrm{F}\right)$ :

Inlet Sat. Temperature $\left({ }^{\circ} \mathrm{F}\right)$ :

Condenser Capacity (Btu/h) : (LIQUID LINE AND TXV)

Cond Unit Exit Temp $\left({ }^{\circ} \mathrm{F}\right)$ : Cond Unit Exit Pres (psia): Liq-line Pressure Drop (psid): TXV Upstream Pressure (psia): TXV Pressure Drop (psid): (COMPRESSOR) Temperature Drop $\left({ }^{\circ} \mathrm{F}\right)$ :

Suction Temperature $\left({ }^{\circ} \mathrm{F}\right)$ :

Discharge Temperature $\left({ }^{\circ} \mathrm{F}\right)$ : Suction Pressure (psia):

Discharge Pressure (psia): Discharge Superheat $\left({ }^{\circ} \mathrm{F}\right)$ : Comp Bottom Shell Temp $\left({ }^{\circ} \mathrm{F}\right)$ : Mass Flow Rate $(1 \mathrm{bm} / \mathrm{h})$ : Comp Power Consumption (W) :

Cond Unit Inlet Temp $\left({ }^{\circ} \mathrm{F}\right)$ : Cond Unit Inlet Pres (psia):
30.63

80.12

60.49

69.96

80.12

60.49

58.74

55.71

0.512

0.896

21.38

1019.6

419.70

69.96

87.16

17.20

163.05

8542.0

23978.2

32520.3

0.737

2089.8

15.56

3.99

53.51

68.14

164.06

155.47

8.60

18.73

49.41

34307.5

133.88

77.85

294.52

291.65

2.87

10.15

91.57

40243.2

78.81

284.72

12.81

271.91

107.85

0.19

69.92

137.42

152.95

295.95

45.78

104.81

427.24

1507.0

69.09

154.24 
HEAT PUMP FAULT TEST SUMMARY

INDOOR/OUTDOOR CONDITION \# : 04

FAULT TYPE: NO-FAULT

FAULT LEVEL [\%]: 0

RUNNING CONDITIONS

Barometric Pressure (inHg): Indoor Dry-Bulb Temperature $\left({ }^{\circ} \mathrm{F}\right)$ : Indoor Dew-Point Temperature $\left({ }^{\circ} \mathrm{F}\right)$ : Outdoor Dry-Bulb Temperature $\left({ }^{\circ} \mathrm{F}\right)$ : AIR SIDE CONDITIONS

(INDOOR UNIT)

Inlet Dry-Bulb Temperature $\left({ }^{\circ} \mathrm{F}\right)$ : Inlet Dew-Point Temperature $\left({ }^{\circ} \mathrm{F}\right)$ : Exit Dry-Bulb Temperature $\left({ }^{\circ} \mathrm{F}\right)$ : Exit Dew-Point Temperature $\left({ }^{\circ} \mathrm{F}\right)$ : Inlet Relative Humidity (-): Exit Relative Humidity (-): Evaporator Coil Temp Drop $\left({ }^{\circ} \mathrm{F}\right)$ : Air Flow Rate (SCFM): Fan Power Consumption (W): (OUTDOOR UNIT)

Inlet Temperature $\left({ }^{\circ} \mathrm{F}\right)$ : Exit Temperature $\left({ }^{\circ} \mathrm{F}\right)$ : Condensing Unit Temp Gain $\left({ }^{\circ} \mathrm{F}\right)$ : Fan Power Consumption (W): (OVERALL PERFORMANCE)

Latent Capacity (Btu/h): Sensible Capacity (Btu/h): Overall Capacity (Btu/h): Sensible Heat Ratio (-): Overall Power Consumption (W): NET Cooling EER (Btu/h.W): Evaporator Energy Imbalance (\%): REFRIGERANT SIDE CONDITIONS

(EVAPORATOR)

Inlet Temperature $\left({ }^{\circ} \mathrm{F}\right)$ : Exit Temperature $\left({ }^{\circ} \mathrm{F}\right)$ : Inlet Pressure (psia): Exit Pressure (psia): Pressure Drop (psid): Exit Superheat $\left({ }^{\circ} \mathrm{F}\right)$ : Exit Sat. Temperature $\left({ }^{\circ} \mathrm{F}\right)$ : Evaporator Capacity (Btu/h): (CONDENSER)

$$
\begin{array}{rr}
\text { Inlet Temperature }\left({ }^{\circ} \mathrm{F}\right): & 147.04 \\
\text { Exit Temperature }\left({ }^{\circ} \mathrm{F}\right): & 89.79 \\
\text { Inlet Pressure (psia): } & 332.63 \\
\text { Exit Pressure }(\mathrm{psia}): & 330.42 \\
\text { Pressure Drop }(\mathrm{psid}): & 2.21 \\
\text { Exit Subcooling }\left({ }^{\circ} \mathrm{F}\right): & 7.89 \\
\text { Inlet Sat. Temperature }\left({ }^{\circ} \mathrm{F}\right): & 100.35
\end{array}
$$
Condenser Capacity (Btu/h): (LIQUID LINE AND TXV)

Cond Unit Exit Temp $\left({ }^{\circ} \mathrm{F}\right)$ : Cond Unit Exit Pres (psia): Liq-line Pressure Drop (psid): TXV Upstream Pressure (psia): TXV Pressure Drop (psid): Temperature Drop $\left({ }^{\circ} \mathrm{F}\right)$ : (COMPRESSOR)

Suction Temperature $\left({ }^{\circ} \mathrm{F}\right)$ : Discharge Temperature $\left({ }^{\circ} \mathrm{F}\right)$ : Suction Pressure (psia):

Discharge Pressure (psia): Discharge Superheat $\left({ }^{\circ} \mathrm{F}\right)$ : Comp Bottom Shell Temp $\left({ }^{\circ} \mathrm{F}\right)$ : Mass Flow Rate (l bm/h):

Comp Power Consumption (W) :

Cond Unit Inlet Temp $\left({ }^{\circ} \mathrm{F}\right)$ : Cond Unit Inlet Pres (psia):
30.35

69.87

50.47

81.73

69.87

50.47

50.73

47.15

0.501

0.875

19.14

1030.9

425.01

81.73

96.67

14.94

159.78

4455.9

21596.0

26051.8

0.829

2276.8

11.44

4.08

46.30

55.65

147.59

138.41

9.18

13.22

42.43

27602.0

34588.4

90.44

324.50

10.47

314.03

166.44

0.94

60.53

151.47

136.16

333.65

51.16

108.08

377.89

1692.0

57.80

137.45
HEAT PUMP FAULT TEST SUMMARY

INDOOR/OUTDOOR CONDITION \#: 05 FAULT TYPE: NO-FAULT FAULT LEVEL [응 : 0

RUNNING CONDITIONS

Barometric Pressure (inHg): Indoor Dry-Bulb Temperature $\left({ }^{\circ} \mathrm{F}\right)$ : Indoor Dew-Point Temperature $\left({ }^{\circ} \mathrm{F}\right)$ : Outdoor Dry-Bulb Temperature $\left({ }^{\circ} \mathrm{F}\right)$ : AIR SIDE CONDITIONS (INDOOR UNIT)

Inlet Dry-Bulb Temperature $\left({ }^{\circ} \mathrm{F}\right)$ : Inlet Dew-Point Temperature $\left({ }^{\circ} \mathrm{F}\right)$ : Exit Dry-Bulb Temperature $\left({ }^{\circ} \mathrm{F}\right)$ : Exit Dew-Point Temperature $\left({ }^{\circ} \mathrm{F}\right)$ : Inlet Relative Humidity (-) : Exit Relative Humidity (-) : Evaporator Coil Temp Drop $\left({ }^{\circ} \mathrm{F}\right)$ : Air Flow Rate (SCFM): Fan Power Consumption (W): (OUTDOOR UNIT)

Inlet Temperature $\left({ }^{\circ} \mathrm{F}\right)$ : Exit Temperature $\left({ }^{\circ} \mathrm{F}\right)$ : Condensing Unit Temp Gain $\left({ }^{\circ} \mathrm{F}\right)$ : Fan Power Consumption (W): (OVERALL PERFORMANCE)

Latent Capacity (Btu/h): Sensible Capacity (Btu/h): Overall Capacity (Btu/h): Sensible Heat Ratio (-) :

Overall Power Consumption (W) : NET Cooling EER (Btu/h.W): Evaporator Energy Imbalance (\%): REFRIGERANT SIDE CONDITIONS

(EVAPORATOR)

Inlet Temperature $\left({ }^{\circ} \mathrm{F}\right)$ : Exit Temperature $\left({ }^{\circ} \mathrm{F}\right)$ : Inlet Pressure (psia): Exit Pressure (psia): Pressure Drop (psid): Exit Superheat $\left({ }^{\circ} \mathrm{F}\right)$ : Exit Sat. Temperature $\left({ }^{\circ} \mathrm{F}\right)$ : Evaporator Capacity (Btu/h): (CONDENSER)

Inlet Temperature $\left({ }^{\circ} \mathrm{F}\right)$ : Exit Temperature $\left({ }^{\circ} \mathrm{F}\right)$ : Inlet Pressure (psia): Exit Pressure (psia): Pressure Drop (psid): Exit Subcooling $\left({ }^{\circ} \mathrm{F}\right)$ :

Inlet Sat. Temperature $\left({ }^{\circ} \mathrm{F}\right)$ :

Condenser Capacity (Btu/h): (LIQUID LINE AND TXV)

Cond Unit Exit Temp $\left({ }^{\circ} \mathrm{F}\right)$ : Cond Unit Exit Pres (psia): Liq-line Pressure Drop (psid): TXV Upstream Pressure (psia): TXV Pressure Drop (psid): (COMPRESSOR) Temperature Drop $\left({ }^{\circ} \mathrm{F}\right)$ :

Suction Temperature $\left({ }^{\circ} \mathrm{F}\right)$ :

Discharge Temperature $\left({ }^{\circ} \mathrm{F}\right)$ : Suction Pressure (psia): Discharge Pressure (psia): Discharge Superheat $\left({ }^{\circ} \mathrm{F}\right)$ : Comp Bottom Shell Temp $\left({ }^{\circ} \mathrm{F}\right)$ : Mass Flow Rate $(1 \mathrm{bm} / \mathrm{h})$ : Comp Power Consumption (W) : Cond Unit Inlet Temp $\left({ }^{\circ} \mathrm{F}\right)$ : Cond Unit Inlet Pres (psia):
30.42

80.00

60.38

81.76

80.00

60.38

59.45

56.16

0.512

0.888

20.55

1011.9

417.19

81.76

98.97

17.21

159.70

7574.1

22880.0

30454.2

0.751

2334.6

13.05

4. 30

54.33

65.66

168.84

158.78

10.05

14.96

50.71

32257.1

147.23

90.77

344.71

342.08

2.64

8.55

102.97

39257.0

92.01

334.55

14.14

320.41

151.58

0.63

68.82

150.92

156.32

345.92

47.96

109.48

435.58

1757.7

67.15

157.57 
HEAT PUMP FAULT TEST SUMMARY

INDOOR/OUTDOOR CONDITION \#: 06

FAULT TYPE: NO-FAULT

FAULT LEVEL [\%]: 0

RUNNING CONDITIONS

Barometric Pressure (inHg): Indoor Dry-Bulb Temperature $\left({ }^{\circ} \mathrm{F}\right)$ : Indoor Dew-Point Temperature $\left({ }^{\circ} \mathrm{F}\right)$ : Outdoor Dry-Bulb Temperature $\left({ }^{\circ} \mathrm{F}\right)$ : AIR SIDE CONDITIONS

(INDOOR UNIT)

Inlet Dry-Bulb Temperature $\left({ }^{\circ} \mathrm{F}\right)$ : Inlet Dew-Point Temperature $\left({ }^{\circ} \mathrm{F}\right)$ : Exit Dry-Bulb Temperature $\left({ }^{\circ} \mathrm{F}\right)$ : Exit Dew-Point Temperature $\left({ }^{\circ} \mathrm{F}\right)$ : Inlet Relative Humidity (-): Exit Relative Humidity (-): Evaporator Coil Temp Drop $\left({ }^{\circ} \mathrm{F}\right)$ : Air Flow Rate (SCFM): Fan Power Consumption (W): (OUTDOOR UNIT)

Inlet Temperature $\left({ }^{\circ} \mathrm{F}\right)$ : Exit Temperature $\left({ }^{\circ} \mathrm{F}\right)$ : Condensing Unit Temp Gain $\left({ }^{\circ} \mathrm{F}\right)$ : Fan Power Consumption (W) : (OVERALL PERFORMANCE)

Latent Capacity (Btu/h): Sensible Capacity (Btu/h): Overall Capacity (Btu/h): Sensible Heat Ratio (-): Overall Power Consumption (W): NET Cooling EER (Btu/h.W): Evaporator Energy Imbalance (\%): REFRIGERANT SIDE CONDITIONS (EVAPORATOR)

Inlet Temperature $\left({ }^{\circ} \mathrm{F}\right)$ : Exit Temperature $\left({ }^{\circ} \mathrm{F}\right)$ : Inlet Pressure (psia): Exit Pressure (psia): Pressure Drop (psid): Exit Superheat $\left({ }^{\circ} \mathrm{F}\right)$ : Exit Sat. Temperature $\left({ }^{\circ} \mathrm{F}\right)$ : Evaporator Capacity (Btu/h): (CONDENSER)

$\begin{array}{rr}\text { Inlet Temperature }\left({ }^{\circ} \mathrm{F}\right): & 159.88 \\ \text { Exit Temperature }\left({ }^{\circ} \mathrm{F}\right): & 98.38 \\ \text { Inlet Pressure (psia): } & 370.75 \\ \text { Exit Pressure (psia): } & 368.71 \\ \text { Pressure Drop (psid): } & 2.04 \\ \text { Exit Subcooling }\left({ }^{\circ} \mathrm{F}\right): & 7.65 \\ \text { Sat. Temperature }\left({ }^{\circ} \mathrm{F}\right): & 108.38\end{array}$

Inlet sat. Temperature $\left({ }^{\circ} \mathrm{F}\right): 0108.38$ (LIQUID LINE AND TXV)

Cond Unit Exit Temp $\left({ }^{\circ} \mathrm{F}\right)$ :

Cond Unit Exit Pres (psia): Liq-line Pressure Drop (psid): TXV Upstream Pressure (psia): TXV Pressure Drop (psid): Temperature Drop $\left({ }^{\circ} \mathrm{F}\right)$ : (COMPRESSOR)

Suction Temperature $\left({ }^{\circ} \mathrm{F}\right)$ : Discharge Temperature $\left({ }^{\circ} \mathrm{F}\right)$ : Suction Pressure (psia):

Discharge Pressure (psia): Discharge Superheat $\left({ }^{\circ} \mathrm{F}\right)$ : Comp Bottom Shell Temp $\left({ }^{\circ} \mathrm{F}\right)$ : Mass Flow Rate (l bm/h):

Comp Power Consumption (W):

Cond Unit Inlet Temp $\left({ }^{\circ} \mathrm{F}\right)$ : Cond Unit Inlet Pres (psia):
30.68

69.84

50.29

90.03

69.84

50.29

50.92

47.59

0.498

0.883

18.93

1041.5

429.06

90.03

104.76

14.73

159.61

3632.5

21574.1

25206.5

0.856

2516.9

10.02

1. 90

47.03

55.89

149.74

140.11

9.63

12.73

43.16

26132.9

33921.2

98.84

362.52

10.68

351.85

202.10

1.28

61.75

164.74

137.97

371.68

56.42

115.57

376.74

1928.2

58.41

139.24
HEAT PUMP FAULT TEST SUMMARY

INDOOR/OUTDOOR CONDITION \#: 07

FAULT TYPE: NO-FAULT

FAULT LEVEL [] : 0

RUNNING CONDITIONS

Barometric Pressure (inHg): Indoor Dry-Bulb Temperature $\left({ }^{\circ} \mathrm{F}\right)$ : Indoor Dew-Point Temperature $\left({ }^{\circ} \mathrm{F}\right)$ : Outdoor Dry-Bulb Temperature $\left({ }^{\circ} \mathrm{F}\right)$ : AIR SIDE CONDITIONS (INDOOR UNIT)

Inlet Dry-Bulb Temperature $\left({ }^{\circ} \mathrm{F}\right)$ : Inlet Dew-Point Temperature $\left({ }^{\circ} \mathrm{F}\right)$ : Exit Dry-Bulb Temperature $\left({ }^{\circ} \mathrm{F}\right)$ : Exit Dew-Point Temperature $\left({ }^{\circ} \mathrm{F}\right)$ : Inlet Relative Humidity (-) : Exit Relative Humidity (-) : Evaporator Coil Temp Drop $\left({ }^{\circ} \mathrm{F}\right)$ : Air Flow Rate (SCFM): Fan Power Consumption (W) : (OUTDOOR UNIT)

Inlet Temperature $\left({ }^{\circ} \mathrm{F}\right)$ : Exit Temperature $\left({ }^{\circ} \mathrm{F}\right)$ : Condensing Unit Temp Gain $\left({ }^{\circ} \mathrm{F}\right)$ : Fan Power Consumption (W): (OVERALL PERFORMANCE)

Latent Capacity (Btu/h): Sensible Capacity (Btu/h): Overall Capacity (Btu/h): Sensible Heat Ratio (-) :

Overall Power Consumption (W) : NET Cooling EER (Btu/h.W): Evaporator Energy Imbalance (\%): REFRIGERANT SIDE CONDITIONS

(EVAPORATOR)

Inlet Temperature $\left({ }^{\circ} \mathrm{F}\right)$ : Exit Temperature $\left({ }^{\circ} \mathrm{F}\right)$ : Inlet Pressure (psia): Exit Pressure (psia): Pressure Drop (psid): Exit Superheat $\left({ }^{\circ} \mathrm{F}\right)$ : Exit Sat. Temperature $\left({ }^{\circ} \mathrm{F}\right)$ : Evaporator Capacity (Btu/h): (CONDENSER)

Inlet Temperature $\left({ }^{\circ} \mathrm{F}\right)$ : Exit Temperature $\left({ }^{\circ} \mathrm{F}\right)$ : Inlet Pressure (psia): Exit Pressure (psia): Pressure Drop (psid): Exit Subcooling $\left({ }^{\circ} \mathrm{F}\right)$ :

Inlet Sat. Temperature $\left({ }^{\circ} \mathrm{F}\right)$ :

Condenser Capacity (Btu/h): (LIQUID LINE AND TXV)

Cond Unit Exit Temp $\left({ }^{\circ} \mathrm{F}\right)$ : Cond Unit Exit Pres (psia): Liq-line Pressure Drop (psid): TXV Upstream Pressure (psia): TXV Pressure Drop (psid): (COMPRESSOR) Temperature Drop $\left({ }^{\circ} \mathrm{F}\right)$ :

Suction Temperature $\left({ }^{\circ} \mathrm{F}\right)$ :

Discharge Temperature $\left({ }^{\circ} \mathrm{F}\right)$ : Suction Pressure (psia):

Discharge Pressure (psia):

Discharge Superheat $\left({ }^{\circ} \mathrm{F}\right)$ :

Comp Bottom Shell Temp $\left({ }^{\circ} \mathrm{F}\right)$ : Mass Flow Rate $(1 \mathrm{bm} / \mathrm{h})$ : Comp Power Consumption (W) :

Cond Unit Inlet Temp $\left({ }^{\circ} \mathrm{F}\right)$ : Cond Unit Inlet Pres (psia):
30.35

79.97

60.84

89.95

79.97

60.84

59.76

56.86

0.521

0.901

20.21

1008.6

416.91

89.95

107.28

17.33

157.98

7266.5

22444.3

29710.8

0.755

2540.5

11.70

2.67

55.27

66.05

173.22

161.98

11.24

14.12

51.93

30955.0

158.87

99.28

384.20

381.75

2.45

8.29

111.07

38794.1

100.53

373.92

14.63

359.29

186.07

0.84

69.92

162.88

159.47

385.52

51.80

115.29

440.16

1965.6

67.68

160.73 
HEAT PUMP FAULT TEST SUMMARY

INDOOR/OUTDOOR CONDITION \#: 08

FAULT TYPE: NO-FAULT

FAULT LEVEL [\%]: 0

RUNNING CONDITIONS

Barometric Pressure (inHg): Indoor Dry-Bulb Temperature $\left({ }^{\circ} \mathrm{F}\right)$ : Indoor Dew-Point Temperature $\left({ }^{\circ} \mathrm{F}\right)$ : Outdoor Dry-Bulb Temperature $\left({ }^{\circ} \mathrm{F}\right)$ : AIR SIDE CONDITIONS

(INDOOR UNIT)

Inlet Dry-Bulb Temperature $\left({ }^{\circ} \mathrm{F}\right)$ : Inlet Dew-Point Temperature $\left({ }^{\circ} \mathrm{F}\right)$ : Exit Dry-Bulb Temperature $\left({ }^{\circ} \mathrm{F}\right)$ : Exit Dew-Point Temperature $\left({ }^{\circ} \mathrm{F}\right)$ : Inlet Relative Humidity (-): Exit Relative Humidity (-): Evaporator Coil Temp Drop $\left({ }^{\circ} \mathrm{F}\right)$ : Air Flow Rate (SCFM): Fan Power Consumption (W): (OUTDOOR UNIT)

Inlet Temperature $\left({ }^{\circ} \mathrm{F}\right)$ : Exit Temperature $\left({ }^{\circ} \mathrm{F}\right)$ : Condensing Unit Temp Gain $\left({ }^{\circ} \mathrm{F}\right)$ : Fan Power Consumption (W) : (OVERALL PERFORMANCE)

Latent Capacity (Btu/h): Sensible Capacity (Btu/h): Overall Capacity (Btu/h): Sensible Heat Ratio (-): Overall Power Consumption (W): NET Cooling EER (Btu/h.W): Evaporator Energy Imbalance (\%): REFRIGERANT SIDE CONDITIONS (EVAPORATOR)

Inlet Temperature $\left({ }^{\circ} \mathrm{F}\right)$ : Exit Temperature $\left({ }^{\circ} \mathrm{F}\right)$ : Inlet Pressure (psia): Exit Pressure (psia): Pressure Drop (psid): Exit Superheat $\left({ }^{\circ} \mathrm{F}\right)$ : Exit Sat. Temperature $\left({ }^{\circ} \mathrm{F}\right)$ : Evaporator Capacity (Btu/h): (CONDENSER)

$\begin{array}{rr}\text { Inlet Temperature }\left({ }^{\circ} \mathrm{F}\right): & 176.41 \\ \text { Exit Temperature }\left({ }^{\circ} \mathrm{F}\right): & 109.39 \\ \text { Inlet Pressure (psia): } & 420.23 \\ \text { Exit Pressure (psia): } & 418.32 \\ \text { Pressure Drop (psid): } & 1.91 \\ \text { Exit Subcooling }\left({ }^{\circ} \mathrm{F}\right): & 6.84 \\ \text { Sat. Temperature }\left({ }^{\circ} \mathrm{F}\right): & 117.91\end{array}$

Inlet Sat. Temperature $\left({ }^{\circ} \mathrm{F}\right): \quad 117.91$ (LIQUID LINE AND TXV)

Cond Unit Exit Temp $\left({ }^{\circ} \mathrm{F}\right)$ :

Cond Unit Exit Pres (psia): Liq-line Pressure Drop (psid): TXV Upstream Pressure (psia): TXV Pressure Drop (psid): Temperature Drop $\left({ }^{\circ} \mathrm{F}\right)$ : (COMPRESSOR)

Suction Temperature $\left({ }^{\circ} \mathrm{F}\right)$ Discharge Temperature $\left({ }^{\circ} \mathrm{F}\right)$ : Suction Pressure (psia):

Discharge Pressure (psia): Discharge Superheat $\left({ }^{\circ} \mathrm{F}\right)$ : Comp Bottom Shell Temp $\left({ }^{\circ} \mathrm{F}\right)$ : Mass Flow Rate (l bm/h):

Comp Power Consumption (W):

Cond Unit Inlet Temp $\left({ }^{\circ} \mathrm{F}\right)$ : Cond Unit Inlet Pres (psia):
30.17

69.96

50.40

99.92

69.96

50.40

51.88

48.28

0.498

0.875

18.09

1023.0

421.35

99.92

114.81

14.89

155.77

2884.0

20253.5

23137.5

0.875

2778.5

8.33

3.07

48.03

56.61

152.98

142.36

10.62

12.51

44.10

24305.6

33119.3

109.44

412.50

11.18

401.32

248.34

1.40

63.55

181.89

140.18

421.36

64.00

126.54

375.25

2201.3

59.30

141.41
HEAT PUMP FAULT TEST SUMMARY

INDOOR/OUTDOOR CONDITION \#: 09 FAULT TYPE: NO-FAULT FAULT LEVEL [] : 0

RUNNING CONDITIONS

Barometric Pressure (inHg): Indoor Dry-Bulb Temperature $\left({ }^{\circ} \mathrm{F}\right)$ : Indoor Dew-Point Temperature $\left({ }^{\circ} \mathrm{F}\right)$ : Outdoor Dry-Bulb Temperature $\left({ }^{\circ} \mathrm{F}\right)$ : AIR SIDE CONDITIONS (INDOOR UNIT)

Inlet Dry-Bulb Temperature $\left({ }^{\circ} \mathrm{F}\right)$ : Inlet Dew-Point Temperature $\left({ }^{\circ} \mathrm{F}\right)$ : Exit Dry-Bulb Temperature $\left({ }^{\circ} \mathrm{F}\right)$ : Exit Dew-Point Temperature $\left({ }^{\circ} \mathrm{F}\right)$ : Inlet Relative Humidity (-) : Exit Relative Humidity (-) : Evaporator Coil Temp Drop $\left({ }^{\circ} \mathrm{F}\right)$ : Air Flow Rate (SCFM) : Fan Power Consumption (W): (OUTDOOR UNIT)

Inlet Temperature $\left({ }^{\circ} \mathrm{F}\right)$ : Exit Temperature $\left({ }^{\circ} \mathrm{F}\right)$ : Condensing Unit Temp Gain $\left({ }^{\circ} \mathrm{F}\right)$ : Fan Power Consumption (W): (OVERALL PERFORMANCE)

Latent Capacity (Btu/h): Sensible Capacity (Btu/h): Overall Capacity (Btu/h): Sensible Heat Ratio (-) :

Overall Power Consumption (W) : NET Cooling EER (Btu/h.W): Evaporator Energy Imbalance (\%): REFRIGERANT SIDE CONDITIONS

(EVAPORATOR)

Inlet Temperature $\left({ }^{\circ} \mathrm{F}\right)$ : Exit Temperature $\left({ }^{\circ} \mathrm{F}\right)$ : Inlet Pressure (psia): Exit Pressure (psia): Pressure Drop (psid): Exit Superheat $\left({ }^{\circ} \mathrm{F}\right)$ : Exit Sat. Temperature $\left({ }^{\circ} \mathrm{F}\right)$ : Evaporator Capacity (Btu/h): (CONDENSER)

Inlet Temperature $\left({ }^{\circ} \mathrm{F}\right)$ : Exit Temperature $\left({ }^{\circ} \mathrm{F}\right)$ : Inlet Pressure (psia): Exit Pressure (psia): Pressure Drop (psid): Exit Subcooling $\left({ }^{\circ} \mathrm{F}\right)$ :

Inlet Sat. Temperature $\left({ }^{\circ} \mathrm{F}\right)$ :

Condenser Capacity (Btu/h) : (LIQUID LINE AND TXV)

Cond Unit Exit Temp $\left({ }^{\circ} \mathrm{F}\right)$ : Cond Unit Exit Pres (psia): Liq-line Pressure Drop (psid): TXV Upstream Pressure (psia): TXV Pressure Drop (psid): (COMPRESSOR) Temperature Drop $\left({ }^{\circ} \mathrm{F}\right)$ :

Suction Temperature $\left({ }^{\circ} \mathrm{F}\right)$ :

Discharge Temperature $\left({ }^{\circ} \mathrm{F}\right)$ : Suction Pressure (psia):

Discharge Pressure (psia):

Discharge Superheat $\left({ }^{\circ} \mathrm{F}\right)$ : Comp Bottom Shell Temp $\left({ }^{\circ} \mathrm{F}\right)$ : Mass Flow Rate $(1 \mathrm{bm} / \mathrm{h})$ : Comp Power Consumption (W) :

Cond Unit Inlet Temp $\left({ }^{\circ} \mathrm{F}\right)$ : Cond Unit Inlet Pres (psia):
30.44

79.99

60.58

99.97

79.99

60.58

60.77

57.35

0.516

0.885

19.22

1010.7

418.57

99.97

116.88

16.91

156.68

5927.3

21382.4

27309.7

0.783

2825.1

9.67

2.86

55.87

66.41

174.60

162.94

11.66

14.12

52.29

28544.8

174.98

109.75

433.61

431.41

2.21

7.86

120.33

37455.2

110.48

423.64

15.28

408.36

233.76

1.00

71.38

179.35

160.65

434.60

59.06

125.47

433.15

2249.9

68.44

161.83 
HEAT PUMP FAULT TEST SUMMARY

INDOOR/OUTDOOR CONDITION \#: 10

FAULT TYPE: NO-FAULT

FAULT LEVEL [\%]: 0

RUNNING CONDITIONS

Barometric Pressure (inHg): Indoor Dry-Bulb Temperature $\left({ }^{\circ} \mathrm{F}\right)$ : Indoor Dew-Point Temperature $\left({ }^{\circ} \mathrm{F}\right)$ : Outdoor Dry-Bulb Temperature $\left({ }^{\circ} \mathrm{F}\right)$ : AIR SIDE CONDITIONS

(INDOOR UNIT)

Inlet Dry-Bulb Temperature $\left({ }^{\circ} \mathrm{F}\right)$ : Inlet Dew-Point Temperature $\left({ }^{\circ} \mathrm{F}\right)$ : Exit Dry-Bulb Temperature $\left({ }^{\circ} \mathrm{F}\right)$ : Exit Dew-Point Temperature $\left({ }^{\circ} \mathrm{F}\right)$ : Inlet Relative Humidity (-): Exit Relative Humidity (-): Evaporator Coil Temp Drop $\left({ }^{\circ} \mathrm{F}\right)$ : Air Flow Rate (SCFM) : Fan Power Consumption (W): (OUTDOOR UNIT)

Inlet Temperature $\left({ }^{\circ} \mathrm{F}\right)$ : Exit Temperature $\left({ }^{\circ} \mathrm{F}\right)$ : Condensing Unit Temp Gain $\left({ }^{\circ} \mathrm{F}\right)$ : Fan Power Consumption (W): (OVERALL PERFORMANCE)

Latent Capacity (Btu/h) : Sensible Capacity (Btu/h): Overall Capacity (Btu/h): Sensible Heat Ratio (-): Overall Power Consumption (W): NET Cooling EER (Btu/h.W): Evaporator Energy Imbalance (\%): REFRIGERANT SIDE CONDITIONS

(EVAPORATOR)

Inlet Temperature $\left({ }^{\circ} \mathrm{F}\right)$ : Exit Temperature $\left({ }^{\circ} \mathrm{F}\right)$ : Inlet Pressure (psia): Exit Pressure (psia): Pressure Drop (psid): Exit Superheat $\left({ }^{\circ} \mathrm{F}\right)$ : Exit Sat. Temperature $\left({ }^{\circ} \mathrm{F}\right)$ : Evaporator Capacity (Btu/h): (CONDENSER)

$$
\begin{array}{rrr}
\text { Inlet Temperature }\left({ }^{\circ} \mathrm{F}\right): & 129.87 \\
\text { Exit Temperature }\left({ }^{\circ} \mathrm{F}\right): & 76.96 \\
\text { Inlet Pressure }(\mathrm{psia}): & 277.97 \\
\text { Exit Pressure }(\mathrm{psia}): & 275.68 \\
\text { Pressure Drop }(\mathrm{psid}): & 2.29 \\
\text { Exit Subcooling }\left({ }^{\circ} \mathrm{F}\right): & 7.84 \\
\text { Inlet Sat. Temperature }\left({ }^{\circ} \mathrm{F}\right): & 87.49
\end{array}
$$

Condenser Capacity (Btu/h): (LIQUID LINE AND TXV)

Cond Unit Exit Temp $\left({ }^{\circ} \mathrm{F}\right)$ :

Cond Unit Exit Pres (psia): Liq-line Pressure Drop (psid): TXV Upstream Pressure (psia): TXV Pressure Drop (psid): Temperature Drop $\left({ }^{\circ} \mathrm{F}\right)$ : (COMPRESSOR)

Suction Temperature $\left({ }^{\circ} \mathrm{F}\right)$ : Discharge Temperature $\left({ }^{\circ} \mathrm{F}\right)$ : Suction Pressure (psia):

Discharge Pressure (psia): Discharge Superheat $\left({ }^{\circ} \mathrm{F}\right)$ : Comp Bottom Shell Temp $\left({ }^{\circ} \mathrm{F}\right)$ : Mass Flow Rate (l bm/h):

Comp Power Consumption (W) :

Cond Unit Inlet Temp $\left({ }^{\circ} \mathrm{F}\right)$ : Cond Unit Inlet Pres (psia):
30.85

69.92

32.01

69.91

69.92

32.01

46.40

32.15

0.245

0.573

23.52

1066.7

440.33

69.91

83.82

13.91

166.38

0.0

27277.5

27167.6

1.000

2067.9

13.14

$-0.20$

43.57

51.39

136.13

128.45

7.68

13.35

38.05

27552.1

33602.5

77.55

270.63

8.76

261.87

125.74

0.59

55.73

134.22

126.18

278.91

46.76

99.65

355.07

1461.2

53.48

127.53
HEAT PUMP FAULT TEST SUMMARY

INDOOR/OUTDOOR CONDITION \#: 11 FAULT TYPE: NO-FAULT FAULT LEVEL [\%]: 0

RUNNING CONDITIONS

Barometric Pressure (inHg): Indoor Dry-Bulb Temperature $\left({ }^{\circ} \mathrm{F}\right)$ : Indoor Dew-Point Temperature $\left({ }^{\circ} \mathrm{F}\right)$ : Outdoor Dry-Bulb Temperature $\left({ }^{\circ} \mathrm{F}\right)$ : AIR SIDE CONDITIONS (INDOOR UNIT)

Inlet Dry-Bulb Temperature $\left({ }^{\circ} \mathrm{F}\right)$ : Inlet Dew-Point Temperature $\left({ }^{\circ} \mathrm{F}\right)$ : Exit Dry-Bulb Temperature $\left({ }^{\circ} \mathrm{F}\right)$ : Exit Dew-Point Temperature $\left({ }^{\circ} \mathrm{F}\right)$ : Inlet Relative Humidity $(-)$ : Exit Relative Humidity (-) : Evaporator Coil Temp Drop $\left({ }^{\circ} \mathrm{F}\right)$ : Air Flow Rate (SCFM): Fan Power Consumption (W): (OUTDOOR UNIT)

Inlet Temperature $\left({ }^{\circ} \mathrm{F}\right)$ : Exit Temperature $\left({ }^{\circ} \mathrm{F}\right)$ : Condensing Unit Temp Gain $\left({ }^{\circ} \mathrm{F}\right)$ : Fan Power Consumption (W): (OVERALL PERFORMANCE)

Latent Capacity (Btu/h): Sensible Capacity (Btu/h): Overall Capacity (Btu/h): Sensible Heat Ratio (-):

Overall Power Consumption (W) : NET Cooling EER (Btu/h.W): Evaporator Energy Imbalance (\%): REFRIGERANT SIDE CONDITIONS

(EVAPORATOR)

Inlet Temperature $\left({ }^{\circ} \mathrm{F}\right)$ : Exit Temperature $\left({ }^{\circ} \mathrm{F}\right)$ : Inlet Pressure (psia): Exit Pressure (psia): Pressure Drop (psid): Exit Superheat $\left({ }^{\circ} \mathrm{F}\right)$ : Exit Sat. Temperature $\left({ }^{\circ} \mathrm{F}\right)$ : Evaporator Capacity (Btu/h): (CONDENSER)

Inlet Temperature $\left({ }^{\circ} \mathrm{F}\right)$ : Exit Temperature $\left({ }^{\circ} \mathrm{F}\right)$ : Inlet Pressure (psia): Exit Pressure (psia): Pressure Drop (psid): Exit Subcooling $\left({ }^{\circ} \mathrm{F}\right)$ :

Inlet Sat. Temperature $\left({ }^{\circ} \mathrm{F}\right)$ :

Condenser Capacity (Btu/h): (LIQUID LINE AND TXV)

Cond Unit Exit Temp $\left({ }^{\circ} \mathrm{F}\right)$ : Cond Unit Exit Pres (psia): Liq-line Pressure Drop (psid): TXV Upstream Pressure (psia): TXV Pressure Drop (psid): (COMPRESSOR) Temperature Drop $\left({ }^{\circ} \mathrm{F}\right)$ :

Suction Temperature $\left({ }^{\circ} \mathrm{F}\right)$ :

Discharge Temperature $\left({ }^{\circ} \mathrm{F}\right)$ : Suction Pressure (psia): Discharge Pressure (psia): Discharge Superheat $\left({ }^{\circ} \mathrm{F}\right)$ : Comp Bottom Shell Temp $\left({ }^{\circ} \mathrm{F}\right)$ : Mass Flow Rate $(1 \mathrm{bm} / \mathrm{h})$ : Comp Power Consumption (W) : Cond Unit Inlet Temp $\left({ }^{\circ} \mathrm{F}\right)$ : Cond Unit Inlet Pres (psia):
30.77

80.28

32.01

69.77

80.28

32.01

53.31

32.10

0.173

0.442

26.97

1045.8

434.65

69.77

85.22

15.45

164.81

0.0

30670.9

30602.3

1.000

2074.2

14.75

0.91

49.98

59.86

151.33

143.19

8.14

15.41

44.45

31320.6

130.53

77.40

285.19

282.54

2.65

8.16

89.29

37331.2

78.70

276.34

11.33

265.02

113.69

0.24

62.67

134.21

140.77

285.79

45.04

101.14

397.99

1474.7

61.43

142.08 
HEAT PUMP FAULT TEST SUMMARY

INDOOR/OUTDOOR CONDITION \#: 12

FAULT TYPE: NO-FAULT

FAULT LEVEL [\%]: 0

RUNNING CONDITIONS

Barometric Pressure (inHg): Indoor Dry-Bulb Temperature $\left({ }^{\circ} \mathrm{F}\right)$ : Indoor Dew-Point Temperature $\left({ }^{\circ} \mathrm{F}\right)$ : Outdoor Dry-Bulb Temperature $\left({ }^{\circ} \mathrm{F}\right)$ : AIR SIDE CONDITIONS

(INDOOR UNIT)

Inlet Dry-Bulb Temperature $\left({ }^{\circ} \mathrm{F}\right)$ : Inlet Dew-Point Temperature $\left({ }^{\circ} \mathrm{F}\right)$ : Exit Dry-Bulb Temperature $\left({ }^{\circ} \mathrm{F}\right)$ : Exit Dew-Point Temperature $\left({ }^{\circ} \mathrm{F}\right)$ : Inlet Relative Humidity (-): Exit Relative Humidity (-): Evaporator Coil Temp Drop $\left({ }^{\circ} \mathrm{F}\right)$ : Air Flow Rate (SCFM): Fan Power Consumption (W) : (OUTDOOR UNIT)

Inlet Temperature $\left({ }^{\circ} \mathrm{F}\right)$ : Exit Temperature $\left({ }^{\circ} \mathrm{F}\right)$ : Condensing Unit Temp Gain $\left({ }^{\circ} \mathrm{F}\right)$ : Fan Power Consumption (W): (OVERALL PERFORMANCE)

Latent Capacity (Btu/h) : Sensible Capacity (Btu/h): Overall Capacity (Btu/h): Sensible Heat Ratio (-): Overall Power Consumption (W): NET Cooling EER (Btu/h.W): Evaporator Energy Imbalance (\%): REFRIGERANT SIDE CONDITIONS

(EVAPORATOR)

Inlet Temperature $\left({ }^{\circ} \mathrm{F}\right)$ : Exit Temperature $\left({ }^{\circ} \mathrm{F}\right)$ : Inlet Pressure (psia): Exit Pressure (psia): Pressure Drop (psid): Exit Superheat $\left({ }^{\circ} \mathrm{F}\right)$ : Exit Sat. Temperature $\left({ }^{\circ} \mathrm{F}\right)$ : Evaporator Capacity (Btu/h): (CONDENSER)

$$
\begin{array}{rr}
\text { Inlet Temperature }\left({ }^{\circ} \mathrm{F}\right): & 147.58 \\
\text { Exit Temperature }\left({ }^{\circ} \mathrm{F}\right): & 89.91 \\
\text { Inlet Pressure }(\mathrm{psia}): & 329.20 \\
\text { Exit Pressure }(\mathrm{psia}): & 327.10 \\
\text { Pressure Drop }(\mathrm{psid}): & 2.10 \\
\text { Exit Subcooling }\left({ }^{\circ} \mathrm{F}\right): & 7.43 \\
\text { Inlet Sat. Temperature }\left({ }^{\circ} \mathrm{F}\right): & 99.59
\end{array}
$$

Condenser Capacity (Btu/h): (LIQUID LINE AND TXV)

Cond Unit Exit Temp $\left({ }^{\circ} \mathrm{F}\right)$ :

Cond Unit Exit Pres (psia): Liq-line Pressure Drop (psid): TXV Upstream Pressure (psia): TXV Pressure Drop (psid): Temperature Drop $\left({ }^{\circ} \mathrm{F}\right)$ : (COMPRESSOR)

Suction Temperature $\left({ }^{\circ} \mathrm{F}\right)$ : Discharge Temperature $\left({ }^{\circ} \mathrm{F}\right)$ : Suction Pressure (psia):

Discharge Pressure (psia): Discharge Superheat $\left({ }^{\circ} \mathrm{F}\right)$ : Comp Bottom Shell Temp $\left({ }^{\circ} \mathrm{F}\right)$ : Mass Flow Rate (l bm/h):

Comp Power Consumption (W) :

Cond Unit Inlet Temp $\left({ }^{\circ} \mathrm{F}\right)$ : Cond Unit Inlet Pres (psia):
30.68

70.20

32.01

81.91

70.20

32.01

47.51

32.14

0.242

0.549

22.70

1055.1

434.44

81.91

95.98

14.07

161.76

0.0

26038.7

25939.0

1.000

2312.2

11.22

$-1.51$

45.07

52.55

141.05

132.29

8.75

12.78

39.77

25981.6

32989.5

90.25

321.64

9.40

312.24

171.19

0.99

58.13

152.42

130.01

330.06

52.91

108.50

358.40

1716.0

55.02

131.33
HEAT PUMP FAULT TEST SUMMARY

INDOOR/OUTDOOR CONDITION \#: 13

FAULT TYPE: NO-FAULT

FAULT LEVEL [] : 0

RUNNING CONDITIONS

Barometric Pressure (inHg) : Indoor Dry-Bulb Temperature $\left({ }^{\circ} \mathrm{F}\right)$ : Indoor Dew-Point Temperature $\left({ }^{\circ} \mathrm{F}\right)$ : Outdoor Dry-Bulb Temperature $\left({ }^{\circ} \mathrm{F}\right)$ : AIR SIDE CONDITIONS (INDOOR UNIT)

Inlet Dry-Bulb Temperature $\left({ }^{\circ} \mathrm{F}\right)$ : Inlet Dew-Point Temperature $\left({ }^{\circ} \mathrm{F}\right)$ : Exit Dry-Bulb Temperature $\left({ }^{\circ} \mathrm{F}\right)$ : Exit Dew-Point Temperature $\left({ }^{\circ} \mathrm{F}\right)$ : Inlet Relative Humidity (-) : Exit Relative Humidity (-) : Evaporator Coil Temp Drop $\left({ }^{\circ} \mathrm{F}\right)$ : Air Flow Rate (SCFM) : Fan Power Consumption (W): (OUTDOOR UNIT)

Inlet Temperature $\left({ }^{\circ} \mathrm{F}\right)$ : Exit Temperature $\left({ }^{\circ} \mathrm{F}\right)$ : Condensing Unit Temp Gain $\left({ }^{\circ} \mathrm{F}\right)$ : Fan Power Consumption (W): (OVERALL PERFORMANCE)

Latent Capacity (Btu/h) : Sensible Capacity (Btu/h): Overall Capacity (Btu/h): Sensible Heat Ratio (-) :

Overall Power Consumption (W) : NET Cooling EER (Btu/h.W): Evaporator Energy Imbalance (\%): REFRIGERANT SIDE CONDITIONS

(EVAPORATOR)

Inlet Temperature $\left({ }^{\circ} \mathrm{F}\right)$ : Exit Temperature $\left({ }^{\circ} \mathrm{F}\right)$ : Inlet Pressure (psia): Exit Pressure (psia): Pressure Drop (psid): Exit Superheat $\left({ }^{\circ} \mathrm{F}\right)$ : Exit Sat. Temperature $\left({ }^{\circ} \mathrm{F}\right)$ : Evaporator Capacity (Btu/h): (CONDENSER)

Inlet Temperature $\left({ }^{\circ} \mathrm{F}\right)$ : Exit Temperature $\left({ }^{\circ} \mathrm{F}\right)$ : Inlet Pressure (psia): Exit Pressure (psia): Pressure Drop (psid): Exit Subcooling $\left({ }^{\circ} \mathrm{F}\right)$ :

Inlet Sat. Temperature $\left({ }^{\circ} \mathrm{F}\right)$ :

Condenser Capacity (Btu/h) : (LIQUID LINE AND TXV)

Cond Unit Exit Temp $\left({ }^{\circ} \mathrm{F}\right)$ : Cond Unit Exit Pres (psia): Liq-line Pressure Drop (psid): TXV Upstream Pressure (psia): TXV Pressure Drop (psid): (COMPRESSOR) Temperature Drop $\left({ }^{\circ} \mathrm{F}\right)$ :

Suction Temperature $\left({ }^{\circ} \mathrm{F}\right)$ :

Discharge Temperature $\left({ }^{\circ} \mathrm{F}\right)$ : Suction Pressure (psia):

Discharge Pressure (psia):

Discharge Superheat $\left({ }^{\circ} \mathrm{F}\right)$ : Comp Bottom Shell Temp $\left({ }^{\circ} \mathrm{F}\right)$ : Mass Flow Rate $(1 \mathrm{bm} / \mathrm{h})$ : Comp Power Consumption (W) :

Cond Unit Inlet Temp $\left({ }^{\circ} \mathrm{F}\right)$ : Cond Unit Inlet Pres (psia):
29.90

80.23

35.65

81.83

80.23

35.65

54.02

36.13

0.201

0.506

26.22

1014.9

424.00

81.83

97.67

15.84

159.79

0.0

28969.4

28564.2

1.000

2325.4

12.28

0.27

51.06

59.66

155.32

145.94

9.37

14.07

45.59

29065.5

147.97

90.37

338.02

335.67

2.35

7.92

101.53

36092.7

91.45

329.15

11.77

317.39

162.07

0.62

64.05

151.99

143.53

338.56

50.61

109.54

396.63

1741.6

61.80

144.83 
HEAT PUMP FAULT TEST SUMMARY

INDOOR/OUTDOOR CONDITION \#: 14

FAULT TYPE: NO-FAULT

FAULT LEVEL [\%]: 0

RUNNING CONDITIONS

Barometric Pressure (inHg): Indoor Dry-Bulb Temperature $\left({ }^{\circ} \mathrm{F}\right)$ : Indoor Dew-Point Temperature $\left({ }^{\circ} \mathrm{F}\right)$ : Outdoor Dry-Bulb Temperature $\left({ }^{\circ} \mathrm{F}\right)$ : AIR SIDE CONDITIONS

(INDOOR UNIT)

Inlet Dry-Bulb Temperature $\left({ }^{\circ} \mathrm{F}\right)$ : Inlet Dew-Point Temperature $\left({ }^{\circ} \mathrm{F}\right)$ : Exit Dry-Bulb Temperature $\left({ }^{\circ} \mathrm{F}\right)$ : Exit Dew-Point Temperature $\left({ }^{\circ} \mathrm{F}\right)$ : Inlet Relative Humidity (-): Exit Relative Humidity (-): Evaporator Coil Temp Drop $\left({ }^{\circ} \mathrm{F}\right)$ : Air Flow Rate (SCFM): Fan Power Consumption (W): (OUTDOOR UNIT)

Inlet Temperature $\left({ }^{\circ} \mathrm{F}\right)$ : Exit Temperature $\left({ }^{\circ} \mathrm{F}\right)$ : Condensing Unit Temp Gain $\left({ }^{\circ} \mathrm{F}\right)$ : Fan Power Consumption (W) : (OVERALL PERFORMANCE)

Latent Capacity (Btu/h) : Sensible Capacity (Btu/h): Overall Capacity (Btu/h): Sensible Heat Ratio (-): Overall Power Consumption (W): NET Cooling EER (Btu/h.W): Evaporator Energy Imbalance (\%): REFRIGERANT SIDE CONDITIONS (EVAPORATOR)

Inlet Temperature $\left({ }^{\circ} \mathrm{F}\right)$ : Exit Temperature $\left({ }^{\circ} \mathrm{F}\right)$ : Inlet Pressure (psia): Exit Pressure (psia): Pressure Drop (psid): Exit Superheat $\left({ }^{\circ} \mathrm{F}\right)$ : Exit Sat. Temperature $\left({ }^{\circ} \mathrm{F}\right)$ : Evaporator Capacity (Btu/h): (CONDENSER)

$$
\begin{array}{rr}
\text { Inlet Temperature }\left({ }^{\circ} \mathrm{F}\right): & 160.26 \\
\text { Exit Temperature }\left({ }^{\circ} \mathrm{F}\right): & 98.62 \\
\text { Inlet Pressure (psia): } & 366.24 \\
\text { Exit Pressure (psia): } & 364.29 \\
\text { Pressure Drop (psid): } & 1.95 \\
\text { Exit Subcooling }\left({ }^{\circ} \mathrm{F}\right): & 7.03 \\
\text { Sat. Temperature }\left({ }^{\circ} \mathrm{F}\right): & 107.47
\end{array}
$$

Inlet Sat. Temperature $\left({ }^{\circ} \mathrm{F}\right)$ :

Condenser Capacity (Btu/h): (LIQUID LINE AND TXV)

Cond Unit Exit Temp $\left({ }^{\circ} \mathrm{F}\right)$ :

Cond Unit Exit Pres (psia): Liq-line Pressure Drop (psid): TXV Upstream Pressure (psia): TXV Pressure Drop (psid): Temperature Drop $\left({ }^{\circ} \mathrm{F}\right)$ : (COMPRESSOR)

Suction Temperature $\left({ }^{\circ} \mathrm{F}\right)$ : Discharge Temperature $\left({ }^{\circ} \mathrm{F}\right)$ : Suction Pressure (psia):

Discharge Pressure (psia): Discharge Superheat $\left({ }^{\circ} \mathrm{F}\right)$ : Comp Bottom Shell Temp $\left({ }^{\circ} \mathrm{F}\right)$ : Mass Flow Rate (l bm/h):

Comp Power Consumption (W) :

Cond Unit Inlet Temp $\left({ }^{\circ} \mathrm{F}\right)$ : Cond Unit Inlet Pres (psia):
30.54

70.05

32.01

70.05

2.01

32.39

0.244

21.97

1050.2

89.86

104.06

14.20

$$
0.0
$$

25094.2

1.000

2508.1

$-1.61$

45.87

53.32

134.57

9.45

12.56

40.77

32599.7

98.64

358.56

9.72

348.84

204.83

1.28

59.80

165.53

132.28

367.01

58.16

116.03

360.01

1915.4

56.08

133.60
HEAT PUMP FAULT TEST SUMMARY

INDOOR/OUTDOOR CONDITION \#: 15

FAULT TYPE: NO-FAULT

FAULT LEVEL [\%]: 0

RUNNING CONDITIONS

Barometric Pressure (inHg): Indoor Dry-Bulb Temperature $\left({ }^{\circ} \mathrm{F}\right)$ : Indoor Dew-Point Temperature $\left({ }^{\circ} \mathrm{F}\right)$ : Outdoor Dry-Bulb Temperature $\left({ }^{\circ} \mathrm{F}\right)$ : AIR SIDE CONDITIONS

(INDOOR UNIT)

Inlet Dry-Bulb Temperature $\left({ }^{\circ} \mathrm{F}\right)$ :

Inlet Dew-Point Temperature $\left({ }^{\circ} \mathrm{F}\right)$ :

Exit Dry-Bulb Temperature $\left({ }^{\circ} \mathrm{F}\right)$ :

Exit Dew-Point Temperature $\left({ }^{\circ} \mathrm{F}\right)$ :

Inlet Relative Humidity (-) :

Exit Relative Humidity (-):

Evaporator Coil Temp Drop $\left({ }^{\circ} \mathrm{F}\right)$ : Air Flow Rate (SCFM) : Fan Power Consumption (W): (OUTDOOR UNIT)

Inlet Temperature $\left({ }^{\circ} \mathrm{F}\right)$ : Exit Temperature $\left({ }^{\circ} \mathrm{F}\right)$ :

Condensing Unit Temp Gain $\left({ }^{\circ} \mathrm{F}\right)$ : Fan Power Consumption (W): (OVERALL PERFORMANCE)

Latent Capacity (Btu/h): Sensible Capacity (Btu/h): Overall Capacity (Btu/h): Sensible Heat Ratio (-):

Overall Power Consumption (W) : NET Cooling EER (Btu/h.W) :

Evaporator Energy Imbalance (\%): REFRIGERANT SIDE CONDITIONS

(EVAPORATOR)

Inlet Temperature $\left({ }^{\circ} \mathrm{F}\right)$ : Exit Temperature $\left({ }^{\circ} \mathrm{F}\right)$ : Inlet Pressure (psia): Exit Pressure (psia): Pressure Drop (psid): Exit Superheat $\left({ }^{\circ} \mathrm{F}\right)$ : Exit Sat. Temperature $\left({ }^{\circ} \mathrm{F}\right)$ : Evaporator Capacity (Btu/h): (CONDENSER)

$\begin{array}{rr}\text { Inlet Temperature }\left({ }^{\circ} \mathrm{F}\right): & 160.34 \\ \text { Exit Temperature }\left({ }^{\circ} \mathrm{F}\right): & 99.25 \\ \text { Inlet Pressure (psia): } & 376.95 \\ \text { Exit Pressure (psia): } & 374.78 \\ \text { Pressure Drop (psid): } & 2.17 \\ \text { Exit Subcooling }\left({ }^{\circ} \mathrm{F}\right): & 7.68 \\ \text { Sat. Temperature }\left({ }^{\circ} \mathrm{F}\right): & 109.63 \\ \text { denser Capacity (Btu } / \mathrm{h}): & 35658.4\end{array}$

\section{(LIQUID LINE AND TXV)}

Condenser Capacity (Btu/h):

Cond Unit Exit Temp $\left({ }^{\circ} \mathrm{F}\right)$ : Cond Unit Exit Pres (psia): Liq-line Pressure Drop (psid): TXV Upstream Pressure (psia): TXV Pressure Drop (psid): (COMPRESSOR) Temperature Drop $\left({ }^{\circ} \mathrm{F}\right)$ :

Suction Temperature $\left({ }^{\circ} \mathrm{F}\right)$ :

Discharge Temperature $\left({ }^{\circ} \mathrm{F}\right)$ : Suction Pressure (psia):

Discharge Pressure (psia): Discharge Superheat $\left({ }^{\circ} \mathrm{F}\right)$ : Comp Bottom Shell Temp $\left({ }^{\circ} \mathrm{F}\right)$ : Mass Flow Rate $(1 \mathrm{bm} / \mathrm{h})$ : Comp Power Consumption (W) :

Cond Unit Inlet Temp $\left({ }^{\circ} \mathrm{F}\right)$ : Cond Unit Inlet Pres (psia):
29.93

79.94

36.88

90.09

79.94

36.88

54.75

37.43

0.213

0.519

25.18

1014.9

423.29

90.09

105.95

15.86

157.67

0.0

27840.8

27354.4

1.000

2529.5

10.81

0.16

51.87

60.19

158.68

148.44

10.24

13.58

46.61

27821.6

90.34

.25

774.78

2.17

99.96

368.14

12.38

355.76

197.08

0.85

65.49

164.71

146.08

377.53

55.22

116.03

399.48

1948.5

62.60

147.36 
HEAT PUMP FAULT TEST SUMMARY

INDOOR/OUTDOOR CONDITION \#: 16

FAULT TYPE: NO-FAULT

FAULT LEVEL [\%]: 0

RUNNING CONDITIONS

Barometric Pressure (inHg): Indoor Dry-Bulb Temperature $\left({ }^{\circ} \mathrm{F}\right)$ : Indoor Dew-Point Temperature $\left({ }^{\circ} \mathrm{F}\right)$ : Outdoor Dry-Bulb Temperature $\left({ }^{\circ} \mathrm{F}\right)$ : AIR SIDE CONDITIONS

(INDOOR UNIT)

Inlet Dry-Bulb Temperature $\left({ }^{\circ} \mathrm{F}\right)$ : Inlet Dew-Point Temperature $\left({ }^{\circ} \mathrm{F}\right)$ : Exit Dry-Bulb Temperature $\left({ }^{\circ} \mathrm{F}\right)$ : Exit Dew-Point Temperature $\left({ }^{\circ} \mathrm{F}\right)$ : Inlet Relative Humidity (-): Exit Relative Humidity (-): Evaporator Coil Temp Drop $\left({ }^{\circ} \mathrm{F}\right)$ : Air Flow Rate (SCFM): Fan Power Consumption (W): (OUTDOOR UNIT)

Inlet Temperature $\left({ }^{\circ} \mathrm{F}\right)$ : Exit Temperature $\left({ }^{\circ} \mathrm{F}\right)$ : Condensing Unit Temp Gain $\left({ }^{\circ} \mathrm{F}\right)$ : Fan Power Consumption (W) : (OVERALL PERFORMANCE)

Latent Capacity (Btu/h) : Sensible Capacity (Btu/h): Overall Capacity (Btu/h): Sensible Heat Ratio (-): Overall Power Consumption (W): NET Cooling EER (Btu/h.W): Evaporator Energy Imbalance (\%): REFRIGERANT SIDE CONDITIONS

(EVAPORATOR)

Inlet Temperature $\left({ }^{\circ} \mathrm{F}\right)$ : Exit Temperature $\left({ }^{\circ} \mathrm{F}\right)$ : Inlet Pressure (psia): Exit Pressure (psia): Pressure Drop (psid): Exit Superheat $\left({ }^{\circ} \mathrm{F}\right)$ : Exit Sat. Temperature $\left({ }^{\circ} \mathrm{F}\right)$ : Evaporator Capacity (Btu/h): (CONDENSER)

Inlet Temperature $\left({ }^{\circ} \mathrm{F}\right)$ : Exit Temperature $\left({ }^{\circ} \mathrm{F}\right)$ : Inlet Pressure (psia): Exit Pressure (psia): Pressure Drop (psid): Exit Subcooling $\left({ }^{\circ} \mathrm{F}\right)$ : Inlet Sat. Temperature $\left({ }^{\circ} \mathrm{F}\right)$ : Condenser Capacity (Btu/h): (LIQUID LINE AND TXV)

Cond Unit Exit Temp $\left({ }^{\circ} \mathrm{F}\right)$ : Cond Unit Exit Pres (psia): Liq-line Pressure Drop (psid): TXV Upstream Pressure (psia): TXV Pressure Drop (psid): Temperature Drop $\left({ }^{\circ} \mathrm{F}\right)$ : (COMPRESSOR)

Suction Temperature $\left({ }^{\circ} \mathrm{F}\right)$ : Discharge Temperature $\left({ }^{\circ} \mathrm{F}\right)$ : Suction Pressure (psia):

Discharge Pressure (psia): Discharge Superheat $\left({ }^{\circ} \mathrm{F}\right)$ : Comp Bottom Shell Temp $\left({ }^{\circ} \mathrm{F}\right)$ : Mass Flow Rate (l bm/h):

Comp Power Consumption (W) :

Cond Unit Inlet Temp $\left({ }^{\circ} \mathrm{F}\right)$ : Cond Unit Inlet Pres (psia):
30.39

70.17

32.27

99.88

70.17

32.27

49.57

32.66

0.245

0.519

20.59

1042.4

429.02

99.88

114.20

14.32

156.86

0.0

23345.2

23042.1

1.000

2783.3

8.28

$-1.78$

46.76

54.51

147.67

137.21

10.46

12.60

41.91

23061.9

177.67

109.01

416.69

414.87

1.82

6.56

117.25

31823.0

109.13

409.36

10.13

399.23

251.56

1.45

62.20

183.41

135.08

417.63

66.21

127.71

357.58

2197.4

57.55

136.35
HEAT PUMP FAULT TEST SUMMARY

INDOOR/OUTDOOR CONDITION \#: 17

FAULT TYPE: NO-FAULT

FAULT LEVEL [] : 0

RUNNING CONDITIONS

Barometric Pressure (inHg): Indoor Dry-Bulb Temperature $\left({ }^{\circ} \mathrm{F}\right)$ : Indoor Dew-Point Temperature $\left({ }^{\circ} \mathrm{F}\right)$ : Outdoor Dry-Bulb Temperature $\left({ }^{\circ} \mathrm{F}\right)$ : AIR SIDE CONDITIONS

(INDOOR UNIT)

Inlet Dry-Bulb Temperature $\left({ }^{\circ} \mathrm{F}\right)$ :

Inlet Dew-Point Temperature $\left({ }^{\circ} \mathrm{F}\right)$ :

Exit Dry-Bulb Temperature $\left({ }^{\circ} \mathrm{F}\right)$ :

Exit Dew-Point Temperature $\left({ }^{\circ} \mathrm{F}\right)$ :

Inlet Relative Humidity (-) :

Exit Relative Humidity (-) :

Evaporator Coil Temp Drop $\left({ }^{\circ} \mathrm{F}\right)$ : Air Flow Rate (SCFM) : Fan Power Consumption (W): (OUTDOOR UNIT)

Inlet Temperature $\left({ }^{\circ} \mathrm{F}\right)$ : Exit Temperature $\left({ }^{\circ} \mathrm{F}\right)$ :

Condensing Unit Temp Gain $\left({ }^{\circ} \mathrm{F}\right)$ : Fan Power Consumption (W): (OVERALL PERFORMANCE)

Latent Capacity (Btu/h) : Sensible Capacity (Btu/h): Overall Capacity (Btu/h): Sensible Heat Ratio (-) :

Overall Power Consumption (W) : NET Cooling EER (Btu/h.W):

Evaporator Energy Imbalance (\%): REFRIGERANT SIDE CONDITIONS

(EVAPORATOR)

Inlet Temperature $\left({ }^{\circ} \mathrm{F}\right)$ : Exit Temperature $\left({ }^{\circ} \mathrm{F}\right)$ : Inlet Pressure (psia): Exit Pressure (psia): Pressure Drop (psid): Exit Superheat $\left({ }^{\circ} \mathrm{F}\right)$ : Exit Sat. Temperature $\left({ }^{\circ} \mathrm{F}\right)$ : Evaporator Capacity (Btu/h): (CONDENSER)

Inlet Temperature $\left({ }^{\circ} \mathrm{F}\right)$ : Exit Temperature $\left({ }^{\circ} \mathrm{F}\right)$ : Inlet Pressure (psia): Exit Pressure (psia): Pressure Drop (psid): Exit Subcooling $\left({ }^{\circ} \mathrm{F}\right)$ :

Inlet Sat. Temperature $\left({ }^{\circ} \mathrm{F}\right)$ :

Condenser Capacity (Btu/h): (LIQUID LINE AND TXV)

Cond Unit Exit Temp $\left({ }^{\circ} \mathrm{F}\right)$ : Cond Unit Exit Pres (psia): Liq-line Pressure Drop (psid): TXV Upstream Pressure (psia): TXV Pressure Drop (psid): (COMPRESSOR) Temperature Drop $\left({ }^{\circ} \mathrm{F}\right)$ :

Suction Temperature $\left({ }^{\circ} \mathrm{F}\right)$ :

Discharge Temperature $\left({ }^{\circ} \mathrm{F}\right)$ : Suction Pressure (psia):

Discharge Pressure (psia):

Discharge Superheat $\left({ }^{\circ} \mathrm{F}\right)$ :

Comp Bottom Shell Temp $\left({ }^{\circ} \mathrm{F}\right)$ : Mass Flow Rate $(1 \mathrm{bm} / \mathrm{h})$ : Comp Power Consumption (W) :

Cond Unit Inlet Temp $\left({ }^{\circ} \mathrm{F}\right)$ :

Cond Unit Inlet Pres (psia):
30.73

80.12

32.01

99.89

80.12

32.01

56.42

32.14

0.174

0.396

23.70

1039.5

429.64

99.89

115.61

15.72

158.04

0.0

26791.1

26689.7

1.000

2810.2

9.50

$-2.59$

53.56

61.93

164.61

153.33

11.28

13.36

48.57

26435.9

175.30

109.51

426.19

424.12

2.07

7.09

118.99

35315.5

110.07

417.23

13.33

403.90

239.29

1.04

67.94

180.12

151.01

426.83

61.23

125.52

405.02

2222.5

64.43

152.24 


\section{D.2 Compressor/Reversing Valve Leakage Fault Tests}

Table D.2. List of raw data for compressor/reversing valve leakage fault tests

\begin{tabular}{c|r|r|r|r|r}
\hline \multirow{2}{*}{$\begin{array}{c}\text { Test } \\
\text { condition \# }\end{array}$} & \multicolumn{2}{|c|}{ Nominal chamber condition } & \multirow{2}{*}{ Fault Type } & \multicolumn{2}{c}{$\begin{array}{c}\text { Fault level } \\
(\%)\end{array}$} \\
\cline { 2 - 3 } & $T_{I D}\left({ }^{\circ} \mathrm{F}\right)$ & \multicolumn{1}{c}{$\phi_{I D}(\%)$} & $T_{O D}\left({ }^{\circ} \mathrm{F}\right)$ & \\
\hline 4 & 70 & 50 & 82 & $\mathrm{CMF}$ & 2.5 \\
\hline 4 & 70 & 50 & 82 & $\mathrm{CMF}$ & 5.0 \\
\hline 4 & 70 & 50 & 82 & $\mathrm{CMF}$ & 9.3 \\
\hline 4 & 70 & 50 & 82 & $\mathrm{CMF}$ & 11.4 \\
\hline 5 & 80 & 50 & 82 & $\mathrm{CMF}$ & 4.0 \\
\hline 5 & 80 & 50 & 82 & $\mathrm{CMF}$ & 6.7 \\
\hline 5 & 80 & 50 & 82 & $\mathrm{CMF}$ & 9.5 \\
\hline 5 & 80 & 50 & 82 & $\mathrm{CMF}$ & 27.2 \\
\hline 5 & 80 & 50 & 82 & $\mathrm{CMF}$ & 38.2 \\
\hline 8 & 70 & 50 & 100 & $\mathrm{CMF}$ & 2.5 \\
\hline 8 & 70 & 50 & 100 & $\mathrm{CMF}$ & 5.5 \\
\hline 8 & 70 & 50 & 100 & $\mathrm{CMF}$ & 9.0 \\
\hline 9 & 80 & 50 & 100 & $\mathrm{CMF}$ & 2.4 \\
\hline 9 & 80 & 50 & 100 & $\mathrm{CMF}$ & 5.6 \\
\hline 9 & 80 & 50 & 100 & $\mathrm{CMF}$ & 8.9 \\
\hline 9 & 80 & 50 & 100 & $\mathrm{CMF}$ & 11.5 \\
\hline
\end{tabular}


HEAT PUMP FAULT TEST SUMMARY

INDOOR/OUTDOOR CONDITION \#: 04 FAULT TYPE: COMPRESSOR LEAKAGE FAULT FAULT LEVEL [\%]: 2.5

\section{RUNNING CONDITIONS}

Barometric Pressure (inHg): Indoor Dry-Bulb Temperature $\left({ }^{\circ} \mathrm{F}\right)$ : Indoor Dew-Point Temperature $\left({ }^{\circ} \mathrm{F}\right)$ : Outdoor Dry-Bulb Temperature $\left({ }^{\circ} \mathrm{F}\right)$ : AIR SIDE CONDITIONS

(INDOOR UNIT)

Inlet Dry-Bulb Temperature $\left({ }^{\circ} \mathrm{F}\right)$ : Inlet Dew-Point Temperature $\left({ }^{\circ} \mathrm{F}\right)$ : Exit Dry-Bulb Temperature $\left({ }^{\circ} \mathrm{F}\right)$ : Exit Dew-Point Temperature $\left({ }^{\circ} \mathrm{F}\right)$ : Inlet Relative Humidity (-): Exit Relative Humidity (-): Evaporator Coil Temp Drop $\left({ }^{\circ} \mathrm{F}\right)$ : Air Flow Rate (SCFM): Fan Power Consumption (W) : (OUTDOOR UNIT)

Inlet Temperature $\left({ }^{\circ} \mathrm{F}\right)$ : Exit Temperature $\left({ }^{\circ} \mathrm{F}\right)$ : Condensing Unit Temp Gain $\left({ }^{\circ} \mathrm{F}\right)$ : Fan Power Consumption (W) : (OVERALL PERFORMANCE)

Latent Capacity (Btu/h): Sensible Capacity (Btu/h): Overall Capacity (Btu/h): Sensible Heat Ratio (-): Overall Power Consumption (W): NET Cooling EER (Btu/h.W): Evaporator Energy Imbalance (\%): REFRIGERANT SIDE CONDITIONS (EVAPORATOR)

Inlet Temperature $\left({ }^{\circ} \mathrm{F}\right)$ : Exit Temperature $\left({ }^{\circ} \mathrm{F}\right)$ : Inlet Pressure (psia): Exit Pressure (psia): Pressure Drop (psid): Exit Superheat $\left({ }^{\circ} \mathrm{F}\right)$ : Exit Sat. Temperature $\left({ }^{\circ} \mathrm{F}\right)$ : Evaporator Capacity (Btu/h) : (CONDENSER)

$\begin{array}{rr}\text { Inlet Temperature }\left({ }^{\circ} \mathrm{F}\right): & 147.53 \\ \text { Exit Temperature }\left({ }^{\circ} \mathrm{F}\right): & 90.36 \\ \text { Inlet Pressure (psia): } & 333.33 \\ \text { Exit Pressure (psia): } & 331.19 \\ \text { Pressure Drop (psid): } & 2.14 \\ \text { Exit Subcooling }\left({ }^{\circ} \mathrm{F}\right): & 7.83 \\ \text { Sat. Temperature }\left({ }^{\circ} \mathrm{F}\right): & 100.50\end{array}$

Inlet sat. Temperature $\left({ }^{\circ} \mathrm{F}\right):-100.50$ (LIQUID LINE AND TXV)

Cond Unit Exit Temp $\left({ }^{\circ} \mathrm{F}\right)$ :

Cond Unit Exit Pres (psia): Liq-line Pressure Drop (psid): TXV Upstream Pressure (psia): TXV Pressure Drop (psid): Temperature Drop $\left({ }^{\circ} \mathrm{F}\right)$ : (COMPRESSOR)

Suction Temperature $\left({ }^{\circ} \mathrm{F}\right)$ : Discharge Temperature $\left({ }^{\circ} \mathrm{F}\right)$ : Suction Pressure (psia):

Discharge Pressure (psia): Discharge Superheat $\left({ }^{\circ} \mathrm{F}\right)$ : Comp Bottom Shell Temp $\left({ }^{\circ} \mathrm{F}\right)$ : Mass Flow Rate (l bm/h):

Comp Power Consumption (W) :

Cond Unit Inlet Temp $\left({ }^{\circ} \mathrm{F}\right)$ : Cond Unit Inlet Pres (psia):
30.06

70.11

50.55

82.21

70.11

50.55

51.04

47.61

0.499

0.880

19.07

1021.0

424.13

82.21

96.90

14.69

159.22

3974.5

21311.4

25285.9

0.843

2311.5

10.94

4.15

46.49

55.99

148.48

139.73

8.75

13.00

42.99

6822.0

33714.4

90.72

325.49

10.00

315.49

167.01

1.04

60.98

151.99

137.50

334.32

51.54

108.88

368.34

1728.2

58.17

138.76
HEAT PUMP FAULT TEST SUMMARY

INDOOR/OUTDOOR CONDITION \#: 04 FAULT TYPE: COMPRESSOR LEAKAGE FAULT FAULT LEVEL [\%]: 5.0 RUNNING CONDITIONS

Barometric Pressure (inHg): Indoor Dry-Bulb Temperature $\left({ }^{\circ} \mathrm{F}\right)$ : Indoor Dew-Point Temperature $\left({ }^{\circ} \mathrm{F}\right)$ : Outdoor Dry-Bulb Temperature $\left({ }^{\circ} \mathrm{F}\right)$ : AIR SIDE CONDITIONS (INDOOR UNIT)

Inlet Dry-Bulb Temperature $\left({ }^{\circ} \mathrm{F}\right)$ : Inlet Dew-Point Temperature $\left({ }^{\circ} \mathrm{F}\right)$ : Exit Dry-Bulb Temperature $\left({ }^{\circ} \mathrm{F}\right)$ : Exit Dew-Point Temperature $\left({ }^{\circ} \mathrm{F}\right)$ : Inlet Relative Humidity (-): Exit Relative Humidity (-) : Evaporator Coil Temp Drop $\left({ }^{\circ} \mathrm{F}\right)$ : Air Flow Rate (SCFM): Fan Power Consumption (W): (OUTDOOR UNIT)

Inlet Temperature $\left({ }^{\circ} \mathrm{F}\right)$ : Exit Temperature $\left({ }^{\circ} \mathrm{F}\right)$ : Condensing Unit Temp Gain $\left({ }^{\circ} \mathrm{F}\right)$ : Fan Power Consumption (W): (OVERALL PERFORMANCE)

Latent Capacity (Btu/h): Sensible Capacity (Btu/h): Overall Capacity (Btu/h): Sensible Heat Ratio (-) :

Overall Power Consumption (W) : NET Cooling EER (Btu/h.W): Evaporator Energy Imbalance (\%): REFRIGERANT SIDE CONDITIONS

(EVAPORATOR)

Inlet Temperature $\left({ }^{\circ} \mathrm{F}\right)$ : Exit Temperature $\left({ }^{\circ} \mathrm{F}\right)$ : Inlet Pressure (psia): Exit Pressure (psia): Pressure Drop (psid): Exit Superheat $\left({ }^{\circ} \mathrm{F}\right)$ : Exit Sat. Temperature $\left({ }^{\circ} \mathrm{F}\right)$ : Evaporator Capacity (Btu/h): (CONDENSER)

Inlet Temperature $\left({ }^{\circ} \mathrm{F}\right)$ : Exit Temperature $\left({ }^{\circ} \mathrm{F}\right)$ : Inlet Pressure (psia): Exit Pressure (psia): Pressure Drop (psid): Exit Subcooling $\left({ }^{\circ} \mathrm{F}\right)$ :

Inlet Sat. Temperature $\left({ }^{\circ} \mathrm{F}\right)$ :

Condenser Capacity (Btu/h): (LIQUID LINE AND TXV)

Cond Unit Exit Temp $\left({ }^{\circ} \mathrm{F}\right)$ : Cond Unit Exit Pres (psia): Liq-line Pressure Drop (psid): TXV Upstream Pressure (psia): TXV Pressure Drop (psid): (COMPRESSOR) Temperature Drop $\left({ }^{\circ} \mathrm{F}\right)$ :

Suction Temperature $\left({ }^{\circ} \mathrm{F}\right)$ :

Discharge Temperature $\left({ }^{\circ} \mathrm{F}\right)$ : Suction Pressure (psia): Discharge Pressure (psia): Discharge Superheat $\left({ }^{\circ} \mathrm{F}\right)$ : Comp Bottom Shell Temp $\left({ }^{\circ} \mathrm{F}\right)$ : Mass Flow Rate $(1 \mathrm{bm} / \mathrm{h})$ : Comp Power Consumption (W) :

Cond Unit Inlet Temp $\left({ }^{\circ} \mathrm{F}\right)$ : Cond Unit Inlet Pres (psia):
30.04

69.81

50.54

82.24

69.81

50.54

51.06

47.71

0.504

0.883

18.75

1021.6

424.86

82.24

96.58

14.34

159.18

3834.9

20970.3

24805.2

0.845

2301.4

10.78

3.40

46.59

56.01

148.64

140.43

8.20

12.72

43.29

26118.1

147.48

90.04

331.59

329.52

2.08

7.73

100.12

32933.3

90.51

324.08

9.43

314.65

166.01

0.96

61.18

152.09

138.29

332.50

52.04

109.16

359.03

1717.3

58.22

139.53 
HEAT PUMP FAULT TEST SUMMARY

INDOOR/OUTDOOR CONDITION \#: 04 FAULT TYPE: COMPRESSOR LEAKAGE FAULT FAULT LEVEL [\%]: 9.3

\section{RUNNING CONDITIONS}

Barometric Pressure (inHg): Indoor Dry-Bulb Temperature $\left({ }^{\circ} \mathrm{F}\right)$ : Indoor Dew-Point Temperature $\left({ }^{\circ} \mathrm{F}\right)$ : Outdoor Dry-Bulb Temperature $\left({ }^{\circ} \mathrm{F}\right)$ : AIR SIDE CONDITIONS

(INDOOR UNIT)

Inlet Dry-Bulb Temperature $\left({ }^{\circ} \mathrm{F}\right)$ : Inlet Dew-Point Temperature $\left({ }^{\circ} \mathrm{F}\right)$ : Exit Dry-Bulb Temperature $\left({ }^{\circ} \mathrm{F}\right)$ : Exit Dew-Point Temperature $\left({ }^{\circ} \mathrm{F}\right)$ : Inlet Relative Humidity (-): Exit Relative Humidity (-): Evaporator Coil Temp Drop $\left({ }^{\circ} \mathrm{F}\right)$ : Air Flow Rate (SCFM): Fan Power Consumption (W): (OUTDOOR UNIT)

Inlet Temperature $\left({ }^{\circ} \mathrm{F}\right)$ : Exit Temperature $\left({ }^{\circ} \mathrm{F}\right)$ : Condensing Unit Temp Gain $\left({ }^{\circ} \mathrm{F}\right)$ : Fan Power Consumption (W) : (OVERALL PERFORMANCE)

Latent Capacity (Btu/h): Sensible Capacity (Btu/h): Overall Capacity (Btu/h): Sensible Heat Ratio (-): Overall Power Consumption (W): NET Cooling EER (Btu/h.W): Evaporator Energy Imbalance (\%): REFRIGERANT SIDE CONDITIONS

(EVAPORATOR)

Inlet Temperature $\left({ }^{\circ} \mathrm{F}\right)$ : Exit Temperature $\left({ }^{\circ} \mathrm{F}\right)$ : Inlet Pressure (psia): Exit Pressure (psia): Pressure Drop (psid): Exit Superheat $\left({ }^{\circ} \mathrm{F}\right)$ : Exit Sat. Temperature $\left({ }^{\circ} \mathrm{F}\right)$ : Evaporator Capacity (Btu/h): (CONDENSER)

$\begin{array}{rr}\text { Inlet Temperature }\left({ }^{\circ} \mathrm{F}\right): & 147.23 \\ \text { Exit Temperature }\left({ }^{\circ} \mathrm{F}\right): & 89.63 \\ \text { Inlet Pressure (psia): } & 327.05 \\ \text { Exit Pressure (psia): } & 325.04 \\ \text { Pressure Drop (psid): } & 2.01 \\ \text { Exit Subcooling }\left({ }^{\circ} \mathrm{F}\right): & 7.41 \\ \text { Sat. Temperature }\left({ }^{\circ} \mathrm{F}\right): & 99.12\end{array}$

Condenser Capacity (Btu/h): $\begin{array}{r}31591.7\end{array}$

(LIQUID LINE AND TXV)

Cond Unit Exit Temp $\left({ }^{\circ} \mathrm{F}\right)$ :

Cond Unit Exit Pres (psia): Liq-line Pressure Drop (psid): TXV Upstream Pressure (psia): TXV Pressure Drop (psid): Temperature Drop $\left({ }^{\circ} \mathrm{F}\right)$ : (COMPRESSOR)

Suction Temperature $\left({ }^{\circ} \mathrm{F}\right)$ : Discharge Temperature $\left({ }^{\circ} \mathrm{F}\right)$ : Suction Pressure (psia):

Discharge Pressure (psia): Discharge Superheat $\left({ }^{\circ} \mathrm{F}\right)$ : Comp Bottom Shell Temp $\left({ }^{\circ} \mathrm{F}\right)$ : Mass Flow Rate $(1 \mathrm{bm} / \mathrm{h})$ :

Comp Power Consumption (W):

Cond Unit Inlet Temp $\left({ }^{\circ} \mathrm{F}\right)$ : Cond Unit Inlet Pres (psia):
30.01

69.73

50.51

81.96

69.73

50.51

51.37

48.04

0.504

0.883

18.36

1019.1

423.19

81.96

95.77

13.81

159.09

3363.0

20481.5

23844.5

0.859

2270.0

10.50

2.73

47.01

56.47

149.30

142.02

7.29

12.52

43.96

24947.5

47.23

89.63

.01

89.92

320.09

8.52

311.57

162.27

0.94

61.71

152.12

139.96

328.00

53.07

109.42

342.64

1687.8

58.59

141.15
HEAT PUMP FAULT TEST SUMMARY

INDOOR/OUTDOOR CONDITION \#: 04 FAULT TYPE: COMPRESSOR LEAKAGE FAULT FAULT LEVEL [\%]: 11.4 RUNNING CONDITIONS

Barometric Pressure (inHg): Indoor Dry-Bulb Temperature $\left({ }^{\circ} \mathrm{F}\right)$ : Indoor Dew-Point Temperature $\left({ }^{\circ} \mathrm{F}\right)$ : Outdoor Dry-Bulb Temperature $\left({ }^{\circ} \mathrm{F}\right)$ : AIR SIDE CONDITIONS (INDOOR UNIT)

Inlet Dry-Bulb Temperature $\left({ }^{\circ} \mathrm{F}\right)$ : Inlet Dew-Point Temperature $\left({ }^{\circ} \mathrm{F}\right)$ : Exit Dry-Bulb Temperature $\left({ }^{\circ} \mathrm{F}\right)$ : Exit Dew-Point Temperature $\left({ }^{\circ} \mathrm{F}\right)$ : Inlet Relative Humidity $(-)$ : Exit Relative Humidity (-): Evaporator Coil Temp Drop $\left({ }^{\circ} \mathrm{F}\right)$ : Air Flow Rate (SCFM): Fan Power Consumption (W): (OUTDOOR UNIT)

Inlet Temperature $\left({ }^{\circ} \mathrm{F}\right)$ : Exit Temperature $\left({ }^{\circ} \mathrm{F}\right)$ : Condensing Unit Temp Gain $\left({ }^{\circ} \mathrm{F}\right)$ : Fan Power Consumption (W): (OVERALL PERFORMANCE)

Latent Capacity (Btu/h): Sensible Capacity (Btu/h): Overall Capacity (Btu/h): Sensible Heat Ratio (-):

Overall Power Consumption (W) : NET Cooling EER (Btu/h.W): Evaporator Energy Imbalance (\%): REFRIGERANT SIDE CONDITIONS

(EVAPORATOR)

Inlet Temperature $\left({ }^{\circ} \mathrm{F}\right)$ : Exit Temperature $\left({ }^{\circ} \mathrm{F}\right)$ : Inlet Pressure (psia): Exit Pressure (psia): Pressure Drop (psid): Exit Superheat $\left({ }^{\circ} \mathrm{F}\right)$ : Exit Sat. Temperature $\left({ }^{\circ} \mathrm{F}\right)$ : Evaporator Capacity (Btu/h): (CONDENSER)

Inlet Temperature $\left({ }^{\circ} \mathrm{F}\right)$ : Exit Temperature $\left({ }^{\circ} \mathrm{F}\right)$ : Inlet Pressure (psia): Exit Pressure (psia): Pressure Drop (psid): Exit Subcooling $\left({ }^{\circ} \mathrm{F}\right)$ :

Inlet Sat. Temperature $\left({ }^{\circ} \mathrm{F}\right)$ : Condenser Capacity (Btu/h): (LIQUID LINE AND TXV)

Cond Unit Exit Temp $\left({ }^{\circ} \mathrm{F}\right)$ : Cond Unit Exit Pres (psia): Liq-line Pressure Drop (psid): TXV Upstream Pressure (psia): TXV Pressure Drop (psid): (COMPRESSOR) Temperature Drop $\left({ }^{\circ} \mathrm{F}\right)$ :

Suction Temperature $\left({ }^{\circ} \mathrm{F}\right)$ :

Discharge Temperature $\left({ }^{\circ} \mathrm{F}\right)$ : Suction Pressure (psia): Discharge Pressure (psia): Discharge Superheat $\left({ }^{\circ} \mathrm{F}\right)$ : Comp Bottom Shell Temp $\left({ }^{\circ} \mathrm{F}\right)$ : Mass Flow Rate $(1 \mathrm{bm} / \mathrm{h})$ : Comp Power Consumption (W) : Cond Unit Inlet Temp $\left({ }^{\circ} \mathrm{F}\right)$ : Cond Unit Inlet Pres (psia):
30.01 69.68

50.55

81.96

69.68

50.55

51.61

48.28

0.506

0.884

18.08

1017.0

424.75

81.96

95.47

13.51

159.66

3100.6

20131.2

23231.8

0.867

2264.7

10.26

2.86

47.23

56.76

149.71

142.86

6.85

12.45

44.31

24354.0

147.46

89.49

325.44

323.50

1.95

7.20

98.76

30946.4

89.83

318.77

8.11

310.66

160.96

1.01

62.04

152.53

140.88

326.40

53.83

109.99

334.82

1680.3

58.95

142.03 
HEAT PUMP FAULT TEST SUMMARY

INDOOR/OUTDOOR CONDITION \#: 05 FAULT TYPE: COMPRESSOR LEAKAGE FAULT FAULT LEVEL [\%]: 4.0

\section{RUNNING CONDITIONS}

Barometric Pressure (inHg): Indoor Dry-Bulb Temperature $\left({ }^{\circ} \mathrm{F}\right)$ : Indoor Dew-Point Temperature $\left({ }^{\circ} \mathrm{F}\right)$ : Outdoor Dry-Bulb Temperature $\left({ }^{\circ} \mathrm{F}\right)$ : AIR SIDE CONDITIONS

(INDOOR UNIT)

Inlet Dry-Bulb Temperature $\left({ }^{\circ} \mathrm{F}\right)$ : Inlet Dew-Point Temperature $\left({ }^{\circ} \mathrm{F}\right)$ : Exit Dry-Bulb Temperature $\left({ }^{\circ} \mathrm{F}\right)$ : Exit Dew-Point Temperature $\left({ }^{\circ} \mathrm{F}\right)$ : Inlet Relative Humidity (-): Exit Relative Humidity (-): Evaporator Coil Temp Drop $\left({ }^{\circ} \mathrm{F}\right)$ : Air Flow Rate (SCFM): Fan Power Consumption (W): (OUTDOOR UNIT)

Inlet Temperature $\left({ }^{\circ} \mathrm{F}\right)$ : Exit Temperature $\left({ }^{\circ} \mathrm{F}\right)$ : Condensing Unit Temp Gain $\left({ }^{\circ} \mathrm{F}\right)$ : Fan Power Consumption (W) : (OVERALL PERFORMANCE)

Latent Capacity (Btu/h): Sensible Capacity (Btu/h): Overall Capacity (Btu/h): Sensible Heat Ratio (-): Overall Power Consumption (W): NET Cooling EER (Btu/h.W): Evaporator Energy Imbalance (\%): REFRIGERANT SIDE CONDITIONS (EVAPORATOR)

Inlet Temperature $\left({ }^{\circ} \mathrm{F}\right)$ : Exit Temperature $\left({ }^{\circ} \mathrm{F}\right)$ : Inlet Pressure (psia): Exit Pressure (psia): Pressure Drop (psid): Exit Superheat $\left({ }^{\circ} \mathrm{F}\right)$ : Exit Sat. Temperature $\left({ }^{\circ} \mathrm{F}\right)$ : Evaporator Capacity (Btu/h): (CONDENSER)

$\begin{array}{rr}\text { Inlet Temperature }\left({ }^{\circ} \mathrm{F}\right): & 146.73 \\ \text { Exit Temperature }\left({ }^{\circ} \mathrm{F}\right): & 90.53 \\ \text { Inlet Pressure (psia): } & 342.11 \\ \text { Exit Pressure (psia): } & 339.60 \\ \text { Pressure Drop (psid): } & 2.51 \\ \text { Exit Subcooling }\left({ }^{\circ} \mathrm{F}\right): & 8.41 \\ \text { Sat. Temperature }\left({ }^{\circ} \mathrm{F}\right): & 102.41\end{array}$

Inlet sat. Temperature $\left({ }^{\circ} \mathrm{F}\right): \quad 102.41$ (LIQUID LINE AND TXV)

Cond Unit Exit Temp $\left({ }^{\circ} \mathrm{F}\right)$ :

Cond Unit Exit Pres (psia): Liq-line Pressure Drop (psid): TXV Upstream Pressure (psia): TXV Pressure Drop (psid): Temperature Drop $\left({ }^{\circ} \mathrm{F}\right)$ : (COMPRESSOR)

Suction Temperature $\left({ }^{\circ} \mathrm{F}\right)$ : Discharge Temperature $\left({ }^{\circ} \mathrm{F}\right)$ : Suction Pressure (psia):

Discharge Pressure (psia): Discharge Superheat $\left({ }^{\circ} \mathrm{F}\right)$ : Comp Bottom Shell Temp $\left({ }^{\circ} \mathrm{F}\right)$ : Mass Flow Rate (l bm/h):

Comp Power Consumption (W) :

Cond Unit Inlet Temp $\left({ }^{\circ} \mathrm{F}\right)$ : Cond Unit Inlet Pres (psia):
30.51

80.25

60.23

81.87

80.25

60.23

59.64

56.61

0.505

0.897

20.62

1014.1

417.80

81.87

98.57

16.70

160.27

6523.4

23010.5

29533.9

0.779

2317.8

12.74

3.22

55.33

66.33

170.03

161.25

8.77

14.68

51.65

30947.0

37731.5

91.73

332.65

13.09

319.56

149.53

0.71

69.50

150.51

158.95

343.21

48.13

110.12

418.09

1739.7

67.78

160.12
HEAT PUMP FAULT TEST SUMMARY

INDOOR/OUTDOOR CONDITION \#: 05 FAULT TYPE: COMPRESSOR LEAKAGE FAULT FAULT LEVEL [\%]: 6.7 RUNNING CONDITIONS

Barometric Pressure (inHg): Indoor Dry-Bulb Temperature $\left({ }^{\circ} \mathrm{F}\right)$ : Indoor Dew-Point Temperature $\left({ }^{\circ} \mathrm{F}\right)$ : Outdoor Dry-Bulb Temperature $\left({ }^{\circ} \mathrm{F}\right)$ : AIR SIDE CONDITIONS (INDOOR UNIT)

Inlet Dry-Bulb Temperature $\left({ }^{\circ} \mathrm{F}\right)$ : Inlet Dew-Point Temperature $\left({ }^{\circ} \mathrm{F}\right)$ : Exit Dry-Bulb Temperature $\left({ }^{\circ} \mathrm{F}\right)$ : Exit Dew-Point Temperature $\left({ }^{\circ} \mathrm{F}\right)$ : Inlet Relative Humidity (-) : Exit Relative Humidity (-) : Evaporator Coil Temp Drop $\left({ }^{\circ} \mathrm{F}\right)$ : Air Flow Rate (SCFM): Fan Power Consumption (W): (OUTDOOR UNIT)

Inlet Temperature $\left({ }^{\circ} \mathrm{F}\right)$ : Exit Temperature $\left({ }^{\circ} \mathrm{F}\right)$ : Condensing Unit Temp Gain $\left({ }^{\circ} \mathrm{F}\right)$ : Fan Power Consumption (W): (OVERALL PERFORMANCE)

Latent Capacity (Btu/h): Sensible Capacity (Btu/h): Overall Capacity (Btu/h): Sensible Heat Ratio (-) :

Overall Power Consumption (W) : NET Cooling EER (Btu/h.W): Evaporator Energy Imbalance (\%): REFRIGERANT SIDE CONDITIONS

(EVAPORATOR)

Inlet Temperature $\left({ }^{\circ} \mathrm{F}\right)$ : Exit Temperature $\left({ }^{\circ} \mathrm{F}\right)$ : Inlet Pressure (psia): Exit Pressure (psia): Pressure Drop (psid): Exit Superheat $\left({ }^{\circ} \mathrm{F}\right)$ : Exit Sat. Temperature $\left({ }^{\circ} \mathrm{F}\right)$ : Evaporator Capacity (Btu/h): (CONDENSER)

Inlet Temperature $\left({ }^{\circ} \mathrm{F}\right)$ : Exit Temperature $\left({ }^{\circ} \mathrm{F}\right)$ : Inlet Pressure (psia): Exit Pressure (psia): Pressure Drop (psid): Exit Subcooling $\left({ }^{\circ} \mathrm{F}\right)$ :

Inlet Sat. Temperature $\left({ }^{\circ} \mathrm{F}\right)$ :

Condenser Capacity (Btu/h): (LIQUID LINE AND TXV)

Cond Unit Exit Temp $\left({ }^{\circ} \mathrm{F}\right)$ : Cond Unit Exit Pres (psia): Liq-line Pressure Drop (psid): TXV Upstream Pressure (psia): TXV Pressure Drop (psid): (COMPRESSOR) Temperature Drop $\left({ }^{\circ} \mathrm{F}\right)$ :

Suction Temperature $\left({ }^{\circ} \mathrm{F}\right)$ :

Discharge Temperature $\left({ }^{\circ} \mathrm{F}\right)$ : Suction Pressure (psia):

Discharge Pressure (psia):

Discharge Superheat $\left({ }^{\circ} \mathrm{F}\right)$ : Comp Bottom Shell Temp $\left({ }^{\circ} \mathrm{F}\right)$ : Mass Flow Rate $(1 \mathrm{bm} / \mathrm{h})$ : Comp Power Consumption (W) :

Cond Unit Inlet Temp $\left({ }^{\circ} \mathrm{F}\right)$ : Cond Unit Inlet Pres (psia):
30.56

80.23

60.32

81.90

80.23

60.32

59.92

56.90

0.507

0.897

20.31

1014.9

417.63

81.90

98.18

16.28

160.59

6196.6

22681.1

28877.7

0.785

2305.7

12.53

2.57

55.69

66.60

170.84

162.70

8.14

14.40

52.20

30066.9

146.52

90.41

339.60

337.19

2.41

8.20

101.87

36764.9

91.49

330.61

12.30

318.32

147.47

0.66

69.81

150.49

160.46

340.72

48.65

110.53

406.38

1727.5

67.99

161.61 
HEAT PUMP FAULT TEST SUMMARY

INDOOR/OUTDOOR CONDITION \#: 05 FAULT TYPE: COMPRESSOR LEAKAGE FAULT FAULT LEVEL [\%]: 9.5

\section{RUNNING CONDITIONS}

Barometric Pressure (inHg): Indoor Dry-Bulb Temperature $\left({ }^{\circ} \mathrm{F}\right)$ : Indoor Dew-Point Temperature $\left({ }^{\circ} \mathrm{F}\right)$ : Outdoor Dry-Bulb Temperature $\left({ }^{\circ} \mathrm{F}\right)$ : AIR SIDE CONDITIONS

(INDOOR UNIT)

Inlet Dry-Bulb Temperature $\left({ }^{\circ} \mathrm{F}\right)$ : Inlet Dew-Point Temperature $\left({ }^{\circ} \mathrm{F}\right)$ : Exit Dry-Bulb Temperature $\left({ }^{\circ} \mathrm{F}\right)$ : Exit Dew-Point Temperature $\left({ }^{\circ} \mathrm{F}\right)$ : Inlet Relative Humidity (-): Exit Relative Humidity (-): Evaporator Coil Temp Drop $\left({ }^{\circ} \mathrm{F}\right)$ : Air Flow Rate (SCFM): Fan Power Consumption (W): (OUTDOOR UNIT)

Inlet Temperature $\left({ }^{\circ} \mathrm{F}\right)$ : Exit Temperature $\left({ }^{\circ} \mathrm{F}\right)$ : Condensing Unit Temp Gain $\left({ }^{\circ} \mathrm{F}\right)$ : Fan Power Consumption (W): (OVERALL PERFORMANCE)

Latent Capacity (Btu/h): Sensible Capacity (Btu/h): Overall Capacity (Btu/h): Sensible Heat Ratio (-): Overall Power Consumption (W): NET Cooling EER (Btu/h.W): Evaporator Energy Imbalance (\%): REFRIGERANT SIDE CONDITIONS

(EVAPORATOR)

Inlet Temperature $\left({ }^{\circ} \mathrm{F}\right)$ : Exit Temperature $\left({ }^{\circ} \mathrm{F}\right)$ : Inlet Pressure (psia): Exit Pressure (psia): Pressure Drop (psid): Exit Superheat $\left({ }^{\circ} \mathrm{F}\right)$ : Exit Sat. Temperature $\left({ }^{\circ} \mathrm{F}\right)$ : Evaporator Capacity (Btu/h): (CONDENSER)

$\begin{array}{rr}\text { Inlet Temperature }\left({ }^{\circ} \mathrm{F}\right): & 146.14 \\ \text { Exit Temperature }\left({ }^{\circ} \mathrm{F}\right): & 90.28 \\ \text { Inlet Pressure (psia): } & 335.44 \\ \text { Exit Pressure (psia): } & 333.09 \\ \text { Pressure Drop (psid): } & 2.35 \\ \text { Exit Subcooling }\left({ }^{\circ} \mathrm{F}\right): & 7.77 \\ \text { Sat. Temperature }\left({ }^{\circ} \mathrm{F}\right): & 100.97\end{array}$

Inlet Sat. Temperature $\left({ }^{\circ} \mathrm{F}\right): \quad 100.97$ (LIQUID LINE AND TXV)

Cond Unit Exit Temp $\left({ }^{\circ} \mathrm{F}\right)$ :

Cond Unit Exit Pres (psia): Liq-line Pressure Drop (psid): TXV Upstream Pressure (psia): TXV Pressure Drop (psid): Temperature Drop $\left({ }^{\circ} \mathrm{F}\right)$ : (COMPRESSOR)

Suction Temperature $\left({ }^{\circ} \mathrm{F}\right)$ : Discharge Temperature $\left({ }^{\circ} \mathrm{F}\right)$ : Suction Pressure (psia):

Discharge Pressure (psia): Discharge Superheat $\left({ }^{\circ} \mathrm{F}\right)$ : Comp Bottom Shell Temp $\left({ }^{\circ} \mathrm{F}\right)$ : Mass Flow Rate (l bm/h):

Comp Power Consumption (W) :

Cond Unit Inlet Temp $\left({ }^{\circ} \mathrm{F}\right)$ : Cond Unit Inlet Pres (psia):
30.57

80.31

60.29

81.63

80.31

60.29

60.39

57.25

0.505

0.893

19.92

1014.4

415.14

81.63

97.42

15.79

160.61

5537.7

22237.8

27775.5

0.801

2278.7

12.19

3.48

56.30

66.93

171.40

163.90

7.50

14.27

52.66

29207.2

35796.2

91.11

326.94

11.46

315.49

144.09

0.94

70.23

150.25

161.76

336.43

49.34

111.03

394.41

1703.0

68.59

162.84
HEAT PUMP FAULT TEST SUMMARY

INDOOR/OUTDOOR CONDITION \#: 05 FAULT TYPE: COMPRESSOR LEAKAGE FAULT FAULT LEVEL [\%]: 27.2 RUNNING CONDITIONS

Barometric Pressure (inHg): Indoor Dry-Bulb Temperature $\left({ }^{\circ} \mathrm{F}\right)$ : Indoor Dew-Point Temperature $\left({ }^{\circ} \mathrm{F}\right)$ : Outdoor Dry-Bulb Temperature $\left({ }^{\circ} \mathrm{F}\right)$ : AIR SIDE CONDITIONS (INDOOR UNIT)

Inlet Dry-Bulb Temperature $\left({ }^{\circ} \mathrm{F}\right)$ : Inlet Dew-Point Temperature $\left({ }^{\circ} \mathrm{F}\right)$ : Exit Dry-Bulb Temperature $\left({ }^{\circ} \mathrm{F}\right)$ : Exit Dew-Point Temperature $\left({ }^{\circ} \mathrm{F}\right)$ : Inlet Relative Humidity (-) : Exit Relative Humidity (-) : Evaporator Coil Temp Drop $\left({ }^{\circ} \mathrm{F}\right)$ : Air Flow Rate (SCFM) : Fan Power Consumption (W) : (OUTDOOR UNIT)

Inlet Temperature $\left({ }^{\circ} \mathrm{F}\right)$ : Exit Temperature $\left({ }^{\circ} \mathrm{F}\right)$ : Condensing Unit Temp Gain $\left({ }^{\circ} \mathrm{F}\right)$ : Fan Power Consumption (W): (OVERALL PERFORMANCE)

Latent Capacity (Btu/h) : Sensible Capacity (Btu/h): Overall Capacity (Btu/h): Sensible Heat Ratio (-) :

Overall Power Consumption (W) : NET Cooling EER (Btu/h.W): Evaporator Energy Imbalance (\%): REFRIGERANT SIDE CONDITIONS

(EVAPORATOR)

Inlet Temperature $\left({ }^{\circ} \mathrm{F}\right)$ : Exit Temperature $\left({ }^{\circ} \mathrm{F}\right)$ : Inlet Pressure (psia): Exit Pressure (psia): Pressure Drop (psid): Exit Superheat $\left({ }^{\circ} \mathrm{F}\right)$ : Exit Sat. Temperature $\left({ }^{\circ} \mathrm{F}\right)$ : Evaporator Capacity (Btu/h): (CONDENSER)

$\begin{array}{rr}\text { Inlet Temperature }\left({ }^{\circ} \mathrm{F}\right): & 149.17 \\ \text { Exit Temperature }\left({ }^{\circ} \mathrm{F}\right): & 89.07 \\ \text { Inlet Pressure (psia): } & 322.20 \\ \text { Exit Pressure (psia): } & 320.37 \\ \text { Pressure Drop (psid): } & 1.83 \\ \text { Exit Subcooling }\left({ }^{\circ} \mathrm{F}\right): & 7.09 \\ \text { Sat. Temperature }\left({ }^{\circ} \mathrm{F}\right): & 98.03 \\ \text { denser Capacity }(\mathrm{Btu} / \mathrm{h}): & 29623.7\end{array}$

(LIQUID LINE AND TXV)

Cond Unit Exit Temp $\left({ }^{\circ} \mathrm{F}\right)$ : Cond Unit Exit Pres (psia): Liq-line Pressure Drop (psid): TXV Upstream Pressure (psia): TXV Pressure Drop (psid): (COMPRESSOR) Temperature Drop $\left({ }^{\circ} \mathrm{F}\right)$ :

Suction Temperature $\left({ }^{\circ} \mathrm{F}\right)$ :

Discharge Temperature $\left({ }^{\circ} \mathrm{F}\right)$ : Suction Pressure (psia):

Discharge Pressure (psia):

Discharge Superheat $\left({ }^{\circ} \mathrm{F}\right)$ : Comp Bottom Shell Temp $\left({ }^{\circ} \mathrm{F}\right)$ : Mass Flow Rate $(1 \mathrm{bm} / \mathrm{h})$ : Comp Power Consumption (W) :

Cond Unit Inlet Temp $\left({ }^{\circ} \mathrm{F}\right)$ : Cond Unit Inlet Pres (psia):
30.52

79.63

60.68

81.98

79.63

60.68

62.24

58.94

0.524

0.890

17.39

1009.6

418.90

81.98

95.05

13.07

161.79

3257.0

19341.7

22598.7

0.856

2211.3

10.22

1. 92

57.25

69.39

175.27

170.87

4.40

14.15

55.25

23467.4

49.17

. 37

1.83

8.03

89.42

316.46

7.17

309.30

134.03

0.68

73.16

154.77

169.29

322.49

56.95

119.89

317.20

1630.6

70.85

170.12 
HEAT PUMP FAULT TEST SUMMARY

INDOOR/OUTDOOR CONDITION \#: 05

FAULT TYPE: COMPRESSOR LEAKAGE FAULT

FAULT LEVEL [\%]: 38.2

\section{RUNNING CONDITIONS}

Barometric Pressure (inHg): Indoor Dry-Bulb Temperature $\left({ }^{\circ} \mathrm{F}\right)$ : Indoor Dew-Point Temperature $\left({ }^{\circ} \mathrm{F}\right)$ : Outdoor Dry-Bulb Temperature $\left({ }^{\circ} \mathrm{F}\right)$ : AIR SIDE CONDITIONS

(INDOOR UNIT)

Inlet Dry-Bulb Temperature $\left({ }^{\circ} \mathrm{F}\right)$ : Inlet Dew-Point Temperature $\left({ }^{\circ} \mathrm{F}\right)$ : Exit Dry-Bulb Temperature $\left({ }^{\circ} \mathrm{F}\right)$ : Exit Dew-Point Temperature $\left({ }^{\circ} \mathrm{F}\right)$ : Inlet Relative Humidity (-): Exit Relative Humidity (-): Evaporator Coil Temp Drop $\left({ }^{\circ} \mathrm{F}\right)$ : Air Flow Rate (SCFM): Fan Power Consumption (W): (OUTDOOR UNIT)

Inlet Temperature $\left({ }^{\circ} \mathrm{F}\right)$ : Exit Temperature $\left({ }^{\circ} \mathrm{F}\right)$ : Condensing Unit Temp Gain $\left({ }^{\circ} \mathrm{F}\right)$ : Fan Power Consumption (W): (OVERALL PERFORMANCE)

Latent Capacity (Btu/h): Sensible Capacity (Btu/h): Overall Capacity (Btu/h): Sensible Heat Ratio (-): Overall Power Consumption (W): NET Cooling EER (Btu/h.W): Evaporator Energy Imbalance (\%): REFRIGERANT SIDE CONDITIONS

(EVAPORATOR)

Inlet Temperature $\left({ }^{\circ} \mathrm{F}\right)$ : Exit Temperature $\left({ }^{\circ} \mathrm{F}\right)$ : Inlet Pressure (psia): Exit Pressure (psia): Pressure Drop (psid): Exit Superheat $\left({ }^{\circ} \mathrm{F}\right)$ : Exit Sat. Temperature $\left({ }^{\circ} \mathrm{F}\right)$ : Evaporator Capacity (Btu/h): (CONDENSER)

$\begin{array}{rr}\text { Inlet Temperature }\left({ }^{\circ} \mathrm{F}\right): & 151.28 \\ \text { Exit Temperature }\left({ }^{\circ} \mathrm{F}\right): & 88.62 \\ \text { Inlet Pressure (psia): } & 312.47 \\ \text { Exit Pressure (psia): } & 310.88 \\ \text { Pressure Drop (psid): } & 1.60 \\ \text { Exit Subcooling }\left({ }^{\circ} \mathrm{F}\right): & 5.93 \\ \text { Sat. Temperature }\left({ }^{\circ} \mathrm{F}\right): & 95.81\end{array}$

Inlet sat. Temperature $\left({ }^{\circ} \mathrm{F}\right)$ : (LIQUID LINE AND TXV)

Cond Unit Exit Temp $\left({ }^{\circ} \mathrm{F}\right)$ :

Cond Unit Exit Pres (psia): Liq-line Pressure Drop (psid): TXV Upstream Pressure (psia): TXV Pressure Drop (psid): Temperature Drop $\left({ }^{\circ} \mathrm{F}\right)$ : (COMPRESSOR)

Suction Temperature $\left({ }^{\circ} \mathrm{F}\right)$ : Discharge Temperature $\left({ }^{\circ} \mathrm{F}\right)$ : Suction Pressure (psia):

Discharge Pressure (psia): Discharge Superheat $\left({ }^{\circ} \mathrm{F}\right)$ : Comp Bottom Shell Temp $\left({ }^{\circ} \mathrm{F}\right)$ : Mass Flow Rate (l bm/h):

Comp Power Consumption (W) :

Cond Unit Inlet Temp $\left({ }^{\circ} \mathrm{F}\right)$ : Cond Unit Inlet Pres (psia):
30.50

79.64

60.71

81.91

79.64

60.71

63.33

59.95

0.524

0.887

16.31

1009.5

415.92

81.91

93.29

11.38

161.36

1440.9

18141.8

19582.7

0.926

2158.8

9.07

$-0.91$

58.73

70.94

178.26

175.34

2.92

14.08

56.86

9818.2

25618.4

88.66

308.12

5.07

303.05

124.79

0.72

75.10

158.40

173.94

312.13

62.95

126.79

269.23

1581.6

72.39

174.71
HEAT PUMP FAULT TEST SUMMARY

INDOOR/OUTDOOR CONDITION \#: 08 FAULT TYPE: COMPRESSOR LEAKAGE FAULT FAULT LEVEL [\%]: 2.5 RUNNING CONDITIONS

Barometric Pressure (inHg): Indoor Dry-Bulb Temperature $\left({ }^{\circ} \mathrm{F}\right)$ : Indoor Dew-Point Temperature $\left({ }^{\circ} \mathrm{F}\right)$ : Outdoor Dry-Bulb Temperature $\left({ }^{\circ} \mathrm{F}\right)$ : AIR SIDE CONDITIONS (INDOOR UNIT)

Inlet Dry-Bulb Temperature $\left({ }^{\circ} \mathrm{F}\right)$ : Inlet Dew-Point Temperature $\left({ }^{\circ} \mathrm{F}\right)$ : Exit Dry-Bulb Temperature $\left({ }^{\circ} \mathrm{F}\right)$ : Exit Dew-Point Temperature $\left({ }^{\circ} \mathrm{F}\right)$ : Inlet Relative Humidity $(-)$ : Exit Relative Humidity (-) : Evaporator Coil Temp Drop $\left({ }^{\circ} \mathrm{F}\right)$ : Air Flow Rate (SCFM) : Fan Power Consumption (W): (OUTDOOR UNIT)

Inlet Temperature $\left({ }^{\circ} \mathrm{F}\right)$ : Exit Temperature $\left({ }^{\circ} \mathrm{F}\right)$ : Condensing Unit Temp Gain $\left({ }^{\circ} \mathrm{F}\right)$ : Fan Power Consumption (W): (OVERALL PERFORMANCE)

Latent Capacity (Btu/h): Sensible Capacity (Btu/h): Overall Capacity (Btu/h): Sensible Heat Ratio (-):

Overall Power Consumption (W) : NET Cooling EER (Btu/h.W): Evaporator Energy Imbalance (\%): REFRIGERANT SIDE CONDITIONS

(EVAPORATOR)

Inlet Temperature $\left({ }^{\circ} \mathrm{F}\right)$ : Exit Temperature $\left({ }^{\circ} \mathrm{F}\right)$ : Inlet Pressure (psia): Exit Pressure (psia): Pressure Drop (psid): Exit Superheat $\left({ }^{\circ} \mathrm{F}\right)$ : Exit Sat. Temperature $\left({ }^{\circ} \mathrm{F}\right)$ : Evaporator Capacity (Btu/h): (CONDENSER)

Inlet Temperature $\left({ }^{\circ} \mathrm{F}\right)$ : Exit Temperature $\left({ }^{\circ} \mathrm{F}\right)$ : Inlet Pressure (psia): Exit Pressure (psia): Pressure Drop (psid): Exit Subcooling $\left({ }^{\circ} \mathrm{F}\right)$ :

Inlet Sat. Temperature $\left({ }^{\circ} \mathrm{F}\right)$ :

Condenser Capacity (Btu/h): (LIQUID LINE AND TXV)

Cond Unit Exit Temp $\left({ }^{\circ} \mathrm{F}\right)$ : Cond Unit Exit Pres (psia): Liq-line Pressure Drop (psid): TXV Upstream Pressure (psia): TXV Pressure Drop (psid): (COMPRESSOR) Temperature Drop $\left({ }^{\circ} \mathrm{F}\right)$ :

Suction Temperature $\left({ }^{\circ} \mathrm{F}\right)$ :

Discharge Temperature $\left({ }^{\circ} \mathrm{F}\right)$ : Suction Pressure (psia):

Discharge Pressure (psia): Discharge Superheat $\left({ }^{\circ} \mathrm{F}\right)$ : Comp Bottom Shell Temp $\left({ }^{\circ} \mathrm{F}\right)$ : Mass Flow Rate $(1 \mathrm{bm} / \mathrm{h})$ : Comp Power Consumption (W) : Cond Unit Inlet Temp $\left({ }^{\circ} \mathrm{F}\right)$ : Cond Unit Inlet Pres (psia):
30.06

70.06

50.64

100.11

70.06

50.64

52.44

48.81

0.501

0.874

17.62

1019.5

420.29

100.11

114.70

14.59

155.39

2518.0

19669.1

22187.2

0.887

2774.9

8.00

4.36

48.76

56.91

153.67

143.74

9.93

12.23

44.68

23638.9

176.36

109.66

419.23

417.37

1.86

6.65

117.72

32289.6

109.54

411.99

10.62

401.37

247.70

1.42

63.97

181.86

141.66

420.41

64.15

126.60

365.90

2199.2

59.64

142.84 
HEAT PUMP FAULT TEST SUMMARY

INDOOR/OUTDOOR CONDITION \#: 08 FAULT TYPE: COMPRESSOR LEAKAGE FAULT FAULT LEVEL [\%]: 5.5

\section{RUNNING CONDITIONS}

Barometric Pressure (inHg): Indoor Dry-Bulb Temperature $\left({ }^{\circ} \mathrm{F}\right)$ : Indoor Dew-Point Temperature $\left({ }^{\circ} \mathrm{F}\right)$ : Outdoor Dry-Bulb Temperature $\left({ }^{\circ} \mathrm{F}\right)$ : AIR SIDE CONDITIONS

(INDOOR UNIT)

Inlet Dry-Bulb Temperature $\left({ }^{\circ} \mathrm{F}\right)$ : Inlet Dew-Point Temperature $\left({ }^{\circ} \mathrm{F}\right)$ : Exit Dry-Bulb Temperature $\left({ }^{\circ} \mathrm{F}\right)$ : Exit Dew-Point Temperature $\left({ }^{\circ} \mathrm{F}\right)$ : Inlet Relative Humidity (-): Exit Relative Humidity (-): Evaporator Coil Temp Drop $\left({ }^{\circ} \mathrm{F}\right)$ : Air Flow Rate (SCFM): Fan Power Consumption (W) : (OUTDOOR UNIT)

Inlet Temperature $\left({ }^{\circ} \mathrm{F}\right)$ : Exit Temperature $\left({ }^{\circ} \mathrm{F}\right)$ : Condensing Unit Temp Gain $\left({ }^{\circ} \mathrm{F}\right)$ : Fan Power Consumption (W) : (OVERALL PERFORMANCE)

Latent Capacity (Btu/h): Sensible Capacity (Btu/h): Overall Capacity (Btu/h): Sensible Heat Ratio (-): Overall Power Consumption (W): NET Cooling EER (Btu/h.W): Evaporator Energy Imbalance (\%): REFRIGERANT SIDE CONDITIONS (EVAPORATOR)

Inlet Temperature $\left({ }^{\circ} \mathrm{F}\right)$ : Exit Temperature $\left({ }^{\circ} \mathrm{F}\right)$ : Inlet Pressure (psia): Exit Pressure (psia): Pressure Drop (psid): Exit Superheat $\left({ }^{\circ} \mathrm{F}\right)$ : Exit Sat. Temperature $\left({ }^{\circ} \mathrm{F}\right)$ : Evaporator Capacity (Btu/h): (CONDENSER)

$\begin{array}{rr}\text { Inlet Temperature }\left({ }^{\circ} \mathrm{F}\right): & 176.61 \\ \text { Exit Temperature }\left({ }^{\circ} \mathrm{F}\right): & 109.44 \\ \text { Inlet Pressure (psia): } & 416.38 \\ \text { Exit Pressure (psia): } & 414.57 \\ \text { Pressure Drop (psid): } & 1.81 \\ \text { Exit Subcooling }\left({ }^{\circ} \mathrm{F}\right): & 6.46 \\ \text { Sat. Temperature }\left({ }^{\circ} \mathrm{F}\right): & 117.20\end{array}$

Inlet sat. Temperature $\left({ }^{\circ} \mathrm{F}\right): \quad 117.20$ (LIQUID LINE AND TXV)

Cond Unit Exit Temp $\left({ }^{\circ} \mathrm{F}\right)$ :

Cond Unit Exit Pres (psia): Liq-line Pressure Drop (psid): TXV Upstream Pressure (psia): TXV Pressure Drop (psid): Temperature Drop $\left({ }^{\circ} \mathrm{F}\right)$ : (COMPRESSOR)

Suction Temperature $\left({ }^{\circ} \mathrm{F}\right)$ : Discharge Temperature $\left({ }^{\circ} \mathrm{F}\right)$ : Suction Pressure (psia):

Discharge Pressure (psia): Discharge Superheat $\left({ }^{\circ} \mathrm{F}\right)$ : Comp Bottom Shell Temp $\left({ }^{\circ} \mathrm{F}\right)$ : Mass Flow Rate $(1 \mathrm{bm} / \mathrm{h})$ :

Comp Power Consumption (W) :

Cond Unit Inlet Temp $\left({ }^{\circ} \mathrm{F}\right)$ : Cond Unit Inlet Pres (psia):
30.04

70.00

50.71

100.09

70.00

50.71

52.69

49.03

0.503

0.873

17.31

1016.1

419.31

100.09

114.30

14.21

155.37

2312.2

19256.9

21569.1

0.893

2754.8

7.83

4.03

48.96

57.20

153.95

144.79

9.16

12.09

45.12

22912.2

31433.4

109.25

409.47

9.82

399.65

245.70

1.44

64.40

182.35

142.78

417.52

65.17

126.88

354.63

2180.1

59.97

143.93
HEAT PUMP FAULT TEST SUMMARY

INDOOR/OUTDOOR CONDITION \#: 08 FAULT TYPE: COMPRESSOR LEAKAGE FAULT FAULT LEVEL [\%]: 9.0 RUNNING CONDITIONS

Barometric Pressure (inHg): Indoor Dry-Bulb Temperature $\left({ }^{\circ} \mathrm{F}\right)$ : Indoor Dew-Point Temperature $\left({ }^{\circ} \mathrm{F}\right)$ : Outdoor Dry-Bulb Temperature $\left({ }^{\circ} \mathrm{F}\right)$ : AIR SIDE CONDITIONS (INDOOR UNIT)

Inlet Dry-Bulb Temperature $\left({ }^{\circ} \mathrm{F}\right)$ : Inlet Dew-Point Temperature $\left({ }^{\circ} \mathrm{F}\right)$ : Exit Dry-Bulb Temperature $\left({ }^{\circ} \mathrm{F}\right)$ : Exit Dew-Point Temperature $\left({ }^{\circ} \mathrm{F}\right)$ : Inlet Relative Humidity $(-)$ : Exit Relative Humidity (-) : Evaporator Coil Temp Drop $\left({ }^{\circ} \mathrm{F}\right)$ : Air Flow Rate (SCFM): Fan Power Consumption (W): (OUTDOOR UNIT)

Inlet Temperature $\left({ }^{\circ} \mathrm{F}\right)$ : Exit Temperature $\left({ }^{\circ} \mathrm{F}\right)$ : Condensing Unit Temp Gain $\left({ }^{\circ} \mathrm{F}\right)$ : Fan Power Consumption (W): (OVERALL PERFORMANCE)

Latent Capacity (Btu/h): Sensible Capacity (Btu/h): Overall Capacity (Btu/h): Sensible Heat Ratio (-) :

Overall Power Consumption (W) : NET Cooling EER (Btu/h.W): Evaporator Energy Imbalance (\%): REFRIGERANT SIDE CONDITIONS

(EVAPORATOR)

Inlet Temperature $\left({ }^{\circ} \mathrm{F}\right)$ : Exit Temperature $\left({ }^{\circ} \mathrm{F}\right)$ : Inlet Pressure (psia): Exit Pressure (psia): Pressure Drop (psid): Exit Superheat $\left({ }^{\circ} \mathrm{F}\right)$ : Exit Sat. Temperature $\left({ }^{\circ} \mathrm{F}\right)$ : Evaporator Capacity (Btu/h): (CONDENSER)

Inlet Temperature $\left({ }^{\circ} \mathrm{F}\right)$ : Exit Temperature $\left({ }^{\circ} \mathrm{F}\right)$ : Inlet Pressure (psia): Exit Pressure (psia): Pressure Drop (psid): Exit Subcooling $\left({ }^{\circ} \mathrm{F}\right)$ :

Inlet Sat. Temperature $\left({ }^{\circ} \mathrm{F}\right)$ : Condenser Capacity (Btu/h) : (LIQUID LINE AND TXV)

Cond Unit Exit Temp $\left({ }^{\circ} \mathrm{F}\right)$ : Cond Unit Exit Pres (psia): Liq-line Pressure Drop (psid): TXV Upstream Pressure (psia): TXV Pressure Drop (psid): (COMPRESSOR) Temperature Drop $\left({ }^{\circ} \mathrm{F}\right)$ :

Suction Temperature $\left({ }^{\circ} \mathrm{F}\right)$ :

Discharge Temperature $\left({ }^{\circ} \mathrm{F}\right)$ : Suction Pressure (psia): Discharge Pressure (psia): Discharge Superheat $\left({ }^{\circ} \mathrm{F}\right)$ : Comp Bottom Shell Temp $\left({ }^{\circ} \mathrm{F}\right)$ : Mass Flow Rate $(1 \mathrm{bm} / \mathrm{h})$ : Comp Power Consumption (W) : Cond Unit Inlet Temp $\left({ }^{\circ} \mathrm{F}\right)$ : Cond Unit Inlet Pres (psia):
30.00

70.01

50.70

100.05

70.01

50.70

53.01

49.33

0.503

0.873

17.00

1012.5

418.53

100.05

113.89

13.84

155.18

1890.4

18854.3

20744.7

0.909

2736.8

7.58

4.08

49.15

57.56

154.36

145.89

8.47

11.99

45.57

22062.8

177.26

109.20

413.38

411.64

1.74

6.28

116.64

30453.1

108.96

406.94

9.08

397.85

243.49

1.45

64.95

183.27

143.98

414.54

66.64

127.28

341.54

2163.1

60.37

145.09 
HEAT PUMP FAULT TEST SUMMARY

INDOOR/OUTDOOR CONDITION \#: 09

FAULT TYPE: COMPRESSOR LEAKAGE FAULT FAULT LEVEL [\%]: 2.4

\section{RUNNING CONDITIONS}

Barometric Pressure (inHg): Indoor Dry-Bulb Temperature $\left({ }^{\circ} \mathrm{F}\right)$ : Indoor Dew-Point Temperature $\left({ }^{\circ} \mathrm{F}\right)$ : Outdoor Dry-Bulb Temperature $\left({ }^{\circ} \mathrm{F}\right)$ : AIR SIDE CONDITIONS

(INDOOR UNIT)

Inlet Dry-Bulb Temperature $\left({ }^{\circ} \mathrm{F}\right)$ : Inlet Dew-Point Temperature $\left({ }^{\circ} \mathrm{F}\right)$ : Exit Dry-Bulb Temperature $\left({ }^{\circ} \mathrm{F}\right)$ : Exit Dew-Point Temperature $\left({ }^{\circ} \mathrm{F}\right)$ : Inlet Relative Humidity (-): Exit Relative Humidity (-): Evaporator Coil Temp Drop $\left({ }^{\circ} \mathrm{F}\right)$ : Air Flow Rate (SCFM): Fan Power Consumption (W) : (OUTDOOR UNIT)

Inlet Temperature $\left({ }^{\circ} \mathrm{F}\right)$ : Exit Temperature $\left({ }^{\circ} \mathrm{F}\right)$ : Condensing Unit Temp Gain $\left({ }^{\circ} \mathrm{F}\right)$ : Fan Power Consumption (W): (OVERALL PERFORMANCE)

Latent Capacity (Btu/h): Sensible Capacity (Btu/h): Overall Capacity (Btu/h): Sensible Heat Ratio (-): Overall Power Consumption (W): NET Cooling EER (Btu/h.W): Evaporator Energy Imbalance (\%): REFRIGERANT SIDE CONDITIONS

(EVAPORATOR)

Inlet Temperature $\left({ }^{\circ} \mathrm{F}\right)$ : Exit Temperature $\left({ }^{\circ} \mathrm{F}\right)$ : Inlet Pressure (psia): Exit Pressure (psia): Pressure Drop (psid): Exit Superheat $\left({ }^{\circ} \mathrm{F}\right)$ : Exit Sat. Temperature $\left({ }^{\circ} \mathrm{F}\right)$ : Evaporator Capacity (Btu/h): (CONDENSER)

$\begin{array}{rr}\text { Inlet Temperature }\left({ }^{\circ} \mathrm{F}\right): & 174.44 \\ \text { Exit Temperature }\left({ }^{\circ} \mathrm{F}\right): & 109.21 \\ \text { Inlet Pressure (psia): } & 429.77 \\ \text { Exit Pressure (psia): } & 427.61 \\ \text { Pressure Drop (psid): } & 2.16 \\ \text { Exit Subcooling }\left({ }^{\circ} \mathrm{F}\right): & 7.96 \\ \text { Sat. Temperature }\left({ }^{\circ} \mathrm{F}\right): & 119.64\end{array}$

Inlet sat. Temperature $\left({ }^{\circ} \mathrm{F}\right): \quad 119.64$ (LIQUID LINE AND TXV)

Cond Unit Exit Temp $\left({ }^{\circ} \mathrm{F}\right)$ :

Cond Unit Exit Pres (psia): Liq-line Pressure Drop (psid): TXV Upstream Pressure (psia): TXV Pressure Drop (psid): Temperature Drop $\left({ }^{\circ} \mathrm{F}\right)$ : (COMPRESSOR)

Suction Temperature $\left({ }^{\circ} \mathrm{F}\right)$ : Discharge Temperature $\left({ }^{\circ} \mathrm{F}\right)$ : Suction Pressure (psia):

Discharge Pressure (psia): Discharge Superheat $\left({ }^{\circ} \mathrm{F}\right)$ : Comp Bottom Shell Temp $\left({ }^{\circ} \mathrm{F}\right)$ : Mass Flow Rate (l bm/h):

Comp Power Consumption (W) :

Cond Unit Inlet Temp $\left({ }^{\circ} \mathrm{F}\right)$ : Cond Unit Inlet Pres (psia):
30.40

80.28

60.42

99.69

80.28

60.42

60.83

57.55

0.508

0.889

19.45

1008.0

415.56

99.69

116.28

16.59

156.61

5257.4

21582.8

26840.2

0.804

2789.3

9.62

2.51

56.74

67.23

175.17

164.32

10.86

14.42

52.81

27958.2

36622.6

109.72

420.07

14.34

405.74

230.57

0.94

72.10

178.88

162.13

430.57

59.32

125.73

421.72

2217.1

69.18

163.25
HEAT PUMP FAULT TEST SUMMARY

INDOOR/OUTDOOR CONDITION \#: 09 FAULT TYPE: COMPRESSOR LEAKAGE FAULT FAULT LEVEL [\%]: 5.6 RUNNING CONDITIONS

Barometric Pressure (inHg) : Indoor Dry-Bulb Temperature $\left({ }^{\circ} \mathrm{F}\right)$ : Indoor Dew-Point Temperature $\left({ }^{\circ} \mathrm{F}\right)$ : Outdoor Dry-Bulb Temperature $\left({ }^{\circ} \mathrm{F}\right)$ : AIR SIDE CONDITIONS (INDOOR UNIT)

Inlet Dry-Bulb Temperature $\left({ }^{\circ} \mathrm{F}\right)$ : Inlet Dew-Point Temperature $\left({ }^{\circ} \mathrm{F}\right)$ : Exit Dry-Bulb Temperature $\left({ }^{\circ} \mathrm{F}\right)$ : Exit Dew-Point Temperature $\left({ }^{\circ} \mathrm{F}\right)$ : Inlet Relative Humidity (-) : Exit Relative Humidity (-) : Evaporator Coil Temp Drop $\left({ }^{\circ} \mathrm{F}\right)$ : Air Flow Rate (SCFM): Fan Power Consumption (W) : (OUTDOOR UNIT)

Inlet Temperature $\left({ }^{\circ} \mathrm{F}\right)$ : Exit Temperature $\left({ }^{\circ} \mathrm{F}\right)$ : Condensing Unit Temp Gain $\left({ }^{\circ} \mathrm{F}\right)$ : Fan Power Consumption (W): (OVERALL PERFORMANCE)

Latent Capacity (Btu/h): Sensible Capacity (Btu/h): Overall Capacity (Btu/h): Sensible Heat Ratio (-) :

Overall Power Consumption (W) : NET Cooling EER (Btu/h.W): Evaporator Energy Imbalance (\%): REFRIGERANT SIDE CONDITIONS

(EVAPORATOR)

Inlet Temperature $\left({ }^{\circ} \mathrm{F}\right)$ : Exit Temperature $\left({ }^{\circ} \mathrm{F}\right)$ : Inlet Pressure (psia): Exit Pressure (psia): Pressure Drop (psid): Exit Superheat $\left({ }^{\circ} \mathrm{F}\right)$ : Exit Sat. Temperature $\left({ }^{\circ} \mathrm{F}\right)$ : Evaporator Capacity (Btu/h): (CONDENSER)

Inlet Temperature $\left({ }^{\circ} \mathrm{F}\right)$ : Exit Temperature $\left({ }^{\circ} \mathrm{F}\right)$ : Inlet Pressure (psia): Exit Pressure (psia): Pressure Drop (psid): Exit Subcooling $\left({ }^{\circ} \mathrm{F}\right)$ :

Inlet Sat. Temperature $\left({ }^{\circ} \mathrm{F}\right)$ :

Condenser Capacity (Btu/h): (LIQUID LINE AND TXV)

Cond Unit Exit Temp $\left({ }^{\circ} \mathrm{F}\right)$ : Cond Unit Exit Pres (psia): Liq-line Pressure Drop (psid): TXV Upstream Pressure (psia): TXV Pressure Drop (psid): (COMPRESSOR) Temperature Drop $\left({ }^{\circ} \mathrm{F}\right)$ :

Suction Temperature $\left({ }^{\circ} \mathrm{F}\right)$ :

Discharge Temperature $\left({ }^{\circ} \mathrm{F}\right)$ : Suction Pressure (psia):

Discharge Pressure (psia): Discharge Superheat $\left({ }^{\circ} \mathrm{F}\right)$ : Comp Bottom Shell Temp $\left({ }^{\circ} \mathrm{F}\right)$ : Mass Flow Rate $(1 \mathrm{bm} / \mathrm{h})$ : Comp Power Consumption (W) :

Cond Unit Inlet Temp $\left({ }^{\circ} \mathrm{F}\right)$ : Cond Unit Inlet Pres (psia):
30.97

80.12

60.58

100.08

80.12

60.58

61.48

57.98

0.514

0.883

18.64

1028.4

421.13

100.08

115.98

15.90

158.06

4811.8

21101.8

25913.6

0.814

2784.8

9.31

2. 41

56.25

67.12

174.75

164.83

9.92

14.11

53.01

26983.9

174.95

109.12

427.98

425.89

2.09

8.00

119.32

35586.3

109.47

418.89

13.28

405.61

230.86

1.02

72.36

179.68

162.80

428.84

60.43

126.68

407.75

2205.6

69.21

163.91 
HEAT PUMP FAULT TEST SUMMARY

INDOOR/OUTDOOR CONDITION \#: 09

FAULT TYPE: COMPRESSOR LEAKAGE FAULT FAULT LEVEL [\%]: 8.9

\section{RUNNING CONDITIONS}

Barometric Pressure (inHg): Indoor Dry-Bulb Temperature $\left({ }^{\circ} \mathrm{F}\right)$ : Indoor Dew-Point Temperature $\left({ }^{\circ} \mathrm{F}\right)$ : Outdoor Dry-Bulb Temperature $\left({ }^{\circ} \mathrm{F}\right)$ : AIR SIDE CONDITIONS

(INDOOR UNIT)

Inlet Dry-Bulb Temperature $\left({ }^{\circ} \mathrm{F}\right)$ : Inlet Dew-Point Temperature $\left({ }^{\circ} \mathrm{F}\right)$ : Exit Dry-Bulb Temperature $\left({ }^{\circ} \mathrm{F}\right)$ : Exit Dew-Point Temperature $\left({ }^{\circ} \mathrm{F}\right)$ : Inlet Relative Humidity (-): Exit Relative Humidity (-): Evaporator Coil Temp Drop $\left({ }^{\circ} \mathrm{F}\right)$ : Air Flow Rate (SCFM): Fan Power Consumption (W): (OUTDOOR UNIT)

Inlet Temperature $\left({ }^{\circ} \mathrm{F}\right)$ : Exit Temperature $\left({ }^{\circ} \mathrm{F}\right)$ : Condensing Unit Temp Gain $\left({ }^{\circ} \mathrm{F}\right)$ : Fan Power Consumption (W) : (OVERALL PERFORMANCE)

Latent Capacity (Btu/h): Sensible Capacity (Btu/h): Overall Capacity (Btu/h): Sensible Heat Ratio (-): Overall Power Consumption (W): NET Cooling EER (Btu/h.W): Evaporator Energy Imbalance (\%): REFRIGERANT SIDE CONDITIONS

(EVAPORATOR)

Inlet Temperature $\left({ }^{\circ} \mathrm{F}\right)$ : Exit Temperature $\left({ }^{\circ} \mathrm{F}\right)$ : Inlet Pressure (psia): Exit Pressure (psia): Pressure Drop (psid): Exit Superheat $\left({ }^{\circ} \mathrm{F}\right)$ : Exit Sat. Temperature $\left({ }^{\circ} \mathrm{F}\right)$ : Evaporator Capacity (Btu/h): (CONDENSER)

$\begin{array}{rr}\text { Inlet Temperature }\left({ }^{\circ} \mathrm{F}\right): & 174.93 \\ \text { Exit Temperature }\left({ }^{\circ} \mathrm{F}\right): & 108.83 \\ \text { Inlet Pressure (psia): } & 423.54 \\ \text { Exit Pressure (psia): } & 421.54 \\ \text { Pressure Drop (psid): } & 2.01 \\ \text { Exit Subcooling }\left({ }^{\circ} \mathrm{F}\right): & 7.58\end{array}$

Inlet Sat Temperature $\left({ }^{\circ} \mathrm{F}\right)$ : Condenser Capacity (Btu/h): (LIQUID LINE AND TXV)

Cond Unit Exit Temp $\left({ }^{\circ} \mathrm{F}\right)$ : Cond Unit Exit Pres (psia): Liq-line Pressure Drop (psid): TXV Upstream Pressure (psia): TXV Pressure Drop (psid): Temperature Drop $\left({ }^{\circ} \mathrm{F}\right)$ : (COMPRESSOR)

Suction Temperature $\left({ }^{\circ} \mathrm{F}\right)$ : Discharge Temperature $\left({ }^{\circ} \mathrm{F}\right)$ : Suction Pressure (psia):

Discharge Pressure (psia): Discharge Superheat $\left({ }^{\circ} \mathrm{F}\right)$ : Comp Bottom Shell Temp $\left({ }^{\circ} \mathrm{F}\right)$ : Mass Flow Rate (l bm/h):

Comp Power Consumption (W) :

Cond Unit Inlet Temp $\left({ }^{\circ} \mathrm{F}\right)$ : Cond Unit Inlet Pres (psia):
30.36

80.23

60.52

99.72

80.23

60.52

61.53

58.18

0.511

0.887

18.70

1007.7

419.75

99.72

115.44

15.72

156.92

4343.6

20748.3

25091.9

0.827

2762.3

9.08

2.14

57.41

67.99

176.32

167.08

9.24

14.14

53.85

26068.9

4.93

8.83

1. 54

2.01
7.58

118.51

34489.3

109.17

415.00

12.33

402.67

226.35

0.97

73.11

179.88

165.12

424.27

61.46

126.82

393.46

2185.6

69.99

166.19
HEAT PUMP FAULT TEST SUMMARY

INDOOR/OUTDOOR CONDITION \#: 09 FAULT TYPE: COMPRESSOR LEAKAGE FAULT FAULT LEVEL [\%]: 11.5 RUNNING CONDITIONS

Barometric Pressure (inHg): Indoor Dry-Bulb Temperature $\left({ }^{\circ} \mathrm{F}\right)$ : Indoor Dew-Point Temperature $\left({ }^{\circ} \mathrm{F}\right)$ : Outdoor Dry-Bulb Temperature $\left({ }^{\circ} \mathrm{F}\right)$ : AIR SIDE CONDITIONS (INDOOR UNIT)

Inlet Dry-Bulb Temperature $\left({ }^{\circ} \mathrm{F}\right)$ : Inlet Dew-Point Temperature $\left({ }^{\circ} \mathrm{F}\right)$ : Exit Dry-Bulb Temperature $\left({ }^{\circ} \mathrm{F}\right)$ : Exit Dew-Point Temperature $\left({ }^{\circ} \mathrm{F}\right)$ : Inlet Relative Humidity (-) : Exit Relative Humidity (-) : Evaporator Coil Temp Drop $\left({ }^{\circ} \mathrm{F}\right)$ : Air Flow Rate (SCFM): Fan Power Consumption (W): (OUTDOOR UNIT)

Inlet Temperature $\left({ }^{\circ} \mathrm{F}\right)$ : Exit Temperature $\left({ }^{\circ} \mathrm{F}\right)$ : Condensing Unit Temp Gain $\left({ }^{\circ} \mathrm{F}\right)$ : Fan Power Consumption (W): (OVERALL PERFORMANCE)

Latent Capacity (Btu/h): Sensible Capacity (Btu/h): Overall Capacity (Btu/h): Sensible Heat Ratio (-):

Overall Power Consumption (W) : NET Cooling EER (Btu/h.W): Evaporator Energy Imbalance (\%): REFRIGERANT SIDE CONDITIONS

(EVAPORATOR)

Inlet Temperature $\left({ }^{\circ} \mathrm{F}\right)$ : Exit Temperature $\left({ }^{\circ} \mathrm{F}\right)$ : Inlet Pressure (psia): Exit Pressure (psia): Pressure Drop (psid): Exit Superheat $\left({ }^{\circ} \mathrm{F}\right)$ : Exit Sat. Temperature $\left({ }^{\circ} \mathrm{F}\right)$ : Evaporator Capacity (Btu/h): (CONDENSER)

Inlet Temperature $\left({ }^{\circ} \mathrm{F}\right)$ : Exit Temperature $\left({ }^{\circ} \mathrm{F}\right)$ : Inlet Pressure (psia): Exit Pressure (psia): Pressure Drop (psid): Exit Subcooling $\left({ }^{\circ} \mathrm{F}\right)$ :

Inlet Sat. Temperature $\left({ }^{\circ} \mathrm{F}\right)$ :

Condenser Capacity (Btu/h) : (LIQUID LINE AND TXV)

Cond Unit Exit Temp $\left({ }^{\circ} \mathrm{F}\right)$ : Cond Unit Exit Pres (psia): Liq-line Pressure Drop (psid): TXV Upstream Pressure (psia): TXV Pressure Drop (psid): (COMPRESSOR) Temperature Drop $\left({ }^{\circ} \mathrm{F}\right)$ :

Suction Temperature $\left({ }^{\circ} \mathrm{F}\right)$ :

Discharge Temperature $\left({ }^{\circ} \mathrm{F}\right)$ : Suction Pressure (psia):

Discharge Pressure (psia):

Discharge Superheat $\left({ }^{\circ} \mathrm{F}\right)$ : Comp Bottom Shell Temp $\left({ }^{\circ} \mathrm{F}\right)$ : Mass Flow Rate $(1 \mathrm{bm} / \mathrm{h})$ : Comp Power Consumption (W) :

Cond Unit Inlet Temp $\left({ }^{\circ} \mathrm{F}\right)$ : Cond Unit Inlet Pres (psia):
30.34

80.18

60.72

99.78

80.18

60.72

61.83

58.52

0.515

0.889

18.34

1004.4

416.67

99.78

115.27

15.49

155.89

4108.6

20294.6

24403.2

0.832

2742.9

8.90

1.93

57.74

68.25

177.06

168.45

8.61

13.90

54.35

25309.0

175.37

108.80

421.76

419.81

1.95

7.54

118.19

33623.5

108.95

413.58

11.61

401.97

224.91

0.95

73.55

180.44

166.54

422.49

62.35

127.50

382.09

2170.4

70.32

167.55 


\section{D.3 Improper Outdoor Air Flow Fault Tests}

Table D.3. List of raw data for improper outdoor air flow fault tests

\begin{tabular}{|c|c|c|c|c|c|}
\hline \multirow{2}{*}{$\begin{array}{c}\text { Test } \\
\text { condition \# }\end{array}$} & \multicolumn{3}{|c|}{ Nominal chamber condition } & \multirow{2}{*}{ Fault Type } & \multirow{2}{*}{$\begin{array}{c}\text { Fault level } \\
(\%)\end{array}$} \\
\hline & $T_{I D}\left({ }^{\circ} \mathrm{F}\right)$ & $\phi_{I D}(\%)$ & $T_{O D}\left({ }^{\circ} \mathrm{F}\right)$ & & \\
\hline 4 & 70 & 50 & 82 & $\mathrm{CF}$ & 10.0 \\
\hline 4 & 70 & 50 & 82 & $\mathrm{CF}$ & 20.0 \\
\hline 4 & 70 & 50 & 82 & $\mathrm{CF}$ & 35.0 \\
\hline 5 & 80 & 50 & 82 & $\mathrm{CF}$ & 5.0 \\
\hline 5 & 80 & 50 & 82 & $\mathrm{CF}$ & 10.0 \\
\hline 5 & 80 & 50 & 82 & $\mathrm{CF}$ & 20.0 \\
\hline 5 & 80 & 50 & 82 & $\mathrm{CF}$ & 35.0 \\
\hline 5 & 80 & 50 & 82 & $\mathrm{CF}$ & 50.0 \\
\hline 8 & 70 & 50 & 100 & $\mathrm{CF}$ & 10.0 \\
\hline 8 & 70 & 50 & 100 & $\mathrm{CF}$ & 20.0 \\
\hline 8 & 70 & 50 & 100 & $\mathrm{CF}$ & 35.0 \\
\hline 9 & 80 & 50 & 100 & $\mathrm{CF}$ & 5.0 \\
\hline 9 & 80 & 50 & 100 & $\mathrm{CF}$ & 10.0 \\
\hline 9 & 80 & 50 & 100 & $\mathrm{CF}$ & 20.0 \\
\hline 9 & 80 & 50 & 100 & $\mathrm{CF}$ & 35.0 \\
\hline
\end{tabular}


HEAT PUMP FAULT TEST SUMMARY

INDOOR/OUTDOOR CONDITION \#: 04

FAULT TYPE: IMPROPER OUTDOOR AIR FLOW FAULT FAULT LEVEL [\%]: 10.0

\section{RUNNING CONDITIONS}

Barometric Pressure (inHg): Indoor Dry-Bulb Temperature $\left({ }^{\circ} \mathrm{F}\right)$ : Indoor Dew-Point Temperature $\left({ }^{\circ} \mathrm{F}\right)$ : Outdoor Dry-Bulb Temperature $\left({ }^{\circ} \mathrm{F}\right)$ : AIR SIDE CONDITIONS

(INDOOR UNIT)

Inlet Dry-Bulb Temperature $\left({ }^{\circ} \mathrm{F}\right)$ : Inlet Dew-Point Temperature $\left({ }^{\circ} \mathrm{F}\right)$ : Exit Dry-Bulb Temperature $\left({ }^{\circ} \mathrm{F}\right)$ : Exit Dew-Point Temperature $\left({ }^{\circ} \mathrm{F}\right)$ : Inlet Relative Humidity (-): Exit Relative Humidity (-): Evaporator Coil Temp Drop $\left({ }^{\circ} \mathrm{F}\right)$ : Air Flow Rate (SCFM): Fan Power Consumption (W) : (OUTDOOR UNIT)

Inlet Temperature $\left({ }^{\circ} \mathrm{F}\right)$ : Exit Temperature $\left({ }^{\circ} \mathrm{F}\right)$ : Condensing Unit Temp Gain $\left({ }^{\circ} \mathrm{F}\right)$ : Fan Power Consumption (W): (OVERALL PERFORMANCE)

Latent Capacity (Btu/h): Sensible Capacity (Btu/h): Overall Capacity (Btu/h): Sensible Heat Ratio (-): Overall Power Consumption (W): NET Cooling EER (Btu/h.W): Evaporator Energy Imbalance (\%): REFRIGERANT SIDE CONDITIONS (EVAPORATOR)

Inlet Temperature $\left({ }^{\circ} \mathrm{F}\right)$ : Exit Temperature $\left({ }^{\circ} \mathrm{F}\right)$ : Inlet Pressure (psia): Exit Pressure (psia): Pressure Drop (psid): Exit Superheat $\left({ }^{\circ} \mathrm{F}\right)$ : Exit Sat. Temperature $\left({ }^{\circ} \mathrm{F}\right)$ : Evaporator Capacity (Btu/h): (CONDENSER)

$\begin{array}{rr}\text { Inlet Temperature }\left({ }^{\circ} \mathrm{F}\right): & 147.53 \\ \text { Exit Temperature }\left({ }^{\circ} \mathrm{F}\right): & 88.83 \\ \text { Inlet Pressure (psia): } & 333.00 \\ \text { Exit Pressure (psia): } & 330.81 \\ \text { Pressure Drop (psid): } & 2.19 \\ \text { Exit Subcooling }\left({ }^{\circ} \mathrm{F}\right): & 7.61 \\ \text { Sat. Temperature }\left({ }^{\circ} \mathrm{F}\right): & 100.43\end{array}$

Inlet Sat. Temperature $\left({ }^{\circ} \mathrm{F}\right):-100.43$ (LIQUID LINE AND TXV)

Cond Unit Exit Temp $\left({ }^{\circ} \mathrm{F}\right)$ :

Cond Unit Exit Pres (psia): Liq-line Pressure Drop (psid): TXV Upstream Pressure (psia): TXV Pressure Drop (psid): Temperature Drop $\left({ }^{\circ} \mathrm{F}\right)$ : (COMPRESSOR)

Suction Temperature $\left({ }^{\circ} \mathrm{F}\right)$ : Discharge Temperature $\left({ }^{\circ} \mathrm{F}\right)$ : Suction Pressure (psia):

Discharge Pressure (psia): Discharge Superheat $\left({ }^{\circ} \mathrm{F}\right)$ : Comp Bottom Shell Temp $\left({ }^{\circ} \mathrm{F}\right)$ : Mass Flow Rate (l bm/h):

Comp Power Consumption (W) :

Cond Unit Inlet Temp $\left({ }^{\circ} \mathrm{F}\right)$ : Cond Unit Inlet Pres (psia):
30.55

70.03

50.10

81.54

70.03

50.10

50.62

47.11

0.492

0.877

19.41

1038.1

425.46

81.54

96.54

15.00

160.54

3977.8

22044.2

26021.9

0.847

2315.7

11.24

3. 74

46.10

55.47

147.16

138.00

9.16

13.22

42.25

27475.1

47.53

88.83

33.00

.19

7. 61

34507.4

90.80

324.87

10.38

314.49

167.33

0.99

60.26

151.99

135.72

333.92

51.63

108.47

377.09

1729.7

57.74

137.05
HEAT PUMP FAULT TEST SUMMARY

INDOOR/OUTDOOR CONDITION \#: 04

FAULT TYPE: IMPROPER OUTDOOR AIR FLOW FAULT FAULT LEVEL [\%]: 20.0

\section{RUNNING CONDITIONS}

Barometric Pressure (inHg): Indoor Dry-Bulb Temperature $\left({ }^{\circ} \mathrm{F}\right)$ : Indoor Dew-Point Temperature $\left({ }^{\circ} \mathrm{F}\right)$ : Outdoor Dry-Bulb Temperature $\left({ }^{\circ} \mathrm{F}\right)$ : AIR SIDE CONDITIONS

(INDOOR UNIT)

Inlet Dry-Bulb Temperature $\left({ }^{\circ} \mathrm{F}\right)$ :

Inlet Dew-Point Temperature $\left({ }^{\circ} \mathrm{F}\right)$ :

Exit Dry-Bulb Temperature $\left({ }^{\circ} \mathrm{F}\right)$ :

Exit Dew-Point Temperature $\left({ }^{\circ} \mathrm{F}\right)$ :

Inlet Relative Humidity $(-)$ : Exit Relative Humidity (-): Evaporator Coil Temp Drop $\left({ }^{\circ} \mathrm{F}\right)$ : Air Flow Rate (SCFM): Fan Power Consumption (W): (OUTDOOR UNIT)

Inlet Temperature $\left({ }^{\circ} \mathrm{F}\right)$ : Exit Temperature $\left({ }^{\circ} \mathrm{F}\right)$ :

Condensing Unit Temp Gain $\left({ }^{\circ} \mathrm{F}\right)$ : Fan Power Consumption (W): (OVERALL PERFORMANCE)

Latent Capacity (Btu/h): Sensible Capacity (Btu/h): Overall Capacity (Btu/h): Sensible Heat Ratio (-):

Overall Power Consumption (W) : NET Cooling EER (Btu/h.W): Evaporator Energy Imbalance (\%): REFRIGERANT SIDE CONDITIONS

(EVAPORATOR)

Inlet Temperature $\left({ }^{\circ} \mathrm{F}\right)$ : Exit Temperature $\left({ }^{\circ} \mathrm{F}\right)$ : Inlet Pressure (psia): Exit Pressure (psia): Pressure Drop (psid): Exit Superheat $\left({ }^{\circ} \mathrm{F}\right)$ : Exit Sat. Temperature $\left({ }^{\circ} \mathrm{F}\right)$ : Evaporator Capacity (Btu/h): (CONDENSER)

$\begin{array}{rr}\text { Inlet Temperature }\left({ }^{\circ} \mathrm{F}\right): & 149.24 \\ \text { Exit Temperature }\left({ }^{\circ} \mathrm{F}\right): & 88.18 \\ \text { Inlet Pressure (psia): } & 338.26 \\ \text { Exit Pressure (psia): } & 336.04 \\ \text { Pressure Drop (psid): } & 2.22 \\ \text { Exit Subcooling }\left({ }^{\circ} \mathrm{F}\right): & 1.89 \\ \text { Sat. Temperature }\left({ }^{\circ} \mathrm{F}\right): & 101.58\end{array}$

Inlet sat. Temperature $\left({ }^{\circ} \mathrm{F}\right)$ : (LIQUID LINE AND TXV)

Cond Unit Exit Temp $\left({ }^{\circ} \mathrm{F}\right)$ : Cond Unit Exit Pres (psia): Liq-line Pressure Drop (psid): TXV Upstream Pressure (psia): TXV Pressure Drop (psid): (COMPRESSOR) Temperature Drop $\left({ }^{\circ} \mathrm{F}\right)$ :

Suction Temperature $\left({ }^{\circ} \mathrm{F}\right)$ :

Discharge Temperature $\left({ }^{\circ} \mathrm{F}\right)$ : Suction Pressure (psia):

Discharge Pressure (psia): Discharge Superheat $\left({ }^{\circ} \mathrm{F}\right)$ : Comp Bottom Shell Temp $\left({ }^{\circ} \mathrm{F}\right)$ : Mass Flow Rate $(1 \mathrm{bm} / \mathrm{h})$ : Comp Power Consumption (W) :

Cond Unit Inlet Temp $\left({ }^{\circ} \mathrm{F}\right)$ : Cond Unit Inlet Pres (psia):
30.67

69.93

50.18

81.80

69.93

50.18

50.92

47.46

0.495

0.879

19.00

1040.8

426.70

81.80

96.70

14.90

161.87

3635.3

21640.5

25275.8

0.856

2341.5

10.80

3.17

46.96

56.09

149.05

139.10

9.96

13.36

42.72

6544.2

49.24

8.18

2.22

3680.8

97.36

328.62

10.72

317.90

168.85

1.33

60.75

153.82

136.87

339.27

52.30

108.96

378.71

1752.9

58.16

138.15 
HEAT PUMP FAULT TEST SUMMARY

INDOOR/OUTDOOR CONDITION \#: 04

FAULT TYPE: IMPROPER OUTDOOR AIR FLOW FAULT FAULT LEVEL [\%]: 35.0

\section{RUNNING CONDITIONS}

Barometric Pressure (inHg): Indoor Dry-Bulb Temperature $\left({ }^{\circ} \mathrm{F}\right)$ : Indoor Dew-Point Temperature $\left({ }^{\circ} \mathrm{F}\right)$ : Outdoor Dry-Bulb Temperature $\left({ }^{\circ} \mathrm{F}\right)$ : AIR SIDE CONDITIONS

(INDOOR UNIT)

Inlet Dry-Bulb Temperature $\left({ }^{\circ} \mathrm{F}\right)$ : Inlet Dew-Point Temperature $\left({ }^{\circ} \mathrm{F}\right)$ : Exit Dry-Bulb Temperature $\left({ }^{\circ} \mathrm{F}\right)$ : Exit Dew-Point Temperature $\left({ }^{\circ} \mathrm{F}\right)$ : Inlet Relative Humidity (-): Exit Relative Humidity (-): Evaporator Coil Temp Drop $\left({ }^{\circ} \mathrm{F}\right)$ : Air Flow Rate (SCFM): Fan Power Consumption (W) : (OUTDOOR UNIT)

Inlet Temperature $\left({ }^{\circ} \mathrm{F}\right)$ : Exit Temperature $\left({ }^{\circ} \mathrm{F}\right)$ : Condensing Unit Temp Gain $\left({ }^{\circ} \mathrm{F}\right)$ : Fan Power Consumption (W): (OVERALL PERFORMANCE)

Latent Capacity (Btu/h) : Sensible Capacity (Btu/h): Overall Capacity (Btu/h): Sensible Heat Ratio (-): Overall Power Consumption (W): NET Cooling EER (Btu/h.W): Evaporator Energy Imbalance (\%): REFRIGERANT SIDE CONDITIONS (EVAPORATOR)

Inlet Temperature $\left({ }^{\circ} \mathrm{F}\right)$ : Exit Temperature $\left({ }^{\circ} \mathrm{F}\right)$ : Inlet Pressure (psia): Exit Pressure (psia): Pressure Drop (psid): Exit Superheat $\left({ }^{\circ} \mathrm{F}\right)$ : Exit Sat. Temperature $\left({ }^{\circ} \mathrm{F}\right)$ : Evaporator Capacity (Btu/h): (CONDENSER)

$\begin{array}{rr}\text { Inlet Temperature }\left({ }^{\circ} \mathrm{F}\right): & 156.08 \\ \text { Exit Temperature }\left({ }^{\circ} \mathrm{F}\right): & 86.72 \\ \text { Inlet Pressure (psia): } & 353.75 \\ \text { Exit Pressure (psia): } & 351.66 \\ \text { Pressure Drop (psid): } & 2.10 \\ \text { Exit Subcooling }\left({ }^{\circ} \mathrm{F}\right): & 0.77 \\ \text { Sat. Temperature }\left({ }^{\circ} \mathrm{F}\right): & 104.88\end{array}$

Inlet sat. Temperature $\left({ }^{\circ} \mathrm{F}\right): \quad 104.88$ (LIQUID LINE AND TXV)

Cond Unit Exit Temp $\left({ }^{\circ} \mathrm{F}\right)$ :

Cond Unit Exit Pres (psia): Liq-line Pressure Drop (psid): TXV Upstream Pressure (psia): TXV Pressure Drop (psid): Temperature Drop $\left({ }^{\circ} \mathrm{F}\right)$ : (COMPRESSOR)

Suction Temperature $\left({ }^{\circ} \mathrm{F}\right)$ : Discharge Temperature $\left({ }^{\circ} \mathrm{F}\right)$ : Suction Pressure (psia):

Discharge Pressure (psia): Discharge Superheat $\left({ }^{\circ} \mathrm{F}\right)$ : Comp Bottom Shell Temp $\left({ }^{\circ} \mathrm{F}\right)$ : Mass Flow Rate (l bm/h):

Comp Power Consumption (W) :

Cond Unit Inlet Temp $\left({ }^{\circ} \mathrm{F}\right)$ : Cond Unit Inlet Pres (psia):
30.54

70.03

50.12

81.65

70.03

50.12

51.13

47.67

0.492

0.879

18.90

1037.0

426.11

81.65

96.92

15.26

163.51

3288.1

21452.6

24740.6

0.867

2429.5

10.18

3.92

46.87

58.39

149.87

139.56

10.31

15.48

42.92

6193.3

33592.7

101.67

343.23

12.19

331.04

181.17

2.41

62.92

160.43

137.32

354.58

55.63

112.22

380.75

1839.9

60.47

138.64
HEAT PUMP FAULT TEST SUMMARY

INDOOR/OUTDOOR CONDITION \#: 05

FAULT TYPE: IMPROPER OUTDOOR AIR FLOW FAULT FAULT LEVEL [\%]: 5.0

\section{RUNNING CONDITIONS}

Barometric Pressure (inHg): Indoor Dry-Bulb Temperature $\left({ }^{\circ} \mathrm{F}\right)$ : Indoor Dew-Point Temperature $\left({ }^{\circ} \mathrm{F}\right)$ : Outdoor Dry-Bulb Temperature $\left({ }^{\circ} \mathrm{F}\right)$ : AIR SIDE CONDITIONS (INDOOR UNIT)

Inlet Dry-Bulb Temperature $\left({ }^{\circ} \mathrm{F}\right)$ : Inlet Dew-Point Temperature $\left({ }^{\circ} \mathrm{F}\right)$ : Exit Dry-Bulb Temperature $\left({ }^{\circ} \mathrm{F}\right)$ : Exit Dew-Point Temperature $\left({ }^{\circ} \mathrm{F}\right)$ : Inlet Relative Humidity $(-)$ : Exit Relative Humidity (-) : Evaporator Coil Temp Drop $\left({ }^{\circ} \mathrm{F}\right)$ : Air Flow Rate (SCFM) : Fan Power Consumption (W): (OUTDOOR UNIT)

Inlet Temperature $\left({ }^{\circ} \mathrm{F}\right)$ : Exit Temperature $\left({ }^{\circ} \mathrm{F}\right)$ : Condensing Unit Temp Gain $\left({ }^{\circ} \mathrm{F}\right)$ : Fan Power Consumption (W): (OVERALL PERFORMANCE)

Latent Capacity (Btu/h): Sensible Capacity (Btu/h): Overall Capacity (Btu/h): Sensible Heat Ratio (-):

Overall Power Consumption (W) : NET Cooling EER (Btu/h.W): Evaporator Energy Imbalance (\%): REFRIGERANT SIDE CONDITIONS

(EVAPORATOR)

Inlet Temperature $\left({ }^{\circ} \mathrm{F}\right)$ : Exit Temperature $\left({ }^{\circ} \mathrm{F}\right)$ : Inlet Pressure (psia): Exit Pressure (psia): Pressure Drop (psid): Exit Superheat $\left({ }^{\circ} \mathrm{F}\right)$ : Exit Sat. Temperature $\left({ }^{\circ} \mathrm{F}\right)$ : Evaporator Capacity (Btu/h): (CONDENSER)

Inlet Temperature $\left({ }^{\circ} \mathrm{F}\right)$ : Exit Temperature $\left({ }^{\circ} \mathrm{F}\right)$ : Inlet Pressure (psia): Exit Pressure (psia): Pressure Drop (psid): Exit Subcooling $\left({ }^{\circ} \mathrm{F}\right)$ :

Inlet Sat. Temperature $\left({ }^{\circ} \mathrm{F}\right)$ :

Condenser Capacity (Btu/h): (LIQUID LINE AND TXV)

Cond Unit Exit Temp $\left({ }^{\circ} \mathrm{F}\right)$ : Cond Unit Exit Pres (psia): Liq-line Pressure Drop (psid): TXV Upstream Pressure (psia): TXV Pressure Drop (psid): (COMPRESSOR) Temperature Drop $\left({ }^{\circ} \mathrm{F}\right)$ :

Suction Temperature $\left({ }^{\circ} \mathrm{F}\right)$ :

Discharge Temperature $\left({ }^{\circ} \mathrm{F}\right)$ : Suction Pressure (psia):

Discharge Pressure (psia):

Discharge Superheat $\left({ }^{\circ} \mathrm{F}\right)$ : Comp Bottom Shell Temp $\left({ }^{\circ} \mathrm{F}\right)$ : Mass Flow Rate $(1 \mathrm{bm} / \mathrm{h})$ : Comp Power Consumption (W) :

Cond Unit Inlet Temp $\left({ }^{\circ} \mathrm{F}\right)$ : Cond Unit Inlet Pres (psia):
30.40

80.26

60.41

81.81

80.26

60.41

59.38

56.25

0.508

0.894

20.88

1011.5

417.37

81.81

99.19

17.38

160.21

7482.2

23237.6

30719.7

0.756

2344.1

13.11

3. 62

54.31

65.84

168.99

159.22

9.77

14.97

50.87

32305.8

147.77

90.45

346.28

343.65

2.63

9.17

103.31

39337.9

91.73

336.12

14.10

322.02

153.04

0.63

68.97

151.50

156.77

347.56

48.19

109.72

435.43

1766.5

67.35

158.00 
HEAT PUMP FAULT TEST SUMMARY

INDOOR/OUTDOOR CONDITION \#: 05

FAULT TYPE: IMPROPER OUTDOOR AIR FLOW FAULT FAULT LEVEL [\%]: 10.0

\section{RUNNING CONDITIONS}

Barometric Pressure (inHg): Indoor Dry-Bulb Temperature $\left({ }^{\circ} \mathrm{F}\right)$ : Indoor Dew-Point Temperature $\left({ }^{\circ} \mathrm{F}\right)$ : Outdoor Dry-Bulb Temperature $\left({ }^{\circ} \mathrm{F}\right)$ : AIR SIDE CONDITIONS

(INDOOR UNIT)

Inlet Dry-Bulb Temperature $\left({ }^{\circ} \mathrm{F}\right)$ : Inlet Dew-Point Temperature $\left({ }^{\circ} \mathrm{F}\right)$ : Exit Dry-Bulb Temperature $\left({ }^{\circ} \mathrm{F}\right)$ : Exit Dew-Point Temperature $\left({ }^{\circ} \mathrm{F}\right)$ : Inlet Relative Humidity (-): Exit Relative Humidity (-): Evaporator Coil Temp Drop $\left({ }^{\circ} \mathrm{F}\right)$ : Air Flow Rate (SCFM): Fan Power Consumption (W) : (OUTDOOR UNIT)

Inlet Temperature $\left({ }^{\circ} \mathrm{F}\right)$ : Exit Temperature $\left({ }^{\circ} \mathrm{F}\right)$ : Condensing Unit Temp Gain $\left({ }^{\circ} \mathrm{F}\right)$ : Fan Power Consumption (W): (OVERALL PERFORMANCE)

Latent Capacity (Btu/h): Sensible Capacity (Btu/h): Overall Capacity (Btu/h): Sensible Heat Ratio (-): Overall Power Consumption (W): NET Cooling EER (Btu/h.W): Evaporator Energy Imbalance (\%): REFRIGERANT SIDE CONDITIONS

(EVAPORATOR)

Inlet Temperature $\left({ }^{\circ} \mathrm{F}\right)$ : Exit Temperature $\left({ }^{\circ} \mathrm{F}\right)$ : Inlet Pressure (psia): Exit Pressure (psia): Pressure Drop (psid): Exit Superheat $\left({ }^{\circ} \mathrm{F}\right)$ : Exit Sat. Temperature $\left({ }^{\circ} \mathrm{F}\right)$ : Evaporator Capacity (Btu/h): (CONDENSER)

$\begin{array}{rr}\text { Inlet Temperature }\left({ }^{\circ} \mathrm{F}\right): & 148.06 \\ \text { Exit Temperature }\left({ }^{\circ} \mathrm{F}\right): & 89.79 \\ \text { Inlet Pressure (psia): } & 347.04 \\ \text { Exit Pressure (psia): } & 344.49 \\ \text { Pressure Drop (psid): } & 2.55 \\ \text { Exit Subcooling }\left({ }^{\circ} \mathrm{F}\right): & 8.54\end{array}$

Inlet Sat Temperature $\left({ }^{\circ} \mathrm{F}\right)$ :

Condenser Capacity (Btu/h): (LIQUID LINE AND TXV)

Cond Unit Exit Temp $\left({ }^{\circ} \mathrm{F}\right)$ :

Cond Unit Exit Pres (psia): Liq-line Pressure Drop (psid): TXV Upstream Pressure (psia): TXV Pressure Drop (psid): Temperature Drop $\left({ }^{\circ} \mathrm{F}\right)$ : (COMPRESSOR)

Suction Temperature $\left({ }^{\circ} \mathrm{F}\right)$ : Discharge Temperature $\left({ }^{\circ} \mathrm{F}\right)$ : Suction Pressure (psia):

Discharge Pressure (psia): Discharge Superheat $\left({ }^{\circ} \mathrm{F}\right)$ : Comp Bottom Shell Temp $\left({ }^{\circ} \mathrm{F}\right)$ : Mass Flow Rate (l bm/h):

Comp Power Consumption (W) :

Cond Unit Inlet Temp $\left({ }^{\circ} \mathrm{F}\right)$ : Cond Unit Inlet Pres (psia):
30.39

79.93

60.32

81.75

79.93

60.32

59.44

56.24

0.512

0.891

20.50

1011.9

416.29

81.75

99.05

17.30

160.54

7329.2

22824.4

30153.6

0.757

2348.5

12.84

4.26

54.16

65.20

168.49

158.50

9.99

14.60

50.60

31928.9

48.06

89.79

47.04

2.55

8.54

103.47

38983.0

92.54

336.94

14.20

322.74

154.25

0.57

68.44

151.65

156.04

348.36

48.17

109.80

433.13

1771.7

66.81

157.33
HEAT PUMP FAULT TEST SUMMARY

INDOOR/OUTDOOR CONDITION \#: 05

FAULT TYPE: IMPROPER OUTDOOR AIR FLOW FAULT FAULT LEVEL [\%]: 20.0

\section{RUNNING CONDITIONS}

Barometric Pressure (inHg): Indoor Dry-Bulb Temperature $\left({ }^{\circ} \mathrm{F}\right)$ : Indoor Dew-Point Temperature $\left({ }^{\circ} \mathrm{F}\right)$ : Outdoor Dry-Bulb Temperature $\left({ }^{\circ} \mathrm{F}\right)$ : AIR SIDE CONDITIONS (INDOOR UNIT)

Inlet Dry-Bulb Temperature $\left({ }^{\circ} \mathrm{F}\right)$ : Inlet Dew-Point Temperature $\left({ }^{\circ} \mathrm{F}\right)$ : Exit Dry-Bulb Temperature $\left({ }^{\circ} \mathrm{F}\right)$ : Exit Dew-Point Temperature $\left({ }^{\circ} \mathrm{F}\right)$ : Inlet Relative Humidity $(-)$ : Exit Relative Humidity (-) : Evaporator Coil Temp Drop $\left({ }^{\circ} \mathrm{F}\right)$ : Air Flow Rate (SCFM) : Fan Power Consumption (W): (OUTDOOR UNIT)

Inlet Temperature $\left({ }^{\circ} \mathrm{F}\right)$ : Exit Temperature $\left({ }^{\circ} \mathrm{F}\right)$ : Condensing Unit Temp Gain $\left({ }^{\circ} \mathrm{F}\right)$ : Fan Power Consumption (W): (OVERALL PERFORMANCE)

Latent Capacity (Btu/h) : Sensible Capacity (Btu/h): Overall Capacity (Btu/h): Sensible Heat Ratio (-):

Overall Power Consumption (W) : NET Cooling EER (Btu/h.W): Evaporator Energy Imbalance (\%): REFRIGERANT SIDE CONDITIONS

(EVAPORATOR)

Inlet Temperature $\left({ }^{\circ} \mathrm{F}\right)$ : Exit Temperature $\left({ }^{\circ} \mathrm{F}\right)$ : Inlet Pressure (psia): Exit Pressure (psia): Pressure Drop (psid): Exit Superheat $\left({ }^{\circ} \mathrm{F}\right)$ : Exit Sat. Temperature $\left({ }^{\circ} \mathrm{F}\right)$ : Evaporator Capacity (Btu/h): (CONDENSER)

Inlet Temperature $\left({ }^{\circ} \mathrm{F}\right)$ : Exit Temperature $\left({ }^{\circ} \mathrm{F}\right)$ : Inlet Pressure (psia): Exit Pressure (psia): Pressure Drop (psid): Exit Subcooling $\left({ }^{\circ} \mathrm{F}\right)$ :

Inlet Sat. Temperature $\left({ }^{\circ} \mathrm{F}\right)$ :

Condenser Capacity (Btu/h): (LIQUID LINE AND TXV)

Cond Unit Exit Temp $\left({ }^{\circ} \mathrm{F}\right)$ : Cond Unit Exit Pres (psia): Liq-line Pressure Drop (psid): TXV Upstream Pressure (psia): TXV Pressure Drop (psid): (COMPRESSOR) Temperature Drop $\left({ }^{\circ} \mathrm{F}\right)$ :

Suction Temperature $\left({ }^{\circ} \mathrm{F}\right)$ :

Discharge Temperature $\left({ }^{\circ} \mathrm{F}\right)$ : Suction Pressure (psia):

Discharge Pressure (psia): Discharge Superheat $\left({ }^{\circ} \mathrm{F}\right)$ : Comp Bottom Shell Temp $\left({ }^{\circ} \mathrm{F}\right)$ : Mass Flow Rate $(1 \mathrm{bm} / \mathrm{h})$ : Comp Power Consumption (W) :

Cond Unit Inlet Temp $\left({ }^{\circ} \mathrm{F}\right)$ : Cond Unit Inlet Pres (psia):
30.40 80.17 60.39 81.83

80.17 60.39

59.77

56.60

0.510

0.892

20.40

1011.5

418.75

81.83

98.86

17.03

161.94

6860.1

22712.7

29572.8

0.768

2378.4

12.43

2.82

54.38

68.47

169.75

159.09

10.66

17.65

50.82

30860.6

152.15

88.98

351.90

349.23

2. 67

3.01

104.50

37936.6

98.78

340.19

14.08

326.11

156.36

0.98

71.30

155.72

156.67

353.17

51.22

112.79

429.95

1797.8

69.82

157.90 
HEAT PUMP FAULT TEST SUMMARY

INDOOR/OUTDOOR CONDITION \#: 05

FAULT TYPE: IMPROPER OUTDOOR AIR FLOW FAULT FAULT LEVEL [\%]: 35.0

\section{RUNNING CONDITIONS}

Barometric Pressure (inHg): Indoor Dry-Bulb Temperature $\left({ }^{\circ} \mathrm{F}\right)$ : Indoor Dew-Point Temperature $\left({ }^{\circ} \mathrm{F}\right)$ : Outdoor Dry-Bulb Temperature $\left({ }^{\circ} \mathrm{F}\right)$ : AIR SIDE CONDITIONS

(INDOOR UNIT)

Inlet Dry-Bulb Temperature $\left({ }^{\circ} \mathrm{F}\right)$ : Inlet Dew-Point Temperature $\left({ }^{\circ} \mathrm{F}\right)$ : Exit Dry-Bulb Temperature $\left({ }^{\circ} \mathrm{F}\right)$ : Exit Dew-Point Temperature $\left({ }^{\circ} \mathrm{F}\right)$ : Inlet Relative Humidity (-): Exit Relative Humidity (-): Evaporator Coil Temp Drop $\left({ }^{\circ} \mathrm{F}\right)$ : Air Flow Rate (SCFM): Fan Power Consumption (W): (OUTDOOR UNIT)

Inlet Temperature $\left({ }^{\circ} \mathrm{F}\right)$ : Exit Temperature $\left({ }^{\circ} \mathrm{F}\right)$ : Condensing Unit Temp Gain $\left({ }^{\circ} \mathrm{F}\right)$ : Fan Power Consumption (W): (OVERALL PERFORMANCE)

Latent Capacity (Btu/h): Sensible Capacity (Btu/h): Overall Capacity (Btu/h): Sensible Heat Ratio (-): Overall Power Consumption (W): NET Cooling EER (Btu/h.W): Evaporator Energy Imbalance (\%): REFRIGERANT SIDE CONDITIONS

(EVAPORATOR)

Inlet Temperature $\left({ }^{\circ} \mathrm{F}\right)$ : Exit Temperature $\left({ }^{\circ} \mathrm{F}\right)$ : Inlet Pressure (psia): Exit Pressure (psia): Pressure Drop (psid): Exit Superheat $\left({ }^{\circ} \mathrm{F}\right)$ : Exit Sat. Temperature $\left({ }^{\circ} \mathrm{F}\right)$ : Evaporator Capacity (Btu/h): (CONDENSER)

$\begin{array}{rr}\text { Inlet Temperature }\left({ }^{\circ} \mathrm{F}\right): & 163.41 \\ \text { Exit Temperature }\left({ }^{\circ} \mathrm{F}\right): & 87.54 \\ \text { Inlet Pressure (psia): } & 368.94 \\ \text { Exit Pressure (psia): } & 366.73 \\ \text { Pressure Drop (psid): } & 2.22 \\ \text { Exit Subcooling }\left({ }^{\circ} \mathrm{F}\right): & 0.79 \\ \text { Sat. Temperature }\left({ }^{\circ} \mathrm{F}\right): & 108.02\end{array}$

Inlet Sat. Temperature $\left({ }^{\circ} \mathrm{F}\right): \quad 108.02$

Condenser Capacity (Btu/h): 35699.8

(LIQUID LINE AND TXV)

Cond Unit Exit Temp $\left({ }^{\circ} \mathrm{F}\right): \quad 104.74$

Cond Unit Exit Pres (psia): 357.85

Liq-line Pressure Drop (psid): 12.98

TXV Upstream Pressure (psia): 344.87

TXV Pressure Drop (psid): 180.96 Temperature Drop $\left({ }^{\circ} \mathrm{F}\right): \quad 2.41$

(COMPRESSOR)

Suction Temperature $\left({ }^{\circ} \mathrm{F}\right): \quad 74.01$

Discharge Temperature $\left({ }^{\circ} \mathrm{F}\right)$ :

Suction Pressure (psia):

Discharge Pressure (psia):

Discharge Superheat $\left({ }^{\circ} \mathrm{F}\right)$ :

Comp Bottom Shell Temp $\left({ }^{\circ} \mathrm{F}\right)$ : Mass Flow Rate (l bm/h):

Comp Power Consumption (W):

Cond Unit Inlet Temp $\left({ }^{\circ} \mathrm{F}\right)$ :

Cond Unit Inlet Pres (psia):

167.25

151.29

370.18

59.23

120.64

404.94

1904.9

72.15

152.51
HEAT PUMP FAULT TEST SUMMARY

INDOOR/OUTDOOR CONDITION \#: 05

FAULT TYPE: IMPROPER OUTDOOR AIR FLOW FAULT FAULT LEVEL [\%]: 50.0

RUNNING CONDITIONS

Barometric Pressure (inHg): Indoor Dry-Bulb Temperature $\left({ }^{\circ} \mathrm{F}\right)$ : Indoor Dew-Point Temperature $\left({ }^{\circ} \mathrm{F}\right)$ : Outdoor Dry-Bulb Temperature $\left({ }^{\circ} \mathrm{F}\right)$ : AIR SIDE CONDITIONS (INDOOR UNIT)

Inlet Dry-Bulb Temperature $\left({ }^{\circ} \mathrm{F}\right)$ : Inlet Dew-Point Temperature $\left({ }^{\circ} \mathrm{F}\right)$ : Exit Dry-Bulb Temperature $\left({ }^{\circ} \mathrm{F}\right)$ : Exit Dew-Point Temperature $\left({ }^{\circ} \mathrm{F}\right)$ : Inlet Relative Humidity (-) : Exit Relative Humidity (-) : Evaporator Coil Temp Drop $\left({ }^{\circ} \mathrm{F}\right)$ : Air Flow Rate (SCFM) : Fan Power Consumption (W): (OUTDOOR UNIT)

Inlet Temperature $\left({ }^{\circ} \mathrm{F}\right)$ : Exit Temperature $\left({ }^{\circ} \mathrm{F}\right)$ : Condensing Unit Temp Gain $\left({ }^{\circ} \mathrm{F}\right)$ : Fan Power Consumption (W): (OVERALL PERFORMANCE)

Latent Capacity (Btu/h): Sensible Capacity (Btu/h): Overall Capacity (Btu/h): Sensible Heat Ratio (-) :

Overall Power Consumption (W) : NET Cooling EER (Btu/h.W): Evaporator Energy Imbalance (\%): REFRIGERANT SIDE CONDITIONS

(EVAPORATOR)

Inlet Temperature $\left({ }^{\circ} \mathrm{F}\right)$ : Exit Temperature $\left({ }^{\circ} \mathrm{F}\right)$ : Inlet Pressure (psia): Exit Pressure (psia): Pressure Drop (psid): Exit Superheat $\left({ }^{\circ} \mathrm{F}\right)$ : Exit Sat. Temperature $\left({ }^{\circ} \mathrm{F}\right)$ : Evaporator Capacity (Btu/h): (CONDENSER)

Inlet Temperature $\left({ }^{\circ} \mathrm{F}\right)$ : Exit Temperature $\left({ }^{\circ} \mathrm{F}\right)$ : Inlet Pressure (psia): Exit Pressure (psia): Pressure Drop (psid): Exit Subcooling $\left({ }^{\circ} \mathrm{F}\right)$ :

Inlet Sat. Temperature $\left({ }^{\circ} \mathrm{F}\right)$ :

Condenser Capacity (Btu/h) : (LIQUID LINE AND TXV)

Cond Unit Exit Temp $\left({ }^{\circ} \mathrm{F}\right)$ : Cond Unit Exit Pres (psia): Liq-line Pressure Drop (psid): TXV Upstream Pressure (psia): TXV Pressure Drop (psid): (COMPRESSOR) Temperature Drop $\left({ }^{\circ} \mathrm{F}\right)$ :
30.39

80.20

60.73

81.72

80.20

60.73

61.85

58.38

0.515

0.884

18.34

1009.3

415.13

81.72

97.69

15.97

167.54

4388.1

20391.5

24779.6

0.823

2913.1

8.51

$-0.04$

54.38

71.20

168.74

156.85

11.90

21.24

49.95

25184.2

185.07

87.89

442.19

440.16

2.03

0.45

121.85

33639.6

118.97

429.57

16.32

413.25

244.51

2.43

75.24

187.52

154.62

443.45

65.66

133.68

398.55

2330.4

72.55

155.80 
HEAT PUMP FAULT TEST SUMMARY

INDOOR/OUTDOOR CONDITION \#: 08

FAULT TYPE: IMPROPER OUTDOOR AIR FLOW FAULT FAULT LEVEL [\%]: 10.0

\section{RUNNING CONDITIONS}

Barometric Pressure (inHg): Indoor Dry-Bulb Temperature $\left({ }^{\circ} \mathrm{F}\right)$ : Indoor Dew-Point Temperature $\left({ }^{\circ} \mathrm{F}\right)$ : Outdoor Dry-Bulb Temperature $\left({ }^{\circ} \mathrm{F}\right)$ : AIR SIDE CONDITIONS

(INDOOR UNIT)

Inlet Dry-Bulb Temperature $\left({ }^{\circ} \mathrm{F}\right)$ : Inlet Dew-Point Temperature $\left({ }^{\circ} \mathrm{F}\right)$ : Exit Dry-Bulb Temperature $\left({ }^{\circ} \mathrm{F}\right)$ : Exit Dew-Point Temperature $\left({ }^{\circ} \mathrm{F}\right)$ : Inlet Relative Humidity (-): Exit Relative Humidity (-): Evaporator Coil Temp Drop $\left({ }^{\circ} \mathrm{F}\right)$ : Air Flow Rate (SCFM): Fan Power Consumption (W) : (OUTDOOR UNIT)

Inlet Temperature $\left({ }^{\circ} \mathrm{F}\right)$ : Exit Temperature $\left({ }^{\circ} \mathrm{F}\right)$ : Condensing Unit Temp Gain $\left({ }^{\circ} \mathrm{F}\right)$ : Fan Power Consumption (W) : (OVERALL PERFORMANCE)

Latent Capacity (Btu/h): Sensible Capacity (Btu/h): Overall Capacity (Btu/h): Sensible Heat Ratio (-): Overall Power Consumption (W): NET Cooling EER (Btu/h.W): Evaporator Energy Imbalance (\%): REFRIGERANT SIDE CONDITIONS

(EVAPORATOR)

Inlet Temperature $\left({ }^{\circ} \mathrm{F}\right)$ : Exit Temperature $\left({ }^{\circ} \mathrm{F}\right)$ : Inlet Pressure (psia): Exit Pressure (psia): Pressure Drop (psid): Exit Superheat $\left({ }^{\circ} \mathrm{F}\right)$ : Exit Sat. Temperature $\left({ }^{\circ} \mathrm{F}\right)$ : Evaporator Capacity (Btu/h): (CONDENSER)

$\begin{array}{rr}\text { Inlet Temperature }\left({ }^{\circ} \mathrm{F}\right): & 177.31 \\ \text { Exit Temperature }\left({ }^{\circ} \mathrm{F}\right): & 108.67 \\ \text { Inlet Pressure (psia): } & 422.44 \\ \text { Exit Pressure (psia): } & 420.53 \\ \text { Pressure Drop (psid): } & 1.91 \\ \text { Exit Subcooling }\left({ }^{\circ} \mathrm{F}\right): & 6.38 \\ \text { Sat. Temperature }\left({ }^{\circ} \mathrm{F}\right): & 118.31\end{array}$

Inlet sat. Temperature $\left({ }^{\circ} \mathrm{F}\right): 0118.31$ (LIQUID LINE AND TXV)

Cond Unit Exit Temp $\left({ }^{\circ} \mathrm{F}\right)$ :

Cond Unit Exit Pres (psia): Liq-line Pressure Drop (psid): TXV Upstream Pressure (psia): TXV Pressure Drop (psid): Temperature Drop $\left({ }^{\circ} \mathrm{F}\right)$ : (COMPRESSOR)

Suction Temperature $\left({ }^{\circ} \mathrm{F}\right)$ : Discharge Temperature $\left({ }^{\circ} \mathrm{F}\right)$ : Suction Pressure (psia):

Discharge Pressure (psia): Discharge Superheat $\left({ }^{\circ} \mathrm{F}\right)$ : Comp Bottom Shell Temp $\left({ }^{\circ} \mathrm{F}\right)$ : Mass Flow Rate (l bm/h):

Comp Power Consumption (W) :

Cond Unit Inlet Temp $\left({ }^{\circ} \mathrm{F}\right)$ : Cond Unit Inlet Pres (psia):
29.94

70.06

50.55

99.96

70.06

50.55

52.05

48.48

0.499

0.876

18.02

1012.8

419.71

99.96

115.12

15.17

156.18

2824.2

19979.9

22804.1

0.876

2795.8

8.16

4.25

48.15

56.76

153.37

142.68

10.69

12.52

44.24

24254.4

33127.9

110.31

414.67

11.28

403.39

250.03

1.43

63.60

182.60

140.51

423.63

64.29

126.93

376.55

2219.9

59.46

141.75
HEAT PUMP FAULT TEST SUMMARY

INDOOR/OUTDOOR CONDITION \#: 08

FAULT TYPE: IMPROPER OUTDOOR AIR FLOW FAULT FAULT LEVEL [\%]: 20.0

\section{RUNNING CONDITIONS}

Barometric Pressure (inHg): Indoor Dry-Bulb Temperature $\left({ }^{\circ} \mathrm{F}\right)$ : Indoor Dew-Point Temperature $\left({ }^{\circ} \mathrm{F}\right)$ : Outdoor Dry-Bulb Temperature $\left({ }^{\circ} \mathrm{F}\right)$ : AIR SIDE CONDITIONS

(INDOOR UNIT)

Inlet Dry-Bulb Temperature $\left({ }^{\circ} \mathrm{F}\right)$ :

Inlet Dew-Point Temperature $\left({ }^{\circ} \mathrm{F}\right)$ :

Exit Dry-Bulb Temperature $\left({ }^{\circ} \mathrm{F}\right)$ :

Exit Dew-Point Temperature $\left({ }^{\circ} \mathrm{F}\right)$ :

Inlet Relative Humidity $(-)$ : Exit Relative Humidity (-): Evaporator Coil Temp Drop $\left({ }^{\circ} \mathrm{F}\right)$ : Air Flow Rate (SCFM): Fan Power Consumption (W): (OUTDOOR UNIT)

Inlet Temperature $\left({ }^{\circ} \mathrm{F}\right)$ : Exit Temperature $\left({ }^{\circ} \mathrm{F}\right)$ : Condensing Unit Temp Gain $\left({ }^{\circ} \mathrm{F}\right)$ : Fan Power Consumption (W): (OVERALL PERFORMANCE)

Latent Capacity (Btu/h): Sensible Capacity (Btu/h): Overall Capacity (Btu/h): Sensible Heat Ratio (-):

Overall Power Consumption (W) : NET Cooling EER (Btu/h.W): Evaporator Energy Imbalance (\%): REFRIGERANT SIDE CONDITIONS

(EVAPORATOR)

Inlet Temperature $\left({ }^{\circ} \mathrm{F}\right)$ : Exit Temperature $\left({ }^{\circ} \mathrm{F}\right)$ : Inlet Pressure (psia): Exit Pressure (psia): Pressure Drop (psid): Exit Superheat $\left({ }^{\circ} \mathrm{F}\right)$ : Exit Sat. Temperature $\left({ }^{\circ} \mathrm{F}\right)$ : Evaporator Capacity (Btu/h): (CONDENSER)

Inlet Temperature $\left({ }^{\circ} \mathrm{F}\right)$ : Exit Temperature $\left({ }^{\circ} \mathrm{F}\right)$ : Inlet Pressure (psia): Exit Pressure (psia): Pressure Drop (psid): Exit Subcooling $\left({ }^{\circ} \mathrm{F}\right)$ :

Inlet Sat. Temperature $\left({ }^{\circ} \mathrm{F}\right)$ :

Condenser Capacity (Btu/h): (LIQUID LINE AND TXV)

Cond Unit Exit Temp $\left({ }^{\circ} \mathrm{F}\right)$ : Cond Unit Exit Pres (psia): Liq-line Pressure Drop (psid): TXV Upstream Pressure (psia): TXV Pressure Drop (psid): (COMPRESSOR) Temperature Drop $\left({ }^{\circ} \mathrm{F}\right)$ :

Suction Temperature $\left({ }^{\circ} \mathrm{F}\right)$ :

Discharge Temperature $\left({ }^{\circ} \mathrm{F}\right)$ : Suction Pressure (psia):

Discharge Pressure (psia): Discharge Superheat $\left({ }^{\circ} \mathrm{F}\right)$ : Comp Bottom Shell Temp $\left({ }^{\circ} \mathrm{F}\right)$ : Mass Flow Rate $(1 \mathrm{bm} / \mathrm{h})$ : Comp Power Consumption (W) : Cond Unit Inlet Temp $\left({ }^{\circ} \mathrm{F}\right)$ : Cond Unit Inlet Pres (psia):
29.91

69.93

50.50

100.00

69.93

50.50

52.32

48.74

0.501

0.876

17.62

1011.8

419.29

100.00

115.09

15.09

156.90

2412.2

19517.2

21929.4

0.890

2820.6

7.78

4.16

48.44

57.47

154.58

143.42

11.16

12.93

44.55

23318.3

178.98

107.74

426.68

424.71

1.97

1. 30

119.08

32311.8

115.96

417.78

11.56

406.23

251.64

1.67

64.02

184.58

141.23

427.91

65.50

127.96

377.31

2244.4

60.18

142.43 
HEAT PUMP FAULT TEST SUMMARY

INDOOR/OUTDOOR CONDITION \#: 08

FAULT TYPE: IMPROPER OUTDOOR AIR FLOW FAULT FAULT LEVEL [\%]: 35.0

\section{RUNNING CONDITIONS}

Barometric Pressure (inHg): Indoor Dry-Bulb Temperature $\left({ }^{\circ} \mathrm{F}\right)$ : Indoor Dew-Point Temperature $\left({ }^{\circ} \mathrm{F}\right)$ : Outdoor Dry-Bulb Temperature $\left({ }^{\circ} \mathrm{F}\right)$ : AIR SIDE CONDITIONS

(INDOOR UNIT)

Inlet Dry-Bulb Temperature $\left({ }^{\circ} \mathrm{F}\right)$ : Inlet Dew-Point Temperature $\left({ }^{\circ} \mathrm{F}\right)$ : Exit Dry-Bulb Temperature $\left({ }^{\circ} \mathrm{F}\right)$ : Exit Dew-Point Temperature $\left({ }^{\circ} \mathrm{F}\right)$ : Inlet Relative Humidity (-): Exit Relative Humidity (-): Evaporator Coil Temp Drop $\left({ }^{\circ} \mathrm{F}\right)$ : Air Flow Rate (SCFM) : Fan Power Consumption (W): (OUTDOOR UNIT)

Inlet Temperature $\left({ }^{\circ} \mathrm{F}\right)$ : Exit Temperature $\left({ }^{\circ} \mathrm{F}\right)$ : Condensing Unit Temp Gain $\left({ }^{\circ} \mathrm{F}\right)$ : Fan Power Consumption (W) : (OVERALL PERFORMANCE)

Latent Capacity (Btu/h): Sensible Capacity (Btu/h): Overall Capacity (Btu/h): Sensible Heat Ratio (-): Overall Power Consumption (W): NET Cooling EER (Btu/h.W): Evaporator Energy Imbalance (\%): REFRIGERANT SIDE CONDITIONS (EVAPORATOR)

Inlet Temperature $\left({ }^{\circ} \mathrm{F}\right)$ : Exit Temperature $\left({ }^{\circ} \mathrm{F}\right)$ : Inlet Pressure (psia): Exit Pressure (psia): Pressure Drop (psid): Exit Superheat $\left({ }^{\circ} \mathrm{F}\right)$ : Exit Sat. Temperature $\left({ }^{\circ} \mathrm{F}\right)$ : Evaporator Capacity (Btu/h): (CONDENSER)

$\begin{array}{rr}\text { Inlet Temperature }\left({ }^{\circ} \mathrm{F}\right): & 186.29 \\ \text { Exit Temperature }\left({ }^{\circ} \mathrm{F}\right): & 105.82 \\ \text { Inlet Pressure (psia): } & 446.34 \\ \text { Exit Pressure (psia): } & 444.48 \\ \text { Pressure Drop (psid): } & 1.86 \\ \text { Exit Subcooling }\left({ }^{\circ} \mathrm{F}\right): & 0.40 \\ \text { Sat. Temperature }\left({ }^{\circ} \mathrm{F}\right): & 122.58\end{array}$

Inlet sat. Temperature $\left({ }^{\circ} \mathrm{F}\right):-122.58$ (LIQUID LINE AND TXV)

Cond Unit Exit Temp $\left({ }^{\circ} \mathrm{F}\right)$ :

Cond Unit Exit Pres (psia): Liq-line Pressure Drop (psid): TXV Upstream Pressure (psia): TXV Pressure Drop (psid): Temperature Drop $\left({ }^{\circ} \mathrm{F}\right)$ : (COMPRESSOR)

Suction Temperature $\left({ }^{\circ} \mathrm{F}\right)$ : Discharge Temperature $\left({ }^{\circ} \mathrm{F}\right)$ : Suction Pressure (psia):

Discharge Pressure (psia): Discharge Superheat $\left({ }^{\circ} \mathrm{F}\right)$ : Comp Bottom Shell Temp $\left({ }^{\circ} \mathrm{F}\right)$ : Mass Flow Rate $(1 \mathrm{bm} / \mathrm{h})$ :

Comp Power Consumption (W) :

Cond Unit Inlet Temp $\left({ }^{\circ} \mathrm{F}\right)$ : Cond Unit Inlet Pres (psia):
29.89

70.00

50.53

99.97

70.00

50.53

52.65

49.06

0.500

0.875

17.34

1009.6

418.54

99.97

115.28

15.31

158.53

2023.7

19176.8

21200.5

0.905

2945.7

7.20

3.97

48.79

58.97

156.44

144.36

12.07

14.03

44.94

2511.8

31800.7

120.25

436.51

13.33

423.17

266.74

1.97

65.59

191.44

142.22

447.57

68.85

132.32

375.07

2368.6

61.62

143.44
HEAT PUMP FAULT TEST SUMMARY

INDOOR/OUTDOOR CONDITION \#: 09

FAULT TYPE: IMPROPER OUTDOOR AIR FLOW FAULT FAULT LEVEL [\%]: 5.0

\section{RUNNING CONDITIONS}

Barometric Pressure (inHg): Indoor Dry-Bulb Temperature $\left({ }^{\circ} \mathrm{F}\right)$ : Indoor Dew-Point Temperature $\left({ }^{\circ} \mathrm{F}\right)$ : Outdoor Dry-Bulb Temperature $\left({ }^{\circ} \mathrm{F}\right)$ : AIR SIDE CONDITIONS

(INDOOR UNIT)

Inlet Dry-Bulb Temperature $\left({ }^{\circ} \mathrm{F}\right)$ :

Inlet Dew-Point Temperature $\left({ }^{\circ} \mathrm{F}\right)$ :

Exit Dry-Bulb Temperature $\left({ }^{\circ} \mathrm{F}\right)$ :

Exit Dew-Point Temperature $\left({ }^{\circ} \mathrm{F}\right)$ :

Inlet Relative Humidity $(-)$ : Exit Relative Humidity (-) : Evaporator Coil Temp Drop $\left({ }^{\circ} \mathrm{F}\right)$ : Air Flow Rate (SCFM) : Fan Power Consumption (W): (OUTDOOR UNIT)

Inlet Temperature $\left({ }^{\circ} \mathrm{F}\right)$ : Exit Temperature $\left({ }^{\circ} \mathrm{F}\right)$ : Condensing Unit Temp Gain $\left({ }^{\circ} \mathrm{F}\right)$ : Fan Power Consumption (W): (OVERALL PERFORMANCE)

Latent Capacity (Btu/h): Sensible Capacity (Btu/h): Overall Capacity (Btu/h): Sensible Heat Ratio (-):

Overall Power Consumption (W) : NET Cooling EER (Btu/h.W) : Evaporator Energy Imbalance (\%): REFRIGERANT SIDE CONDITIONS

(EVAPORATOR)

Inlet Temperature $\left({ }^{\circ} \mathrm{F}\right)$ : Exit Temperature $\left({ }^{\circ} \mathrm{F}\right)$ : Inlet Pressure (psia): Exit Pressure (psia): Pressure Drop (psid): Exit Superheat $\left({ }^{\circ} \mathrm{F}\right)$ : Exit Sat. Temperature $\left({ }^{\circ} \mathrm{F}\right)$ : Evaporator Capacity (Btu/h): (CONDENSER)

Inlet Temperature $\left({ }^{\circ} \mathrm{F}\right)$ : Exit Temperature $\left({ }^{\circ} \mathrm{F}\right)$ : Inlet Pressure (psia): Exit Pressure (psia): Pressure Drop (psid): Exit Subcooling ( $\left.{ }^{\circ} \mathrm{F}\right)$ :

Inlet Sat. Temperature $\left({ }^{\circ} \mathrm{F}\right)$ :

Condenser Capacity (Btu/h) : (LIQUID LINE AND TXV)

Cond Unit Exit Temp $\left({ }^{\circ} \mathrm{F}\right)$ : Cond Unit Exit Pres (psia): Liq-line Pressure Drop (psid): TXV Upstream Pressure (psia): TXV Pressure Drop (psid): (COMPRESSOR) Temperature Drop $\left({ }^{\circ} \mathrm{F}\right)$ :

Suction Temperature $\left({ }^{\circ} \mathrm{F}\right)$ :

Discharge Temperature $\left({ }^{\circ} \mathrm{F}\right)$ : Suction Pressure (psia):

Discharge Pressure (psia): Discharge Superheat $\left({ }^{\circ} \mathrm{F}\right)$ : Comp Bottom Shell Temp $\left({ }^{\circ} \mathrm{F}\right)$ : Mass Flow Rate $(1 \mathrm{bm} / \mathrm{h})$ : Comp Power Consumption (W) : Cond Unit Inlet Temp $\left({ }^{\circ} \mathrm{F}\right)$ : Cond Unit Inlet Pres (psia):
30.26

79.99

60.71

99.78

79.99

60.71

60.77

57.40

0.518

0.886

19.23

1005.1

417.67

99.78

116.85

17.07

156.47

6089.6

21275.7

27365.3

0.777

2828.5

9.68

2.65

55.52

65.92

174.23

162.75

11.48

13.70

52.22

28538.3

174.88

109.21

434.24

432.08

2.16

8.81

120.44

37465.2

109.66

424.35

15.16

409.20

234.97

0.90

70.94

179.44

160.45

435.45

59.00

125.32

431.32

2254.3

68.06

161.60 
HEAT PUMP FAULT TEST SUMMARY

INDOOR/OUTDOOR CONDITION \#: 09

FAULT TYPE: IMPROPER OUTDOOR AIR FLOW FAULT FAULT LEVEL [\%]: 10.0

\section{RUNNING CONDITIONS}

Barometric Pressure (inHg): Indoor Dry-Bulb Temperature $\left({ }^{\circ} \mathrm{F}\right)$ : Indoor Dew-Point Temperature $\left({ }^{\circ} \mathrm{F}\right)$ : Outdoor Dry-Bulb Temperature $\left({ }^{\circ} \mathrm{F}\right)$ : AIR SIDE CONDITIONS

(INDOOR UNIT)

Inlet Dry-Bulb Temperature $\left({ }^{\circ} \mathrm{F}\right)$ : Inlet Dew-Point Temperature $\left({ }^{\circ} \mathrm{F}\right)$ : Exit Dry-Bulb Temperature $\left({ }^{\circ} \mathrm{F}\right)$ : Exit Dew-Point Temperature $\left({ }^{\circ} \mathrm{F}\right)$ : Inlet Relative Humidity (-): Exit Relative Humidity (-): Evaporator Coil Temp Drop $\left({ }^{\circ} \mathrm{F}\right)$ : Air Flow Rate (SCFM): Fan Power Consumption (W) : (OUTDOOR UNIT)

Inlet Temperature $\left({ }^{\circ} \mathrm{F}\right)$ : Exit Temperature $\left({ }^{\circ} \mathrm{F}\right)$ : Condensing Unit Temp Gain $\left({ }^{\circ} \mathrm{F}\right)$ : Fan Power Consumption (W): (OVERALL PERFORMANCE)

Latent Capacity (Btu/h): Sensible Capacity (Btu/h): Overall Capacity (Btu/h): Sensible Heat Ratio (-): Overall Power Consumption (W): NET Cooling EER (Btu/h.W): Evaporator Energy Imbalance (\%): REFRIGERANT SIDE CONDITIONS

(EVAPORATOR)

Inlet Temperature $\left({ }^{\circ} \mathrm{F}\right)$ : Exit Temperature $\left({ }^{\circ} \mathrm{F}\right)$ : Inlet Pressure (psia): Exit Pressure (psia): Pressure Drop (psid): Exit Superheat $\left({ }^{\circ} \mathrm{F}\right)$ : Exit Sat. Temperature $\left({ }^{\circ} \mathrm{F}\right)$ : Evaporator Capacity (Btu/h): (CONDENSER)

$$
\begin{array}{rr}
\text { Inlet Temperature }\left({ }^{\circ} \mathrm{F}\right): & 175.51 \\
\text { Exit Temperature }\left({ }^{\circ} \mathrm{F}\right): & 108.63 \\
\text { Inlet Pressure (psia): } & 435.43 \\
\text { Exit Pressure (psia): } & 433.27 \\
\text { Pressure Drop }(\mathrm{psid}): & 2.16 \\
\text { Exit Subcooling }\left({ }^{\circ} \mathrm{F}\right): & 7.95 \\
\text { Inlet Sat. Temperature }\left({ }^{\circ} \mathrm{F}\right): & 120.66
\end{array}
$$
Condenser Capacity (Btu/h): (LIQUID LINE AND TXV)

Cond Unit Exit Temp $\left({ }^{\circ} \mathrm{F}\right)$ : Cond Unit Exit Pres (psia): Liq-line Pressure Drop (psid): TXV Upstream Pressure (psia): TXV Pressure Drop (psid): Temperature Drop $\left({ }^{\circ} \mathrm{F}\right)$ : (COMPRESSOR)

Suction Temperature $\left({ }^{\circ} \mathrm{F}\right)$ : Discharge Temperature $\left({ }^{\circ} \mathrm{F}\right)$ : Suction Pressure (psia):

Discharge Pressure (psia): Discharge Superheat $\left({ }^{\circ} \mathrm{F}\right)$ : Comp Bottom Shell Temp $\left({ }^{\circ} \mathrm{F}\right)$ : Mass Flow Rate (l bm/h):

Comp Power Consumption (W) :

Cond Unit Inlet Temp $\left({ }^{\circ} \mathrm{F}\right)$ : Cond Unit Inlet Pres (psia):
30.25

79.95

60.81

99.72

79.95

60.81

60.82

57.51

0.521

0.888

19.13

1003.6

99.72

116.89

17.17

156.59

6082.3

21139.2

27221.5

0.777

2836.8

9.60

2.78

55.57

66.15

174.75

163.13

11.63

13.79

52.37

28427.6

37389.9

110.72

425.47

15.30

410.17

235.41

1.02

71.11

179.86

160.76

436.61

59.21

125.75

432.56

2263.6

68.29

161.95
416.60
HEAT PUMP FAULT TEST SUMMARY

INDOOR/OUTDOOR CONDITION \#: 09

FAULT TYPE: IMPROPER OUTDOOR AIR FLOW FAULT FAULT LEVEL [\%]: 20.0

\section{RUNNING CONDITIONS}

Barometric Pressure (inHg): Indoor Dry-Bulb Temperature $\left({ }^{\circ} \mathrm{F}\right)$ : Indoor Dew-Point Temperature $\left({ }^{\circ} \mathrm{F}\right)$ : Outdoor Dry-Bulb Temperature $\left({ }^{\circ} \mathrm{F}\right)$ : AIR SIDE CONDITIONS (INDOOR UNIT)

Inlet Dry-Bulb Temperature $\left({ }^{\circ} \mathrm{F}\right)$ : Inlet Dew-Point Temperature $\left({ }^{\circ} \mathrm{F}\right)$ : Exit Dry-Bulb Temperature $\left({ }^{\circ} \mathrm{F}\right)$ : Exit Dew-Point Temperature $\left({ }^{\circ} \mathrm{F}\right)$ : Inlet Relative Humidity $(-)$ : Exit Relative Humidity (-) : Evaporator Coil Temp Drop $\left({ }^{\circ} \mathrm{F}\right)$ : Air Flow Rate (SCFM) : Fan Power Consumption (W) : (OUTDOOR UNIT)

Inlet Temperature $\left({ }^{\circ} \mathrm{F}\right)$ : Exit Temperature $\left({ }^{\circ} \mathrm{F}\right)$ : Condensing Unit Temp Gain $\left({ }^{\circ} \mathrm{F}\right)$ : Fan Power Consumption (W): (OVERALL PERFORMANCE)

Latent Capacity (Btu/h): Sensible Capacity (Btu/h): Overall Capacity (Btu/h): Sensible Heat Ratio (-):

Overall Power Consumption (W) : NET Cooling EER (Btu/h.W): Evaporator Energy Imbalance (\%): REFRIGERANT SIDE CONDITIONS

(EVAPORATOR)

Inlet Temperature $\left({ }^{\circ} \mathrm{F}\right)$ : Exit Temperature $\left({ }^{\circ} \mathrm{F}\right)$ : Inlet Pressure (psia): Exit Pressure (psia): Pressure Drop (psid): Exit Superheat $\left({ }^{\circ} \mathrm{F}\right)$ : Exit Sat. Temperature $\left({ }^{\circ} \mathrm{F}\right)$ : Evaporator Capacity (Btu/h): (CONDENSER)

Inlet Temperature $\left({ }^{\circ} \mathrm{F}\right)$ : Exit Temperature $\left({ }^{\circ} \mathrm{F}\right)$ : Inlet Pressure (psia): Exit Pressure (psia): Pressure Drop (psid): Exit Subcooling $\left({ }^{\circ} \mathrm{F}\right)$ :

Inlet Sat. Temperature $\left({ }^{\circ} \mathrm{F}\right)$ :

Condenser Capacity (Btu/h): (LIQUID LINE AND TXV)

Cond Unit Exit Temp $\left({ }^{\circ} \mathrm{F}\right)$ : Cond Unit Exit Pres (psia): Liq-line Pressure Drop (psid): TXV Upstream Pressure (psia): TXV Pressure Drop (psid): (COMPRESSOR) Temperature Drop $\left({ }^{\circ} \mathrm{F}\right)$ :

Suction Temperature $\left({ }^{\circ} \mathrm{F}\right)$ :

Discharge Temperature $\left({ }^{\circ} \mathrm{F}\right)$ : Suction Pressure (psia):

Discharge Pressure (psia): Discharge Superheat $\left({ }^{\circ} \mathrm{F}\right)$ : Comp Bottom Shell Temp $\left({ }^{\circ} \mathrm{F}\right)$ : Mass Flow Rate $(1 \mathrm{bm} / \mathrm{h})$ : Comp Power Consumption (W) :

Cond Unit Inlet Temp $\left({ }^{\circ} \mathrm{F}\right)$ : Cond Unit Inlet Pres (psia):
30.48

80.19

60.24

100.15

80.19

60.24

60.90

57.63

0.507

0.890

19.28

1012.3

417.42

100.15

117.00

16.85

158.47

4786.5

21487.1

26273.5

0.818

2877.6

9.13

1.58

56.48

66.67

176.46

164.16

12.30

13.91

52.76

27120.4

177.68

108.27

442.08

439.81

2.27

2. 32

121.83

36262.1

117.30

430.69

15.93

414.76

238.30

1.45

71.45

182.24

161.82

443.26

60.42

127.19

433.37

2301.7

68.75

163.01 


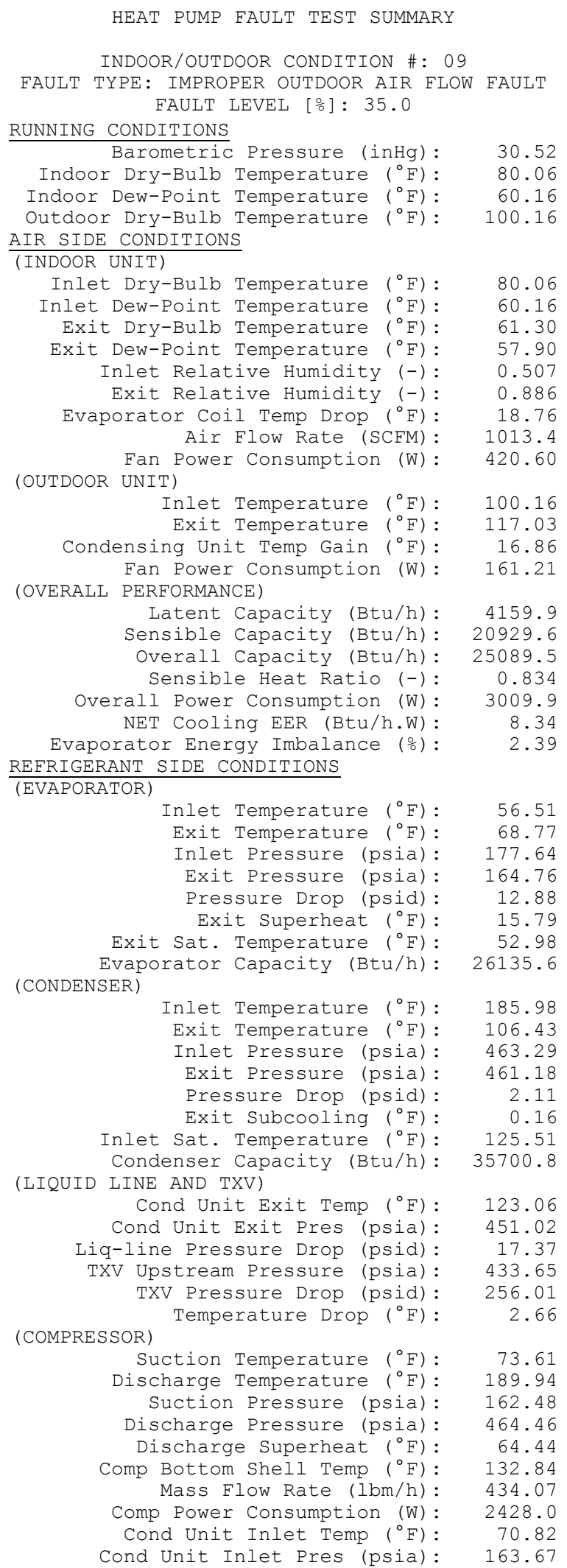




\section{D.4 Improper Indoor Air Flow Fault Tests}

Table D.4. List of raw data for improper indoor air flow fault tests

\begin{tabular}{|c|c|c|c|c|c|}
\hline \multirow{2}{*}{$\begin{array}{c}\text { Test } \\
\text { condition \# }\end{array}$} & \multicolumn{3}{|c|}{ Nominal chamber condition } & \multirow{2}{*}{ Fault Type } & \multirow{2}{*}{$\begin{array}{c}\text { Fault level } \\
(\%)\end{array}$} \\
\hline & $T_{I D}\left({ }^{\circ} \mathrm{F}\right)$ & $\phi_{I D}(\%)$ & $T_{O D}\left({ }^{\circ} \mathrm{F}\right)$ & & \\
\hline 4 & 70 & 50 & 82 & $\mathrm{EF}$ & 13.0 \\
\hline 4 & 70 & 50 & 82 & $\mathrm{EF}$ & 22.5 \\
\hline 4 & 70 & 50 & 82 & $\mathrm{EF}$ & 31.4 \\
\hline 5 & 80 & 50 & 82 & $\mathrm{EF}$ & 5.9 \\
\hline 5 & 80 & 50 & 82 & $\mathrm{EF}$ & 11.0 \\
\hline 5 & 80 & 50 & 82 & $\mathrm{EF}$ & 20.7 \\
\hline 5 & 80 & 50 & 82 & $\mathrm{EF}$ & 30.8 \\
\hline 8 & 70 & 50 & 100 & $\mathrm{EF}$ & 11.8 \\
\hline 8 & 70 & 50 & 100 & $\mathrm{EF}$ & 21.1 \\
\hline 8 & 70 & 50 & 100 & $\mathrm{EF}$ & 33.1 \\
\hline 9 & 80 & 50 & 100 & $\mathrm{EF}$ & 5.7 \\
\hline 9 & 80 & 50 & 100 & $\mathrm{EF}$ & 10.6 \\
\hline 9 & 80 & 50 & 100 & $\mathrm{EF}$ & 20.9 \\
\hline 9 & 80 & 50 & 100 & $\mathrm{EF}$ & 30.5 \\
\hline 12 & 70 & dry & 82 & $\mathrm{EF}$ & 14.3 \\
\hline 12 & 70 & dry & 82 & $\mathrm{EF}$ & 24.1 \\
\hline 12 & 70 & dry & 82 & $\mathrm{EF}$ & 34.6 \\
\hline 13 & 80 & dry & 82 & $\mathrm{EF}$ & 6.1 \\
\hline 13 & 80 & dry & 82 & $\mathrm{EF}$ & 11.0 \\
\hline 13 & 80 & dry & 82 & $\mathrm{EF}$ & 21.1 \\
\hline 13 & 80 & dry & 82 & $\mathrm{EF}$ & 30.9 \\
\hline
\end{tabular}


HEAT PUMP FAULT TEST SUMMARY

INDOOR/OUTDOOR CONDITION \#: 04

FAULT TYPE: IMPROPER INDOOR AIR FLOW FAULT FAULT LEVEL [\%]: 13.0

\section{RUNNING CONDITIONS}

Barometric Pressure (inHg): Indoor Dry-Bulb Temperature $\left({ }^{\circ} \mathrm{F}\right)$ : Indoor Dew-Point Temperature $\left({ }^{\circ} \mathrm{F}\right)$ : Outdoor Dry-Bulb Temperature $\left({ }^{\circ} \mathrm{F}\right)$ : AIR SIDE CONDITIONS

(INDOOR UNIT)

Inlet Dry-Bulb Temperature $\left({ }^{\circ} \mathrm{F}\right)$ : Inlet Dew-Point Temperature $\left({ }^{\circ} \mathrm{F}\right)$ : Exit Dry-Bulb Temperature $\left({ }^{\circ} \mathrm{F}\right)$ : Exit Dew-Point Temperature $\left({ }^{\circ} \mathrm{F}\right)$ : Inlet Relative Humidity (-): Exit Relative Humidity (-): Evaporator Coil Temp Drop $\left({ }^{\circ} \mathrm{F}\right)$ : Air Flow Rate (SCFM): Fan Power Consumption (W): (OUTDOOR UNIT)

Inlet Temperature $\left({ }^{\circ} \mathrm{F}\right)$ : Exit Temperature $\left({ }^{\circ} \mathrm{F}\right)$ : Condensing Unit Temp Gain $\left({ }^{\circ} \mathrm{F}\right)$ : Fan Power Consumption (W) : (OVERALL PERFORMANCE)

Latent Capacity (Btu/h): Sensible Capacity (Btu/h): Overall Capacity (Btu/h): Sensible Heat Ratio (-): Overall Power Consumption (W): NET Cooling EER (Btu/h.W): Evaporator Energy Imbalance (\%): REFRIGERANT SIDE CONDITIONS (EVAPORATOR)

Inlet Temperature $\left({ }^{\circ} \mathrm{F}\right)$ : Exit Temperature $\left({ }^{\circ} \mathrm{F}\right)$ : Inlet Pressure (psia): Exit Pressure (psia): Pressure Drop (psid): Exit Superheat $\left({ }^{\circ} \mathrm{F}\right)$ : Exit Sat. Temperature $\left({ }^{\circ} \mathrm{F}\right)$ : Evaporator Capacity (Btu/h): (CONDENSER)

$\begin{array}{rr}\text { Inlet Temperature }\left({ }^{\circ} \mathrm{F}\right): & 146.75 \\ \text { Exit Temperature }\left({ }^{\circ} \mathrm{F}\right): & 89.16 \\ \text { Inlet Pressure (psia): } & 329.92 \\ \text { Exit Pressure (psia): } & 327.75 \\ \text { Pressure Drop (psid): } & 2.17 \\ \text { Exit Subcooling }\left({ }^{\circ} \mathrm{F}\right): & 7.97 \\ \text { Sat. Temperature }\left({ }^{\circ} \mathrm{F}\right): & 99.75\end{array}$

Inlet Sat. Temperature $\left({ }^{\circ} \mathrm{F}\right)$ : (LIQUID LINE AND TXV)

Cond Unit Exit Temp $\left({ }^{\circ} \mathrm{F}\right)$ :

Cond Unit Exit Pres (psia): Liq-line Pressure Drop (psid): TXV Upstream Pressure (psia): TXV Pressure Drop (psid): Temperature Drop $\left({ }^{\circ} \mathrm{F}\right)$ : (COMPRESSOR)

Suction Temperature $\left({ }^{\circ} \mathrm{F}\right)$ : Discharge Temperature $\left({ }^{\circ} \mathrm{F}\right)$ : Suction Pressure (psia):

Discharge Pressure (psia): Discharge Superheat $\left({ }^{\circ} \mathrm{F}\right)$ : Comp Bottom Shell Temp $\left({ }^{\circ} \mathrm{F}\right)$ : Mass Flow Rate (l bm/h):

Comp Power Consumption (W) :

Cond Unit Inlet Temp $\left({ }^{\circ} \mathrm{F}\right)$ : Cond Unit Inlet Pres (psia):
30.66

70.10

50.32

81.48

70.10

50.32

49.21

45.81

0.494

0.880

20.89

896.8

397.43

81.48

96.03

14.55

160.92

5062.2

20497.6

25559.7

0.802

2272.0

11.25

4. 10

45.28

54.28

144.63

135.93

8.70

12.92

41.36

27066.9

33922.2

89.79

321.99

9.89

312.10

167.47

0.92

59.44

151.29

133.70

331.02

51.57

108.02

369.19

1713.6

56.47

135.07
HEAT PUMP FAULT TEST SUMMARY

INDOOR/OUTDOOR CONDITION \#: 04

FAULT TYPE: IMPROPER INDOOR AIR FLOW FAULT FAULT LEVEL [\%]: 22.5

\section{RUNNING CONDITIONS}

Barometric Pressure (inHg): Indoor Dry-Bulb Temperature $\left({ }^{\circ} \mathrm{F}\right)$ : Indoor Dew-Point Temperature $\left({ }^{\circ} \mathrm{F}\right)$ : Outdoor Dry-Bulb Temperature $\left({ }^{\circ} \mathrm{F}\right)$ : AIR SIDE CONDITIONS

(INDOOR UNIT)

Inlet Dry-Bulb Temperature $\left({ }^{\circ} \mathrm{F}\right)$ :

Inlet Dew-Point Temperature $\left({ }^{\circ} \mathrm{F}\right)$ :

Exit Dry-Bulb Temperature $\left({ }^{\circ} \mathrm{F}\right)$ :

Exit Dew-Point Temperature $\left({ }^{\circ} \mathrm{F}\right)$ :

Inlet Relative Humidity $(-)$ : Exit Relative Humidity (-): Evaporator Coil Temp Drop $\left({ }^{\circ} \mathrm{F}\right)$ : Air Flow Rate (SCFM): Fan Power Consumption (W): (OUTDOOR UNIT)

Inlet Temperature $\left({ }^{\circ} \mathrm{F}\right)$ : Exit Temperature $\left({ }^{\circ} \mathrm{F}\right)$ :

Condensing Unit Temp Gain $\left({ }^{\circ} \mathrm{F}\right)$ : Fan Power Consumption (W): (OVERALL PERFORMANCE)

Latent Capacity (Btu/h): Sensible Capacity (Btu/h): Overall Capacity (Btu/h): Sensible Heat Ratio (-):

Overall Power Consumption (W) : NET Cooling EER (Btu/h.W): Evaporator Energy Imbalance (\%): REFRIGERANT SIDE CONDITIONS

(EVAPORATOR)

Inlet Temperature $\left({ }^{\circ} \mathrm{F}\right)$ : Exit Temperature $\left({ }^{\circ} \mathrm{F}\right)$ : Inlet Pressure (psia): Exit Pressure (psia): Pressure Drop (psid): Exit Superheat $\left({ }^{\circ} \mathrm{F}\right)$ : Exit Sat. Temperature $\left({ }^{\circ} \mathrm{F}\right)$ : Evaporator Capacity (Btu/h): (CONDENSER)

$\begin{array}{rr}\text { Inlet Temperature }\left({ }^{\circ} \mathrm{F}\right): & 146.89 \\ \text { Exit Temperature }\left({ }^{\circ} \mathrm{F}\right): & 89.15 \\ \text { Inlet Pressure (psia): } & 328.79 \\ \text { Exit Pressure (psia): } & 326.68 \\ \text { Pressure Drop (psid): } & 2.11 \\ \text { Exit Subcooling }\left({ }^{\circ} \mathrm{F}\right): & 7.84 \\ \text { Sat. Temperature }\left({ }^{\circ} \mathrm{F}\right): & 99.50\end{array}$

Inlet sat. Temperature $\left({ }^{\circ} \mathrm{F}\right)$ : (LIQUID LINE AND TXV)

Cond Unit Exit Temp $\left({ }^{\circ} \mathrm{F}\right)$ : Cond Unit Exit Pres (psia): Liq-line Pressure Drop (psid): TXV Upstream Pressure (psia): TXV Pressure Drop (psid): (COMPRESSOR) Temperature Drop $\left({ }^{\circ} \mathrm{F}\right)$ :

Suction Temperature $\left({ }^{\circ} \mathrm{F}\right)$ :

Discharge Temperature $\left({ }^{\circ} \mathrm{F}\right)$ : Suction Pressure (psia):

Discharge Pressure (psia): Discharge Superheat $\left({ }^{\circ} \mathrm{F}\right)$ : Comp Bottom Shell Temp $\left({ }^{\circ} \mathrm{F}\right)$ : Mass Flow Rate $(1 \mathrm{bm} / \mathrm{h})$ : Comp Power Consumption (W) :

Cond Unit Inlet Temp $\left({ }^{\circ} \mathrm{F}\right)$ : Cond Unit Inlet Pres (psia):
30.66

69.88

50.36

81.51

69.88

50.36

47.94

44.60

0.499

0.881

21.94

798.5

379.53

81.51

95.83

14.32

161.02

5654.4

19161.0

24815.4

0.772

2252.2

11.02

5.39

44.19

53.03

142.16

133.63

8.54

12.68

40.36

6629.7

15

2.11

89.73

321.11

9.51

311.60

169.44

1.05

58.45

151.58

131.42

329.90

52.10

108.11

363.28

1711.6

55.41

132.74 
HEAT PUMP FAULT TEST SUMMARY

INDOOR/OUTDOOR CONDITION \#: 04

FAULT TYPE: IMPROPER INDOOR AIR FLOW FAULT FAULT LEVEL [\%]: 31.4

\section{RUNNING CONDITIONS}

Barometric Pressure (inHg): Indoor Dry-Bulb Temperature $\left({ }^{\circ} \mathrm{F}\right)$ : Indoor Dew-Point Temperature $\left({ }^{\circ} \mathrm{F}\right)$ : Outdoor Dry-Bulb Temperature $\left({ }^{\circ} \mathrm{F}\right)$ : AIR SIDE CONDITIONS

(INDOOR UNIT)

Inlet Dry-Bulb Temperature $\left({ }^{\circ} \mathrm{F}\right)$ : Inlet Dew-Point Temperature $\left({ }^{\circ} \mathrm{F}\right)$ : Exit Dry-Bulb Temperature $\left({ }^{\circ} \mathrm{F}\right)$ : Exit Dew-Point Temperature $\left({ }^{\circ} \mathrm{F}\right)$ : Inlet Relative Humidity (-): Exit Relative Humidity (-): Evaporator Coil Temp Drop $\left({ }^{\circ} \mathrm{F}\right)$ : Air Flow Rate (SCFM): Fan Power Consumption (W) : (OUTDOOR UNIT)

Inlet Temperature $\left({ }^{\circ} \mathrm{F}\right)$ : Exit Temperature $\left({ }^{\circ} \mathrm{F}\right)$ : Condensing Unit Temp Gain $\left({ }^{\circ} \mathrm{F}\right)$ : Fan Power Consumption (W): (OVERALL PERFORMANCE)

Latent Capacity (Btu/h): Sensible Capacity (Btu/h): Overall Capacity (Btu/h): Sensible Heat Ratio (-): Overall Power Consumption (W): NET Cooling EER (Btu/h.W): Evaporator Energy Imbalance (\%): REFRIGERANT SIDE CONDITIONS (EVAPORATOR)

Inlet Temperature $\left({ }^{\circ} \mathrm{F}\right)$ : Exit Temperature $\left({ }^{\circ} \mathrm{F}\right)$ : Inlet Pressure (psia): Exit Pressure (psia): Pressure Drop (psid): Exit Superheat $\left({ }^{\circ} \mathrm{F}\right)$ : Exit Sat. Temperature $\left({ }^{\circ} \mathrm{F}\right)$ : Evaporator Capacity (Btu/h): (CONDENSER)

$$
\begin{array}{rr}
\text { Inlet Temperature }\left({ }^{\circ} \mathrm{F}\right): & 147.15 \\
\text { Exit Temperature }\left({ }^{\circ} \mathrm{F}\right): & 89.05 \\
\text { Inlet Pressure (psia): } & 327.38 \\
\text { Exit Pressure }(\mathrm{psia}): & 325.31 \\
\text { Pressure Drop }(\mathrm{psid}): & 2.07 \\
\text { Exit Subcooling }\left({ }^{\circ} \mathrm{F}\right): & 7.68 \\
\text { Inlet Sat. Temperature }\left({ }^{\circ} \mathrm{F}\right): & 99.19
\end{array}
$$

Condenser Capacity (Btu/h): (LIQUID LINE AND TXV)

Cond Unit Exit Temp $\left({ }^{\circ} \mathrm{F}\right)$ :

Cond Unit Exit Pres (psia): Liq-line Pressure Drop (psid): TXV Upstream Pressure (psia): TXV Pressure Drop (psid): Temperature Drop $\left({ }^{\circ} \mathrm{F}\right)$ : (COMPRESSOR)

Suction Temperature $\left({ }^{\circ} \mathrm{F}\right)$ : Discharge Temperature $\left({ }^{\circ} \mathrm{F}\right)$ : Suction Pressure (psia):

Discharge Pressure (psia): Discharge Superheat $\left({ }^{\circ} \mathrm{F}\right)$ : Comp Bottom Shell Temp $\left({ }^{\circ} \mathrm{F}\right)$ : Mass Flow Rate $(1 \mathrm{bm} / \mathrm{h})$ : Comp Power Consumption (W) :

Cond Unit Inlet Temp $\left({ }^{\circ} \mathrm{F}\right)$ : Cond Unit Inlet Pres (psia):
30.67

69.88

50.36

69.88

50.36

43.28

0.499

0.882

706.7

366.17

81.53

14.08

161.69

6020.6

18009.3

0.749

2235.3

10.75
6.41

43.09

1.85
39.58

131.19

8.39

12.57
39.27

6067.7

32821.7

89.62

319.92

9.05

310.87

171.29

1.02

57.50

151.99

128.97

328.45

52.83

108.28

355.70

1707.4

54.24

130.31
HEAT PUMP FAULT TEST SUMMARY

INDOOR/OUTDOOR CONDITION \#: 05

FAULT TYPE: IMPROPER INDOOR AIR FLOW FAULT FAULT LEVEL [\%]: 5.9

\section{RUNNING CONDITIONS}

Barometric Pressure (inHg): Indoor Dry-Bulb Temperature $\left({ }^{\circ} \mathrm{F}\right)$ : Indoor Dew-Point Temperature $\left({ }^{\circ} \mathrm{F}\right)$ : Outdoor Dry-Bulb Temperature $\left({ }^{\circ} \mathrm{F}\right)$ : AIR SIDE CONDITIONS

(INDOOR UNIT)

Inlet Dry-Bulb Temperature $\left({ }^{\circ} \mathrm{F}\right)$ :

Inlet Dew-Point Temperature $\left({ }^{\circ} \mathrm{F}\right)$ :

Exit Dry-Bulb Temperature $\left({ }^{\circ} \mathrm{F}\right)$ :

Exit Dew-Point Temperature $\left({ }^{\circ} \mathrm{F}\right)$ :

Inlet Relative Humidity $(-)$ : Exit Relative Humidity (-): Evaporator Coil Temp Drop $\left({ }^{\circ} \mathrm{F}\right)$ : Air Flow Rate (SCFM): Fan Power Consumption (W): (OUTDOOR UNIT)

Inlet Temperature $\left({ }^{\circ} \mathrm{F}\right)$ : Exit Temperature $\left({ }^{\circ} \mathrm{F}\right)$ :

Condensing Unit Temp Gain $\left({ }^{\circ} \mathrm{F}\right)$ : Fan Power Consumption (W): (OVERALL PERFORMANCE)

Latent Capacity (Btu/h): Sensible Capacity (Btu/h): Overall Capacity (Btu/h): Sensible Heat Ratio (-):

Overall Power Consumption (W) : NET Cooling EER (Btu/h.W): Evaporator Energy Imbalance (\%): REFRIGERANT SIDE CONDITIONS

(EVAPORATOR)

Inlet Temperature $\left({ }^{\circ} \mathrm{F}\right)$ : Exit Temperature $\left({ }^{\circ} \mathrm{F}\right)$ : Inlet Pressure (psia): Exit Pressure (psia): Pressure Drop (psid): Exit Superheat $\left({ }^{\circ} \mathrm{F}\right)$ : Exit Sat. Temperature $\left({ }^{\circ} \mathrm{F}\right)$ : Evaporator Capacity (Btu/h): (CONDENSER)

Inlet Temperature $\left({ }^{\circ} \mathrm{F}\right)$ : Exit Temperature $\left({ }^{\circ} \mathrm{F}\right)$ : Inlet Pressure (psia): Exit Pressure (psia): Pressure Drop (psid): Exit Subcooling $\left({ }^{\circ} \mathrm{F}\right)$ :

Inlet Sat. Temperature $\left({ }^{\circ} \mathrm{F}\right)$ : Condenser Capacity (Btu/h): (LIQUID LINE AND TXV)

Cond Unit Exit Temp $\left({ }^{\circ} \mathrm{F}\right)$ : Cond Unit Exit Pres (psia): Liq-line Pressure Drop (psid): TXV Upstream Pressure (psia): TXV Pressure Drop (psid): (COMPRESSOR) Temperature Drop $\left({ }^{\circ} \mathrm{F}\right)$ :

Suction Temperature $\left({ }^{\circ} \mathrm{F}\right)$ :

Discharge Temperature $\left({ }^{\circ} \mathrm{F}\right)$ : Suction Pressure (psia): Discharge Pressure (psia): Discharge Superheat $\left({ }^{\circ} \mathrm{F}\right)$ : Comp Bottom Shell Temp $\left({ }^{\circ} \mathrm{F}\right)$ : Mass Flow Rate $(1 \mathrm{bm} / \mathrm{h})$ : Comp Power Consumption (W) : Cond Unit Inlet Temp $\left({ }^{\circ} \mathrm{F}\right)$ : Cond Unit Inlet Pres (psia):
30.45 79.78 60.42 81.82

79.78

60.42

58.63

55.51

0.517

0.894

21.15

951.7

402.79

81.82

99.00

17.18

159.33

8202.1

22147.6

30349.7

0.730

2322.4

13.07

3.84

53.90

64.95

167.80

158.04

9.76

14.53

50.42

31980.4

147.18

90.77

344.89

342.27

2.63

8.60

103.01

38943.4

92.01

334.82

13.92

320.91

153.11

0.71

68.23

150.93

155.60

346.12

47.92

109.27

432.14

1760.3

66.51

156.83 
HEAT PUMP FAULT TEST SUMMARY

INDOOR/OUTDOOR CONDITION \#: 05

FAULT TYPE: IMPROPER INDOOR AIR FLOW FAULT FAULT LEVEL [\%]: 11.0

\section{RUNNING CONDITIONS}

Barometric Pressure (inHg): Indoor Dry-Bulb Temperature $\left({ }^{\circ} \mathrm{F}\right)$ : Indoor Dew-Point Temperature $\left({ }^{\circ} \mathrm{F}\right)$ : Outdoor Dry-Bulb Temperature $\left({ }^{\circ} \mathrm{F}\right)$ : AIR SIDE CONDITIONS

(INDOOR UNIT)

Inlet Dry-Bulb Temperature $\left({ }^{\circ} \mathrm{F}\right)$ : Inlet Dew-Point Temperature $\left({ }^{\circ} \mathrm{F}\right)$ : Exit Dry-Bulb Temperature $\left({ }^{\circ} \mathrm{F}\right)$ : Exit Dew-Point Temperature $\left({ }^{\circ} \mathrm{F}\right)$ : Inlet Relative Humidity (-): Exit Relative Humidity (-): Evaporator Coil Temp Drop $\left({ }^{\circ} \mathrm{F}\right)$ : Air Flow Rate (SCFM): Fan Power Consumption (W) : (OUTDOOR UNIT)

Inlet Temperature $\left({ }^{\circ} \mathrm{F}\right)$ : Exit Temperature $\left({ }^{\circ} \mathrm{F}\right)$ : Condensing Unit Temp Gain $\left({ }^{\circ} \mathrm{F}\right)$ : Fan Power Consumption (W) : (OVERALL PERFORMANCE)

Latent Capacity (Btu/h): Sensible Capacity (Btu/h): Overall Capacity (Btu/h): Sensible Heat Ratio (-): Overall Power Consumption (W): NET Cooling EER (Btu/h.W): Evaporator Energy Imbalance (\%): REFRIGERANT SIDE CONDITIONS (EVAPORATOR)

Inlet Temperature $\left({ }^{\circ} \mathrm{F}\right)$ : Exit Temperature $\left({ }^{\circ} \mathrm{F}\right)$ : Inlet Pressure (psia): Exit Pressure (psia): Pressure Drop (psid): Exit Superheat $\left({ }^{\circ} \mathrm{F}\right)$ : Exit Sat. Temperature $\left({ }^{\circ} \mathrm{F}\right)$ : Evaporator Capacity (Btu/h): (CONDENSER)

$$
\begin{array}{rr}
\text { Inlet Temperature }\left({ }^{\circ} \mathrm{F}\right): & 147.51 \\
\text { Exit Temperature }\left({ }^{\circ} \mathrm{F}\right): & 90.62 \\
\text { Inlet Pressure (psia): } & 344.52 \\
\text { Exit Pressure }(\mathrm{psia}): & 341.93 \\
\text { Pressure Drop }(\mathrm{psid}): & 2.59 \\
\text { Exit Subcooling }\left({ }^{\circ} \mathrm{F}\right): & 8.65 \\
\text { Inlet Sat. Temperature }\left({ }^{\circ} \mathrm{F}\right): & 102.93
\end{array}
$$

Condenser Capacity $($ Btu/h): 38768.9

(LIQUID LINE AND TXV)

Cond Unit Exit Temp $\left({ }^{\circ} \mathrm{F}\right)$ :

Cond Unit Exit Pres (psia): Liq-line Pressure Drop (psid): TXV Upstream Pressure (psia): TXV Pressure Drop (psid): Temperature Drop $\left({ }^{\circ} \mathrm{F}\right)$ : (COMPRESSOR)

Suction Temperature $\left({ }^{\circ} \mathrm{F}\right)$ : Discharge Temperature $\left({ }^{\circ} \mathrm{F}\right)$ : Suction Pressure (psia):

Discharge Pressure (psia): Discharge Superheat $\left({ }^{\circ} \mathrm{F}\right)$ : Comp Bottom Shell Temp $\left({ }^{\circ} \mathrm{F}\right)$ : Mass Flow Rate (l bm/h):

Comp Power Consumption (W) :

Cond Unit Inlet Temp $\left({ }^{\circ} \mathrm{F}\right)$ : Cond Unit Inlet Pres (psia):

91.90

334.52

13.77

320.76

153.69

0.74

68.26

151.26

154.90

345.78

48.33

109.50

429.42

1760.2

66.47

156.20
HEAT PUMP FAULT TEST SUMMARY

INDOOR/OUTDOOR CONDITION \#: 05

FAULT TYPE: IMPROPER INDOOR AIR FLOW FAULT FAULT LEVEL [\%]: 20.7

\section{RUNNING CONDITIONS}

Barometric Pressure (inHg): Indoor Dry-Bulb Temperature $\left({ }^{\circ} \mathrm{F}\right)$ : Indoor Dew-Point Temperature $\left({ }^{\circ} \mathrm{F}\right)$ : Outdoor Dry-Bulb Temperature $\left({ }^{\circ} \mathrm{F}\right)$ : AIR SIDE CONDITIONS (INDOOR UNIT)

Inlet Dry-Bulb Temperature $\left({ }^{\circ} \mathrm{F}\right)$ : Inlet Dew-Point Temperature $\left({ }^{\circ} \mathrm{F}\right)$ : Exit Dry-Bulb Temperature $\left({ }^{\circ} \mathrm{F}\right)$ : Exit Dew-Point Temperature $\left({ }^{\circ} \mathrm{F}\right)$ : Inlet Relative Humidity $(-)$ : Exit Relative Humidity (-) : Evaporator Coil Temp Drop $\left({ }^{\circ} \mathrm{F}\right)$ : Air Flow Rate (SCFM) : Fan Power Consumption (W): (OUTDOOR UNIT)

Inlet Temperature $\left({ }^{\circ} \mathrm{F}\right)$ : Exit Temperature $\left({ }^{\circ} \mathrm{F}\right)$ : Condensing Unit Temp Gain $\left({ }^{\circ} \mathrm{F}\right)$ : Fan Power Consumption (W): (OVERALL PERFORMANCE)

Latent Capacity (Btu/h) : Sensible Capacity (Btu/h): Overall Capacity (Btu/h): Sensible Heat Ratio (-):

Overall Power Consumption (W) : NET Cooling EER (Btu/h.W): Evaporator Energy Imbalance (\%): REFRIGERANT SIDE CONDITIONS

(EVAPORATOR)

Inlet Temperature $\left({ }^{\circ} \mathrm{F}\right)$ : Exit Temperature $\left({ }^{\circ} \mathrm{F}\right)$ : Inlet Pressure (psia): Exit Pressure (psia): Pressure Drop (psid): Exit Superheat $\left({ }^{\circ} \mathrm{F}\right)$ : Exit Sat. Temperature $\left({ }^{\circ} \mathrm{F}\right)$ : Evaporator Capacity (Btu/h): (CONDENSER)

$\begin{array}{rr}\text { Inlet Temperature }\left({ }^{\circ} \mathrm{F}\right): & 147.36 \\ \text { Exit Temperature }\left({ }^{\circ} \mathrm{F}\right): & 90.47 \\ \text { Inlet Pressure (psia): } & 342.91 \\ \text { Exit Pressure (psia): } & 340.39 \\ \text { Pressure Drop (psid): } & 2.52 \\ \text { Exit Subcooling }\left({ }^{\circ} \mathrm{F}\right): & 8.63 \\ \text { Sat. Temperature }\left({ }^{\circ} \mathrm{F}\right): & 102.58\end{array}$

Inlet sat. Temperature $\left({ }^{\circ} \mathrm{F}\right)$ : (LIQUID LINE AND TXV)

Cond Unit Exit Temp $\left({ }^{\circ} \mathrm{F}\right)$ :

30.42 80.13 60.75

81.78

80.13

60.75

57.22

54.12

0.517

0.894

22.92

802.7

378.75

81.78

98.63

16.85

161.04

9197.4

20231.3

29428.7

0.687

2295.9

12.82

5.17

53.17

63.91

164.80

155.25

9.55

14.57

49.33

31430.9

47.36

.47

30.39

2.52

38310.3

91.65

333.28

13.40

Lig-line Pressure Drop (psid):

TXV Upstream Pressure (psia):

TXV Pressure Drop (psid):

(COMPRESSOR) Temperature Drop $\left({ }^{\circ} \mathrm{F}\right)$ :

Suction Temperature $\left({ }^{\circ} \mathrm{F}\right)$ :

Discharge Temperature $\left({ }^{\circ} \mathrm{F}\right)$ : Suction Pressure (psia):

Discharge Pressure (psia):

Discharge Superheat $\left({ }^{\circ} \mathrm{F}\right)$ :

Comp Bottom Shell Temp $\left({ }^{\circ} \mathrm{F}\right)$ : Mass Flow Rate $(1 \mathrm{bm} / \mathrm{h})$ :

Comp Power Consumption (W) :

Cond Unit Inlet Temp $\left({ }^{\circ} \mathrm{F}\right)$ :

Cond Unit Inlet Pres (psia):
319.89

155.09

0.68

67.36

151.24

152.78

344.17

48.66

109.29

423.49

1756.1

65.39

154.07 
HEAT PUMP FAULT TEST SUMMARY

INDOOR/OUTDOOR CONDITION \#: 05

FAULT TYPE: IMPROPER INDOOR AIR FLOW FAULT FAULT LEVEL [\%]: 30.8

\section{RUNNING CONDITIONS}

Barometric Pressure (inHg): Indoor Dry-Bulb Temperature $\left({ }^{\circ} \mathrm{F}\right)$ : Indoor Dew-Point Temperature $\left({ }^{\circ} \mathrm{F}\right)$ : Outdoor Dry-Bulb Temperature $\left({ }^{\circ} \mathrm{F}\right)$ : AIR SIDE CONDITIONS

(INDOOR UNIT)

Inlet Dry-Bulb Temperature $\left({ }^{\circ} \mathrm{F}\right)$ : Inlet Dew-Point Temperature $\left({ }^{\circ} \mathrm{F}\right)$ : Exit Dry-Bulb Temperature $\left({ }^{\circ} \mathrm{F}\right)$ : Exit Dew-Point Temperature $\left({ }^{\circ} \mathrm{F}\right)$ : Inlet Relative Humidity (-): Exit Relative Humidity (-): Evaporator Coil Temp Drop $\left({ }^{\circ} \mathrm{F}\right)$ : Air Flow Rate (SCFM): Fan Power Consumption (W) : (OUTDOOR UNIT)

Inlet Temperature $\left({ }^{\circ} \mathrm{F}\right)$ : Exit Temperature $\left({ }^{\circ} \mathrm{F}\right)$ : Condensing Unit Temp Gain $\left({ }^{\circ} \mathrm{F}\right)$ : Fan Power Consumption (W): (OVERALL PERFORMANCE)

Latent Capacity (Btu/h): Sensible Capacity (Btu/h): Overall Capacity (Btu/h): Sensible Heat Ratio (-): Overall Power Consumption (W): NET Cooling EER (Btu/h.W): Evaporator Energy Imbalance (\%): REFRIGERANT SIDE CONDITIONS (EVAPORATOR)

Inlet Temperature $\left({ }^{\circ} \mathrm{F}\right)$ : Exit Temperature $\left({ }^{\circ} \mathrm{F}\right)$ : Inlet Pressure (psia): Exit Pressure (psia): Pressure Drop (psid): Exit Superheat $\left({ }^{\circ} \mathrm{F}\right)$ : Exit Sat. Temperature $\left({ }^{\circ} \mathrm{F}\right)$ : Evaporator Capacity (Btu/h): (CONDENSER)

$\begin{array}{rr}\text { Inlet Temperature }\left({ }^{\circ} \mathrm{F}\right): & 147.33 \\ \text { Exit Temperature }\left({ }^{\circ} \mathrm{F}\right): & 90.46 \\ \text { Inlet Pressure (psia): } & 341.23 \\ \text { Exit Pressure (psia): } & 338.77 \\ \text { Pressure Drop (psid): } & 2.47 \\ \text { Exit Subcooling }\left({ }^{\circ} \mathrm{F}\right): & 8.44 \\ \text { Sat. Temperature }\left({ }^{\circ} \mathrm{F}\right): & 102.22\end{array}$

Inlet Sat. Temperature $\left({ }^{\circ} \mathrm{F}\right): \quad 102.22$ (LIQUID LINE AND TXV)

Cond Unit Exit Temp $\left({ }^{\circ} \mathrm{F}\right)$ :

Cond Unit Exit Pres (psia): Liq-line Pressure Drop (psid): TXV Upstream Pressure (psia): TXV Pressure Drop (psid): Temperature Drop $\left({ }^{\circ} \mathrm{F}\right)$ : (COMPRESSOR)

Suction Temperature $\left({ }^{\circ} \mathrm{F}\right)$ : Discharge Temperature $\left({ }^{\circ} \mathrm{F}\right)$ : Suction Pressure (psia):

Discharge Pressure (psia): Discharge Superheat $\left({ }^{\circ} \mathrm{F}\right)$ : Comp Bottom Shell Temp $\left({ }^{\circ} \mathrm{F}\right)$ : Mass Flow Rate (l bm/h):

Comp Power Consumption (W) :

Cond Unit Inlet Temp $\left({ }^{\circ} \mathrm{F}\right)$ : Cond Unit Inlet Pres (psia):
30.42

80.10

60.35

81.85

80.10

60.35

55.52

52.38

0.510

0.892

24.59

700.3

362.56

81.85

98.34

16.49

161.65

9318.7

18927.9

28246.6

0.670

2276.7

12.41

6.42

51.59

62.07

161.18

151.80

9.39

14.11

47.96

30573.2

37392.4

91.54

331.94

12.71

319.23

158.05

0.68

65.87

151.33

149.30

342.45

49.11

108.99

412.66

1752.5

63.67

150.63
HEAT PUMP FAULT TEST SUMMARY

INDOOR/OUTDOOR CONDITION \#: 08

FAULT TYPE: IMPROPER INDOOR AIR FLOW FAULT FAULT LEVEL [\%]: 11.8

\section{RUNNING CONDITIONS}

Barometric Pressure (inHg): Indoor Dry-Bulb Temperature $\left({ }^{\circ} \mathrm{F}\right)$ : Indoor Dew-Point Temperature $\left({ }^{\circ} \mathrm{F}\right)$ : Outdoor Dry-Bulb Temperature $\left({ }^{\circ} \mathrm{F}\right)$ : AIR SIDE CONDITIONS

(INDOOR UNIT)

Inlet Dry-Bulb Temperature $\left({ }^{\circ} \mathrm{F}\right)$ :

Inlet Dew-Point Temperature $\left({ }^{\circ} \mathrm{F}\right)$ :

Exit Dry-Bulb Temperature $\left({ }^{\circ} \mathrm{F}\right)$ :

Exit Dew-Point Temperature $\left({ }^{\circ} \mathrm{F}\right)$ :

Inlet Relative Humidity $(-)$ : Exit Relative Humidity (-): Evaporator Coil Temp Drop $\left({ }^{\circ} \mathrm{F}\right)$ : Air Flow Rate (SCFM): Fan Power Consumption (W): (OUTDOOR UNIT)

Inlet Temperature $\left({ }^{\circ} \mathrm{F}\right)$ : Exit Temperature $\left({ }^{\circ} \mathrm{F}\right)$ :

Condensing Unit Temp Gain $\left({ }^{\circ} \mathrm{F}\right)$ : Fan Power Consumption (W): (OVERALL PERFORMANCE)

Latent Capacity (Btu/h): Sensible Capacity (Btu/h): Overall Capacity (Btu/h): Sensible Heat Ratio (-):

Overall Power Consumption (W) : NET Cooling EER (Btu/h.W): Evaporator Energy Imbalance (\%): REFRIGERANT SIDE CONDITIONS

(EVAPORATOR)

Inlet Temperature $\left({ }^{\circ} \mathrm{F}\right)$ : Exit Temperature $\left({ }^{\circ} \mathrm{F}\right)$ : Inlet Pressure (psia): Exit Pressure (psia): Pressure Drop (psid): Exit Superheat $\left({ }^{\circ} \mathrm{F}\right)$ : Exit Sat. Temperature $\left({ }^{\circ} \mathrm{F}\right)$ : Evaporator Capacity (Btu/h): (CONDENSER)

Inlet Temperature $\left({ }^{\circ} \mathrm{F}\right)$ : Exit Temperature $\left({ }^{\circ} \mathrm{F}\right)$ : Inlet Pressure (psia): Exit Pressure (psia): Pressure Drop (psid): Exit Subcooling $\left({ }^{\circ} \mathrm{F}\right)$ :

Inlet Sat. Temperature $\left({ }^{\circ} \mathrm{F}\right)$ :

Condenser Capacity (Btu/h): (LIQUID LINE AND TXV)

Cond Unit Exit Temp $\left({ }^{\circ} \mathrm{F}\right)$ : Cond Unit Exit Pres (psia): Liq-line Pressure Drop (psid): TXV Upstream Pressure (psia): TXV Pressure Drop (psid): (COMPRESSOR) Temperature Drop $\left({ }^{\circ} \mathrm{F}\right)$ :

Suction Temperature $\left({ }^{\circ} \mathrm{F}\right)$ :

Discharge Temperature $\left({ }^{\circ} \mathrm{F}\right)$ : Suction Pressure (psia):

Discharge Pressure (psia): Discharge Superheat $\left({ }^{\circ} \mathrm{F}\right)$ : Comp Bottom Shell Temp $\left({ }^{\circ} \mathrm{F}\right)$ : Mass Flow Rate $(1 \mathrm{bm} / \mathrm{h})$ : Comp Power Consumption (W) :

Cond Unit Inlet Temp $\left({ }^{\circ} \mathrm{F}\right)$ : Cond Unit Inlet Pres (psia):
29.90

70.16

50.57

99.98

70.16

50.57

50.93

47.41

0.498

0.877

19.23

899.5

396.40

99.98

114.81

14.83

155.01

3768.2

18934.7

22702.9

0.834

2767.6

8.20

3.68

46.93

56.08

151.09

140.55

10.54

12.74

43.34

23981.7

177.63

109.21

420.37

418.50

1.87

7.03

117.93

32730.5

109.30

412.73

10.81

401.92

250.83

1.45

63.28

183.23

138.38

421.42

65.33

127.81

368.91

2216.2

58.86

139.63 
HEAT PUMP FAULT TEST SUMMARY

INDOOR/OUTDOOR CONDITION \#: 08

FAULT TYPE: IMPROPER INDOOR AIR FLOW FAULT FAULT LEVEL [\%]: 21.1

\section{RUNNING CONDITIONS}

Barometric Pressure (inHg): Indoor Dry-Bulb Temperature $\left({ }^{\circ} \mathrm{F}\right)$ : Indoor Dew-Point Temperature $\left({ }^{\circ} \mathrm{F}\right)$ : Outdoor Dry-Bulb Temperature $\left({ }^{\circ} \mathrm{F}\right)$ : AIR SIDE CONDITIONS

(INDOOR UNIT)

Inlet Dry-Bulb Temperature $\left({ }^{\circ} \mathrm{F}\right)$ : Inlet Dew-Point Temperature $\left({ }^{\circ} \mathrm{F}\right)$ : Exit Dry-Bulb Temperature $\left({ }^{\circ} \mathrm{F}\right)$ : Exit Dew-Point Temperature $\left({ }^{\circ} \mathrm{F}\right)$ : Inlet Relative Humidity (-): Exit Relative Humidity (-): Evaporator Coil Temp Drop $\left({ }^{\circ} \mathrm{F}\right)$ : Air Flow Rate (SCFM): (OUTDOOR UNIT) Fan Power Consumption (W):

Inlet Temperature $\left({ }^{\circ} \mathrm{F}\right)$ : Exit Temperature $\left({ }^{\circ} \mathrm{F}\right)$ : Condensing Unit Temp Gain $\left({ }^{\circ} \mathrm{F}\right)$ : Fan Power Consumption (W) : (OVERALL PERFORMANCE)

Latent Capacity (Btu/h): Sensible Capacity (Btu/h): Overall Capacity (Btu/h): Sensible Heat Ratio (-): Overall Power Consumption (W): NET Cooling EER (Btu/h.W): Evaporator Energy Imbalance (\%): REFRIGERANT SIDE CONDITIONS (EVAPORATOR)

Inlet Temperature $\left({ }^{\circ} \mathrm{F}\right)$ : Exit Temperature $\left({ }^{\circ} \mathrm{F}\right)$ : Inlet Pressure (psia): Exit Pressure (psia): Pressure Drop (psid): Exit Superheat $\left({ }^{\circ} \mathrm{F}\right)$ : Exit Sat. Temperature $\left({ }^{\circ} \mathrm{F}\right)$ : Evaporator Capacity (Btu/h): (CONDENSER)

Inlet Temperature $\left({ }^{\circ} \mathrm{F}\right)$ : Exit Temperature $\left({ }^{\circ} \mathrm{F}\right)$ : Inlet Pressure (psia): Exit Pressure (psia): Pressure Drop (psid): Exit Subcooling $\left({ }^{\circ} \mathrm{F}\right)$ : Inlet Sat. Temperature $\left({ }^{\circ} \mathrm{F}\right)$ : Condenser Capacity (Btu/h): (LIQUID LINE AND TXV)

Cond Unit Exit Temp $\left({ }^{\circ} \mathrm{F}\right)$ : Cond Unit Exit Pres (psia): Liq-line Pressure Drop (psid): TXV Upstream Pressure (psia): TXV Pressure Drop (psid): Temperature Drop $\left({ }^{\circ} \mathrm{F}\right)$ : (COMPRESSOR)

Suction Temperature $\left({ }^{\circ} \mathrm{F}\right)$ : Discharge Temperature $\left({ }^{\circ} \mathrm{F}\right)$ : Suction Pressure (psia):

Discharge Pressure (psia): Discharge Superheat $\left({ }^{\circ} \mathrm{F}\right)$ : Comp Bottom Shell Temp $\left({ }^{\circ} \mathrm{F}\right)$ : Mass Flow Rate (l bm/h):

Comp Power Consumption (W) :

Cond Unit Inlet Temp $\left({ }^{\circ} \mathrm{F}\right)$ : Cond Unit Inlet Pres (psia):
29.90

69.90

50.19

99.98

69.90

50.19

49.60

46.17

0.495

0.879

20.31

802.5

378.55

99.98

114.52

14.54

155.02

4165.5

17831.2

21996.7

0.811

2743.8

8.02

4. 94

45.87

54.66

148.35

137.98

10.37

12.41

42.24

23537.2

177.89

109.09

418.63

416.80

1.83

6.91

117.61

32224.8

109.15

411.30

10.38

400.92

252.58

1.53

62.26

183.67

135.82

419.70

66.09

128.00

362.12

2210.3

57.58

137.07
HEAT PUMP FAULT TEST SUMMARY

INDOOR/OUTDOOR CONDITION \#: 08

FAULT TYPE: IMPROPER INDOOR AIR FLOW FAULT FAULT LEVEL [\%]: 33.1

\section{RUNNING CONDITIONS}

Barometric Pressure (inHg): Indoor Dry-Bulb Temperature $\left({ }^{\circ} \mathrm{F}\right)$ : Indoor Dew-Point Temperature $\left({ }^{\circ} \mathrm{F}\right)$ : Outdoor Dry-Bulb Temperature $\left({ }^{\circ} \mathrm{F}\right)$ : AIR SIDE CONDITIONS

(INDOOR UNIT)

Inlet Dry-Bulb Temperature $\left({ }^{\circ} \mathrm{F}\right)$ :

Inlet Dew-Point Temperature $\left({ }^{\circ} \mathrm{F}\right)$ :

Exit Dry-Bulb Temperature $\left({ }^{\circ} \mathrm{F}\right)$ :

Exit Dew-Point Temperature $\left({ }^{\circ} \mathrm{F}\right)$ :

Inlet Relative Humidity $(-)$ : Exit Relative Humidity (-): Evaporator Coil Temp Drop $\left({ }^{\circ} \mathrm{F}\right)$ : Air Flow Rate (SCFM): Fan Power Consumption (W): (OUTDOOR UNIT)

Inlet Temperature $\left({ }^{\circ} \mathrm{F}\right)$ : Exit Temperature $\left({ }^{\circ} \mathrm{F}\right)$ :

Condensing Unit Temp Gain $\left({ }^{\circ} \mathrm{F}\right)$ : Fan Power Consumption (W): (OVERALL PERFORMANCE)

Latent Capacity (Btu/h): Sensible Capacity (Btu/h): Overall Capacity (Btu/h): Sensible Heat Ratio (-):

Overall Power Consumption (W) : NET Cooling EER (Btu/h.W): Evaporator Energy Imbalance (\%): REFRIGERANT SIDE CONDITIONS

(EVAPORATOR)

Inlet Temperature $\left({ }^{\circ} \mathrm{F}\right)$ : Exit Temperature $\left({ }^{\circ} \mathrm{F}\right)$ : Inlet Pressure (psia): Exit Pressure (psia): Pressure Drop (psid): Exit Superheat $\left({ }^{\circ} \mathrm{F}\right)$ : Exit Sat. Temperature $\left({ }^{\circ} \mathrm{F}\right)$ : Evaporator Capacity (Btu/h): (CONDENSER)

Inlet Temperature $\left({ }^{\circ} \mathrm{F}\right)$ : Exit Temperature $\left({ }^{\circ} \mathrm{F}\right)$ : Inlet Pressure (psia): Exit Pressure (psia): Pressure Drop (psid): Exit Subcooling $\left({ }^{\circ} \mathrm{F}\right)$ :

Inlet Sat. Temperature $\left({ }^{\circ} \mathrm{F}\right)$ :

Condenser Capacity (Btu/h): (LIQUID LINE AND TXV)

Cond Unit Exit Temp $\left({ }^{\circ} \mathrm{F}\right)$ : Cond Unit Exit Pres (psia): Liq-line Pressure Drop (psid): TXV Upstream Pressure (psia): TXV Pressure Drop (psid): (COMPRESSOR) Temperature Drop $\left({ }^{\circ} \mathrm{F}\right)$ :

Suction Temperature $\left({ }^{\circ} \mathrm{F}\right)$ :

Discharge Temperature $\left({ }^{\circ} \mathrm{F}\right)$ : Suction Pressure (psia):

Discharge Pressure (psia): Discharge Superheat $\left({ }^{\circ} \mathrm{F}\right)$ : Comp Bottom Shell Temp $\left({ }^{\circ} \mathrm{F}\right)$ : Mass Flow Rate $(1 \mathrm{bm} / \mathrm{h})$ : Comp Power Consumption (W) :

Cond Unit Inlet Temp $\left({ }^{\circ} \mathrm{F}\right)$ : Cond Unit Inlet Pres (psia):
30.09

69.98

50.47

99.87

69.98

50.47

48.34

44.95

0.499

0.880

21.64

695.1

363.59

99.87

114.06

14.19

156.34

4841.2

16453.2

21294.4

0.773

2722.1

7.82

5.90

44.60

53.07

145.23

135.02

10.21

12.11

40.97

23015.4

178.04

108.78

415.86

414.08

1.78

6.89

117.10

31624.7

108.72

408.91

9.79

399.12

253.88

1.51

61.15

184.05

132.86

416.96

66.98

127.87

353.69

2202.1

56.23

134.13 
HEAT PUMP FAULT TEST SUMMARY

INDOOR/OUTDOOR CONDITION \#: 09

FAULT TYPE: IMPROPER INDOOR AIR FLOW FAULT FAULT LEVEL [\%]: 5.7

\section{RUNNING CONDITIONS}

Barometric Pressure (inHg): Indoor Dry-Bulb Temperature $\left({ }^{\circ} \mathrm{F}\right)$ : Indoor Dew-Point Temperature $\left({ }^{\circ} \mathrm{F}\right)$ : Outdoor Dry-Bulb Temperature $\left({ }^{\circ} \mathrm{F}\right)$ : AIR SIDE CONDITIONS

(INDOOR UNIT)

Inlet Dry-Bulb Temperature $\left({ }^{\circ} \mathrm{F}\right)$ : Inlet Dew-Point Temperature $\left({ }^{\circ} \mathrm{F}\right)$ : Exit Dry-Bulb Temperature $\left({ }^{\circ} \mathrm{F}\right)$ : Exit Dew-Point Temperature $\left({ }^{\circ} \mathrm{F}\right)$ : Inlet Relative Humidity (-): Exit Relative Humidity (-): Evaporator Coil Temp Drop $\left({ }^{\circ} \mathrm{F}\right)$ : Air Flow Rate (SCFM): Fan Power Consumption (W) : (OUTDOOR UNIT)

Inlet Temperature $\left({ }^{\circ} \mathrm{F}\right)$ : Exit Temperature $\left({ }^{\circ} \mathrm{F}\right)$ : Condensing Unit Temp Gain $\left({ }^{\circ} \mathrm{F}\right)$ : Fan Power Consumption (W) : (OVERALL PERFORMANCE)

Latent Capacity (Btu/h): Sensible Capacity (Btu/h): Overall Capacity (Btu/h): Sensible Heat Ratio (-): Overall Power Consumption (W): NET Cooling EER (Btu/h.W): Evaporator Energy Imbalance (\%): REFRIGERANT SIDE CONDITIONS

(EVAPORATOR)

Inlet Temperature $\left({ }^{\circ} \mathrm{F}\right)$ : Exit Temperature $\left({ }^{\circ} \mathrm{F}\right)$ : Inlet Pressure (psia): Exit Pressure (psia): Pressure Drop (psid): Exit Superheat $\left({ }^{\circ} \mathrm{F}\right)$ : Exit Sat. Temperature $\left({ }^{\circ} \mathrm{F}\right)$ : Evaporator Capacity (Btu/h): (CONDENSER)

$\begin{array}{rr}\text { Inlet Temperature }\left({ }^{\circ} \mathrm{F}\right): & 174.95 \\ \text { Exit Temperature }\left({ }^{\circ} \mathrm{F}\right): & 109.10 \\ \text { Inlet Pressure (psia): } & 432.63 \\ \text { Exit Pressure (psia): } & 430.48 \\ \text { Pressure Drop (psid): } & 2.16 \\ \text { Exit Subcooling }\left({ }^{\circ} \mathrm{F}\right): & 8.37 \\ \text { Sat. Temperature }\left({ }^{\circ} \mathrm{F}\right): & 120.15\end{array}$

Inlet Sat. Temperature $\left({ }^{\circ} \mathrm{F}\right): \quad 120.15$ (LIQUID LINE AND TXV)

Cond Unit Exit Temp $\left({ }^{\circ} \mathrm{F}\right)$ :

Cond Unit Exit Pres (psia): Liq-line Pressure Drop (psid): TXV Upstream Pressure (psia): TXV Pressure Drop (psid): Temperature Drop $\left({ }^{\circ} \mathrm{F}\right)$ : (COMPRESSOR)

Suction Temperature $\left({ }^{\circ} \mathrm{F}\right)$ : Discharge Temperature $\left({ }^{\circ} \mathrm{F}\right)$ : Suction Pressure (psia):

Discharge Pressure (psia): Discharge Superheat $\left({ }^{\circ} \mathrm{F}\right)$ : Comp Bottom Shell Temp $\left({ }^{\circ} \mathrm{F}\right)$ : Mass Flow Rate (l bm/h):

Comp Power Consumption (W) :

Cond Unit Inlet Temp $\left({ }^{\circ} \mathrm{F}\right)$ : Cond Unit Inlet Pres (psia):
30.56

79.98

60.42

99.80

79.98

60.42

60.14

56.68

0.513

0.883

19.84

954.5

408.00

99.80

116.56

16.76

157.62

6365.0

20839.0

27204.0

0.766

2811.2

9.68

2.41

55.25

65.66

172.96

161.52

11.44

13.90

51.76

28293.3

37143.5

109.81

422.79

15.08

407.71

234.76

1.07

70.78

179.44

159.22

433.79

59.29

125.49

427.66

2245.6

67.72

160.44
HEAT PUMP FAULT TEST SUMMARY

INDOOR/OUTDOOR CONDITION \#: 09

FAULT TYPE: IMPROPER INDOOR AIR FLOW FAULT FAULT LEVEL [\%]: 10.6

\section{RUNNING CONDITIONS}

Barometric Pressure (inHg): Indoor Dry-Bulb Temperature $\left({ }^{\circ} \mathrm{F}\right)$ : Indoor Dew-Point Temperature $\left({ }^{\circ} \mathrm{F}\right)$ : Outdoor Dry-Bulb Temperature $\left({ }^{\circ} \mathrm{F}\right)$ : AIR SIDE CONDITIONS

(INDOOR UNIT)

Inlet Dry-Bulb Temperature $\left({ }^{\circ} \mathrm{F}\right)$ :

Inlet Dew-Point Temperature $\left({ }^{\circ} \mathrm{F}\right)$ :

Exit Dry-Bulb Temperature $\left({ }^{\circ} \mathrm{F}\right)$ :

Exit Dew-Point Temperature $\left({ }^{\circ} \mathrm{F}\right)$ :

Inlet Relative Humidity $(-)$ : Exit Relative Humidity (-): Evaporator Coil Temp Drop $\left({ }^{\circ} \mathrm{F}\right)$ : Air Flow Rate (SCFM) : Fan Power Consumption (W): (OUTDOOR UNIT)

Inlet Temperature $\left({ }^{\circ} \mathrm{F}\right)$ : Exit Temperature $\left({ }^{\circ} \mathrm{F}\right)$ :

Condensing Unit Temp Gain $\left({ }^{\circ} \mathrm{F}\right)$ : Fan Power Consumption (W): (OVERALL PERFORMANCE)

Latent Capacity (Btu/h): Sensible Capacity (Btu/h): Overall Capacity (Btu/h): Sensible Heat Ratio (-):

Overall Power Consumption (W) : NET Cooling EER (Btu/h.W):

Evaporator Energy Imbalance (\%): REFRIGERANT SIDE CONDITIONS

(EVAPORATOR)

Inlet Temperature $\left({ }^{\circ} \mathrm{F}\right)$ : Exit Temperature $\left({ }^{\circ} \mathrm{F}\right)$ : Inlet Pressure (psia): Exit Pressure (psia): Pressure Drop (psid): Exit Superheat $\left({ }^{\circ} \mathrm{F}\right)$ : Exit Sat. Temperature $\left({ }^{\circ} \mathrm{F}\right)$ : Evaporator Capacity (Btu/h): (CONDENSER)

Inlet Temperature $\left({ }^{\circ} \mathrm{F}\right)$ : Exit Temperature $\left({ }^{\circ} \mathrm{F}\right)$ : Inlet Pressure (psia): Exit Pressure (psia): Pressure Drop (psid): Exit Subcooling $\left({ }^{\circ} \mathrm{F}\right)$ :

Inlet Sat. Temperature $\left({ }^{\circ} \mathrm{F}\right)$ :

Condenser Capacity (Btu/h): (LIQUID LINE AND TXV)

Cond Unit Exit Temp $\left({ }^{\circ} \mathrm{F}\right)$ : Cond Unit Exit Pres (psia): Liq-line Pressure Drop (psid): TXV Upstream Pressure (psia): TXV Pressure Drop (psid): (COMPRESSOR) Temperature Drop $\left({ }^{\circ} \mathrm{F}\right)$ :

Suction Temperature $\left({ }^{\circ} \mathrm{F}\right)$ :

Discharge Temperature $\left({ }^{\circ} \mathrm{F}\right)$ : Suction Pressure (psia):

Discharge Pressure (psia): Discharge Superheat $\left({ }^{\circ} \mathrm{F}\right)$ : Comp Bottom Shell Temp $\left({ }^{\circ} \mathrm{F}\right)$ : Mass Flow Rate $(1 \mathrm{bm} / \mathrm{h})$ : Comp Power Consumption (W) :

Cond Unit Inlet Temp $\left({ }^{\circ} \mathrm{F}\right)$ : Cond Unit Inlet Pres (psia):
30.61

79.94

60.49

99.80

79.94

60.49

59.71

56.32

0.515

0.885

20.23

904.7

398.80

99.80

116.47

16.67

157.67

6676.2

20142.3

26818.5

0.751

2799.3

9.58

3.19

54.89

65.19

172.02

160.62

11.40

13.78

51.41

28114.9

175.04

109.09

432.01

429.88

2.13

8.30

120.04

36941.1

109.79

422.35

14.90

407.45

235.43

1.13

70.45

179.58

158.28

433.22

59.54

125.62

424.96

2242.8

67.38

159.50 
HEAT PUMP FAULT TEST SUMMARY

INDOOR/OUTDOOR CONDITION \#: 09

FAULT TYPE: IMPROPER INDOOR AIR FLOW FAULT FAULT LEVEL [\%]: 20.9

\section{RUNNING CONDITIONS}

Barometric Pressure (inHg): Indoor Dry-Bulb Temperature $\left({ }^{\circ} \mathrm{F}\right)$ : Indoor Dew-Point Temperature $\left({ }^{\circ} \mathrm{F}\right)$ : Outdoor Dry-Bulb Temperature $\left({ }^{\circ} \mathrm{F}\right)$ : AIR SIDE CONDITIONS

(INDOOR UNIT)

Inlet Dry-Bulb Temperature $\left({ }^{\circ} \mathrm{F}\right)$ : Inlet Dew-Point Temperature $\left({ }^{\circ} \mathrm{F}\right)$ : Exit Dry-Bulb Temperature $\left({ }^{\circ} \mathrm{F}\right)$ : Exit Dew-Point Temperature $\left({ }^{\circ} \mathrm{F}\right)$ : Inlet Relative Humidity (-): Exit Relative Humidity (-): Evaporator Coil Temp Drop $\left({ }^{\circ} \mathrm{F}\right)$ : Air Flow Rate (SCFM): Fan Power Consumption (W): (OUTDOOR UNIT)

Inlet Temperature $\left({ }^{\circ} \mathrm{F}\right)$ : Exit Temperature $\left({ }^{\circ} \mathrm{F}\right)$ : Condensing Unit Temp Gain $\left({ }^{\circ} \mathrm{F}\right)$ : Fan Power Consumption (W) : (OVERALL PERFORMANCE)

Latent Capacity (Btu/h): Sensible Capacity (Btu/h): Overall Capacity (Btu/h): Sensible Heat Ratio (-): Overall Power Consumption (W): NET Cooling EER (Btu/h.W): Evaporator Energy Imbalance (\%): REFRIGERANT SIDE CONDITIONS

(EVAPORATOR)

Inlet Temperature $\left({ }^{\circ} \mathrm{F}\right)$ : Exit Temperature $\left({ }^{\circ} \mathrm{F}\right)$ : Inlet Pressure (psia): Exit Pressure (psia): Pressure Drop (psid): Exit Superheat $\left({ }^{\circ} \mathrm{F}\right)$ : Exit Sat. Temperature $\left({ }^{\circ} \mathrm{F}\right)$ : Evaporator Capacity (Btu/h): (CONDENSER)

$\begin{array}{rr}\text { Inlet Temperature }\left({ }^{\circ} \mathrm{F}\right): & 175.00 \\ \text { Exit Temperature }\left({ }^{\circ} \mathrm{F}\right): & 109.71 \\ \text { Inlet Pressure (psia): } & 429.88 \\ \text { Exit Pressure (psia): } & 427.73 \\ \text { Pressure Drop (psid): } & 2.15 \\ \text { Exit Subcooling }\left({ }^{\circ} \mathrm{F}\right): & 7.81 \\ \text { Sat. Temperature }\left({ }^{\circ} \mathrm{F}\right): & 119.66\end{array}$

Inlet Sat. Temperature $\left({ }^{\circ} \mathrm{F}\right):-119.66$ (LIQUID LINE AND TXV)

Cond Unit Exit Temp $\left({ }^{\circ} \mathrm{F}\right)$ :

Cond Unit Exit Pres (psia): Liq-line Pressure Drop (psid): TXV Upstream Pressure (psia): TXV Pressure Drop (psid): Temperature Drop $\left({ }^{\circ} \mathrm{F}\right)$ : (COMPRESSOR)

Suction Temperature $\left({ }^{\circ} \mathrm{F}\right)$ : Discharge Temperature $\left({ }^{\circ} \mathrm{F}\right)$ : Suction Pressure (psia):

Discharge Pressure (psia): Discharge Superheat $\left({ }^{\circ} \mathrm{F}\right)$ : Comp Bottom Shell Temp $\left({ }^{\circ} \mathrm{F}\right)$ : Mass Flow Rate (l bm/h):

Comp Power Consumption (W) :

Cond Unit Inlet Temp $\left({ }^{\circ} \mathrm{F}\right)$ : Cond Unit Inlet Pres (psia):
31.02

80.18

60.36

100.02

80.18

60.36

58.65

55.15

0.509

0.881

21.53

800.5

374.75

100.02

116.29

16.27

158.90

7142.4

18951.3

26093.7

0.726

2768.3

9.43

4.47

54.28

64.37

169.77

158.32

11.45

13.84

50.53

27706.7

36399.8

109.93

420.37

14.05

406.32

236.55

1.00

69.80

179.59

156.16

430.84

59.98

125.09

418.60

2234.6

66.49

157.32
HEAT PUMP FAULT TEST SUMMARY

INDOOR/OUTDOOR CONDITION \#: 09

FAULT TYPE: IMPROPER INDOOR AIR FLOW FAULT FAULT LEVEL [\%]: 30.5

\section{RUNNING CONDITIONS}

Barometric Pressure (inHg): Indoor Dry-Bulb Temperature $\left({ }^{\circ} \mathrm{F}\right)$ : Indoor Dew-Point Temperature $\left({ }^{\circ} \mathrm{F}\right)$ : Outdoor Dry-Bulb Temperature $\left({ }^{\circ} \mathrm{F}\right)$ : AIR SIDE CONDITIONS (INDOOR UNIT)

Inlet Dry-Bulb Temperature $\left({ }^{\circ} \mathrm{F}\right)$ : Inlet Dew-Point Temperature $\left({ }^{\circ} \mathrm{F}\right)$ : Exit Dry-Bulb Temperature $\left({ }^{\circ} \mathrm{F}\right)$ : Exit Dew-Point Temperature $\left({ }^{\circ} \mathrm{F}\right)$ : Inlet Relative Humidity $(-)$ : Exit Relative Humidity (-) : Evaporator Coil Temp Drop $\left({ }^{\circ} \mathrm{F}\right)$ : Air Flow Rate (SCFM) : Fan Power Consumption (W): (OUTDOOR UNIT)

Inlet Temperature $\left({ }^{\circ} \mathrm{F}\right)$ : Exit Temperature $\left({ }^{\circ} \mathrm{F}\right)$ : Condensing Unit Temp Gain $\left({ }^{\circ} \mathrm{F}\right)$ : Fan Power Consumption (W): (OVERALL PERFORMANCE)

Latent Capacity (Btu/h) : Sensible Capacity (Btu/h): Overall Capacity (Btu/h): Sensible Heat Ratio (-):

Overall Power Consumption (W) : NET Cooling EER (Btu/h.W): Evaporator Energy Imbalance (\%): REFRIGERANT SIDE CONDITIONS

(EVAPORATOR)

Inlet Temperature $\left({ }^{\circ} \mathrm{F}\right)$ : Exit Temperature $\left({ }^{\circ} \mathrm{F}\right)$ : Inlet Pressure (psia): Exit Pressure (psia): Pressure Drop (psid): Exit Superheat $\left({ }^{\circ} \mathrm{F}\right)$ : Exit Sat. Temperature $\left({ }^{\circ} \mathrm{F}\right)$ : Evaporator Capacity (Btu/h): (CONDENSER)

Inlet Temperature $\left({ }^{\circ} \mathrm{F}\right)$ : Exit Temperature $\left({ }^{\circ} \mathrm{F}\right)$ : Inlet Pressure (psia): Exit Pressure (psia): Pressure Drop (psid): Exit Subcooling $\left({ }^{\circ} \mathrm{F}\right)$ :

Inlet Sat. Temperature $\left({ }^{\circ} \mathrm{F}\right)$ :

Condenser Capacity (Btu/h): (LIQUID LINE AND TXV)

Cond Unit Exit Temp $\left({ }^{\circ} \mathrm{F}\right)$ : Cond Unit Exit Pres (psia): Liq-line Pressure Drop (psid): TXV Upstream Pressure (psia): TXV Pressure Drop (psid): (COMPRESSOR) Temperature Drop $\left({ }^{\circ} \mathrm{F}\right)$ :

Suction Temperature $\left({ }^{\circ} \mathrm{F}\right)$ :

Discharge Temperature $\left({ }^{\circ} \mathrm{F}\right)$ : Suction Pressure (psia):

Discharge Pressure (psia): Discharge Superheat $\left({ }^{\circ} \mathrm{F}\right)$ : Comp Bottom Shell Temp $\left({ }^{\circ} \mathrm{F}\right)$ : Mass Flow Rate $(1 \mathrm{bm} / \mathrm{h})$ : Comp Power Consumption (W) : Cond Unit Inlet Temp $\left({ }^{\circ} \mathrm{F}\right)$ : Cond Unit Inlet Pres (psia):
30.96

79.99

60.65

100.03

79.99

60.65

57.44

54.15

0.517

0.887

22.55

703.4

360.50

100.03

116.15

16.12

157.34

7755.3

17438.6

25193.9

0.692

2743.9

9.18

6.11

53.18

63.28

166.59

155.57

11.02

13.82

49.46

27216.3

175.79

109.36

428.84

426.75

2.08

8.04

119.47

35894.1

109.58

419.72

13.45

406.27

239.68

1.05

68.90

180.61

153.34

429.86

61.17

125.73

410.36

2226.1

65.41

154.57 
HEAT PUMP FAULT TEST SUMMARY

INDOOR/OUTDOOR CONDITION \#: 12

FAULT TYPE: IMPROPER INDOOR AIR FLOW FAULT FAULT LEVEL [\%]: 14.3

\section{RUNNING CONDITIONS}

Barometric Pressure (inHg): Indoor Dry-Bulb Temperature $\left({ }^{\circ} \mathrm{F}\right)$ : Indoor Dew-Point Temperature $\left({ }^{\circ} \mathrm{F}\right)$ : Outdoor Dry-Bulb Temperature $\left({ }^{\circ} \mathrm{F}\right)$ : AIR SIDE CONDITIONS

(INDOOR UNIT)

Inlet Dry-Bulb Temperature $\left({ }^{\circ} \mathrm{F}\right)$ : Inlet Dew-Point Temperature $\left({ }^{\circ} \mathrm{F}\right)$ : Exit Dry-Bulb Temperature $\left({ }^{\circ} \mathrm{F}\right)$ : Exit Dew-Point Temperature $\left({ }^{\circ} \mathrm{F}\right)$ : Inlet Relative Humidity (-): Exit Relative Humidity (-): Evaporator Coil Temp Drop $\left({ }^{\circ} \mathrm{F}\right)$ : Air Flow Rate (SCFM): Fan Power Consumption (W): (OUTDOOR UNIT)

Inlet Temperature $\left({ }^{\circ} \mathrm{F}\right)$ : Exit Temperature $\left({ }^{\circ} \mathrm{F}\right)$ : Condensing Unit Temp Gain $\left({ }^{\circ} \mathrm{F}\right)$ : Fan Power Consumption (W): (OVERALL PERFORMANCE)

Latent Capacity (Btu/h): Sensible Capacity (Btu/h): Overall Capacity (Btu/h): Sensible Heat Ratio (-): Overall Power Consumption (W): NET Cooling EER (Btu/h.W): Evaporator Energy Imbalance (\%): REFRIGERANT SIDE CONDITIONS (EVAPORATOR)

Inlet Temperature $\left({ }^{\circ} \mathrm{F}\right)$ : Exit Temperature $\left({ }^{\circ} \mathrm{F}\right)$ : Inlet Pressure (psia): Exit Pressure (psia): Pressure Drop (psid): Exit Superheat $\left({ }^{\circ} \mathrm{F}\right)$ : Exit Sat. Temperature $\left({ }^{\circ} \mathrm{F}\right)$ : Evaporator Capacity (Btu/h): (CONDENSER)

$$
\begin{array}{rr}
\text { Inlet Temperature }\left({ }^{\circ} \mathrm{F}\right): & 147.50 \\
\text { Exit Temperature }\left({ }^{\circ} \mathrm{F}\right): & 89.63 \\
\text { Inlet Pressure (psia): } & 325.66 \\
\text { Exit Pressure (psia): } & 323.66 \\
\text { Pressure Drop }(\text { psid): } & 2.01 \\
\text { Exit Subcooling }\left({ }^{\circ} \mathrm{F}\right): & 7.17 \\
\text { Inlet Sat. Temperature }\left({ }^{\circ} \mathrm{F}\right): & 98.81
\end{array}
$$

Condenser Capacity (Btu/h): (LIQUID LINE AND TXV)

Cond Unit Exit Temp $\left({ }^{\circ} \mathrm{F}\right)$ :

Cond Unit Exit Pres (psia): Liq-line Pressure Drop (psid): TXV Upstream Pressure (psia): TXV Pressure Drop (psid): Temperature Drop $\left({ }^{\circ} \mathrm{F}\right)$ : (COMPRESSOR)

Suction Temperature $\left({ }^{\circ} \mathrm{F}\right)$ : Discharge Temperature $\left({ }^{\circ} \mathrm{F}\right)$ : Suction Pressure (psia):

Discharge Pressure (psia): Discharge Superheat $\left({ }^{\circ} \mathrm{F}\right)$ : Comp Bottom Shell Temp $\left({ }^{\circ} \mathrm{F}\right)$ : Mass Flow Rate (l bm/h):

Comp Power Consumption (W) :

Cond Unit Inlet Temp $\left({ }^{\circ} \mathrm{F}\right)$ : Cond Unit Inlet Pres (psia):
30.64

81.74

69.60

2.01

32.13

0.248

24.97

902.4

81.74

95.30

163.35

24498.9

4415.6

1.000
2277.9

10.72

0.59

42.72

9.80

127.33

8.44

12.26
37.54

4970.9

31871.9

89.82

318.55

8.56

309.99

174.22

0.97

55.95

152.74

125.04

326.47

54.02

108.47

344.62

1707.5

52.41

126.42
HEAT PUMP FAULT TEST SUMMARY

INDOOR/OUTDOOR CONDITION \#: 12

FAULT TYPE: IMPROPER INDOOR AIR FLOW FAULT FAULT LEVEL [\%]: 24.1

\section{RUNNING CONDITIONS}

Barometric Pressure (inHg): Indoor Dry-Bulb Temperature $\left({ }^{\circ} \mathrm{F}\right)$ : Indoor Dew-Point Temperature $\left({ }^{\circ} \mathrm{F}\right)$ : Outdoor Dry-Bulb Temperature $\left({ }^{\circ} \mathrm{F}\right)$ : AIR SIDE CONDITIONS

(INDOOR UNIT)

Inlet Dry-Bulb Temperature $\left({ }^{\circ} \mathrm{F}\right)$ :

Inlet Dew-Point Temperature $\left({ }^{\circ} \mathrm{F}\right)$ :

Exit Dry-Bulb Temperature $\left({ }^{\circ} \mathrm{F}\right)$ :

Exit Dew-Point Temperature $\left({ }^{\circ} \mathrm{F}\right)$ :

Inlet Relative Humidity $(-)$ : Exit Relative Humidity (-): Evaporator Coil Temp Drop $\left({ }^{\circ} \mathrm{F}\right)$ : Air Flow Rate (SCFM): Fan Power Consumption (W) : (OUTDOOR UNIT)

Inlet Temperature $\left({ }^{\circ} \mathrm{F}\right)$ : Exit Temperature $\left({ }^{\circ} \mathrm{F}\right)$ :

Condensing Unit Temp Gain $\left({ }^{\circ} \mathrm{F}\right)$ : Fan Power Consumption (W): (OVERALL PERFORMANCE)

Latent Capacity (Btu/h) : Sensible Capacity (Btu/h): Overall Capacity (Btu/h): Sensible Heat Ratio (-):

Overall Power Consumption (W) : NET Cooling EER (Btu/h.W): Evaporator Energy Imbalance (\%): REFRIGERANT SIDE CONDITIONS

(EVAPORATOR)

Inlet Temperature $\left({ }^{\circ} \mathrm{F}\right)$ : Exit Temperature $\left({ }^{\circ} \mathrm{F}\right)$ : Inlet Pressure (psia): Exit Pressure (psia): Pressure Drop (psid): Exit Superheat $\left({ }^{\circ} \mathrm{F}\right)$ : Exit Sat. Temperature $\left({ }^{\circ} \mathrm{F}\right)$ : Evaporator Capacity (Btu/h): (CONDENSER)

$\begin{array}{rr}\text { Inlet Temperature }\left({ }^{\circ} \mathrm{F}\right): & 147.74 \\ \text { Exit Temperature }\left({ }^{\circ} \mathrm{F}\right): & 89.47 \\ \text { Inlet Pressure (psia): } & 323.32 \\ \text { Exit Pressure (psia): } & 321.34 \\ \text { Pressure Drop (psid): } & 1.98 \\ \text { Exit Subcooling }\left({ }^{\circ} \mathrm{F}\right): & 6.90 \\ \text { Sat. Temperature }\left({ }^{\circ} \mathrm{F}\right): & 98.28\end{array}$

Inlet sat. Temperature $\left({ }^{\circ} \mathrm{F}\right)$ : (LIQUID LINE AND TXV)

Cond Unit Exit Temp $\left({ }^{\circ} \mathrm{F}\right): \quad 89.62$

Cond Unit Exit Pres (psia): 316.50

Liq-line Pressure Drop (psid):

TXV Upstream Pressure (psia):

TXV Pressure Drop (psid):

(COMPRESSOR)

308.51

175.99

1.10

54.66

153.19

121.94

324.10

55.01

108.78

335.22

1701.6

Cond Unit Inlet Temp $\left({ }^{\circ} \mathrm{F}\right): \quad r .95$ 
HEAT PUMP FAULT TEST SUMMARY

INDOOR/OUTDOOR CONDITION \#: 12

FAULT TYPE: IMPROPER INDOOR AIR FLOW FAULT FAULT LEVEL [\%]: 34.6

\section{RUNNING CONDITIONS}

Barometric Pressure (inHg): Indoor Dry-Bulb Temperature $\left({ }^{\circ} \mathrm{F}\right)$ : Indoor Dew-Point Temperature $\left({ }^{\circ} \mathrm{F}\right)$ : Outdoor Dry-Bulb Temperature $\left({ }^{\circ} \mathrm{F}\right)$ : AIR SIDE CONDITIONS

(INDOOR UNIT)

Inlet Dry-Bulb Temperature $\left({ }^{\circ} \mathrm{F}\right)$ : Inlet Dew-Point Temperature $\left({ }^{\circ} \mathrm{F}\right)$ : Exit Dry-Bulb Temperature $\left({ }^{\circ} \mathrm{F}\right)$ : Exit Dew-Point Temperature $\left({ }^{\circ} \mathrm{F}\right)$ : Inlet Relative Humidity (-): Exit Relative Humidity (-): Evaporator Coil Temp Drop $\left({ }^{\circ} \mathrm{F}\right)$ : Air Flow Rate (SCFM): Fan Power Consumption (W) : (OUTDOOR UNIT)

Inlet Temperature $\left({ }^{\circ} \mathrm{F}\right)$ : Exit Temperature $\left({ }^{\circ} \mathrm{F}\right)$ : Condensing Unit Temp Gain $\left({ }^{\circ} \mathrm{F}\right)$ : Fan Power Consumption (W): (OVERALL PERFORMANCE)

Latent Capacity (Btu/h): Sensible Capacity (Btu/h): Overall Capacity (Btu/h): Sensible Heat Ratio (-): Overall Power Consumption (W): NET Cooling EER (Btu/h.W): Evaporator Energy Imbalance (\%): REFRIGERANT SIDE CONDITIONS (EVAPORATOR)

Inlet Temperature $\left({ }^{\circ} \mathrm{F}\right)$ : Exit Temperature $\left({ }^{\circ} \mathrm{F}\right)$ : Inlet Pressure (psia): Exit Pressure (psia): Pressure Drop (psid): Exit Superheat $\left({ }^{\circ} \mathrm{F}\right)$ : Exit Sat. Temperature $\left({ }^{\circ} \mathrm{F}\right)$ : Evaporator Capacity (Btu/h): (CONDENSER)

$\begin{array}{rr}\text { Inlet Temperature }\left({ }^{\circ} \mathrm{F}\right): & 148.38 \\ \text { Exit Temperature }\left({ }^{\circ} \mathrm{F}\right): & 89.31 \\ \text { Inlet Pressure (psia): } & 320.82 \\ \text { Exit Pressure (psia): } & 318.98 \\ \text { Pressure Drop (psid): } & 1.84 \\ \text { Exit Subcooling }\left({ }^{\circ} \mathrm{F}\right): & 6.69 \\ \text { Sat. Temperature }\left({ }^{\circ} \mathrm{F}\right): & 97.72\end{array}$

Condenser Capacity (Btu/h): 30064.2

(LIQUID LINE AND TXV)

Cond Unit Exit Temp $\left({ }^{\circ} \mathrm{F}\right)$ :

Cond Unit Exit Pres (psia): Liq-line Pressure Drop (psid): TXV Upstream Pressure (psia): TXV Pressure Drop (psid): Temperature Drop $\left({ }^{\circ} \mathrm{F}\right)$ : (COMPRESSOR)

Suction Temperature $\left({ }^{\circ} \mathrm{F}\right)$ : Discharge Temperature $\left({ }^{\circ} \mathrm{F}\right)$ : Suction Pressure (psia):

Discharge Pressure (psia): Discharge Superheat $\left({ }^{\circ} \mathrm{F}\right)$ : Comp Bottom Shell Temp $\left({ }^{\circ} \mathrm{F}\right)$ : Mass Flow Rate $(1 \mathrm{bm} / \mathrm{h})$ :

Comp Power Consumption (W) :

Cond Unit Inlet Temp $\left({ }^{\circ} \mathrm{F}\right)$ : Cond Unit Inlet Pres (psia):
30.62

70.02

32.01

81.60

70.02

32.01

40.98

32.14

0.244

0.705

29.04

695.9

362.25

81.60

94.44

12.84

160.84

0.0

21976.9

21908.4

1.000

2214.9

9.89

4.50

39.49

45.62

127.80

119.94

7.87

11.53

34.10

3319.9

48.38

9.31

.84

89.37

314.52

7.27

307.24

179.44

1.17

52.91

154.13

117.65

321.63

56.51

109.23

322.26

1691.8

48.80

119.02
HEAT PUMP FAULT TEST SUMMARY

INDOOR/OUTDOOR CONDITION \#: 13

FAULT TYPE: IMPROPER INDOOR AIR FLOW FAULT FAULT LEVEL [\%]: 6.1

RUNNING CONDITIONS

Barometric Pressure (inHg) : Indoor Dry-Bulb Temperature $\left({ }^{\circ} \mathrm{F}\right)$ : Indoor Dew-Point Temperature $\left({ }^{\circ} \mathrm{F}\right)$ : Outdoor Dry-Bulb Temperature $\left({ }^{\circ} \mathrm{F}\right)$ : AIR SIDE CONDITIONS (INDOOR UNIT)

Inlet Dry-Bulb Temperature $\left({ }^{\circ} \mathrm{F}\right)$ : Inlet Dew-Point Temperature $\left({ }^{\circ} \mathrm{F}\right)$ : Exit Dry-Bulb Temperature $\left({ }^{\circ} \mathrm{F}\right)$ : Exit Dew-Point Temperature $\left({ }^{\circ} \mathrm{F}\right)$ : Inlet Relative Humidity $(-)$ : Exit Relative Humidity (-) : Evaporator Coil Temp Drop $\left({ }^{\circ} \mathrm{F}\right)$ : Air Flow Rate (SCFM): Fan Power Consumption (W): (OUTDOOR UNIT)

Inlet Temperature $\left({ }^{\circ} \mathrm{F}\right)$ : Exit Temperature $\left({ }^{\circ} \mathrm{F}\right)$ : Condensing Unit Temp Gain $\left({ }^{\circ} \mathrm{F}\right)$ : Fan Power Consumption (W): (OVERALL PERFORMANCE)

Latent Capacity (Btu/h): Sensible Capacity (Btu/h): Overall Capacity (Btu/h): Sensible Heat Ratio (-):

Overall Power Consumption (W) : NET Cooling EER (Btu/h.W): Evaporator Energy Imbalance (\%): REFRIGERANT SIDE CONDITIONS

(EVAPORATOR)

Inlet Temperature $\left({ }^{\circ} \mathrm{F}\right)$ : Exit Temperature $\left({ }^{\circ} \mathrm{F}\right)$ : Inlet Pressure (psia): Exit Pressure (psia): Pressure Drop (psid): Exit Superheat $\left({ }^{\circ} \mathrm{F}\right)$ : Exit Sat. Temperature $\left({ }^{\circ} \mathrm{F}\right)$ : Evaporator Capacity (Btu/h): (CONDENSER)

Inlet Temperature $\left({ }^{\circ} \mathrm{F}\right)$ : Exit Temperature $\left({ }^{\circ} \mathrm{F}\right)$ : Inlet Pressure (psia): Exit Pressure (psia): Pressure Drop (psid): Exit Subcooling $\left({ }^{\circ} \mathrm{F}\right)$ :

Inlet Sat. Temperature $\left({ }^{\circ} \mathrm{F}\right)$ : Condenser Capacity (Btu/h): (LIQUID LINE AND TXV)

Cond Unit Exit Temp $\left({ }^{\circ} \mathrm{F}\right)$ : Cond Unit Exit Pres (psia): Liq-line Pressure Drop (psid): TXV Upstream Pressure (psia): TXV Pressure Drop (psid): (COMPRESSOR) Temperature Drop $\left({ }^{\circ} \mathrm{F}\right)$ :

Suction Temperature $\left({ }^{\circ} \mathrm{F}\right)$ :

Discharge Temperature $\left({ }^{\circ} \mathrm{F}\right)$ : Suction Pressure (psia):

Discharge Pressure (psia): Discharge Superheat $\left({ }^{\circ} \mathrm{F}\right)$ : Comp Bottom Shell Temp $\left({ }^{\circ} \mathrm{F}\right)$ : Mass Flow Rate $(1 \mathrm{bm} / \mathrm{h})$ : Comp Power Consumption (W) :

Cond Unit Inlet Temp $\left({ }^{\circ} \mathrm{F}\right)$ : Cond Unit Inlet Pres (psia):
30.02

80.15

34.99

81.90

80.15

34.99

52.80

35.48

0.196

0.516

27.35

950.5

413.46

81.90

97.58

15.68

160.10

0.0

28301.6

27920.1

1.000

2308.3

12.10

1.29

50.27

58.63

153.17

143.92

9.24

13.88

44.76

28704.3

147.72

90.47

336.71

334.39

2.32

7.75

101.24

35694.7

91.39

328.14

11.53

316.61

163.45

0.61

63.20

151.94

141.55

337.27

50.85

108.81

391.94

1734.8

60.86

142.86 
HEAT PUMP FAULT TEST SUMMARY

INDOOR/OUTDOOR CONDITION \#: 13

FAULT TYPE: IMPROPER INDOOR AIR FLOW FAULT FAULT LEVEL [\%]: 11.0

\section{RUNNING CONDITIONS}

Barometric Pressure (inHg): Indoor Dry-Bulb Temperature $\left({ }^{\circ} \mathrm{F}\right)$ : Indoor Dew-Point Temperature $\left({ }^{\circ} \mathrm{F}\right)$ : Outdoor Dry-Bulb Temperature $\left({ }^{\circ} \mathrm{F}\right)$ : AIR SIDE CONDITIONS

(INDOOR UNIT)

Inlet Dry-Bulb Temperature $\left({ }^{\circ} \mathrm{F}\right)$ : Inlet Dew-Point Temperature $\left({ }^{\circ} \mathrm{F}\right)$ : Exit Dry-Bulb Temperature $\left({ }^{\circ} \mathrm{F}\right)$ : Exit Dew-Point Temperature $\left({ }^{\circ} \mathrm{F}\right)$ : Inlet Relative Humidity (-): Exit Relative Humidity (-): Evaporator Coil Temp Drop $\left({ }^{\circ} \mathrm{F}\right)$ : Air Flow Rate (SCFM): Fan Power Consumption (W): (OUTDOOR UNIT)

Inlet Temperature $\left({ }^{\circ} \mathrm{F}\right)$ : Exit Temperature $\left({ }^{\circ} \mathrm{F}\right)$ : Condensing Unit Temp Gain $\left({ }^{\circ} \mathrm{F}\right)$ : Fan Power Consumption (W): (OVERALL PERFORMANCE)

Latent Capacity (Btu/h) : Sensible Capacity (Btu/h): Overall Capacity (Btu/h): Sensible Heat Ratio (-): Overall Power Consumption (W): NET Cooling EER (Btu/h.W): Evaporator Energy Imbalance (\%): REFRIGERANT SIDE CONDITIONS (EVAPORATOR)

Inlet Temperature $\left({ }^{\circ} \mathrm{F}\right)$ : Exit Temperature $\left({ }^{\circ} \mathrm{F}\right)$ : Inlet Pressure (psia): Exit Pressure (psia): Pressure Drop (psid): Exit Superheat $\left({ }^{\circ} \mathrm{F}\right)$ : Exit Sat. Temperature $\left({ }^{\circ} \mathrm{F}\right)$ : Evaporator Capacity (Btu/h): (CONDENSER)

$\begin{array}{rr}\text { Inlet Temperature }\left({ }^{\circ} \mathrm{F}\right): & 147.55 \\ \text { Exit Temperature }\left({ }^{\circ} \mathrm{F}\right): & 90.42 \\ \text { Inlet Pressure (psia): } & 335.32 \\ \text { Exit Pressure (psia): } & 333.00 \\ \text { Pressure Drop (psid): } & 2.31 \\ \text { Exit Subcooling }\left({ }^{\circ} \mathrm{F}\right): & 7.58 \\ \text { Sat. Temperature }\left({ }^{\circ} \mathrm{F}\right): & 100.94\end{array}$

Inlet Sat. Temperature $\left({ }^{\circ} \mathrm{F}\right): \quad 100.94$ (LIQUID LINE AND TXV)

Cond Unit Exit Temp $\left({ }^{\circ} \mathrm{F}\right)$ :

Cond Unit Exit Pres (psia): Liq-line Pressure Drop (psid): TXV Upstream Pressure (psia): TXV Pressure Drop (psid): Temperature Drop $\left({ }^{\circ} \mathrm{F}\right)$ : (COMPRESSOR)

Suction Temperature $\left({ }^{\circ} \mathrm{F}\right)$ : Discharge Temperature $\left({ }^{\circ} \mathrm{F}\right)$ : Suction Pressure (psia):

Discharge Pressure (psia): Discharge Superheat $\left({ }^{\circ} \mathrm{F}\right)$ : Comp Bottom Shell Temp $\left({ }^{\circ} \mathrm{F}\right)$ : Mass Flow Rate (l bm/h):

Comp Power Consumption (W) :

Cond Unit Inlet Temp $\left({ }^{\circ} \mathrm{F}\right)$ : Cond Unit Inlet Pres (psia):
30.01

79.99

34.22

81.85

79.99

34.22

51.76

34.71

0.191

0.520

28.23

900.1

402.36

81.85

97.37

15.51

159.95

0.0

27655.3

27305.9

1.000

2293.9

11.90

2. 24

49.54

57.45

151.05

141.95

9.10

13.52

43.93

28342.1

35307.6

91.29

326.91

11.13

315.78

164.73

0.62

62.17

151.87

139.61

335.90

51.07

108.60

387.32

1731.6

59.66

140.91
HEAT PUMP FAULT TEST SUMMARY

INDOOR/OUTDOOR CONDITION \#: 13

FAULT TYPE: IMPROPER INDOOR AIR FLOW FAULT FAULT LEVEL [\%]: 21.1

\section{RUNNING CONDITIONS}

Barometric Pressure (inHg): Indoor Dry-Bulb Temperature $\left({ }^{\circ} \mathrm{F}\right)$ : Indoor Dew-Point Temperature $\left({ }^{\circ} \mathrm{F}\right)$ : Outdoor Dry-Bulb Temperature $\left({ }^{\circ} \mathrm{F}\right)$ : AIR SIDE CONDITIONS

(INDOOR UNIT)

Inlet Dry-Bulb Temperature $\left({ }^{\circ} \mathrm{F}\right)$ :

Inlet Dew-Point Temperature $\left({ }^{\circ} \mathrm{F}\right)$ :

Exit Dry-Bulb Temperature $\left({ }^{\circ} \mathrm{F}\right)$ :

Exit Dew-Point Temperature $\left({ }^{\circ} \mathrm{F}\right)$ :

Inlet Relative Humidity $(-)$ : Exit Relative Humidity (-) : Evaporator Coil Temp Drop $\left({ }^{\circ} \mathrm{F}\right)$ : Air Flow Rate (SCFM): Fan Power Consumption (W): (OUTDOOR UNIT)

Inlet Temperature $\left({ }^{\circ} \mathrm{F}\right)$ : Exit Temperature $\left({ }^{\circ} \mathrm{F}\right)$ : Condensing Unit Temp Gain $\left({ }^{\circ} \mathrm{F}\right)$ : Fan Power Consumption (W): (OVERALL PERFORMANCE)

Latent Capacity (Btu/h): Sensible Capacity (Btu/h): Overall Capacity (Btu/h): Sensible Heat Ratio (-):

Overall Power Consumption (W) : NET Cooling EER (Btu/h.W): Evaporator Energy Imbalance (\%): REFRIGERANT SIDE CONDITIONS

(EVAPORATOR)

Inlet Temperature $\left({ }^{\circ} \mathrm{F}\right)$ : Exit Temperature $\left({ }^{\circ} \mathrm{F}\right)$ : Inlet Pressure (psia): Exit Pressure (psia): Pressure Drop (psid): Exit Superheat $\left({ }^{\circ} \mathrm{F}\right)$ : Exit Sat. Temperature $\left({ }^{\circ} \mathrm{F}\right)$ : Evaporator Capacity (Btu/h): (CONDENSER)

$\begin{array}{rr}\text { Inlet Temperature }\left({ }^{\circ} \mathrm{F}\right): & 148.07 \\ \text { Exit Temperature }\left({ }^{\circ} \mathrm{F}\right): & 90.32 \\ \text { Inlet Pressure (psia): } & 333.44 \\ \text { Exit Pressure (psia): } & 331.23 \\ \text { Pressure Drop (psid): } & 2.21 \\ \text { Exit Subcooling }\left({ }^{\circ} \mathrm{F}\right): & 7.53 \\ \text { Sat. Temperature }\left({ }^{\circ} \mathrm{F}\right): & 100.53\end{array}$

Inlet sat. Temperature $\left({ }^{\circ} \mathrm{F}\right)$ : (LIQUID LINE AND TXV)

Cond Unit Exit Temp $\left({ }^{\circ} \mathrm{F}\right)$ : Cond Unit Exit Pres (psia): Liq-line Pressure Drop (psid): TXV Upstream Pressure (psia): TXV Pressure Drop (psid): (COMPRESSOR) Temperature Drop $\left({ }^{\circ} \mathrm{F}\right)$ :

Suction Temperature $\left({ }^{\circ} \mathrm{F}\right)$ :

Discharge Temperature $\left({ }^{\circ} \mathrm{F}\right)$ : Suction Pressure (psia):

Discharge Pressure (psia): Discharge Superheat $\left({ }^{\circ} \mathrm{F}\right)$ : Comp Bottom Shell Temp $\left({ }^{\circ} \mathrm{F}\right)$ : Mass Flow Rate $(1 \mathrm{bm} / \mathrm{h})$ : Comp Power Consumption (W) :

Cond Unit Inlet Temp $\left({ }^{\circ} \mathrm{F}\right)$ : Cond Unit Inlet Pres (psia):
30.01 80.10 33.50 81.92

80.10

33.50

49.90

33.94

0.185

0.540

30.20

802.4

383.30

81.92

97.01

15.09

159.78

0.0

26363.7

26091.5

1.000

2268.7

11.50

3.44

47.92

55.53

146.92

138.00

8.92

13.27

42.26

27418.9

48.07

90.32

. 21

4326.2

91.03

325.52

10.45

315.07

168.15

0.63

60.80

152.59

135.68

334.03

52.20

108.84

374.88

1725.6

58.00

137.00 
HEAT PUMP FAULT TEST SUMMARY

INDOOR/OUTDOOR CONDITION \#: 13

FAULT TYPE: IMPROPER INDOOR AIR FLOW FAULT

FAULT LEVEL [\%]: 30.9

RUNNING CONDITIONS

Barometric Pressure (inHg):

Indoor Dry-Bulb Temperature $\left({ }^{\circ} \mathrm{F}\right)$ :

Indoor Dew-Point Temperature $\left({ }^{\circ} \mathrm{F}\right)$ :

Outdoor Dry-Bulb Temperature $\left({ }^{\circ} \mathrm{F}\right)$ :

AIR SIDE CONDITIONS

(INDOOR UNIT)

Inlet Dry-Bulb Temperature $\left({ }^{\circ} \mathrm{F}\right)$ : Inlet Dew-Point Temperature $\left({ }^{\circ} \mathrm{F}\right)$ :

Exit Dry-Bulb Temperature $\left({ }^{\circ} \mathrm{F}\right)$ :

Exit Dew-Point Temperature $\left({ }^{\circ} \mathrm{F}\right)$ :

Inlet Relative Humidity (-):

Exit Relative Humidity (-):

Evaporator Coil Temp Drop ( $\left.{ }^{\circ} \mathrm{F}\right)$ :

Air Flow Rate (SCFM):

Fan Power Consumption (W):

(OUTDOOR UNIT)

Inlet Temperature $\left({ }^{\circ} \mathrm{F}\right)$ : Exit Temperature $\left({ }^{\circ} \mathrm{F}\right)$ :

Condensing Unit Temp Gain $\left({ }^{\circ} \mathrm{F}\right)$ : Fan Power Consumption (W): (OVERALL PERFORMANCE)

Latent Capacity $(\mathrm{Btu} / \mathrm{h})$ : Sensible Capacity (Btu/h): Overall Capacity (Btu/h): Sensible Heat Ratio (-): Overall Power Consumption (W): NET Cooling EER (Btu/h.W):

Evaporator Energy Imbalance (\%): REFRIGERANT SIDE CONDITIONS

(EVAPORATOR)

Inlet Temperature $\left({ }^{\circ} \mathrm{F}\right)$ :

Exit Temperature $\left({ }^{\circ} \mathrm{F}\right)$ :

Inlet Pressure (psia):

Exit Pressure (psia):

Pressure Drop (psid):

Exit Superheat $\left({ }^{\circ} \mathrm{F}\right)$ :

Exit Sat. Temperature $\left({ }^{\circ} \mathrm{F}\right)$ :

Evaporator Capacity (Btu/h): (CONDENSER)

$\begin{array}{rr}\text { Inlet Temperature }\left({ }^{\circ} \mathrm{F}\right): & 147.97 \\ \text { Exit Temperature }\left({ }^{\circ} \mathrm{F}\right): & 89.89 \\ \text { Inlet Pressure (psia): } & 330.23 \\ \text { Exit Pressure (psia): } & 328.18 \\ \text { Pressure Drop (psid): } & 2.05 \\ \text { Exit Subcooling }\left({ }^{\circ} \mathrm{F}\right): & 7.38 \\ \text { t Sat. Temperature }\left({ }^{\circ} \mathrm{F}\right): & 99.82 \\ \text { denser Capacity }(\mathrm{Btu} / \mathrm{h}): & 32884.7\end{array}$

(LIQUID LINE AND TXV)

Cond Unit Exit Temp $\left({ }^{\circ} \mathrm{F}\right): \quad 90.59$

Cond Unit Exit Pres (psia): 322.92

Liq-line Pressure Drop (psid): $\quad 9.42$

TXV Upstream Pressure (psia): 313.50

TXV Pressure Drop (psid): 171.87

(COMPRESSOR) Temperature Drop $\left({ }^{\circ} \mathrm{F}\right): \quad 0.60$

Suction Temperature $\left({ }^{\circ} \mathrm{F}\right): \quad 58.52$

Discharge Temperature $\left({ }^{\circ} \mathrm{F}\right): \quad 152.74$

Suction Pressure (psia): 130.77

Discharge Pressure (psia): 330.84

Discharge Superheat $\left({ }^{\circ} \mathrm{F}\right): \quad 53.06$

Comp Bottom Shell Temp $\left({ }^{\circ} \mathrm{F}\right): \quad 108.70$

Mass Flow Rate $(1 \mathrm{bm} / \mathrm{h}): \quad 357.66$

Comp Power Consumption (W) : 1718.3

Cond Unit Inlet Temp $\left({ }^{\circ} \mathrm{F}\right): \quad 55.24$

Cond Unit Inlet Pres (psia): 132.13 


\section{D.5 Liquid Line Restriction Fault Tests}

Table D.5. List of raw data for liquid line restriction fault tests

\begin{tabular}{c|r|r|r|r|r}
\hline \multirow{2}{*}{$\begin{array}{c}\text { Test } \\
\text { condition \# }\end{array}$} & \multicolumn{3}{|c|}{ Nominal chamber condition } & \multirow{2}{*}{ Fault Type } & \multicolumn{2}{c}{$\begin{array}{c}\text { Fault level } \\
(\%)\end{array}$} \\
\cline { 2 - 3 } & $T_{I D}\left({ }^{\circ} \mathrm{F}\right)$ & \multicolumn{1}{c}{$\phi_{I D}(\boldsymbol{\%})$} & $T_{O D}\left({ }^{\circ} \mathrm{F}\right)$ & \\
\hline 4 & 70 & 50 & 82 & LL & 3.7 \\
\hline 4 & 70 & 50 & 82 & LL & 7.0 \\
\hline 4 & 70 & 50 & 82 & LL & 12.5 \\
\hline 4 & 70 & 50 & 82 & LL & 19.0 \\
\hline 5 & 80 & 50 & 82 & LL & 5.3 \\
\hline 5 & 80 & 50 & 82 & LL & 10.4 \\
\hline 5 & 80 & 50 & 82 & LL & 20.2 \\
\hline 5 & 80 & 50 & 82 & LL & 31.9 \\
\hline 8 & 70 & 50 & 100 & LL & 4.4 \\
\hline 8 & 70 & 50 & 100 & LL & 8.8 \\
\hline 8 & 70 & 50 & 100 & LL & 13.3 \\
\hline 9 & 80 & 50 & 100 & LL & 7.1 \\
\hline 9 & 80 & 50 & 100 & LL & 13.3 \\
\hline 9 & 80 & 50 & 100 & LL & 20.0 \\
\hline
\end{tabular}


HEAT PUMP FAULT TEST SUMMARY

INDOOR/OUTDOOR CONDITION \#: 04

FAULT TYPE: LIQUID LINE RESTRICTION FAULT FAULT LEVEL [\%]: 3.7

\section{RUNNING CONDITIONS}

Barometric Pressure (inHg): Indoor Dry-Bulb Temperature $\left({ }^{\circ} \mathrm{F}\right)$ : Indoor Dew-Point Temperature $\left({ }^{\circ} \mathrm{F}\right)$ : Outdoor Dry-Bulb Temperature $\left({ }^{\circ} \mathrm{F}\right)$ : AIR SIDE CONDITIONS

(INDOOR UNIT)

Inlet Dry-Bulb Temperature $\left({ }^{\circ} \mathrm{F}\right)$ : Inlet Dew-Point Temperature $\left({ }^{\circ} \mathrm{F}\right)$ : Exit Dry-Bulb Temperature $\left({ }^{\circ} \mathrm{F}\right)$ : Exit Dew-Point Temperature $\left({ }^{\circ} \mathrm{F}\right)$ : Inlet Relative Humidity (-): Exit Relative Humidity (-): Evaporator Coil Temp Drop $\left({ }^{\circ} \mathrm{F}\right)$ : Air Flow Rate (SCFM): Fan Power Consumption (W): (OUTDOOR UNIT)

Inlet Temperature $\left({ }^{\circ} \mathrm{F}\right)$ : Exit Temperature $\left({ }^{\circ} \mathrm{F}\right)$ : Condensing Unit Temp Gain $\left({ }^{\circ} \mathrm{F}\right)$ : Fan Power Consumption (W): (OVERALL PERFORMANCE)

Latent Capacity (Btu/h): Sensible Capacity (Btu/h): Overall Capacity (Btu/h): Sensible Heat Ratio (-): Overall Power Consumption (W): NET Cooling EER (Btu/h.W): Evaporator Energy Imbalance (\%): REFRIGERANT SIDE CONDITIONS

(EVAPORATOR)

Inlet Temperature $\left({ }^{\circ} \mathrm{F}\right)$ : Exit Temperature $\left({ }^{\circ} \mathrm{F}\right)$ : Inlet Pressure (psia): Exit Pressure (psia): Pressure Drop (psid): Exit Superheat $\left({ }^{\circ} \mathrm{F}\right)$ : Exit Sat. Temperature $\left({ }^{\circ} \mathrm{F}\right)$ : Evaporator Capacity (Btu/h): (CONDENSER)

$$
\begin{array}{rr}
\text { Inlet Temperature }\left({ }^{\circ} \mathrm{F}\right): & 147.53 \\
\text { Exit Temperature }\left({ }^{\circ} \mathrm{F}\right): & 89.74 \\
\text { Inlet Pressure (psia): } & 333.13 \\
\text { Exit Pressure (psia): } & 330.97 \\
\text { Pressure Drop (psid): } & 2.16 \\
\text { Exit Subcooling }\left({ }^{\circ} \mathrm{F}\right): & 8.21 \\
\text { Sat. Temperature }\left({ }^{\circ} \mathrm{F}\right): & 100.46
\end{array}
$$

Inlet Sat. Temperature $\left({ }^{\circ} \mathrm{F}\right)$ :

Condenser Capacity (Btu/h): (LIQUID LINE AND TXV)

Cond Unit Exit Temp $\left({ }^{\circ} \mathrm{F}\right)$ :

Cond Unit Exit Pres (psia): Liq-line Pressure Drop (psid): TXV Upstream Pressure (psia): TXV Pressure Drop (psid): Temperature Drop $\left({ }^{\circ} \mathrm{F}\right)$ : (COMPRESSOR)

Suction Temperature $\left({ }^{\circ} \mathrm{F}\right)$ : Discharge Temperature $\left({ }^{\circ} \mathrm{F}\right)$ : Suction Pressure (psia):

Discharge Pressure (psia): Discharge Superheat $\left({ }^{\circ} \mathrm{F}\right)$ : Comp Bottom Shell Temp $\left({ }^{\circ} \mathrm{F}\right)$ : Mass Flow Rate (l bm/h):

Comp Power Consumption (W):

Cond Unit Inlet Temp $\left({ }^{\circ} \mathrm{F}\right)$ : Cond Unit Inlet Pres (psia):
30.33

69.84

50.31

69.84

0.31

47.12

0.499

19.33

1031.7

81.82

96.75

14.93

4268.5

21820.3

6088.7

2309.9

3.45

46.13

55.62

138.00

9.09

13.37

42.25

34444.5

90.24

325.04

16.70

308.34

161.25

0.95

60.59

151.99

135.68

334.02

51.60

108.39

375.44

1726.5

57.76

137.00
HEAT PUMP FAULT TEST SUMMARY

INDOOR/OUTDOOR CONDITION \#: 04 FAULT TYPE: LIQUID LINE RESTRICTION FAULT FAULT LEVEL [\%]: 7.0

RUNNING CONDITIONS

Barometric Pressure (inHg): Indoor Dry-Bulb Temperature $\left({ }^{\circ} \mathrm{F}\right)$ : Indoor Dew-Point Temperature $\left({ }^{\circ} \mathrm{F}\right)$ : Outdoor Dry-Bulb Temperature $\left({ }^{\circ} \mathrm{F}\right)$ : AIR SIDE CONDITIONS

(INDOOR UNIT)

Inlet Dry-Bulb Temperature $\left({ }^{\circ} \mathrm{F}\right)$ :

Inlet Dew-Point Temperature $\left({ }^{\circ} \mathrm{F}\right)$ : Exit Dry-Bulb Temperature $\left({ }^{\circ} \mathrm{F}\right)$ : Exit Dew-Point Temperature $\left({ }^{\circ} \mathrm{F}\right)$ : Inlet Relative Humidity $(-)$ : Exit Relative Humidity (-): Evaporator Coil Temp Drop $\left({ }^{\circ} \mathrm{F}\right)$ : Air Flow Rate (SCFM): Fan Power Consumption (W): (OUTDOOR UNIT)

Inlet Temperature $\left({ }^{\circ} \mathrm{F}\right)$ : Exit Temperature $\left({ }^{\circ} \mathrm{F}\right)$ : Condensing Unit Temp Gain $\left({ }^{\circ} \mathrm{F}\right)$ : Fan Power Consumption (W): (OVERALL PERFORMANCE)

Latent Capacity (Btu/h) : Sensible Capacity (Btu/h): Overall Capacity (Btu/h): Sensible Heat Ratio (-):

Overall Power Consumption (W) : NET Cooling EER (Btu/h.W): Evaporator Energy Imbalance (\%): REFRIGERANT SIDE CONDITIONS

(EVAPORATOR)

Inlet Temperature $\left({ }^{\circ} \mathrm{F}\right)$ : Exit Temperature $\left({ }^{\circ} \mathrm{F}\right)$ : Inlet Pressure (psia): Exit Pressure (psia): Pressure Drop (psid): Exit Superheat $\left({ }^{\circ} \mathrm{F}\right)$ : Exit Sat. Temperature $\left({ }^{\circ} \mathrm{F}\right)$ : Evaporator Capacity (Btu/h): (CONDENSER)

$\begin{array}{rr}\text { Inlet Temperature }\left({ }^{\circ} \mathrm{F}\right): & 147.18 \\ \text { Exit Temperature }\left({ }^{\circ} \mathrm{F}\right): & 89.80 \\ \text { Inlet Pressure (psia): } & 332.36 \\ \text { Exit Pressure (psia): } & 330.16 \\ \text { Pressure Drop (psid): } & 2.20 \\ \text { Exit Subcooling }\left({ }^{\circ} \mathrm{F}\right): & 7.79 \\ \text { Sat. Temperature }\left({ }^{\circ} \mathrm{F}\right): & 100.29 \\ \text { denser Capacity (Btu/h): } & 34614.2\end{array}$

\section{(LIQUID LINE AND TXV)}

Condenser Capacity (Btu/h) :

Cond Unit Exit Temp $\left({ }^{\circ} \mathrm{F}\right)$ : Cond Unit Exit Pres (psia): Liq-line Pressure Drop (psid): TXV Upstream Pressure (psia): TXV Pressure Drop (psid): (COMPRESSOR) Temperature Drop $\left({ }^{\circ} \mathrm{F}\right)$ :

Suction Temperature $\left({ }^{\circ} \mathrm{F}\right)$ :

Discharge Temperature $\left({ }^{\circ} \mathrm{F}\right)$ : Suction Pressure (psia):

Discharge Pressure (psia): Discharge Superheat $\left({ }^{\circ} \mathrm{F}\right)$ : Comp Bottom Shell Temp $\left({ }^{\circ} \mathrm{F}\right)$ : Mass Flow Rate $(1 \mathrm{bm} / \mathrm{h})$ : Comp Power Consumption (W) :

Cond Unit Inlet Temp $\left({ }^{\circ} \mathrm{F}\right)$ : Cond Unit Inlet Pres (psia):
30.24

69.96

50.46

81.69

69.96

50.46

50.77

47.12

0.499

0.872

19.19

1027.7

425.08

81.69

96.65

14.96

159.88

4472.6

21584.3

26056.9

0.828

2307.5

11.29

4.17

46.26

55.95

147.62

138.36

9.26

13.54

42.41

27635.1

87.18

32.36

.16

7.79

34614.2

90.49

324.28

22.12

302.16

154.54

1.00

60.79

151.62

136.12

333.45

51.36

108.30

378.03

1722.6

58.05

137.41 
HEAT PUMP FAULT TEST SUMMARY

INDOOR/OUTDOOR CONDITION \#: 04

FAULT TYPE: LIQUID LINE RESTRICTION FAULT FAULT LEVEL [\%]: 12.5

\section{RUNNING CONDITIONS}

Barometric Pressure (inHg): Indoor Dry-Bulb Temperature $\left({ }^{\circ} \mathrm{F}\right)$ : Indoor Dew-Point Temperature $\left({ }^{\circ} \mathrm{F}\right)$ : Outdoor Dry-Bulb Temperature $\left({ }^{\circ} \mathrm{F}\right)$ : AIR SIDE CONDITIONS

(INDOOR UNIT)

Inlet Dry-Bulb Temperature $\left({ }^{\circ} \mathrm{F}\right)$ : Inlet Dew-Point Temperature $\left({ }^{\circ} \mathrm{F}\right)$ : Exit Dry-Bulb Temperature $\left({ }^{\circ} \mathrm{F}\right)$ : Exit Dew-Point Temperature $\left({ }^{\circ} \mathrm{F}\right)$ : Inlet Relative Humidity (-): Exit Relative Humidity (-): Evaporator Coil Temp Drop $\left({ }^{\circ} \mathrm{F}\right)$ : Air Flow Rate (SCFM): Fan Power Consumption (W): (OUTDOOR UNIT)

Inlet Temperature $\left({ }^{\circ} \mathrm{F}\right)$ : Exit Temperature $\left({ }^{\circ} \mathrm{F}\right)$ : Condensing Unit Temp Gain $\left({ }^{\circ} \mathrm{F}\right)$ : Fan Power Consumption (W) : (OVERALL PERFORMANCE)

Latent Capacity (Btu/h): Sensible Capacity (Btu/h): Overall Capacity (Btu/h): Sensible Heat Ratio (-): Overall Power Consumption (W): NET Cooling EER (Btu/h.W): Evaporator Energy Imbalance (\%): REFRIGERANT SIDE CONDITIONS

(EVAPORATOR)

Inlet Temperature $\left({ }^{\circ} \mathrm{F}\right)$ : Exit Temperature $\left({ }^{\circ} \mathrm{F}\right)$ : Inlet Pressure (psia): Exit Pressure (psia): Pressure Drop (psid): Exit Superheat $\left({ }^{\circ} \mathrm{F}\right)$ : Exit Sat. Temperature $\left({ }^{\circ} \mathrm{F}\right)$ : Evaporator Capacity (Btu/h): (CONDENSER)

$\begin{array}{rr}\text { Inlet Temperature }\left({ }^{\circ} \mathrm{F}\right): & 147.19 \\ \text { Exit Temperature }\left({ }^{\circ} \mathrm{F}\right): & 89.57 \\ \text { Inlet Pressure (psia): } & 330.92 \\ \text { Exit Pressure (psia): } & 328.67 \\ \text { Pressure Drop (psid): } & 2.26 \\ \text { Exit Subcooling }\left({ }^{\circ} \mathrm{F}\right): & 7.69 \\ \text { Sat. Temperature }\left({ }^{\circ} \mathrm{F}\right): & 99.97\end{array}$

Inlet sat. Temperature $\left({ }^{\circ} \mathrm{F}\right)$ : (LIQUID LINE AND TXV)

Cond Unit Exit Temp $\left({ }^{\circ} \mathrm{F}\right)$ :

Cond Unit Exit Pres (psia): Liq-line Pressure Drop (psid): TXV Upstream Pressure (psia): TXV Pressure Drop (psid): Temperature Drop $\left({ }^{\circ} \mathrm{F}\right)$ : (COMPRESSOR)

Suction Temperature $\left({ }^{\circ} \mathrm{F}\right)$ : Discharge Temperature $\left({ }^{\circ} \mathrm{F}\right)$ : Suction Pressure (psia):

Discharge Pressure (psia): Discharge Superheat $\left({ }^{\circ} \mathrm{F}\right)$ : Comp Bottom Shell Temp $\left({ }^{\circ} \mathrm{F}\right)$ : Mass Flow Rate (l bm/h):

Comp Power Consumption (W) :

Cond Unit Inlet Temp $\left({ }^{\circ} \mathrm{F}\right)$ : Cond Unit Inlet Pres (psia):
30.25

69.91

50.42

81.47

69.91

50.42

50.94

46.53

0.500

0.848

18.97

1027.2

424.23

81.47

96.52

15.05

159.95

5151.7

21323.2

26474.9

0.805

2298.7

11.52

2.77

46.06

56.32

147.32

138.05

9.27

14.05

42.27

27663.9

47.19

89.57

30.92

.67

.26
7.69

4610.4

90.29

322.94

31.34

291.59

144.28

0.96

61.14

151.62

135.89

332.10

51.65

108.33

377.36

1714.5

58.41

137.16
HEAT PUMP FAULT TEST SUMMARY

INDOOR/OUTDOOR CONDITION \#: 04 FAULT TYPE: LIQUID LINE RESTRICTION FAULT FAULT LEVEL [\%]: 19.0

RUNNING CONDITIONS

Barometric Pressure (inHg): Indoor Dry-Bulb Temperature $\left({ }^{\circ} \mathrm{F}\right)$ : Indoor Dew-Point Temperature $\left({ }^{\circ} \mathrm{F}\right)$ : Outdoor Dry-Bulb Temperature $\left({ }^{\circ} \mathrm{F}\right)$ : AIR SIDE CONDITIONS

(INDOOR UNIT)

Inlet Dry-Bulb Temperature $\left({ }^{\circ} \mathrm{F}\right)$ :

Inlet Dew-Point Temperature $\left({ }^{\circ} \mathrm{F}\right)$ : Exit Dry-Bulb Temperature $\left({ }^{\circ} \mathrm{F}\right)$ : Exit Dew-Point Temperature $\left({ }^{\circ} \mathrm{F}\right)$ : Inlet Relative Humidity $(-)$ : Exit Relative Humidity (-): Evaporator Coil Temp Drop $\left({ }^{\circ} \mathrm{F}\right)$ : Air Flow Rate (SCFM): Fan Power Consumption (W): (OUTDOOR UNIT)

Inlet Temperature $\left({ }^{\circ} \mathrm{F}\right)$ : Exit Temperature $\left({ }^{\circ} \mathrm{F}\right)$ : Condensing Unit Temp Gain $\left({ }^{\circ} \mathrm{F}\right)$ : Fan Power Consumption (W): (OVERALL PERFORMANCE)

Latent Capacity $($ Btu/h) : Sensible Capacity (Btu/h): Overall Capacity (Btu/h): Sensible Heat Ratio (-):

Overall Power Consumption (W) : NET Cooling EER (Btu/h.W): Evaporator Energy Imbalance (\%): REFRIGERANT SIDE CONDITIONS

(EVAPORATOR)

Inlet Temperature $\left({ }^{\circ} \mathrm{F}\right)$ : Exit Temperature $\left({ }^{\circ} \mathrm{F}\right)$ : Inlet Pressure (psia): Exit Pressure (psia): Pressure Drop (psid): Exit Superheat $\left({ }^{\circ} \mathrm{F}\right)$ : Exit Sat. Temperature $\left({ }^{\circ} \mathrm{F}\right)$ : Evaporator Capacity (Btu/h): (CONDENSER)

Inlet Temperature $\left({ }^{\circ} \mathrm{F}\right)$ : Exit Temperature $\left({ }^{\circ} \mathrm{F}\right)$ : Inlet Pressure (psia): Exit Pressure (psia): Pressure Drop (psid): Exit Subcooling $\left({ }^{\circ} \mathrm{F}\right)$ :

Inlet Sat. Temperature $\left({ }^{\circ} \mathrm{F}\right)$ :

Condenser Capacity (Btu/h): (LIQUID LINE AND TXV)

Cond Unit Exit Temp $\left({ }^{\circ} \mathrm{F}\right)$ : Cond Unit Exit Pres (psia): Liq-line Pressure Drop (psid): TXV Upstream Pressure (psia): TXV Pressure Drop (psid): (COMPRESSOR) Temperature Drop $\left({ }^{\circ} \mathrm{F}\right)$ :

Suction Temperature $\left({ }^{\circ} \mathrm{F}\right)$ :

Discharge Temperature $\left({ }^{\circ} \mathrm{F}\right)$ : Suction Pressure (psia):

Discharge Pressure (psia): Discharge Superheat $\left({ }^{\circ} \mathrm{F}\right)$ : Comp Bottom Shell Temp $\left({ }^{\circ} \mathrm{F}\right)$ : Mass Flow Rate $(1 \mathrm{bm} / \mathrm{h})$ : Comp Power Consumption (W) :

Cond Unit Inlet Temp $\left({ }^{\circ} \mathrm{F}\right)$ : Cond Unit Inlet Pres (psia):
30.23

69.81

50.53

81.49

69.81

50.53

51.12

46.89

0.503

0.854

18.69

1026.6

424.94

81.49

96.46

14.97

160.09

4853.7

21000.2

25853.9

0.812

2308.1

11.20

4.69

45.71

58.06

145.89

136.80

9.09

16.33

41.74

27570.7

149.68

88.94

331.81

329.69

2.12

8. 98

100.17

34497.9

89.27

324.15

42.08

282.07

136.18

1.93

62.83

154.27

134.63

332.96

54.12

110.78

371.45

1723.0

60.12

135.90 
HEAT PUMP FAULT TEST SUMMARY

INDOOR/OUTDOOR CONDITION \#: 05

FAULT TYPE: LIQUID LINE RESTRICTION FAULT FAULT LEVEL [\%]: 5.3

\section{RUNNING CONDITIONS}

Barometric Pressure (inHg): Indoor Dry-Bulb Temperature $\left({ }^{\circ} \mathrm{F}\right)$ : Indoor Dew-Point Temperature $\left({ }^{\circ} \mathrm{F}\right)$ : Outdoor Dry-Bulb Temperature $\left({ }^{\circ} \mathrm{F}\right)$ : AIR SIDE CONDITIONS

(INDOOR UNIT)

Inlet Dry-Bulb Temperature $\left({ }^{\circ} \mathrm{F}\right)$ : Inlet Dew-Point Temperature $\left({ }^{\circ} \mathrm{F}\right)$ : Exit Dry-Bulb Temperature $\left({ }^{\circ} \mathrm{F}\right)$ : Exit Dew-Point Temperature $\left({ }^{\circ} \mathrm{F}\right)$ : Inlet Relative Humidity (-): Exit Relative Humidity (-): Evaporator Coil Temp Drop $\left({ }^{\circ} \mathrm{F}\right)$ : Air Flow Rate (SCFM): Fan Power Consumption (W): (OUTDOOR UNIT)

Inlet Temperature $\left({ }^{\circ} \mathrm{F}\right)$ : Exit Temperature $\left({ }^{\circ} \mathrm{F}\right)$ : Condensing Unit Temp Gain $\left({ }^{\circ} \mathrm{F}\right)$ : Fan Power Consumption (W): (OVERALL PERFORMANCE)

Latent Capacity (Btu/h): Sensible Capacity (Btu/h): Overall Capacity (Btu/h): Sensible Heat Ratio (-): Overall Power Consumption (W): NET Cooling EER (Btu/h.W): Evaporator Energy Imbalance (\%): REFRIGERANT SIDE CONDITIONS

(EVAPORATOR)

Inlet Temperature $\left({ }^{\circ} \mathrm{F}\right)$ : Exit Temperature $\left({ }^{\circ} \mathrm{F}\right)$ : Inlet Pressure (psia): Exit Pressure (psia): Pressure Drop (psid): Exit Superheat $\left({ }^{\circ} \mathrm{F}\right)$ : Exit Sat. Temperature $\left({ }^{\circ} \mathrm{F}\right)$ : Evaporator Capacity (Btu/h): (CONDENSER)

$\begin{array}{rr}\text { Inlet Temperature }\left({ }^{\circ} \mathrm{F}\right): & 147.10 \\ \text { Exit Temperature }\left({ }^{\circ} \mathrm{F}\right): & 90.87 \\ \text { Inlet Pressure (psia): } & 345.24 \\ \text { Exit Pressure (psia): } & 342.61 \\ \text { Pressure Drop (psid): } & 2.63 \\ \text { Exit Subcooling }\left({ }^{\circ} \mathrm{F}\right): & 8.57 \\ \text { Sat. Temperature }\left({ }^{\circ} \mathrm{F}\right): & 103.08\end{array}$

Inlet Sat. Temperature $\left({ }^{\circ} \mathrm{F}\right)$ :

Condenser Capacity (Btu/h): (LIQUID LINE AND TXV)

Cond Unit Exit Temp $\left({ }^{\circ} \mathrm{F}\right)$ :

Cond Unit Exit Pres (psia): Liq-line Pressure Drop (psid): TXV Upstream Pressure (psia): TXV Pressure Drop (psid): Temperature Drop $\left({ }^{\circ} \mathrm{F}\right)$ : (COMPRESSOR)

Suction Temperature $\left({ }^{\circ} \mathrm{F}\right)$ : Discharge Temperature $\left({ }^{\circ} \mathrm{F}\right)$ : Suction Pressure (psia):

Discharge Pressure (psia): Discharge Superheat $\left({ }^{\circ} \mathrm{F}\right)$ : Comp Bottom Shell Temp $\left({ }^{\circ} \mathrm{F}\right)$ : Mass Flow Rate (l bm/h):

Comp Power Consumption (W):

Cond Unit Inlet Temp $\left({ }^{\circ} \mathrm{F}\right)$ : Cond Unit Inlet Pres (psia):
30.43

80.13

60.36

81.80

80.13

60.36

59.17

56.18

0.510

0.898

20.96

1013.8

421.74

81.80

99.08

17.28

161.18

7527.5

23388.1

30915.6

0.757

2344.8

13.19

3.03

54.73

65.87

169.66

159.43

10.23

14.91

50.95

32316.8

47.10

90.87

2.61

2.63
8.57

103.08

39330.8

92.09

335.01

22.16

312.84

143.18

0.70

68.94

150.90

156.96

346.48

47.82

109.48

436.71

1761.9

67.26

158.20
HEAT PUMP FAULT TEST SUMMARY

INDOOR/OUTDOOR CONDITION \#: 05 FAULT TYPE: LIOUID LINE RESTRICTION FAULT FAULT LEVEL [\%]: 10.4

RUNNING CONDITIONS

Barometric Pressure (inHg): Indoor Dry-Bulb Temperature $\left({ }^{\circ} \mathrm{F}\right)$ : Indoor Dew-Point Temperature $\left({ }^{\circ} \mathrm{F}\right)$ : Outdoor Dry-Bulb Temperature $\left({ }^{\circ} \mathrm{F}\right)$ : AIR SIDE CONDITIONS (INDOOR UNIT)

Inlet Dry-Bulb Temperature $\left({ }^{\circ} \mathrm{F}\right)$ : Inlet Dew-Point Temperature $\left({ }^{\circ} \mathrm{F}\right)$ : Exit Dry-Bulb Temperature $\left({ }^{\circ} \mathrm{F}\right)$ : Exit Dew-Point Temperature $\left({ }^{\circ} \mathrm{F}\right)$ : Inlet Relative Humidity $(-)$ : Exit Relative Humidity (-): Evaporator Coil Temp Drop $\left({ }^{\circ} \mathrm{F}\right)$ : Air Flow Rate (SCFM): Fan Power Consumption (W): (OUTDOOR UNIT)

Inlet Temperature $\left({ }^{\circ} \mathrm{F}\right)$ : Exit Temperature $\left({ }^{\circ} \mathrm{F}\right)$ : Condensing Unit Temp Gain $\left({ }^{\circ} \mathrm{F}\right)$ : Fan Power Consumption (W): (OVERALL PERFORMANCE)

Latent Capacity (Btu/h) : Sensible Capacity (Btu/h): Overall Capacity (Btu/h): Sensible Heat Ratio (-):

Overall Power Consumption (W) : NET Cooling EER (Btu/h.W): Evaporator Energy Imbalance (\%): REFRIGERANT SIDE CONDITIONS

(EVAPORATOR)

Inlet Temperature $\left({ }^{\circ} \mathrm{F}\right)$ : Exit Temperature $\left({ }^{\circ} \mathrm{F}\right)$ : Inlet Pressure (psia): Exit Pressure (psia): Pressure Drop (psid): Exit Superheat $\left({ }^{\circ} \mathrm{F}\right)$ : Exit Sat. Temperature $\left({ }^{\circ} \mathrm{F}\right)$ : Evaporator Capacity (Btu/h): (CONDENSER)

$\begin{array}{rr}\text { Inlet Temperature }\left({ }^{\circ} \mathrm{F}\right): & 148.28 \\ \text { Exit Temperature }\left({ }^{\circ} \mathrm{F}\right): & 90.86 \\ \text { Inlet Pressure (psia): } & 344.47 \\ \text { Exit Pressure (psia): } & 341.85 \\ \text { Pressure Drop (psid): } & 2.62 \\ \text { Exit Subcooling }\left({ }^{\circ} \mathrm{F}\right): & 8.53 \\ \text { Sat. Temperature }\left({ }^{\circ} \mathrm{F}\right): & 102.92\end{array}$

Inlet sat. Temperature (o $\mathrm{F})$ : (LIQUID LINE AND TXV)

Cond Unit Exit Temp $\left({ }^{\circ} \mathrm{F}\right)$ : Cond Unit Exit Pres (psia): Liq-line Pressure Drop (psid): TXV Upstream Pressure (psia): TXV Pressure Drop (psid): (COMPRESSOR) Temperature Drop $\left({ }^{\circ} \mathrm{F}\right)$ :

Suction Temperature $\left({ }^{\circ} \mathrm{F}\right)$ :

Discharge Temperature $\left({ }^{\circ} \mathrm{F}\right)$ : Suction Pressure (psia):

Discharge Pressure (psia): Discharge Superheat $\left({ }^{\circ} \mathrm{F}\right)$ : Comp Bottom Shell Temp $\left({ }^{\circ} \mathrm{F}\right)$ : Mass Flow Rate $(1 \mathrm{bm} / \mathrm{h})$ : Comp Power Consumption (W) :

Cond Unit Inlet Temp $\left({ }^{\circ} \mathrm{F}\right)$ : Cond Unit Inlet Pres (psia):
30.39

80.03

60.50

81.80

80.03

60.50

59.67

56.21

0.514

0.883

20.35

1012.0

418.16

81.80

98.96

17.16

159.95

7729.5

22667.9

30397.4

0.746

2336.3

13.01

4.51

54.50

66.84

168.49

158.15

10.35

16.39

50.46

32272.1

48.28

90.86

44.47

39244.3

92.01

334.44

29.95

304.48

135.99

0.66

69.90

152.05

155.75

345.60

49.16

110.56

433.78

1758.2

68.25

156.96 
HEAT PUMP FAULT TEST SUMMARY

INDOOR/OUTDOOR CONDITION \#: 05

FAULT TYPE: LIQUID LINE RESTRICTION FAULT FAULT LEVEL [\%]: 20.2

\section{RUNNING CONDITIONS}

Barometric Pressure (inHg): Indoor Dry-Bulb Temperature $\left({ }^{\circ} \mathrm{F}\right)$ : Indoor Dew-Point Temperature $\left({ }^{\circ} \mathrm{F}\right)$ : Outdoor Dry-Bulb Temperature $\left({ }^{\circ} \mathrm{F}\right)$ : AIR SIDE CONDITIONS

(INDOOR UNIT)

Inlet Dry-Bulb Temperature $\left({ }^{\circ} \mathrm{F}\right)$ : Inlet Dew-Point Temperature $\left({ }^{\circ} \mathrm{F}\right)$ : Exit Dry-Bulb Temperature $\left({ }^{\circ} \mathrm{F}\right)$ : Exit Dew-Point Temperature $\left({ }^{\circ} \mathrm{F}\right)$ : Inlet Relative Humidity (-): Exit Relative Humidity (-): Evaporator Coil Temp Drop $\left({ }^{\circ} \mathrm{F}\right)$ : Air Flow Rate (SCFM): Fan Power Consumption (W): (OUTDOOR UNIT)

Inlet Temperature $\left({ }^{\circ} \mathrm{F}\right)$ : Exit Temperature $\left({ }^{\circ} \mathrm{F}\right)$ : Condensing Unit Temp Gain $\left({ }^{\circ} \mathrm{F}\right)$ : Fan Power Consumption (W): (OVERALL PERFORMANCE)

Latent Capacity (Btu/h): Sensible Capacity (Btu/h): Overall Capacity (Btu/h): Sensible Heat Ratio (-): Overall Power Consumption (W): NET Cooling EER (Btu/h.W): Evaporator Energy Imbalance (\%): REFRIGERANT SIDE CONDITIONS

(EVAPORATOR)

Inlet Temperature $\left({ }^{\circ} \mathrm{F}\right)$ : Exit Temperature $\left({ }^{\circ} \mathrm{F}\right)$ : Inlet Pressure (psia): Exit Pressure (psia): Pressure Drop (psid): Exit Superheat $\left({ }^{\circ} \mathrm{F}\right)$ : Exit Sat. Temperature $\left({ }^{\circ} \mathrm{F}\right)$ : Evaporator Capacity (Btu/h): (CONDENSER)

$\begin{array}{rr}\text { Inlet Temperature }\left({ }^{\circ} \mathrm{F}\right): & 155.46 \\ \text { Exit Temperature }\left({ }^{\circ} \mathrm{F}\right): & 89.64 \\ \text { Inlet Pressure (psia): } & 342.89 \\ \text { Exit Pressure (psia): } & 340.65 \\ \text { Pressure Drop (psid): } & 2.24 \\ \text { Exit Subcooling }\left({ }^{\circ} \mathrm{F}\right): & 10.72 \\ \text { Sat. Temperature }\left({ }^{\circ} \mathrm{F}\right): & 102.58\end{array}$

Inlet sat. Temperature $\left({ }^{\circ} \mathrm{F}\right): \quad 102.58$ (LIQUID LINE AND TXV)

Cond Unit Exit Temp $\left({ }^{\circ} \mathrm{F}\right)$ :

Cond Unit Exit Pres (psia): Liq-line Pressure Drop (psid): TXV Upstream Pressure (psia): TXV Pressure Drop (psid): Temperature Drop $\left({ }^{\circ} \mathrm{F}\right)$ : (COMPRESSOR)

Suction Temperature $\left({ }^{\circ} \mathrm{F}\right)$ Discharge Temperature $\left({ }^{\circ} \mathrm{F}\right)$ : Suction Pressure (psia):

Discharge Pressure (psia): Discharge Superheat $\left({ }^{\circ} \mathrm{F}\right)$ : Comp Bottom Shell Temp $\left({ }^{\circ} \mathrm{F}\right)$ : Mass Flow Rate (l bm/h):

Comp Power Consumption (W) :

Cond Unit Inlet Temp $\left({ }^{\circ} \mathrm{F}\right)$ : Cond Unit Inlet Pres (psia):
30.35

79.96

60.66

82.06

79.96

60.66

60.35

56.54

0.518

0.872

19.62

1008.8

418.33

82.06

98.24

16.17

159.45

7477.4

21783.3

29260.6

0.744

2344.8

12.48

2.73

51.13

70.12

157.98

148.60

9.38

23.45

46.68

30511.2

37348.4

89.83

334.52

44.81

289.71

131.73

0.48

73.48

159.83

146.40

343.76

57.33

116.77

398.43

1767.0

71.47

147.57
HEAT PUMP FAULT TEST SUMMARY

INDOOR/OUTDOOR CONDITION \#: 05 FAULT TYPE: LIQUID LINE RESTRICTION FAULT FAULT LEVEL [\%]: 31.9

RUNNING CONDITIONS

Barometric Pressure (inHg): Indoor Dry-Bulb Temperature $\left({ }^{\circ} \mathrm{F}\right)$ : Indoor Dew-Point Temperature $\left({ }^{\circ} \mathrm{F}\right)$ : Outdoor Dry-Bulb Temperature $\left({ }^{\circ} \mathrm{F}\right)$ : AIR SIDE CONDITIONS (INDOOR UNIT)

Inlet Dry-Bulb Temperature $\left({ }^{\circ} \mathrm{F}\right)$ : Inlet Dew-Point Temperature $\left({ }^{\circ} \mathrm{F}\right)$ : Exit Dry-Bulb Temperature $\left({ }^{\circ} \mathrm{F}\right)$ : Exit Dew-Point Temperature $\left({ }^{\circ} \mathrm{F}\right)$ : Inlet Relative Humidity (-) : Exit Relative Humidity (-): Evaporator Coil Temp Drop $\left({ }^{\circ} \mathrm{F}\right)$ : Air Flow Rate (SCFM): Fan Power Consumption (W): (OUTDOOR UNIT)

Inlet Temperature $\left({ }^{\circ} \mathrm{F}\right)$ : Exit Temperature $\left({ }^{\circ} \mathrm{F}\right)$ : Condensing Unit Temp Gain $\left({ }^{\circ} \mathrm{F}\right)$ : Fan Power Consumption (W): (OVERALL PERFORMANCE)

Latent Capacity (Btu/h): Sensible Capacity (Btu/h): Overall Capacity (Btu/h): Sensible Heat Ratio (-):

Overall Power Consumption (W) : NET Cooling EER (Btu/h.W): Evaporator Energy Imbalance (\%): REFRIGERANT SIDE CONDITIONS

(EVAPORATOR)

Inlet Temperature $\left({ }^{\circ} \mathrm{F}\right)$ : Exit Temperature $\left({ }^{\circ} \mathrm{F}\right)$ : Inlet Pressure (psia): Exit Pressure (psia): Pressure Drop (psid): Exit Superheat $\left({ }^{\circ} \mathrm{F}\right)$ : Exit Sat. Temperature $\left({ }^{\circ} \mathrm{F}\right)$ : Evaporator Capacity (Btu/h): (CONDENSER)

$\begin{array}{rr}\text { Inlet Temperature }\left({ }^{\circ} \mathrm{F}\right): & 168.00 \\ \text { Exit Temperature }\left({ }^{\circ} \mathrm{F}\right): & 88.02 \\ \text { Inlet Pressure (psia): } & 331.54 \\ \text { Exit Pressure (psia): } & 329.96 \\ \text { Pressure Drop (psid): } & 1.58 \\ \text { Exit Subcooling }\left({ }^{\circ} \mathrm{F}\right): & 11.25 \\ \text { Sat. Temperature }\left({ }^{\circ} \mathrm{F}\right): & 100.11 \\ \text { denser Capacity (Btu/h): } & 30039.5\end{array}$
(LIQUID LINE AND TXV)

Cond Unit Exit Temp $\left({ }^{\circ} \mathrm{F}\right)$ : Cond Unit Exit Pres (psia): Liq-line Pressure Drop (psid): TXV Upstream Pressure (psia): TXV Pressure Drop (psid): (COMPRESSOR) Temperature Drop $\left({ }^{\circ} \mathrm{F}\right)$ :

Suction Temperature $\left({ }^{\circ} \mathrm{F}\right)$ :

Discharge Temperature $\left({ }^{\circ} \mathrm{F}\right)$ : Suction Pressure (psia):

Discharge Pressure (psia): Discharge Superheat $\left({ }^{\circ} \mathrm{F}\right)$ : Comp Bottom Shell Temp $\left({ }^{\circ} \mathrm{F}\right)$ : Mass Flow Rate $(1 \mathrm{bm} / \mathrm{h})$ : Comp Power Consumption (W) :

Cond Unit Inlet Temp $\left({ }^{\circ} \mathrm{F}\right)$ : Cond Unit Inlet Pres (psia):
30.33

79.93

60.65

82.10

79.93

60.65

62.48

58.21

0.518

0.859

17.45

1005.9

419.60

82.10

95.71

13.62

160.32

4541.8

19333.4

23875.2

0.810

2321.7

10.28

$-2.53$

41.30

71.61

132.00

124.46

7.54

35.39

36.22

23696.0

68.00

88.02

29. 96

1.58

87.49

326.31

62.45

263.87

131.87

4.83

76.13

174.64

122.37

332.47

74.60

125.89

302.35

1741.7

73.13

123.62 
HEAT PUMP FAULT TEST SUMMARY

INDOOR/OUTDOOR CONDITION \#: 08

FAULT TYPE: LIQUID LINE RESTRICTION FAULT FAULT LEVEL [\%]: 4.4

\section{RUNNING CONDITIONS}

Barometric Pressure (inHg): Indoor Dry-Bulb Temperature $\left({ }^{\circ} \mathrm{F}\right)$ : Indoor Dew-Point Temperature $\left({ }^{\circ} \mathrm{F}\right)$ : Outdoor Dry-Bulb Temperature $\left({ }^{\circ} \mathrm{F}\right)$ : AIR SIDE CONDITIONS

(INDOOR UNIT)

Inlet Dry-Bulb Temperature $\left({ }^{\circ} \mathrm{F}\right)$ : Inlet Dew-Point Temperature $\left({ }^{\circ} \mathrm{F}\right)$ : Exit Dry-Bulb Temperature $\left({ }^{\circ} \mathrm{F}\right)$ : Exit Dew-Point Temperature $\left({ }^{\circ} \mathrm{F}\right)$ : Inlet Relative Humidity (-): Exit Relative Humidity (-): Evaporator Coil Temp Drop $\left({ }^{\circ} \mathrm{F}\right)$ : Air Flow Rate (SCFM): Fan Power Consumption (W) : (OUTDOOR UNIT)

Inlet Temperature $\left({ }^{\circ} \mathrm{F}\right)$ : Exit Temperature $\left({ }^{\circ} \mathrm{F}\right)$ : Condensing Unit Temp Gain $\left({ }^{\circ} \mathrm{F}\right)$ : Fan Power Consumption (W) : (OVERALL PERFORMANCE)

Latent Capacity (Btu/h): Sensible Capacity (Btu/h): Overall Capacity (Btu/h): Sensible Heat Ratio (-): Overall Power Consumption (W): NET Cooling EER (Btu/h.W): Evaporator Energy Imbalance (\%): REFRIGERANT SIDE CONDITIONS

(EVAPORATOR)

Inlet Temperature $\left({ }^{\circ} \mathrm{F}\right)$ : Exit Temperature $\left({ }^{\circ} \mathrm{F}\right)$ : Inlet Pressure (psia): Exit Pressure (psia): Pressure Drop (psid): Exit Superheat $\left({ }^{\circ} \mathrm{F}\right)$ : Exit Sat. Temperature $\left({ }^{\circ} \mathrm{F}\right)$ : Evaporator Capacity (Btu/h): (CONDENSER)

$\begin{array}{rr}\text { Inlet Temperature }\left({ }^{\circ} \mathrm{F}\right): & 177.10 \\ \text { Exit Temperature }\left({ }^{\circ} \mathrm{F}\right): & 109.53 \\ \text { Inlet Pressure (psia): } & 421.33 \\ \text { Exit Pressure (psia): } & 419.43 \\ \text { Pressure Drop (psid): } & 1.90 \\ \text { Exit Subcooling }\left({ }^{\circ} \mathrm{F}\right): & 6.97\end{array}$

Inlet sat. Temperature $\left({ }^{\circ} \mathrm{F}\right)$ : Condenser Capacity (Btu/h): (LIQUID LINE AND TXV)

Cond Unit Exit Temp $\left({ }^{\circ} \mathrm{F}\right)$ : Cond Unit Exit Pres (psia): Liq-line Pressure Drop (psid): TXV Upstream Pressure (psia): TXV Pressure Drop (psid): Temperature Drop $\left({ }^{\circ} \mathrm{F}\right)$ : (COMPRESSOR)

Suction Temperature $\left({ }^{\circ} \mathrm{F}\right)$ : Discharge Temperature $\left({ }^{\circ} \mathrm{F}\right)$ : Suction Pressure (psia):

Discharge Pressure (psia): Discharge Superheat $\left({ }^{\circ} \mathrm{F}\right)$ : Comp Bottom Shell Temp $\left({ }^{\circ} \mathrm{F}\right)$ : Mass Flow Rate (l bm/h):

Comp Power Consumption (W) :

Cond Unit Inlet Temp $\left({ }^{\circ} \mathrm{F}\right)$ : Cond Unit Inlet Pres (psia):
29.70

70.21

50.35

100.02

70.21

50.35

52.06

47.84

0.493

0.855

18.15

1005.6

416.67

100.02

115.09

15.07

154.18

3384.8

19980.4

23365.2

0.855

2785.2

8.39

2.00

47.61

56.61

152.66

142.13

10.53

12.61

44.00

24267.9

109. 53

19.43

1.90
6.97

118.11

33103.3

109.56

413.86

22.22

391.64

238.98

1. 41

63.58

182.55

139.96

422.70

64.42

127.07

374.64

2214.4

59.30

141.17
HEAT PUMP FAULT TEST SUMMARY

INDOOR/OUTDOOR CONDITION \#: 08 FAULT TYPE: LIOUID LINE RESTRICTION FAULT FAULT LEVEL [\%]: 8.8

RUNNING CONDITIONS

Barometric Pressure (inHg): Indoor Dry-Bulb Temperature $\left({ }^{\circ} \mathrm{F}\right)$ : Indoor Dew-Point Temperature $\left({ }^{\circ} \mathrm{F}\right)$ : Outdoor Dry-Bulb Temperature $\left({ }^{\circ} \mathrm{F}\right)$ : AIR SIDE CONDITIONS (INDOOR UNIT)

Inlet Dry-Bulb Temperature $\left({ }^{\circ} \mathrm{F}\right)$ :

Inlet Dew-Point Temperature $\left({ }^{\circ} \mathrm{F}\right)$ : Exit Dry-Bulb Temperature $\left({ }^{\circ} \mathrm{F}\right)$ : Exit Dew-Point Temperature $\left({ }^{\circ} \mathrm{F}\right)$ : Inlet Relative Humidity $(-)$ : Exit Relative Humidity (-) : Evaporator Coil Temp Drop $\left({ }^{\circ} \mathrm{F}\right)$ : Air Flow Rate (SCFM): Fan Power Consumption (W) : (OUTDOOR UNIT)

Inlet Temperature $\left({ }^{\circ} \mathrm{F}\right)$ : Exit Temperature $\left({ }^{\circ} \mathrm{F}\right)$ : Condensing Unit Temp Gain $\left({ }^{\circ} \mathrm{F}\right)$ : Fan Power Consumption (W): (OVERALL PERFORMANCE)

Latent Capacity (Btu/h): Sensible Capacity (Btu/h): Overall Capacity (Btu/h): Sensible Heat Ratio (-):

Overall Power Consumption (W) : NET Cooling EER (Btu/h.W): Evaporator Energy Imbalance (\%): REFRIGERANT SIDE CONDITIONS

(EVAPORATOR)

Inlet Temperature $\left({ }^{\circ} \mathrm{F}\right)$ : Exit Temperature $\left({ }^{\circ} \mathrm{F}\right)$ : Inlet Pressure (psia): Exit Pressure (psia): Pressure Drop (psid): Exit Superheat $\left({ }^{\circ} \mathrm{F}\right)$ : Exit Sat. Temperature $\left({ }^{\circ} \mathrm{F}\right)$ : Evaporator Capacity (Btu/h): (CONDENSER)

Inlet Temperature $\left({ }^{\circ} \mathrm{F}\right)$ : Exit Temperature $\left({ }^{\circ} \mathrm{F}\right)$ : Inlet Pressure (psia): Exit Pressure (psia): Pressure Drop (psid): Exit Subcooling $\left({ }^{\circ} \mathrm{F}\right)$ :

Inlet Sat. Temperature $\left({ }^{\circ} \mathrm{F}\right)$ :

Condenser Capacity (Btu/h) : (LIQUID LINE AND TXV)

Cond Unit Exit Temp $\left({ }^{\circ} \mathrm{F}\right)$ : Cond Unit Exit Pres (psia): Liq-line Pressure Drop (psid): TXV Upstream Pressure (psia): TXV Pressure Drop (psid): (COMPRESSOR) Temperature Drop $\left({ }^{\circ} \mathrm{F}\right)$ :

Suction Temperature $\left({ }^{\circ} \mathrm{F}\right)$ :

Discharge Temperature $\left({ }^{\circ} \mathrm{F}\right)$ : Suction Pressure (psia):

Discharge Pressure (psia): Discharge Superheat $\left({ }^{\circ} \mathrm{F}\right)$ : Comp Bottom Shell Temp $\left({ }^{\circ} \mathrm{F}\right)$ : Mass Flow Rate $(1 \mathrm{bm} / \mathrm{h})$ : Comp Power Consumption (W) :

Cond Unit Inlet Temp $\left({ }^{\circ} \mathrm{F}\right)$ : Cond Unit Inlet Pres (psia):
29.71

70.17

50.41

100.09

70.17

50.41

51.95

48.08

0.495

0.866

18.22

1010.3

417.00

100.09

115.15

15.07

154.48

3163.7

20156.4

23320.2

0.864

2790.7

8.36

2.84

48.02

57.00

153.09

142.51

10.58

12.84

44.16

24431.2

177.05

109.84

421.62

419.72

1.91

6.71

118.16

33281.2

109.86

414.02

33.14

380.88

227.80

1.54

63.91

182.47

140.34

422.82

64.31

126.95

377.41

2219.2

59.69

141.58 
HEAT PUMP FAULT TEST SUMMARY

INDOOR/OUTDOOR CONDITION \#: 08

FAULT TYPE: LIQUID LINE RESTRICTION FAULT FAULT LEVEL [\%]: 13.3

\section{RUNNING CONDITIONS}

Barometric Pressure (inHg): Indoor Dry-Bulb Temperature $\left({ }^{\circ} \mathrm{F}\right)$ : Indoor Dew-Point Temperature $\left({ }^{\circ} \mathrm{F}\right)$ : Outdoor Dry-Bulb Temperature $\left({ }^{\circ} \mathrm{F}\right)$ : AIR SIDE CONDITIONS

(INDOOR UNIT)

Inlet Dry-Bulb Temperature $\left({ }^{\circ} \mathrm{F}\right)$ : Inlet Dew-Point Temperature $\left({ }^{\circ} \mathrm{F}\right)$ : Exit Dry-Bulb Temperature $\left({ }^{\circ} \mathrm{F}\right)$ : Exit Dew-Point Temperature $\left({ }^{\circ} \mathrm{F}\right)$ : Inlet Relative Humidity (-): Exit Relative Humidity (-): Evaporator Coil Temp Drop $\left({ }^{\circ} \mathrm{F}\right)$ : Air Flow Rate (SCFM) : Fan Power Consumption (W): (OUTDOOR UNIT)

Inlet Temperature $\left({ }^{\circ} \mathrm{F}\right)$ : Exit Temperature $\left({ }^{\circ} \mathrm{F}\right)$ : Condensing Unit Temp Gain $\left({ }^{\circ} \mathrm{F}\right)$ : Fan Power Consumption (W) : (OVERALL PERFORMANCE)

Latent Capacity (Btu/h): Sensible Capacity (Btu/h): Overall Capacity (Btu/h): Sensible Heat Ratio (-): Overall Power Consumption (W): NET Cooling EER (Btu/h.W): Evaporator Energy Imbalance (\%): REFRIGERANT SIDE CONDITIONS

(EVAPORATOR)

Inlet Temperature $\left({ }^{\circ} \mathrm{F}\right)$ : Exit Temperature $\left({ }^{\circ} \mathrm{F}\right)$ : Inlet Pressure (psia): Exit Pressure (psia): Pressure Drop (psid): Exit Superheat $\left({ }^{\circ} \mathrm{F}\right)$ : Exit Sat. Temperature $\left({ }^{\circ} \mathrm{F}\right)$ : Evaporator Capacity (Btu/h): (CONDENSER)

$\begin{array}{rr}\text { Inlet Temperature }\left({ }^{\circ} \mathrm{F}\right): & 177.51 \\ \text { Exit Temperature }\left({ }^{\circ} \mathrm{F}\right): & 109.67 \\ \text { Inlet Pressure (psia): } & 422.30 \\ \text { Exit Pressure (psia): } & 420.41 \\ \text { Pressure Drop (psid): } & 1.90 \\ \text { Exit Subcooling }\left({ }^{\circ} \mathrm{F}\right): & 7.16 \\ \text { Sat. Temperature }\left({ }^{\circ} \mathrm{F}\right): & 118.29\end{array}$

Inlet sat. Temperature $\left({ }^{\circ} \mathrm{F}\right): 0118.29$ (LIQUID LINE AND TXV)

Cond Unit Exit Temp $\left({ }^{\circ} \mathrm{F}\right)$ :

Cond Unit Exit Pres (psia): Liq-line Pressure Drop (psid): TXV Upstream Pressure (psia): TXV Pressure Drop (psid): Temperature Drop $\left({ }^{\circ} \mathrm{F}\right)$ : (COMPRESSOR)

Suction Temperature $\left({ }^{\circ} \mathrm{F}\right)$ : Discharge Temperature $\left({ }^{\circ} \mathrm{F}\right)$ : Suction Pressure (psia):

Discharge Pressure (psia): Discharge Superheat $\left({ }^{\circ} \mathrm{F}\right)$ : Comp Bottom Shell Temp $\left({ }^{\circ} \mathrm{F}\right)$ : Mass Flow Rate (l bm/h):

Comp Power Consumption (W):

Cond Unit Inlet Temp $\left({ }^{\circ} \mathrm{F}\right)$ : Cond Unit Inlet Pres (psia):
29.71

70.24

50.45

100.09

70.24

50.45

51.97

47.92

0.495

0.860

18.27

1011.1

416.91

100.09

115.17

15.09

154.33

3443.1

20228.9

23672.0

0.855

2794.6

8.47

1. 28

48.15

57.35

153.04

142.53

10.52

13.18

44.17

24400.5

33224.3

109.54

414.77

44.12

370.64

217.60

1.90

64.23

182.95

140.36

423.50

64.67

127.34

375.62

2223.4

60.03

141.59
HEAT PUMP FAULT TEST SUMMARY

INDOOR/OUTDOOR CONDITION \#: 09 FAULT TYPE: LIOUID LINE RESTRICTION FAULT FAULT LEVEL [\%]: 7.1

RUNNING CONDITIONS

Barometric Pressure (inHg): Indoor Dry-Bulb Temperature $\left({ }^{\circ} \mathrm{F}\right)$ : Indoor Dew-Point Temperature $\left({ }^{\circ} \mathrm{F}\right)$ : Outdoor Dry-Bulb Temperature $\left({ }^{\circ} \mathrm{F}\right)$ : AIR SIDE CONDITIONS (INDOOR UNIT)

Inlet Dry-Bulb Temperature $\left({ }^{\circ} \mathrm{F}\right)$ : Inlet Dew-Point Temperature $\left({ }^{\circ} \mathrm{F}\right)$ : Exit Dry-Bulb Temperature $\left({ }^{\circ} \mathrm{F}\right)$ : Exit Dew-Point Temperature $\left({ }^{\circ} \mathrm{F}\right)$ : Inlet Relative Humidity $(-)$ : Exit Relative Humidity (-): Evaporator Coil Temp Drop $\left({ }^{\circ} \mathrm{F}\right)$ : Air Flow Rate (SCFM): Fan Power Consumption (W): (OUTDOOR UNIT)

Inlet Temperature $\left({ }^{\circ} \mathrm{F}\right)$ : Exit Temperature $\left({ }^{\circ} \mathrm{F}\right)$ : Condensing Unit Temp Gain $\left({ }^{\circ} \mathrm{F}\right)$ : Fan Power Consumption (W): (OVERALL PERFORMANCE)

Latent Capacity (Btu/h) : Sensible Capacity (Btu/h): Overall Capacity (Btu/h): Sensible Heat Ratio (-):

Overall Power Consumption (W) : NET Cooling EER (Btu/h.W): Evaporator Energy Imbalance (\%): REFRIGERANT SIDE CONDITIONS

(EVAPORATOR)

Inlet Temperature $\left({ }^{\circ} \mathrm{F}\right)$ : Exit Temperature $\left({ }^{\circ} \mathrm{F}\right)$ : Inlet Pressure (psia): Exit Pressure (psia): Pressure Drop (psid): Exit Superheat $\left({ }^{\circ} \mathrm{F}\right)$ : Exit Sat. Temperature $\left({ }^{\circ} \mathrm{F}\right)$ : Evaporator Capacity (Btu/h): (CONDENSER)

Inlet Temperature $\left({ }^{\circ} \mathrm{F}\right)$ : Exit Temperature $\left({ }^{\circ} \mathrm{F}\right)$ : Inlet Pressure (psia): Exit Pressure (psia): Pressure Drop (psid): Exit Subcooling $\left({ }^{\circ} \mathrm{F}\right)$ :

Inlet Sat. Temperature $\left({ }^{\circ} \mathrm{F}\right)$ :

Condenser Capacity (Btu/h): (LIQUID LINE AND TXV)

Cond Unit Exit Temp $\left({ }^{\circ} \mathrm{F}\right)$ : Cond Unit Exit Pres (psia): Liq-line Pressure Drop (psid): TXV Upstream Pressure (psia): TXV Pressure Drop (psid): (COMPRESSOR) Temperature Drop $\left({ }^{\circ} \mathrm{F}\right)$ :

Suction Temperature $\left({ }^{\circ} \mathrm{F}\right)$ :

Discharge Temperature $\left({ }^{\circ} \mathrm{F}\right)$ : Suction Pressure (psia):

Discharge Pressure (psia): Discharge Superheat $\left({ }^{\circ} \mathrm{F}\right)$ : Comp Bottom Shell Temp $\left({ }^{\circ} \mathrm{F}\right)$ : Mass Flow Rate $(1 \mathrm{bm} / \mathrm{h})$ : Comp Power Consumption (W) :

Cond Unit Inlet Temp $\left({ }^{\circ} \mathrm{F}\right)$ : Cond Unit Inlet Pres (psia):
30.44

80.03

60.59

99.84

80.03

60.59

60.83

57.33

0.515

0.882

19.20

1010.0

421.72

99.84

116.65

16.81

157.83

5967.9

21346.4

27314.3

0.782

2821.4

9.68

3.33

56.06

66.95

174.74

162.97

11.78

14.64

52.30

28691.9

174.80

109.74

432.19

429.95

2.24

7.46

120.08

37570.0

110.59

422.06

31.93

390.12

215.38

1.09

71.84

179.07

160.68

432.78

59.10

125.29

434.90

2241.8

68.93

161.85 
HEAT PUMP FAULT TEST SUMMARY

INDOOR/OUTDOOR CONDITION \#: 09

FAULT TYPE: LIQUID LINE RESTRICTION FAULT FAULT LEVEL [\%]: 13.3

\section{RUNNING CONDITIONS}

Barometric Pressure (inHg): Indoor Dry-Bulb Temperature $\left({ }^{\circ} \mathrm{F}\right)$ : Indoor Dew-Point Temperature $\left({ }^{\circ} \mathrm{F}\right)$ : Outdoor Dry-Bulb Temperature $\left({ }^{\circ} \mathrm{F}\right)$ : AIR SIDE CONDITIONS

(INDOOR UNIT)

Inlet Dry-Bulb Temperature $\left({ }^{\circ} \mathrm{F}\right)$ : Inlet Dew-Point Temperature $\left({ }^{\circ} \mathrm{F}\right)$ : Exit Dry-Bulb Temperature $\left({ }^{\circ} \mathrm{F}\right)$ : Exit Dew-Point Temperature $\left({ }^{\circ} \mathrm{F}\right)$ : Inlet Relative Humidity (-): Exit Relative Humidity (-): Evaporator Coil Temp Drop $\left({ }^{\circ} \mathrm{F}\right)$ : Air Flow Rate (SCFM): Fan Power Consumption (W): (OUTDOOR UNIT)

Inlet Temperature $\left({ }^{\circ} \mathrm{F}\right)$ : Exit Temperature $\left({ }^{\circ} \mathrm{F}\right)$ : Condensing Unit Temp Gain $\left({ }^{\circ} \mathrm{F}\right)$ : Fan Power Consumption (W) : (OVERALL PERFORMANCE)

Latent Capacity (Btu/h): Sensible Capacity (Btu/h): Overall Capacity (Btu/h): Sensible Heat Ratio (-): Overall Power Consumption (W): NET Cooling EER (Btu/h.W): Evaporator Energy Imbalance (\%): REFRIGERANT SIDE CONDITIONS

(EVAPORATOR)

Inlet Temperature $\left({ }^{\circ} \mathrm{F}\right)$ : Exit Temperature $\left({ }^{\circ} \mathrm{F}\right)$ : Inlet Pressure (psia): Exit Pressure (psia): Pressure Drop (psid): Exit Superheat $\left({ }^{\circ} \mathrm{F}\right)$ : Exit Sat. Temperature $\left({ }^{\circ} \mathrm{F}\right)$ : Evaporator Capacity (Btu/h): (CONDENSER)

$\begin{array}{rr}\text { Inlet Temperature }\left({ }^{\circ} \mathrm{F}\right): & 176.32 \\ \text { Exit Temperature }\left({ }^{\circ} \mathrm{F}\right): & 109.97 \\ \text { Inlet Pressure (psia): } & 433.40 \\ \text { Exit Pressure (psia): } & 431.22 \\ \text { Pressure Drop (psid): } & 2.18 \\ \text { Exit Subcooling }\left({ }^{\circ} \mathrm{F}\right): & 7.53 \\ \text { Sat. Temperature }\left({ }^{\circ} \mathrm{F}\right): & 120.29\end{array}$

Inlet Sat. Temperature $\left({ }^{\circ} \mathrm{F}\right):-120.29$ (LIQUID LINE AND TXV)

Cond Unit Exit Temp $\left({ }^{\circ} \mathrm{F}\right)$ :

Cond Unit Exit Pres (psia): Liq-line Pressure Drop (psid): TXV Upstream Pressure (psia): TXV Pressure Drop (psid): Temperature Drop $\left({ }^{\circ} \mathrm{F}\right)$ : (COMPRESSOR)

Suction Temperature $\left({ }^{\circ} \mathrm{F}\right)$ Discharge Temperature $\left({ }^{\circ} \mathrm{F}\right)$ : Suction Pressure (psia):

Discharge Pressure (psia): Discharge Superheat $\left({ }^{\circ} \mathrm{F}\right)$ : Comp Bottom Shell Temp $\left({ }^{\circ} \mathrm{F}\right)$ : Mass Flow Rate (l bm/h):

Comp Power Consumption (W):

Cond Unit Inlet Temp $\left({ }^{\circ} \mathrm{F}\right)$ : Cond Unit Inlet Pres (psia):
30.03

79.82

60.71

99.93

79.82

60.71

60.87

57.20

0.521

0.877

18.95

997.9

417.67

99.93

116.87

16.94

156.06

6452.9

20822.8

27275.7

0.763

2826.4

9.65

3.36

55.57

67.86

174.41

162.47

11.94

15.75

52.12

8655.6

176.32

109.97

33.40

.22

.18
7.53

37538.5

110.84

423.82

46.34

377.48

203.07

1.26

72.74

180.55

160.23

434.42

60.29

126.84

433.09

2252.7

69.86

161.32
HEAT PUMP FAULT TEST SUMMARY

INDOOR/OUTDOOR CONDITION \#: 09 FAULT TYPE: LIOUID LINE RESTRICTION FAULT FAULT LEVEL [\%]: 20.0

RUNNING CONDITIONS

Barometric Pressure (inHg): Indoor Dry-Bulb Temperature $\left({ }^{\circ} \mathrm{F}\right)$ : Indoor Dew-Point Temperature $\left({ }^{\circ} \mathrm{F}\right)$ : Outdoor Dry-Bulb Temperature $\left({ }^{\circ} \mathrm{F}\right)$ : AIR SIDE CONDITIONS (INDOOR UNIT)

Inlet Dry-Bulb Temperature $\left({ }^{\circ} \mathrm{F}\right)$ :

Inlet Dew-Point Temperature $\left({ }^{\circ} \mathrm{F}\right)$ : Exit Dry-Bulb Temperature $\left({ }^{\circ} \mathrm{F}\right)$ : Exit Dew-Point Temperature $\left({ }^{\circ} \mathrm{F}\right)$ : Inlet Relative Humidity (-): Exit Relative Humidity (-): Evaporator Coil Temp Drop $\left({ }^{\circ} \mathrm{F}\right)$ : Air Flow Rate (SCFM): Fan Power Consumption (W): (OUTDOOR UNIT)

Inlet Temperature $\left({ }^{\circ} \mathrm{F}\right)$ : Exit Temperature $\left({ }^{\circ} \mathrm{F}\right)$ : Condensing Unit Temp Gain $\left({ }^{\circ} \mathrm{F}\right)$ : Fan Power Consumption (W): (OVERALL PERFORMANCE)

Latent Capacity (Btu/h) : Sensible Capacity (Btu/h): Overall Capacity (Btu/h): Sensible Heat Ratio (-):

Overall Power Consumption (W) : NET Cooling EER (Btu/h.W): Evaporator Energy Imbalance (\%): REFRIGERANT SIDE CONDITIONS

(EVAPORATOR)

Inlet Temperature $\left({ }^{\circ} \mathrm{F}\right)$ : Exit Temperature $\left({ }^{\circ} \mathrm{F}\right)$ : Inlet Pressure (psia): Exit Pressure (psia): Pressure Drop (psid): Exit Superheat $\left({ }^{\circ} \mathrm{F}\right)$ : Exit Sat. Temperature $\left({ }^{\circ} \mathrm{F}\right)$ : Evaporator Capacity (Btu/h): (CONDENSER)

Inlet Temperature $\left({ }^{\circ} \mathrm{F}\right)$ : Exit Temperature $\left({ }^{\circ} \mathrm{F}\right)$ : Inlet Pressure (psia): Exit Pressure (psia): Pressure Drop (psid): Exit Subcooling $\left({ }^{\circ} \mathrm{F}\right)$ :

Inlet Sat. Temperature $\left({ }^{\circ} \mathrm{F}\right)$ :

Condenser Capacity (Btu/h): (LIQUID LINE AND TXV)

Cond Unit Exit Temp $\left({ }^{\circ} \mathrm{F}\right)$ : Cond Unit Exit Pres (psia): Liq-line Pressure Drop (psid): TXV Upstream Pressure (psia): TXV Pressure Drop (psid): (COMPRESSOR) Temperature Drop $\left({ }^{\circ} \mathrm{F}\right)$ :

Suction Temperature $\left({ }^{\circ} \mathrm{F}\right)$ :

Discharge Temperature $\left({ }^{\circ} \mathrm{F}\right)$ : Suction Pressure (psia):

Discharge Pressure (psia): Discharge Superheat $\left({ }^{\circ} \mathrm{F}\right)$ : Comp Bottom Shell Temp $\left({ }^{\circ} \mathrm{F}\right)$ : Mass Flow Rate $(1 \mathrm{bm} / \mathrm{h})$ : Comp Power Consumption (W) :

Cond Unit Inlet Temp $\left({ }^{\circ} \mathrm{F}\right)$ : Cond Unit Inlet Pres (psia):
30.04

79.92

60.79

100.01

79.92

60.79

61.18

57.44

0.521

0.875

18.74

996.6

415.15

100.01

116.57

16.56

155.46

6166.6

20571.1

26737.7

0.769

2841.6

9.41

4.30

53.72

70.76

168.12

157.01

11.11

20.74

50.02

28373.9

182.67

108.79

433.62

431.64

1.98

9.71

120.33

37334.5

108.90

425.19

62.14

363.05

194.93

2.71

75.92

187.42

154.83

434.67

67.12

133.55

416.41

2271.0

72.72

155.95 


\section{D.6 Refrigerant Undercharge Fault Tests}

Table D.6. List of raw data for refrigerant undercharge fault tests

\begin{tabular}{c|r|r|r|r|r}
\hline \multirow{2}{*}{$\begin{array}{c}\text { Test } \\
\text { condition \# }\end{array}$} & \multicolumn{2}{|c|}{ Nominal chamber condition } & \multirow{2}{*}{ Fault Type } & $\begin{array}{c}\text { Fault level } \\
(\%)\end{array}$ \\
\cline { 2 - 3 } & $T_{I D}\left({ }^{\circ} \mathrm{F}\right)$ & \multicolumn{1}{c}{$\phi_{I D}(\boldsymbol{\%})$} & $T_{O D}\left({ }^{\circ} \mathrm{F}\right)$ & \\
\hline 4 & 70 & 50 & 82 & UC & 10.0 \\
\hline 4 & 70 & 50 & 82 & UC & 20.0 \\
\hline 4 & 70 & 50 & 82 & UC & 30.0 \\
\hline 5 & 80 & 50 & 82 & UC & 10.0 \\
\hline 5 & 80 & 50 & 82 & UC & 20.0 \\
\hline 5 & 80 & 50 & 82 & UC & 30.0 \\
\hline 8 & 70 & 50 & 100 & UC & 10.0 \\
\hline 8 & 70 & 50 & 100 & UC & 20.0 \\
\hline 8 & 70 & 50 & 100 & UC & 30.0 \\
\hline 9 & 80 & 50 & 100 & UC & 10.0 \\
\hline 9 & 80 & 50 & 100 & UC & 20.0 \\
\hline 9 & 80 & 50 & 100 & UC & 30.0 \\
\hline
\end{tabular}


HEAT PUMP FAULT TEST SUMMARY

INDOOR/OUTDOOR CONDITION \#: 04

FAULT TYPE: REFRIGERANT UNDERCHARGE FAULT FAULT LEVEL [\%]: 10.0

\section{RUNNING CONDITIONS}

Barometric Pressure (inHg): Indoor Dry-Bulb Temperature $\left({ }^{\circ} \mathrm{F}\right)$ : Indoor Dew-Point Temperature $\left({ }^{\circ} \mathrm{F}\right)$ : Outdoor Dry-Bulb Temperature $\left({ }^{\circ} \mathrm{F}\right)$ : AIR SIDE CONDITIONS

(INDOOR UNIT)

Inlet Dry-Bulb Temperature $\left({ }^{\circ} \mathrm{F}\right)$ : Inlet Dew-Point Temperature $\left({ }^{\circ} \mathrm{F}\right)$ : Exit Dry-Bulb Temperature $\left({ }^{\circ} \mathrm{F}\right)$ : Exit Dew-Point Temperature $\left({ }^{\circ} \mathrm{F}\right)$ : Inlet Relative Humidity (-): Exit Relative Humidity (-): Evaporator Coil Temp Drop $\left({ }^{\circ} \mathrm{F}\right)$ : Air Flow Rate (SCFM): Fan Power Consumption (W): (OUTDOOR UNIT)

Inlet Temperature $\left({ }^{\circ} \mathrm{F}\right)$ : Exit Temperature $\left({ }^{\circ} \mathrm{F}\right)$ : Condensing Unit Temp Gain $\left({ }^{\circ} \mathrm{F}\right)$ : Fan Power Consumption (W) : (OVERALL PERFORMANCE)

Latent Capacity (Btu/h): Sensible Capacity (Btu/h): Overall Capacity (Btu/h): Sensible Heat Ratio (-): Overall Power Consumption (W): NET Cooling EER (Btu/h.W): Evaporator Energy Imbalance (\%): REFRIGERANT SIDE CONDITIONS

(EVAPORATOR)

Inlet Temperature $\left({ }^{\circ} \mathrm{F}\right)$ : Exit Temperature $\left({ }^{\circ} \mathrm{F}\right)$ : Inlet Pressure (psia): Exit Pressure (psia): Pressure Drop (psid): Exit Superheat $\left({ }^{\circ} \mathrm{F}\right)$ : Exit Sat. Temperature $\left({ }^{\circ} \mathrm{F}\right)$ : Evaporator Capacity (Btu/h): (CONDENSER)

$$
\begin{array}{rr}
\text { Inlet Temperature }\left({ }^{\circ} \mathrm{F}\right): & 146.64 \\
\text { Exit Temperature }\left({ }^{\circ} \mathrm{F}\right): & 92.80 \\
\text { Inlet Pressure (psia): } & 328.67 \\
\text { Exit Pressure (psia): } & 326.17 \\
\text { Pressure Drop }(\mathrm{psid}): & 2.49 \\
\text { Exit Subcooling }\left({ }^{\circ} \mathrm{F}\right): & 2.28 \\
\text { Inlet Sat. Temperature }\left({ }^{\circ} \mathrm{F}\right): & 99.47
\end{array}
$$

30.31

69.98

50.28

81.67

69.98

50.28

51.29

47.41

0.496

0.865

18.69

1028.0

424.78

81.67

96.28

14.61

159.71

3843.0

21026.8

24869.8

0.845

2291.7

10.85

5.62

46.08

56.90

149.07

138.77

10.30

14.32

42.58

26800.8

33638.7

94.99

319.83

10.68

309.15

160.09

1.57

61.55

150.77

136.59

329.62

51.35

108.31

375.69

1707.2

58.83

137.86
HEAT PUMP FAULT TEST SUMMARY

INDOOR/OUTDOOR CONDITION \#: 04 FAULT TYPE: REFRIGERANT UNDERCHARGE FAULT FAULT LEVEL [\%]: 20.0

\section{RUNNING CONDITIONS}

Barometric Pressure (inHg): Indoor Dry-Bulb Temperature $\left({ }^{\circ} \mathrm{F}\right)$ : Indoor Dew-Point Temperature $\left({ }^{\circ} \mathrm{F}\right)$ : Outdoor Dry-Bulb Temperature $\left({ }^{\circ} \mathrm{F}\right)$ : AIR SIDE CONDITIONS (INDOOR UNIT)

Inlet Dry-Bulb Temperature $\left({ }^{\circ} \mathrm{F}\right)$ :

Inlet Dew-Point Temperature $\left({ }^{\circ} \mathrm{F}\right)$ : Exit Dry-Bulb Temperature $\left({ }^{\circ} \mathrm{F}\right)$ : Exit Dew-Point Temperature $\left({ }^{\circ} \mathrm{F}\right)$ : Inlet Relative Humidity $(-)$ : Exit Relative Humidity (-): Evaporator Coil Temp Drop $\left({ }^{\circ} \mathrm{F}\right)$ : Air Flow Rate (SCFM): Fan Power Consumption (W): (OUTDOOR UNIT)

Inlet Temperature $\left({ }^{\circ} \mathrm{F}\right)$ : Exit Temperature $\left({ }^{\circ} \mathrm{F}\right)$ : Condensing Unit Temp Gain $\left({ }^{\circ} \mathrm{F}\right)$ : Fan Power Consumption (W): (OVERALL PERFORMANCE)

Latent Capacity (Btu/h) : Sensible Capacity (Btu/h): Overall Capacity (Btu/h): Sensible Heat Ratio (-):

Overall Power Consumption (W) : NET Cooling EER (Btu/h.W): Evaporator Energy Imbalance (\%): REFRIGERANT SIDE CONDITIONS

(EVAPORATOR)

Inlet Temperature $\left({ }^{\circ} \mathrm{F}\right)$ : Exit Temperature $\left({ }^{\circ} \mathrm{F}\right)$ : Inlet Pressure (psia): Exit Pressure (psia): Pressure Drop (psid): Exit Superheat $\left({ }^{\circ} \mathrm{F}\right)$ : Exit Sat. Temperature $\left({ }^{\circ} \mathrm{F}\right)$ : Evaporator Capacity (Btu/h): (CONDENSER)

$\begin{array}{rr}\text { Inlet Temperature }\left({ }^{\circ} \mathrm{F}\right): & 150.71 \\ \text { Exit Temperature }\left({ }^{\circ} \mathrm{F}\right): & 93.65 \\ \text { Inlet Pressure (psia): } & 325.56 \\ \text { Exit Pressure (psia): } & 323.14 \\ \text { Pressure Drop (psid): } & 2.42 \\ \text { Exit Subcooling }\left({ }^{\circ} \mathrm{F}\right): & 1.52 \\ \text { Sat. Temperature }\left({ }^{\circ} \mathrm{F}\right): & 98.78 \\ \text { denser Capacity (Btu } / \mathrm{h}): & 33325.3\end{array}$

\section{(LIQUID LINE AND TXV)}

Condenser Capacity (Btu/h):

Cond Unit Exit Temp $\left({ }^{\circ} \mathrm{F}\right)$ : Cond Unit Exit Pres (psia): Liq-line Pressure Drop (psid): TXV Upstream Pressure (psia): TXV Pressure Drop (psid): (COMPRESSOR) Temperature Drop $\left({ }^{\circ} \mathrm{F}\right)$ :

Suction Temperature $\left({ }^{\circ} \mathrm{F}\right)$ :

Discharge Temperature $\left({ }^{\circ} \mathrm{F}\right)$ : Suction Pressure (psia):

Discharge Pressure (psia):

Discharge Superheat $\left({ }^{\circ} \mathrm{F}\right)$ :

Comp Bottom Shell Temp $\left({ }^{\circ} \mathrm{F}\right)$ : Mass Flow Rate $(1 \mathrm{bm} / \mathrm{h})$ : Comp Power Consumption (W) :

Cond Unit Inlet Temp $\left({ }^{\circ} \mathrm{F}\right)$ : Cond Unit Inlet Pres (psia):
30.31

69.98

50.87

81.65

69.98

50.87

51.80

47.66

0.507

0.857

18.18

1027.1

422.39

81.65

95.90

14.25

158.83

4351.0

20438.8

24789.8

0.824

2279.9

10.87

4.97

44.98

60.57

145.63

135.67

9.96

19.33

41.25

26530.7

. 65

3. 14

2. 42

98.78

95.06

316.76

11.37

305.39

159.76

2.25

65.21

155.31

133.62

326.84

56.51

113.23

366.43

1698.7

62.65

134.85 
HEAT PUMP FAULT TEST SUMMARY

INDOOR/OUTDOOR CONDITION \#: 04

FAULT TYPE: REFRIGERANT UNDERCHARGE FAULT FAULT LEVEL [\%]: 30.0

\section{RUNNING CONDITIONS}

Barometric Pressure (inHg): Indoor Dry-Bulb Temperature $\left({ }^{\circ} \mathrm{F}\right)$ : Indoor Dew-Point Temperature $\left({ }^{\circ} \mathrm{F}\right)$ : Outdoor Dry-Bulb Temperature $\left({ }^{\circ} \mathrm{F}\right)$ : AIR SIDE CONDITIONS

(INDOOR UNIT)

Inlet Dry-Bulb Temperature $\left({ }^{\circ} \mathrm{F}\right)$ : Inlet Dew-Point Temperature $\left({ }^{\circ} \mathrm{F}\right)$ : Exit Dry-Bulb Temperature $\left({ }^{\circ} \mathrm{F}\right)$ : Exit Dew-Point Temperature $\left({ }^{\circ} \mathrm{F}\right)$ : Inlet Relative Humidity (-): Exit Relative Humidity (-): Evaporator Coil Temp Drop $\left({ }^{\circ} \mathrm{F}\right)$ : Air Flow Rate (SCFM): Fan Power Consumption (W): (OUTDOOR UNIT)

Inlet Temperature $\left({ }^{\circ} \mathrm{F}\right)$ : Exit Temperature $\left({ }^{\circ} \mathrm{F}\right)$ : Condensing Unit Temp Gain $\left({ }^{\circ} \mathrm{F}\right)$ : Fan Power Consumption (W): (OVERALL PERFORMANCE)

Latent Capacity (Btu/h): Sensible Capacity (Btu/h): Overall Capacity (Btu/h): Sensible Heat Ratio (-): Overall Power Consumption (W): NET Cooling EER (Btu/h.W): Evaporator Energy Imbalance (\%): REFRIGERANT SIDE CONDITIONS

(EVAPORATOR)

Inlet Temperature $\left({ }^{\circ} \mathrm{F}\right)$ : Exit Temperature $\left({ }^{\circ} \mathrm{F}\right)$ : Inlet Pressure (psia): Exit Pressure (psia): Pressure Drop (psid): Exit Superheat $\left({ }^{\circ} \mathrm{F}\right)$ : Exit Sat. Temperature $\left({ }^{\circ} \mathrm{F}\right)$ : (CONDENSER)

Evaporator Capacity (Btu/h):

$$
\begin{array}{rr}
\text { Inlet Temperature }\left({ }^{\circ} \mathrm{F}\right): & 155.24 \\
\text { Exit Temperature }\left({ }^{\circ} \mathrm{F}\right): & 93.80 \\
\text { Inlet Pressure }(\text { psia): } & 319.93 \\
\text { Exit Pressure }(\text { psia): } & 317.69 \\
\text { Pressure Drop }(\text { psid): } & 2.23 \\
\text { Exit Subcooling }\left({ }^{\circ} \mathrm{F}\right): & 1.13 \\
\text { Inlet Sat. Temperature }\left({ }^{\circ} \mathrm{F}\right): & 97.51 \\
\text { Condenser Capacity }(\mathrm{Btu} / \mathrm{h}): & \mathrm{N} / \mathrm{A}
\end{array}
$$

(LIQUID LINE AND TXV)

Cond Unit Exit Temp $\left({ }^{\circ} \mathrm{F}\right)$ :

Cond Unit Exit Pres (psia):

Liq-line Pressure Drop (psid):

TXV Upstream Pressure (psia):

TXV Pressure Drop (psid): Temperature Drop $\left({ }^{\circ} \mathrm{F}\right)$ :

(COMPRESSOR)

Suction Temperature $\left({ }^{\circ} \mathrm{F}\right)$ :

Discharge Temperature $\left({ }^{\circ} \mathrm{F}\right)$ :

Suction Pressure (psia):

Discharge Pressure (psia):

Discharge Superheat $\left({ }^{\circ} \mathrm{F}\right)$ :

Comp Bottom Shell Temp $\left({ }^{\circ} \mathrm{F}\right)$ : Mass Flow Rate $(1 \mathrm{bm} / \mathrm{h})$ :

Comp Power Consumption (W) :

Cond Unit Inlet Temp $\left({ }^{\circ} \mathrm{F}\right)$ :

Cond Unit Inlet Pres (psia):

94.24

311.50

11.30

300.20

164.05

2.48

66.13

160.71

124.75

321.04

63.22

117.41

127.80

1677.8

63.08

126.03
HEAT PUMP FAULT TEST SUMMARY

INDOOR/OUTDOOR CONDITION \#: 05 FAULT TYPE: REFRIGERANT UNDERCHARGE FAULT FAULT LEVEL [\%]: 10.0

RUNNING CONDITIONS

Barometric Pressure (inHg): Indoor Dry-Bulb Temperature $\left({ }^{\circ} \mathrm{F}\right)$ : Indoor Dew-Point Temperature $\left({ }^{\circ} \mathrm{F}\right)$ : Outdoor Dry-Bulb Temperature $\left({ }^{\circ} \mathrm{F}\right)$ : AIR SIDE CONDITIONS

(INDOOR UNIT)

Inlet Dry-Bulb Temperature $\left({ }^{\circ} \mathrm{F}\right)$ :

Inlet Dew-Point Temperature $\left({ }^{\circ} \mathrm{F}\right)$ :

Exit Dry-Bulb Temperature $\left({ }^{\circ} \mathrm{F}\right)$ :

Exit Dew-Point Temperature $\left({ }^{\circ} \mathrm{F}\right)$ :

Inlet Relative Humidity $(-)$ : Exit Relative Humidity (-): Evaporator Coil Temp Drop $\left({ }^{\circ} \mathrm{F}\right)$ : Air Flow Rate (SCFM) : Fan Power Consumption (W): (OUTDOOR UNIT)

Inlet Temperature $\left({ }^{\circ} \mathrm{F}\right)$ : Exit Temperature $\left({ }^{\circ} \mathrm{F}\right)$ :

Condensing Unit Temp Gain $\left({ }^{\circ} \mathrm{F}\right)$ : Fan Power Consumption (W): (OVERALL PERFORMANCE)

Latent Capacity (Btu/h): Sensible Capacity (Btu/h): Overall Capacity (Btu/h): Sensible Heat Ratio (-):

Overall Power Consumption (W) : NET Cooling EER (Btu/h.W): Evaporator Energy Imbalance (\%): REFRIGERANT SIDE CONDITIONS

(EVAPORATOR)

Inlet Temperature $\left({ }^{\circ} \mathrm{F}\right)$ : Exit Temperature $\left({ }^{\circ} \mathrm{F}\right)$ : Inlet Pressure (psia): Exit Pressure (psia): Pressure Drop (psid): Exit Superheat $\left({ }^{\circ} \mathrm{F}\right)$ : Exit Sat. Temperature $\left({ }^{\circ} \mathrm{F}\right)$ : Evaporator Capacity (Btu/h): (CONDENSER)

Inlet Temperature $\left({ }^{\circ} \mathrm{F}\right)$ : Exit Temperature $\left({ }^{\circ} \mathrm{F}\right)$ : Inlet Pressure (psia): Exit Pressure (psia): Pressure Drop (psid): Exit Subcooling $\left({ }^{\circ} \mathrm{F}\right)$ :

Inlet Sat. Temperature $\left({ }^{\circ} \mathrm{F}\right)$ :

Condenser Capacity (Btu/h): (LIQUID LINE AND TXV)

Cond Unit Exit Temp $\left({ }^{\circ} \mathrm{F}\right)$ :

30.26

79.97

60.19

81.71

79.97

60.19

60.15

56.44

0.509

0.875

19.82

1004.8

416.88

81.71

98.16

16.45

158.63

6739.9

21920.5

28660.4

0.765

2311.7

12.40

5.92

53.23

69.91

166.21

155.32

10.88

20.55

49.36

30905.9

150.71

93.28

338.29

335.53

2.77

3.40

101.59

37679.2

95.74

328.17

13.61 Liq-line Pressure Drop (psid): TXV Upstream Pressure (psia): TXV Pressure Drop (psid): (COMPRESSOR) Temperature Drop $\left({ }^{\circ} \mathrm{F}\right)$ :

Suction Temperature $\left({ }^{\circ} \mathrm{F}\right)$ :

Discharge Temperature $\left({ }^{\circ} \mathrm{F}\right)$ : Suction Pressure (psia):

Discharge Pressure (psia):

Discharge Superheat $\left({ }^{\circ} \mathrm{F}\right)$ :

Comp Bottom Shell Temp $\left({ }^{\circ} \mathrm{F}\right)$ : Mass Flow Rate $(1 \mathrm{bm} / \mathrm{h})$ :

Comp Power Consumption (W):

Cond Unit Inlet Temp $\left({ }^{\circ} \mathrm{F}\right)$ :

Cond Unit Inlet Pres (psia):
314.56

148.35

0.98

72.91

154.39

153.10

339.25

52.87

114.01

419.53

1736.2

71.25

154.28 
HEAT PUMP FAULT TEST SUMMARY

INDOOR/OUTDOOR CONDITION \#: 05

FAULT TYPE: REFRIGERANT UNDERCHARGE FAULT FAULT LEVEL [\%]: 20.0

\section{RUNNING CONDITIONS}

Barometric Pressure (inHg): Indoor Dry-Bulb Temperature $\left({ }^{\circ} \mathrm{F}\right)$ : Indoor Dew-Point Temperature $\left({ }^{\circ} \mathrm{F}\right)$ : Outdoor Dry-Bulb Temperature $\left({ }^{\circ} \mathrm{F}\right)$ : AIR SIDE CONDITIONS

(INDOOR UNIT)

Inlet Dry-Bulb Temperature $\left({ }^{\circ} \mathrm{F}\right)$ : Inlet Dew-Point Temperature $\left({ }^{\circ} \mathrm{F}\right)$ : Exit Dry-Bulb Temperature $\left({ }^{\circ} \mathrm{F}\right)$ : Exit Dew-Point Temperature $\left({ }^{\circ} \mathrm{F}\right)$ : Inlet Relative Humidity (-): Exit Relative Humidity (-): Evaporator Coil Temp Drop $\left({ }^{\circ} \mathrm{F}\right)$ : Air Flow Rate (SCFM): Fan Power Consumption (W): (OUTDOOR UNIT)

Inlet Temperature $\left({ }^{\circ} \mathrm{F}\right)$ : Exit Temperature $\left({ }^{\circ} \mathrm{F}\right)$ : Condensing Unit Temp Gain $\left({ }^{\circ} \mathrm{F}\right)$ : Fan Power Consumption (W) : (OVERALL PERFORMANCE)

Latent Capacity (Btu/h): Sensible Capacity (Btu/h): Overall Capacity (Btu/h): Sensible Heat Ratio (-): Overall Power Consumption (W): NET Cooling EER (Btu/h.W): Evaporator Energy Imbalance (\%): REFRIGERANT SIDE CONDITIONS

(EVAPORATOR)

Inlet Temperature $\left({ }^{\circ} \mathrm{F}\right)$ : Exit Temperature $\left({ }^{\circ} \mathrm{F}\right)$ : Inlet Pressure (psia): Exit Pressure (psia): Pressure Drop (psid): Exit Superheat $\left({ }^{\circ} \mathrm{F}\right)$ : Exit Sat. Temperature $\left({ }^{\circ} \mathrm{F}\right)$ : Evaporator Capacity (Btu/h): (CONDENSER)

$$
\begin{array}{rr}
\text { Inlet Temperature }\left({ }^{\circ} \mathrm{F}\right): & 155.38 \\
\text { Exit Temperature }\left({ }^{\circ} \mathrm{F}\right): & 94.51 \\
\text { Inlet Pressure (psia): } & 331.79 \\
\text { Exit Pressure (psia): } & 329.31 \\
\text { Pressure Drop }(\mathrm{psid}): & 2.48 \\
\text { Exit Subcooling }\left({ }^{\circ} \mathrm{F}\right): & 1.55 \\
\text { Inlet Sat. Temperature }\left({ }^{\circ} \mathrm{F}\right): & 100.16
\end{array}
$$

Condenser Capacity (Btu/h): 35967.3

(LIQUID LINE AND TXV)

Cond Unit Exit Temp $\left({ }^{\circ} \mathrm{F}\right)$ : $\quad 96.48$

Cond Unit Exit Pres (psia): 323.16

Liq-line Pressure Drop (psid): 11.63

TXV Upstream Pressure (psia): 311.53

TXV Pressure Drop (psid): 157.21

Temperature Drop $\left({ }^{\circ} \mathrm{F}\right): \quad 2.20$

(COMPRESSOR)

Suction Temperature $\left({ }^{\circ} \mathrm{F}\right)$ :

Discharge Temperature $\left({ }^{\circ} \mathrm{F}\right)$ :

Suction Pressure (psia):

Discharge Pressure (psia):

Discharge Superheat $\left({ }^{\circ} \mathrm{F}\right)$ :

Comp Bottom Shell Temp $\left({ }^{\circ} \mathrm{F}\right)$ : Mass Flow Rate (l bm/h):

Comp Power Consumption $(W)$ :

Cond Unit Inlet Temp $\left({ }^{\circ} \mathrm{F}\right)$ :

Cond Unit Inlet Pres (psia):
73.65

159.89

141.99

332.76

59.78

118.72

393.74

1720.9

71.73

143.18

HEAT PUMP FAULT TEST SUMMARY

INDOOR/OUTDOOR CONDITION \#: 05 FAULT TYPE: REFRIGERANT UNDERCHARGE FAULT FAULT LEVEL [\%]: 30.0

RUNNING CONDITIONS

Barometric Pressure (inHg): Indoor Dry-Bulb Temperature $\left({ }^{\circ} \mathrm{F}\right)$ : Indoor Dew-Point Temperature $\left({ }^{\circ} \mathrm{F}\right)$ : Outdoor Dry-Bulb Temperature $\left({ }^{\circ} \mathrm{F}\right)$ : AIR SIDE CONDITIONS

(INDOOR UNIT)

Inlet Dry-Bulb Temperature $\left({ }^{\circ} \mathrm{F}\right)$ :

Inlet Dew-Point Temperature $\left({ }^{\circ} \mathrm{F}\right)$ : Exit Dry-Bulb Temperature $\left({ }^{\circ} \mathrm{F}\right)$ : Exit Dew-Point Temperature $\left({ }^{\circ} \mathrm{F}\right)$ : Inlet Relative Humidity $(-)$ : Exit Relative Humidity (-) : Evaporator Coil Temp Drop $\left({ }^{\circ} \mathrm{F}\right)$ : Air Flow Rate (SCFM): Fan Power Consumption (W): (OUTDOOR UNIT)

Inlet Temperature $\left({ }^{\circ} \mathrm{F}\right)$ : Exit Temperature $\left({ }^{\circ} \mathrm{F}\right)$ : Condensing Unit Temp Gain $\left({ }^{\circ} \mathrm{F}\right)$ : Fan Power Consumption (W): (OVERALL PERFORMANCE)

Latent Capacity (Btu/h) : Sensible Capacity (Btu/h): Overall Capacity (Btu/h): Sensible Heat Ratio (-):

Overall Power Consumption (W) : NET Cooling EER (Btu/h.W): Evaporator Energy Imbalance (\%): REFRIGERANT SIDE CONDITIONS

(EVAPORATOR)

Inlet Temperature $\left({ }^{\circ} \mathrm{F}\right)$ : Exit Temperature $\left({ }^{\circ} \mathrm{F}\right)$ : Inlet Pressure (psia): Exit Pressure (psia): Pressure Drop (psid): Exit Superheat $\left({ }^{\circ} \mathrm{F}\right)$ : Exit Sat. Temperature $\left({ }^{\circ} \mathrm{F}\right)$ : Evaporator Capacity (Btu/h): (CONDENSER)

$$
\begin{array}{rr}
\text { Inlet Temperature }\left({ }^{\circ} \mathrm{F}\right): & 159.91 \\
\text { Exit Temperature }\left({ }^{\circ} \mathrm{F}\right): & 94.40 \\
\text { Inlet Pressure }(\mathrm{psia}): & 324.11 \\
\text { Exit Pressure }(\mathrm{psia}): & 321.81 \\
\text { Pressure Drop }(\mathrm{psid}): & 2.30 \\
\text { Exit Subcooling }\left({ }^{\circ} \mathrm{F}\right): & 1.34 \\
\text { Inlet Sat. Temperature }\left({ }^{\circ} \mathrm{F}\right): & 98.46
\end{array}
$$

Condenser Capacity (Btu/h): (LIQUID LINE AND TXV)

Cond Unit Exit Temp $\left({ }^{\circ} \mathrm{F}\right)$ : Cond Unit Exit Pres (psia): Liq-line Pressure Drop (psid): TXV Upstream Pressure (psia): TXV Pressure Drop (psid): (COMPRESSOR) Temperature Drop $\left({ }^{\circ} \mathrm{F}\right)$ :

Suction Temperature $\left({ }^{\circ} \mathrm{F}\right)$ :

Discharge Temperature $\left({ }^{\circ} \mathrm{F}\right)$ : Suction Pressure (psia):

Discharge Pressure (psia):

Discharge Superheat $\left({ }^{\circ} \mathrm{F}\right)$ :

Comp Bottom Shell Temp $\left({ }^{\circ} \mathrm{F}\right)$ : Mass Flow Rate $(1 \mathrm{bm} / \mathrm{h})$ : Comp Power Consumption (W) :

Cond Unit Inlet Temp $\left({ }^{\circ} \mathrm{F}\right)$ : Cond Unit Inlet Pres (psia):
30.12

79.90

60.71

81.87

79.90

60.71

62.52

57.83

0.520

0.846

17.39

1006.9

418.47

81.87

95.89

14.02

158.95

5383.2

19281.0

24664.2

0.782

2269.7

10.87

$-0.99$

45.32

70.96

142.95

133.74

9.21

30.56

40.40

24836.1

31162.1

95.00

315.71

11.88

303.83

160.88

2.40

74.86

165.34

131.62

324.87

66.98

122.43

332.07

1692.3

72.52

132.86 
HEAT PUMP FAULT TEST SUMMARY

INDOOR/OUTDOOR CONDITION \#: 08

FAULT TYPE: REFRIGERANT UNDERCHARGE FAULT FAULT LEVEL [\%]: 10.0

\section{RUNNING CONDITIONS}

Barometric Pressure (inHg): Indoor Dry-Bulb Temperature $\left({ }^{\circ} \mathrm{F}\right)$ : Indoor Dew-Point Temperature $\left({ }^{\circ} \mathrm{F}\right)$ : Outdoor Dry-Bulb Temperature $\left({ }^{\circ} \mathrm{F}\right)$ : AIR SIDE CONDITIONS

(INDOOR UNIT)

Inlet Dry-Bulb Temperature $\left({ }^{\circ} \mathrm{F}\right)$ : Inlet Dew-Point Temperature $\left({ }^{\circ} \mathrm{F}\right)$ : Exit Dry-Bulb Temperature $\left({ }^{\circ} \mathrm{F}\right)$ : Exit Dew-Point Temperature $\left({ }^{\circ} \mathrm{F}\right)$ : Inlet Relative Humidity (-): Exit Relative Humidity (-): Evaporator Coil Temp Drop $\left({ }^{\circ} \mathrm{F}\right)$ : Air Flow Rate (SCFM): Fan Power Consumption (W) : (OUTDOOR UNIT)

Inlet Temperature $\left({ }^{\circ} \mathrm{F}\right)$ : Exit Temperature $\left({ }^{\circ} \mathrm{F}\right)$ : Condensing Unit Temp Gain $\left({ }^{\circ} \mathrm{F}\right)$ : Fan Power Consumption (W) : (OVERALL PERFORMANCE)

Latent Capacity (Btu/h): Sensible Capacity (Btu/h): Overall Capacity (Btu/h): Sensible Heat Ratio (-): Overall Power Consumption (W): NET Cooling EER (Btu/h.W): Evaporator Energy Imbalance (\%): REFRIGERANT SIDE CONDITIONS

(EVAPORATOR)

Inlet Temperature $\left({ }^{\circ} \mathrm{F}\right)$ : Exit Temperature $\left({ }^{\circ} \mathrm{F}\right)$ : Inlet Pressure (psia): Exit Pressure (psia): Pressure Drop (psid): Exit Superheat $\left({ }^{\circ} \mathrm{F}\right)$ : Exit Sat. Temperature $\left({ }^{\circ} \mathrm{F}\right)$ : Evaporator Capacity (Btu/h): (CONDENSER)

$\begin{array}{rr}\text { Inlet Temperature }\left({ }^{\circ} \mathrm{F}\right): & 176.08 \\ \text { Exit Temperature }\left({ }^{\circ} \mathrm{F}\right): & 113.15 \\ \text { Inlet Pressure (psia): } & 417.08 \\ \text { Exit Pressure (psia): } & 414.97 \\ \text { Pressure Drop (psid): } & 2.11 \\ \text { Exit Subcooling }\left({ }^{\circ} \mathrm{F}\right): & 0.94 \\ \text { Sat. Temperature }\left({ }^{\circ} \mathrm{F}\right): & 117.33\end{array}$

Inlet sat. Temperature $\left({ }^{\circ} \mathrm{F}\right):-117.33$ (LIQUID LINE AND TXV)

Cond Unit Exit Temp $\left({ }^{\circ} \mathrm{F}\right)$ :

Cond Unit Exit Pres (psia): Liq-line Pressure Drop (psid): TXV Upstream Pressure (psia): TXV Pressure Drop (psid): Temperature Drop $\left({ }^{\circ} \mathrm{F}\right)$ : (COMPRESSOR)

Suction Temperature $\left({ }^{\circ} \mathrm{F}\right)$ : Discharge Temperature $\left({ }^{\circ} \mathrm{F}\right)$ : Suction Pressure (psia):

Discharge Pressure (psia): Discharge Superheat $\left({ }^{\circ} \mathrm{F}\right)$ : Comp Bottom Shell Temp $\left({ }^{\circ} \mathrm{F}\right)$ : Mass Flow Rate (l bm/h):

Comp Power Consumption (W):

Cond Unit Inlet Temp $\left({ }^{\circ} \mathrm{F}\right)$ : Cond Unit Inlet Pres (psia):
30.33

70.00

50.60

100.28

70.00

50.60

52.57

48.76

0.501

0.868

17.43

1026.3

421.19

100.28

114.77

14.49

155.11

2523.8

19586.3

22110.1

0.886

2771.8

7.98

3.97

47.81

57.82

155.22

143.18

12.04

13.37

44.45

23461.8

32141.0

114.55

408.29

11.62

396.67

241.44

1. 91

64.51

181.09

141.11

417.99

63.83

126.81

375.23

2195.5

60.40

142.35
HEAT PUMP FAULT TEST SUMMARY

INDOOR/OUTDOOR CONDITION \#: 08 FAULT TYPE: REFRIGERANT UNDERCHARGE FAULT FAULT LEVEL [\%]: 20.0

RUNNING CONDITIONS

Barometric Pressure (inHg): Indoor Dry-Bulb Temperature $\left({ }^{\circ} \mathrm{F}\right)$ : Indoor Dew-Point Temperature $\left({ }^{\circ} \mathrm{F}\right)$ : Outdoor Dry-Bulb Temperature $\left({ }^{\circ} \mathrm{F}\right)$ : AIR SIDE CONDITIONS (INDOOR UNIT)

Inlet Dry-Bulb Temperature $\left({ }^{\circ} \mathrm{F}\right)$ : Inlet Dew-Point Temperature $\left({ }^{\circ} \mathrm{F}\right)$ : Exit Dry-Bulb Temperature $\left({ }^{\circ} \mathrm{F}\right)$ : Exit Dew-Point Temperature $\left({ }^{\circ} \mathrm{F}\right)$ : Inlet Relative Humidity $(-)$ : Exit Relative Humidity (-): Evaporator Coil Temp Drop $\left({ }^{\circ} \mathrm{F}\right)$ : Air Flow Rate (SCFM): Fan Power Consumption (W): (OUTDOOR UNIT)

Inlet Temperature $\left({ }^{\circ} \mathrm{F}\right)$ : Exit Temperature $\left({ }^{\circ} \mathrm{F}\right)$ : Condensing Unit Temp Gain $\left({ }^{\circ} \mathrm{F}\right)$ : Fan Power Consumption (W): (OVERALL PERFORMANCE)

Latent Capacity (Btu/h): Sensible Capacity (Btu/h): Overall Capacity (Btu/h): Sensible Heat Ratio (-):

Overall Power Consumption (W) : NET Cooling EER (Btu/h.W): Evaporator Energy Imbalance (\%): REFRIGERANT SIDE CONDITIONS

(EVAPORATOR)

Inlet Temperature $\left({ }^{\circ} \mathrm{F}\right)$ : Exit Temperature $\left({ }^{\circ} \mathrm{F}\right)$ : Inlet Pressure (psia): Exit Pressure (psia): Pressure Drop (psid): Exit Superheat $\left({ }^{\circ} \mathrm{F}\right)$ : Exit Sat. Temperature $\left({ }^{\circ} \mathrm{F}\right)$ : Evaporator Capacity (Btu/h): (CONDENSER)

Inlet Temperature $\left({ }^{\circ} \mathrm{F}\right)$ : Exit Temperature $\left({ }^{\circ} \mathrm{F}\right)$ : Inlet Pressure (psia): Exit Pressure (psia): Pressure Drop (psid): Exit Subcooling $\left({ }^{\circ} \mathrm{F}\right)$ :

Inlet Sat. Temperature $\left({ }^{\circ} \mathrm{F}\right)$ :

Condenser Capacity (Btu/h): (LIQUID LINE AND TXV)

Cond Unit Exit Temp $\left({ }^{\circ} \mathrm{F}\right)$ : Cond Unit Exit Pres (psia): Liq-line Pressure Drop (psid): TXV Upstream Pressure (psia): TXV Pressure Drop (psid): (COMPRESSOR) Temperature Drop $\left({ }^{\circ} \mathrm{F}\right)$ :

Suction Temperature $\left({ }^{\circ} \mathrm{F}\right)$ :

Discharge Temperature $\left({ }^{\circ} \mathrm{F}\right)$ : Suction Pressure (psia):

Discharge Pressure (psia): Discharge Superheat $\left({ }^{\circ} \mathrm{F}\right)$ : Comp Bottom Shell Temp $\left({ }^{\circ} \mathrm{F}\right)$ : Mass Flow Rate $(1 \mathrm{bm} / \mathrm{h})$ : Comp Power Consumption (W) : Cond Unit Inlet Temp $\left({ }^{\circ} \mathrm{F}\right)$ : Cond Unit Inlet Pres (psia):
30.37

69.80

50.28

99.91

69.80

50.28

52.59

48.20

0.499

0.849

17.21

1029.1

424.20

99.91

114.05

14.14

156.75

2828.5

19386.1

22214.6

0.873

2751.6

8.07

1.29

47. 16

58.14

153.89

141.60

12.30

14.36

43.78

22935.0

176.01

113.48

411.89

409.71

2.19

0.90

116.36

31419.9

113.46

402.27

13.90

388.38

234.48

2.24

65.00

181.25

139.52

412.78

64.95

127.21

363.53

2170.6

60.79

140.69 
HEAT PUMP FAULT TEST SUMMARY

INDOOR/OUTDOOR CONDITION \#: 08

FAULT TYPE: REFRIGERANT UNDERCHARGE FAULT FAULT LEVEL [\%]: 30.0

\section{RUNNING CONDITIONS}

Barometric Pressure (inHg): Indoor Dry-Bulb Temperature $\left({ }^{\circ} \mathrm{F}\right)$ : Indoor Dew-Point Temperature $\left({ }^{\circ} \mathrm{F}\right)$ : Outdoor Dry-Bulb Temperature $\left({ }^{\circ} \mathrm{F}\right)$ : AIR SIDE CONDITIONS

(INDOOR UNIT)

Inlet Dry-Bulb Temperature $\left({ }^{\circ} \mathrm{F}\right)$ : Inlet Dew-Point Temperature $\left({ }^{\circ} \mathrm{F}\right)$ : Exit Dry-Bulb Temperature $\left({ }^{\circ} \mathrm{F}\right)$ : Exit Dew-Point Temperature $\left({ }^{\circ} \mathrm{F}\right)$ : Inlet Relative Humidity (-): Exit Relative Humidity (-): Evaporator Coil Temp Drop $\left({ }^{\circ} \mathrm{F}\right)$ : Air Flow Rate (SCFM): Fan Power Consumption (W): (OUTDOOR UNIT)

Inlet Temperature $\left({ }^{\circ} \mathrm{F}\right)$ : Exit Temperature $\left({ }^{\circ} \mathrm{F}\right)$ : Condensing Unit Temp Gain $\left({ }^{\circ} \mathrm{F}\right)$ : Fan Power Consumption (W) : (OVERALL PERFORMANCE)

Latent Capacity (Btu/h): Sensible Capacity (Btu/h): Overall Capacity (Btu/h): Sensible Heat Ratio (-): Overall Power Consumption (W): NET Cooling EER (Btu/h.W): Evaporator Energy Imbalance (\%): REFRIGERANT SIDE CONDITIONS

(EVAPORATOR)

Inlet Temperature $\left({ }^{\circ} \mathrm{F}\right)$ : Exit Temperature $\left({ }^{\circ} \mathrm{F}\right)$ : Inlet Pressure (psia): Exit Pressure (psia): Pressure Drop (psid): Exit Superheat $\left({ }^{\circ} \mathrm{F}\right)$ : Exit Sat. Temperature $\left({ }^{\circ} \mathrm{F}\right)$ : Evaporator Capacity (Btu/h): (CONDENSER)

$\begin{array}{rr}\text { Inlet Temperature }\left({ }^{\circ} \mathrm{F}\right): & 182.08 \\ \text { Exit Temperature }\left({ }^{\circ} \mathrm{F}\right): & 113.03 \\ \text { Inlet Pressure (psia): } & 405.55 \\ \text { Exit Pressure (psia): } & 403.47 \\ \text { Pressure Drop (psid): } & 2.08 \\ \text { Exit Subcooling }\left({ }^{\circ} \mathrm{F}\right): & 0.71 \\ \text { Sat. Temperature }\left({ }^{\circ} \mathrm{F}\right): & 115.18\end{array}$

Inlet Sat. Temperature $\left({ }^{\circ} \mathrm{F}\right)$ : 115.18 (LIQUID LINE AND TXV)

Cond Unit Exit Temp $\left({ }^{\circ} \mathrm{F}\right)$ :

Cond Unit Exit Pres (psia): Liq-line Pressure Drop (psid): TXV Upstream Pressure (psia): TXV Pressure Drop (psid): Temperature Drop $\left({ }^{\circ} \mathrm{F}\right)$ : (COMPRESSOR)

Suction Temperature $\left({ }^{\circ} \mathrm{F}\right)$ : Discharge Temperature $\left({ }^{\circ} \mathrm{F}\right)$ : Suction Pressure (psia):

Discharge Pressure (psia): Discharge Superheat $\left({ }^{\circ} \mathrm{F}\right)$ : Comp Bottom Shell Temp $\left({ }^{\circ} \mathrm{F}\right)$ : Mass Flow Rate $(1 \mathrm{bm} / \mathrm{h})$ :

Comp Power Consumption (W) :

Cond Unit Inlet Temp $\left({ }^{\circ} \mathrm{F}\right)$ : Cond Unit Inlet Pres (psia):
29.98

69.87

50.62

99.78

69.87

50.62

53.29

48.73

0.504

0.844

16.58

1017.8

423.70

99.78

113.23

13.45

156.05

2608.3

18478.4

21086.7

0.876

2726.1

7.74

0.28

44.79

61.41

146.27

135.01

11.27

20.45

40.96

21569.9

. 03

.08

9799.4

112.38

395.66

14.42

381.23

234.96

2.39

68.76

188.17

133.03

406.52

73.05

133.96

334.03

2146.3

64.16

134.25
HEAT PUMP FAULT TEST SUMMARY

INDOOR/OUTDOOR CONDITION \#: 09 FAULT TYPE: REFRIGERANT UNDERCHARGE FAULT FAULT LEVEL [\%]: 10.0 RUNNING CONDITIONS

Barometric Pressure (inHg): Indoor Dry-Bulb Temperature $\left({ }^{\circ} \mathrm{F}\right)$ : Indoor Dew-Point Temperature $\left({ }^{\circ} \mathrm{F}\right)$ : Outdoor Dry-Bulb Temperature $\left({ }^{\circ} \mathrm{F}\right)$ : AIR SIDE CONDITIONS (INDOOR UNIT)

Inlet Dry-Bulb Temperature $\left({ }^{\circ} \mathrm{F}\right)$ : Inlet Dew-Point Temperature $\left({ }^{\circ} \mathrm{F}\right)$ : Exit Dry-Bulb Temperature $\left({ }^{\circ} \mathrm{F}\right)$ : Exit Dew-Point Temperature $\left({ }^{\circ} \mathrm{F}\right)$ : Inlet Relative Humidity $(-)$ : Exit Relative Humidity (-): Evaporator Coil Temp Drop $\left({ }^{\circ} \mathrm{F}\right)$ : Air Flow Rate (SCFM) : Fan Power Consumption (W): (OUTDOOR UNIT)

Inlet Temperature $\left({ }^{\circ} \mathrm{F}\right)$ : Exit Temperature $\left({ }^{\circ} \mathrm{F}\right)$ : Condensing Unit Temp Gain $\left({ }^{\circ} \mathrm{F}\right)$ : Fan Power Consumption (W): (OVERALL PERFORMANCE)

Latent Capacity (Btu/h): Sensible Capacity (Btu/h): Overall Capacity (Btu/h): Sensible Heat Ratio (-):

Overall Power Consumption (W) : NET Cooling EER (Btu/h.W): Evaporator Energy Imbalance (\%): REFRIGERANT SIDE CONDITIONS

(EVAPORATOR)

Inlet Temperature $\left({ }^{\circ} \mathrm{F}\right)$ : Exit Temperature $\left({ }^{\circ} \mathrm{F}\right)$ : Inlet Pressure (psia): Exit Pressure (psia): Pressure Drop (psid): Exit Superheat $\left({ }^{\circ} \mathrm{F}\right)$ : Exit Sat. Temperature $\left({ }^{\circ} \mathrm{F}\right)$ : Evaporator Capacity (Btu/h): (CONDENSER)

Inlet Temperature $\left({ }^{\circ} \mathrm{F}\right)$ : Exit Temperature $\left({ }^{\circ} \mathrm{F}\right)$ : Inlet Pressure (psia): Exit Pressure (psia): Pressure Drop (psid): Exit Subcooling $\left({ }^{\circ} \mathrm{F}\right)$ :

Inlet Sat. Temperature $\left({ }^{\circ} \mathrm{F}\right)$ :

Condenser Capacity (Btu/h): (LIQUID LINE AND TXV)

Cond Unit Exit Temp $\left({ }^{\circ} \mathrm{F}\right)$ : Cond Unit Exit Pres (psia): Liq-line Pressure Drop (psid): TXV Upstream Pressure (psia): TXV Pressure Drop (psid): (COMPRESSOR) Temperature Drop $\left({ }^{\circ} \mathrm{F}\right)$ :

Suction Temperature $\left({ }^{\circ} \mathrm{F}\right)$ :

Discharge Temperature $\left({ }^{\circ} \mathrm{F}\right)$ : Suction Pressure (psia):

Discharge Pressure (psia): Discharge Superheat $\left({ }^{\circ} \mathrm{F}\right)$ : Comp Bottom Shell Temp $\left({ }^{\circ} \mathrm{F}\right)$ : Mass Flow Rate $(1 \mathrm{bm} / \mathrm{h})$ : Comp Power Consumption (W) :

Cond Unit Inlet Temp $\left({ }^{\circ} \mathrm{F}\right)$ : Cond Unit Inlet Pres (psia):
30.38

79.92

60.18

99.29

79.92

60.18

61.11

57.38

0.510

0.875

18.82

1006.2

415.59

99.29

115.59

16.30

155.24

5086.7

20840.6

25927.3

0.804

2767.3

9.37

4.64

55.27

69.02

175.14

161.94

13.20

17.11

51.92

27624.8

174.67

113.53

422.87

420.44

2.43

1.09

118.39

36243.1

115.12

412.12

15.74

396.38

221.24

2.37

73.81

178.70

159.71

423.63

60.40

126.66

429.29

2196.5

70.92

160.86 
HEAT PUMP FAULT TEST SUMMARY

INDOOR/OUTDOOR CONDITION \#: 09

FAULT TYPE: REFRIGERANT UNDERCHARGE FAULT FAULT LEVEL [\%]: 20.0

\section{RUNNING CONDITIONS}

Barometric Pressure (inHg): Indoor Dry-Bulb Temperature $\left({ }^{\circ} \mathrm{F}\right)$ : Indoor Dew-Point Temperature $\left({ }^{\circ} \mathrm{F}\right)$ : Outdoor Dry-Bulb Temperature $\left({ }^{\circ} \mathrm{F}\right)$ : AIR SIDE CONDITIONS

(INDOOR UNIT)

Inlet Dry-Bulb Temperature $\left({ }^{\circ} \mathrm{F}\right)$ : Inlet Dew-Point Temperature $\left({ }^{\circ} \mathrm{F}\right)$ : Exit Dry-Bulb Temperature $\left({ }^{\circ} \mathrm{F}\right)$ : Exit Dew-Point Temperature $\left({ }^{\circ} \mathrm{F}\right)$ : Inlet Relative Humidity (-): Exit Relative Humidity (-): Evaporator Coil Temp Drop $\left({ }^{\circ} \mathrm{F}\right)$ : Air Flow Rate (SCFM): Fan Power Consumption (W): (OUTDOOR UNIT)

Inlet Temperature $\left({ }^{\circ} \mathrm{F}\right)$ : Exit Temperature $\left({ }^{\circ} \mathrm{F}\right)$ : Condensing Unit Temp Gain $\left({ }^{\circ} \mathrm{F}\right)$ : Fan Power Consumption (W) : (OVERALL PERFORMANCE)

Latent Capacity (Btu/h): Sensible Capacity (Btu/h): Overall Capacity (Btu/h): Sensible Heat Ratio (-): Overall Power Consumption (W): NET Cooling EER (Btu/h.W): Evaporator Energy Imbalance (\%): REFRIGERANT SIDE CONDITIONS

(EVAPORATOR)

Inlet Temperature $\left({ }^{\circ} \mathrm{F}\right)$ : Exit Temperature $\left({ }^{\circ} \mathrm{F}\right)$ : Inlet Pressure (psia): Exit Pressure (psia): Pressure Drop (psid): Exit Superheat $\left({ }^{\circ} \mathrm{F}\right)$ : Exit Sat. Temperature $\left({ }^{\circ} \mathrm{F}\right)$ : Evaporator Capacity (Btu/h): (CONDENSER)

$\begin{array}{rr}\text { Inlet Temperature }\left({ }^{\circ} \mathrm{F}\right): & 180.82 \\ \text { Exit Temperature }\left({ }^{\circ} \mathrm{F}\right): & 114.62 \\ \text { Inlet Pressure (psia): } & 420.94 \\ \text { Exit Pressure (psia): } & 418.64 \\ \text { Pressure Drop (psid): } & 2.30 \\ \text { Exit Subcooling }\left({ }^{\circ} \mathrm{F}\right): & 0.95\end{array}$

Inlet Sat. Temperature $\left({ }^{\circ} \mathrm{F}\right)$ : Condenser Capacity (Btu/h): (LIQUID LINE AND TXV)

Cond Unit Exit Temp $\left({ }^{\circ} \mathrm{F}\right)$ : Cond Unit Exit Pres (psia): Liq-line Pressure Drop (psid): TXV Upstream Pressure (psia): TXV Pressure Drop (psid): Temperature Drop $\left({ }^{\circ} \mathrm{F}\right)$ : (COMPRESSOR)

Suction Temperature $\left({ }^{\circ} \mathrm{F}\right)$ : Discharge Temperature $\left({ }^{\circ} \mathrm{F}\right)$ : Suction Pressure (psia):

Discharge Pressure (psia): Discharge Superheat $\left({ }^{\circ} \mathrm{F}\right)$ : Comp Bottom Shell Temp $\left({ }^{\circ} \mathrm{F}\right)$ : Mass Flow Rate (l bm/h):

Comp Power Consumption (W) :

Cond Unit Inlet Temp $\left({ }^{\circ} \mathrm{F}\right)$ : Cond Unit Inlet Pres (psia):
29.51

79.95

60.56

99.78

79.95

60.56

62.07

57.74

0.516

0.857

17.88

980.1

414.03

99.78

115.58

15.81

154.61

5212.2

19311.4

24523.6

0.787

2776.7

8.83

4.74

52.50

70.70

166.94

154.37

12.57

21.72

48.98

6177.5

180.82

114.62

8.64

2.30
0.95

118.04

34794.6

115.06

411.04

15.03

396.01

229.08

2.25

75.91

185.60

152.22

421.80

67.63

133.42

401.82

2208.0

72.78

153.39
HEAT PUMP FAULT TEST SUMMARY

INDOOR/OUTDOOR CONDITION \#: 09 FAULT TYPE: REFRIGERANT UNDERCHARGE FAULT FAULT LEVEL [\%]: 30.0

\section{RUNNING CONDITIONS}

Barometric Pressure (inHg): Indoor Dry-Bulb Temperature $\left({ }^{\circ} \mathrm{F}\right)$ : Indoor Dew-Point Temperature $\left({ }^{\circ} \mathrm{F}\right)$ : Outdoor Dry-Bulb Temperature $\left({ }^{\circ} \mathrm{F}\right)$ : AIR SIDE CONDITIONS

(INDOOR UNIT)

Inlet Dry-Bulb Temperature $\left({ }^{\circ} \mathrm{F}\right)$ :

Inlet Dew-Point Temperature $\left({ }^{\circ} \mathrm{F}\right)$ : Exit Dry-Bulb Temperature $\left({ }^{\circ} \mathrm{F}\right)$ : Exit Dew-Point Temperature $\left({ }^{\circ} \mathrm{F}\right)$ : Inlet Relative Humidity $(-)$ : Exit Relative Humidity (-) : Evaporator Coil Temp Drop $\left({ }^{\circ} \mathrm{F}\right)$ : Air Flow Rate (SCFM): Fan Power Consumption (W): (OUTDOOR UNIT)

Inlet Temperature $\left({ }^{\circ} \mathrm{F}\right)$ : Exit Temperature $\left({ }^{\circ} \mathrm{F}\right)$ : Condensing Unit Temp Gain $\left({ }^{\circ} \mathrm{F}\right)$ : Fan Power Consumption (W): (OVERALL PERFORMANCE)

Latent Capacity (Btu/h) : Sensible Capacity (Btu/h): Overall Capacity (Btu/h): Sensible Heat Ratio (-):

Overall Power Consumption (W) : NET Cooling EER (Btu/h.W): Evaporator Energy Imbalance (\%): REFRIGERANT SIDE CONDITIONS

(EVAPORATOR)

Inlet Temperature $\left({ }^{\circ} \mathrm{F}\right)$ : Exit Temperature $\left({ }^{\circ} \mathrm{F}\right)$ : Inlet Pressure (psia): Exit Pressure (psia): Pressure Drop (psid): Exit Superheat $\left({ }^{\circ} \mathrm{F}\right)$ : Exit Sat. Temperature $\left({ }^{\circ} \mathrm{F}\right)$ : Evaporator Capacity (Btu/h): (CONDENSER)

Inlet Temperature $\left({ }^{\circ} \mathrm{F}\right)$ : Exit Temperature $\left({ }^{\circ} \mathrm{F}\right)$ : Inlet Pressure (psia): Exit Pressure (psia): Pressure Drop (psid): Exit Subcooling $\left({ }^{\circ} \mathrm{F}\right)$ :

Inlet Sat. Temperature $\left({ }^{\circ} \mathrm{F}\right)$ :

Condenser Capacity (Btu/h): (LIQUID LINE AND TXV)

Cond Unit Exit Temp $\left({ }^{\circ} \mathrm{F}\right)$ : Cond Unit Exit Pres (psia): Liq-line Pressure Drop (psid): TXV Upstream Pressure (psia): TXV Pressure Drop (psid): (COMPRESSOR) Temperature Drop $\left({ }^{\circ} \mathrm{F}\right)$ :

Suction Temperature $\left({ }^{\circ} \mathrm{F}\right)$ :

Discharge Temperature $\left({ }^{\circ} \mathrm{F}\right)$ : Suction Pressure (psia):

Discharge Pressure (psia): Discharge Superheat $\left({ }^{\circ} \mathrm{F}\right)$ : Comp Bottom Shell Temp $\left({ }^{\circ} \mathrm{F}\right)$ : Mass Flow Rate $(1 \mathrm{bm} / \mathrm{h})$ : Comp Power Consumption (W) :

Cond Unit Inlet Temp $\left({ }^{\circ} \mathrm{F}\right)$ : Cond Unit Inlet Pres (psia):
30.01 79.85 60.56 99.89

79.85 60.56 63.06 58.36 0.518 0.846 16.79 1000.3

419.79

99.89

114.14

14.25

156.28

4121.4

18506.7

22628.1

0.818

2743.8

8.25

0.27

48.08

71.03

153.40

142.24

11.16

26.98

44.05

23109.5

186.53

113.86

410.71

408.56

2.15

0.81

116.14

31316.3

113.31

400.99

14.82

386.17

232.77

2.39

77.11

192.49

140.19

411.35

76.46

139.07

348.62

2167.7

73.32

141.34 


\section{D.7 Refrigerant Overcharge Fault Tests}

Table D.7. List of raw data for refrigerant overcharge fault tests

\begin{tabular}{c|r|r|r|r|r}
\hline \multirow{2}{*}{$\begin{array}{c}\text { Test } \\
\text { condition \# }\end{array}$} & \multicolumn{2}{|c|}{ Nominal chamber condition } & \multirow{2}{*}{ Fault Type } & $\begin{array}{c}\text { Fault level } \\
(\%)\end{array}$ \\
\cline { 2 - 3 } & $T_{I D}\left({ }^{\circ} \mathrm{F}\right)$ & \multicolumn{1}{c}{$\phi_{I D}(\boldsymbol{\%})$} & $T_{O D}\left({ }^{\circ} \mathrm{F}\right)$ & OC & 10.0 \\
\hline 4 & 70 & 50 & 82 & OC & 20.0 \\
\hline 4 & 70 & 50 & 82 & OC & 30.0 \\
\hline 4 & 70 & 50 & 82 & OC & 10.0 \\
\hline 5 & 80 & 50 & 82 & OC & 20.0 \\
\hline 5 & 80 & 50 & 82 & OC & 30.0 \\
\hline 5 & 80 & 50 & 82 & OC & 10.0 \\
\hline 8 & 70 & 50 & 100 & OC \\
\hline 8 & 70 & 50 & 100 & OC & 30.0 \\
\hline 8 & 70 & 50 & 100 & OC & 10.0 \\
\hline 9 & 80 & 50 & 100 & OC & 20.0 \\
\hline 9 & 80 & 50 & 100 & OC & 30.0 \\
\hline 9 & 80 & 50 & 100 & & \\
\hline
\end{tabular}


HEAT PUMP FAULT TEST SUMMARY

INDOOR/OUTDOOR CONDITION \#: 04

FAULT TYPE: REFRIGERANT OVERCHARGE FAULT FAULT LEVEL [\%]: 10.0

\section{RUNNING CONDITIONS}

Barometric Pressure (inHg): Indoor Dry-Bulb Temperature $\left({ }^{\circ} \mathrm{F}\right)$ : Indoor Dew-Point Temperature $\left({ }^{\circ} \mathrm{F}\right)$ : Outdoor Dry-Bulb Temperature $\left({ }^{\circ} \mathrm{F}\right)$ : AIR SIDE CONDITIONS

(INDOOR UNIT)

Inlet Dry-Bulb Temperature $\left({ }^{\circ} \mathrm{F}\right)$ : Inlet Dew-Point Temperature $\left({ }^{\circ} \mathrm{F}\right)$ : Exit Dry-Bulb Temperature $\left({ }^{\circ} \mathrm{F}\right)$ : Exit Dew-Point Temperature $\left({ }^{\circ} \mathrm{F}\right)$ : Inlet Relative Humidity (-): Exit Relative Humidity (-): Evaporator Coil Temp Drop $\left({ }^{\circ} \mathrm{F}\right)$ : Air Flow Rate (SCFM): Fan Power Consumption (W): (OUTDOOR UNIT)

Inlet Temperature $\left({ }^{\circ} \mathrm{F}\right)$ : Exit Temperature $\left({ }^{\circ} \mathrm{F}\right)$ : Condensing Unit Temp Gain $\left({ }^{\circ} \mathrm{F}\right)$ : Fan Power Consumption (W): (OVERALL PERFORMANCE)

Latent Capacity (Btu/h): Sensible Capacity (Btu/h): Overall Capacity (Btu/h): Sensible Heat Ratio (-): Overall Power Consumption (W): NET Cooling EER (Btu/h.W): Evaporator Energy Imbalance (\%): REFRIGERANT SIDE CONDITIONS

(EVAPORATOR)

Inlet Temperature $\left({ }^{\circ} \mathrm{F}\right)$ : Exit Temperature $\left({ }^{\circ} \mathrm{F}\right)$ : Inlet Pressure (psia): Exit Pressure (psia): Pressure Drop (psid): Exit Superheat $\left({ }^{\circ} \mathrm{F}\right)$ : Exit Sat. Temperature $\left({ }^{\circ} \mathrm{F}\right)$ : Evaporator Capacity (Btu/h): (CONDENSER)

$\begin{array}{rr}\text { Inlet Temperature }\left({ }^{\circ} \mathrm{F}\right): & 148.41 \\ \text { Exit Temperature }\left({ }^{\circ} \mathrm{F}\right): & 88.71 \\ \text { Inlet Pressure (psia): } & 338.11 \\ \text { Exit Pressure (psia): } & 336.02 \\ \text { Pressure Drop (psid): } & 2.09 \\ \text { Exit Subcooling }\left({ }^{\circ} \mathrm{F}\right): & 10.84 \\ \text { Sat. Temperature }\left({ }^{\circ} \mathrm{F}\right): & 101.55\end{array}$

Condenser Capacity (Btu/h): 35085.1

(LIQUID LINE AND TXV)

Cond Unit Exit Temp $\left({ }^{\circ} \mathrm{F}\right)$ :

Cond Unit Exit Pres (psia): Liq-line Pressure Drop (psid): TXV Upstream Pressure (psia): TXV Pressure Drop (psid): Temperature Drop $\left({ }^{\circ} \mathrm{F}\right)$ : (COMPRESSOR)

Suction Temperature $\left({ }^{\circ} \mathrm{F}\right)$ : Discharge Temperature $\left({ }^{\circ} \mathrm{F}\right)$ : Suction Pressure (psia):

Discharge Pressure (psia): Discharge Superheat $\left({ }^{\circ} \mathrm{F}\right)$ : Comp Bottom Shell Temp $\left({ }^{\circ} \mathrm{F}\right)$ : Mass Flow Rate $(1 \mathrm{bm} / \mathrm{h})$ :

Comp Power Consumption (W) :

Cond Unit Inlet Temp $\left({ }^{\circ} \mathrm{F}\right)$ : Cond Unit Inlet Pres (psia):
30.31

70.09

50.63

81.92

70.09

50.63

50.99

47.57

0.500

0.880

19.10

1027.8

426.17

81.92

97.01

15.09

160.18

4123.1

21482.0

25605.1

0.839

2342.0

10.93

7.22

46.45

56.18

149.35

139.71

9.63

13.20

42.99

28058.3

48.41

88.71
38.11

6.02

2.09
0.84

88.72

330.01

10.65

319.36

170.02

0.77

61.05

152.56

137.51

339.21

51.05

108.81

380.01

1755.7

58.21

138.73
HEAT PUMP FAULT TEST SUMMARY

INDOOR/OUTDOOR CONDITION \#: 04 FAULT TYPE: REFRIGERANT OVERCHARGE FAULT FAULT LEVEL [\%]: 20.0

RUNNING CONDITIONS

Barometric Pressure (inHg): Indoor Dry-Bulb Temperature $\left({ }^{\circ} \mathrm{F}\right)$ : Indoor Dew-Point Temperature $\left({ }^{\circ} \mathrm{F}\right)$ : Outdoor Dry-Bulb Temperature $\left({ }^{\circ} \mathrm{F}\right)$ : AIR SIDE CONDITIONS (INDOOR UNIT)

Inlet Dry-Bulb Temperature $\left({ }^{\circ} \mathrm{F}\right)$ : Inlet Dew-Point Temperature $\left({ }^{\circ} \mathrm{F}\right)$ : Exit Dry-Bulb Temperature $\left({ }^{\circ} \mathrm{F}\right)$ : Exit Dew-Point Temperature $\left({ }^{\circ} \mathrm{F}\right)$ : Inlet Relative Humidity $(-)$ : Exit Relative Humidity (-) : Evaporator Coil Temp Drop $\left({ }^{\circ} \mathrm{F}\right)$ : Air Flow Rate (SCFM): Fan Power Consumption (W): (OUTDOOR UNIT)

Inlet Temperature $\left({ }^{\circ} \mathrm{F}\right)$ : Exit Temperature $\left({ }^{\circ} \mathrm{F}\right)$ : Condensing Unit Temp Gain $\left({ }^{\circ} \mathrm{F}\right)$ : Fan Power Consumption (W): (OVERALL PERFORMANCE)

Latent Capacity (Btu/h): Sensible Capacity (Btu/h): Overall Capacity (Btu/h): Sensible Heat Ratio (-):

Overall Power Consumption (W) : NET Cooling EER (Btu/h.W): Evaporator Energy Imbalance (\%): REFRIGERANT SIDE CONDITIONS

(EVAPORATOR)

Inlet Temperature $\left({ }^{\circ} \mathrm{F}\right)$ : Exit Temperature $\left({ }^{\circ} \mathrm{F}\right)$ : Inlet Pressure (psia): Exit Pressure (psia): Pressure Drop (psid): Exit Superheat $\left({ }^{\circ} \mathrm{F}\right)$ : Exit Sat. Temperature $\left({ }^{\circ} \mathrm{F}\right)$ : Evaporator Capacity (Btu/h): (CONDENSER)

Inlet Temperature $\left({ }^{\circ} \mathrm{F}\right)$ : Exit Temperature $\left({ }^{\circ} \mathrm{F}\right)$ : Inlet Pressure (psia): Exit Pressure (psia): Pressure Drop (psid): Exit Subcooling $\left({ }^{\circ} \mathrm{F}\right)$ :

Inlet Sat. Temperature $\left({ }^{\circ} \mathrm{F}\right)$ :

Condenser Capacity (Btu/h): (LIQUID LINE AND TXV)

Cond Unit Exit Temp $\left({ }^{\circ} \mathrm{F}\right)$ : Cond Unit Exit Pres (psia): Liq-line Pressure Drop (psid): TXV Upstream Pressure (psia): TXV Pressure Drop (psid): (COMPRESSOR) Temperature Drop $\left({ }^{\circ} \mathrm{F}\right)$ :

Suction Temperature $\left({ }^{\circ} \mathrm{F}\right)$ :

Discharge Temperature $\left({ }^{\circ} \mathrm{F}\right)$ : Suction Pressure (psia):

Discharge Pressure (psia): Discharge Superheat $\left({ }^{\circ} \mathrm{F}\right)$ : Comp Bottom Shell Temp $\left({ }^{\circ} \mathrm{F}\right)$ : Mass Flow Rate $(1 \mathrm{bm} / \mathrm{h})$ : Comp Power Consumption (W) :

Cond Unit Inlet Temp $\left({ }^{\circ} \mathrm{F}\right)$ : Cond Unit Inlet Pres (psia):
30.44

70.33

50.43

81.79

70.33

50.43

50.86

47.03

0.493

0.867

19.47

1032.4

421.13

81.79

96.74

14.96

159.59

4533.8

22001.0

26534.8

0.829

2365.9

11.22

4.06

46. 11

55.16

148.29

138.66

9.63

12.62

42.54

28095.8

149.60

87.44

342.92

340.99

1.93

13.65

102.59

35197.9

87.05

335.19

10.42

324.77

176.48

0.69

60.26

153.88

136.56

343.94

51.34

109.07

377.70

1785.2

57.37

137.81 
HEAT PUMP FAULT TEST SUMMARY

INDOOR/OUTDOOR CONDITION \#: 04

FAULT TYPE: REFRIGERANT OVERCHARGE FAULT FAULT LEVEL [\%]: 30.0

\section{RUNNING CONDITIONS}

Barometric Pressure (inHg): Indoor Dry-Bulb Temperature $\left({ }^{\circ} \mathrm{F}\right)$ : Indoor Dew-Point Temperature $\left({ }^{\circ} \mathrm{F}\right)$ : Outdoor Dry-Bulb Temperature $\left({ }^{\circ} \mathrm{F}\right)$ : AIR SIDE CONDITIONS

(INDOOR UNIT)

Inlet Dry-Bulb Temperature $\left({ }^{\circ} \mathrm{F}\right)$ : Inlet Dew-Point Temperature $\left({ }^{\circ} \mathrm{F}\right)$ : Exit Dry-Bulb Temperature $\left({ }^{\circ} \mathrm{F}\right)$ : Exit Dew-Point Temperature $\left({ }^{\circ} \mathrm{F}\right)$ : Inlet Relative Humidity (-): Exit Relative Humidity (-): Evaporator Coil Temp Drop $\left({ }^{\circ} \mathrm{F}\right)$ : Air Flow Rate (SCFM): Fan Power Consumption (W): (OUTDOOR UNIT)

Inlet Temperature $\left({ }^{\circ} \mathrm{F}\right)$ : Exit Temperature $\left({ }^{\circ} \mathrm{F}\right)$ : Condensing Unit Temp Gain $\left({ }^{\circ} \mathrm{F}\right)$ : Fan Power Consumption (W): (OVERALL PERFORMANCE)

Latent Capacity (Btu/h): Sensible Capacity (Btu/h): Overall Capacity (Btu/h): Sensible Heat Ratio (-): Overall Power Consumption (W): NET Cooling EER (Btu/h.W): Evaporator Energy Imbalance (\%): REFRIGERANT SIDE CONDITIONS

(EVAPORATOR)

Inlet Temperature $\left({ }^{\circ} \mathrm{F}\right)$ : Exit Temperature $\left({ }^{\circ} \mathrm{F}\right)$ : Inlet Pressure (psia): Exit Pressure (psia): Pressure Drop (psid): Exit Superheat $\left({ }^{\circ} \mathrm{F}\right)$ : Exit Sat. Temperature $\left({ }^{\circ} \mathrm{F}\right)$ : Evaporator Capacity (Btu/h): (CONDENSER)

$\begin{array}{rr}\text { Inlet Temperature }\left({ }^{\circ} \mathrm{F}\right): & 152.67 \\ \text { Exit Temperature }\left({ }^{\circ} \mathrm{F}\right): & 87.69 \\ \text { Inlet Pressure (psia): } & 353.92 \\ \text { Exit Pressure (psia): } & 352.12 \\ \text { Pressure Drop (psid): } & 1.80 \\ \text { Exit Subcooling }\left({ }^{\circ} \mathrm{F}\right): & 15.98 \\ \text { Sat. Temperature }\left({ }^{\circ} \mathrm{F}\right): & 104.92\end{array}$

Condenser Capacity (Btu/h): $\quad 35495.2$

(LIQUID LINE AND TXV)

Cond Unit Exit Temp $\left({ }^{\circ} \mathrm{F}\right)$ :

Cond Unit Exit Pres (psia): Liq-line Pressure Drop (psid): TXV Upstream Pressure (psia): TXV Pressure Drop (psid): Temperature Drop $\left({ }^{\circ} \mathrm{F}\right)$ : (COMPRESSOR)

Suction Temperature $\left({ }^{\circ} \mathrm{F}\right)$ : Discharge Temperature $\left({ }^{\circ} \mathrm{F}\right)$ : Suction Pressure (psia):

Discharge Pressure (psia): Discharge Superheat $\left({ }^{\circ} \mathrm{F}\right)$ : Comp Bottom Shell Temp $\left({ }^{\circ} \mathrm{F}\right)$ : Mass Flow Rate $(1 \mathrm{bm} / \mathrm{h})$ :

Comp Power Consumption (W) :

Cond Unit Inlet Temp $\left({ }^{\circ} \mathrm{F}\right)$ : Cond Unit Inlet Pres (psia):
30.28

70.08

50.99

82.21

70.08

50.99

50.83

47.58

0.507

0.885

19.25

1026.0

420.00

82.21

97.29

15.08

158.81

4630.6

21623.1

26253.7

0.824

2418.2

10.86

5.53

46.40

55.51

148.92

139.70

9.22

12.53

42.98

28236.0

52.67

87.69

3. 92

5.98

87.11

346.24

10.56

335.68

186.76

0.69

60.66

156.95

137.58

354.91

52.08

110.60

379.41

1839.4

57.70

138.83
HEAT PUMP FAULT TEST SUMMARY

INDOOR/OUTDOOR CONDITION \#: 05 FAULT TYPE: REFRIGERANT OVERCHARGE FAULT FAULT LEVEL [\%]: 10.0

RUNNING CONDITIONS

Barometric Pressure (inHg): Indoor Dry-Bulb Temperature $\left({ }^{\circ} \mathrm{F}\right)$ : Indoor Dew-Point Temperature $\left({ }^{\circ} \mathrm{F}\right)$ : Outdoor Dry-Bulb Temperature $\left({ }^{\circ} \mathrm{F}\right)$ : AIR SIDE CONDITIONS (INDOOR UNIT)

Inlet Dry-Bulb Temperature $\left({ }^{\circ} \mathrm{F}\right)$ : Inlet Dew-Point Temperature $\left({ }^{\circ} \mathrm{F}\right)$ : Exit Dry-Bulb Temperature $\left({ }^{\circ} \mathrm{F}\right)$ : Exit Dew-Point Temperature $\left({ }^{\circ} \mathrm{F}\right)$ : Inlet Relative Humidity $(-)$ : Exit Relative Humidity (-): Evaporator Coil Temp Drop $\left({ }^{\circ} \mathrm{F}\right)$ : Air Flow Rate (SCFM): Fan Power Consumption (W): (OUTDOOR UNIT)

Inlet Temperature $\left({ }^{\circ} \mathrm{F}\right)$ : Exit Temperature $\left({ }^{\circ} \mathrm{F}\right)$ : Condensing Unit Temp Gain $\left({ }^{\circ} \mathrm{F}\right)$ : Fan Power Consumption (W): (OVERALL PERFORMANCE)

Latent Capacity $($ Btu/h) : Sensible Capacity (Btu/h): Overall Capacity (Btu/h): Sensible Heat Ratio (-):

Overall Power Consumption (W) : NET Cooling EER (Btu/h.W): Evaporator Energy Imbalance (\%): REFRIGERANT SIDE CONDITIONS

(EVAPORATOR)

Inlet Temperature $\left({ }^{\circ} \mathrm{F}\right)$ : Exit Temperature $\left({ }^{\circ} \mathrm{F}\right)$ : Inlet Pressure (psia): Exit Pressure (psia): Pressure Drop (psid): Exit Superheat $\left({ }^{\circ} \mathrm{F}\right)$ : Exit Sat. Temperature $\left({ }^{\circ} \mathrm{F}\right)$ : Evaporator Capacity (Btu/h): (CONDENSER)

Inlet Temperature $\left({ }^{\circ} \mathrm{F}\right)$ : Exit Temperature $\left({ }^{\circ} \mathrm{F}\right)$ : Inlet Pressure (psia): Exit Pressure (psia): Pressure Drop (psid): Exit Subcooling $\left({ }^{\circ} \mathrm{F}\right)$ :

Inlet Sat. Temperature $\left({ }^{\circ} \mathrm{F}\right)$ :

Condenser Capacity (Btu/h): (LIQUID LINE AND TXV)

Cond Unit Exit Temp $\left({ }^{\circ} \mathrm{F}\right)$ : Cond Unit Exit Pres (psia): Liq-line Pressure Drop (psid): TXV Upstream Pressure (psia): TXV Pressure Drop (psid): (COMPRESSOR) Temperature Drop $\left({ }^{\circ} \mathrm{F}\right)$ :

Suction Temperature $\left({ }^{\circ} \mathrm{F}\right)$ :

Discharge Temperature $\left({ }^{\circ} \mathrm{F}\right)$ : Suction Pressure (psia):

Discharge Pressure (psia): Discharge Superheat $\left({ }^{\circ} \mathrm{F}\right)$ : Comp Bottom Shell Temp $\left({ }^{\circ} \mathrm{F}\right)$ : Mass Flow Rate $(1 \mathrm{bm} / \mathrm{h})$ : Comp Power Consumption (W) :

Cond Unit Inlet Temp $\left({ }^{\circ} \mathrm{F}\right)$ : Cond Unit Inlet Pres (psia):
30.74

80.03

60.49

81.77

80.03

60.49

59.87

56.71

0.514

0.893

20.16

1017.0

417.27

81.77

98.84

17.07

158.93

6835.6

22562.4

29398.0

0.767

2352.0

12.50

9.58

54.94

66.64

170.67

159.91

10.76

15.50

51.14

32975.3

148.29

89.43

348.25

345.72

2.53

11.41

103.72

39940.5

89.93

338.16

14.67

323.49

152.82

0.39

69.74

151.54

157.65

349.04

47.91

110.20

438.77

1775.8

68.08

158.78 
HEAT PUMP FAULT TEST SUMMARY

INDOOR/OUTDOOR CONDITION \#: 05 FAULT TYPE: REFRIGERANT OVERCHARGE FAULT FAULT LEVEL [\%]: 20.0

\section{RUNNING CONDITIONS}

Barometric Pressure (inHg): Indoor Dry-Bulb Temperature $\left({ }^{\circ} \mathrm{F}\right)$ : Indoor Dew-Point Temperature $\left({ }^{\circ} \mathrm{F}\right)$ : Outdoor Dry-Bulb Temperature $\left({ }^{\circ} \mathrm{F}\right)$ : AIR SIDE CONDITIONS

(INDOOR UNIT)

Inlet Dry-Bulb Temperature $\left({ }^{\circ} \mathrm{F}\right)$ : Inlet Dew-Point Temperature $\left({ }^{\circ} \mathrm{F}\right)$ : Exit Dry-Bulb Temperature $\left({ }^{\circ} \mathrm{F}\right)$ : Exit Dew-Point Temperature $\left({ }^{\circ} \mathrm{F}\right)$ : Inlet Relative Humidity (-): Exit Relative Humidity (-): Evaporator Coil Temp Drop $\left({ }^{\circ} \mathrm{F}\right)$ : Air Flow Rate (SCFM): Fan Power Consumption (W): (OUTDOOR UNIT)

Inlet Temperature $\left({ }^{\circ} \mathrm{F}\right)$ : Exit Temperature $\left({ }^{\circ} \mathrm{F}\right)$ : Condensing Unit Temp Gain $\left({ }^{\circ} \mathrm{F}\right)$ : Fan Power Consumption (W): (OVERALL PERFORMANCE)

Latent Capacity (Btu/h): Sensible Capacity (Btu/h): Overall Capacity (Btu/h): Sensible Heat Ratio (-): Overall Power Consumption (W): NET Cooling EER (Btu/h.W): Evaporator Energy Imbalance (\%): REFRIGERANT SIDE CONDITIONS

(EVAPORATOR)

Inlet Temperature $\left({ }^{\circ} \mathrm{F}\right)$ : Exit Temperature $\left({ }^{\circ} \mathrm{F}\right)$ : Inlet Pressure (psia): Exit Pressure (psia): Pressure Drop (psid): Exit Superheat $\left({ }^{\circ} \mathrm{F}\right)$ : Exit Sat. Temperature $\left({ }^{\circ} \mathrm{F}\right)$ : Evaporator Capacity (Btu/h): (CONDENSER)

$\begin{array}{rr}\text { Inlet Temperature }\left({ }^{\circ} \mathrm{F}\right): & 149.51 \\ \text { Exit Temperature }\left({ }^{\circ} \mathrm{F}\right): & 88.14 \\ \text { Inlet Pressure (psia): } & 354.57 \\ \text { Exit Pressure (psia): } & 352.27 \\ \text { Pressure Drop (psid): } & 2.30 \\ \text { Exit Subcooling }\left({ }^{\circ} \mathrm{F}\right): & 14.74 \\ \text { Sat. Temperature }\left({ }^{\circ} \mathrm{F}\right): & 105.06 \\ \text { enser Capacity (Btu/h): } & 40080.4\end{array}$

(LIQUID LINE AND TXV)

Cond Unit Exit Temp $\left({ }^{\circ} \mathrm{F}\right)$ :

Cond Unit Exit Pres (psia): Liq-line Pressure Drop (psid): TXV Upstream Pressure (psia): TXV Pressure Drop (psid): Temperature Drop $\left({ }^{\circ} \mathrm{F}\right)$ : (COMPRESSOR)

Suction Temperature $\left({ }^{\circ} \mathrm{F}\right)$ : Discharge Temperature $\left({ }^{\circ} \mathrm{F}\right)$ : Suction Pressure (psia):

Discharge Pressure (psia): Discharge Superheat $\left({ }^{\circ} \mathrm{F}\right)$ : Comp Bottom Shell Temp $\left({ }^{\circ} \mathrm{F}\right)$ : Mass Flow Rate (l bm/h):

Comp Power Consumption (W) :

Cond Unit Inlet Temp $\left({ }^{\circ} \mathrm{F}\right)$ : Cond Unit Inlet Pres (psia):
30.42

80.01

60.24

81.66

80.01

60.24

59.17

56.22

0.510

0.899

20.84

1012.3

413.24

81.66

98.74

17.08

158.62

7227.7

23217.1

30444.7

0.763

2385.2

12.76

6.49

54.03

65.23

168.97

158.66

10.31

14.58

50.66

33001.2

49.51

8.14

2.27

. 30

105.06

88.02

344.72

14.20

330.52

161.55

0.34

68.50

152.90

156.43

355.53

47.91

110.19

435.95

1813.3

66.76

157.59
HEAT PUMP FAULT TEST SUMMARY

INDOOR/OUTDOOR CONDITION \#: 05 FAULT TYPE: REFRIGERANT OVERCHARGE FAULT FAULT LEVEL [\%]: 30.0

\section{RUNNING CONDITIONS}

Barometric Pressure (inHg): Indoor Dry-Bulb Temperature $\left({ }^{\circ} \mathrm{F}\right)$ : Indoor Dew-Point Temperature $\left({ }^{\circ} \mathrm{F}\right)$ : Outdoor Dry-Bulb Temperature $\left({ }^{\circ} \mathrm{F}\right)$ : AIR SIDE CONDITIONS (INDOOR UNIT)

Inlet Dry-Bulb Temperature $\left({ }^{\circ} \mathrm{F}\right)$ : Inlet Dew-Point Temperature $\left({ }^{\circ} \mathrm{F}\right)$ : Exit Dry-Bulb Temperature $\left({ }^{\circ} \mathrm{F}\right)$ : Exit Dew-Point Temperature $\left({ }^{\circ} \mathrm{F}\right)$ : Inlet Relative Humidity $(-)$ : Exit Relative Humidity (-): Evaporator Coil Temp Drop $\left({ }^{\circ} \mathrm{F}\right)$ : Air Flow Rate (SCFM): Fan Power Consumption (W): (OUTDOOR UNIT)

Inlet Temperature $\left({ }^{\circ} \mathrm{F}\right)$ : Exit Temperature $\left({ }^{\circ} \mathrm{F}\right)$ : Condensing Unit Temp Gain $\left({ }^{\circ} \mathrm{F}\right)$ : Fan Power Consumption (W): (OVERALL PERFORMANCE)

Latent Capacity (Btu/h): Sensible Capacity (Btu/h): Overall Capacity (Btu/h): Sensible Heat Ratio (-):

Overall Power Consumption (W) : NET Cooling EER (Btu/h.W): Evaporator Energy Imbalance (\%): REFRIGERANT SIDE CONDITIONS

(EVAPORATOR)

Inlet Temperature $\left({ }^{\circ} \mathrm{F}\right)$ : Exit Temperature $\left({ }^{\circ} \mathrm{F}\right)$ : Inlet Pressure (psia): Exit Pressure (psia): Pressure Drop (psid): Exit Superheat $\left({ }^{\circ} \mathrm{F}\right)$ : Exit Sat. Temperature $\left({ }^{\circ} \mathrm{F}\right)$ : Evaporator Capacity (Btu/h): (CONDENSER)

$\begin{array}{rr}\text { Inlet Temperature }\left({ }^{\circ} \mathrm{F}\right): & 151.76 \\ \text { Exit Temperature }\left({ }^{\circ} \mathrm{F}\right): & 87.90 \\ \text { Inlet Pressure (psia): } & 363.93 \\ \text { Exit Pressure (psia): } & 361.79 \\ \text { Pressure Drop (psid): } & 2.14 \\ \text { Exit Subcooling }\left({ }^{\circ} \mathrm{F}\right): & 17.46 \\ \text { Sat. Temperature }\left({ }^{\circ} \mathrm{F}\right): & 106.99 \\ \text { denser Capacity (Btu } / \mathrm{h}): & 40320.6\end{array}$

\section{(LIQUID LINE AND TXV)}

Condenser Capacity (Btu/h):

Cond Unit Exit Temp $\left({ }^{\circ} \mathrm{F}\right)$ : Cond Unit Exit Pres (psia): Liq-line Pressure Drop (psid): TXV Upstream Pressure (psia): TXV Pressure Drop (psid): (COMPRESSOR) Temperature Drop $\left({ }^{\circ} \mathrm{F}\right)$ :

Suction Temperature $\left({ }^{\circ} \mathrm{F}\right)$ :

Discharge Temperature $\left({ }^{\circ} \mathrm{F}\right)$ : Suction Pressure (psia):

Discharge Pressure (psia): Discharge Superheat $\left({ }^{\circ} \mathrm{F}\right)$ : Comp Bottom Shell Temp $\left({ }^{\circ} \mathrm{F}\right)$ : Mass Flow Rate $(1 \mathrm{bm} / \mathrm{h})$ : Comp Power Consumption (W) :

Cond Unit Inlet Temp $\left({ }^{\circ} \mathrm{F}\right)$ : Cond Unit Inlet Pres (psia):
30.07

79.94

60.48

81.78

79.94

60.48

58.88

56.07

0.515

0.904

21.06

999.2

426.19

81.78

98.90

17.12

161.90

7929.7

23163.4

31093.1

0.745

2452.7

12.68

4.63

53.89

64.66

168.47

158.44

10.03

14.09

50.57

33048.6

51.76

7.90

7.79

2.14

17.46

87.35

354.39

14.33

340.06

171.60

0.19

68.00

155.12

156.15

364.63

48.24

110.96

436.20

1864.6

66.16

157.36 
HEAT PUMP FAULT TEST SUMMARY

INDOOR/OUTDOOR CONDITION \#: 08 FAULT TYPE: REFRIGERANT OVERCHARGE FAULT FAULT LEVEL [\%]: 10.0

\section{RUNNING CONDITIONS}

Barometric Pressure (inHg): Indoor Dry-Bulb Temperature $\left({ }^{\circ} \mathrm{F}\right)$ : Indoor Dew-Point Temperature $\left({ }^{\circ} \mathrm{F}\right)$ : Outdoor Dry-Bulb Temperature $\left({ }^{\circ} \mathrm{F}\right)$ : AIR SIDE CONDITIONS

(INDOOR UNIT)

Inlet Dry-Bulb Temperature $\left({ }^{\circ} \mathrm{F}\right)$ : Inlet Dew-Point Temperature $\left({ }^{\circ} \mathrm{F}\right)$ : Exit Dry-Bulb Temperature $\left({ }^{\circ} \mathrm{F}\right)$ : Exit Dew-Point Temperature $\left({ }^{\circ} \mathrm{F}\right)$ : Inlet Relative Humidity (-): Exit Relative Humidity (-): Evaporator Coil Temp Drop $\left({ }^{\circ} \mathrm{F}\right)$ : Air Flow Rate (SCFM): Fan Power Consumption (W): (OUTDOOR UNIT)

Inlet Temperature $\left({ }^{\circ} \mathrm{F}\right)$ : Exit Temperature $\left({ }^{\circ} \mathrm{F}\right)$ : Condensing Unit Temp Gain $\left({ }^{\circ} \mathrm{F}\right)$ : Fan Power Consumption (W) : (OVERALL PERFORMANCE)

Latent Capacity (Btu/h): Sensible Capacity (Btu/h): Overall Capacity (Btu/h): Sensible Heat Ratio (-): Overall Power Consumption (W): NET Cooling EER (Btu/h.W): Evaporator Energy Imbalance (\%): REFRIGERANT SIDE CONDITIONS

(EVAPORATOR)

Inlet Temperature $\left({ }^{\circ} \mathrm{F}\right)$ : Exit Temperature $\left({ }^{\circ} \mathrm{F}\right)$ : Inlet Pressure (psia): Exit Pressure (psia): Pressure Drop (psid): Exit Superheat $\left({ }^{\circ} \mathrm{F}\right)$ : Exit Sat. Temperature $\left({ }^{\circ} \mathrm{F}\right)$ : Evaporator Capacity (Btu/h): (CONDENSER)

$\begin{array}{rr}\text { Inlet Temperature }\left({ }^{\circ} \mathrm{F}\right): & 178.02 \\ \text { Exit Temperature }\left({ }^{\circ} \mathrm{F}\right): & 107.46 \\ \text { Inlet Pressure (psia): } & 425.27 \\ \text { Exit Pressure (psia): } & 423.49 \\ \text { Pressure Drop (psid): } & 1.78 \\ \text { Exit Subcooling }\left({ }^{\circ} \mathrm{F}\right): & 10.18 \\ \text { Sat. Temperature }\left({ }^{\circ} \mathrm{F}\right): & 118.83 \\ \text { enser Capacity (Btu/h): } & 33287.1\end{array}$

(LIQUID LINE AND TXV)

Cond Unit Exit Temp $\left({ }^{\circ} \mathrm{F}\right)$ :

Cond Unit Exit Pres (psia): Liq-line Pressure Drop (psid): TXV Upstream Pressure (psia): TXV Pressure Drop (psid): Temperature Drop $\left({ }^{\circ} \mathrm{F}\right)$ : (COMPRESSOR)

Suction Temperature $\left({ }^{\circ} \mathrm{F}\right)$ : Discharge Temperature $\left({ }^{\circ} \mathrm{F}\right)$ : Suction Pressure (psia):

Discharge Pressure (psia): Discharge Superheat $\left({ }^{\circ} \mathrm{F}\right)$ : Comp Bottom Shell Temp $\left({ }^{\circ} \mathrm{F}\right)$ : Mass Flow Rate (l bm/h):

Comp Power Consumption (W) :

Cond Unit Inlet Temp $\left({ }^{\circ} \mathrm{F}\right)$ : Cond Unit Inlet Pres (psia):
30.48

70.17

50.38

99.91

70.17

50.38

51.71

48.02

0.494

0.872

18.47

1036.9

416.94

99.91

114.69

14.78

154.98

3216.7

20956.3

24173.0

0.867

2820.0

8.57

$-0.51$

48.05

56.20

153.33

141.76

11.57

12.35

43.85

24464.2

178.02

107.46

25.27

1.78

10.18

33287.1

107.04

417.60

11.08

406.52

253.19

1.34

63.34

183.28

139.80

426.18

64.52

127.95

371.49

2248.0

58.90

141.05
HEAT PUMP FAULT TEST SUMMARY

INDOOR/OUTDOOR CONDITION \#: 08 FAULT TYPE: REFRIGERANT OVERCHARGE FAULT FAULT LEVEL [\%]: 20.0

RUNNING CONDITIONS

Barometric Pressure (inHg): Indoor Dry-Bulb Temperature $\left({ }^{\circ} \mathrm{F}\right)$ : Indoor Dew-Point Temperature $\left({ }^{\circ} \mathrm{F}\right)$ : Outdoor Dry-Bulb Temperature $\left({ }^{\circ} \mathrm{F}\right)$ : AIR SIDE CONDITIONS (INDOOR UNIT)

Inlet Dry-Bulb Temperature $\left({ }^{\circ} \mathrm{F}\right)$ :

Inlet Dew-Point Temperature $\left({ }^{\circ} \mathrm{F}\right)$ : Exit Dry-Bulb Temperature $\left({ }^{\circ} \mathrm{F}\right)$ : Exit Dew-Point Temperature $\left({ }^{\circ} \mathrm{F}\right)$ : Inlet Relative Humidity $(-)$ : Exit Relative Humidity (-): Evaporator Coil Temp Drop $\left({ }^{\circ} \mathrm{F}\right)$ : Air Flow Rate (SCFM): Fan Power Consumption (W): (OUTDOOR UNIT)

Inlet Temperature $\left({ }^{\circ} \mathrm{F}\right)$ : Exit Temperature $\left({ }^{\circ} \mathrm{F}\right)$ : Condensing Unit Temp Gain $\left({ }^{\circ} \mathrm{F}\right)$ : Fan Power Consumption (W): (OVERALL PERFORMANCE)

Latent Capacity (Btu/h): Sensible Capacity (Btu/h): Overall Capacity (Btu/h): Sensible Heat Ratio (-):

Overall Power Consumption (W) : NET Cooling EER (Btu/h.W): Evaporator Energy Imbalance (\%): REFRIGERANT SIDE CONDITIONS

(EVAPORATOR)

Inlet Temperature $\left({ }^{\circ} \mathrm{F}\right)$ : Exit Temperature $\left({ }^{\circ} \mathrm{F}\right)$ : Inlet Pressure (psia): Exit Pressure (psia): Pressure Drop (psid): Exit Superheat $\left({ }^{\circ} \mathrm{F}\right)$ : Exit Sat. Temperature $\left({ }^{\circ} \mathrm{F}\right)$ : Evaporator Capacity (Btu/h): (CONDENSER)

Inlet Temperature $\left({ }^{\circ} \mathrm{F}\right)$ : Exit Temperature $\left({ }^{\circ} \mathrm{F}\right)$ : Inlet Pressure (psia): Exit Pressure (psia): Pressure Drop (psid): Exit Subcooling $\left({ }^{\circ} \mathrm{F}\right)$ :

Inlet Sat. Temperature $\left({ }^{\circ} \mathrm{F}\right)$ :

Condenser Capacity (Btu/h): (LIQUID LINE AND TXV)

Cond Unit Exit Temp $\left({ }^{\circ} \mathrm{F}\right)$ : Cond Unit Exit Pres (psia): Liq-line Pressure Drop (psid): TXV Upstream Pressure (psia): TXV Pressure Drop (psid): (COMPRESSOR) Temperature Drop $\left({ }^{\circ} \mathrm{F}\right)$ :

Suction Temperature $\left({ }^{\circ} \mathrm{F}\right)$ :

Discharge Temperature $\left({ }^{\circ} \mathrm{F}\right)$ : Suction Pressure (psia):

Discharge Pressure (psia): Discharge Superheat $\left({ }^{\circ} \mathrm{F}\right)$ : Comp Bottom Shell Temp $\left({ }^{\circ} \mathrm{F}\right)$ : Mass Flow Rate $(1 \mathrm{bm} / \mathrm{h})$ : Comp Power Consumption (W) :

Cond Unit Inlet Temp $\left({ }^{\circ} \mathrm{F}\right)$ : Cond Unit Inlet Pres (psia):
30.48

70.18

50.22

99.86

70.18

50.22

51.72

47.99

0.491

0.870

18.47

1036.7

419.09

99.86

114.60

14.74

155.74

3021.9

20951.8

23973.7

0.874

2872.3

8.35

0.85

47.82

55.94

152.63

141.34

11.29

12.26

43.67

24603.0

180.26

106.24

433.74

432.06

1.68

13.38

120.35

33540.5

105.44

426.30

10.90

415.40

262.77

1.17

63.22

185.65

139.35

434.61

65.36

128.37

369.70

2297.4

58.63

140.51 
HEAT PUMP FAULT TEST SUMMARY

INDOOR/OUTDOOR CONDITION \#: 08 FAULT TYPE: REFRIGERANT OVERCHARGE FAULT FAULT LEVEL [\%]: 30.0

\section{RUNNING CONDITIONS}

Barometric Pressure (inHg): Indoor Dry-Bulb Temperature $\left({ }^{\circ} \mathrm{F}\right)$ : Indoor Dew-Point Temperature $\left({ }^{\circ} \mathrm{F}\right)$ : Outdoor Dry-Bulb Temperature $\left({ }^{\circ} \mathrm{F}\right)$ : AIR SIDE CONDITIONS

(INDOOR UNIT)

Inlet Dry-Bulb Temperature $\left({ }^{\circ} \mathrm{F}\right)$ : Inlet Dew-Point Temperature $\left({ }^{\circ} \mathrm{F}\right)$ : Exit Dry-Bulb Temperature $\left({ }^{\circ} \mathrm{F}\right)$ : Exit Dew-Point Temperature $\left({ }^{\circ} \mathrm{F}\right)$ : Inlet Relative Humidity (-): Exit Relative Humidity (-): Evaporator Coil Temp Drop $\left({ }^{\circ} \mathrm{F}\right)$ : Air Flow Rate (SCFM): Fan Power Consumption (W): (OUTDOOR UNIT)

Inlet Temperature $\left({ }^{\circ} \mathrm{F}\right)$ : Exit Temperature $\left({ }^{\circ} \mathrm{F}\right)$ : Condensing Unit Temp Gain $\left({ }^{\circ} \mathrm{F}\right)$ : Fan Power Consumption (W): (OVERALL PERFORMANCE)

Latent Capacity (Btu/h): Sensible Capacity (Btu/h): Overall Capacity (Btu/h): Sensible Heat Ratio (-): Overall Power Consumption (W): NET Cooling EER (Btu/h.W): Evaporator Energy Imbalance (\%): REFRIGERANT SIDE CONDITIONS

(EVAPORATOR)

Inlet Temperature $\left({ }^{\circ} \mathrm{F}\right)$ : Exit Temperature $\left({ }^{\circ} \mathrm{F}\right)$ : Inlet Pressure (psia): Exit Pressure (psia): Pressure Drop (psid): Exit Superheat $\left({ }^{\circ} \mathrm{F}\right)$ : Exit Sat. Temperature $\left({ }^{\circ} \mathrm{F}\right)$ : Evaporator Capacity (Btu/h): (CONDENSER)

$\begin{array}{rr}\text { Inlet Temperature }\left({ }^{\circ} \mathrm{F}\right): & 182.53 \\ \text { Exit Temperature }\left({ }^{\circ} \mathrm{F}\right): & 106.02 \\ \text { Inlet Pressure (psia): } & 444.48 \\ \text { Exit Pressure (psia): } & 442.89 \\ \text { Pressure Drop (psid): } & 1.59 \\ \text { Exit Subcooling }\left({ }^{\circ} \mathrm{F}\right): & 15.58 \\ \text { Sat. Temperature }\left({ }^{\circ} \mathrm{F}\right): & 122.26\end{array}$

Inlet Sat. Temperature $\left({ }^{\circ} \mathrm{F}\right):-122.26$ (LIQUID LINE AND TXV)

Cond Unit Exit Temp $\left({ }^{\circ} \mathrm{F}\right)$ :

Cond Unit Exit Pres (psia): Liq-line Pressure Drop (psid): TXV Upstream Pressure (psia): TXV Pressure Drop (psid): Temperature Drop $\left({ }^{\circ} \mathrm{F}\right)$ : (COMPRESSOR)

Suction Temperature $\left({ }^{\circ} \mathrm{F}\right)$ : Discharge Temperature $\left({ }^{\circ} \mathrm{F}\right)$ : Suction Pressure (psia):

Discharge Pressure (psia): Discharge Superheat $\left({ }^{\circ} \mathrm{F}\right)$ : Comp Bottom Shell Temp $\left({ }^{\circ} \mathrm{F}\right)$ : Mass Flow Rate (l bm/h):

Comp Power Consumption (W):

Cond Unit Inlet Temp $\left({ }^{\circ} \mathrm{F}\right)$ : Cond Unit Inlet Pres (psia):
30.28

70.03

51.06

99.66

70.03

51.06

51.57

48.62

0.510

0.896

18.46

1025.0

416.46

99.66

114.67

15.01

154.84

3380.6

20717.9

24098.4

0.860

2924.7

8.24

1.93

47.72

56.02

154.99

143.69

11.30

11.36

44.66

24998.3

34179.5

105.18

437.05

11.14

425.91

270.92

1.27

63.33

187.84

141.69

445.33

65.64

130.81

375.22

2353.4

58.85

142.90
HEAT PUMP FAULT TEST SUMMARY

INDOOR/OUTDOOR CONDITION \#: 09 FAULT TYPE: REFRIGERANT OVERCHARGE FAULT FAULT LEVEL [\%]: 10.0

RUNNING CONDITIONS

Barometric Pressure (inHg): Indoor Dry-Bulb Temperature $\left({ }^{\circ} \mathrm{F}\right)$ : Indoor Dew-Point Temperature $\left({ }^{\circ} \mathrm{F}\right)$ : Outdoor Dry-Bulb Temperature $\left({ }^{\circ} \mathrm{F}\right)$ : AIR SIDE CONDITIONS (INDOOR UNIT)

Inlet Dry-Bulb Temperature $\left({ }^{\circ} \mathrm{F}\right)$ : Inlet Dew-Point Temperature $\left({ }^{\circ} \mathrm{F}\right)$ : Exit Dry-Bulb Temperature $\left({ }^{\circ} \mathrm{F}\right)$ : Exit Dew-Point Temperature $\left({ }^{\circ} \mathrm{F}\right)$ : Inlet Relative Humidity $(-)$ : Exit Relative Humidity (-): Evaporator Coil Temp Drop $\left({ }^{\circ} \mathrm{F}\right)$ : Air Flow Rate (SCFM): Fan Power Consumption (W) : (OUTDOOR UNIT)

Inlet Temperature $\left({ }^{\circ} \mathrm{F}\right)$ : Exit Temperature $\left({ }^{\circ} \mathrm{F}\right)$ : Condensing Unit Temp Gain $\left({ }^{\circ} \mathrm{F}\right)$ : Fan Power Consumption (W): (OVERALL PERFORMANCE)

Latent Capacity (Btu/h) : Sensible Capacity (Btu/h): Overall Capacity (Btu/h): Sensible Heat Ratio (-):

Overall Power Consumption (W) : NET Cooling EER (Btu/h.W): Evaporator Energy Imbalance (\%): REFRIGERANT SIDE CONDITIONS

(EVAPORATOR)

Inlet Temperature $\left({ }^{\circ} \mathrm{F}\right)$ : Exit Temperature $\left({ }^{\circ} \mathrm{F}\right)$ : Inlet Pressure (psia): Exit Pressure (psia): Pressure Drop (psid): Exit Superheat $\left({ }^{\circ} \mathrm{F}\right)$ : Exit Sat. Temperature $\left({ }^{\circ} \mathrm{F}\right)$ : Evaporator Capacity (Btu/h): (CONDENSER)

Inlet Temperature $\left({ }^{\circ} \mathrm{F}\right)$ : Exit Temperature $\left({ }^{\circ} \mathrm{F}\right)$ : Inlet Pressure (psia): Exit Pressure (psia): Pressure Drop (psid): Exit Subcooling $\left({ }^{\circ} \mathrm{F}\right)$ :

Inlet Sat. Temperature $\left({ }^{\circ} \mathrm{F}\right)$ :

Condenser Capacity (Btu/h): (LIQUID LINE AND TXV)

Cond Unit Exit Temp $\left({ }^{\circ} \mathrm{F}\right)$ : Cond Unit Exit Pres (psia): Liq-line Pressure Drop (psid): TXV Upstream Pressure (psia): TXV Pressure Drop (psid): (COMPRESSOR) Temperature Drop $\left({ }^{\circ} \mathrm{F}\right)$ :

Suction Temperature $\left({ }^{\circ} \mathrm{F}\right)$ :

Discharge Temperature $\left({ }^{\circ} \mathrm{F}\right)$ : Suction Pressure (psia):

Discharge Pressure (psia): Discharge Superheat $\left({ }^{\circ} \mathrm{F}\right)$ : Comp Bottom Shell Temp $\left({ }^{\circ} \mathrm{F}\right)$ : Mass Flow Rate $(1 \mathrm{bm} / \mathrm{h})$ : Comp Power Consumption (W) :

Cond Unit Inlet Temp $\left({ }^{\circ} \mathrm{F}\right)$ : Cond Unit Inlet Pres (psia):
30.74

80.31

60.09

99.75

80.31

60.09

61.04

57.29

0.502

0.875

19.28

1016.9

421.38

99.75

116.54

16.79

156.86

5069.7

21572.8

26642.5

0.810

2858.3

9.32

7.21

55.71

66.39

175.88

163.27

12.61

13.97

52.42

29167.9

175.36

108.25

437.39

435.25

2.14

10.85

121.00

38070.9

108.20

427.59

15.53

412.06

236.18

0.78

71.35

179.35

161.02

438.10

58.44

125.32

435.65

2280.0

68.36

162.17 
HEAT PUMP FAULT TEST SUMMARY

INDOOR/OUTDOOR CONDITION \#: 09

FAULT TYPE: REFRIGERANT OVERCHARGE FAULT FAULT LEVEL [\%]: 20.0

\section{RUNNING CONDITIONS}

Barometric Pressure (inHg): Indoor Dry-Bulb Temperature $\left({ }^{\circ} \mathrm{F}\right)$ : Indoor Dew-Point Temperature $\left({ }^{\circ} \mathrm{F}\right)$ : Outdoor Dry-Bulb Temperature $\left({ }^{\circ} \mathrm{F}\right)$ : AIR SIDE CONDITIONS

(INDOOR UNIT)

Inlet Dry-Bulb Temperature $\left({ }^{\circ} \mathrm{F}\right)$ : Inlet Dew-Point Temperature $\left({ }^{\circ} \mathrm{F}\right)$ : Exit Dry-Bulb Temperature $\left({ }^{\circ} \mathrm{F}\right)$ : Exit Dew-Point Temperature $\left({ }^{\circ} \mathrm{F}\right)$ : Inlet Relative Humidity (-): Exit Relative Humidity (-): Evaporator Coil Temp Drop $\left({ }^{\circ} \mathrm{F}\right)$ : Air Flow Rate (SCFM): Fan Power Consumption (W): (OUTDOOR UNIT)

Inlet Temperature $\left({ }^{\circ} \mathrm{F}\right)$ : Exit Temperature $\left({ }^{\circ} \mathrm{F}\right)$ : Condensing Unit Temp Gain $\left({ }^{\circ} \mathrm{F}\right)$ : Fan Power Consumption (W) : (OVERALL PERFORMANCE)

Latent Capacity (Btu/h): Sensible Capacity (Btu/h): Overall Capacity (Btu/h): Sensible Heat Ratio (-): Overall Power Consumption (W): NET Cooling EER (Btu/h.W): Evaporator Energy Imbalance (\%): REFRIGERANT SIDE CONDITIONS

(EVAPORATOR)

Inlet Temperature $\left({ }^{\circ} \mathrm{F}\right)$ : Exit Temperature $\left({ }^{\circ} \mathrm{F}\right)$ : Inlet Pressure (psia): Exit Pressure (psia): Pressure Drop (psid): Exit Superheat $\left({ }^{\circ} \mathrm{F}\right)$ : Exit Sat. Temperature $\left({ }^{\circ} \mathrm{F}\right)$ : Evaporator Capacity (Btu/h): (CONDENSER)

$\begin{array}{rr}\text { Inlet Temperature }\left({ }^{\circ} \mathrm{F}\right): & 178.03 \\ \text { Exit Temperature }\left({ }^{\circ} \mathrm{F}\right): & 106.89 \\ \text { Inlet Pressure (psia): } & 447.24 \\ \text { Exit Pressure (psia): } & 445.23 \\ \text { Pressure Drop (psid): } & 2.01 \\ \text { Exit Subcooling }\left({ }^{\circ} \mathrm{F}\right): & 14.41 \\ \text { Sat. Temperature }\left({ }^{\circ} \mathrm{F}\right): & 122.74 \\ \text { enser Capacity (Btu/h): } & 38523.0\end{array}$

(LIQUID LINE AND TXV)

Cond Unit Exit Temp $\left({ }^{\circ} \mathrm{F}\right)$ :

Cond Unit Exit Pres (psia): Liq-line Pressure Drop (psid): TXV Upstream Pressure (psia): TXV Pressure Drop (psid): Temperature Drop $\left({ }^{\circ} \mathrm{F}\right)$ : (COMPRESSOR)

Suction Temperature $\left({ }^{\circ} \mathrm{F}\right)$ : Discharge Temperature $\left({ }^{\circ} \mathrm{F}\right)$ : Suction Pressure (psia):

Discharge Pressure (psia): Discharge Superheat $\left({ }^{\circ} \mathrm{F}\right)$ : Comp Bottom Shell Temp $\left({ }^{\circ} \mathrm{F}\right)$ : Mass Flow Rate (l bm/h):

Comp Power Consumption (W):

Cond Unit Inlet Temp $\left({ }^{\circ} \mathrm{F}\right)$ : Cond Unit Inlet Pres (psia):
30.39

79.72

60.69

99.72

79.72

60.69

60.31

57.40

0.523

0.901

19.41

1008.0

412.00

99.72

116.78

17.06

154.91

6048.6

21541.2

27589.8

0.781

2901.9

9.51

4.95

55.54

66.13

176.40

163.49

12.91

13.63

52.50

9458.5

6.89

.01

2. 74

106.43

106.43

437.52

15.27

422.25

245.84

0.69

71.21

182.07

161.33

447.93

59.42

127.27

434.57

2335.0

68.02

162.46
HEAT PUMP FAULT TEST SUMMARY

INDOOR/OUTDOOR CONDITION \#: 09 FAULT TYPE: REFRIGERANT OVERCHARGE FAULT FAULT LEVEL [\%]: 30.0

RUNNING CONDITIONS

Barometric Pressure (inHg): Indoor Dry-Bulb Temperature $\left({ }^{\circ} \mathrm{F}\right)$ : Indoor Dew-Point Temperature $\left({ }^{\circ} \mathrm{F}\right)$ : Outdoor Dry-Bulb Temperature $\left({ }^{\circ} \mathrm{F}\right)$ : AIR SIDE CONDITIONS (INDOOR UNIT)

Inlet Dry-Bulb Temperature $\left({ }^{\circ} \mathrm{F}\right)$ : Inlet Dew-Point Temperature $\left({ }^{\circ} \mathrm{F}\right)$ : Exit Dry-Bulb Temperature $\left({ }^{\circ} \mathrm{F}\right)$ : Exit Dew-Point Temperature $\left({ }^{\circ} \mathrm{F}\right)$ : Inlet Relative Humidity (-): Exit Relative Humidity (-): Evaporator Coil Temp Drop $\left({ }^{\circ} \mathrm{F}\right)$ : Air Flow Rate (SCFM): Fan Power Consumption (W): (OUTDOOR UNIT)

Inlet Temperature $\left({ }^{\circ} \mathrm{F}\right)$ : Exit Temperature $\left({ }^{\circ} \mathrm{F}\right)$ : Condensing Unit Temp Gain $\left({ }^{\circ} \mathrm{F}\right)$ : Fan Power Consumption (W): (OVERALL PERFORMANCE)

Latent Capacity $($ Btu/h) : Sensible Capacity (Btu/h): Overall Capacity (Btu/h): Sensible Heat Ratio (-):

Overall Power Consumption (W) : NET Cooling EER (Btu/h.W): Evaporator Energy Imbalance (\%): REFRIGERANT SIDE CONDITIONS

(EVAPORATOR)

Inlet Temperature $\left({ }^{\circ} \mathrm{F}\right)$ : Exit Temperature $\left({ }^{\circ} \mathrm{F}\right)$ : Inlet Pressure (psia): Exit Pressure (psia): Pressure Drop (psid): Exit Superheat $\left({ }^{\circ} \mathrm{F}\right)$ : Exit Sat. Temperature $\left({ }^{\circ} \mathrm{F}\right)$ : Evaporator Capacity (Btu/h): (CONDENSER)

Inlet Temperature $\left({ }^{\circ} \mathrm{F}\right)$ : Exit Temperature $\left({ }^{\circ} \mathrm{F}\right)$ : Inlet Pressure (psia): Exit Pressure (psia): Pressure Drop (psid): Exit Subcooling $\left({ }^{\circ} \mathrm{F}\right)$ :

Inlet Sat. Temperature $\left({ }^{\circ} \mathrm{F}\right)$ : Condenser Capacity (Btu/h): (LIQUID LINE AND TXV)

Cond Unit Exit Temp $\left({ }^{\circ} \mathrm{F}\right)$ : Cond Unit Exit Pres (psia): Liq-line Pressure Drop (psid): TXV Upstream Pressure (psia): TXV Pressure Drop (psid): (COMPRESSOR) Temperature Drop $\left({ }^{\circ} \mathrm{F}\right)$ :

Suction Temperature $\left({ }^{\circ} \mathrm{F}\right)$ :

Discharge Temperature $\left({ }^{\circ} \mathrm{F}\right)$ : Suction Pressure (psia):

Discharge Pressure (psia): Discharge Superheat $\left({ }^{\circ} \mathrm{F}\right)$ : Comp Bottom Shell Temp $\left({ }^{\circ} \mathrm{F}\right)$ : Mass Flow Rate $(1 \mathrm{bm} / \mathrm{h})$ : Comp Power Consumption (W) :

Cond Unit Inlet Temp $\left({ }^{\circ} \mathrm{F}\right)$ : Cond Unit Inlet Pres (psia):
30.37

79.99

60.66

99.76

79.99

60.66

60.28

57.47

0.517

0.904

19.71

1007.9

412.94

99.76

116.84

17.07

155.43

5861.8

21874.4

27736.1

0.789

2981.4

9.30

4.97

55.73

66.15

176.69

164.10

12.59

13.42

52.73

29620.9

181.51

106.62

460.50

458.64

1.87

17.36

125.03

38942.4

105.86

451.06

15.17

435.90

259.20

0.74

71.39

185.62

161.97

461.19

60.67

129.32

435.25

2413.0

68.19

163.05 


\section{D.8 Presence of Non-Condensable Gas Fault Tests}

Table D.8. List of raw data for presence of non-condensable gas fault tests

\begin{tabular}{c|r|r|r|r|r}
\hline \multirow{2}{*}{$\begin{array}{c}\text { Test } \\
\text { condition } \#\end{array}$} & \multicolumn{2}{|c|}{ Nominal chamber condition } & \multirow{2}{*}{ Fault Type } & \multicolumn{2}{c}{$\begin{array}{c}\text { Fault level } \\
(\%)\end{array}$} \\
\cline { 2 - 3 } & $T_{I D}\left({ }^{\circ} \mathrm{F}\right)$ & \multicolumn{1}{c}{$\phi_{I D}(\%)$} & $T_{O D}\left({ }^{\circ} \mathrm{F}\right)$ & \\
\hline 4 & 70 & 50 & 82 & NON & 5.0 \\
\hline 5 & 80 & 50 & 82 & NON & 5.0 \\
\hline 5 & 80 & 50 & 82 & NON & 10.0 \\
\hline 5 & 80 & 50 & 82 & NON & 16.0 \\
\hline 5 & 80 & 50 & 82 & NON & 20.0 \\
\hline 8 & 70 & 50 & 100 & NON & 5.0 \\
\hline 8 & 70 & 50 & 100 & NON & 10.0 \\
\hline 8 & 70 & 50 & 100 & NON & 16.0 \\
\hline 8 & 70 & 50 & 100 & NON & 20.0 \\
\hline 9 & 80 & 50 & 100 & NON & 5.0 \\
\hline
\end{tabular}


HEAT PUMP FAULT TEST SUMMARY

INDOOR/OUTDOOR CONDITION \#: 04

FAULT TYPE: NON-CONDENSABLE GAS FAULT FAULT LEVEL [\%]: 5.0

\section{RUNNING CONDITIONS}

Barometric Pressure (inHg): Indoor Dry-Bulb Temperature $\left({ }^{\circ} \mathrm{F}\right)$ : Indoor Dew-Point Temperature $\left({ }^{\circ} \mathrm{F}\right)$ : Outdoor Dry-Bulb Temperature $\left({ }^{\circ} \mathrm{F}\right)$ : AIR SIDE CONDITIONS

(INDOOR UNIT)

Inlet Dry-Bulb Temperature $\left({ }^{\circ} \mathrm{F}\right)$ : Inlet Dew-Point Temperature $\left({ }^{\circ} \mathrm{F}\right)$ : Exit Dry-Bulb Temperature $\left({ }^{\circ} \mathrm{F}\right)$ : Exit Dew-Point Temperature $\left({ }^{\circ} \mathrm{F}\right)$ : Inlet Relative Humidity (-): Exit Relative Humidity (-): Evaporator Coil Temp Drop $\left({ }^{\circ} \mathrm{F}\right)$ : Air Flow Rate (SCFM): Fan Power Consumption (W): (OUTDOOR UNIT)

Inlet Temperature $\left({ }^{\circ} \mathrm{F}\right)$ : Exit Temperature $\left({ }^{\circ} \mathrm{F}\right)$ : Condensing Unit Temp Gain $\left({ }^{\circ} \mathrm{F}\right)$ : Fan Power Consumption (W) : (OVERALL PERFORMANCE)

Latent Capacity (Btu/h): Sensible Capacity (Btu/h): Overall Capacity (Btu/h): Sensible Heat Ratio (-): Overall Power Consumption (W): NET Cooling EER (Btu/h.W): Evaporator Energy Imbalance (\%): REFRIGERANT SIDE CONDITIONS

(EVAPORATOR)

Inlet Temperature $\left({ }^{\circ} \mathrm{F}\right)$ : Exit Temperature $\left({ }^{\circ} \mathrm{F}\right)$ : Inlet Pressure (psia): Exit Pressure (psia): Pressure Drop (psid): Exit Superheat $\left({ }^{\circ} \mathrm{F}\right)$ : Exit Sat. Temperature $\left({ }^{\circ} \mathrm{F}\right)$ : Evaporator Capacity (Btu/h): (CONDENSER)

$\begin{array}{rr}\text { Inlet Temperature }\left({ }^{\circ} \mathrm{F}\right): & 148.94 \\ \text { Exit Temperature }\left({ }^{\circ} \mathrm{F}\right): & 88.38 \\ \text { Inlet Pressure (psia): } & 337.79 \\ \text { Exit Pressure (psia): } & 335.72 \\ \text { Pressure Drop (psid): } & 2.08 \\ \text { Exit Subcooling }\left({ }^{\circ} \mathrm{F}\right): & 10.87 \\ \text { Sat. Temperature }\left({ }^{\circ} \mathrm{F}\right): & 101.48 \\ \text { enser Capacity (Btu/h): } & 34733.7\end{array}$

(LIQUID LINE AND TXV)

Cond Unit Exit Temp $\left({ }^{\circ} \mathrm{F}\right)$ :

Cond Unit Exit Pres (psia): Liq-line Pressure Drop (psid): TXV Upstream Pressure (psia): TXV Pressure Drop (psid): Temperature Drop $\left({ }^{\circ} \mathrm{F}\right)$ : (COMPRESSOR)

Suction Temperature $\left({ }^{\circ} \mathrm{F}\right)$ : Discharge Temperature $\left({ }^{\circ} \mathrm{F}\right)$ : Suction Pressure (psia):

Discharge Pressure (psia): Discharge Superheat $\left({ }^{\circ} \mathrm{F}\right)$ : Comp Bottom Shell Temp $\left({ }^{\circ} \mathrm{F}\right)$ : Mass Flow Rate (l bm/h):

Comp Power Consumption (W) :

Cond Unit Inlet Temp $\left({ }^{\circ} \mathrm{F}\right)$ : Cond Unit Inlet Pres (psia):
30.65

70.09

50.70

81.69

70.09

50.70

50.70

47.27

0.502

0.880

19.39

1037.9

436.15

81.69

96.48

14.78

164.27

4601.5

22022.8

26624.4

0.827

2359.8

11.28

2.08

45.67

55.45

148.70

138.81

9.89

12.84

42.60

27633.8

48.94

88.38

37.79

2.08

10.87

34733.7

88.64

329.77

10.27

319.50

170.79

0.88

60.54

153.07

136.69

338.63

51.67

110.43

375.41

1759.4

57.74

137.94
HEAT PUMP FAULT TEST SUMMARY

INDOOR/OUTDOOR CONDITION \#: 05 FAULT TYPE: NON-CONDENSABLE GAS FAULT FAULT LEVEL [\%]: 5.0 RUNNING CONDITIONS

Barometric Pressure (inHg): Indoor Dry-Bulb Temperature $\left({ }^{\circ} \mathrm{F}\right)$ : Indoor Dew-Point Temperature $\left({ }^{\circ} \mathrm{F}\right)$ : Outdoor Dry-Bulb Temperature $\left({ }^{\circ} \mathrm{F}\right)$ : AIR SIDE CONDITIONS (INDOOR UNIT)

Inlet Dry-Bulb Temperature $\left({ }^{\circ} \mathrm{F}\right)$ : Inlet Dew-Point Temperature $\left({ }^{\circ} \mathrm{F}\right)$ : Exit Dry-Bulb Temperature $\left({ }^{\circ} \mathrm{F}\right)$ : Exit Dew-Point Temperature $\left({ }^{\circ} \mathrm{F}\right)$ : Inlet Relative Humidity $(-)$ : Exit Relative Humidity (-) : Evaporator Coil Temp Drop $\left({ }^{\circ} \mathrm{F}\right)$ : Air Flow Rate (SCFM): Fan Power Consumption (W): (OUTDOOR UNIT)

Inlet Temperature $\left({ }^{\circ} \mathrm{F}\right)$ : Exit Temperature $\left({ }^{\circ} \mathrm{F}\right)$ : Condensing Unit Temp Gain $\left({ }^{\circ} \mathrm{F}\right)$ : Fan Power Consumption (W): (OVERALL PERFORMANCE)

Latent Capacity (Btu/h): Sensible Capacity (Btu/h): Overall Capacity (Btu/h): Sensible Heat Ratio (-):

Overall Power Consumption (W) : NET Cooling EER (Btu/h.W): Evaporator Energy Imbalance (\%): REFRIGERANT SIDE CONDITIONS

(EVAPORATOR)

Inlet Temperature $\left({ }^{\circ} \mathrm{F}\right)$ : Exit Temperature $\left({ }^{\circ} \mathrm{F}\right)$ : Inlet Pressure (psia): Exit Pressure (psia): Pressure Drop (psid): Exit Superheat $\left({ }^{\circ} \mathrm{F}\right)$ : Exit Sat. Temperature $\left({ }^{\circ} \mathrm{F}\right)$ : Evaporator Capacity (Btu/h): (CONDENSER)

$\begin{array}{rr}\text { Inlet Temperature }\left({ }^{\circ} \mathrm{F}\right): & 147.79 \\ \text { Exit Temperature }\left({ }^{\circ} \mathrm{F}\right): & 90.00 \\ \text { Inlet Pressure (psia): } & 347.48 \\ \text { Exit Pressure (psia): } & 344.91 \\ \text { Pressure Drop (psid): } & 2.57 \\ \text { Exit Subcooling }\left({ }^{\circ} \mathrm{F}\right): & 10.52 \\ \text { Sat. Temperature }\left({ }^{\circ} \mathrm{F}\right): & 103.56\end{array}$

Inlet sat. Temperature $\left({ }^{\circ} \mathrm{F}\right)$ : (LIQUID LINE AND TXV)

Cond Unit Exit Temp ( $\left.{ }^{\circ} \mathrm{F}\right): \quad 90.66$

Cond Unit Exit Pres (psia): 337.44

Liq-line Pressure Drop (psid): 14.44

TXV Upstream Pressure (psia): 323.00 TXV Pressure Drop (psid): 153.13 (COMPRESSOR) Temperature Drop $\left({ }^{\circ} \mathrm{F}\right)$ :

Suction Temperature $\left({ }^{\circ} \mathrm{F}\right)$ :

Discharge Temperature $\left({ }^{\circ} \mathrm{F}\right)$ : Suction Pressure (psia):

Discharge Pressure (psia): Discharge Superheat $\left({ }^{\circ} \mathrm{F}\right)$ : Comp Bottom Shell Temp $\left({ }^{\circ} \mathrm{F}\right)$ : Mass Flow Rate $(1 \mathrm{bm} / \mathrm{h})$ : Comp Power Consumption (W) :

Cond Unit Inlet Temp $\left({ }^{\circ} \mathrm{F}\right)$ : Cond Unit Inlet Pres (psia):
0.46

30.74

60.50

81.80

80.01

56.24

.514

20.78

018.0

81.80

16.93

164.38

7639.1

30915.2

0.753

375.2

2.67

54.04

159.40

10.46

14.15
50.94

7. 48

03.56

68.35

151.07

157.15

348.29

47.60

110.01

433.53

1777.1

66.77

158.34 
HEAT PUMP FAULT TEST SUMMARY

INDOOR/OUTDOOR CONDITION \#: 05

FAULT TYPE: NON-CONDENSABLE GAS FAULT FAULT LEVEL [\%]: 10.0

\section{RUNNING CONDITIONS}

Barometric Pressure (inHg): Indoor Dry-Bulb Temperature $\left({ }^{\circ} \mathrm{F}\right)$ : Indoor Dew-Point Temperature $\left({ }^{\circ} \mathrm{F}\right)$ : Outdoor Dry-Bulb Temperature $\left({ }^{\circ} \mathrm{F}\right)$ : AIR SIDE CONDITIONS

(INDOOR UNIT)

Inlet Dry-Bulb Temperature $\left({ }^{\circ} \mathrm{F}\right)$ : Inlet Dew-Point Temperature $\left({ }^{\circ} \mathrm{F}\right)$ : Exit Dry-Bulb Temperature $\left({ }^{\circ} \mathrm{F}\right)$ : Exit Dew-Point Temperature $\left({ }^{\circ} \mathrm{F}\right)$ : Inlet Relative Humidity (-): Exit Relative Humidity (-): Evaporator Coil Temp Drop $\left({ }^{\circ} \mathrm{F}\right)$ : Air Flow Rate (SCFM): Fan Power Consumption (W): (OUTDOOR UNIT)

Inlet Temperature $\left({ }^{\circ} \mathrm{F}\right)$ : Exit Temperature $\left({ }^{\circ} \mathrm{F}\right)$ : Condensing Unit Temp Gain $\left({ }^{\circ} \mathrm{F}\right)$ : Fan Power Consumption (W): (OVERALL PERFORMANCE)

Latent Capacity (Btu/h): Sensible Capacity (Btu/h): Overall Capacity (Btu/h): Sensible Heat Ratio (-): Overall Power Consumption (W): NET Cooling EER (Btu/h.W): Evaporator Energy Imbalance (\%): REFRIGERANT SIDE CONDITIONS

(EVAPORATOR)

Inlet Temperature $\left({ }^{\circ} \mathrm{F}\right)$ : Exit Temperature $\left({ }^{\circ} \mathrm{F}\right)$ : Inlet Pressure (psia): Exit Pressure (psia): Pressure Drop (psid): Exit Superheat $\left({ }^{\circ} \mathrm{F}\right)$ : Exit Sat. Temperature $\left({ }^{\circ} \mathrm{F}\right)$ : Evaporator Capacity (Btu/h): (CONDENSER)

$\begin{array}{rr}\text { Inlet Temperature }\left({ }^{\circ} \mathrm{F}\right): & 147.50 \\ \text { Exit Temperature }\left({ }^{\circ} \mathrm{F}\right): & 89.84 \\ \text { Inlet Pressure (psia): } & 348.89 \\ \text { Exit Pressure (psia): } & 346.42 \\ \text { Pressure Drop (psid): } & 2.47 \\ \text { Exit Subcooling }\left({ }^{\circ} \mathrm{F}\right): & 11.12 \\ \text { Sat. Temperature }\left({ }^{\circ} \mathrm{F}\right): & 103.86 \\ \text { enser Capacity (Btu/h): } & 39523.1\end{array}$

(LIQUID LINE AND TXV)

Cond Unit Exit Temp $\left({ }^{\circ} \mathrm{F}\right)$ :

Cond Unit Exit Pres (psia): Liq-line Pressure Drop (psid): TXV Upstream Pressure (psia): TXV Pressure Drop (psid): Temperature Drop $\left({ }^{\circ} \mathrm{F}\right)$ : (COMPRESSOR)

Suction Temperature $\left({ }^{\circ} \mathrm{F}\right)$ : Discharge Temperature $\left({ }^{\circ} \mathrm{F}\right)$ : Suction Pressure (psia):

Discharge Pressure (psia): Discharge Superheat $\left({ }^{\circ} \mathrm{F}\right)$ : Comp Bottom Shell Temp $\left({ }^{\circ} \mathrm{F}\right)$ : Mass Flow Rate (l bm/h):

Comp Power Consumption (W) :

Cond Unit Inlet Temp $\left({ }^{\circ} \mathrm{F}\right)$ : Cond Unit Inlet Pres (psia):
30.77

80.07

60.64

81.79

80.07

60.64

59.33

56.23

0.516

0.895

20.75

1020.5

431.00

81.79

98.63

16.84

163.94

7928.9

23298.9

31227.8

0.746

2381.7

13.11

2.65

53.94

65.41

170.56

159.60

10.96

14.39

51.02

32520.7

47.50

89.84

2.47

9523.1

90.37

338.82

14.54

324.28

153.72

0.42

68.53

150.77

157.23

349.80

46.99

108.61

436.31

1786.8

66.97

158.46
HEAT PUMP FAULT TEST SUMMARY

INDOOR/OUTDOOR CONDITION \#: 05

FAULT TYPE: NON-CONDENSABLE GAS FAULT FAULT LEVEL [\%]: 16.0

RUNNING CONDITIONS

Barometric Pressure (inHg): Indoor Dry-Bulb Temperature $\left({ }^{\circ} \mathrm{F}\right)$ : Indoor Dew-Point Temperature $\left({ }^{\circ} \mathrm{F}\right)$ : Outdoor Dry-Bulb Temperature $\left({ }^{\circ} \mathrm{F}\right)$ : AIR SIDE CONDITIONS (INDOOR UNIT)

Inlet Dry-Bulb Temperature $\left({ }^{\circ} \mathrm{F}\right)$ : Inlet Dew-Point Temperature $\left({ }^{\circ} \mathrm{F}\right)$ : Exit Dry-Bulb Temperature $\left({ }^{\circ} \mathrm{F}\right)$ : Exit Dew-Point Temperature $\left({ }^{\circ} \mathrm{F}\right)$ : Inlet Relative Humidity $(-)$ : Exit Relative Humidity (-) : Evaporator Coil Temp Drop $\left({ }^{\circ} \mathrm{F}\right)$ : Air Flow Rate (SCFM): Fan Power Consumption (W): (OUTDOOR UNIT)

Inlet Temperature $\left({ }^{\circ} \mathrm{F}\right)$ : Exit Temperature $\left({ }^{\circ} \mathrm{F}\right)$ : Condensing Unit Temp Gain $\left({ }^{\circ} \mathrm{F}\right)$ : Fan Power Consumption (W): (OVERALL PERFORMANCE)

Latent Capacity (Btu/h): Sensible Capacity (Btu/h): Overall Capacity (Btu/h): Sensible Heat Ratio (-) :

Overall Power Consumption (W) : NET Cooling EER (Btu/h.W): Evaporator Energy Imbalance (\%): REFRIGERANT SIDE CONDITIONS

(EVAPORATOR)

Inlet Temperature $\left({ }^{\circ} \mathrm{F}\right)$ : Exit Temperature $\left({ }^{\circ} \mathrm{F}\right)$ : Inlet Pressure (psia): Exit Pressure (psia): Pressure Drop (psid): Exit Superheat $\left({ }^{\circ} \mathrm{F}\right)$ : Exit Sat. Temperature $\left({ }^{\circ} \mathrm{F}\right)$ : Evaporator Capacity (Btu/h): (CONDENSER)

Inlet Temperature $\left({ }^{\circ} \mathrm{F}\right)$ : Exit Temperature $\left({ }^{\circ} \mathrm{F}\right)$ : Inlet Pressure (psia): Exit Pressure (psia): Pressure Drop (psid): Exit Subcooling $\left({ }^{\circ} \mathrm{F}\right)$ :

Inlet Sat. Temperature $\left({ }^{\circ} \mathrm{F}\right)$ :

Condenser Capacity (Btu/h): (LIQUID LINE AND TXV)

Cond Unit Exit Temp $\left({ }^{\circ} \mathrm{F}\right)$ : Cond Unit Exit Pres (psia): Liq-line Pressure Drop (psid): TXV Upstream Pressure (psia): TXV Pressure Drop (psid): (COMPRESSOR) Temperature Drop $\left({ }^{\circ} \mathrm{F}\right)$ :

Suction Temperature $\left({ }^{\circ} \mathrm{F}\right)$ :

Discharge Temperature $\left({ }^{\circ} \mathrm{F}\right)$ : Suction Pressure (psia):

Discharge Pressure (psia): Discharge Superheat $\left({ }^{\circ} \mathrm{F}\right)$ : Comp Bottom Shell Temp $\left({ }^{\circ} \mathrm{F}\right)$ : Mass Flow Rate $(1 \mathrm{bm} / \mathrm{h})$ : Comp Power Consumption (W) :

Cond Unit Inlet Temp $\left({ }^{\circ} \mathrm{F}\right)$ : Cond Unit Inlet Pres (psia):
30.41 80.05 60.26 81.72

80.05

60.26

59.19

56.26

0.509

0.900

20.86

1008.7

435.35

81.72

98.64

16.92

163.66

7164.5

23148.6

30313.1

0.764

2435.4

12.45

5.46

53.36

68.28

170.42

159.69

10.73

17.23

51.05

32523.7

153.95

89.43

358.72

355.35

3.38

13.76

105.92

39785.9

89.91

349.00

14.13

334.87

164.45

1.54

71.57

157.41

157.45

359.79

51.53

115.08

431.12

1836.4

69.83

158.63 
HEAT PUMP FAULT TEST SUMMARY

INDOOR/OUTDOOR CONDITION \#: 05

FAULT TYPE: NON-CONDENSABLE GAS FAULT FAULT LEVEL [\%]: 20.0

\section{RUNNING CONDITIONS}

Barometric Pressure (inHg): Indoor Dry-Bulb Temperature $\left({ }^{\circ} \mathrm{F}\right)$ : Indoor Dew-Point Temperature $\left({ }^{\circ} \mathrm{F}\right)$ : Outdoor Dry-Bulb Temperature $\left({ }^{\circ} \mathrm{F}\right)$ : AIR SIDE CONDITIONS

(INDOOR UNIT)

Inlet Dry-Bulb Temperature $\left({ }^{\circ} \mathrm{F}\right)$ : Inlet Dew-Point Temperature $\left({ }^{\circ} \mathrm{F}\right)$ : Exit Dry-Bulb Temperature $\left({ }^{\circ} \mathrm{F}\right)$ : Exit Dew-Point Temperature $\left({ }^{\circ} \mathrm{F}\right)$ : Inlet Relative Humidity (-): Exit Relative Humidity (-): Evaporator Coil Temp Drop $\left({ }^{\circ} \mathrm{F}\right)$ : Air Flow Rate (SCFM): Fan Power Consumption (W) : (OUTDOOR UNIT)

Inlet Temperature $\left({ }^{\circ} \mathrm{F}\right)$ : Exit Temperature $\left({ }^{\circ} \mathrm{F}\right)$ : Condensing Unit Temp Gain $\left({ }^{\circ} \mathrm{F}\right)$ : Fan Power Consumption (W): (OVERALL PERFORMANCE)

Latent Capacity (Btu/h): Sensible Capacity (Btu/h): Overall Capacity (Btu/h): Sensible Heat Ratio (-): Overall Power Consumption (W): NET Cooling EER (Btu/h.W): Evaporator Energy Imbalance (\%): REFRIGERANT SIDE CONDITIONS

(EVAPORATOR)

Inlet Temperature $\left({ }^{\circ} \mathrm{F}\right)$ : Exit Temperature $\left({ }^{\circ} \mathrm{F}\right)$ : Inlet Pressure (psia): Exit Pressure (psia): Pressure Drop (psid): Exit Superheat $\left({ }^{\circ} \mathrm{F}\right)$ : Exit Sat. Temperature $\left({ }^{\circ} \mathrm{F}\right)$ : Evaporator Capacity (Btu/h): (CONDENSER)

$\begin{array}{rr}\text { Inlet Temperature }\left({ }^{\circ} \mathrm{F}\right): & 157.55 \\ \text { Exit Temperature }\left({ }^{\circ} \mathrm{F}\right): & 89.03 \\ \text { Inlet Pressure (psia): } & 365.89 \\ \text { Exit Pressure (psia): } & 362.89 \\ \text { Pressure Drop (psid): } & 3.00 \\ \text { Exit Subcooling }\left({ }^{\circ} \mathrm{F}\right): & 16.42 \\ \text { Sat. Temperature }\left({ }^{\circ} \mathrm{F}\right): & 107.40 \\ \text { enser Capacity (Btu } / \mathrm{h}): & 38933.0\end{array}$

(LIQUID LINE AND TXV)

Cond Unit Exit Temp $\left({ }^{\circ} \mathrm{F}\right)$ :

Cond Unit Exit Pres (psia): Liq-line Pressure Drop (psid): TXV Upstream Pressure (psia): TXV Pressure Drop (psid): Temperature Drop $\left({ }^{\circ} \mathrm{F}\right)$ : (COMPRESSOR)

Suction Temperature $\left({ }^{\circ} \mathrm{F}\right)$ Discharge Temperature $\left({ }^{\circ} \mathrm{F}\right)$ : Suction Pressure (psia):

Discharge Pressure (psia): Discharge Superheat $\left({ }^{\circ} \mathrm{F}\right)$ : Comp Bottom Shell Temp $\left({ }^{\circ} \mathrm{F}\right)$ : Mass Flow Rate (l bm/h):

Comp Power Consumption (W) :

Cond Unit Inlet Temp $\left({ }^{\circ} \mathrm{F}\right)$ : Cond Unit Inlet Pres (psia):
30.39

79.92

60.28

81.77

79.92

60.28

59.35

56.22

0.512

0.894

20.57

1007.2

81.77

98.57

16.79

162.79

7261.9

22794.9

30056.8

0.758

2473.0

12.15

3.88

52.78

69.41

169.29

158.78

10.51

18.70

50.70

31717.7

57.55

89.03

65.89

3.00

16.42

38933.0

88.78

356.27

14.91

341.35

172.06

1.67

72.77

161.15

156.56

366.83

53.82

117.74

416.21

1878.4

70.90

157.74
431.75
HEAT PUMP FAULT TEST SUMMARY

INDOOR/OUTDOOR CONDITION \#: 08 FAULT TYPE: NON-CONDENSABLE GAS FAULT FAULT LEVEL [\%]: 5.0

RUNNING CONDITIONS

Barometric Pressure (inHg): Indoor Dry-Bulb Temperature $\left({ }^{\circ} \mathrm{F}\right)$ : Indoor Dew-Point Temperature $\left({ }^{\circ} \mathrm{F}\right)$ : Outdoor Dry-Bulb Temperature $\left({ }^{\circ} \mathrm{F}\right)$ : AIR SIDE CONDITIONS (INDOOR UNIT)

Inlet Dry-Bulb Temperature $\left({ }^{\circ} \mathrm{F}\right)$ : Inlet Dew-Point Temperature $\left({ }^{\circ} \mathrm{F}\right)$ : Exit Dry-Bulb Temperature $\left({ }^{\circ} \mathrm{F}\right)$ : Exit Dew-Point Temperature $\left({ }^{\circ} \mathrm{F}\right)$ : Inlet Relative Humidity (-): Exit Relative Humidity (-): Evaporator Coil Temp Drop $\left({ }^{\circ} \mathrm{F}\right)$ : Air Flow Rate (SCFM): Fan Power Consumption (W): (OUTDOOR UNIT)

Inlet Temperature $\left({ }^{\circ} \mathrm{F}\right)$ : Exit Temperature $\left({ }^{\circ} \mathrm{F}\right)$ : Condensing Unit Temp Gain $\left({ }^{\circ} \mathrm{F}\right)$ : Fan Power Consumption (W): (OVERALL PERFORMANCE)

Latent Capacity (Btu/h): Sensible Capacity (Btu/h): Overall Capacity (Btu/h): Sensible Heat Ratio (-):

Overall Power Consumption (W) : NET Cooling EER (Btu/h.W): Evaporator Energy Imbalance (\%): REFRIGERANT SIDE CONDITIONS

(EVAPORATOR)

Inlet Temperature $\left({ }^{\circ} \mathrm{F}\right)$ : Exit Temperature $\left({ }^{\circ} \mathrm{F}\right)$ : Inlet Pressure (psia): Exit Pressure (psia): Pressure Drop (psid): Exit Superheat $\left({ }^{\circ} \mathrm{F}\right)$ : Exit Sat. Temperature $\left({ }^{\circ} \mathrm{F}\right)$ : Evaporator Capacity (Btu/h): (CONDENSER)

Inlet Temperature $\left({ }^{\circ} \mathrm{F}\right)$ : Exit Temperature $\left({ }^{\circ} \mathrm{F}\right)$ : Inlet Pressure (psia): Exit Pressure (psia): Pressure Drop (psid): Exit Subcooling $\left({ }^{\circ} \mathrm{F}\right)$ :

Inlet Sat. Temperature $\left({ }^{\circ} \mathrm{F}\right)$ :

Condenser Capacity (Btu/h): (LIQUID LINE AND TXV)

Cond Unit Exit Temp $\left({ }^{\circ} \mathrm{F}\right)$ : Cond Unit Exit Pres (psia): Liq-line Pressure Drop (psid): TXV Upstream Pressure (psia): TXV Pressure Drop (psid): (COMPRESSOR) Temperature Drop $\left({ }^{\circ} \mathrm{F}\right)$ :

Suction Temperature $\left({ }^{\circ} \mathrm{F}\right)$ :

Discharge Temperature $\left({ }^{\circ} \mathrm{F}\right)$ : Suction Pressure (psia):

Discharge Pressure (psia): Discharge Superheat $\left({ }^{\circ} \mathrm{F}\right)$ : Comp Bottom Shell Temp $\left({ }^{\circ} \mathrm{F}\right)$ : Mass Flow Rate $(1 \mathrm{bm} / \mathrm{h})$ : Comp Power Consumption (W) :

Cond Unit Inlet Temp $\left({ }^{\circ} \mathrm{F}\right)$ : Cond Unit Inlet Pres (psia):
30.65

69.98

50.61

99.94

69.98

50.61

51.46

48.19

0.502

0.885

18.53

1035.5

437.65

99.94

114.63

14.70

160.95

3292.8

20998.0

24290.8

0.864

2836.6

8.56

$-1.92$

47. 16

56.17

154.71

142.93

11.78

11.83

44.34

24261.8

177.70

107.81

425.15

423.33

1.81

9.62

118.80

33142.4

107.55

417.31

11.09

406.22

251.51

1.30

63.29

182.83

140.92

425.90

64.11

127.08

371.39

2238.0

58.96

142.13 
HEAT PUMP FAULT TEST SUMMARY

INDOOR/OUTDOOR CONDITION \#: 08

FAULT TYPE: NON-CONDENSABLE GAS FAULT FAULT LEVEL [\%]: 10.0

\section{RUNNING CONDITIONS}

Barometric Pressure (inHg): Indoor Dry-Bulb Temperature $\left({ }^{\circ} \mathrm{F}\right)$ : Indoor Dew-Point Temperature $\left({ }^{\circ} \mathrm{F}\right)$ : Outdoor Dry-Bulb Temperature $\left({ }^{\circ} \mathrm{F}\right)$ : AIR SIDE CONDITIONS

(INDOOR UNIT)

Inlet Dry-Bulb Temperature $\left({ }^{\circ} \mathrm{F}\right)$ : Inlet Dew-Point Temperature $\left({ }^{\circ} \mathrm{F}\right)$ : Exit Dry-Bulb Temperature $\left({ }^{\circ} \mathrm{F}\right)$ : Exit Dew-Point Temperature $\left({ }^{\circ} \mathrm{F}\right)$ : Inlet Relative Humidity (-): Exit Relative Humidity (-): Evaporator Coil Temp Drop $\left({ }^{\circ} \mathrm{F}\right)$ : Air Flow Rate (SCFM): Fan Power Consumption (W): (OUTDOOR UNIT)

Inlet Temperature $\left({ }^{\circ} \mathrm{F}\right)$ : Exit Temperature $\left({ }^{\circ} \mathrm{F}\right)$ : Condensing Unit Temp Gain $\left({ }^{\circ} \mathrm{F}\right)$ : Fan Power Consumption (W): (OVERALL PERFORMANCE)

Latent Capacity (Btu/h): Sensible Capacity (Btu/h): Overall Capacity (Btu/h): Sensible Heat Ratio (-): Overall Power Consumption (W): NET Cooling EER (Btu/h.W): Evaporator Energy Imbalance (\%): REFRIGERANT SIDE CONDITIONS

(EVAPORATOR)

Inlet Temperature $\left({ }^{\circ} \mathrm{F}\right)$ : Exit Temperature $\left({ }^{\circ} \mathrm{F}\right)$ : Inlet Pressure (psia): Exit Pressure (psia): Pressure Drop (psid): Exit Superheat $\left({ }^{\circ} \mathrm{F}\right)$ : Exit Sat. Temperature $\left({ }^{\circ} \mathrm{F}\right)$ : Evaporator Capacity (Btu/h): (CONDENSER)

$\begin{array}{rr}\text { Inlet Temperature }\left({ }^{\circ} \mathrm{F}\right): & 158.32 \\ \text { Exit Temperature }\left({ }^{\circ} \mathrm{F}\right): & 88.79 \\ \text { Inlet Pressure (psia): } & 368.68 \\ \text { Exit Pressure (psia): } & 366.70 \\ \text { Pressure Drop (psid): } & 1.99 \\ \text { Exit Subcooling }\left({ }^{\circ} \mathrm{F}\right): & 17.86 \\ \text { Sat. Temperature }\left({ }^{\circ} \mathrm{F}\right): & 107.96 \\ \text { enser Capacity (Btu/h): } & 38225.9\end{array}$

(LIQUID LINE AND TXV)

Cond Unit Exit Temp $\left({ }^{\circ} \mathrm{F}\right)$ :

Cond Unit Exit Pres (psia): Liq-line Pressure Drop (psid): TXV Upstream Pressure (psia): TXV Pressure Drop (psid): Temperature Drop $\left({ }^{\circ} \mathrm{F}\right)$ : (COMPRESSOR)

Suction Temperature $\left({ }^{\circ} \mathrm{F}\right)$ : Discharge Temperature $\left({ }^{\circ} \mathrm{F}\right)$ : Suction Pressure (psia):

Discharge Pressure (psia): Discharge Superheat $\left({ }^{\circ} \mathrm{F}\right)$ : Comp Bottom Shell Temp $\left({ }^{\circ} \mathrm{F}\right)$ : Mass Flow Rate (l bm/h):

Comp Power Consumption (W) :

Cond Unit Inlet Temp $\left({ }^{\circ} \mathrm{F}\right)$ : Cond Unit Inlet Pres (psia):
30.51

79.50

59.89

81.82

79.50

59.89

59.41

56.59

0.512

0.904

20.09

1018.2

434.36

81.82

98.24

16.42

164.45

5925.6

22512.1

28437.7

0.792

2500.9

11.37

7.16

51.61

68.88

166.79

155.87

10.92

19.30

49.57

31098.2

58.32

88.79

68.68

1.99

17.86

38225.9

87.93

359.13

15.13

344.00

177.21

1.50

72.31

162.16

153.73

369.53

54.28

116.43

406.35

1902.1

70.40

154.98
HEAT PUMP FAULT TEST SUMMARY

INDOOR/OUTDOOR CONDITION \#: 08

FAULT TYPE: NON-CONDENSABLE GAS FAULT FAULT LEVEL [\%]: 16.0

RUNNING CONDITIONS

Barometric Pressure (inHg) : Indoor Dry-Bulb Temperature $\left({ }^{\circ} \mathrm{F}\right)$ : Indoor Dew-Point Temperature $\left({ }^{\circ} \mathrm{F}\right)$ : Outdoor Dry-Bulb Temperature $\left({ }^{\circ} \mathrm{F}\right)$ : AIR SIDE CONDITIONS (INDOOR UNIT)

Inlet Dry-Bulb Temperature $\left({ }^{\circ} \mathrm{F}\right)$ : Inlet Dew-Point Temperature $\left({ }^{\circ} \mathrm{F}\right)$ : Exit Dry-Bulb Temperature $\left({ }^{\circ} \mathrm{F}\right)$ : Exit Dew-Point Temperature $\left({ }^{\circ} \mathrm{F}\right)$ : Inlet Relative Humidity $(-)$ : Exit Relative Humidity (-) : Evaporator Coil Temp Drop $\left({ }^{\circ} \mathrm{F}\right)$ : Air Flow Rate (SCFM): Fan Power Consumption (W): (OUTDOOR UNIT)

Inlet Temperature $\left({ }^{\circ} \mathrm{F}\right)$ : Exit Temperature $\left({ }^{\circ} \mathrm{F}\right)$ : Condensing Unit Temp Gain $\left({ }^{\circ} \mathrm{F}\right)$ : Fan Power Consumption (W): (OVERALL PERFORMANCE)

Latent Capacity (Btu/h): Sensible Capacity (Btu/h): Overall Capacity (Btu/h): Sensible Heat Ratio (-):

Overall Power Consumption (W) : NET Cooling EER (Btu/h.W): Evaporator Energy Imbalance (\%): REFRIGERANT SIDE CONDITIONS

(EVAPORATOR)

Inlet Temperature $\left({ }^{\circ} \mathrm{F}\right)$ : Exit Temperature $\left({ }^{\circ} \mathrm{F}\right)$ : Inlet Pressure (psia): Exit Pressure (psia): Pressure Drop (psid): Exit Superheat $\left({ }^{\circ} \mathrm{F}\right)$ : Exit Sat. Temperature $\left({ }^{\circ} \mathrm{F}\right)$ : Evaporator Capacity (Btu/h): (CONDENSER)

Inlet Temperature $\left({ }^{\circ} \mathrm{F}\right)$ : Exit Temperature $\left({ }^{\circ} \mathrm{F}\right)$ : Inlet Pressure (psia): Exit Pressure (psia): Pressure Drop (psid): Exit Subcooling $\left({ }^{\circ} \mathrm{F}\right)$ :

Inlet Sat. Temperature $\left({ }^{\circ} \mathrm{F}\right)$ :

Condenser Capacity (Btu/h): (LIQUID LINE AND TXV)

Cond Unit Exit Temp $\left({ }^{\circ} \mathrm{F}\right)$ : Cond Unit Exit Pres (psia): Liq-line Pressure Drop (psid): TXV Upstream Pressure (psia): TXV Pressure Drop (psid): (COMPRESSOR) Temperature Drop $\left({ }^{\circ} \mathrm{F}\right)$ :

Suction Temperature $\left({ }^{\circ} \mathrm{F}\right)$ :

Discharge Temperature $\left({ }^{\circ} \mathrm{F}\right)$ : Suction Pressure (psia):

Discharge Pressure (psia): Discharge Superheat $\left({ }^{\circ} \mathrm{F}\right)$ : Comp Bottom Shell Temp $\left({ }^{\circ} \mathrm{F}\right)$ : Mass Flow Rate $(1 \mathrm{bm} / \mathrm{h})$ : Comp Power Consumption (W) : Cond Unit Inlet Temp $\left({ }^{\circ} \mathrm{F}\right)$ : Cond Unit Inlet Pres (psia):
30.42

70.02

50.26

99.69

70.02

50.26

51.48

48.07

0.495

0.881

18.54

1027.5

436.23

99.69

114.52

14.84

159.75

2948.7

20850.8

23799.5

0.876

2892.1

8.23

$-0.37$

46.80

56.44

156.21

144.32

11.90

11.53

44.92

24146.9

180.71

107.81

435.34

433.36

1.98

11.45

120.64

33186.5

107.58

427.50

11.22

416.28

260.06

1.23

63.73

185.92

142.26

436.15

65.35

129.45

369.72

2296.2

59.21

143.51 
HEAT PUMP FAULT TEST SUMMARY

INDOOR/OUTDOOR CONDITION \#: 08

FAULT TYPE: NON-CONDENSABLE GAS FAULT FAULT LEVEL [\%]: 20.0

\section{RUNNING CONDITIONS}

Barometric Pressure (inHg): Indoor Dry-Bulb Temperature $\left({ }^{\circ} \mathrm{F}\right)$ : Indoor Dew-Point Temperature $\left({ }^{\circ} \mathrm{F}\right)$ : Outdoor Dry-Bulb Temperature $\left({ }^{\circ} \mathrm{F}\right)$ : AIR SIDE CONDITIONS

(INDOOR UNIT)

Inlet Dry-Bulb Temperature $\left({ }^{\circ} \mathrm{F}\right)$ : Inlet Dew-Point Temperature $\left({ }^{\circ} \mathrm{F}\right)$ : Exit Dry-Bulb Temperature $\left({ }^{\circ} \mathrm{F}\right)$ : Exit Dew-Point Temperature $\left({ }^{\circ} \mathrm{F}\right)$ : Inlet Relative Humidity (-): Exit Relative Humidity (-): Evaporator Coil Temp Drop $\left({ }^{\circ} \mathrm{F}\right)$ : Air Flow Rate (SCFM): Fan Power Consumption (W): (OUTDOOR UNIT)

Inlet Temperature $\left({ }^{\circ} \mathrm{F}\right)$ : Exit Temperature $\left({ }^{\circ} \mathrm{F}\right)$ : Condensing Unit Temp Gain $\left({ }^{\circ} \mathrm{F}\right)$ : Fan Power Consumption (W) : (OVERALL PERFORMANCE)

Latent Capacity (Btu/h): Sensible Capacity (Btu/h): Overall Capacity (Btu/h): Sensible Heat Ratio (-): Overall Power Consumption (W): NET Cooling EER (Btu/h.W): Evaporator Energy Imbalance (\%): REFRIGERANT SIDE CONDITIONS

(EVAPORATOR)

Inlet Temperature $\left({ }^{\circ} \mathrm{F}\right)$ : Exit Temperature $\left({ }^{\circ} \mathrm{F}\right)$ : Inlet Pressure (psia): Exit Pressure (psia): Pressure Drop (psid): Exit Superheat $\left({ }^{\circ} \mathrm{F}\right)$ : Exit Sat. Temperature $\left({ }^{\circ} \mathrm{F}\right)$ : Evaporator Capacity (Btu/h): (CONDENSER)

$\begin{array}{rr}\text { Inlet Temperature }\left({ }^{\circ} \mathrm{F}\right): & 182.90 \\ \text { Exit Temperature }\left({ }^{\circ} \mathrm{F}\right): & 107.46 \\ \text { Inlet Pressure (psia): } & 443.51 \\ \text { Exit Pressure (psia): } & 441.45 \\ \text { Pressure Drop (psid): } & 2.06 \\ \text { Exit Subcooling }\left({ }^{\circ} \mathrm{F}\right): & 13.63 \\ \text { Sat. Temperature }\left({ }^{\circ} \mathrm{F}\right): & 122.09 \\ \text { enser Capacity (Btu/h): } & 33938.0\end{array}$

(LIQUID LINE AND TXV)

Cond Unit Exit Temp $\left({ }^{\circ} \mathrm{F}\right)$ :

Cond Unit Exit Pres (psia): Liq-line Pressure Drop (psid): TXV Upstream Pressure (psia): TXV Pressure Drop (psid): Temperature Drop $\left({ }^{\circ} \mathrm{F}\right)$ : (COMPRESSOR)

Suction Temperature $\left({ }^{\circ} \mathrm{F}\right)$ : Discharge Temperature $\left({ }^{\circ} \mathrm{F}\right)$ : Suction Pressure (psia):

Discharge Pressure (psia): Discharge Superheat $\left({ }^{\circ} \mathrm{F}\right)$ : Comp Bottom Shell Temp $\left({ }^{\circ} \mathrm{F}\right)$ : Mass Flow Rate $(1 \mathrm{bm} / \mathrm{h})$ :

Comp Power Consumption (W) :

Cond Unit Inlet Temp $\left({ }^{\circ} \mathrm{F}\right)$ : Cond Unit Inlet Pres (psia):
30.33

70.21

50.81

99.68

70.21

50.81

51.51

48.42

0.502

0.891

18.70

1023.5

435.92

99.68

114.77

15.09

160.08

3268.8

20954.3

24223.1

0.865

2936.0

8.25

0.34

46.80

57.66

158.41

146.07

12.34

12.02

45.64

24743.6

182.90

107.46

43.51

2.06

3.63

3938.0

106.82

435.39

11.91

423.49

265.08

1.59

64.82

188.06

144.01

444.38

66.03

130.99

375.25

2340.0

60.20

145.25
HEAT PUMP FAULT TEST SUMMARY

INDOOR/OUTDOOR CONDITION \#: 09 FAULT TYPE: NON-CONDENSABLE GAS FAULT FAULT LEVEL [\%]: 5.0

RUNNING CONDITIONS

Barometric Pressure (inHg) : Indoor Dry-Bulb Temperature $\left({ }^{\circ} \mathrm{F}\right)$ : Indoor Dew-Point Temperature $\left({ }^{\circ} \mathrm{F}\right)$ : Outdoor Dry-Bulb Temperature $\left({ }^{\circ} \mathrm{F}\right)$ : AIR SIDE CONDITIONS (INDOOR UNIT)

Inlet Dry-Bulb Temperature $\left({ }^{\circ} \mathrm{F}\right)$ : Inlet Dew-Point Temperature $\left({ }^{\circ} \mathrm{F}\right)$ : Exit Dry-Bulb Temperature $\left({ }^{\circ} \mathrm{F}\right)$ : Exit Dew-Point Temperature $\left({ }^{\circ} \mathrm{F}\right)$ : Inlet Relative Humidity $(-)$ : Exit Relative Humidity (-) : Evaporator Coil Temp Drop $\left({ }^{\circ} \mathrm{F}\right)$ : Air Flow Rate (SCFM): Fan Power Consumption (W): (OUTDOOR UNIT)

Inlet Temperature $\left({ }^{\circ} \mathrm{F}\right)$ : Exit Temperature $\left({ }^{\circ} \mathrm{F}\right)$ : Condensing Unit Temp Gain $\left({ }^{\circ} \mathrm{F}\right)$ : Fan Power Consumption (W): (OVERALL PERFORMANCE)

Latent Capacity (Btu/h): Sensible Capacity (Btu/h): Overall Capacity (Btu/h): Sensible Heat Ratio (-):

Overall Power Consumption (W) : NET Cooling EER (Btu/h.W): Evaporator Energy Imbalance (\%): REFRIGERANT SIDE CONDITIONS

(EVAPORATOR)

Inlet Temperature $\left({ }^{\circ} \mathrm{F}\right)$ : Exit Temperature $\left({ }^{\circ} \mathrm{F}\right)$ : Inlet Pressure (psia): Exit Pressure (psia): Pressure Drop (psid): Exit Superheat $\left({ }^{\circ} \mathrm{F}\right)$ : Exit Sat. Temperature $\left({ }^{\circ} \mathrm{F}\right)$ : Evaporator Capacity (Btu/h): (CONDENSER)

Inlet Temperature $\left({ }^{\circ} \mathrm{F}\right)$ : Exit Temperature $\left({ }^{\circ} \mathrm{F}\right)$ : Inlet Pressure (psia): Exit Pressure (psia): Pressure Drop (psid): Exit Subcooling $\left({ }^{\circ} \mathrm{F}\right)$ :

Inlet Sat. Temperature $\left({ }^{\circ} \mathrm{F}\right)$ :

Condenser Capacity (Btu/h): (LIQUID LINE AND TXV)

Cond Unit Exit Temp $\left({ }^{\circ} \mathrm{F}\right)$ : Cond Unit Exit Pres (psia): Liq-line Pressure Drop (psid): TXV Upstream Pressure (psia): TXV Pressure Drop (psid): (COMPRESSOR) Temperature Drop $\left({ }^{\circ} \mathrm{F}\right)$ :

Suction Temperature $\left({ }^{\circ} \mathrm{F}\right)$ :

Discharge Temperature $\left({ }^{\circ} \mathrm{F}\right)$ : Suction Pressure (psia):

Discharge Pressure (psia): Discharge Superheat $\left({ }^{\circ} \mathrm{F}\right)$ : Comp Bottom Shell Temp $\left({ }^{\circ} \mathrm{F}\right)$ : Mass Flow Rate $(1 \mathrm{bm} / \mathrm{h})$ : Comp Power Consumption (W) :

Cond Unit Inlet Temp $\left({ }^{\circ} \mathrm{F}\right)$ : Cond Unit Inlet Pres (psia):
30.84

79.97

60.51

99.77

79.97

60.51

60.55

57.23

0.515

0.888

19.42

1019.8

430.82

99.77

116.41

16.64

160.80

5971.4

21799.3

27770.8

0.785

2876.2

9.66

1.89

55.19

66.25

175.79

163.10

12.69

13.90

52.35

28743.5

176.38

108.17

438.33

436.18

2.15

10.87

121.17

37719.1

108.37

428.62

15.29

413.32

237.54

0.87

71.33

180.36

160.91

439.10

59.27

126.67

430.66

2284.5

68.41

162.05 